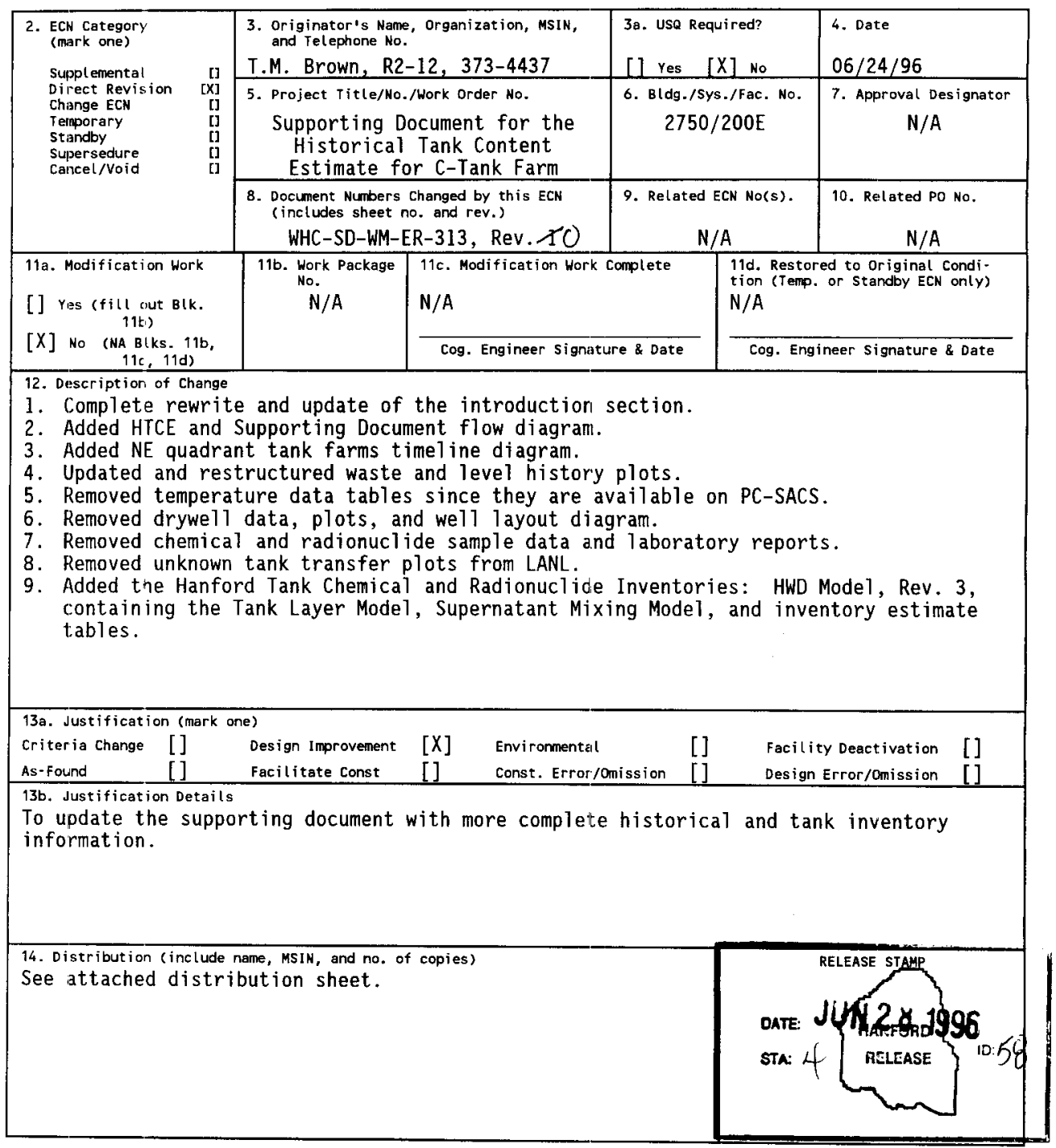




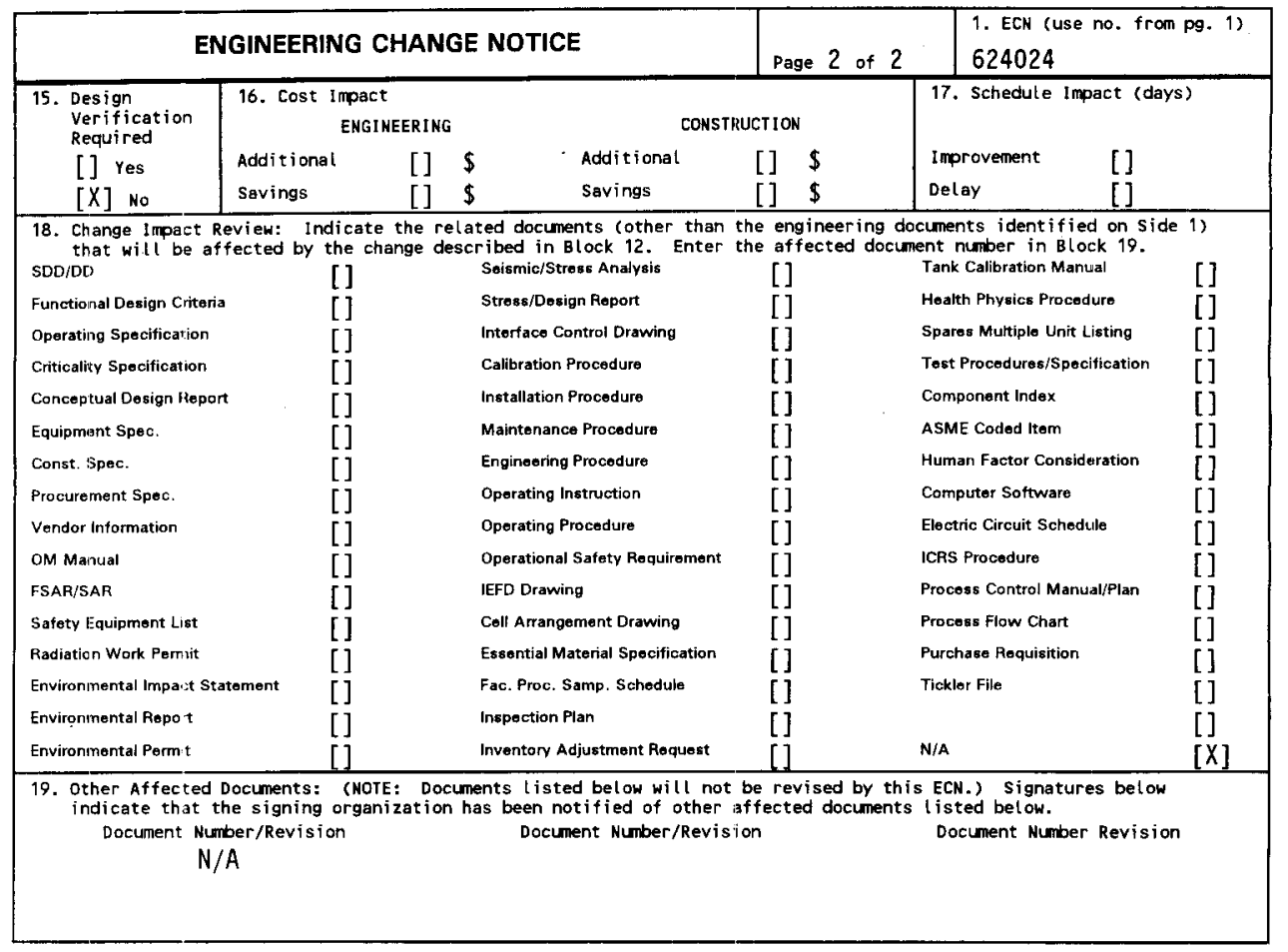

20. Approvals

Signature OPERATIONS AND ENGINEERING

Cog. Eng. T. M. Brown

Cog. Mgr. J. W. Cammann QA

Safety

Environ.

other

\section{Jow brom gev Cammann

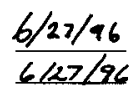

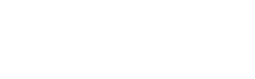

$\because$
Date
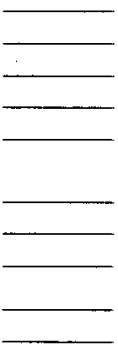

\section{ARCH I TECT -EMGINEER}

Date

PE

QA

Safety

Design R. L. Newell $R$ Llleweep

Environ.

other

Lead Engineer J. W. Funk f.iv. Fued $6 / 27 / 96$

Project Mgr. c. H. BrevickCAbrearide 6/27/46

DEPARTMENT OF EMERGY

signature or a Control Number that

tracks the Approval signature

ADOITIONAL 


\title{
Supporting Document for the Historical Tank Content Estimate for C-Tank Farm
}

\author{
C. H. Brevick, R. L. Newell, J. W. Funk
}

ICF Kaiser Hanford Company, Richland, WA 99352

U.S. Department of Energy Contract DE-ACO6-87RL10930

EDT/ECN: 624024

Org Code: 5 A400

UC: 2070

B\&R Code: EW3120074

Charge Code: E44205

Tota1 Pages: 467

Key Words: Northeast quadrant, Historical Tank Content Estimate, tank farms, tank level, tank temperature, aerial photos, in-tank montages, TLM, SMM, waste temperature plots, inventory estimates, riser locations

Abstract: This Supporting Document provides historical in-depth characterization information on C-Tank Farm, such as historical waste transfer and level data, tank physical information, temperature plots, liquid observation well plots, chemical analyte and radionuclide inventories for the Historical Tank Content Estimate Report for the northeast quadrant of the Hanford 200 East Area.

TRADEMARK DISCLAIMER. Reference herein to any specific commercial product, process, or service by trade name, trademark, manufacturer, or otherwise, does not necessarily constitute or imply its endorsement, recommendation, or favoring by the United States Government or any agency thereof or $i$ ts contractors or subcontractors.

P:-inted in the United States of America. To obtain copiles of this document, contact: WHC/BCs Discument Control Services, P.O. Box 1970, Mailst op H6-08, Richland WA 99352, Phone (509) 372-2420; FilX (509) 376-4989.
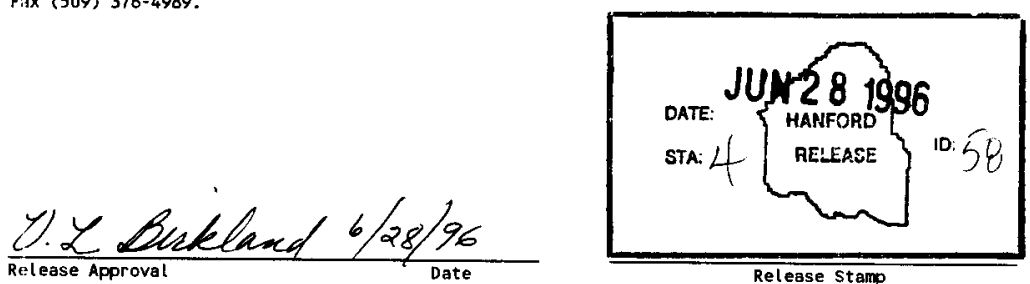

\section{Approved for Public Release}




\section{RECORD OF REVISION}

(2) Title

Supporting Document for the Historical Tank Content Estimate for C-Tank Farm

CHANGE CONTROL RECORD

\begin{tabular}{|c|c|c|c|c|}
\hline \multirow{2}{*}{ (3) } & \multirow{2}{*}{ Revision } & \multirow{2}{*}{ (4) Deseription of Change - Replace, Add, and Delete Pages } & \multicolumn{2}{|c|}{ Authorized for Rel ease } \\
\hline & & & (5) Cog. Engr. & (6) Cog. Mgr. \\
\hline & 0 & (7) Initial issue, EDT $609114,9 / 30 / 94$ & T.M. Brown & C.S. Haller \\
\hline RS & 1 & $\begin{array}{l}\text { 1. Complete rewrite and update of introduct ion section. } \\
\text { 2. Added HTCE and Supporting Document flow diagram. } \\
\text { 3. Added NE quadrant tank farms timel ine diagram. } \\
\text { 4. Updated and restructured waste and level history plots. } \\
\text { 5. Removed temperature data tables. } \\
\text { 6. Removed drywet l data tables and plots. } \\
\text { 7. Removed sample data and reports. } \\
\text { 8. Removed unknown tank transfer plots. } \\
\text { 9. Added more extensive tank waste inventory tables. } \\
\text { Incorporates ECN } 624024\end{array}$ & $\begin{array}{l}\text { T.M. Brown } \\
\text { Jode Berom } \\
6 / 27 / 16\end{array}$ & $\begin{array}{l}\text { J.W. Cammann } \\
Q \angle U \text { Cammann } \\
\angle 127 / 96\end{array}$ \\
\hline & & & & \\
\hline & & & & \\
\hline & & & & \\
\hline & & & & \\
\hline & & & & \\
\hline & & & & \\
\hline & & & & \\
\hline & & & & \\
\hline & & & & \\
\hline & & & & \\
\hline & & & & \\
\hline & & & & \\
\hline & & & & \\
\hline & & & & \\
\hline & & & & \\
\hline & & & & \\
\hline & & & & \\
\hline & & & & \\
\hline
\end{tabular}




\section{SUPPORTING DOCUMENT FOR THE HISTORICAL TANK CONTENT ESTIMATE FOR}

\section{TANK FARM}

\section{WORK ORDER E44205}

Prepared for

Westinghouse Hanford Company

May 1996

Prepared by

S.D. Consort

K.L. Ewer

J.W. Funk

R.G. Hale

G.A. Lisle

C.V. Salois

ICF Kaiser Hanford Company

Richland, Washington 


\title{
SUPPORTING DOCUMENT FOR THE HISTORICAL TANK CONTENT ESTIMATE FOR
}

\section{TANK FARM}

\section{WORK ORDER E44205}

\author{
Prepared by
}

ICF Kaiser Hanford Company

Richland, Washington

for

Westinghouse Hanford Company

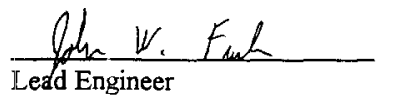

$\frac{6 / 27 / 96}{\text { Date }}$

$\frac{\text { Bresda S. Sastoris }}{\text { Technical Documents }}$

$\frac{6 / 27 / 96}{\text { Date }}$

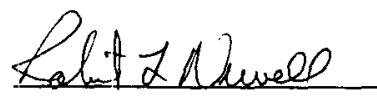

Design Agent

$6 / 2756$

Date

Chastigured

Project Manager

$6 / 27 / 96$

Date

Westinghouse Hanford Company

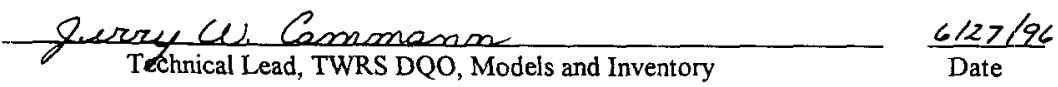




\section{ACKNOWLEDGMENTS}

A project of the this magnitude would not be possible without the help of a significant number of persons and organizations. ICF Kaiser Hanford Company would like to acknowledge the contributions made by our Los Alamos National Laboratory counterparts: Stephen F. Agnew, Kenneth A. Jurgensen, Robert A Corbin, Tomasita B. Duran, Bonnie L. Young, Theodore P. Ortiz, John FitzPatrick, and James Boyer. Also, Todd Brown and Brett Simpson of Westinghouse Hanford Company are recognized for their contributions. 
INFORMATION FEEDBACK CARD

\section{SUPPORTING DOCUMENT FOR THE HISTORICAL TANK CONTENT ESTIMATE FOR C TANK FARM}

\section{E44205}

\section{COMMENTS AND CONTRIBUTIONS}

The reader is requested to use this card to comment on this document, report any discrepancies, or contribute new information to improve the accuracy and content of the report. Please use the space provided, add additional pages if necessary, and retum the comments to the person noted at the address listed below.

Send Comments to: Mr. John W Hunt

TWRS Technical Baseline Integration

P.O. Box 1970, MSIN R2-12

Richland, WA 99352

- iii - 


\section{TABLE OF CONTENTS}

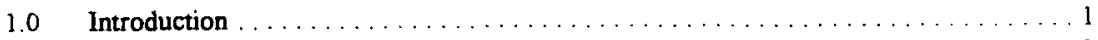

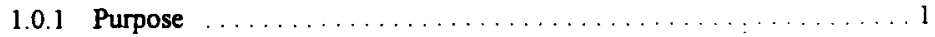

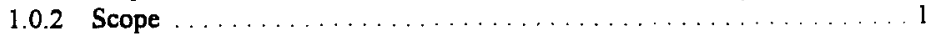

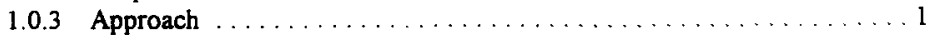

1.1 Safety Issues . . . . . . . . . . . . . . . . . . . . . . . . .

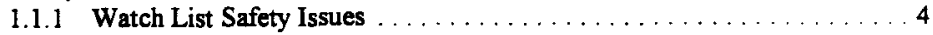

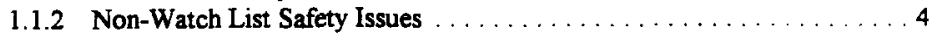

1.1 .3 Occurrences . . . . . . . . . . . . . . . . . . . . 5

1.2 Waste Generating Plants and Processes $\ldots \ldots \ldots \ldots \ldots \ldots \ldots \ldots$

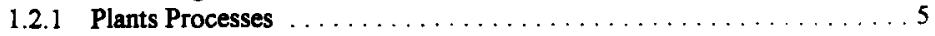

1.2 .2 Waste Management Operations . . . . . . . . . . . . . . . 9

1.2 .3 Miscellaneous Waste Sources and Equipment $\ldots \ldots \ldots \ldots \ldots \ldots$

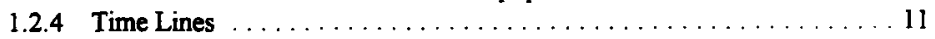

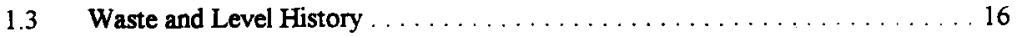

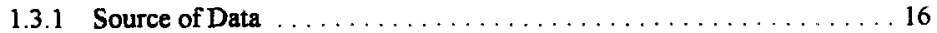

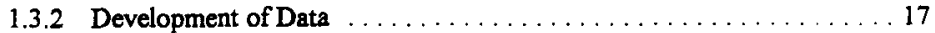

1.3 .3 Assumptions . . . . . . . . . . . . . . . . . . . . 19

1.3 .4 Quality of Data . . . . . . . . . . . . . . . . . . 19

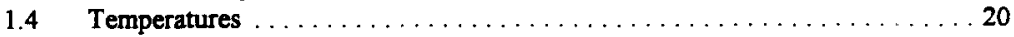

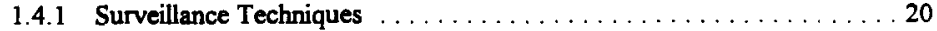

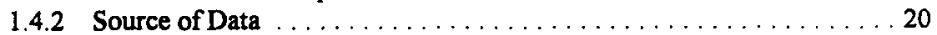

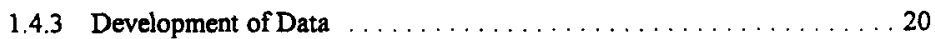

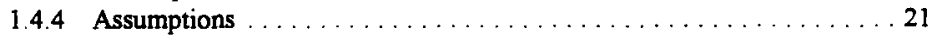

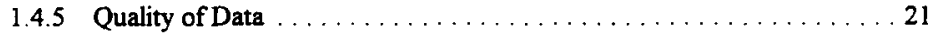

1.5 Waste Surface Level . . . . . . . . . . . . . . . . . . . . . 21

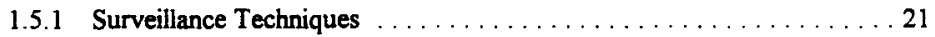

1.5 .2 Source of Data . . . . . . . . . . . . . . . . . . 22

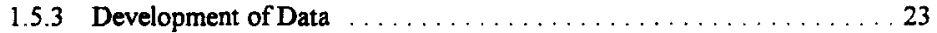

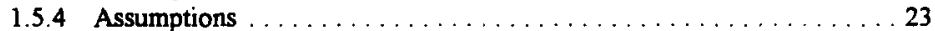

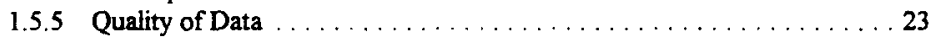

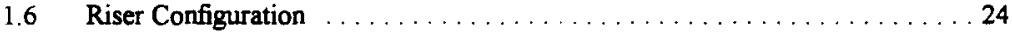

1.6 .1 Source of Data ... . . . . . . . . . . . . . . . . . 24

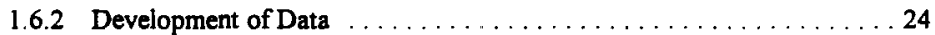

1.6 .3 Assumptions . . . . . . . . . . . . . . . . . . . . . . 24

1.6 .4 Quality of Data . . . . . . . . . . . . . . . . . . 24

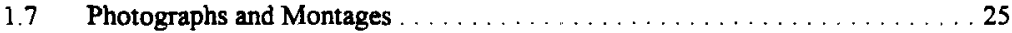

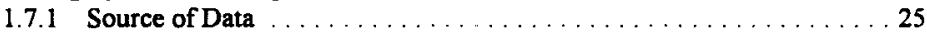

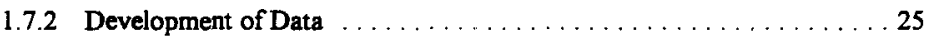

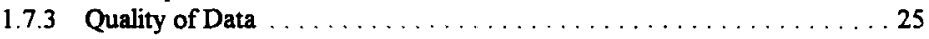

1.8 Tank Layer Model, Supernatant Mixing Model, and Inventory Estimates . . . 25

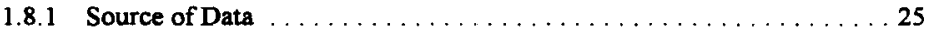

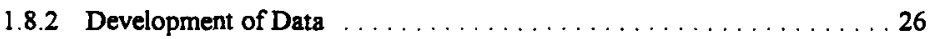




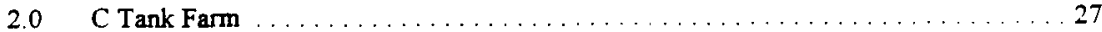

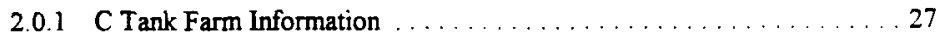

2.0 .2 C Tank Farm Waste and Level History . . . . . . . . . . . . . 27

2.0 .3 C Tank Farm Temperature History . . . . . . . . . . . . . 27

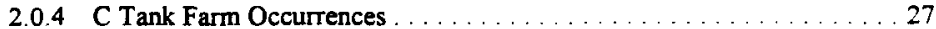

2.0 .5 C Tank Farm Current Status . . . . . . . . . . . . . . . . 27

2.0 .6 C Tank Farm Photograph and Montages . . . . . . . . . . . . 28

2.0.7 C Tank Farm Tank Layer Model, Supernatant Mixing Model, and

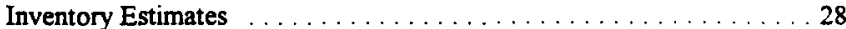

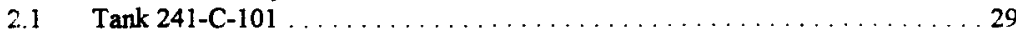

2.1.1 Waste and Level History of Tank 241-C-101 . . . . . . . . . . 29

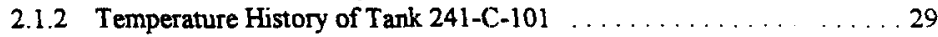

2.1.3 Occurrences for Tank $241-C-101 \ldots \ldots \ldots \ldots \ldots$

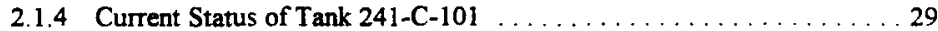

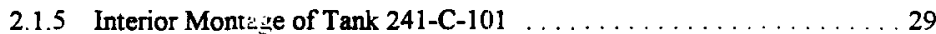

2.1.6 Tank Layer Model, Supernatant Mixing Model, and Inventory Estimate of

Tank 241-C-101 . . . . . . . . . . . . . . . . . . . . . . 30

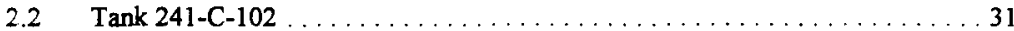

2.2.1 Waste and Level History of Tank $241-\mathrm{C}-102 \ldots \ldots \ldots \ldots$

2.2.2 Temperature History of Tank $241-C-102 \ldots \ldots \ldots \ldots \ldots \ldots$

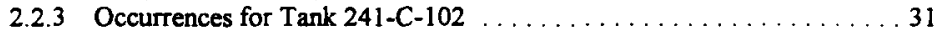

2.2.4 Current Status of Tank $241-\mathrm{C}-102 \ldots \ldots \ldots \ldots \ldots \ldots \ldots$

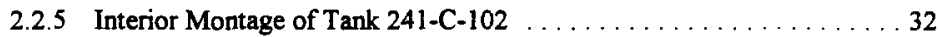

2.2.6 Tank Layer Model, Supernatant Mixing Model, and Inventory Estinnate of

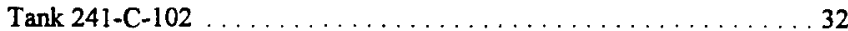

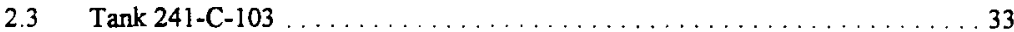

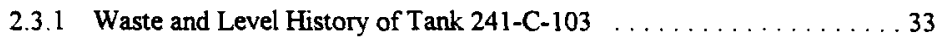

2.3.2 Temperature History of Tank $241-\mathrm{C}-103 \ldots \ldots \ldots \ldots \ldots$

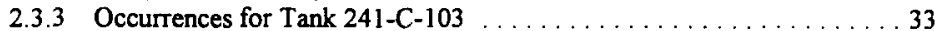

2.3.4 Current Status of Tank $241-C-103 \ldots \ldots \ldots \ldots \ldots \ldots \ldots \ldots$

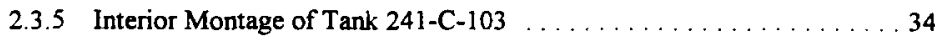

2.3.6 Tank Layer Model, Supernatant Mixing Model, and Inventory Estimate of

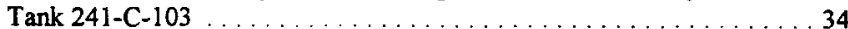

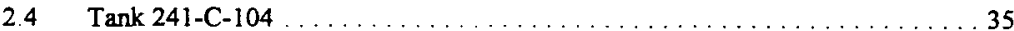

2.4.1 Waste and Level History of Tank $241-C-104 \ldots \ldots \ldots \ldots$

2.4.2 Temperature History of Tank $241-\mathrm{C}-104 \ldots \ldots \ldots \ldots \ldots$

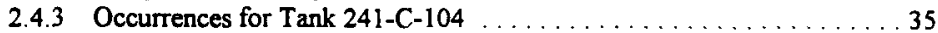

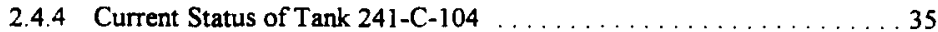

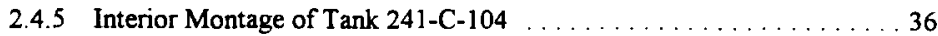

2.4.6 Tank Layer Model, Supernatant Mixing Model, and Inventory Estimate of

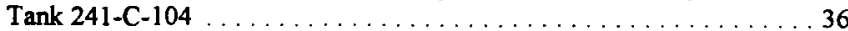

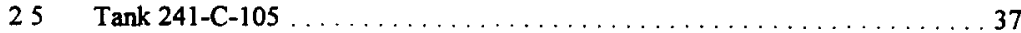

2.5.1 Waste and Level History of Tank $241-C-105 \ldots \ldots \ldots \ldots \ldots$

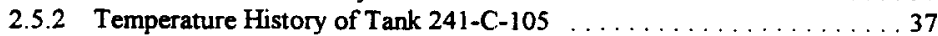

2.5.3 Occurrences for Tank $241-C-105 \ldots \ldots \ldots \ldots \ldots \ldots$

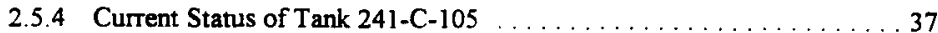




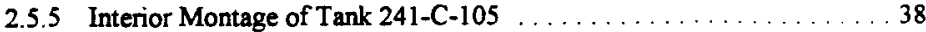

2.5.6 Tank Layer Model, Supernatant Mixing Model, and Inventory Estimate of

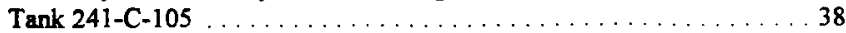

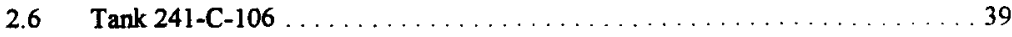

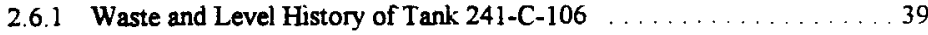

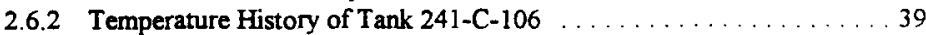

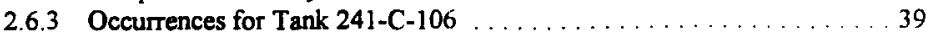

2.6.4 Current Status of Tank $241-\mathrm{C}-106 \ldots \ldots \ldots \ldots \ldots \ldots$

2.6.5 Interior Montage of Tank 241-C-106 . . . . . . . . . . . 40

2.6.6 Tank Layer Model, Supernatant Mixing Model, and Inventory Estimate of

Tank 241-C-106 . . . . . . . . . . . . . . . . . . . . 40

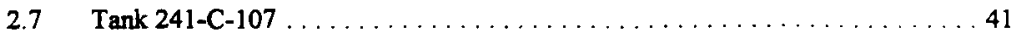

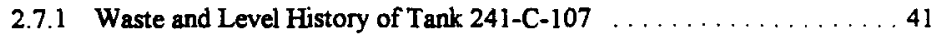

2.7.2 Temperature History of Tank $241-C-107 \ldots \ldots \ldots \ldots \ldots \ldots$

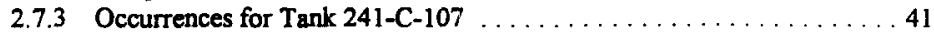

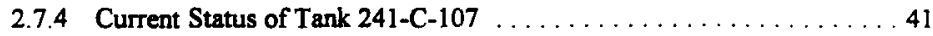

2.7.5 Interior Montage of Tank 241-C $-107 \ldots \ldots \ldots \ldots \ldots \ldots \ldots \ldots \ldots$

2.7.6 Tank Layer Model, Supernatant Mixing Model, and Inventory Estimate of

Tank 241-C-107 . . . . . . . . . . . . . . . . . . 42

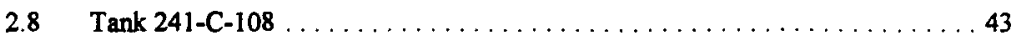

2.8.1 Waste and Level History of Tank $241-C-108 \ldots \ldots \ldots \ldots 4$

2.8.2 Temperature History of Tank $241-C-108 \ldots \ldots \ldots \ldots \ldots \ldots \ldots$

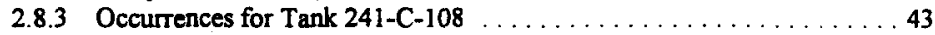

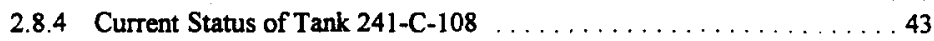

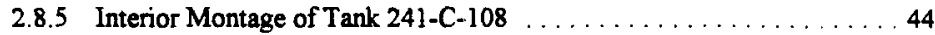

2.8.6 Tank Layer Model, Supernatant Mixing Model, and Inventory Estimate of

Tank 241-C-108 . . . . . . . . . . . . . . . . . . . 44

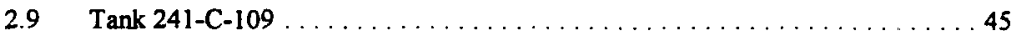

2.9.1 Waste and Level History of Tank $241-C-109 \ldots \ldots \ldots \ldots \ldots$

2.9.2 Temperature History of Tank $241-C-109 \ldots \ldots \ldots \ldots \ldots$

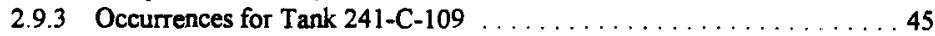

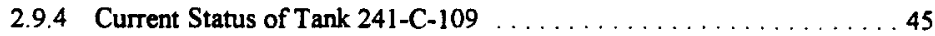

2.9.5 Interior Montage of Tank 241-C-109 . . . . . . . . . . . 46

2.9.6 Tank Layer Model, Supernatant Mixing Model, and Inventory Estimate of

Tank 241-C-109 . . . . . . . . . . . . . . . . . . . 46

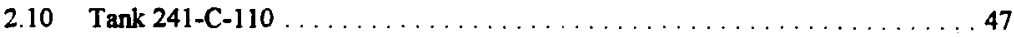

2.10.1 Waste and Level History of Tank $241-C-110 \ldots \ldots \ldots \ldots 7$

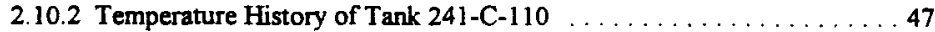

2.10 .3 Occurrences for Tank $241-C-110 \ldots \ldots \ldots \ldots \ldots \ldots . \ldots \ldots 7$

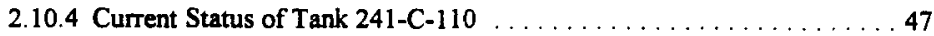

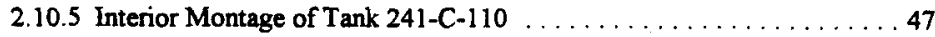

2.10.6 Tank Layer Model, Supernatant Mixing Model, and Inventory Estimate of

Tank $241-\mathrm{C}-110 \ldots \ldots \ldots \ldots \ldots \ldots \ldots$

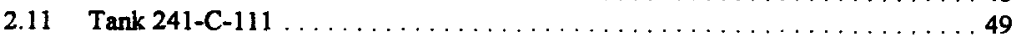

2.11.1 Waste and Level History of Tank 241-C-111 . . . . . . . . . . 49

2.11.2 Temperature History of Tank $241-C-111 \ldots \ldots \ldots \ldots$ 
2.11 .3 Occurrences for $\operatorname{Tank} 241-C-111 \ldots \ldots \ldots \ldots \ldots . \ldots \ldots$

2.11.4 Current Status of Tank $241-C-111 \ldots \ldots \ldots \ldots \ldots . \ldots \ldots$

2.11 .5 Interior Montage of Tank $241-C-111 \ldots \ldots \ldots \ldots \ldots \ldots . \ldots . \ldots 50$

2.11.6 Tank Layer Model, Supernatant Mixing Model, and Inventory Estimate of

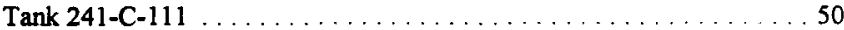

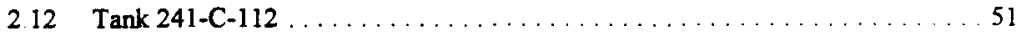

2.12.1 Waste and Level History of Tank $241-C-112 \ldots \ldots \ldots \ldots$. . . . . . .

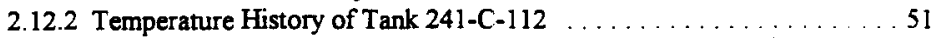

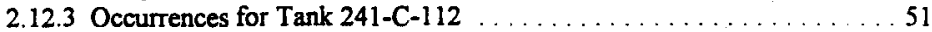

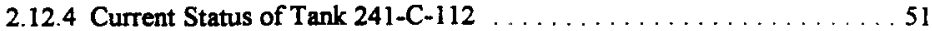

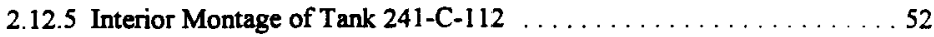

2.12.6 Tank Layer Model, Supernatant Mixing Model, and Inventory Estimate of

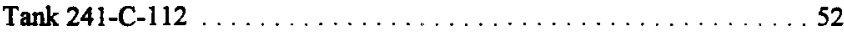

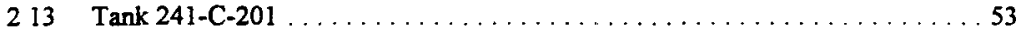

2.13.1 Waste and Level History of Tank $241-C-201 \ldots \ldots \ldots \ldots$

2.13.2 Temperature History of Tank $241-C-201 \ldots \ldots \ldots \ldots \ldots$

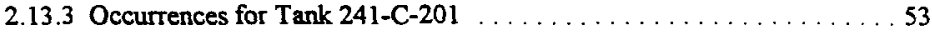

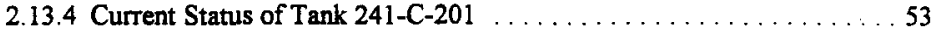

2.13.5 Interior Montage of Tank 241-C-201 . . . . . . . . . . . 53

2.13.6 Tank Layer Model, Supernatant Mixing Model, and Inventory Estimate of

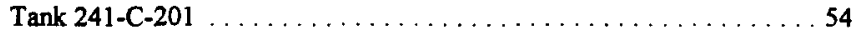

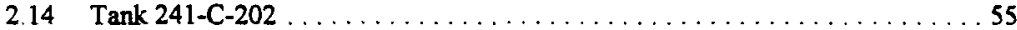

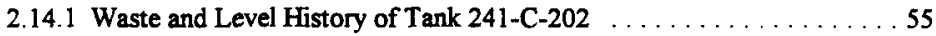

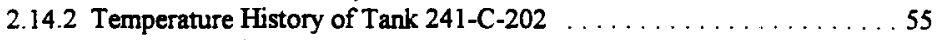

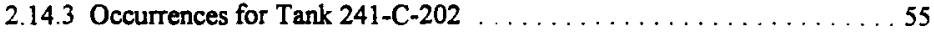

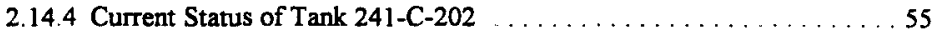

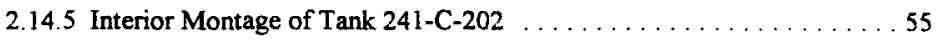

2.14.6 Tank Layer Model, Supernatant Mixing Model, and Inventory Estimate of

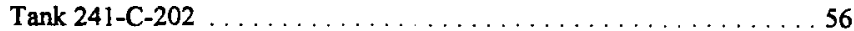

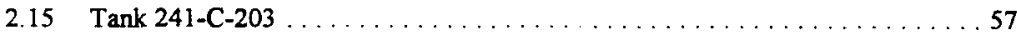

2.15.1 Waste and Level History of Tank $241-C-203 \ldots \ldots \ldots 7$

2.15.2 Temperature History of Tank $241-C-203 \ldots \ldots \ldots \ldots$. . . . . . . 57

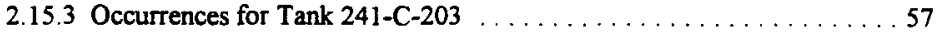

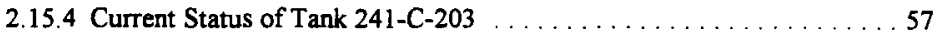

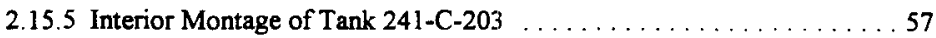

2.15.6 Tank Layer Model, Supernatant Mixing Model, and Inventory Estimate of

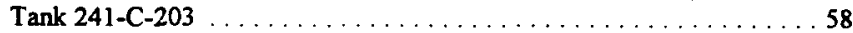

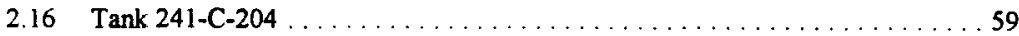

2.16.1 Waste and Level History of Tank 241-C-204 . . . . . . . . . . . 59

2.16.2 Temperature History of Tank 241-C-204 . . . . . . . . . . . . . . 59

2.16.3 Occurrences for Tank 241-C-204 . . . . . . . . . . . . . . . 59

2.16.4 Current Status of Tank $24-C-204 \ldots \ldots \ldots \ldots \ldots$

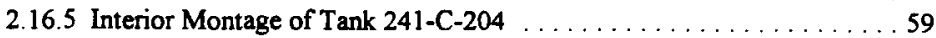

2.16.6 Tank Layer Model, Supernatant Mixing Model, and Inventory Estimate of

Tank 241-C-204 


\section{APPENDICES}

Appendix A Glossary

Appendix B References

Appendix C Waste and Level History Sketches and Data

Appendix D Temperature Graphs

Appendix E Surface Level Graphs

Appendix F Riser Configurations and Tank Cross Sections

Appendix G Tank Farm Photograph and Tank Montages

Appendix H Tank Layer Model, Supernatant Mixing Model, and Inventory Estimates 


\section{TRADEMARKS}

Microsoft Excel is a registered trademark of Microsoft Corporation.

ENRAF is a registered trademark of Delft Instruments.

AutoCAD is a registered trademark of Autodesk, Inc. 


\subsection{Introduction}

\subsubsection{Purpose}

The purpose of this historical characterization document is to present the synthesized summaries of the historical records concerning the physical, radiological, and chemical composition of mixed wastes stored in underground single-shell tanks and the physical conditions of these tanks. The single-shell tanks are located on the Department of Energy Hanford Site, approximately 25 miles northwest of Richland, Washington. The document will be used to assist in characterizing the waste in the tanks in conjunction with the current program of sampling and analyzing the tank wastes. Los Alamos National Laboratory (LANL) developed computer models that used the historical data to attempt to characterize the wastes and to generate estimates of each tank's inventory. A historical review of the tanks may reveal anomalies or unusual contents that could be critical to characterization and post characterization activities.

This report was developed by reviewing the operating plant process histories, waste transfer data, and available physical and chemical data from numerous resources. These resources were generated by numerous contractors from 1945 to the present.

Waste characterization, the process of describing the character or quality of a waste, is required by Federal law (Resource Conservation and Recovery Act) and state law (Washington Administrative Code (WAC) 173-303, Dangerous Waste Regulations). Characterixing the waste is necessary to determine methods to safely retrieve, transport, and/or treat the wastes.

This document is not intended for use as a total design basis document. Further investigations of the information may be required before using this data for design purposes or safety analysis.

\subsubsection{Scope}

The scope of this document covers available information about the wastes contained in the singleshell tanks in the C Tank Farm. Waste transfer and level data, tank physical information, and surveillance data of tanks and wastes have been compiled for this report. The inventory estimates of waste types and volumes generated by the computer modeling programs developed by LANL are included also. A summary of this information is contained in the Historical Tank Content Estimate (HTCE) for the Northeast Quadrant of the Hanford 200-East Area(Brevick et al., 1994). The northeast quadrant document covers six single-shell tank farms. These six tank farms, A, AX, B, BX, BY, and $C$, are located in the 200-East Area and are shown on the map in Figure 1. A flow diagram showing the relationships between the sources of data, the HTCE, and the supporting documents is in Figure 2.

This document also includes information on the safety issues affecting the tanks and the plants and processes that produced the waste in the underground waste storage tanks.

\subsubsection{Approach}

This report was compiled from work performed by ICF Kaiser Hanford Company (ICF KH), LANL, and Westinghouse Hanford Company (WHC). ICF KH reviewed the historical records of the 


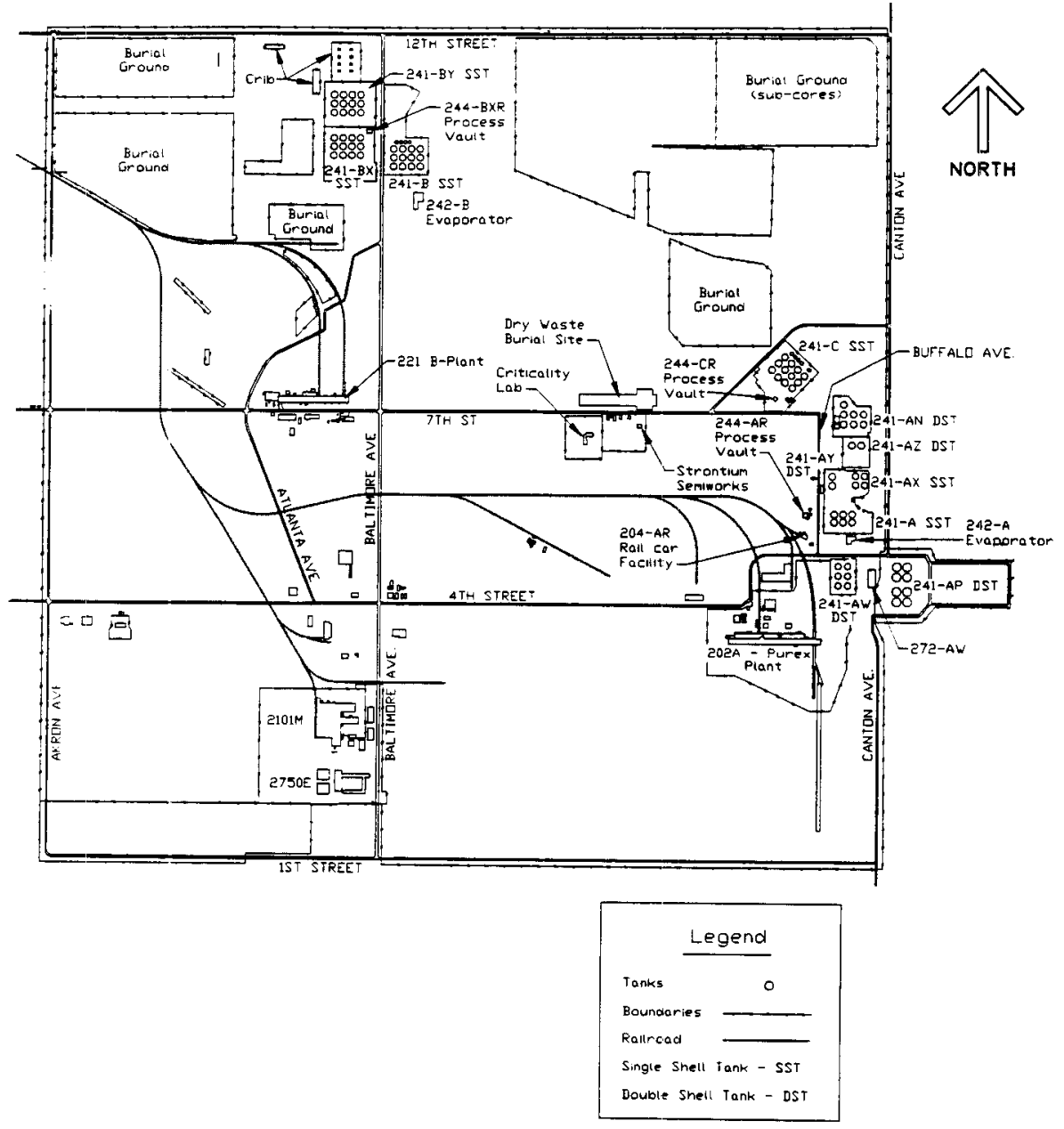

FIGURE 1: 200 EAST AREA 


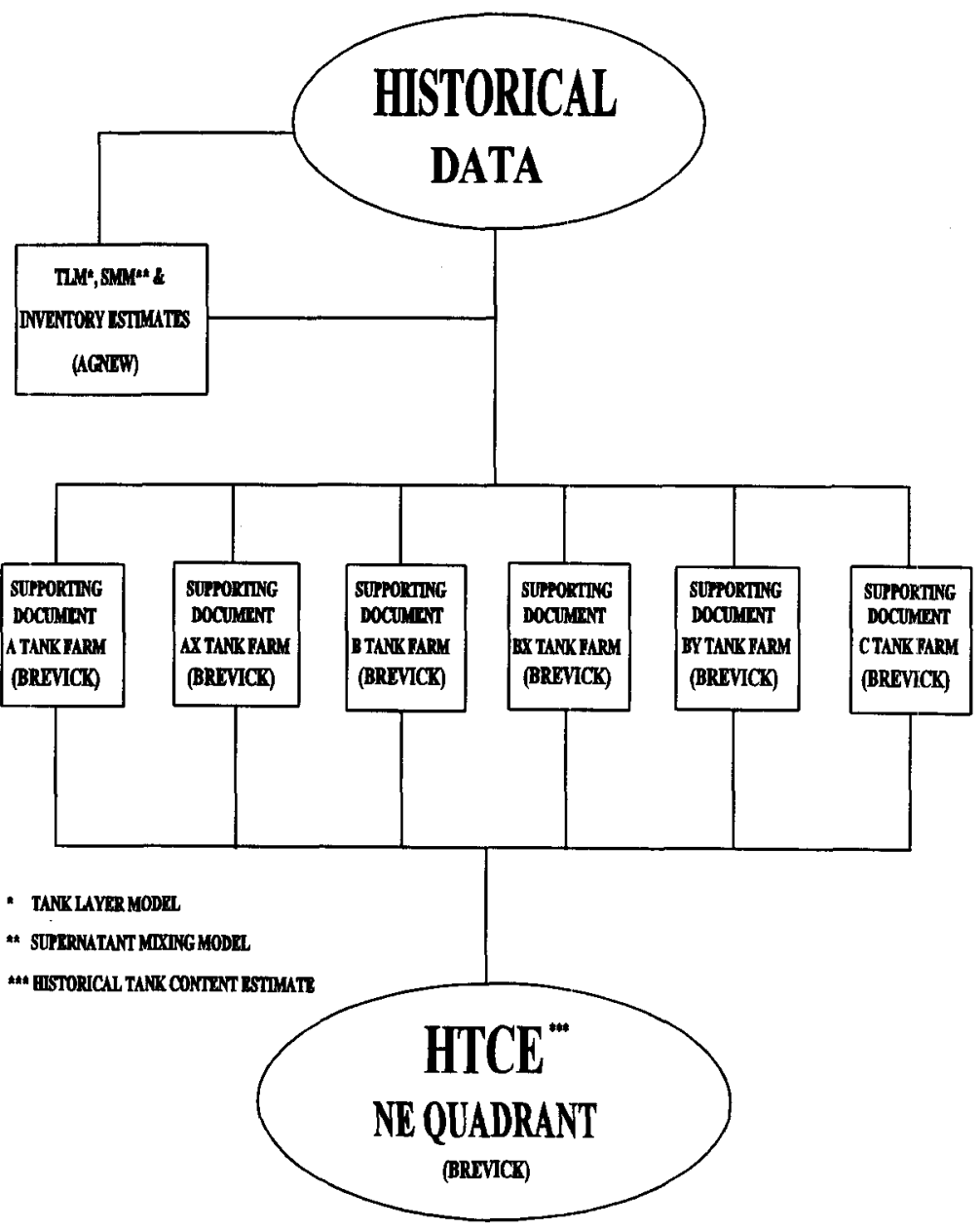

Figure 2 HTCE and Supporting Document Flow Diagram 
tanks and incorporated the inventory estimates and models of waste layers in the tanks being developed by LANL into the report.

\subsection{Safety Issues}

The safety issues that affect the tanks can be divided into two groups: watch list and non-watch list. The watch lists are a listing of all tanks that are believed to pose potential safety hazards to workers, the environment, and the public. Non-watch list issues are of concern because of the possible impact on workers and the environment. Occurrences are unusual events on the Hanford Site that sometimes are related to safety issues.

\subsubsection{Watch List Safety Issues}

Watch list safety issues for these tanks were identified as "issues/situations that contain most of the most necessary conditions that could lead to worker (onsite) or offsite radiation exposure through an uncontrolled release of fission products" under Public Law 101-510, Section 3137, of the National Defense Authorization Act of Fiscal Year 1991 (i.e., the Wyden Amendment). As of November 1995, 48 single-shell tanks and 6 double-shell tanks are on watch lists. See the Approach for Tank Safety Characterization of Hanford Site Waste(Eberlein et al., 1995) for more information on the watch list issues.

\subsubsection{Non-Watch List Safety Issues}

Non-watch list issues include safety hazards such as leaking tanks. Tank leaks are a safety hazard because of the potential to release chemicals and radioactive liquids to the ground. Corrosion is the main cause of tank leaks. Three other safety issues that do not require a watch list and continual monitoring under the Wyden Amendment include criticality, tank bumps, and toxic vapor releases. The following sections provide a general description of the different non-watch list safety issues. See the Hanford Site Tank Farm Facilities Interim Safety Basis(Leach and Stahl, 1993) for more information.

\section{- Corrosion}

Corrosion is the most probable degradation mechanism of the steel tank liners resulting from contact with liquid, liquid-vapor, vapor, and solid phases of the wastes. The corrosion mechanisms producing a reduction in the thickness of the carbon steel liners can be divided into two categories: localized and general or uniform. Localized corrosion occurs on a localized area of the liner surface. Some of the localized corrosion mechanisms include pitting corrosion, stress corrosion cracking, and crevice corrosion. General or uniform corrosion occurs over the entire liner surface. Corrosion of the steel tank liners may take the form of one or more of the mentioned mechanisms. Corrosion is a safety issue because it has the potential to degrade the tank liner to the point of causing a leak or, more seriously, structural failure of the tank. Either condition could release contamination to the environment.

\section{Criticality}

Criticality is a self-sustained, nuclear chain reaction that can occur when a sufficient mass of fissile material is present in the proper configuration along with a neutron source to start the nuclear reaction. Criticality in the tank farms has been declared an unreviewed safety question, even though the Hanford Site Tank Farm Facilities Interim Safety Basis(Leach and Stahl, 1993) indicates that a “...nuclear 
criticality accident in the tank farms is probably not an imminent risk." The unreviewed safety question on criticality in the tank farms remains because the inventory of fissile material and its distribution within the tanks cannot be confirmed as being within the approved safety envelope defined in the current safety analysis reports. Criticality is a safety issue because of the potential to cause a release of contamination to the environment.

\section{Tank Bumps}

A tank bump is the sudden pressurization of the tank. This occurs when solids overheat in the lower portion of the tank followed by uncontrolled mixing of these solids. The stirred hot solids rapidly transfer heat to the liquid in the tank, some of which quickly vaporizes. The rapid vapor generation causes a sudden internal tank pressurization that causes a bump. Uncontrolled mixing of heated solids can occur when an airlift circulator fails allowing the solids to heat up followed by rapid startup of the airlift circulator which causes rapid mixing. Also, uncontrolled mixing can occur when a natural "rollover" of waste occurs in the tank. Tank bumps are a safety issue because of the potential to cause a release of contamination to the environment.

\section{Toxic Vapor Releases}

Toxic vapor releases are a recently analyzed safety concern at the Hanford Site. The entire issue of toxic gas releases at the tank farms is being investigated (Leach and Stahl, 1993).

\subsubsection{Occurrences}

Over the years, unusual events (occurrences) have occurred at the $\mathrm{C}$ Tank Farm. An occurrence is an event that falls outside of the normal operating, maintenance and/or construction procedures of the tank farm. Occurrences have been documented by various reporting methods including unusual occurrences reports, off normal reports, event fact sheets, and occurrence reports. The occurrence documentation in each report that could be located was evaluated for its significance in determining the waste content of the tanks before being inchuded in this document. The types of significant occurrences included are occurrences written about surface level changes, temperature changes, and radioactivity changes (activity in the drywells). This document does not contain complete information from the reports, only summaries of the events. For more information on occurrences, refer to the Occurrences section for the specific tank.

\subsection{Waste Generating Plants and Processes}

\subsubsection{Plants Processes}

Brief descriptions and histories of the plants and processes that generated waste now contained in the single-shell and double-shell tanks are presented in alphabetical order. Typically, the name of the plant and the process are synonymous. The dates and events described in the following brief histories are presented on time lines in Figures 3 and 4. Although not all of the processes listed below contributed waste directly to tanks in the northeast quadrant, the waste they generated could have been transferred indirectly tank-to-tank. 


\section{- A Plant (PUREX)}

The Plutonium Uranium Extraction (PUREX) plant (i.e., A Plant) began operating in January 1956 (Gerber, 1993b). "The PUREX process is an advanced solvent extraction process that uses a tributyl phosphate in kerosene solvent for recovering uranium and plutonium from nitric acid solutions of irradiated uranium. Nitric acid is used instead of metallic nitrates to promote the extraction of uranium and plutonium from aqueous phase to an organic phase." (Wilson and Reep, 1991, p. B-4) Two campaigns of the Thorex process were conducted in 1966 and 1971 (Jungfleisch, 1984). The Thorex process recovered ${ }^{23} \mathrm{U}$ from thorium irradiated in the Hanford Site reactors (Wilson and Reep, 1991). PUREX reprocessed aluminum-clad fuel elements and zirconium alloy clad fuel elements, and provided plutonium for research reactor development, safety programs, and defense. Also, PUREX recovered slightly enriched uranium to be recycled as fuel in reactors generating electricity and plutonium (Rockwell, 1985). PUREX was put on standby in 1972 (Gerber, 1993b).

The PUREX plant was restarted in November 1983 but was shut down in December 1988 (see Figure 3). The plant was shut down due to the lack of steam pressure needed to operate the suppor backup safety equipment. There was a brief stabilization run in early 1990. In October 1990, PUREX was placed on standby by Secretary of Energy James Watkins. DOE issued the final closure order in December 1992 (Gerber, 1993c).

\section{B Plant}

B Plant used the bismuth phosphate process at first, and later changed its processing capabilities to strontium and cesium fractionation. The bismuth phosphate process "separated plutoniurn from uranium and the bulk of fission products in irradiated fuel by co-precipitation with bismuth phosphate from a uranium nitrate solution. The plutonium was then separated from fission products by successive precipitation cycles using bismuth phosphate and lanthanum fluoride. The plutonium was isolated as a peroxide and, after dissolving in nitric acid, was concentrated as plutonium nitrate. The waste containing the uranium from which the plutonium had been separated, was made alkaline (neutralized) and stored in underground single-shell tanks. Other acid waste (which included most of the fission products) generated by this process was neutralized and stored in other single-shell tanks." (Wilson and Reep, 1991, p. B-3). "Some of the strontium and cesium fission products were removed (fractionated) from the waste and separately isolated to reduce the heat generation in the tanks. B Plant......was modified in 1968 to permit removal of these fission products by a combination of precipitation, solvent extraction, and ion-exchange steps. The residual acid waste from the processing was neutralized and stored in single-shell tanks." (Wilson and Reep, 1991, pp. B-4 and B-5).

B Plant began its first batch run on April 13, 1945 (Anderson, 1990) and was shutdown in 1952 (Gerber, 1993c) (see Figure 3). Shortly after the renovations to B Plant were completed in December 1955, the 4X Program was abandoned. The 4X Program "planned to utilize the capabilities of all four Hanford processing plants (B, T, REDOX, and PUREX)" (Gerber, 1993c, p. 12); however, the large production and economic efficiency of the PUREX plant caused the $4 X$ Program to be abandoned (Gerber, 1993c). B Plant restarted in 1968 to recover cesium and strontium from stored liquid waste. Cesium and strontium recovery was completed in September 1983 and February 1985, respectively (Rockwell, 1985). 


\section{5-B (WESF)}

The Waste Encapsulation and Storage Facility (WESF) converted solutions of cesium and strontium nitrates recovered in B Plant to strontium fluoride and cesium chloride solids that are doubly encapsulated in metal (Ballinger and Hall, 1991). "Strontium and cesium capsules have been used in applications of fission byproducts for gamma and heat sources" (Wilson and Reep, 1991, p. B-5)

WESF was constructed in 1974 (see Figure 3). The process optimization for cesium and strontium was completed in 1978 and 1981, respectively (Rockwell, 1985). The cesium processing ended in 1983 and strontium encapsulation in 1985. The capsule return program started in 1988 and ended in 1995 (Gerber, 1996).

\section{Plant (Strontium Semiworks)}

The Strontium or Hot Semiworks facility (i.e., C Plant) began operating in 1952 as a hot pilot plant for the REDOX process (see Figure 3). In 1954, the plant was converted to a pilot plant for the PUREX process and continued operating until 1956 (Ballinger and Hall, 1991). "The process building (201-C) contains three hot cells equipped only for contact maintenance and is supported by an aqueous makeup and control building $(271-C)$ and a solvent handling building (276-C). The facility also includes a fiberglass exhaust filter and a $200-\mathrm{ft}$ stack." (PNL, 1991, Vol. 1, p. 3.6). In 1960, the piant was reactivated as a pilot plant used to recover strontium 90, promethium 147, and cesium 144 from PUREX waste. The plant was shut down in 1967 and the building and the site have been decontaminated and decommissioned (PNL, 1991).

\section{- S Plant (REDOX)}

The Reduction and Oxidation extraction (REDOX) plant (i.e., S Plant) began processing on January 9, 1952 (Anderson, 1990) (see Figure 3). "The REDOX extraction process was a secondgeneration recovery process and the first process to recover both plutonium and uranium. It used a continuous solvent extraction process to extract plutonium and uranium from dissolved fuel into a methyl isobutyl ketone (hexone) solvent. The slightly acidic wastestream contained the fission products and large quantities of aluminum nitrate that were used to promote the extraction of plutonium and uranium. This waste was neutralized and stored in single-shell tanks. The volume of high-level waste from this process was much smaller than that from the bismuth phosphate process, but larger than that from the PUREX process." (Wilson and Reep, 1991, pp. B-3 and B-4). REDOX operated until 1967 (Rockwell, 1985).

\section{T Plant}

T Plant was the first full-scale separations plant at the Hanford Site. $T$ plant used the bismuth phosphate process to separate plutonium from uranium and the bulk of fission products in irradiated fuel (B Plant used the same process). "The waste containing the uranium from which the plutonium had been separated was made alkaline (neutralized) and stored in underground single-shell tanks. Other acid waste (which included most of the fission products) generated by this process was neutralized and stored in other single-shell tanks." (Wilson and Reep, 1991, p. B-3).

T Plant began operating in 1944 (Rockwell, 1985) as a separations plant and continued until March 1956 (Gerber, 1994a) (see Figure 4). T Plant's mission was changed in 1957 to the repair and high-level decontamination of equipment (Rockwell, 1985). T Plant was converted to a "central decontamination facility for the site. As such, failed and contaminated equipment was assessed and 
either repaired or discarded there for over three decades." (Gerber, 1994a, p. 1). Early decontamination operations used steam, sand, chemicals, and detergents. "Smaller equipment pieces were immersed in decontamination solutions in thimble tanks,' and larger pieces were flushed with water, chemical solutions, sand-blasted, steam-blasted, high-pressure sprayed (using pressures up to 10,000 pounds per square inch), and/or scrubbed with detergents. During the initial years, a strong nitric acid flush (approximately 60\%) usually began the decontamination process, followed by a caustic wash with sodium hydroxide combined with sodium phosphate, boric acid, versene, sodium dichromate, sodium tartrate, or sodium citrate. However, it was learned that versene and tartrate, in particular, adversely affected the ability of soil cribs to absorb the rinsate materials. High-pressure sprays often used 1,1,1 trichloroethane or perchloroethylene, and detergents generally were chloride-based. By the mid-1960s, commercially prepared and trademarked chemical mixtures had replaced most of the simpler chemicals used in the early years. Many commercial products were based on oxalic acid, phosphates, nitric acidferrous ammonium sulfate combinations, potassium permanganate, and sodium bisulfate, with some unknown additives." (Gerber, 1994a, pp. 40-42). The facility was modified in 1978 to store pressurized water reactor (PWR) core II fuel assemblies (Rockwell, 1985).

\section{U Plant}

U Plant (221-U) was built as one of ' ree original bismuth phosphate process facilities, but it was not used for that purpose. U Plant was modified extensively and used for the uranium recovery process, operating from 1952 to 1958 (see Figure 4). Uranium in waste from the bismuth pnosphate process initially was stored in the single-shell tanks. Later, the waste was sluiced, dissolved in nitric acid, and processed through a solvent extraction process using tributyl phosphate in kerosene to recover the uranium. The process was similar to that used later in the plutonium-uranium extraction (PUREX) process except that plutonium was not recovered. The acid waste from the uranium recovery process was made alkaline and returned to single-shell tanks. The tributyl phosphate waste was treated with potassium ferrocyanide as a cesium and strontium scavenger. The recovery process resulted in an increase in nonradioactive salts and a small increase in waste volume (Wilson and Reep, 1991).

\section{- Uranium Trioxide Plant}

The 224-U Building was converted to a uranium trioxide $\left(\mathrm{UO}_{3}\right)$ plant which began operating in 1952 (see Figure 4). The $\mathrm{UO}_{3}$ plant was capable of handling the uranyl nitrate hexahydrate (UNH) stream from REDOX, U Plant, and PUREX. "The basic $\mathrm{UO}_{3}$ process, calcining, consisted of concentrating and then heating liquid UNH until it converted to a stable, orange-yellow powder. The nitric acid in the UNH solution could be recovered in the same process. The $\mathrm{UO}_{3}$ powder was the base material needied for the manufacture of uranium hexafluoride (UF $)_{6}$ ), the primary feed material for the United States' gaseous diffusion plants. Because the largest of these plants was located in Ohio and Tennessee, it was considered safer to ship the material across the country in powder rather than in liquid form." (Gerber, 1993c, pp. 33-34). The $\mathrm{UO}_{3}$ plant was shut down in 1972, but restarted in 1984. Since 1984, there have been 17 campaigns at the plant averaging eight days each. Final deactivation was ordered for the plant in 1992. In April 1993, the $\mathrm{UO}_{3}$ plant resumed operations to convert 200,000 gallons of remaining $\mathrm{UNH}$ to $\mathrm{UO}_{3}$ powder. A final deactivation plan was written in the summer of 1993 (Gerber, 1993c).

\section{Z Plant (Plutonium Finishing Plant)}

The Plutonium Finishing Plant (PFP) or Z Plant, previously called Plutonium Recovery and Finishing Operations, processed plutonium and prepared plutonium products. "Waste from this plant 
contained only minor amounts of fission products but did contain low concentration of plutonium and other transuranic elements and was high in metallic nitrates. Initially, this waste was discharged via cribs to soil columns, which absorbed the transuranic elements and retained them close to the point of discharge. Beginning in 1973, waste from PFP was stored with other waste in underground tanks." (Wilson and Reep, 1991, p. B-4). "Three types of feed materials are processed at the PFP to produce plutonium metal. Feed material types are handled differently in different process lines...Historically, the main feed for the PFP was purified plutonium nitrate solution that was produced elsewhere in a fuel reprocessing plant. This feed was charged directly to one of the main process lines, which was initially a glovebox line. The glovebox line was replaced by remote mechanical lines, which were upgraded over the years. In time, processes were added to handle rework and scrap plutonium. These processes were used to convert the rework and scrap materials into a purified plutonium nitrate solution that could be handled by the main process." (Duncan and Mayancsik, 1993, pp. 2-1-2-2).

In July 1949, PFP began operations with a glove box line (see Figure 4). The remote mechanical A line replaced the glove box line in May 1953. Installment of the Recuplex Facility at PFP was completed in April 1955. The remote mechanical C line was installed in July 1960. In September 1961, the 232-Z Building was installed with an incinerator and leaching equipment. In June 1964, the Plutonum Reclamation Facility (PRF) replaced the functions of the Recuplex Facility. Fabrication of plutonium metal nuclear weapon components ceased at the PFP in December 1965. In April 1973, the 232-Z Incinerator was shut down and the remote mechanical $C$ line was placed on standby. The PRF was placed on standby in February 1979, and the remote mechanical $A$ line was shutdown in December 1979. In January 1984, the PRF was restarted for a series of campaigns. The remote mechanical C line was restarted in June 1985 for a series of campaigns. In September 1986, operations at PFP were halted for nine months. This partial listing of the process history in the Plutonium Finishing Plant is from D.R. Duncan et al. (1993).

\subsubsection{Waste Management Operations}

This section describes the different methods used to concentrate waste in the 200 Areas. Evaporating, concentrating, and scavenging are all methods used to reduce liquid volumes or precipitate solids from supernate. Brief descriptions and histories of the operations are presented in alphabetical order. The events and dates described in the brief histories are presented on a time line (Figure 5).

\section{2-A Evaporator-Crystallizer}

"The program objective was to reduce the volume of tanked waste liquors through the boiloff of water. This was accomplished by boiling the liquor in an enclosed vessel at reduced pressure. The evaporation was carried out until a slurry containing about $30 \mathrm{wt} \%$ solids was formed. The slurry was returned to underground waste tanks for cooling, crystallization, and settling. The principal products of waste solidification have been large volumes of sodium nitrate salt cakes and waste liquors that are rich in sodium hydroxide and sodium aluminate." (Wilson and Reep, 1991, p. B-5).

The 242-A Evaporator-Crystallizer began operating on March 18, 1977 (Anderson, 1990) (see Figure 5). In 1981, the evaporator was shut down for ten months to tie AW Tank Farm into the process (Rockwell, 1985). The evaporator was shut down in 1989 because of regulatory issues, but was restarted in 1994 after extensive modifications (Gerber, 1996) 


\section{2-B Evaporator}

"The first type of waste solidification facility, the 242-B and 242-T Concentrators, was originally used for concentration of bismuth phosphate process waste. In 1951, they began to concentrate cladding/first cycle waste. These concentrators were steam-heated pot evaporators operated outside the waste tanks and at atmospheric pressure. The liquors were partially boiled down and cycled to underground waste storage tanks." (Jungfleisch, 1984, p. 1-5). This evaporator ran for approximately 4 years (Anderson, 1990) (see Figure 5).

\section{2-S Evaporator-Crystallizer}

The 242-S Evaporator-Crystallizer was designed to boil off water from the waste in an enclosed vessel at reduced pressure, similar to the 242-A Evaporator-Crystallizer. "The evaporation was carried out until a slurry containing about $30 \mathrm{wt} \%$ solids was formed. The slurry was returned to underground waste tanks for cooling, crystallization, and settling. The principal products of waste solidification have beer large volumes of sodium nitrate salt cakes and waste liquors that are rich in sodium hydroxide and s. um aluminate." (v ison and Reep, 1991, p. B-5). The evaporator began operating on November 1. 973 (Anderson, 1:0) and was shut down in 1981 (Gerber, 1996) (see Figure 5).

\section{2-T Evaporator}

The 242-T Evaporator, like the 242-B Evaporator, began operating in 1951 (Gerber, 1992) to reclaim nonboiling waste storage capacity in existing tanks (see Figure 5). The evaporator was shut down in the summer of 1955 and modified for tributyl phosphate scavenging (Godfrey, 1965), although scavenging was never performed in this evaporator. The evaporator was restarted on December 3, 1965 and operated until April 15, 1976 (Anderson, 1990).

\section{In-Tank Solidification}

The in-tank solidification systems immobilized high level wastes, that were not self-boiling, by concentrating the waste directly inside of the tanks to form radionuclide-bearing salt cakes (Shefcik, 1964). The first in-tank solidification unit (ITS-1) and the second in-tank solidification unit (ITS-2) operated in tanks in the BY Tank Farm (Caudill, 1965 and 1967). "...one used a hot air sparge (ITS-1) and the other used an immersed electrical heater (ITS-2). The ITS-1 operations were conducted in individual tanks. The ITS-2 concentrations were performed by heating the contents of one tank and moving the heated liquor through a series of other tanks." (Wilson and Reep, 1991, p. B-5).

In-tank solidification units 1 and 2 began operating on March 19, 1965 and February 17, 1968, respectively (see Figure 5). ITS-1 was converted to a cooler for ITS-2 on August 24, 1971. Both units : "e shut down on June 30, 1974 (Anderson, 1990).

\subsubsection{Miscellaneous Waste Sources and Equipment}

Wastes from various other sources on the Hanford Site have been added to the tanks. Some wastes are from the 300 Area, 100 Area production reactors, various laboratories, and catch tanks.

\section{- Critical Mass Laboratories}

The critical mass laboratories were used to study the physics of plutonium solutions and solids to avoid accidently creating a criticality or self-sustained nuclear reaction. The first facility began operating in the 120 Building near 100-F in April 1950 and closed in December 1951. The second 
facility, the 209-E Building, was located next to the Strontium Semiworks and began operating in July 1961 (Ballinger and Hall, 1991). The plutonium used in the lab was reprocessed in PUREX.

\section{4-AR, -BXR, and -CR Process Vaults}

Three of the process vaults are the 244-AR Vault, the 244-BXR Vault, and the 244-CR Vault. These vaults were composed of several process vessels or tanks used to prepare waste for treatment or storage. Specific wastes from tanks can be pumped temporarily to the vaults and later sent directly to desired tanks or processing facilities.

The AR Vault is located north and west of the A Tank Farm and was constructed in 1966. The vaut facilities include a canyon building with process cells containing tanks. The AR Vault has been on standby since 1978 (Leach and Stahl, 1993).

The 244-BXR Vault, located south of the BX Tank Farm began operating in 1952 (Rodenhizer, 1987) and became inactive in 1956. The waste in the vault was difficult to handle, so the vault was jetted with high-pressure steam in 1976. The 244-BXR Vault was used to process sludge in the recovery of uranium from bismuth phosphate metal waste in the tanks (Rodenhizer, 1987).

The 244-CR Vault was constructed in 1952 and is located south of the C Tank Farrn (Leach and Stahl, 1993). Salt-well waste from the C Tank Farm is interimly stored in the CR Vault. The 244-CR Vault was used to process sludge in the recovery of uranium from bismuth phosphate metal waste in the tanks (Rodenhizer, 1987).

\section{4-AR and 204-S Railroad Car Facilities}

The 204-AR rail car unloading facility was built in 1981 (Leach and Stahl, 1993) and replaced the 204-S rail car unloading facility. The facilities were built for pumping liquid radioactive waste from tank cars and sending the waste to 200 East Area tank farms (Leach and Stahl, 1993).

\subsubsection{Time Lines}

Time lines are presented on the following pages that represent many of the events that occurred during the history of the major plants and waste management operations on the Hanford Site. These are the same events as those described in the description of each facility. The plants, associated processes, and methods for managing waste were the main sources of the wastes currently stored in the tanks. Abbreviations are defined in the preceding text and the glossary in Appendix A.

One time line represents the history of each of the tank farms in the northeast quadrant of the 200-East Area (Figure 6). The events represented include the dates of construction, individual tank's entry into service and removal from service, and the deactivation of each tank farm. 


\section{PLANTS / PROCESS - TIME LINE}

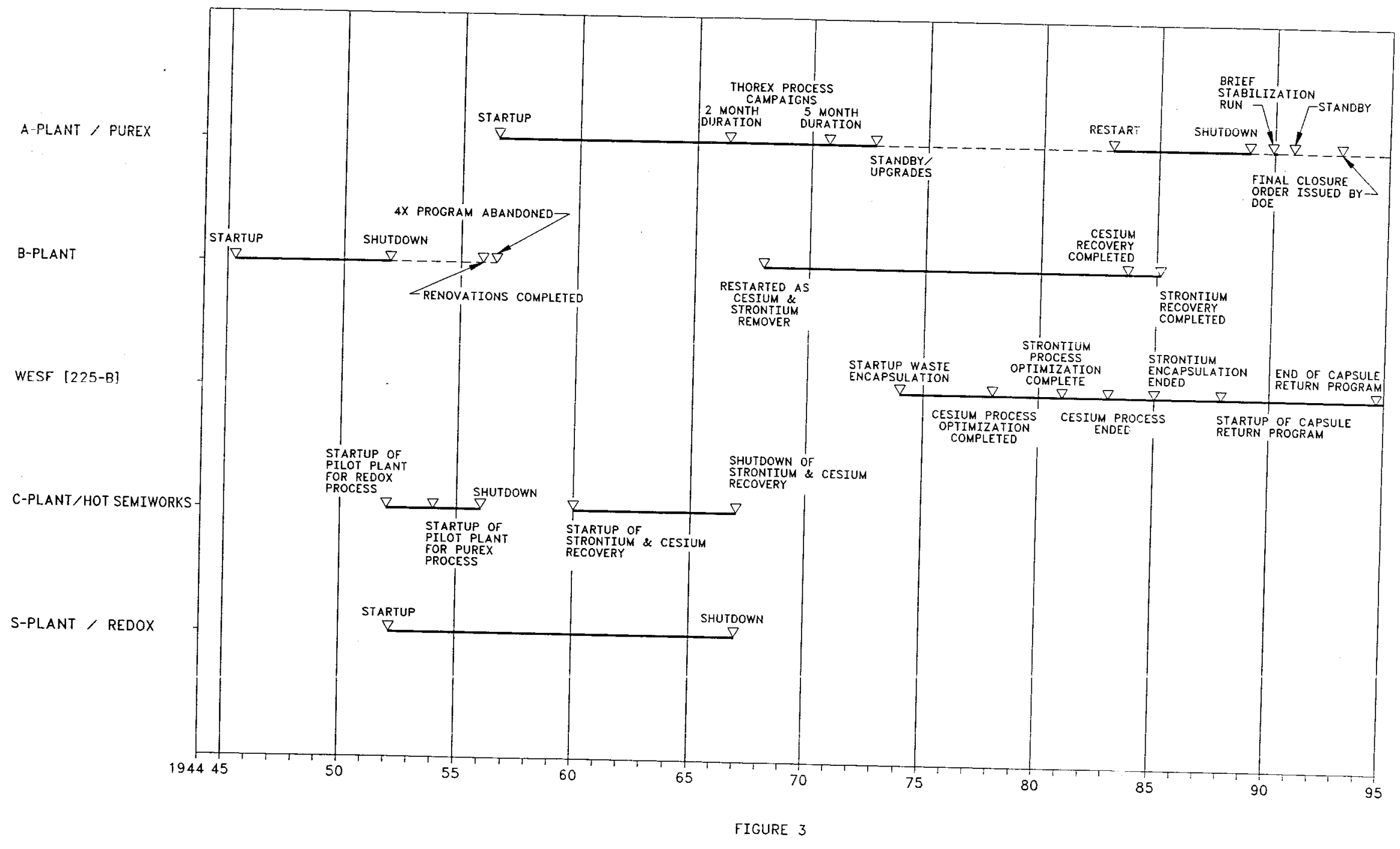




\section{PLANTS / PROCESS - TIME LINE}

T-PLANT

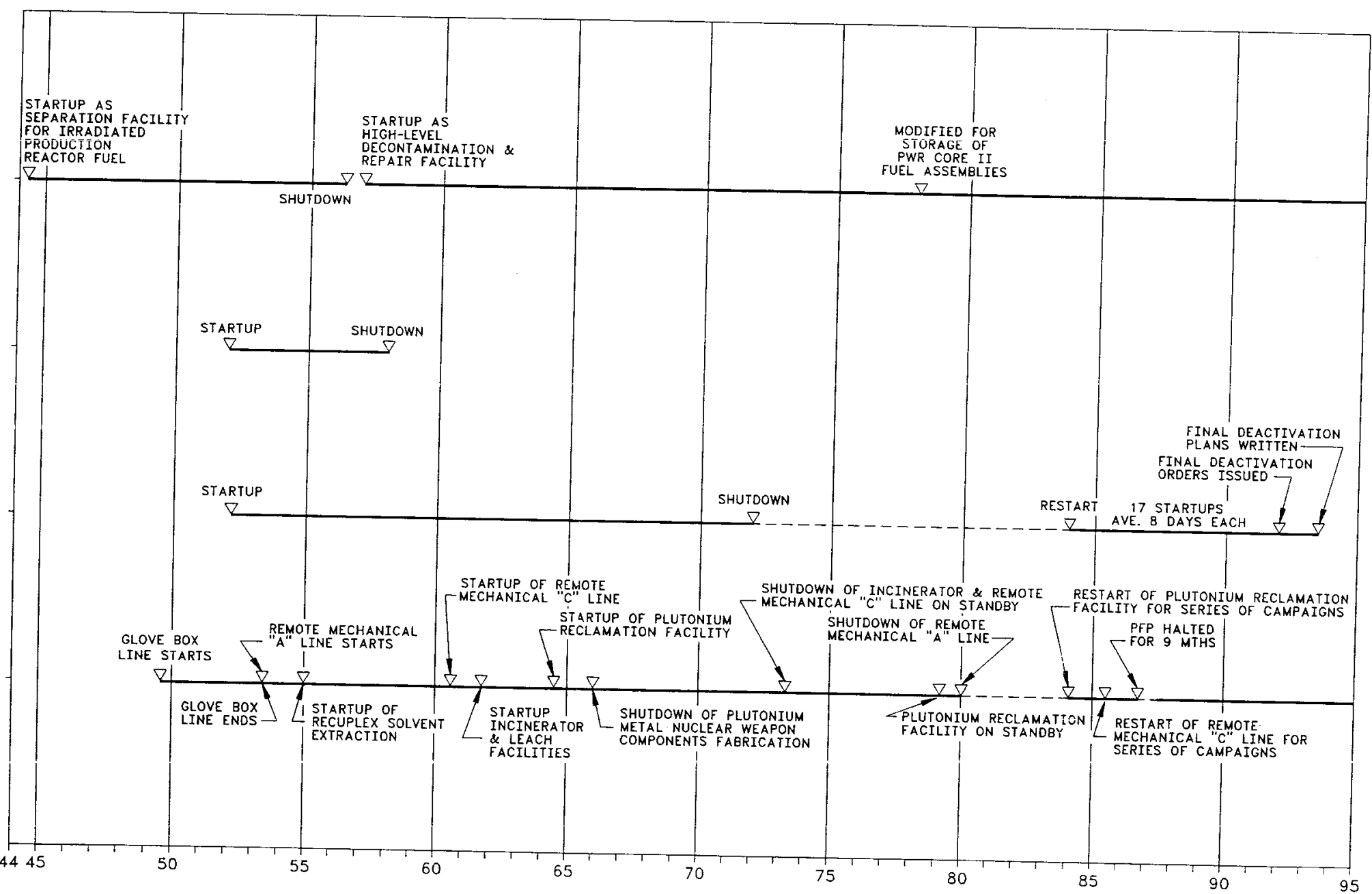

FIGURE 4 

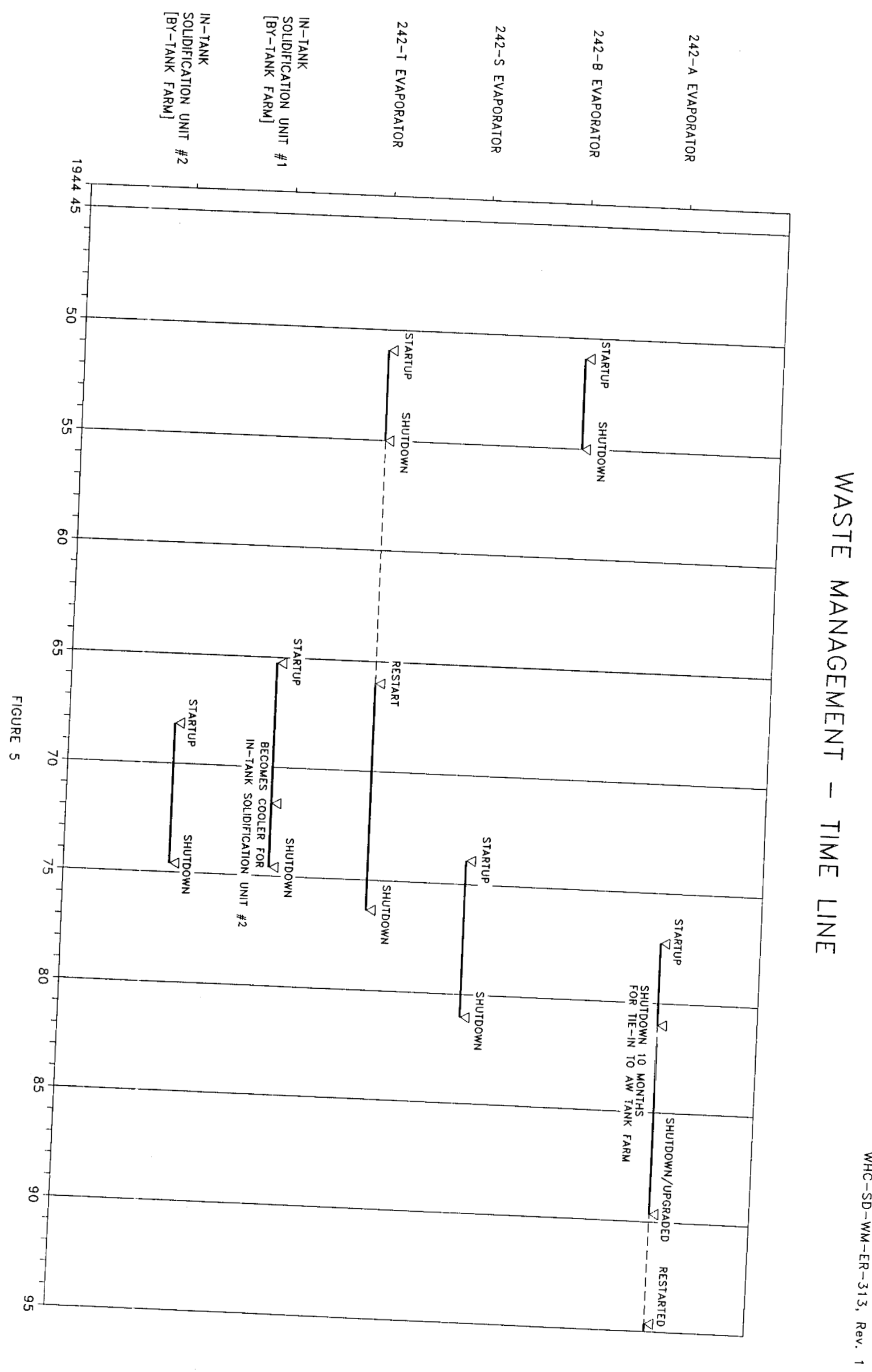


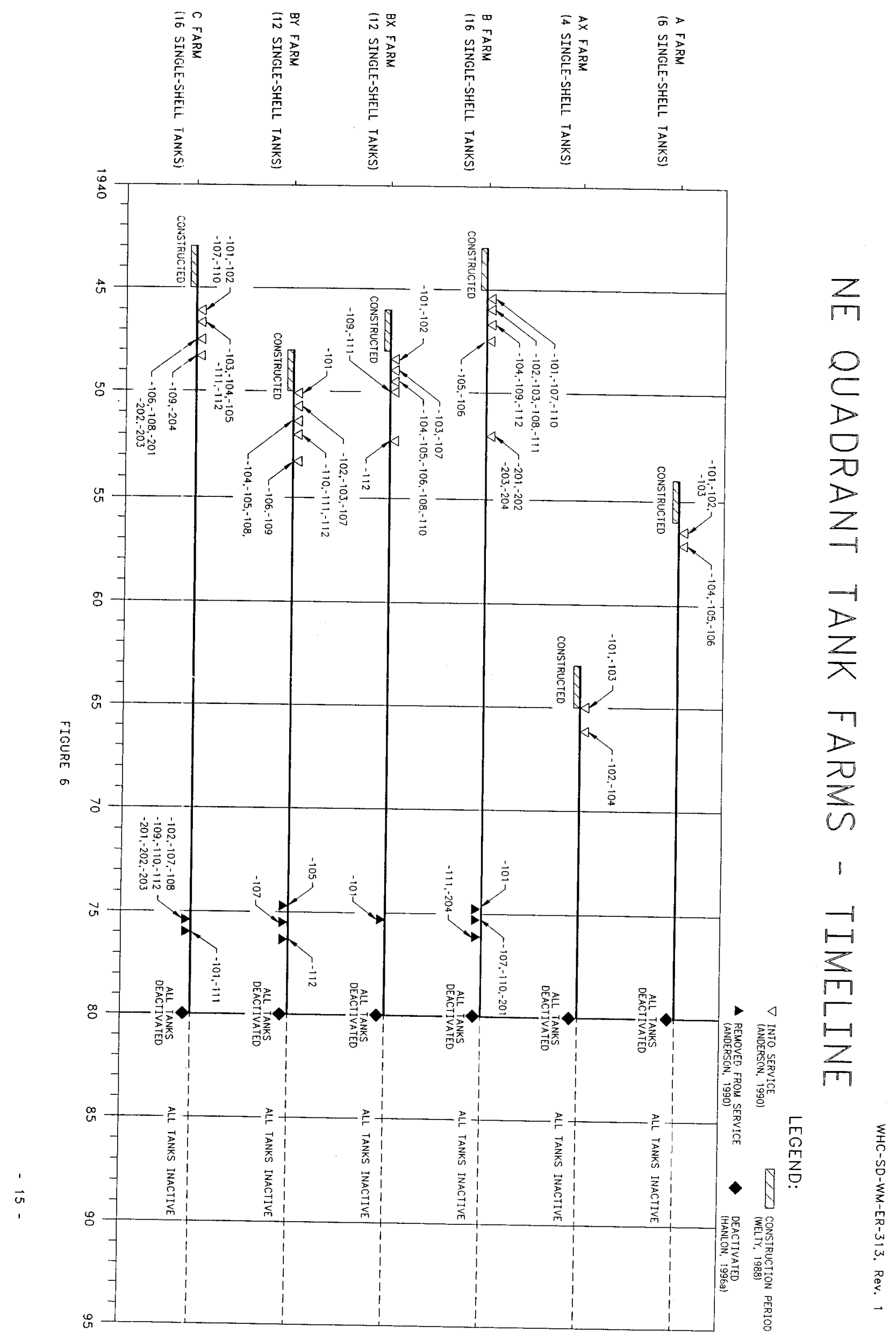




\subsection{Waste and Level History}

The Waste and Level History section of this document is presented by a combination of two methods and is represented by sketches shown in Appendix $C$. The first method presents a graph of waste levels versus time for each tank. The waste levels graphed include the total waste level and the solid waste level. The waste level graphs also include information on transfers, stabilization, intrusion prevention (isolation), salt-well and jet pumping activities, level adjustments, $\mathrm{pH}$, photographs, and a few other miscellaneous items. The second method presents a time line showing the periods of time that different waste types were added to each tank. The time line and the waste level graphs for a given tank have been arranged so that the time axis for each method correlates with one another.

\subsubsection{Source of Data}

The references used to create the total waste level graph and the solid waste level graph for each level history graph are listed below in chronological order beginning with the oldest documents. Anderson (1990) was the source used for level information from when the tanks entered service until the end of 1980 . Level information from 1981 to the present was taken from a series of documents that basically contain the same type of information. These documents have been given various titles over the years but they all reflect the monthly waste status (i.e., waste volumes) for all the tanks. Beginning in 1981, these "monthly waste status reports" have been authored by the following people: O.C. Mudd, O.C. Mudd \& D.C. McCann, D.C. McCann, D.C. McCann \& T.S. Vail, T.S. Vail, T.S. Vail \& G.D. Murry, T.S. Vail \& G.J. Carter, G.J. Carter, G.A Escobar, J.M. Thurman, and B.M. Hanion. The last "monthly waste status report" reviewed was for October 31, 1995 (Hanlon, 1996a). See Appendix B for more complete reference information.

The reference for the transfer information is only Anderson (1990). Anderson has information for all the tanks through 1980. Transfers that may have occurred after 1980 have not been identified on the sketches of the Waste and Level History. For more transfer information not included in this document see Waste Status and Transaction Record Summary for the Northeast Quadrant (Agnew et al., 1995).

The reference for stabilization information is Hanlon (1996a).

For tanks that were intrusion prevented before June 1988, the references Welty (1988). For tanks that were intrusion prevented after June 1988, the references are various "monthly waste status reports". For more complete reference information on intrusion prevention after June 1988, refer to the Waste and Level History sketches in Appendix $\mathrm{C}$ where the references for intrusion prevention have been identified.

The reference for the salt-well pumping completion dates and jet pumping completion dates is Welty (1988). Salt-well and jet pumping activities that may have occurred after the release of Welty's document have not been identified on the Waste and Level History sketches.

Level adjustment dates were taken from various "monthly waste status reports" after and including 1981 and from Anderson (1990) prior to 1981. Anderson's document did not contain a complete listing of the level adjustments prior to 1981. For more complete information on level 
adjustments, refer to the individual "monthly waste status reports." For more complete reference information on level adjustments after 1980, refer to the Waste and Level History sketches in. Appendix $\mathrm{C}$ where the references for these level adjustments have been identified.

The reference source for the $\mathrm{pH}$ information is Borsheim and Kirch (1991). The $\mathrm{pH}$ information after the release of Borsheim and Kirch's document has not been identified on the Waste and Level History sketches.

The photographic information was taken from Appendix $\mathrm{G}$ of this document.

The information on the time lines came from two sources. The reference for the Waste Types Added Time Line was Anderson (1990). The reference for the Primary Additions Time Line was Agnew et al. (1995b).

\subsubsection{Development of Data}

The total waste level graphs and the solids waste level graphs were developed from waste volume information from Anderson (1990) and the "monthly waste status reports." Anderson compiled a listing of total waste volume: and solids waste volumes for all the tanks on a quarterly basis prior to January 1981. Since Anderson's document is a compilation of the "monthly waste status reports" prior to January 1981 , specific "monthly waste status reports" were reviewed when typographical errors were found. In order to continue on a quarterly basis after January 1981, the total waste volumes and the solids waste volumes were taken from the March, June, September, and December additions of the reports. The waste volumes were converted into equivalent waste levels based upon the following equations:

Tanks 241-C-101 through -112:

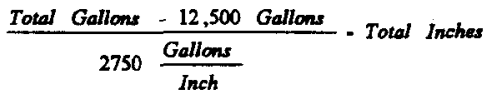

Tanks 241-C-201 through -204:

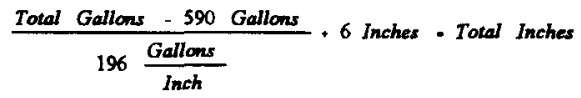

The "0" reference point for the total waste levels and the solids waste levels for tanks 241-C-101 through -112 is at the bottom knuckle inside of the tank. This places the " 0 " reference point 12 inches above the bottom of the tank. The " 0 " reference point for the total waste levels and the solids waste 
levels for tanks 241-C-201 through -204 is at the bottom inside of the tank. The waste levels have been rounded to the nearest thousand gallons $(\mathrm{Kgal})$. In the event that the total waste level and the solids waste level were the same, the reported volumes were reviewed to determine if the reported volumes were the same. If the volumes were the same, only the solids level was graphed. If the volumes were not the same, then both the total waste level and the solids waste level were graphed. The quarteriy waste volumes and associated waste levels have been arranged in tables and are titled the Level History tables. The Level History tables were developed within Microsoft Excel ${ }^{\star}$ and are presented in Appendix C.

The total waste level graphs and the solids waste level graphs were all created within AutoCAD In order to expedite the creation of these graphs, script files were generated from the information contained within the Level History tables. The script files were generated by arranging the waste level information and the corresponding dates from the Level History tables into a Cartesian coordinate system (i.e., $x, y$ coordinates). The script files allowed AutoCAD ${ }^{\circ}$ to automatically generate the graphs on the Waste and Level History sketches.

Transfer information was taken from the "Remarks" column of the Waste Status Summary tables from Anderson (1990). Transfer information was available on a quarterly basis. However, due to the scale of the time axis on the Waste and Level History sketch, the transfer information was placed near the total waste level graph corresponding to the appropriate year. Because of space limitations on the sketches, not all the transfer information available within Anderson's document could be included. For more details about the transfer information, see Anderson (1990).

Intrusion prevention (isolation) dates were taken from Welty (1988) and various "monthly waste status reports". However, Welty and the various "monthly waste status reports" issued before 1993 use the old terminology of interim isolated. In 1993, the term "interim isolated" was replaced with "intrusion prevention." In order to remain consistent with current terms, the Waste and Level History sketches have used the interim isolation dates given by Welty and changed the terminology to intrusion prevention.

The Waste Types Added Time Line information was taken from the "Type Waste" column of the Waste Status Summary tables from Anderson (1990). Since Anderson's document is a compilation of the "monthly waste status reports" prior to January 1981, specific "monthly waste status reports" were reviewed when typographical errors were found. The vertical lines on the time line are boundaries between which the types of wastes identified have been added to the tanks. The vertical lines are spaced a minimum of three years apart.

The Primary Additions Time Line information was taken from the spreadsheets located in Appendix C of the Waste Status and Transaction Record Summary for the Northeast Quadrant (Agnew et al., 1995b). Two columns in the spreadsheet were reviewed to determine the information that would appear on the time line. The first column reviewed was the "Type" column. The "Type" column describes the type of transaction that occurred in a tank. The type of transactions that were reviewed were the transactions that Agnew et al. labeled as "XIN" or "xin". Agnew et al. used these two labels to indicate an addition of primary waste into a tank. According to Agnew et al., "XIN" is an addition of primary waste from a plant and "xin" is a transaction that was derived. If the "Type" column indicated either an "XIN" or "xin", then the "DWXT" column was reviewed for the type of waste added to the 
tank. The waste types defined in the "DWXT" column that corresponded to an "XIN" or "xin" from the "Type" column were the waste types added to the time line. The vertical lines on the Primary Additions Time Line are boundaries between which the types of wastes identified have been added to the tanks. The vertical lines are spaced a minimum of three years apart.

\subsubsection{Assumptions}

An assumption was required in order to begin developing the total waste level graphs and the solid waste level graphs. The assumption was that the tanks did not contain waste prior to the time when Anderson (1990) started recording information.

The waste volume information taken from Anderson (1990) and the various "monthly waste status reports" required an assumption in order to apply the waste volume information to waste level formulas. The actual total waste surface and the actual solid waste surface were assumed to be flat and level.

The total waste level graphs and the solid waste level graphs required an assumption in order to make complete graphs. There were many cases within the Waste Status Summary tables (Anderson, 1990) where the tables lacked waste volume information for one or more consecutive quarters. When this occurred, it was assumed that the waste volume followed an increasing, decreasing, or horizontal linear trend across the quarters in which Anderson lacked the volume information. Because of the linear nature of the waste volume to waste level formulas used to convert waste volumes into waste levels, a linear trend in the volumes results in a linear trend of waste levels on the Waste and Level Fistory sketches.

The solid waste level graphs required an assumption about the time period when the tanks began receiving waste. Information on the solids volume was not recorded in the Waste Status Summary ribles (Anderson, 1990) until well after the tanks started receiving waste. The first accumulation of solids within the tanks was not apparent from information by Anderson. An assumption was made that the first accumulation of solids within each tank followed an increasing linear trend. The first accumulation of solids was also assumed to start at the point where the tank was considered empty. In some tanks, solids were assumed to begin accumulating when the tank first started receiving waste.

\subsubsection{Quality of Data}

The total waste level graphs and the solids waste level graphs on the Waste and Level History sketches were developed by using the waste volume to waste level formulas. There are some limitations with the formulas that affect the waste level results. The formulas have been applied for all volumetric values. However, the formulas do not yield realistic results when the waste volume is less than the volume that can be held below the top of the knuckle. The formulas do not account for construction tolerances on the tanks, the knuckle geometry on the tanks, and the irregularities in the surface of the solid wastes.

The total waste level graphs were developed from the volume data from Anderson (1990) and the "monthly waste status reports." The frequency in which these references have their volume information updated is not consistent with the frequency in which the surface level readings of the SACS 
database are updated. Therefore, a discrepancy may be noticed between the total waste level graphs of the Waste and Level History sketches in Appendix C and the surface level graphs in Appendix $E$.

\subsection{Temperatures}

\subsubsection{Surveillance Techniques}

Interior tank temperatures of the single-shell tanks in C Tank Farm are moritored with thermocouples. Thermocouples are simple devices that develop a millivoltage when parts of the thermocouple are exposed to temperature differentials. The millivoltage can be converted to a temperature reading based upon a specific voltage versus temperature curve inherent to the type of thermocouple being used. Thermocouples are attached to a fabricated assembly called a thermocouple tree. The number of thermocouples attached to the tree varies as a function of the depth of the tank as well as the thermocouple tree design. The thermocouples are spaced at intervals, along trees that have many thermocouples, so that a vertical temperature profile of the tank contents can be developed. The thermocouple tree is installed in a riser and left in place inside the tank. If necessary, the thermocouple tree can be removed from the tank.

\subsubsection{Source of Data}

The source of the interior tank temperature data is from the Westinghouse Hanford Company's Surveillance Analysis Computer System (SACS). SACS is a database that stores temperature data along with other types of surveillance data. PCSACS software on a personal computer is the user interface to the SACS database via the Hanford Local Area Network(HLAN). The SACS database was queried back to 1950 for temperature data. Temperature data identified by the query were categorized and located by SACS in several types of files. These files were evaluated for their usefulness in this document.

The SACS database for temperature data contained one of two types of files depending on the specific tank. One type of file contained data that were not correlated to thermocouple, thermocouple tree, or tiser. This type of file was not used in this document because the lack of information made the data unusable. The second type of file contained interior tank temperature data that were correlated to a particular thermocouple, thermocouple tree, and/or riser. Files of the second type were the only files from SACS that were used in this document for temperature data. After the SACS data files were evaluated, the files that were selected for use in this document were imported using PCSACS into spreadsheets in Microsoft Excel ${ }^{\oplus}$ software.

\subsubsection{Development of Data}

Interior tank temperature data imported from SACS into spreadsheets (Microsoft Excel ${ }^{\oplus}$ ) were rearranged onto separate spreadsheets depending on the data qualifier assigned by SACS custodians. The SACS database custodians labeled the interior tank temperature data using three data qualifiers or categories. The categories are good $(\mathrm{G})$, transcribed $(\mathrm{T})$, and suspect $(\mathrm{S})$. The temperature data were then filtered to remove all the $S$ data, leaving only the $G$ and $T$ data. The filtered data were used to develop graphs of individual thermocouple data. The graphs were developed within Microsoft Excel ${ }^{\star}$. There were two conditions about the temperature data that were evaluated before the graphs of 
individual thermocouple data were developed. The first condition evaluated was the number of data points from a particular thermocouple. If a thermocouple had five or less data points, then a graph was not developed for that particular thermocouple. The second condition evaluated was the time span between consecutive data points. If the time span between consecutive data points was greater than 36 months, then the graph was shown as discontinuous across the span (see Appendix D)

The thermocouple elevations that were identified on the individual thermocouple graphs were determined from design drawings listed in the narratives and from the Thermocouple Starus Single Shell and Double Shell Tanks(Tran, 1993). Tran's document contained design drawing references along with thermocouple elevations. If the design drawings listed in Tran's document could be verified for the individual tanks, then the thermocouple elevations listed by Tran were used. If the design drawings listed in Tran's document could not be verified for an individual tank or if there was no design drawings located, then the thermocouple elevations were labeled as unknown. If Tran's document lacked information about thermocouple elevations for a particular tank and design drawings were located, then the thermocouple elevations were labeled as approximate.

\subsubsection{Assumptions}

The transcribed data points are data points that have not been verified or validated by Westinghouse Hanford Company. Transcribed data were assumed to be good data and were included in the graphs of individual thermocouple data and the statistics. Individual judgements were not made on particular transcribed data points even though they had a high probability of being suspect. Verification and/or validation of data is not the function of this document.

\subsubsection{Quality of Data}

The quality of the interior tank temperature data is noted by the three category labels assigned by the custodians of the SACS database. The good and suspect data points have been verified and/or validated by Westinghouse Hanford Company. The transcribed data points have not been reviewed by Westinghouse Hanford Company. The transcribed data could be classified as either good or suspect at a later date.

This document has treated the transcribed data as good data. However, an area where the transcribed data points have a high probability of being suspect is when the temperature data values are below $45-50^{\circ} \mathrm{F}$. The approximate temperature of the surrounding soil is $45-50^{\circ} \mathrm{F}$ and the soil will prevent the temperature of the tank from dropping below this point. Some of the tanks have many data points below the $45-50^{\circ} \mathrm{F}$ range and should be evaluated carefully as to whether or not they should be considered as good data points.

\subsection{Waste Surface Level}

\subsubsection{Surveillance Techniques}

One of four types of waste surface level devices are used to monitor waste surface levels in a single-shell tank. These devices are: a level indicating transmitter or Food Instrument Corpioration 
(FIC) gauge, a level indicator assembly or manual tape, a high-level detector (an FIC gauge in intrusion mode), and the ENRAF 854 ATG Liquid Level Indicator/Transmitter.

The Food Instrument Corporation gauge is based on conductivity. A plummet is lowered into the tank. When the plummet contacts an electrically conducting surface that is in contact with the edge of the tank, a circuit is completed between the probe and the tank which is grounded to the instrument This triggers the drive motor to stop and the motor brake to engage. The brake is held for 60 seconds, before the motor raises the plummet. The plummet is raised until the circuit is broken. This instrument is used as a high-level detector and an actual level detector. The high-level mode is used to detect intrusions (i.e., any unexplained addition to the tank like rainwater) within the tank. The actual level mode can be read automatically, manually, or both. The automatic FIC reading is automatically read in the field and loaded on the surveillance automated computer system (SACS). FIC readings are aiso read manually in the field and entered into the SACS.

The manual tape flake boxes are an access point for measuring liquid levels manually if other devices fail or do not exist. A hand crank on the flake box is used to lower the tape probe until liquid is contacted and a circuit is completed between the tank and the instruments (similar to the FIC gauge). If the circuit is not closed, the probe is lowered until the tape is slack; then a measurement is recorded.

The ENRAF 854 ATG Liquid Level Indicator/Transmitter has been installed on several tanks and will eventually replace the oid level measurement devices. The ENRAF 854 ATG is a microprocessor controlled surface level gauge. Level detection is based on the principle of buoyancy of a non-floating polyethylene displacer. The displacer is attached to a stainless steel measuring wire. The measuring wire is attached to a measuring drum which is fixed to a riser of known elevation. The weight of the displacer is entered into the memory of a force transducer. A second weight of about 1015 grams less than the actual weight of the displacer is entered into the transducer as the control point. An electronic servomechanism turns the measuring drum causing the displacer to move. As the displacer is put in contact with the surface in question, the displacer will exert a smaller force on the transducer due to buoyancy. The displacer is continually lowered until the force exerted on the transducer is equal to the control point. By knowing the elevations of the riser and tank bottom, and the distance from the riser to the surface of the waste, the surface level of the waste can be determined. If the surface level changes, the displacer will be raised or lowered by the measuring drum depending on the force exerted on the transducer relative to the control point. The ENRAF ${ }^{\circ}$ can be read automatically, manually or both. The automatic ENRAF ${ }^{\circ}$ reading is loaded on the Westinghouse Hanford Company surveiliance automated computer system (SACS). Manual ENRAF ${ }^{\circ}$ readings are taken at any time of day and are manually entered into the SACS.

\subsubsection{Source of Data}

The data recorded from January 1, 1991 to the present for the waste surface levels were obtained from the SACS. PCSACS software on a personal computer is the user interface to the SACS database. The information was parsed in a spreadsheet in Microsoft Exce ${ }^{\circ}$ software and displayed on graphs. Since the intrusion FIC is fixed at a certain elevation, it only records that elevation unless there is an unexplained addition. The device does not truly measure the waste surface level, so the data were not displayed. 


\subsubsection{Development of Data}

Surface level data imported from SACS into spreadsheets (Microsoft Excel ${ }^{\oplus}$ ) were rearranged onto separate spreadsheets depending on the data qualifier assigned by SACS custodians. The SACS database custodians label the surface level data using three data qualifiers or categories. The categories are good $(G)$, transcribed $(T)$, and suspect $(S)$. The surface level data were then filtered to mov all the $S$ data, leaving only the $G$ and $T$ data. The good and transcribed data were displayed on grat: 35 . The graphs show waste level versus time. The data are displayed using the best representative scale on the $y$ axis. If the tank has more than one device to measure the waste surface level, an individual graph was made to display the data from each device. The safety limit maximum waste level is placed in the title of each graph (Dougherty, 1995). Current information on the waste surface levels is in Appendix E.

\subsubsection{Assumptions}

The data obtained from PCSACS are the best available data. The data quality designation, instrument type, and level measurement are accurate. The devices are in good condition and give accurate readings assuming the following: internal tank temperature changes do not cause the tape, wire, or probe to change length; the tape, wire, and probe are straight; the surface profile of the waste is flat; and changes in atmospheric temperature do not effect the portions of the measuring device exposed to the atmosphere.

\subsubsection{Quality of Data}

Surface level readings may be affected by plummet (i.e., manual tape) error, flushing water accumulation, waste surface irregularities, and gas generation. Crystalline wastes (i.e., salt cake) can build up gradually on the end of the plummet and contact the waste which indicates a false surface level increase. Significant level discrepancies occur when the encrusting waste breaks off or when the measuring instrument plummet is flushed to remove the encrusting salt cake. Flushing the Food Instrument Corporation gauge, manual tapes, or any other equipment may cause accumulated wash water to collect under the plummet which can also indicate a false increase in the overall volume of waste within the tank. Surface level readings are often difficult to obtain from tanks with a relatively dry waste surface of salt cake. Some tanks have crystalline waste built up on internal tank equipment (e.g., pumps, thermocouples, and other protruding equipment). As the supernatant liquid is pumped from the tanks, the crystalline structure may remain attached to the equipment and be suspended above the liquid. Therefore, an accurate surface level measurement would be difficult if the breakup $=$ the crystalline structure was inconsistent and a nonuniform waste surface was created. Steel tapes . wires that are bent or warped from operation or those discarded on the waste surface are other sources of altered surface level readings.

Data from the SACS were obtained electronically from the Westinghouse Hanford Company surveillance group and were plotted. The data are actual surface levels recorded from the surveillance equipment. If the surveillance equipment in a particular tank riser was removed from service, the readings may show a level change when a new instrument and/or riser is used, especially if the waste surface shows severe heterogeneity. 
The data used to produce the plots and the data obtained from the surveillance group have been verified as identical. However, errors in the data prior to the exchange of information could still exist. The SACS data were understood to be unverified prior to the exchange. Westinghouse Hanford Company qualified the data with $\mathrm{G}, \mathrm{S}$, and $\mathrm{T}$ for good, suspect, and transcribed, respectively. Data that is labeled transcribed has not been validated or verified by Westinghouse Hanford Company. The criteria for determining data labeled good or suspect is unknown.

\subsection{Riser Configuration}

\subsubsection{Source of Data}

The riser configuration drawings and tables in this report were compiled from design and/or as-built drawings including engineering change notices dated before November 1, 199.5, the Riser Configuration Document for Single-Shell Waste Tanks(Alstad, 1993), and Waste Tank Risers Available for Sampling(Lipnicki, 1995b).

\subsubsection{Development of Data}

There are two drawings and a table in Appendix F that show each tank's approximate riser locations, construction materials, dimensions, and riser function. Alstad (1993) was used as a guide; however, the design and as-built drawings and engineering change notices take precedence. The tables in Appendix F contain the riser number, diameter, sampling, and description of each riser and nozzle. The sampling column lists risers that are tentatively available for sampling (Lipnicki, 1995b). The description and comment column describes the riser's intended use and, if applicable, gives a brief explanation, date, and number of the pertaining engineering change notices in parentheses.

\subsubsection{Assumptions}

The design and as-built drawings are the best available data. All the engineering change notices written against the referenced drawings are released and accurate. Since figures or sources were not listed in Lipnicki (1995), the riser numbers labeled tentatively available for sampling are assumed to be the same as riser numbers listed in Alstad (1993).

\subsubsection{Quality of Data}

The riser configuration section of this document is a mixture of data from three main sources: design and as-built drawings, Riser Configuration Document for Single-Shell Waste Tanks(Alstad, 1993), and Waste Tank Risers Available for Sampling(Lipnicki, 1995b). All these sources do not agree all the time. Alstad (1993) and Lipnicki (1995) reference the design and as-built drawings in their respective documents. The design and as-built drawings contain a plan view of the tank dome and a table explaining the function of each riser. Sometimes the plan view and table do not match. If there was a discrepancy, a comment was made below the table for that tank. Other design and as-built drawings show a cross-sectional view of the tank. Changes made to the structure of a tank may not have been documented by an engineering change notice. The drawings and tables are intended to give the reader information as to approximate location, number of risers, and what equipment the riser might contain. The drawings are not to scale. 


\subsection{Photographs and Montages}

\subsubsection{Source of Data}

The photographs include an aerial photograph of the tank farm and a photographic montage of each tank interior, if available(see Appendix G). All of the photographs were obtained from Boeing Computer Services Richland-Photography. The aerial photographs were reviewed to determine the clearest and most recent representation of the $C$ Tank Farm to be used in this document. Th: nontages were created from sets of interior tank photographs. These sets were also reviewed to determine which ones were the clearest and most recent photographs available. Only interior tank photographs rc resenting the waste surface were used. In some cases, existing montages were the clearest and most ז. :nt; therefore, a new montage was not created.

\subsubsection{Development of Data}

The tank farm aerial photograph was labeled to show tank orientation, identifiable equipment, and structures. Arrows were placed on the tank farm aerial photograph to indicate the cascade overflows. The clearest and most recent montage of the tank interior was labeled to show identifiable monitoring equipment, piping, and risers. A table was also developed listing aerial photograph numbers, ii fior tank montage numbers, photographic set numbers, and the date(see Appendix G).

\subsubsection{Quality of Data}

The interior tank photographs may not represent the actual colors of the waste surface due to possible alteration of colors during copying of the original photographs. To see the colors of the original montage, an original may be ordered through Boeing Computer Services Richland-Photography. Also, radiation could affect the film distorting the apparent colors of the waste. Some tanks had fogging problems in the vapor space which prevented use of the latest photographs. The montage may not reflect the current waste level and waste type due to pumping, additions, mixing, and/or settling of the waste after the photographs were taken. Also, the equipment configuration may not reflect tank upgrades and/or maintenance.

\subsection{Tank Layer Model, Supernatant Mixing Model, and Inventory Estimates}

The Tank Layer Model (TLM), Supernatant Mixing Model (SMM), and Inventory Estimates developed by Los Alamos National Laboratory (LANL) are presented in Appendix $\mathrm{H}$ along with their approach and development sections. The TLM, SMM, and Inventory Estimates presented in this document represent an estimated waste content of the tanks in C Tank Farm based on an inventory estimate date of December 31, 1993.

\subsubsection{Source of Data}

The TLM, SMM, Inventory Estimates, and their approach and development sections presented in this document are from the Hanford Tank Chemical and Radiomuclide Imentories: HDW Model Rev. 3(Agnew et al., 1996). 


\subsubsection{Development of Data}

The data presented in Appendix $\mathrm{H}$ were selectively taken from the Hanford Tank Chemical and Radiomuclide Imventories: HDW Model Rev. 3(Agnew et al., 1996) document to include the TLM, SMM, and the Inventory Estimates for C Tank Farm. The introduction for Agnew's document was included in its entirety. Any reference to appendices in Agnew's introduction and tables in Appendix $\mathrm{H}$ are the appendices of his document. The TLM Working Worksheet(Agnew, 1996, Appendix C) was included for only C Tank Farm. The SMM and TLM Volume Tables(Agnew, 1996, Appendix D) was included for all tanks. The Inventory Estimates(Agnew, 1996, Appendix E) was included for only C Tank Farm. 


\subsection{Tank Farm}

\subsubsection{Tank Farm Information}

The C Tank Farm is located west of Canton Avenue and north of 7th Street in the 200-East Area The farm contains twelve 100 series and four 200 series, dish bottom design, single-shell tanks built in 1943 and 1944 (Welty, 1988). The 100 series tanks are 75 feet in diameter with an operating capacity of 530,000 gallons (Hanlon, 1996a) (see tank cross-section in Appendix F). The 200 series tanks are 20 feet in diameter with an operating capacity of 55,000 gallons (Hanlon, 1996a). The tanks are constructed of a reinforced concrete shell with a steel liner on the interior bottom and sides. The tanks were designed to hold non-boiling waste at a maximum fluid temperature of $220^{\circ} \mathrm{F}$ (Leach and Stahl, 1993). The dome of each tank is penetrated by risers varying in diameter from 4 to 42 inches. All of the tanks have at least five and $a$ half feet of earth cover.

The twelve 100 series tanks were constructed at different elevations with connecting overflow lines that allowed waste to cascade from tank to tank. The 200 series tanks are not connected by cascade lines. There are four cascade sequences in the $\mathrm{C}$ Tank Farm. One cascade is from Tank 241-C-101 through -102 and -103 . The second is from Tank 241-C-104 through -105 and -106 . The third is from Tank 241-C-107 through -108 and -109 , and the fourth is from Tank 241-C-110 through -111 and -112 .

\subsubsection{Tank Farm Waste and Level History}

The Waste and Level History sketches in Appendix C present the waste history and level history of C Tank Farm.

\subsubsection{Tank Farm Temperature History}

Interior tank temperature data for C Tank Farm is quite limited compared to the span of time in which the tanks have been operating. Information about the various temperature monitoring devices and their locations throughout history is also quite limited. The information that was available came from the Surveillance Analysis Computer System (SACS) database. The SACS database had several types of temperature data files available. Data from the files were available as far back as early 1974.

\subsubsection{Tank Farm Occurrences}

Only the occurrences determined as significant are included. The reports presented are incomplete because not all of the documentation on occurrences for $\mathrm{C}$ Tank Farm could be located.

\subsubsection{Tank Farm Current Status}

The tanks in C Tank Farm entered service from 1946 to 1953 (Anderson, 1990). The dates the tanks entered service are based on when the tank first received waste or test water. This date may vary in other documents. The total waste volume for all of the tanks is approximately $1,976,000$ gallons as of November 30, 1995 (Hanlon, 1996b). All tanks are out of service. Tanks 241-C-102, -103, -104, $-105,-106,-107,-108,-109$, and -112 are categorized as sound and Tanks 241-C-101, -110, -111, -201, 
$-202,-203$, and -204 are assumed leakers. Tanks 241-C-102, $-103,-106,-108,-109,-111$, and -112 are on watch lists. See Appendix E for waste surface level graphs. The risers tentatively available for sampling are listed in Appendix F.

\subsubsection{Tank Farm Photograph and Montages}

The photographs for C Tank Farm include an aerial photograph of the farm and a montage of interior tank photographs for each tank. The aerial photograph shows the tank orientation, equipment, and structures. Arrows were placed between the tanks to represent the cascade overflow lines and the flow directions. The interior tank photographs were arranged into montages to show the waste surface, monitoring equipment, piping, and risers in each tank. The photographs and a table listing the photographs, montage numbers, photograph set numbers, and dates of the photographs in this document are in Appendix $\mathbf{G}$.

\subsubsection{Tank Farm Tank Layer Model, Supernatant Mixing Model, and Inventory Estimates}

The Tank Layer Model (TLM), Supernatant Mixing Model (SMM), and Inventory Estimates developed by Los Alamos National Laboratory (Agnew et al., 1996) for C Tank Farm are presented in Appendix $\mathrm{H}$ along with their introduction sections. 


\subsection{Tank 241-C-101}

\subsubsection{Waste and Level History of Tank 241-C-101}

The Waste and Level History sketch in Appendix $C$ presents the waste history and level history of Tank 241-C-101.

\subsubsection{Temperature History of Tank 241-C-101}

Interior tank temperature data for Tank 241-C-101 were recorded by 11 thermocouples attached to one thermocouple tree. Documentation of the design configuration of the thermocouple tree was not located. The design of the thermocouple tree is unclear and the elevations of the individual thermocouples are unknown. The Surveillance Analysis Computer System (SACS) indicates that the thermocouple tree is located in riser 2 . In the past, other risers and equipment may have been used to monitor the temperature in the tank. However, the thermocouple tree located at riser 2 is the only source of temperature data for this document. The temperature data were obtained from the SACS database on January 9, 1996. The earliest data retrieved from the SACS were from late July 1974.

Graphs of individual thermocouple data are presented in Appendix D. A graph was created for each thermocouple. The following statistical information was taken from all 11 thermocouples. The maximum temperature was $111.992^{\circ} \mathrm{F}$ taken by thermocouples 1 and 2 on September 30,1974 and by thermocouples 1 and 10 on October 7, 1974. The minimum temperature was $62^{\circ} \mathrm{F}$ taken by thermocouple 11 on March 7, 1980. The maximum and minimum temperatures are labeled as good data points within the SACS. The average temperature for all the thermocouples is $90^{\circ} \mathrm{F}$

\subsubsection{Occurrences for Tank 241-C-101}

No significant occurrences are associated only with Tank 241-C-101.

\subsubsection{Current Status of Tank 241-C-101}

Tank 241-C-101 entered service during the first quarter of 1946 (Anderson, 1990) and as of November 30, 1995 stores approximately 88,000 gallons of waste (Hanlon, 1996b). The waste surface level in the tank is measured with a manual tape as of January 1996. The minimum waste surface level was 20.5 inches on October 22, 1994. The maximum waste surface level was 28.5 inches on July 1, 1991 and April 13, 1994. See Appendix E for details on waste surface level. The tank is out of service with interim stabilization and intrusion prevention completed. The tank is listed as an assumed leaker and is passively ventilated. A plan view in Appendix F depicts the approximate riser locations as of February 2, 1996. Tank 241-C-101 has 10 risers with three tentatively available for sampling: two 4-inch risers (Nos. 1 and 8) and one 12-inch riser (No. 7) (Lipnicki, 1995b).

\subsubsection{Interior Montage of Tank 241-C-101}

The clearest and most recent set of interior tank photographs was taken on November 17, 1987. Other interior tank photographs are available, but only the photographs showing the waste surface were 
used to create a montage. The montage has labels identifying some of the monitoring equipment, piping, and risers in the tank. The montage and photographic information are shown in Appendix $G$.

2.1.6 Tank Layer Model, Supernatant Mixing Model, and Inventory Estimate of Tank 241-C-101

The Tank Layer Model(TLM), Supernatant Mixing Model(SMM), and Inventory Estimate developed by Los Alamos National Laboratory (Agnew et al., 1996) for Tank 241-C-101 are presented in Appendix $\mathrm{H}$ along with their introduction sections. 


\subsubsection{Waste and Level History of Tank 241-C-102}

The Waste and Level History sketch in Appendix $\mathrm{C}$ presents the waste history and level history of Tank 241-C-102. The assumed solids level for this tank does not follow the assumptions developed in the introduction. Due to there being only one data point for the solids volume in 1958, it was assumed the solids level went up to that point and then went back down to zero within that year since the tank was being scavenged. The assumed solids line from 1959 to 1965 was drawn in so that the solids did not exceed the total waste level during that period.

\subsubsection{Temperature History of Tank 241-C-102}

Interior tank temperature data for Tank 241-C-102 were recorded by 11 thermocouples attached to one thermocouple tree. Documentation of the design configuration of the thermocouple tree was not located. The design of the thermocouple tree is unclear and the elevations of the individual thermocouples are unknown. The Surveillance Analysis Computer System (SACS) indicates that the thermocouple tree is located in riser 7. Drawing H-2-73342, Rev. 4, indicates that riser I was once associated with temperature monitoring. It is unclear what type of information was gathered or what type of temperature monitoring equipment was located at this riser. In the past, other risers and equipment may have been used to monitor the temperanure in the tank. However, the thermocouple tree located at riser 7 is the only source of temperature data for this document. The temperature data were obtained from the SACS database on January 9, 1996. The earliest data retrieved from the SACS were from early November 1975.

Graphs of individual thermocouple data are presented in Appendix D. A graph was created for each thermocouple. The following statistical information was taken from all 11 thermocouples. The maximum temperature was $106^{\circ} \mathrm{F}$ taken by thermocouple 1 on February 26,1978 . The minimum temperature was $52^{\circ} \mathrm{F}$ taken by thermocouple 11 on March 29, 1978. The maximum and minimum temperatures are labeled as good data points within the SACS. The average temperature for all the thermocouples is $80^{\circ} \mathrm{F}$.

\subsubsection{Occurrences for Tank 241-C-102}

No significant occurrences are associated only with Tank 241-C-102.

\subsubsection{Current Status of Tank 241-C-102}

Tank 241-C-102 entered service during the second quarter of 1946 (Anderson, 1990) and as of November 30, 1995 stores approximately 316,000 gallons of waste (Hanlon, 1996b). The waste surface level in the tank is measured with a manual FIC level gauge as of January 1996. The minimum waste surface level was 146 inches on July 31, 1995. The maximum waste surface level was 149.9 inches on numerous dates from January 21, 1991 through March 1, 1993. See Appendix E for details on waste surface level. The tank is out of service with interim stabilization and partial interim isolation completed. The tank is listed as sound and is passively ventilated. Tank 241-C-102 was added to the Organics Watch List in May 1994. A plan view in Appendix F depicts the approximate riser locations as of 
February 2, 1996. Tank 241-C-102 has 10 risers with two tentatively available for sampling: two 12-inch risers (Nos. 2 and 3) (Lipnicki, 1995b).

\subsubsection{Interior Montage of Tank 241-C-102}

The clearest and most recent set of interior tank photographs was taken on Mav 17, 1976. Other interior tank photographs are available, but only the photographs showing the waste surface were used to create a montage. The montage has labels identifying some of the monitoring equipment, piping, and risers in the tank. The montage and photographic information are shown in Appendix $\mathrm{G}$.

\subsubsection{Tank Layer Model, Supernatant Mixing Model, and Inventory Estimate of Tank 241-C-102}

The Tank Layer Model(TLM), Supernatant Mixing Model(SMM), and Inventory Estimate developed by Los Alamos National Laboratory (Agnew et al., 1996) for Tank 241-C-102 are presented in Appendix $\mathrm{H}$ along with their introduction sections. 


\subsection{Tank 241-C-103}

\subsubsection{Waste and Level History of Tank 241-C-103}

The Waste and Level History sketch in Appendix C presents the waste history and level history of Tank 241-C-103.

\subsubsection{Temperature History of Tank 241-C-103}

Interior tank temperature data for Tank 241-C-103 were recorded by six thermocouples attached to one thermocouple tree. Drawing H-2-90342, Sht. 2, Rev. 2, indicates that a thermocouple tree is located in riser 1 and is designed as shown on Drawing H-2-90342, Sht. 1, Rev. 4. However, the thermocouple tree design only indicates three thermocouples. The Surveillance Analysis Computer System (SACS) indicates that the thermocouple tree is located in riser 1 with six thermocouples. The design of the thermocouple tree is unclear and the elevations of the individual thermocouples are unknown. In the past, other risers and equipment may have been used to monitor the temperature in the tank. However, the thermocouple tree located at riser 1 is the only source of temperature data for this document. The temperature data were obtained from the SACS database on January 9, 1996. The earliest data retrieved from the SACS were from late July 1974.

Graphs of individual thermocouple data are presented in Appendix D. A graph was created for each thermocouple. The following statistical information was taken from all six thermocouples. The maximum temperature was $168^{\circ} \mathrm{F}$ taken by thermocouple 2 on November 29, 1977. The minimum temperature was $57^{\circ} \mathrm{F}$ taken by thermocouple No. 6 on August 10,1977. The maximum and minimum temperatures are labeled as good data points within the SACS. The average temperature for all the thermocouples is $112^{\circ} \mathrm{F}$.

\subsubsection{Occurrences for Tank 241-C-103}

An unusual occurrence report was issued in October 1988 due to a decrease in the surface level. The loss of liquid was attributed to natural breathing of the tank.

An off-normal occurrence report was issued in November 1990 due to a decrease in the surface level. The loss of liquid was attributed to evaporation.

\subsubsection{Current Status of Tank 241-C-103}

Tank 241-C-103 entered service during the third quarter of 1946 (Anderson, 1990) and as of November 30, 1995 stores approximately 195,000 gallons of waste (Hanlon, 1996b). The waste surface level in the tank is measured with an automatic and manual ENRAF level gauge as of January 1996. The minimum waste surface level was 65.9 inches on October 18, 1993. The maximum waste surface level was 69.27 inches on May 21, 1995. See Appendix E for details on waste surface level. Tank 241-C-103 was added to the Organics Watch List in January 1991. The tank is out of service with interim stabilization and partial interim isolation completed. The tank is listed as sound and is passively 
ventilated. A plan view in Appendix F depicts the approximate riser locations as of February 2, 1996. Tank 241-C-103 has 10 risers with two tentatively available for sampling: two 12-inch risers (Nos. 2 and 7) (Lipnicki, 1995b).

\subsubsection{Interior Montage of Tank 241-C-103}

The clearest and most recent set of interior tank photographs was taken on July 28, 1987. Other interior tank photographs are available, but only the photographs showing the waste surface were used to create a montage. The montage has labels identifying some of the monitoring equipment, piping, and risers in the tank. The montage and photographic information are shown in Appendix $G$.

2.3.6 Tank Layer Model, Supernatant Mixing Model, and Inventory Estimate of Tank 241-C-103

The Tank Layer Model(TLM), Supernatant Mixing Model(SMM), and Inventory Estimate developed by Los Alamos National Laboratory (Agnew et al., 1996) for Tank 241-C-103 are presented in Appendix $\mathrm{H}$ along with their introduction sections. 


\subsection{Tank 241-C-104}

\subsubsection{Waste and Level History of Tank 241-C-104}

The Waste and Level History sketch in Appendix $C$ presents the waste history and level history of 'Tank 241-C-104.

\subsubsection{Temperature History of Tank 241-C-104}

Interior tank temperature data for Tank 241-C-104 were recorded by 12 thermocouples attached to one thermocouple tree. Drawing H-2-99138, Sht. 2, Rev. 1, indicates that a thermocouple tree is located in riser 7 and is designed as shown on Drawing H-2-99138, Sht. 1, Rev. I. However, the thermocouple tree design only indicates 10 thermocouples. The Surveillance Analysis Computer System (SACS) indicates that the thermocouple tree is located in riser 7 with 12 thermocouples. The design of the thermocouple tree is unclear and the elevations of the individual thermocouples are unknown. In the past, other risers and equipment may have been used to monitor the temperature in the tank. However, the thermocouple tree located at riser 7 is the only source of temperature data for this document. The temperature data were obtained from the SACS database on January 9, 1996. The earliest data retrieved from the SACS were from late July 1974.

Graphs of individual thermocouple data are presented in Appendix D. A graph was created for each thermocouple. The following statistical information was taken from all 12 thermocouples. The maximum temperature was $195^{\circ} \mathrm{F}$ taken by thermocouple No. 3 on July 24, 1982. The minimum temperature was $53^{\circ} \mathrm{F}$ taken by thermocouple No. 5 on January 14, 1978. The maximum and minimum temperatures are labeled as good data points within the SACS. The average temperature for all the thermocouples is $95^{\circ} \mathrm{F}$.

\subsubsection{Occurrences for Tank 241-C-104}

No significant occurrences are associated only with Tank 241-C-104.

\subsubsection{Current Status of Tank 241-C-104}

Tank 241-C-104 entered service during the fourth quarter of 1946 (Anderson, 1990) and as of November 30, 1995 stores approximately 295,000 gallons of waste (Hanlon, 1996b). The waste surface level in the tank is measured with a manual FIC level gauge as of January 1996. The minimum waste surface level was 86.05 inches on January 1, 1996. The maximum waste surface level was 90.2 inches on numerous dates from January 3, 1991 through February 5, 1991. See Appendix E for details on waste surface level. The tank is out of service with interim stabilization and intrusion prevention completed. The tank is listed as sound and is actively ventilated. A plan view in Appendix $F$ depicts the approximate riser locations as of February 2, 1996. Tank 241-C-104 has 11 risers with two tentatively available for sampling: one 10-inch riser (No. 2) and one 12-inch riser (No. 3) (Lipnicki, 1995b). 


\subsubsection{Interior Montage of Tank 241-C-104}

The clearest and most recent set of interior tank photographs was taken on July 25, 1990 Other interior tank photographs are available, but only the photographs showing the waste surface were used to create a montage. The montage has labels identifying some of the monitoring equipment, piping, and risers in the tank. The montage and photographic information are shown in Appendix G.

2.4.6 Tank Layer Model, Supernatant Mixing Model, and Inventory Estimate of Tank 241-C-104

The Tank Layer Model(TLM), Supernatant Mixing Model(SMM), and Inventory Estimate developed by Los Alamos National Laboratory (Agnew et al., 1996) for Tank 241-C-104 are presented in Appendix $\mathrm{H}$ along with their introduction sections. 


\subsection{Tank 241-C-105}

\subsubsection{Waste and Level History of Tank 241-C-105}

The Waste and Level History sketch in Appendix $\mathrm{C}$ presents the waste history and level history of Tank 241-C-105. The level history data for the second quarter of 1987 through the fourth quarter of 1987 are questionable because the solids waste is greater than the total waste.

\subsubsection{Temperature History of Tank 241-C-105}

Interior tank temperature data for Tank 241-C-105 were recorded by six thermocouples attached to one thermocouple tree. Drawing H-2-90342, Sht. 2, Rev. 2, indicates that a thermocouple tree is located in riser 1 and is designed as shown on Drawing H-2-90342, Sht. 1, Rev. 4. However, the thermocouple tree design only indicates three thermocouples. Drawing H-2-99138, Sht. 2, Rev. 1, indicates that a thermocouple tree is located in riser 1 and riser 6 and they are designed as shown on Drawing H-2-99138, Sht. 1, Rev. 1. However, these thermocouple tree designs only indicate ten thermocouples each. The Surveillance Analysis Computer System (SACS) indicates that the thermocouple tree is located in riser 1 with six thermocouples. The design of the thermocouple tree is unclear and the elevations of the individual thermocouples are unknown. In the past, other risers and equipment may have been used to monitor the temperature in the tank. However, the thermocouple tree located at riser 1 is the only source of temperature data for this document. The temperature data were obtained from the SACS database on January 9, 1996. The earliest data retrieved from the SACS were from mid August 1974.

Graphs of individual thermocouple data are presented in Appendix D. A graph was created for each thermocouple. The following statistical information was taken from all six thermocouples. The maximum temperature was $156.2^{\circ} \mathrm{F}$ taken by thermocouple No. 1 on November 5,1976 . The minimum temperature was $40^{\circ} \mathrm{F}$ taken by thermocouple No. 1 on May 10, 1982. The maximum and minimum temperatures are labeled as good data points within the SACS. The average temperature for all the thermocouples is $95^{\circ} \mathrm{F}$.

\subsubsection{Occurrences for Tank 241-C-105}

No significant occurrences are associated only with Tank 241-C-105.

\subsubsection{Current Status of Tank 241-C-105}

Tank 241-C-105 entered service during the first quarter of 1947 (Anderson, 1990) and as of November 30, 1995 stores approximately 134,000 gallons of waste (Hanlon, 1996b). The waste surface level in the tank is measured with a manual FIC level gauge as of January 1996. The minimum waste surface level was 43.55 inches on January 29,1996 . The maximum waste surface level was 48.9 inches on numerous dates from January 1, 1991 through January 12, 1991. See Appendix E for details on waste surface level. The tank is out of service with interim stabilization and partial interim isolation completed. The tank is listed as sound and is actively ventilated. A plan view in Appendix F depicts the approximate riser locations as of February 2, 1996. Tank 241-C-105 has 12 risers with two tentatively available for sampling: one 4-inch riser (No. 8) and one 12-inch riser (No. 2) (Lipnicki, 1995b). 


\subsubsection{Interior Montage of Tank 241-C-105}

The clearest and most recent set of interior tank photographs was taken on April 1, 1988. Other interior tank photographs are available, but only the photographs showing the waste surface were used to create a montage. The montage has labels identifying some of the monitoring equipment, piping, and risers in the tank. The montage and photographic information are shown in Appendix $G$.

2.5.6 Tank Layer Model, Supernatant Mixing Model, and Inventory Estimate of Tank 241-C-105

The Tank Layer Model(TLM), Supernatant Mixing Model(SMM), and Inventory Estimate developed by Los Alamos National Laboratory (Agnew et al., 1996) for Tank 241-C-105 are presented in Appendix $\mathrm{H}$ along with their introduction sections. 


\subsection{Tank 241-C-106}

\subsubsection{Waste and Level History of Tank 241-C-106}

The Waste and Level History sketch in Appendix C presents the waste history and level history of Tank 241-C-106.

\subsubsection{Temperature History of Tank 241-C-106}

Interior tank temperature data for Tank 241-C-106 were recorded by thermocouples located on two different thermocouple trees. Drawing H-2-90342, Sht. 2, Rev. 2, indicates that a thermocouple tree is located in riser 8 and is designed as shown on Drawing H-2-90342, Sht. 1, Rev. 4 with six thermocouples. The Surveillance Analysis Computer System (SACS) indicates that a thermocouple tree is located in riser 8. Drawing H-2-99138, Sht. 2, Rev. 1, indicates that a thermocouple tree is located in riser 8 and riser 14 and they are designed as shown on Drawing H-2-99138, Sht. 1, Rev. 1. However, these thermocouple tree designs indicate ten thermocouples each. The SACS indicates that the thermocouple tree located in riser 8 has six thermocouples. It is assumed that the thermocouple tree in riser 8 is designed as shown on drawing H-2-90342, Sht. 1, Rev. 4. The SACS indicates that the thermocouple tree located in riser 14 has 12 thermocouples. The design of the thermocouple tree in riser 14 is unclear and the elevations of the individual thermocouples are unknown. In the past, other risers and equipment may have been used to monitor the temperature in the tank. However, the thermocouple trees located at Risers 8 and 14 are the only sources of temperature data for this document.

The temperature data were obtained from the SACS database on January 9, 1996. The SACS database contained two file types for temperature data: a historical file and a file with temperature data tied to Risers 8 and 14. Since there was no way to correlate the data in the historical file with a particular thermocouple, thermocouple tree, or riser, data from this file were not included in this document. Only data from the files that tied the temperature data to Risers 8 and 14 were used. The earliest data retrieved from the SACS were from mid April 1984.

Graphs of individual thermocouple data are presented in Appendix D. A graph was created for each thermocouple. The following statistical information was taken from all 18 thermocouples. The maximum temperature was $216.5^{\circ} \mathrm{F}$ taken by thermocouple No. 1 in riser 14 on August 2,1994 . The

minimum temperature was $45^{\circ} \mathrm{F}$ taken by thermocouple No. 10 in riser 14 on June 11,1982 . The maximum and minimum temperatures are labeled as good data points within SACS. The average temperature for all the thermocouples is $99^{\circ} \mathrm{F}$.

\subsubsection{Occurrences for Tank 241-C-106}

An occurrence report was issued in November 1990 when the liquid level slowly rose to the increase limit of two inches. The increase was preceded by the failure of both the exhauster and the FIC gauge. 


\subsubsection{Current Status of Tank 241-C-106}

Tank 241-C-106 entered service during the third quarter of 1947 (Anderson, 1990) and as of November 30, 1995 stores approximately 229,000 gallons of waste (Hanlon, 1996b). The waste surface level in the tank is measured with an automatic ENRAF level gauge as of January 1996 . The minimum waste surface level was 69.2 inches on June 1,1994 . The maximum waste surface level was 79.1. inches on July 27, 1994. See Appendix E for details on waste surface level. Tank 241-C-106 was added to the High Heat Load Watch List in January 1991. The tank is out of service with partial interim isolation completed. The tank is listed as sound and is actively ventilated. A plan view in Appendix $F$ depicts the approximate riser locations as of February 2, 1996. Tank 241-C-106 has 13 risers with two tentatively available for sampling: one 4-inch riser (No. 1) and one 12-inch riser (No. 7) (Lipnicki, 1995b).

\subsubsection{Interior Montage of Tank 241-C-106}

The clearest and most recent set of interior tank photographs was taken on April 5, 1979. Other interior tank photographs are available, but only the photographs showing the waste surface were used to create a montage. The montage has labels identifying some of the monitoring equipment, piping, and risers in the tank. The montage and photographic information are shown in Appendix $G$.

\subsubsection{Tank Layer Model, Supernatant Mixing Model, and Inventory Estimate of Tank 241-C-106}

The Tank Layer Model(TLM), Supernatant Mixing Model(SMM), and Inventory Estimate developed by Los Alamos National Laboratory (Agnew et al., 1996) for Tank 241-C-106 are presented in Appendix $\mathrm{H}$ along with their introduction sections. 


\subsection{Tank 241-C-107}

\subsubsection{Waste and Level History of Tank 241-C-107}

The Waste and Level History sketch in Appendix $\mathrm{C}$ presents the waste history and level history of Tank 241-C-107.

\subsubsection{Temperature History of Tank 241-C-107}

Interior tank temperature data for Tank 241-C-107 were recorded by six thermocouples attached to one thermocouple tree. Drawing H-2-90342, Sht. 2, Rev. 2, indicates that a thermocouple tree is located in tiser 5 and is designed as shown on Drawing H-2-90342, Sht. 1, Rev. 4. The Surveillance Analysis Computer System SACS indicates that the thermocouple tree is located in riser 5 . In the past, other risers and equipment may have been used to monitor the temperature in the tank. The temperature data were obtained from the SACS database on January 9, 1996. The earliest data retrieved from SACS were from late April 1975.

Graphs of individual thermocouple data are presented in Appendix D. A graph was created for each thermocouple. The following statistical information was taken from all six thermocouples. The maximum temperature was $168^{\circ} \mathrm{F}$ taken by thermocouple No. 3 on December 6,1988 . The minimum temperature was $71^{\circ} \mathrm{F}$ taken by thermocouple No. 1 on September 3, 1977. The maximum temperature is labeled as a transcribed data point and the minimum temperature is labeled as a good data point within the SACS. The average temperature for all the thermocouples is $117^{\circ} \mathrm{F}$.

\subsubsection{Occurrences for Tank 241-C-107}

An occurrence report was issued in August 1992 because of increasing activity monitored from the top 20 feet of a drywell. The increasing activity was due to residual radioactive waste within the 110-C saltwell transfer line. When the line was flushed, the drywell readings returned to pre-event levels.

\subsubsection{Current Status of Tank 241-C-107}

Tank 241-C-107 entered service during the second quarter of 1946 (Anderson, 1990) and as of November 30, 1995 stores approximately 237,000 gallons of waste (Hanlon, 1996b). The waste surface level in the tank is measured with an automatic and manual ENRAF ${ }^{\circ}$ level gauge as of January 1996. The minimum waste surface level was 86.1 inches on September 22, 1995 and January 14, 1996. The maximum waste surface level was 106.2 inches on April 29, 1991. See Appendix E for details on waste surface level. The tank is out of service with interim stabilization and partial interim isolation completed. The tank is listed as sound and is passively ventilated. A plan view in Appendix F depicts the approximate riser locations as of February 2, 1996. Tank 241-C-107 has 9 risers with four tentatively available for sampling: one 4-inch riser (No. 4) and three 12-inch risers (Nos. 2, 3, and 7) (Lipnicki, 1995b). 
WHC-SD-WM-ER-313. Rev. 1

\subsubsection{Interior Montage of Tank 241-C-107}

No clear and recent set of interior tank photographs was available.

2.7.6 Tank Layer Model, Supernatant Mixing Model, and Inventory Estimate of Tank 241-C-107

The Tank Layer Model(TLM), Supernatant Mixing Model(SMM), and Inventory Estimate developed by Los Alamos National Laboratory (Agnew et al., 1996) for Tank 241-C-107 are presented in Appendix $\mathrm{H}$ along with their introduction sections. 


\subsection{Tank 241-C-108}

\subsubsection{Waste and Level History of Tank 241-C-108}

The Waste and Level History sketch in Appendix C presents the waste history and level history of Tank 241-C-108.

\subsubsection{Temperature History of Tank 241-C-108}

Interior tank temperature data for Tank 241-C-108 were recorded by thermocouples located on two different thermocouple trees. ECN No. 169757 and ECN No. 193105 indicate that a thermocouple tree is located in riser 1 and is designed as shown on Drawing H-2-83312, Sht. 1, Rev. 0, with six thermocouples. The Surveillance Analysis Computer System (SACS) indicates that the thermocouple tree is located in riser 1. The SACS indicates that the thermocouple tree located in riser 5 has 11 thermocouples. Documentation of the design configuration of the thermocouple tree in riser 5 was not located. The design of the thermocouple tree in riser 5 is unclear and the elevations of the individual thermocouples are unknown. In the past, other risers and equipment may have been used to monitor the temperature in the tank. However, the thermocouple trees located at Risers 1 and 5 are the only sources of temperature data for this document.

The temperature data were obtained from the SACS database on January 9, 1996. The SACS database contained two file types for temperature data: a historical file and a file with temperature data tied to Risers 1 and 5 . Since there was no way to correlate the data in the historical file with a particular thermocouple, thermocouple tree, or riser, data from this file were not included in this document. Only data from the files that tied the temperature data to Risers $I$ and 5 were used. The earliest data retrieved from the SACS were from late January 1975.

Graphs of individual thermocouple data are presented in Appendix D. A graph was created for each thermocouple. The following statistical information was taken from all 17 thermocouples. The maximum temperature was $98.6^{\circ} \mathrm{F}$ taken by thermocouple No. 1 in riser 5 on May 4, 1980. The minimum temperature was $52^{\circ} \mathrm{F}$ taken by thermocouple No. 2 in riser 5 on March 24, 1994. The maximum and minimum temperatures are labeled as good data points within the SACS. The average temperature for all the thermocouples is $76^{\circ} \mathrm{F}$.

\subsubsection{Occurrences for Tank 241-C-108}

An occurrence report was issued in 1974 because of increasing activity in a drywell. The activity was attributed to the migration of existing contamination.

\subsubsection{Current Status of Tank 241-C-108}

Tank 241-C-108 entered service during the third quarter of 1947 (Anderson, 1990) and as of November 30, 1995 stores approximately 66,000 gallons of waste (Hanlon, 1996b). The waste surface level in the tank is measured with a manual tape as of January 1996. The minimum waste surface level was 13.25 inches on April 1, 1992. The maximum waste surface level was 20 inches on numerous dates from October 6, 1992 through January 4, 1993. See Appendix E for details on waste surface level. 
Tank 241-C-108 was added to the Ferrocyanide Watch List in January 1991. The tank is out of service with interim stabilization and intrusion prevention completed. The tank is listed as sound and is passively ventilated. A plan view in Appendix F depicts the approximate riser locations as of February 2, 1996. Tank 241-C-108 has 9 risers with five tentatively available for sampling: one 4-inch riser (No. 4) and four 12-inch risers (Nos. 2, 3, 6, and 7) (Lipnicki, 1995b).

\subsubsection{Interior Montage of Tank 241-C-108}

No clear and recent set of interior tank photographs was available.

2.8.6 Tank Layer Model, Supernatant Mixing Model, and Inventory Estimate of Tank 241-C-108

The Tank Layer Model(TLM), Supernatant Mixing Model(SMM), and Inventory Estimate developed by Los Alamos National Laboratory (Agnew et al., 1996) for Tank 241-C-108 are presented in Appendix $\mathrm{H}$ along with their introduction sections. 


\subsubsection{Waste and Level History of Tank 241-C-109}

The Waste and Level History sketch in Appendix C presents the waste history and level history of Tank 241-C-109.

\subsubsection{Temperature History of Tank 241-C-109}

Interior tank temperature data for Tank 241-C-109 were recorded by thermocouples located on two different thermocouple trees. Drawing No. H-2-99138, Sht. 2, Rev. 1, indicates that a thermocouple tree is located in riser 3 and is designed as shown on Drawing H-2-99138, Sht. 1, Rev. 1, with 10 thermocouples. The Surveillance Analysis Computer System (SACS) indicates that the thermocouple tree is located in Risers 3. The SACS indicates that the thermocouple tree located in riser 8 has 11 thermocouples. Documentation of the design configuration of the thermocouple tree in riser

8 was not located. The design of the thermocouple tree in riser 8 is unclear and the elevations of the individual thermocouples are unknown. In the past, other risers and equipment may have been used to monitor the temperature in the tank. However, the thermocouple trees located at Risers 3 and 8 are the only sources of temperature data for this document.

The temperature data were obtained from the SACS database on January 9, 1996. The SACS database contained two file types for temperature data: a historical file and a file with temperature data tied to Risers 3 and 8 . Since there was no way to correlate the data in the historical file with a particular thermocouple, thermocouple tree, or riser, data from this file were not included in this document. Only data from the files that tied the temperature data to Risers 3 and 8 were used. The earliest data retrieved from the SACS were from late April 1975.

Graphs of individual thermocouple data are presented in Appendix D. A graph was created for each thermocouple except for thermocouples 6 through 9 in riser 3. Thermocouples Nos. 6 through 9 were not graphed due to a lack of data. The following statistical information was taken from all 21 thermocouples. The maximum temperature was $102^{\circ} \mathrm{F}$ taken by thermocouple No. 1 in riser 8 on November 29,1977 . The minimum temperature was $56^{\circ} \mathrm{F}$ taken by thermocouple No. 11 in riser 8 on May 11, 1983. The maximum and minimum temperatures are labeled as good data points within the SACS. The average temperature for all the thermocouples is $79^{\circ} \mathrm{F}$.

\subsubsection{Occurrences for Tank 241-C-109}

An occurrence report was issued in January 1982 because of increasing activity in a drywell. The activity was attributed to the migration of existing contamination in the vicinity of Tank 241-C-108.

\subsubsection{Current Status of Tank 241-C-109}

Tank 241-C-109 entered service during the second quarter of 1948 (Anderson, 1990) and as of November 30, 1995 stores approximately 66,000 gallons of waste (Hanlon, 1996b). The waste surface level in the tank is measured with a manual tape as of January 1996. The minimum waste surface level was 18 inches on numerous dates from January 21, 1992 through July 2, 1994. The maximum waste 
surface level was 19.5 inches on April 1, 1992. See Appendix E for details on waste surface level. Tank 241-C-109 was added to the Ferrocyanide Watch List in January 1991. The tank is out of service with interim stabilization and intrusion prevention completed. The tank is listed as sound and is passively ventilated. A plan view in Appendix F depicts the approximate riser locations as of February 2, 1996. Tank 241-C-109 has 9 risers with five tentatively available for sampling: one 4-inch riser (No. 4) and four 12-inch risers (Nos. 2, 3,6 and 7) (Lipnicki, 1995b).

\subsubsection{Interior Montage of Tank 241-C-109}

The clearest and most recent set of interior tank photographs was taken on December 9, 1974. Other interior tank photographs are available, but only the photographs showing the waste surface were used to create a montage. The montage has labels identifying some of the monitoring equipment, piping, and risers in the tank. The montage and photographic information are shown in Appendix G.

\subsubsection{Tank Layer Model, Supernatant Mixing Model, and Inventory Estimate of Tank 241-C-109}

The Tank Layer Model(TLM), Supernatant Mixing Model(SMM), and Inventory Estimate developed by Los Alamos National Laboratory (Agnew et al., 1996) for Tank 241-C-109 are presented in Appendix $\mathrm{H}$ along with their introduction sections. 
WHC-SD-WM-ER-313, Rer : 1

\subsection{Tank 241-C-110}

\subsubsection{Waste and Level History of Tank 241-C-110}

The Waste and Level History sketch in Appendix C presents the waste history and level history of Tank 241-C-110.

\subsubsection{Temperature History of Tank 241-C-110}

Interior tank temperature data for Tank $241-\mathrm{C}-110$ were recorded by 11 thermocouples attached to one thermocouple tree. Documentation of the design configuration of the thermocouple tree was not located. The design of the thermocouple tree is unclear and the elevations of the individual thermocouples are unknown. The Surveillance Analysis Computer System (SACS) indicates that the thermocouple tree is located in riser 8 . In the past, other risers and equipment may have been used to monitor the temperature in the tank. However, the thermocouple tree located at riser 8 is the only source of temperature data for this document. The temperature data were obtained from the SACS database on January 9, 1996. The earliest data retrieved from the SACS were from late July 1974

Graphs of individual thermocouple data are presented in Appendix D. A graph was created for each thermocouple. The following statistical information was taken from all 11 thermocouples. The maximum temperature was $118^{\circ} \mathrm{F}$ taken by thermocouple No. 2 on July 10, 1985. The minimum temperature was $31.1^{\circ} \mathrm{F}$ taken by thermocouple No. 1 on January 7,1994 . The maximum temperature is labeled as a good data point and the minimum temperature is labeled as a transcribed data point within the SACS. The average temperature for all the thermocouples is $69^{\circ} \mathrm{F}$.

\subsubsection{Occurrences for Tank 241-C-110}

No significant occurrences are associated only with Tank 241-C-110.

\subsubsection{Current Status of Tank 241-C-110}

Tank 241-C-110 entered service during the second quarter of 1946 (Anderson, 1990) and as of November 30, 1995 stores approximately 178,000 gallons of waste (Hanlon, 1996b). The waste surface level in the tank is measured with a manual tape as of January 1996. The minimum waste surface level was 60.5 inches on numerous dates from May 20, 1995 through June 12, 1995. The maximum waste surface level was 69 inches on numerous dates from April 1, 1991 through November 25, 1991. See Appendix $\mathrm{E}$ for details on waste surface level. The tank is out of service with interim stabilization and partial interim isolation completed. The tank is listed as an assumed leaker and is passively ventilated. A plan view in Appendix F depicts the approximate riser locations as of February 2, 1996. Tank 241-C-110 has 9 risers with six tentatively available for sampling: two 4-inch risers (Nos. 1 and 5) and four 12-inch risers (Nos. 2, 3, 6, and 7) (Lipnicki, 1995b).

\subsubsection{Interior Montage of Tank 241-C-110}

The clearest and most recent set of interior tank photographs was taken on August 12, 1986. Other interior tank photographs are available, but only the photographs showing the waste surface were 
WHC-SD-WM-ER-313, Rev 1

used to create a montage. The montage has labels identifying some of the monitoring equipment, piping, and risers in the tank. The montage and photographic information are shown in Appendix $G$.

2.10.6 Tank Layer Model, Supernatant Mixing Model, and Inventory Estimate of Tank 241-C:-110

The Tank Layer Model(TLM), Supernatant Mixing Model(SMM), and Inventory Estimate developed by Los Alamos National Laboratory (Agnew et al., 1996) for Tank 241-C-110 are presented in Appendix $\mathrm{H}$ along with their introduction sections. 
WHC-SD-WM-ER-313, Rev 1

\subsection{Tank 241-C-111}

\subsubsection{Waste and Level History of Tank 241-C-111}

The Waste and Level History sketch in Appendix C presents the waste history and level history of Tank 241-C-111.

\subsubsection{Temperature History of Tank 241-C-111}

Interior tank termperature data for Tank 241-C-111 were recorded by 11 thermocouples attached to one thermocouple tree. Documentation of the design configuration of the thermocouple tree was not located. The design of the thermocouple tree is unclear and the elevations of the individual thermocouples are unknown. The Surveillance Analysis Computer System (SACS) indicates that the thermocouple tree is located in riser 5 . In the past, other risers and equipment may have been used to monitor the temperature in the tank. However, the thermocouple tree located at riser 5 is the only source of temperature data for this document. The temperature data were obtained from the SACS database on January 9, 1996. The earliest data retrieved from the SACS were from late January 1975.

Graphs of individual thermocouple data are presented in Appendix D. A graph was created for each thermocouple. The following statistical information was taken from all 11 thermocouples. The maximum temperature was $105.8^{\circ} \mathrm{F}$ taken by thermocouple No. 7 on May 10, 1982. The minimum temperature was $52.7^{\circ} \mathrm{F}$ taken by thermocouple No. 9 on April 5, 1994. The maximum and minimum temperatures are labeled as good data points within the SACS. The average temperature for all the thermocouples is $74^{\circ} \mathrm{F}$.

\subsubsection{Occurrences for Tank 24I-C-111}

No significant occurrences are associated only with Tank 241-C-111.

\subsubsection{Current Status of Tank 241-C-111}

Tank 241-C-111 entered service during the third quarter of 1946 (Anderson, 1990) and as of November 30, 1995 stores approximately 57,000 gallons of waste (Hanlon, 1996b). The waste surface level in the tank is measured with a manual tape as of January 1996. The minimum waste surface level was 15 inches on numerous dates from January 3,1994 through February 3, 1994. The maximum waste surface level was 16.5 inches on numerous dates from January 1, 1991 through January 1, 1996. See Appendix E for details on waste surface level. Tank 241-C-111 was added to the Ferrocyanide Watch List in January 1991. The tank is out of service with interim stabilization and intrusion prevention completed. The tank is listed as an assumed leaker and is passively ventilated. A plan view in Appendix $F$ depicts the approximate riser locations as of February 2, 1996. Tank 241-C-111 has 9 risers with six tentatively available for sampling: two 4-inch risers (Nos. 1 and 4) and four 12-inch risers (Nos. 2, 3, 6, and 7) (Lipnicki, 1995b). 


\subsubsection{Interior Montage of Tank 241-C-111}

The clearest and most recent set of interior tank photographs was taken on February 25, 1970. Other interior tank photographs are available, but only the photographs showing the waste surface were used to create a montage. The montage has labels identifying some of the monitoring equipment, piping, and risers in the tank. The montage and photographic information are shown in Appendix $G$.

2.11.6 Tank Layer Model, Supernatant Mixing Model, and Inventory Estimate of Tank 241-C-111

The Tank Layer Model(TLM), Supernatant Mixing Model(SMM), and Inventory Estimate developed by Los Alamos National Laboratory (Agnew et al., 1996) for Tank 241-C-111 are presented in Appendix $\mathrm{H}$ along with their introduction sections. 


\section{12 Tank 241-C-112}

2.12.1 Waste and Level History of Tank 241-C-112

The Waste and Level History sketch in Appendix C presents the waste history and level history of Tank 241-C-112.

\subsubsection{Temperature History of Tank 241-C-112}

Interior tank temperature data for Tank 241-C-112 were recorded by thermocouples located on two different thermocouple trees. Drawing No. H-2-99138, Sht. 2, Rev. 1, indicates that a thermocouple tree is located in riser 8 and is designed as shown on Drawing H-2-99138, Sht. 1, Rev. 1 with 10 thermocouples. The Surveillance Analysis Computer System (SACS) indicates that the thermocouple tree is located in riser 8. The SACS indicates that the thermocouple tree located in riser 1 has 11 thermocouples. Documentation of the design configuration of the thermocouple tree in riser 1 was not located. The design of the thermocouple tree in riser 1 is unclear and the elevations of the individual thermocouples are unknown. In the past, other risers and equipment may have been used to monitor the temperature in the tank. However, the thermocouple trees located at Risers 1 and 8 are the only sources of temperature data for this document.

The temperature data were obtained from the SACS database on January 9, 1996. The SACS database contained two file types for temperature data: a historical file and a file with temperature data tied to Risers 1 and 8 . Since there was no way to correlate the data in the historical file with a particular thermocouple, thermocouple tree, or riser, data from this file were not included in this document. Only data from the files that tied the temperature data to Risers 1 and 8 were used. The earliest data retrieved from SACS were from late April 1975.

Graphs of individual thermocouple data are presented in Appendix D. A graph was created for each thermocouple except for thermocouples 2,5,6, and 7 in riser 1 and thermocouples Nos. 6 through 9 in riser 8. Thermocouple No. 2 in riser 1 was not graphed due to a lack of data. Thermocouples 5 , 6 , and 7 in riser 1 were not graphed because there were no temperature data available. Thermocouples 6 through 9 in riser 8 were not graphed due to a lack of data. The following statistical information was taken from the 15 thermocouples that had temperature data. The maximum temperature was $87.8^{\circ} \mathrm{F}$ taken by thermocouple No. 4 in riser 8 on October 1, 7, 9, 10, and 13, 1994. The minimum temperature was $56^{\circ} \mathrm{F}$ taken by thermocouple No. 8 in riser 1 on March 24, 1994. The maximum and minimum temperatures are labeled as good data points within the SACS. The average temperature for all the thermocouples is $81^{\circ} \mathrm{F}$.

\subsubsection{Occurrences for Tank 241-C-112}

No significant occurrences are associated only with Tank 241-C-112.

\subsubsection{Current Status of Tank 241-C-112}

Tank 241-C-112 entered service during the fourth quarter of 1946 (Anderson, 1990) and as of November 30, 1995 stores approximately 104,000 gallons of waste (Hanlon, 1996b). The waste surface 
level in the tank is measured with a manual tape as of January 1996. The minimum waste surface level was 22.5 inches on January 31,1996 . The maximum waste surface level was 35 inches on November 20, 1992. See Appendix E for details on waste surface level. Tank 241-C-112 was added to the Ferrocyanide Watch List in January 1991. The tank is out of service with interim stabilization and partial interim isolation completed. The tank is listed as sound and is passively ventilated. A plan view in Appendix F depicts the approximate riser locations as of February 2, 1996. Tank 241-C-112 has 9 risers with five tentatively available for sampling: one -inch riser (No. 4) and four 12-inch risers (Nos. 2, 3, 6, and 7) (Lipnicki, 1995b).

\subsubsection{Interior Montage of Tank 241-C-112}

The clearest and most recent set of interior tank photographs was taken on September 18, 1990. Other interior tank photographs are available, but only the photographs showing the waste surface were used to create a montage. The montage has labels identifying some of the monitoring equipment, piping, and risers in the tank. The montage and photographic information are shown in Appendix $G$.

2.12.6 Tank Layer Model, Supernatant Mixing Model, and Inventory Estimate of Tank 241-C-112

The Tank Layer Model(TLM), Supernatant Mixing Model(SMM), and Inventory Estimate developed by Los Alamos National Laboratory (Agnew et al., 1996) for Tank 241-C-112 are presented in Appendix $\mathrm{H}$ along with their introduction sections. 


\subsection{Tank 241-C-201}

\subsubsection{Waste and Level History of Tank 241-C-201}

The Waste and Level History sketch in Appendix $\mathrm{C}$ presents the waste history and level history of Tank 241-C-201.

\subsubsection{Temperature History of Tank 241-C-201}

Interior tank temperature data for Tank 241-C-201 were recorded by 11 thermocouples attached to one thermocouple tree. Documentation of the design configuration of the thermocouple tree was not located. The design of the thermocouple tree is unclear and the elevations of the individual thermocouples are unknown. The Surveillance Analysis Computer System (SACS) indicates that the thermocouple tree is located in riser 6 . In the past, other risers and equipment may have been used to monitor the temperature in the tank. However, the thermocouple tree located at riser 6 is the only source of temperature data for this document. The temperature data were obtained from the SACS database on January 9, 1996. The earliest data retrieved from the SACS were from late April 1975.

Graphs of individual thermocouple data are presented in Appendix D. A graph was created for each thermocouple. The following statistical information was taken from all 11 thermocouples. The maximum temperature was $81^{\circ} \mathrm{F}$ taken by thermocouple No. 1 on February 26, 1978. The minimum temperature was $36^{\circ} \mathrm{F}$ taken by thermocouples 1 through 9 on August 10, 1977. The maximum and minimum temperatures are labeled as transcribed data points within the SACS. The average temperature for all the thermocouples is $63^{\circ} \mathrm{F}$.

\subsubsection{Occurrences for Tank 241-C-201}

No significant occurrences are associated only with Tank 241-C-201.

\subsubsection{Current Status of Tank 241-C-201}

Tank 241-C-201 entered service during the fourth quarter of 1947 (Anderson, 1990) and as of November 30, 1995 stores approximately 2,000 gallons of waste (Hanlon, 1996b). The waste surface level in the tank is measured with a manual tape as of January 1996. The minimum waste surface level was 11 inches on numerous dates from April 1, 1991 through October 1, 1995. The maximum waste surface level was 14 inches on April 13, 1994. See Appendix E for details on waste surface level. The tank is out of service with interim stabilization and intrusion prevention completed. The tank is listed as an assumed leaker and is passively ventilated. A plan view in Appendix F depicts the approximate riser locations as of February 2, 1996. Tank 241-C-201 has 6 risers with two tentatively available for sampling: one 4-inch riser (No. 8) and one 12-inch riser (No. 7) (Lipnicki, 1995b).

\subsubsection{Interior Montage of Tank 241-C-201}

The clearest and most recent set of interior tank photographs was taken on December 2, 1986. Other interior tank photographs are available, but only the photographs showing the waste surface were 
used to create a montage. The montage has labels identifying some of the monitoring equipment, piping, and risers in the tank. The montage and photographic information are shown in Appendix $G$.

2.13.6 Tank Layer Model, Supernatant Mixing Model, and Inventory Estimate of Tank 241-C-201

The Tank Layer Model(TLM), Supernatant Mixing Model(SMM), and Inventory Estimate developed by Los Alamos National Laboratory (Agnew et al., 1996) for Tank 241-C-201 are presented in Appendix $\mathrm{H}$ along with their introduction sections. 


\subsection{Tank 241-C-202}

\subsubsection{Waste and Level History of Tank 241-C-202}

The Waste and Level History sketch in Appendix $\mathrm{C}$ presents the waste history and level history of Tank 241-C-202.

\subsubsection{Temperature History of Tank 241-C-202}

Interior tank temperature data for Tank $241-\mathrm{C}-202$ were recorded by 11 thermocouples attached to one thermocouple tree. Documentation of the design configuration of the thermocouple tree was not located. The design of the thermocouple tree is unclear and the elevations of the individual thermocouples are unknown. The Surveillance Analysis Computer System (SACS) indicates that the thermocouple tree is located in riser 6 . In the past, other risers and equipment may have been used to monitor the temperature in the tank. However, the thermocouple tree located at riser 6 is the only source of temperature data for this document. The temperature data were obtained from the (SACS) database on January 9, 1996. The earliest data retrieved from the SACS were from late April 1975.

Graphs of individual thermocouple data are presented in Appendix D. A graph was created for each thermocouple. The following statistical information was taken from all 11 thermocouples. The maximum temperature was $80^{\circ} \mathrm{F}$ taken by thermocouple No. 1 on February 26, 1978. The minimum temperature was $51.998^{\circ} \mathrm{F}$ taken by thermocouple No. 11 on May 19, 1975. The maximum and minimum temperatures are labeled as good data points within the SACS. The average temperature for all the thermocouples is $63^{\circ} \mathrm{F}$.

\subsubsection{Occurrences for Tank 241-C-202}

No significant occurrences are associated only with Tank 241-C-202.

\subsubsection{Current Status of Tank 241-C-202}

Tank 241-C-202 entered service during the fourth quarter of 1947 (Anderson, 1990) and as of November 30, 1995 stores approximately 1,000 gallons of waste (Hanlon, 1996b). The waste surface level in the tank is measured with a manual tape as of January 1996. The minimum waste surface level was 3.25 inches on January 1, 1995. The maximum waste surface level was 9 inches on April 13, 1994 and January 1, 1996. See Appendix E for details on waste surface level. The tank is out of service with interim stabilization and intrusion prevention completed. The tank is listed as an assumed leaker and is passively ventilated. A plan view in Appendix $\mathrm{F}$ depicts the approximate riser locations as of February 2, 1996. Tank 241-C-202 has 6 risers with two tentatively available for sampling: one 4-inch riser (No. 8) and one 12-inch riser (No. 7) (Lipnicki, 1995b).

\subsubsection{Interior Montage of Tank 241-C-202}

The clearest and most recent set of interior tank photographs was taken on December 9, 1986. Other interior tank photographs are available, but only the photographs showing the waste surface were 
used to create a montage. The montage has labels identifying some of the monitoring equipment, piping, and risers in the tank. The montage and photographic information are shown in Appendix $G$.

2.14.6 Tank Layer Model, Supernatant Mixing Model, and Inventory Estimate of Tank 241-C-202

The Tank Layer Model(TLM), Supernatant Mixing Model(SMM), and Inventory Estimate developed by Los Alamos National Laboratory (Agnew et al., 1996) for Tank 241-C-202 are presented in Appendix $\mathrm{H}$ along with their introduction sections. 


\subsection{Tank 241-C-203}

\subsubsection{Waste and Level History of Tank 241-C-203}

The Waste and Level History sketch in Appendix C presents the waste history and level history of Tank 241-C-203.

\subsubsection{Temperature History of Tank 241-C-203}

Interior tank temperature data for Tank 241-C-203 were recorded by 11 thermocouples attached to one thermocouple tree. Documentation of the design configuration of the thermocouple tree was not located. The design of the thermocouple tree is unclear and the elevations of the individual thermocouples are unknown. The Surveillance Analysis Computer System (SACS) indicates that the thermocouple tree is located in riser 6 . In the past, other risers and equipment may have been used to monitor the temperature in the tank. However, the thermocouple tree located at riser 6 is the only source of temperature data for this document. The temperature data were obtained from the SACS database on January 9, 1996. The earliest data retrieved from the SACS were from late April 1975

Graphs of individual thermocouple data are presented in Appendix D. A graph was created for each thermocouple. The following statistical information was taken from all 11 thermocouples. The maximum temperature was $83^{\circ} \mathrm{F}$ taken by thermocouple No. 1 on February 26, 1978. The minimum temperature was $47^{\circ} \mathrm{F}$ taken by thermocouples 4 through 11 on May 10, 1982. The maximum and minimum temperatures are labeled as good data points within the SACS. The average temperature for all the thermocouples is $61^{\circ} \mathrm{F}$.

\subsubsection{Occurrences for Tank 241-C-203}

No significant occurrences are associated only with Tank 241-C-203.

\subsubsection{Current Status of Tank 241-C-203}

Tank 241-C-203 entered service during the fourth quarter of 1947 (Anderson, 1990) and as of November 30, 1995 stores approximately 5,000 gallons of waste (Hanlon, 1996b). The waste surface level in the tank is measured with a manual tape as of January 1996. The minimum waste surface level was 18 inches on January 1, 1996. The maximum waste surface level was 21.5 inches on April 1, 1991. See Appendix E for details on waste surface level. The tank is out of service with interim stabilization and intrusion prevention completed. The tank is listed as an assumed leaker and is passively ventilated. A plan view in Appendix F depicts the approximate riser locations as of February 2, 1996. Tank 241-C-203 has 6 risers with two tentatively available for sampling: one 4-inch riser (No. 8) and one 12inch riser (No. 7) (Lipnicki, 1995b).

\subsubsection{Interior Montage of Tank 241-C-203}

The clearest and most recent set of interior tank photographs was taken on December 9, 1986. Other interior tank photographs are available, but only the photographs showing the waste surface were 
WHC-SD-WM-ER-3 I3, Rev. I

used to create a montage. The montage has labels identifying some of the monitoring equipment, piping, and risers in the tank. The montage and photographic information are shown in Appendix $G$.

2.15.6 Tank Layer Model, Supernatant Mixing Model, and Inventory Estimate of Tank 241-C-203

The Tank Layer Model(TLM), Supernatant Mixing Model(SMM), and Inventory Estimate developed by Los Alamos National Laboratory (Agnew et al., 1996) for Tank 241-C-203 are presented in Appendix $\mathrm{H}$ along with their introduction sections. 
WHC-SD-WM-ER-313, Rev. 1

\subsection{Tank 241-C-204}

\subsubsection{Waste and Level History of Tank 241-C-204}

The Waste and Level History sketch in Appendix C presents the waste history and level history of Tank 241-C-204.

\subsubsection{Temperature History of Tank 241-C-204}

The Surveillance Analysis Computer System database did not contain any temperature data for tank 241-C-204.

\subsubsection{Occurrences for Tank 241-C-204}

No significant occurrences are associated only with Tank 241-C-204.

\subsubsection{Current Status of Tank 241-C-204}

Tank 241-C-204 entered service during the first quarter of 1948 (Anderson, 1990) and as of November 30, 1995 stores approximately 3,000 gallons of waste (Hanlon, 1996b). The waste surface level in the tank is measured with a manual tape as of January 1996. The minimum waste surface level was 8 inches on numerous dates from January 1, 1991 through May 21, 1994. The maximum waste surface level was 17 inches on May 27, 1994. See Appendix $E$ for details on waste surface level. The tank is out of service with interim stabilization and intrusion prevention completed. The tank is listed as an assumed leaker and is passively ventilated. A plan view in Appendix F depicts the approximate riser locations as of February 2, 1996. Tank 241-C-204 has 6 risers with two tentatively available for sampling: one 4-inch riser (No. 8) and one 12-inch riser (No. 7) (Lipnicki, 1995b).

\subsubsection{Interior Montage of Tank 241-C-204}

The clearest and most recent set of interior tank photographs was taken on December 9, 1986. Other interior tank photographs are available, but only the photographs showing the waste surface were used to create a montage. The montage has labels identifying some of the monitoring equipment, piping, and risers in the tank. The montage and photographic information are shown in Appendix $G$.

\subsubsection{Tank Layer Model, Supernatant Mixing Model, and Inventory Estimate of Tank 241-C-204}

The Tank Layer Model(TLM), Supernatant Mixing Model(SMM), and Inventory Estimate developed by Los Alamos National Laboratory (Agnew et al., 1996) for Tank 241-C-204 are presented in Appendix $\mathrm{H}$ along with their introduction sections. 


\section{GLOSSARY}

This glossary of Hanford terminology has been compiled from numerous sources. A lot of the terms have come from Anderson(1991), Jungfleisch(1984) and Agnew(1996). These definitions may conflict with other sources.

$1 C$

$1 \mathrm{Cl}$

$1 \mathrm{C} 2$

224

2C

$2 \mathrm{Cl}$

$2 \mathrm{C} 2$

Active Drywell
First-cycle decontamination waste from the bismuth phosphate(BiPO, process at $\mathbf{B}$ and $\mathrm{T}$ Plants consisting of byproducts co-precipitated from a solution containing plutonium (contains $10 \%$ of the original fission product activity and $2 \%$ of the products). By-product cake solution was mixed with product waste and neutralized with $50 \%$ caustic. Coating waste from removing aluminum fuel element cladding was added and comprised about $24 \%$ of the waste.

First-cycle decontamination waste from the bismuth phosphate(BiPO) process, 1944-49 (LANL defined waste \#3)

First-cycle decontamination waste from the bismuth phosphate(BiPO ) process, 1950-56 (LANL defined waste \#4)

224-U Waste. $\mathrm{LaF}_{3}$ finishing waste from $\mathrm{BiPO} 4$ process and uranium recovery in the 224 buildings by T Plant and B Plant and the Plutonium Finishing Plant (LANL defined waste \#7)

Second-cycle decontamination waste from the bismuth phosphate $\left(\mathrm{BiPO}_{4}\right)$ process at $\mathrm{B}$ and $\mathrm{T}$ Plants (see second-cycle decontamination waste)

Second-cycle decontamination waste from the bismuth phosphate $\left(\mathrm{BiPO}_{4}\right.$ ) process, 1944-49 (LANL defined waste \#5)

Second-cycle decontamination waste from the bismuth phosphate(BiPO) process, 1950-56 (LANL defined waste \#6)

Waste from cell 5 tank 6 in B Plant; the hot waste collected in the bottom of cell 5 when the liquid boiled over during dissolving and neutralizing phases of the $\mathrm{BiPO}_{4}$ process.

Drywell in which radiation readings of greater than 50 counts per second are detected. The readings must be consistent as to depth and radiation level for repeated readings to be considered active. 
Airlift Circulator

$\mathrm{AR}$

Assumed Leaker

B

BG

BL.

BM

BNW

BSLTCK

BYSLTCK

Cascade

Catch Tanks
A device installed in aging waste tanks to promote mixing of the supernate. By maintaing motion within the body of the liquid, the circulators minimize superheat buildup and, consequently, minimize burping.

Washed PUREX sludge from the 244-AR Vault (LANL defined waste \#31)

A waste storage tank for which past surveillance data has indicated a loss of liquid attributed to a breach of integrity. In 1984, the designations of "suspect leaker," "questionable integrity," "confirmed leaker," "declared leaker," "dormant", and "borderline" were merged into one category called "assumed leaker."

High-level waste from PUREX acidified waste processed through B Plant to extract strontium (LANL defined waste \#32)

Below grade

B Plant low-level waste beginning 1968 (LANL defined waste \#33)

Bench mark

Battelle Northwest Laboratory waste

Salt cake waste generated from the 242-B Evaporator, 1951-53 (LANL defined waste \#4l)

Salt cake waste generated from in-tank solidification units 1 and 2 in BY Tank Farm, 1965-74 (LANL defined waste \#44)

Eleven of the single-shell tank farms (all except the AX Tank Farm) were equipped with overflow lines between tanks. The tanks were connected in series and were placed at different elevations creating a downhill gradient for liquids to flow (cascade) from one tank to another. Thus, multiple tanks could be filled with one pump.

Small capacity single-shell tanks associated with diversion boxes and diverter stations. The tanks are designed to receive any transfer line clean out, spills or leakage from the boxes, or leakage from the adjacent pipe encasement. 
CC

CCPLX

$\mathrm{CCW}$

CEM

CF

CPLX

Crib

CSR

$\mathrm{CW}$

CWZRI

CWZR2

CWP

CWP1

CWP2

Complexant concentrate waste or concentrated complexant; concentrated product from evaporating dilute complexed waste which contained high concentrations of organic complexants, such as HEDTA, EDTA, and citric acid.

Complexant concentrate or concentrated complexant waste; see CC.

Concentrated customer waste; the product of concentrating waste received from $100 \mathrm{~N}$ or the Fast Flux Test Facility having phosphate and/or sulfate concentrations which, after concentration, exhibit the characteristics of a complexed liquid

Cement

Cesium feed; a PUREX sludge supernate.

Complexed waste; dilute waste containing relatively high concentrations of organic chelating agents such as EDTA and HEDTA form B Plant waste fractionization.

An underground structure filled with aggregate designed to receive liquid waste, usually through a perforated pipe. The filtration and ion exchange properties of the soil in and around the crib were used to contain the radionuclides.

Waste (supernate) from cesium recovery of tank supernate at B Plant (LANL defined waste \#35)

Coating (cladding) waste produced at PUREX from dissolution of Zircaloy or aluminum fuel cladding.

Coating (cladding) waste (PUREX), Zircaloy cladding; 1968-72 (LANL defined waste \#23)

Coating (cladding) waste (PUREX), Zircaloy cladding; 1983-88 (LANL defined waste \#47); see NCRW and PD; also known as CWP/ZR2

Coating (cladding) waste (PUREX)

Coating (cladding) waste (PUREX); (LANL defined waste \#21, CWP/Al, 1956-60)

Cladding (coating) waste (PUREX), (LANL defined waste \#22, CWP/Al, 1961-72) 
CWP/ZR

CWRI

CWR2

DC

$\mathrm{DE}$

Ditch

Diversion Box

DSSF

Drywell

$\tau W$

EB

$\mathrm{EF}$

EVAP

Evaporator Feed
Now called PD or NCRW

REDOX cladding (coating) waste, (LANL defined waste \#15, CWR/Al, 1952-60)

Coating (cladding) waste (REDOX), (LANL defined waste \#16, CWL/Al with some $\mathrm{Zr}, 1961-72$ )

Dilute complexed waste characterized by organic carbon including organic complexants: EDTA, citric acid, HEDTA, and iminodiacetate.

Diatomaceous Earth; Diatomite( $\left.\mathrm{SiO}_{2}\right)$; a light friable siliceous material derived from diatom (algal) remains; added to some underground waste storage tanks to absorb residual liquids.

A linear excavation often used for the temporary diversion or disposal of process waste streams.

A below grade, concrete enclosure containing the remotely maintained jumpers and spare nozzles for routing waste solution to storage tank farms.

Double-shell slurry feed; Waste concentrated in evaporators until the solution is nearly saturated with sodium aluminate without exceeding receiver tank composition limits. This form is not as concentrated as double-shell slurry.

A steel casing, generally 6-inch internal diameter, drilled into the ground to various depths (but do not reach the water table) and used to insert monitoring instruments for measuring the presence of radioactivity or moisture content.

Decontamination waste; a wash solution from equipment decontamination at T Plant (LANL defined waste \#39)

Evaporator bottoms; a slurry from the evaporators

Evaporator feed; various supernatant liquids whose composition depends on the source

Evaporator feed (post 1976 designation)

Any waste liquid that can be concentrated to form salt cake; e.g., aged waste, low heat waste, dilute interstitial liquor, and other radioactive waste solutions. 
FD

Ferrocyanide

$\mathrm{H}_{2} \mathrm{O}$

HDRL

HLO

HS

ILL

Inactive Tank

Interim Isolation

Interim Stabilization

Interstitial Liquid

Intrusion Prevention
Feed dilute

An ion composed of iron and cyanide with the chemical formula of $\mathrm{Fe}(\mathrm{CN})_{6}^{-4}$.

Water

Hanford defense residual liquor; late 1970s designation for terminal liquors remaining after evaporation; includes complexed and noncomplexed waste, partially neutralized waste, and DSSF (see RESID).

Hanford Laboratory Operations; also, Hanford laboratory operations waste; laboratory waste from the 300 Area

Hot Semiworks (C Plant); a pilot facility with a variety of operations. Also, Hot or Strontium Semiworks waste (LANL defined waste \#28); see SSW.

Interstitial liquid level

A tank that has been removed from liquid-processing service, has been pumped to less than 33,000 gallons of waste, and will be, or is in the process of being, stabilized followed by intrusion prevention. This includes all tanks not in active or activerestricted categories. Also included are inactive spare tanks that would be used if an active tank failed.

An administrative designation reflecting the completion of the physical effort required to minimize the addition of liquids into an inactive storage tank, process vault, sump, catch tank, or diversion box. (In June 1993, "interim isolation" was replaced by "intrusion prevention".)

A tank which contains less than 50,000 gallons of drainable interstitial liquid and less than 5,000 gallons of supernate. If a jet pump was used to achieve interim stabilization, then the jet pump flowrate must have been at or below 0.05 gallons per minute before interim stabilization was completed.

The interstitial liquid within the tanks is the liquid that fills the interstitial(voids) spaces of the solid waste.

An administrative designation reflecting the completion of the physical effort required to minimize the addition of liquids into an inactive storage tank, process vault, catch tank, sump, or diversion box. 
IWW

IX

Knuckle

Level Adjustment

Liquid Observation Well (LOW)

LW

Mixed Waste

MW

MW1

MW2

N
Inorganic wash waste (i.e., concentrated neutralized high-level waste from PUREX); see NCAW and P. This was also designated as IWW because it is bottoms waste from the \#l acid concentrator.

Ion exchange waste from the cesium recovery process at B Plant

Point where the side wall and the bottom curved surface of a tank meet.

Any update in the waste inventory (or tank level) in a tank. The adjustments usually result from surveillance observations or historical investigations.

A liquid observation well is a fiber glass or tefzel-reinforced epoxy-polyester resin, $89 \mathrm{~mm}$ ( 3.5 inches) diameter pipe that is capped on the bottom end. This end is placed within $25 \mathrm{~mm}$ ( 1 inch) above the bottom portion of the steel tank liner. Three types of probes are used in the LOW to monitor changes in the interstitial liquid level: acoustic, gamma, and neutron.

Laboratory waste from the 222-S Building

Waste containing both radioactive and hazardous (dangerous as defined in WAC 173-303) waste.

Waste from the bismuth phosphate process (which extracted plutonium) containing all the uranium, approximately $90 \%$ of the original fission product activity, and approximately $1 \%$ of the product. This waste was brought to the neutral point with $50 \%$ caustic and then treated with an excess of sodium carbonate. This procedure yieiced almost completely soluble waste at a minimum total volume. The exact composition of the carbonate compounds was not known, but was assumed to be a uranium phosphate carbonate mixture. The term "metal" was the code word for plutonium.

Metal waste from $\mathrm{BiPO}_{4}, 1944-49$ (LANL defined waste \#1, same as $\mathrm{MW}$ )

Metal waste from BiPO, 1950-56 (LANL defined waste \#2, same as $\mathrm{MW}$ )

Phosphate decontamination waste from N Reactor (L.ANL defined waste \#40) 
NCAW

NCPLX

NCRW

NIT

Non-Complexed

Out-of-Service-Tank

oww

oww1

OWW2

oww3

P

P]

P2

P2'

P3

Partial Interim Isolation

PASF

PD
Neutralized current acid waste, primary high-level waste stream from PUREX process (LANL defined waste \#45, formerly P3, 1983-88)

Non-complexed waste; general term for supernates and salt well liquors that did not contain organic complexants.

Neutralized cladding removal waste, same as CWP/Zr.

$\mathrm{HNO}_{3} / \mathrm{KMNO}_{4}$ solution added during evaporator operation

General waste term applied to all Hanford Site liquors not identified as complexed (containing organics).

A tank that does not meet the definition of an in-service tank. Before September 1988, these tanks were defined as inactive. (Note: All single-shell tanks are out of service.)

Organic Wash Waste; The solvent used in PUREX was treated before reuse by washing with potassium permanganate and sodium carbonate, followed by dilute nitric acid.

Organic wash waste, 1956-62, also known as CARB (LANL defined waste \#24)

Organic wash waste, 1963-67 (LANL defined waste \#25)

Organic wash waste, 1968-72 (LANL defined waste \#26)

High-level neutralized acid waste from PUREX

PUREX high-level waste, 1956-62 (LANL defined waste \#17)

PUREX high-level waste, 1963-67 (LANL defined waste \#18)

1968-1972, assigned to P2.

1983-1988, now called PXNAW or NCAW.

The administrative designation for completing the physical effort required for interim isolation, except for isolating the risers and piping that will be required for jet pumping or for other methods of stabilization.

PUREX ammonia scrubber feed (LANL defined waste \#48)

PUREX decladding waste 
PFeCN 1

$\mathrm{PFeCN} 2$

$\mathrm{pH}$

PL

PL1

PL2

Primary Addition

PSIS

PXMSC

PXNAW

R

R1

R2

RESID

Riser

$\mathrm{RDX}$

RSLTCK

RSIN

SACS
Ferrocyanide sludge produced by in-plant scavenging (using $0.005 \mathrm{M}$ ferrocyanide) of waste from uranium recovery (L.ANL defined waste \#9)

Same as PFeCN1 except $0.0025 \mathrm{M}$ ferrocyanide used (LANL defined waste \#10)

A measure of the hydrogen ion concentration in solution.

Low-level waste from PUREX

PUREX low-level waste (LANL defined waste \#20)

1983-88, now called PXMSC, among other things.

An addition of waste from a specific plant or process vault.

PUREX sludge supernate; produced by leaching PUREX sludge

Dilute, non-complexed waste from PUREX misc. streams

Aging waste from PUREX high level waste; see NCAW (LANL defined waste \#45, formerly P3, 1983-88)

High-level waste from REDOX

REDOX waste, 1952-57 (LANL defined waste \#13)

REDOX waste, 1958-66 (LANL defined waste \#14)

Hanford defense residual liquor (see HDRL)

A vertical pipe through a tank dome (access to the tank interior).

REDOX ion exchange waste produced at B Plant by extractng cesium from REDOX supernate

Salt-cake waste from the REDOX concentrator (LANL defined waste \#43)

REDOX supernate

Surveillance analysis computer system 
Salt Cake

Salt Well

Scavenged Waste

Self-Concentrating Waste

SIX

Sluicing, or sluiced

Slurry

SMM

SMP

SMMA1

SMMA2

Sound

SRR
Crystallized nitrate and other salts deposited in waste tanks, usually after the waste is concentrated by evaporation.

A hole drilled or sluiced into salt cake and lined with a cylindrical screen to permit drainage and jet pumping of interstitial liquids.

Waste which has been treated with ferrocyanide to remove cesium from the supernate by precipitating it into a sludge

Liquid, high-level radioactive waste whose decaying radionuclides heat the solution sufficiently to boil off (i.e., evaporate) the water, thus concentrating the waste.

Waste from removing cesium from PUREX sludge supernate by ion exchange at B Plant

To wash with water. At Hanford, this has meant to dissolve or suspend waste in solution using a high pressure water stream.

Insoluble material suspended in water or aqueous solution.

Supernatant Mixing Model (created at LANL) that calculates the composition of tank liquids and concentrates as linear combinations of supernates from the Hanford Defined Wastes: Chemical and Radiomuclide Compositions (Agnew, 1995a)

Sludge measuring port

Solids from concentrate calculated by SMM. Waste type is tank dependent.

Solids from concentrate calculated by SMM. Waste type is tank dependent.

The integrity classification of a waste storage tank for which surveiliance data indicate no loss of liquid attributed to a breach of integrity.

Sluiced PUREX sludge from A and AX Tank Farms sent to B Plant to recover strontium from 1967-76 (LANL defined waste \#34). The sludge returned from B Plant was sent to the AR Vault and the supernate was sent to 241-C-105. 
SRS

SST

SSW

Stabilization

Supernatant or Supernate

TISLTCK

T2SLTCK

Tank Farm

TBP

Terminal Liquor

$\mathrm{TFeCN}$

TH1

TH2
Strontium sludge; PUREX sludges sluiced for strontium recovery at $B$ Plant were washed in the $A R$ Vault with supernate from 241-C-105, and the resulting supernates were sent to CSR.

Single-shell tank

Strontium Semiworks waste; produced from the strontium extraction process at the Strontium Semiworks after 1961

The removal or immobilization, as completely as possible, of the liquid contained in a radioactive waste storage tank by pumping via a salt well, adding diatomaceous earth, etc

Liquid floating above the solids in the waste storage tanks. Supernate is usually derived by subtracting the solids level measurement from the liquid level measurement.

Salt-cake waste generated from the 242-T Evaporator, 1951-56 (LANL defined waste \#42)

Salt-cake waste generated from the 242-T Evaporator, 1965-76

An area containing underground storage tanks for storing waste.

Tributyl phosphate, a solvent used in the uranium extraction process at U Plant; also, a waste which is sometimes called uranium recovery waste (UR).

The concentrated supernatant liquid decanted from the evaporator bottoms (produced by the evaporators), which may not be concentrated further without forming solids that was unacceptable for storage in single-shell tanks (see HDRL). Terminal liquor is characterized by a caustic concentration of approximately $5.5 \mathrm{M}$ (the caustic molarity was lower if the aluminum salt saturation was reached first).

Ferrocyanide sludge produced by in-tank or in-farm scavenging (LANL defined waste \#11)

Thoria high-level or cladding waste, 1966 (LANL defined waste \#29, formerly TH66)

Thoria high-level or cladding waste, 1970 (LANL defined waste $\# 30$, formerly $T H 70$ ) 
TH66

TH70

Thermocouple

Thermocouple Tree

Thorium

TLM

Trench

TRUEX

UNK

UR
See THI.

Thoria 1970

Thermocouples are simple devices that develop a millivoltage when parts of the thermocouple are exposed to temperature differentials. The millivoltage can be converted to a temperature reading based upon a specific voltage versus temperature curve inherent to the type of thermocouple being used. Thermocouples are attached to a fabricated assembly called a thermocouple tree.

Thermocouples are attached to a fabricated assembly called a thermocouple tree. The number of thermocouples attached to the tree varies as a function of the depth of the tank as well as the thermocouple tree design. The thermocouples are spaced at intervals, along trees that have many thermocouples, so that a vertical temperature profile of the tank contents can be developed. The thermocouple tree is installed in a riser and left in place inside the tank.

A chemical element which is fertile material. Fertile means that when it is subjected to radiation in a nuclear reactor, it will be converted, in this case, to ${ }^{233} \mathrm{U}$, a potential fuel.

Tank Layer Model (created at LANL and derived from Waste Status and Transaction Record Summary database) models the volumes of wastes in the tanks.

A linear excavation used for the disposal of solid waste.

Transuranic extraction process

Unknown waste type (LANL defined waste)

Uranium recovery operation in U Plant, 1952-57. Created uranium recovery waste (UR) (LANL defined waste \#8), also known as tributyl phosphate (TBP) waste, and FeCN (scavenging wastes). See TFeCN and PFeCN. 
Watch List Tank

WC

WESF

WTR

Wyden Amendment

Z
An underground storage tank requiring special safety precautions because the tank potentially could release high-level radioactive waste if uncontrolled increases in pressure or temperature occur. Special restrictions have been placed on the tanks by "Safery Measures for Waste Tanks at Hanford Nuclear Reservation," Section 3137, National Defense Authorization Act for Fiscal Year 1991, November 5, 1990, Public Law 101-501 (also called the Wyden Amendment).

Weather cover

Waste Encapsulation and Storage Facility

Water; flush water from miscellaneous sources.

See watch list tank

Waste discharged from Z Plant (PFP) (LANL defined waste \#27) 


\section{REFERENCES}

Agnew, S.F., R.A Corbin, T.B. Duran, K.A. Jurgensen, T.P. Ortiz, and B.L. Young; September 1995; Waste Status and Transaction Record Summary for the Northeast Quadrant, WHC-SD-WM-TI-615, Rev. 1; Los Alamos National Laboratory, Los Alamos, New Mexico.

Agnew, S.F., J. Boyer, R.A. Corbin, T.B. Duran, J. FitzPatrick, K.A. Jurgensen, T.P. Ortiz, and B.L. Young; May 1996; Hanford Tank Chemical and Radionuclide Inventories: HDW Model Rev. 3; LA-UR-96- 858 ; Los Alamos National Laboratory, Los Alamos, New Mexico.

Alstad, A.T.; September 1991; Riser Configuration Document for Single-Shell Waste Tanks; WHC-SD-RE-TI-053, Rev. 8; Westinghouse Hanford Company, Richiand, Washington.

Alstad, A.T.; December 1993; Riser Configuration Document for Single-Shell Waste Tanks; WHC-SD-RE-TI-053, Rev. 9; Westinghouse Hanford Company, Richland, Washington.

Anderson, J.D.; June 1990; A History of the 200 Areas Tank Farms; WHC-MR-0132; Westinghouse Hanford Company, Richland, Washington.

Ballinger, M.Y., and R.B. Hall; March 1991; A History of Major Hanford Facilities and Processes Involving Radioactive Material; PNL-6964 HEDR; Pacific Northwest Laboratory, Richland, Washington.

Borsheim, G.L., and N.W. Kirch; March 1991; Summary of Single-Shell Tank Waste Stability, WHC-EP-0347; Westinghouse Hanford Company, Richland, Washington.

Brevick, C.H., L.A. Gaddis, and W.W. Pickett; June 1994; Historical Tank Content Estimate for the Northeast Quadrant of the Hanford 200 East Area; WHC-SD-WM-ER-349, Rev. OA; ICF Kaiser Hanford, Richland, Washington.

Carter, G.J.; May 1986a; Waste Status Summary, April 1986; RHO-RE-SR-14; Rockwell Hanford Operations, Richland, Washington.

Carter, G.J.; June 1986b; Waste Status Summary, May 1986; RHO-RE-SR-14; Rockwell Hanford Operations, Richland, Washington.

Carter, G.J.; July 1986c; Waste Status Summary, June 1986; RHO-RE-SR-14; Rockwell Hanford Operations, Richland, Washington.

Carter, G.J.; August 1986d; Waste Status Summary, July 1986; RHO-RE-SR-14; Rockwell Hanford Operations, Richland, Washington.

Carter, G.J.; September 1986e; Waste Stanus Summany, August 1986; RHO-RE-SR-14; Rockwell Hanford Operations, Richland, Washington.

Carter, G.J.; October 1986; Waste Status Summary, September 1986; RHO-RE-SR-14; Rockwell Hanford Operations, Richland, Washington. 
Caudill H.L.; June 1965; Design Criteria for a Second In-Tank Waste Solidification System; RL-SEP-499; General Electric Company, Richland, Washington.

Caudill H.L.; March 1967; Design Criteria Modifications for Increased Capacity in the First In-Tank Solidification System; ISO-869; Isochem, Inc., Richland, Washington.

Dougherty, L.F.; March 23, 1995; Single-Shell Tank Interim Operational Safety Requirements; WHC-SD-WM-OSR-005, Rev. OB; Westinghouse Hanford Company, Richland, Washington.

Duncan, D.R., B.A. Mayancsik, J.A. Pottmeyer, E.J. Vejvoda, J.A. Reddick, K.M. Sheldon, and M.I. Weyns; February 1993; Characterization of Past and Present Solid Waste Streams from the Plutonium Finishing Plant; WHC-EP-0621; Westinghouse Hanford Company, Richland, Washington.

Escobar, G.A.; December 1986a; Waste Status Summary, October 1986; RHO-RE-SR-14; Rockwell Hanford Operations, Richland, Washington.

Escobar, G.A; December 1986b; Waste Status Summary, November 1986; RHO-RE-SR-14; Rockwell Hanford Operations, Richland, Washington.

Escobar, G.A.; January 1987a; Waste Status Summary, December 1986; RHO-RE-SR-14; Rockwell Hanford Operations, Richland, Washington.

Escobar, G.A.; February 1987b; Waste Status Summary, Jamuary 1987; RHO-RE-SR-14; Rockwell Hanford Operations, Richland, Washington.

Gertier, M.S., September 1992; Legend and Legacy: Fifty Years of Defense Production at the Hanford Site; WHC-MR-0293, Rev. 2; Westinghouse Hanford Company, Richland, Washington.

Gerber, M.S.; October 1993b; The Hanford Site: An Anthology of Early Histories; WHC-MR-0435; Westinghouse Hanford Company, Richland, Washington.

Gerber, M.S.; November 1993c; A Brief History of the PUREX and UO, Facilities; WHC-MR-0437; Westinghouse Hanford Company, Richland, Washington.

Gerber, M.S.; April 1994a; Dramatic Change at T Plant; WHC-MR-0452; Westinghouse Hanford Company, Richland, Washington.

Gerber, M.S.; 1996; Correspondence to C.V. Salois of ICF Kaiser Hanford; Westinghouse Hanford Company, Richland, Washington.

Godfrey, W.L.; June 1965; 242-T Evaporator Facility, Information Mamual; RL-SEP-396; Hanford Atomic Products Operation, General Electric Company, Richland, Washington.

Hanlon, B.M.; March 1990a; Tank Farm Surveillance and Waste Status Summary Report for November 1989; WHC-EP-0182-20; Westinghouse Hanford Company, Richland, Washington. 
Hanlon, B.M.; March 1990b; Tank Fam Surveillance and Waste Status Summary Report for December 1989; WHC-EP-0182-21; Westinghouse Hanford Company, Richland, Washington.

Hanlon, B.M.; March 1990c; Tank Farm Surveillance and Waste Status Summary Report for January 1990; WHC-EP-0182-22; Westinghouse Hanford Company, Richland, Washington.

Hanlon, B.M.; April 1990d; Tank Farm Surveillance and Waste Status Summary Report for February 1990; WHC-EP-0182-23; Westinghouse Hanford Company, Richland, Washington.

Hanlon, B.M.; June 1990e; Tank Farm Sumeillance and Waste Status Summary Report for March 1990, WHC-EP-0182-24; Westinghouse Hanford Company, Richland, Washington.

Hanion, B.M; June 1990f, Tank Farm Surveillance and Waste Status Summary Report for April 1990; WHC-EP-0182-25; Westinghouse Hanford Company, Richland, Washington.

Hanlon, B.M.; August 1990g; Tank Farm Surveillance and Waste Status Summary Report for May 1990; WHC-EP-0182-26; Westinghouse Hanford Company, Richland, Washington.

Hanlon, B.M.; September 1990h; Tank Farm Surveillance and Waste Status Summary Report for June 1990; WHC-EP-0182-27; Westinghouse Hanford Company, Richland, Washington.

Hanlon, B.M.; Novernber 1990i; Tank Farm Surveillance and Waste Status Summary Report for July 1990; WHC-EP-0182-28; Westinghouse Hanford Company, Richland, Washington.

Hanlon, B.M; January 1991a; Tank Farm Surveillance and Waste Status Summary Report for August 1990; WHC-EP-0182-29; Westinghouse Hanford Company, Richland, Washington.

Hanlon, B.M; January 1991b; Tank Farm Surveillance and Waste Status Summary Report for November 1990; WHC-EP-0182-32; Westinghouse Hanford Company, Richland, Washington.

Hanlon, B.M.; February 1991c; Tank Farm Surveillance and Waste Status Summary Report for September 1990; WHC-EP-0182-30; Westinghouse Hanford Company, Richland, Washington.

Hanlon, B.M.; February 1991d; Tank Farm Surveillance and Waste Status Summary Report for October 1990; WHC-EP-0182-31; Westinghouse Hanford Company, Richland, Washington.

Hanlon, B.M.; February 1991e; Tank Farm Surveillance and Waste Status Summary Report for January 1991; WHC-EP-0182-34; Westinghouse Hanford Company, Richland, Washington.

Hanlon, B.M.; April 1991f, Tank Farm Surveillance and Waste Status Summary Report for December 1990; WHC-EP-0182-33; Westinghouse Hanford Company, Richland, Washington.

Hanlon, B.M.; May 1991g; Tank Farm Surveillance and Waste Status Summary Report for February 1991; WHC-EP-0182-35; Westinghouse Hanford Company, Richland, Washington.

Hanlon, B.M; June 1991h; Tank Farm Sumeillance and Waste Status Summary Report for March 1991; WHC-EP-0182-36; Westinghouse Hanford Company, Richland, Washington. 
Hanlon, B.M.; July 1991i; Tank Farm Surveillance and Waste Status Summary Report for April 1991, WHC-EP-0182-37; Westinghouse Hanford Company, Richland, Washington.

Hanlon, B.M.; August 1991j; Tank Farm Surveillance and Waste Status Summary Report for May 1991, WHC-EP-0182-38; Westinghouse Hanford Company, Richland, Washington.

Hanion, B.M; September 1991k; Tank Farm Surveillance and Waste Status Summary Report for June 1991; WHC-EP-0182-39; Westinghouse Hanford Company, Richland, Washington.

Hanlon, B.M.; September 19911; Tank Farm Surveillance and Waste Status Summary Report for July 1991; WHC-EP-0182-40; Westinghouse Hanford Company, Richland, Washington.

Hanlon, B.M; October 1991m; Tank Farm Surveillance and Waste Status Summary Report for August 1991; WHC-EP-0182-41; Westinghouse Hanford Company, Richland, Washington.

Harlon, B.M; November 1991n; Tank Farm Surveillance and Waste Status Summary Report for September 1991; WHC-EP-0182-42; Westinghouse Hanford Company, Richland, Washington.

Hanion, B.M; January 1992a; Tank Farm Surveillance and Waste Status Summary Report for October 1991; WHC-EP-0182-43; Westinghouse Hanford Company, Richland, Washington.

Hanlon, B.M.; February 1992b; Tank Farm Surveillance and Waste Status Summary Report for November 1991; WHC-EP-0182-44; Westinghouse Hanford Company, Richland, Washington.

Hanlon, B.M.; March 1992c; Tank Farm Surveillance and Waste Status Summary Report for December 1991; WHC-EP-0182-45; Westinghouse Hanford Company, Richland, Washington.

Hanlon, B.M.; April 1992d; Tank Farm Surveillance and Waste Status Summary Report for January 1992; WHC-EP-0182-46; Westinghouse Hanford Company, Richland, Washington.

Hanlon, B.M.; May 1992e; Tank Farm Surveillance and Waste Status Summary Report for February 199.2; WHC-EP-0182-47; Westinghouse Hanford Company, Richland, Washington.

Hanion, B.M; June 1992f; Tank Farm Surveillance and waste Status Summary Report for March 1992; WHC-EP-0182-48; Westinghouse Hanford Company. ...shand, Washington.

Hanlon, B.M; July 1992g; Tank Farm ‘ :nveillance and Waste Status Summary Report for April 1992; WHC-EP-0182-49; Westinghouse Hai_tord Company, Richland, Washington.

Hanion, B.M.; August 1992h; Tank Farm Surveillance and Waste Status Summary Report for May 199?; WHC-EP-0182-50; Westinghouse Hanford Company, Richland, Washington.

Hanlon, B.M.; September 1992i; Tank Farm Surveillance and Waste Status Summary Report for June 199,; WHC-EP-0182-51; Westinghouse Hanford Company, Richland, Washington.

Hanlon, B.M ; October 1992j; Tank Farm Surveillance and Waste Status Summary Report for July 1992; WHC-EP-0182-52; Westinghouse Hanford Company, Richland, Washington. 
Hanlon, B.M; November 1992k; Tank Farm Surveillance and Waste Status Summary Report for August 1992; WHC-EP-0182-53; Westinghouse Hanford Company, Richland, Washington.

Hanlon, B.M.; December 19921; Tank Farm Surveillance and Waste Status Summary Report for September 1992; WHC-EP-0182-54; Westinghouse Hanford Company, Richland, Washington.

Hanlon, B.M.; January 1993a; Tank Farm Surveillance and Waste Status Summary Report for October 1992; WHC-EP-0182-55; Westinghouse Hanford Company, Richland, Washington

Hanlon, B.M.; February 1993b; Tank Farm Surveillance and Waste Status Summary Report for November 1992; WHC-EP-0182-56; Westinghouse Hanford Company, Richland, Washington.

Hanlon, B.M.; February 1993c; Tank Farm Surveillance and Waste Status Summary Report for December 1992; WHC-EP-0182-57; Westinghouse Hanford Company, Richland, Washington.

Hanlon, B.M:; March 1993d; Tank Farm Surveillance and Waste Status Summary Report for Jamuary 1993; WHC-EP-0182-58; Westinghouse Hanford Company, Richland, Washington.

Hanlon B.M; April 1993e; Tank Farm Surveillance and Waste Status Summary Report for February 1993; WHC-EP-0182-59; Westinghouse Hanford Company, Richland, Washington.

Hanlon, B.M; May 1993f, Tank Farm Surveillance and Waste Status Summary Report for March 1993; WHC-EP-0182-60; Westinghouse Hanford Company, Richland, Washington.

Hanlon, B.M; July 1993g; Tank Farm Surveillance and Waste Status Summary Report for April 1993; WHC-EP-0182-61; Westinghouse Hanford Company, Richland, Washington.

Hanlon, B.M.; August 1993h; Tank Farm Surveillance and Waste Status Summary Report for May 1993; WHC-EP-0182-62; Westinghouse Hanford Company, Richland, Washington.

Hanlon, B.M.; October 1993i; Tank Farm Surveillance and Waste Status Summary Report for June 1993; WHC-EP-0182-63; Westinghouse Hanford Company, Richland, Washington.

Hanlon, B.M.; November 1993j; Tank Farm Surveillance and Waste Status Summary Report for July 1993; WHC-EP-0182-64; Westinghouse Hanford Company, Richland, Washington.

Hanlon, B.M.; December 1993k; Tank Farm Surveillance and Waste Status Summary Report for August 1993; WHC-EP-0182-65; Westinghouse Hanford Company, Richland, Washington.

Hanlon, B.M.; January 1994a; Tank Farm Surveillance and Waste Status Summary Report for September 1993; WHC-EP-0182-66; Westinghouse Hanford Company, Richland, Washington.

Hanlon, B.M; January 1994b; Tank Farm Surveillance and Waste Status Summary Report for October 1993; WHC-EP-0182-67; Westinghouse Hanford Company, Richland, Washington.

Hanlon, B.M.; February 1994c; Tank Farm Surveillance and Waste Status Summary Report for November 1993; WHC-EP-0182-68; Westinghouse Hanford Company, Richland, Washington. 
Hanlon, B.M.; April 1994d; Tank Farm Surveillance and Waste Status Summary Report for December 1993; WHC-EP-0182-69; Westinghouse Hanford Company, Richland, Washington.

Hanlon, B.M.; May 1994e; Tank Farm Surveillance and Waste Status Summary Report for Jamuary 1994; WHC-EP-0182-70; Westinghouse Hanford Company, Richland, Washington.

Hanlon, B.M.; May 1994f; Tank Farm Surveillance and Waste Status Summary Report for February 199.4; WHC-EP-0182-71; Westinghouse Hanford Company, Richland, Washington.

Hanlon, B.M.; June 1994g; Tank Farm Surveillance and Waste Status Summary Report for March 199.4; WHC-EP-0182-72; Westinghouse Hanford Company, Richland, Washington.

Hanlon, B.M; July 1994h; Tank Farm Surveillance and Waste Status Summary Report for April 1994; WHC-EP-0182-73; Westinghouse Hanford Company, Richland, Washington.

Hanion, B.M.; August 1994i; Tank Farm Surveillance and Waste Status Summary Report for May 1994; WHC-EP-0182-74; Westinghouse Hanford Company, Richland, Washington.

Hanion, B.M.; September 1994j; Tank Farm Surveillance and Waste Status Summary Report for June 1994; WHC-EP-0182-75; Westinghouse Hanford Company, Richland, Washington.

Hanlon, B.M:; November 1994k; Waste Tank Summary for Month Ending July 31, 1994; WHC-EP-0182-76; Westinghouse Hanford Company, Richland, Washington.

Hanlon, B.M; November 19941; Waste Tank Summary for Month Ending August 31, 1994; WHC-EP-0182-77; Westinghouse Hanford Company, Richland, Washington.

Hanlon, B.M.; November 1994m; Waste Tank Summary for Month Ending September 30, 1994; WHC-EP-0182-78; Westinghouse Harford Company, Richland, Washington.

Hanlon, B.M.; December 1994n; Waste Tank Summary for Month Ending October 31, 1994; WHC-EP-0182-79; Westinghouse Hanford Company, Richland, Washington.

Hanlon, B.M.; January 1995a; Waste Tank Summary for Month Ending November 30, 1994; WHC-EP-0182-80; Westinghouse Hanford Company, Richland, Washington.

Hanlon, B.M.; February 1995b; Waste Tank Summary for Month Ending December 31, 1994; WHC-EP-0182-81; Westinghouse Hanford Company, Richland, Washington.

Hanlon, B.M; March 1995c; Waste Tank Summary for Month Ending January 31, 1995; WHC-EP-0182-82; Westinghouse Hanford Company, Richland, Washington.

Hanlon, B.M; April 1995d; Waste Tank Summary for Month Ending February 28, 1995; WHC-EP-0182-83; Westinghouse Hanford Company, Richland, Washington.

Hanlon, B.M:; May 1995e; Waste Tank Summary for Month Ending March 31, 1995; WHC-EP-0182-84; Westinghouse Hanford Company, Richland, Washington. 
Hanlon, B.M.; June 1995f, Waste Tank Summary for Month Ending April 30, 1995; WHC-EP-0182-85; Westinghouse Hanford Company, Richland, Washington.

Hanlon, B.M; July 1995g; Waste Tank Summary for Month Ending May 31, 1995; WHC-EP-0182-86; Westinghouse Hanford Company, Richland, Washington.

Hanlon, B.M.; August 1995h; Waste Tank Summary for Month Ending June 30, 1995; WHC-EP-0182-87; Westinghouse Hanford Company, Richland, Washington.

Hanlon, B.M; September 1995i; Waste Tank Summary for Month Ending July 31, 1995; WHC-EP-0182-88; Westinghouse Hanford Company, Richland, Washington.

Hanlon, B.M.; October 1995j; Waste Tank Summary for Month Ending August 31, 1995; WHC-EP-0182-89; Westinghouse Hanford Company, Richland, Washington.

Hanlon, B.M.; December 1995k; Waste Tank Summary for Month Ending September 30, 1995; WHC-EP-0182-90; Westinghouse Hanford Company, Richland, Washington.

Hanlon, B.M; January 1996a; Waste Tank Summary for Month Ending October 31, 1995; WHC-EP-0182-91; Westinghouse Hanford Company, Richland, Washington.

Hanlon, B.M.; February 1996b; Waste Tank Summary for Month Ending November 30, 1995; WHC-EP-0182-92; Westinghouse Hanford Company, Richland, Washington.

HEW; January 11, 1944; CVI, Specifications for Construction of Composite Storage Tanks Bldg. No. 24I, Project 9536; CVI 73550; Hanford Engineer Works, Richland, Washington.

Jungfleisch, F.M.; March 1984; Preliminary Estimation of the Waste Inventories in Hanford Tanks Through 1980; SD-WM-TI-057; Rockwell Hanford Operations, Richland, Washington.

Leach, C.E., and S.M. Stahl; August 1993; Hanford Site Tank Farm Facilities Interim Safety Basis, Vols. 1 \& 2; WHC-SD-WM-ISB-001; Westinghouse Hanford Company, Richland, Washington.

Lipnick, J.; August 1995a; Waste Tank Risers Available for Sampling, WHC-SD-WM-TI-710, Rev. 1; Westinghouse Hanford Company, Richland, Washington.

Lipnicki, J.; December 1995b; Waste Tank Risers Available for Sampling, WHC-SD-WM-TI-710, Rev. 2; Westinghouse Hanford Company, Richland, Washington.

McCann, D.C.; August 1981a; Waste Status Summary, July 1981; RHO-CD-14; Rockwell Hanford Operations, Richland, Washington.

McCann, D.C.; September 1981b; Waste Status Summary, August 1981; RHO-CD-14; Rockwell Hanford Operations, Richland, Washington.

McCann, D.C.; October 1981c; Waste Status Summary. September 1981; RHO-CD-14; Rockwell Hanford Operations, Richland, Washington. 
WHC-SD-WM-ER-313, Rev. I

McCann, D.C.; November 1981d; Waste Status Summary, October 1981; RHO-CD-14; Rockwell Hanford Operations, Richland, Washington.

McCann, D.C.; December 1981e; Waste Status Summary November 1981; RHO-RE-SR-14; Rockwell Hanford Operations, Richland, Washington.

McCann, D.C.; April 1982a; Waste Status Summary, March 1982; RHO-RE-SR-14; Rockwell Hanford Operations, Richland, Washington.

McCann, D.C.; May 1982b; Waste Status Summary, April 1982; RHO-RE-SR-14; Rockwell Hanford Operations, Richland, Washington.

McCann, D.C.; June 1982c; Waste Status Summary, May 1982; RHO-RE-SR-14; Rockwell Hanford Operations, Richland, Washington.

McCann, D.C.; July 1982d; Waste Status Summary, June 1982; RHO-RE-SR-14; Rockwell Hanford Operations, Richland, Washington.

McCann, D.C.; August 1982e; Waste Status Summary, July 1982; RHO-RE-SR-14; Rockwell Hanford Operations, Richland, Washington.

McCann, D.C.; September 1982f; Waste Status Summary, August 1982; RHO-RE-SR-14; Rockwell Hanford Operations, Richland, Washington.

McCann, D.C.; October 1982g; Waste Status Summary, September 1982; RHO-RE-SR-14; Rockwell Hanford Operations, Richland, Washington.

McCann, D.C.; November 1982h; Waste Status Summary, October 1982; RHO-RE-SR-14; Rockwell Hanford Operations, Richland, Washington.

McCann, D.C.; December 1982i; Waste Status Summary, November 1982; RHO-RE-SR-14; Rockwell Hanford Operations, Richland, Washington.

McCann, D.C.; January 1983a; Waste Status Summary, December 1982; RHO-RE-SR-14; Rockwell Hanford Operations, Richland, Washington.

McCann, D.C.; February 1983b; Waste Status Summary, Jamuary 1983; RHO-RE-SR-14; Rockwell Hanford Operations, Richland, Washington.

McCann, D.C.; March 1983c; Waste Status Summary, February 1983; RHO-RE-SR-14; Rockwell Hanford Operations, Richland, Washington.

McCann, D.C.; April 1983d; Waste Status Summary, March 1983; RHO-RE-SR-14; Rockwell Hanford Operations, Richland, Washington.

McCann, D.C.; May 1983e; Waste Status Summary, April 1983; RHO-RE-SR-14; Rockwell Hanford Operations, Richland, Washington. 
McCann, D.C.; June 1983f; Waste Status Summary, May 1983; RHO-RE-SR-14; Rockwell Hanford Operations, Richland, Washington.

McCann, D.C.; July 1983g; Waste Status Summary, June 1983; RHO-RE-SR-14; Rockwell Hanford Operations, Richland, Washington.

McCann, D.C.; August 1983h; Waste Status Summary, July 1983; RHO-RE-SR-14; Rockwell Hanford Operations, Richland, Washington.

McCann, D.C.; September 1983i; Waste Status Summary, August 1983; RHO-RE-SR-14; Rockwell Hanford Operations, Richland, Washington.

McCann, D.C.; October 1983j; Waste Status Summary, September 1983; RHO-RE-SR-14; Rockwell Hanford Operations, Richland, Washington.

McCann, D.C.; November 1983k; Waste Status Summary, October 1983; RHO-RE-SR-14; Rockwell Hanford Operations, Richland, Washington.

McCann, D.C.; December 19831; Waste Status Summary, November 1983; RHO-RE-SR-14; Rockwell Hanford Operations, Richland, Washington.

McCann, D.C.; January 1984a; Waste Status Summary, December 1983; RHO-RE-SR-14; Rockwell Hanford Operations, Richland, Washington.

McCann, D.C.; February 1984b; Waste Status Summary, January 1984; RHO-RE-SR-14; Rockwell Hanford Operations, Richland, Washington.

McCann, D.C.; March 1984c; Waste Status Summary, February 1984; RHO-RE-SR-14; Rockwell Hanford Operations, Richland, Washington.

McCann, D.C.; April 1984d; Waste Status Summary, March 1984; RHO-RE-SR-14; Rockwell Hanford Operations, Richland, Washington.

McCann, D.C.; May 1984e; Waste Status Summary, April 1984; RHO-RE-SR-14; Rockwell Hanford Operations, Richland, Washington.

McCann, D.C.; June 1984f; Waste Status Summary, May 1984; RHO-RE-SR-14; Rockwell Hanford Operations, Richland, Washington.

McCann, D.C.; July 1984g; Waste Status Summary, June 1984; RHO-RE-SR-14; Rockwell Hanford Operations, Richland, Washington.

McCann, D.C.; August 1984h; Waste Status Summary, July 1984; RHO-RE-SR-14; Rockwell Hanford Operations, Richland, Washington.

McCann, D.C., and T.S. Vail; September 1984i; Waste Status Summary, August 1984; RHO-RE-SR-14; Rockwell Hanford Operations, Richland, Washington. 
WHC-SD-WM-ER-313, Rev. 1

McCann, D.C., and T.S. Vail; October 1984j; Waste Status Summary, September 1984; RHO-RE-SR-14; Rockwell Hanford Operations, Richland, Washington.

McCann, D.C., and T.S. Vail; November 1984k; Waste Status Summary, October 1984; RHO-RE-SR-14; Rockwell Hanford Operations, Richland, Washington.

McCann, D.C., and T.S. Vail; December 19841; Waste Status Summary, November 1984; RHO-RE-SR-14; Rockwell Hanford Operations, Richland, Washington.

McCann, D.C., and T.S. Vail; January 1985a; Waste Status Summary, December 1984; RHO-RE-SR-14; Rockwell Hanford Operations, Richland, Washington.

McCann, D.C., and T.S. Vail; February 1985b; Waste Status Summary, Jamuary 1985; RHO-RE-SR-14; Rockwell Hanford Operations, Richland, Washington.

McCam, D.C., and T.S. Vail; March 1985c; Waste Status Summary, February 1985; RHO-RE-SR-14; Rockwell Hanford Operations, Richland, Washington.

Mudd, O.C.; February 1981a; Waste Status Summary, January 1981; RHO-CD-14; Rockwell Hanford Operations, Richland, Washington.

Mudid, O.C., March 1981b; Waste Status Summary, February 1981; RHO-CD-14; Rockwell Hanford Operations, Richland, Washington.

Mudd, O.C.; April 1981c; Waste Status Summary, March 1981; RHO-CD-14; Rockwell Hlanford Operations, Richland, Washington.

Mudd, O.C; May 1981d; Waste Status Summary, April 1981; RHO-CD-14; Rockwell Hanford Operations, Richland, Washington.

Mudd, O.C.; June 1981e; Waste Status Summary, May 1981; RHO-CD-14; Rockwell Hanford Operations, Richland, Washington.

Mudd, O.C., and D.C. McCann; July 1981f; Waste Status Summary, June 1981; RHO-CD-14; Rockwell Hanford Operations, Richland, Washington.

Pianka, E.W.; January 24, 1995; Soil Load above Hanford Waste Storage Tanks; WHC-SD-WM-TI-665, Rev. 0A; Westinghouse Hanford Company, Richland, Washington.

PNL; 1991; Resource Book - Decommissioning of Contaminated Facilities at Hanford; PNL-7008 (originally BNWL-MA-88 in 1975, then PNL-MA-588); Battelle Pacific Northwest Laboratories, Richland, Washington.

Rockwell; August 1985; 200 Areas Fact Book, Rockwell Hanford Company, Richland, Washington.

Rodenhizer, D.G.; 1987; Hanford Waste Tank Sluicing History; SD-WM-TI-302; Westinghouse Hanford Company, Richland, Washington. 
Shefcik, J.J.; December 1964; Process Specifications for In-Tank Solidification of Radiochemical Wastes; RL-SEP-115; General Electric Company, Richland, Washington.

Thurman, J.M.; March 1987a; Waste Status Summary, February 1987; RHO-RE-SR-14; Rockwell Hanford Operations, Richland, Washington.

Thurman, J.M.; April 1987b; Waste Status Summary, March 1987; RHO-RE-SR-14; Rockwell Hanford Operations, Richland, Washington.

Thurman, J.M.; May 1987c; Waste Status Summary, April 1987; RHO-RE-SR-14; Rockwell Hanford Operations, Richland, Washington.

Thurman, J.M.; June 1987d; Waste Status Summary, May 1987; RHO-RE-SR-14; Rockwell Hanford Operations, Richland, Washington.

Thurman, J.M.; July 1987e; Waste Status Summary, June 1987; RHO-RE-SR-14; Rockwell Hanford Operations, Richland, Washington.

Thurman, J.M:; August 1987f; Waste Status Summary for .July 1987; WHC-SP-0038-1; Westinghouse Hanford Company, Richland, Washington.

Thurman, J.M.; September 1987g; Waste Status Summary for August 1987; WHC-SP-0038-2; Westinghouse Hanford Company, Richland, Washington.

Thurman, J.M; October 1987h; Waste Status Summary for September 1987; WHC-SP-0038-3; Westinghouse Hanford Company, Richland, Washington.

Thurman, J.M.; November 1987i; Waste Status Summary for October 1987; WHC-SP-0038-4; Westinghouse Hanford Company, Richland, Washington.

Thurman, J.M.; December 1987j; Waste Status Summary for November 1987; WHC-SP-0038-5; Westinghouse Hanford Company, Richland, Washington.

Thurman, J.M.; January 1988a; Waste Status Summary for December 1987; WHC-SP-0038-6; Westinghouse Hanford Company, Richland, Washington.

Thurman, J.M.; February 1988b; Waste Status Summary for Jamuary 1988; WHC-SP-0038-7; Westinghouse Hanford Company, Richland, Washington.

Thuman, J.M:; March 1988c; Waste Status Summary for February 1988; WHC-SP-0038-8; Westinghouse Hanford Company, Richland, Washington.

Thurman, J.M.; April 1988d; Waste Stanus Summary for March 1988; WHC-SP-0038-9; Westinghouse Hanford Company, Richland, Washington.

Thurman, J.M.; June 1988e; Tank Farm Surveillance and Waste Status Summary Report for April 1988; WHC-EP-0182-1; Westinghouse Hanford Company, Richland, Washington. 
Thurman, J.M.; August 1988f, Tank Farm Surveillance and Waste Status Summary Report for May 1988; WHC-EP-0182-2; Westinghouse Hanford Corr;any, Richland, Washington.

Thurman, J.M.; August 1988g; Tank Farm Surveillance and Waste Status Summary Report for June 1988; WHC-EP-0182-3; Westinghouse Hanford Company, Richland, Washington.

Thurman, J.M.; September 1988h; Tank Farm Sunveillance and Waste Status Summary Report for July 1988; WHC-EP-0182-4; Westinghouse Hanford Company, Richland, Washington.

Thurman, J.M.; December 1988i; Tank Farm Surveillance and Waste Status Summary Report for August 1988; WHC-EP-0182-5; Westinghouse Hanford Company, Richland, Washington.

Thurman, J.M.; December 1988j; Tank Farm Surveitiance and Waste Status Summary Report for September 1988; WHC-EP-0182-6; Westinghouse Hanford Company, Richland, Washington.

Thurman, J.M.; December 1988k; Tank Farm Surveillance and Waste Status Summary Report for Oc:ober 1988; WHC-EP-0182-7; Westinghouse Hanforc Company, Richland, Washington.

Thurman, J.M.; January 1989a; Tank Farm Surveillance and Waste Status Summary Report for November 1988; WHC-EP-0182-8; Westinghouse Hanford Company, Richland, Washington.

Thurman, J.M.; January 1989b; Tank Farm Surveillance and Waste Status Summary Report for December 1988; WHC-EP-0182-9; Westinghouse Hanford Company, Richland, Washington.

Thurman, J.M: March 1989c; Tank Farm Surveillance and Waste Status Summary Report for Jamuary 1989; WHC-EP-0182-10; Westinghouse Hanford Company, Richland, Washington.

Thurman, J.M; April 1989d; Tank Farm Surveillance and Waste Status Summary Report for February 1989; WHC-EP-0182-11; Westinghouse Hanford Company, Richland, Washington.

Thumman, J.M.; May 1989e; Tank Farm Surveillance and Waste Status Summary Report for March 1989; WHC-EP-0182-12; Westinghouse Hanford Company, Richland, Washington.

Thurman, J.M; June 1989f; Tank Farm Surveillance and Waste Status Summary Report for April 1989; WHC-EP-0182-13; Westinghouse Hanford Company, Richland, Washington.

Thurman, J.M; July 1989g; Tank Farm Surveillance and Waste Status Summary Report for May 1989; WHC-EP-0182-14; Westinghouse Hanford Company, Richland, Washington.

Thurman, J.M.; August 1989h; Tank Farm Surveillance and Waste Status Summary Report for June 1989; WHC-EP-0182-15; Westinghouse Hanford Company, Richland, Washington.

Thurman, J.M; September 1989i; Tank Farm Surveillance and Waste Status Summary Report fo: .hly 1989; WHC-EP-0182-16; Westinghouse Hianford Company, Richland, Washington.

Thurman, J.M.; October 1989j; Tank Farm Surveillance and Waste Status Summary Report for August 1989; WHC-EP-0182-17; Westinghouse Hanford Company, Richland, Washington. 
Thurman, J.M.; November 1989k; Tank Farm Surveillance and Waste Status Summary Report for September 1989; WHC-EP-0182-18; Westinghouse Hanford Company, Richland, Washington.

Thurman, J.M.; February 1990; Tank Fam Surveillance and Waste Status Summary Report for October 1989; WHC-EP-0182-19; Westinghouse Hanford Company, Richland, Washington

Tran, T.T.; April 27, 1993; Thermocouple Status Single-Shell and Double-Shell Waste Tanks; WHC-SD-WM-TI-553; Westinghouse Hanford Company, Richland, Washington.

U.S. DOE; December 1987; EIS, Disposal of Hanford Defense High Level, Transuranic, and Tank Wastes, Vols. 1-5; DOE/EIS-0113; Department of Energy, Richland, Washington.

Vail, T.S.; April 1985a; Waste Status Summary, March 1985; RHO-RE-SR-14; Rockwell Hanford Operations, Richland, Washington.

Vail, T.S.; May 1985b; Waste Status Summary, April 1985; RHO-RE-SR-14; Rockwell Hanford Operations, Richland, Washington.

Vail, T.S.; June 1985c; Waste Status Summary, May 1985; RHO-RE-SR-14; Rockwell Hanford Operations, Richland, Washington.

Vail, T.S.; July 1985d; Waste Status Summary, June 1985; RHO-RE-SR-14; Rockwell Hanford Operations, Richland, Washington.

Vail, T S.; August 1985e; Waste Status Summary, July 1985; RHO-RE-SR-14; Rockwell Hanford Operations, Richland, Washington.

Vail, T.S.; September 1985f, Waste Status Summary, August 1985; RHO-RE-SR-14; Rockwell Hanford Operations, Richland, Washington.

Vail, T.S.; October 1985g; Waste Status Summary, September 1985; RHO-RE-SR-14; Rockwell Hanford Operations, Richland, Washington.

Vail, T.S.; November 1985h; Waste Status Summary, October 1985; RHO-RE-SR-14; Rockwell Hanford Operations, Richland, Washington.

Vail, T.S., and G.D. Murry; December 1985i; Waste Status Summary, November 1985; RHO-RE-SR-14; Rockwell Hanford Operations, Richland, Washington.

Vail, T.S., and G.D. Murry; January 1986a; Waste Status Summary, December 1985; RHO-RE-SR-14; Rockwell Hanford Operations, Richland, Washington.

Vail, T.S., and G.D. Murry; February 1986b; Waste Status Summary, Jamuary 1986; RHO-RE-SR-14; Rockwell Hanford Operations, Richland, Washington.

Vail, T.S., and G.J. Carter; March 1986c; Waste Status Summary, February 1986; RHO-RE-SR-14; Rockwell Hanford Operations, Richland, Washington. 
Vail, T.S., and G.J. Carter; April 1986d; Waste Status Summary, March 1986; RHO-RE-SR-14, Rockwell Hanford Operations, Richland, Washington.

Welty, R.K.; September 1988; Waste Storage Tank Status and Leak Detection Criteria; WHC-SD-WM-TI-356, Vols. 1 and 2; Westinghouse Hanford Company, Richland, Washington.

Wilson, G.R., and I.E. Reep; December 1991; A Plan to Implement Remediation of Waste Tank Safety Issues at the Hanford Site; WHC-EP-0422, Rev. 1; Westinghous- Hanford Company, Richland, Washington. 


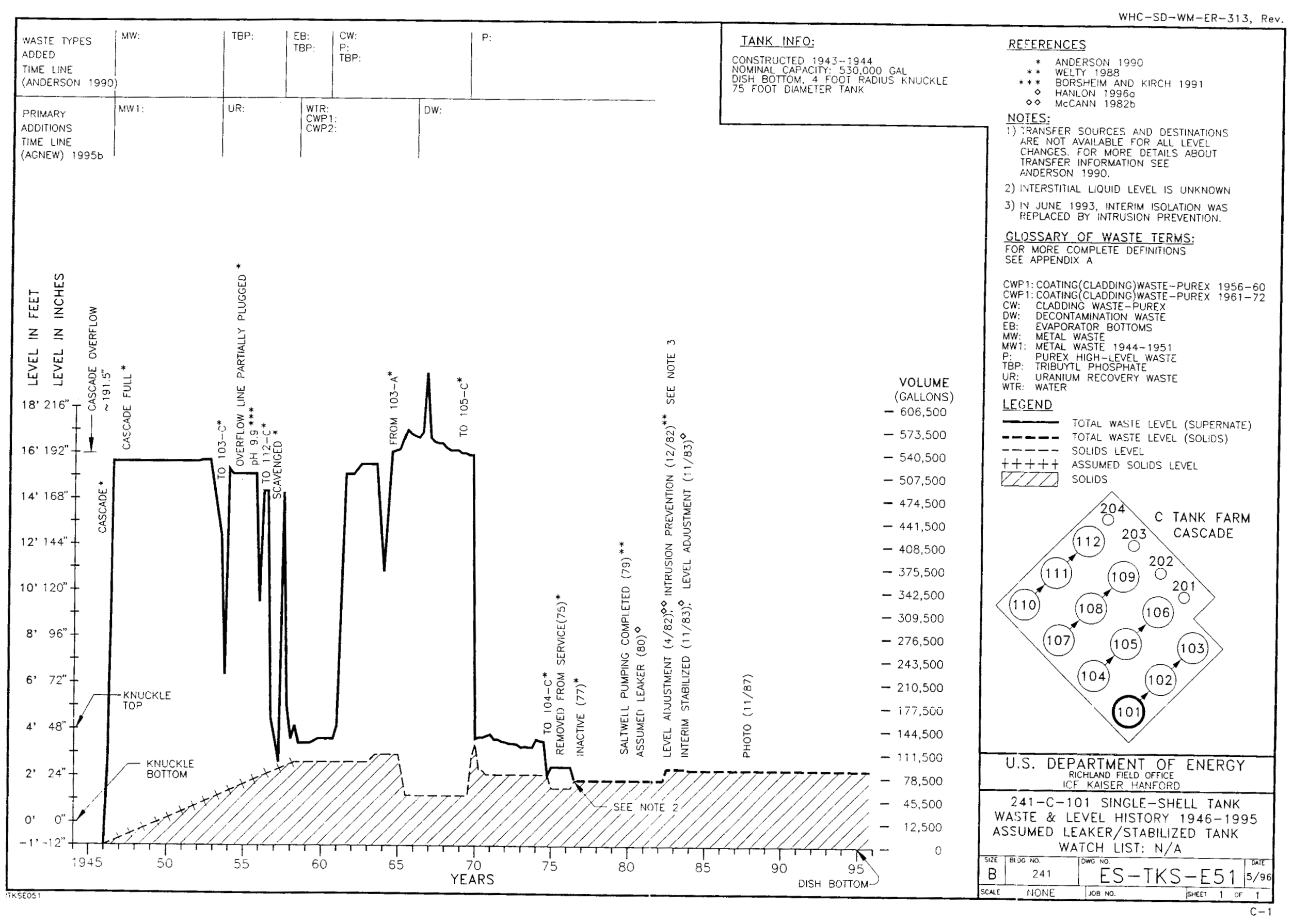




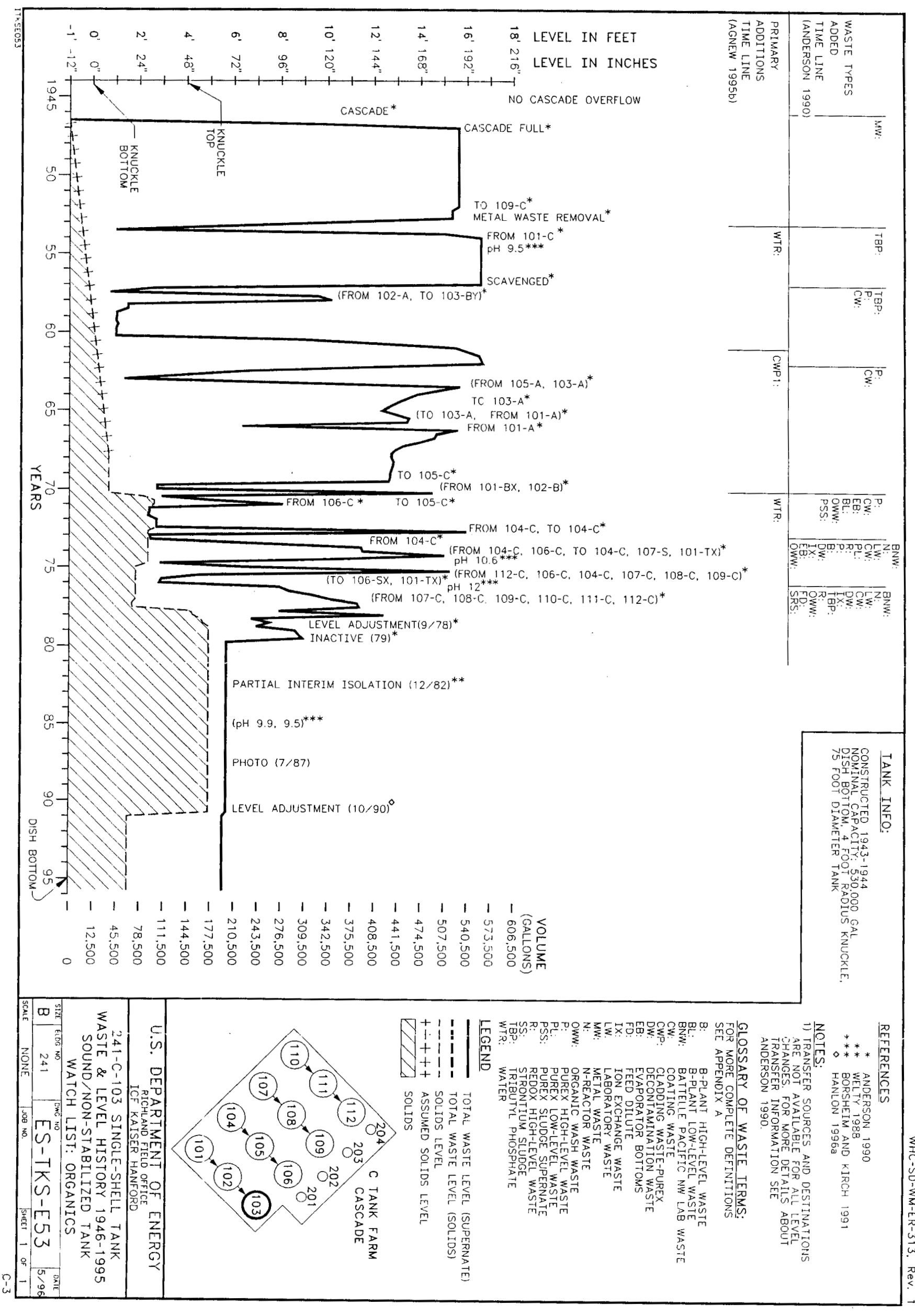




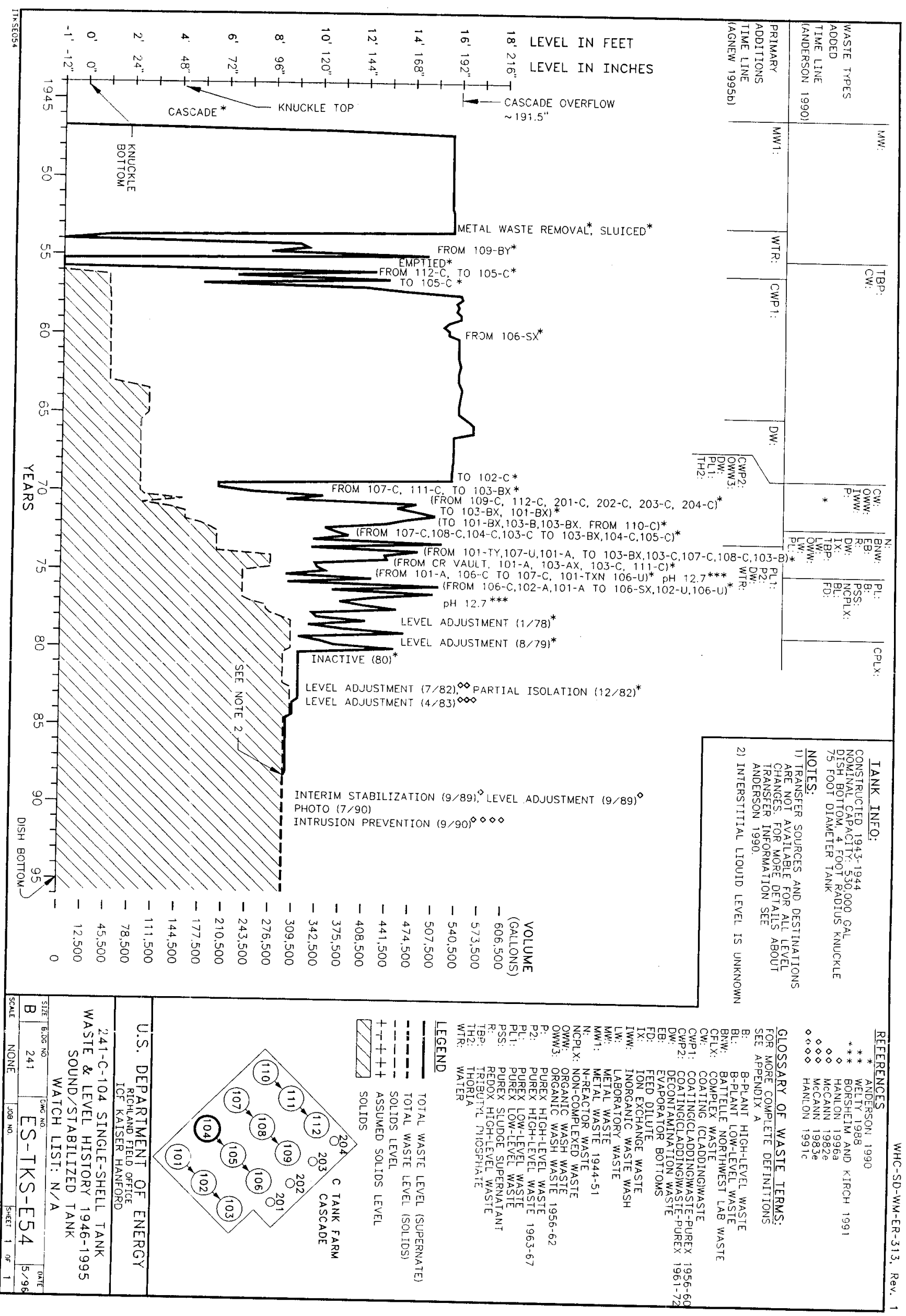




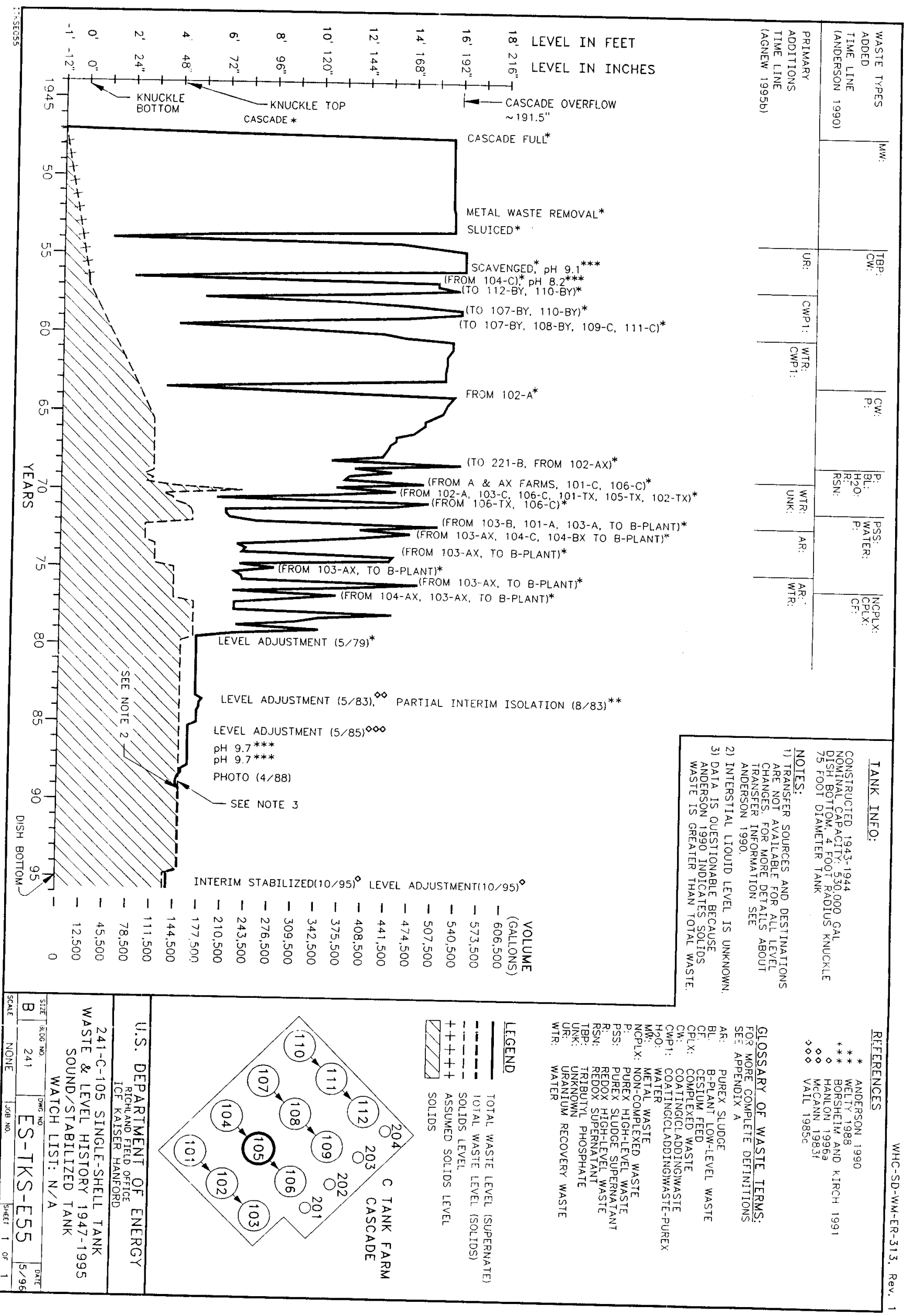




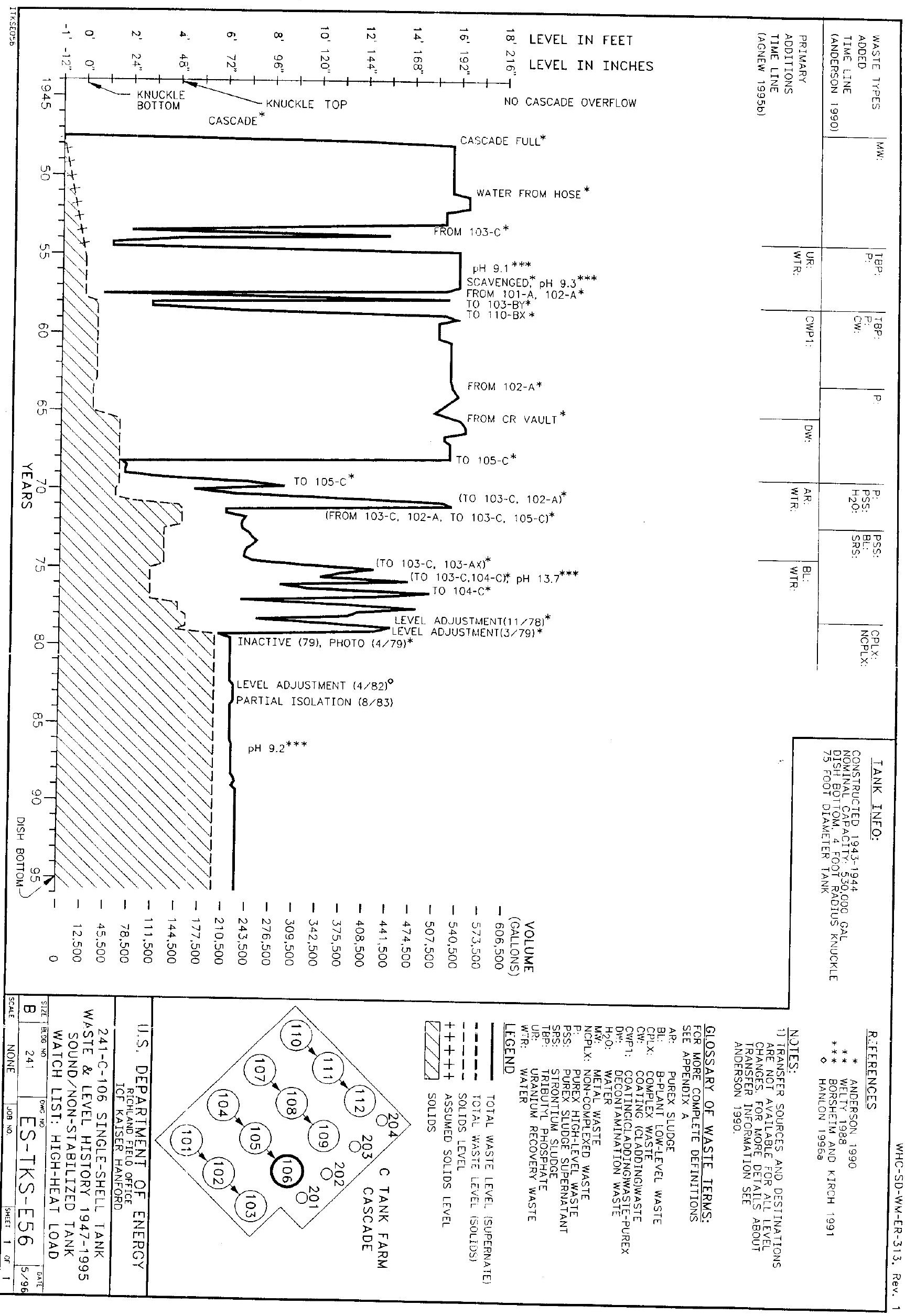




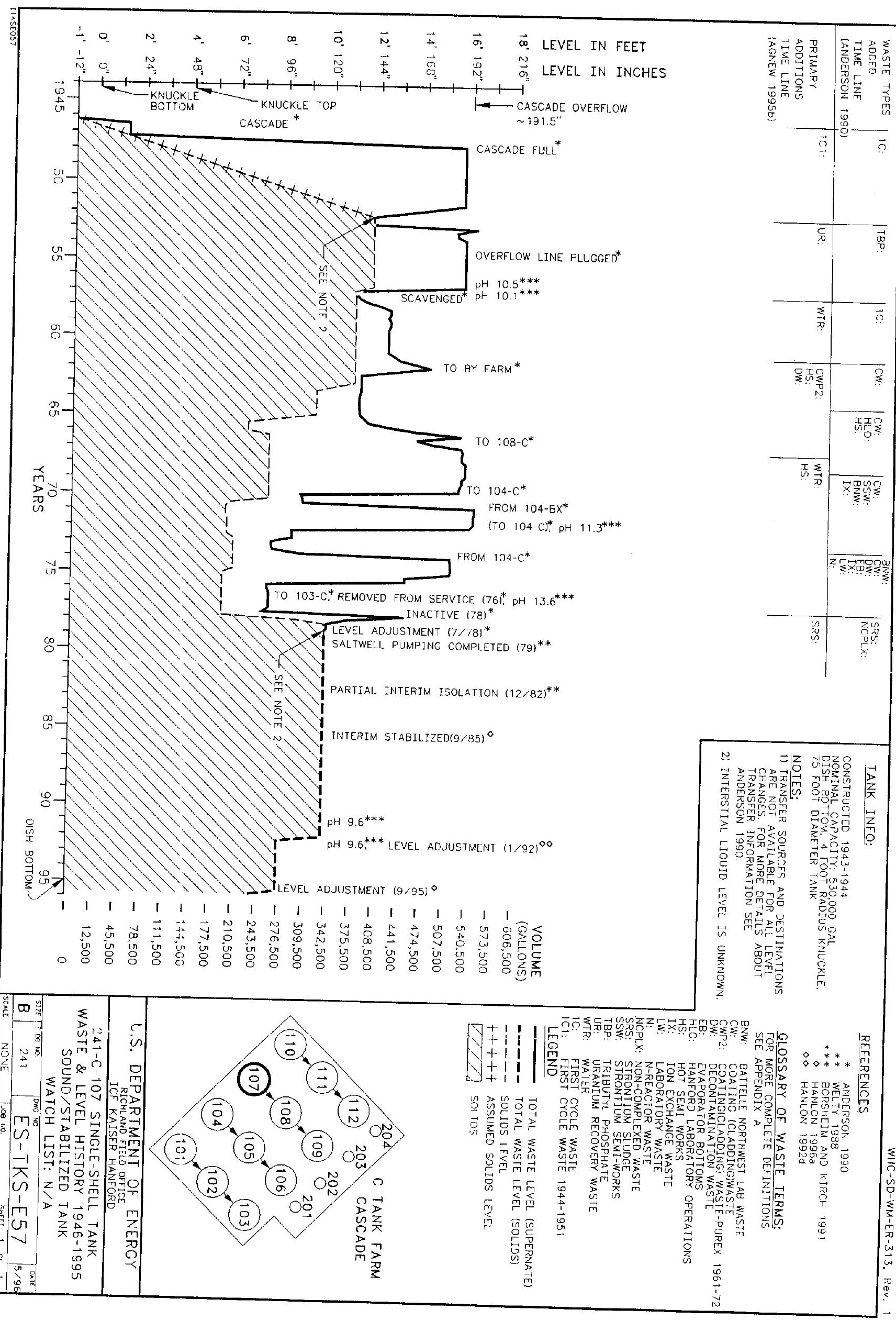




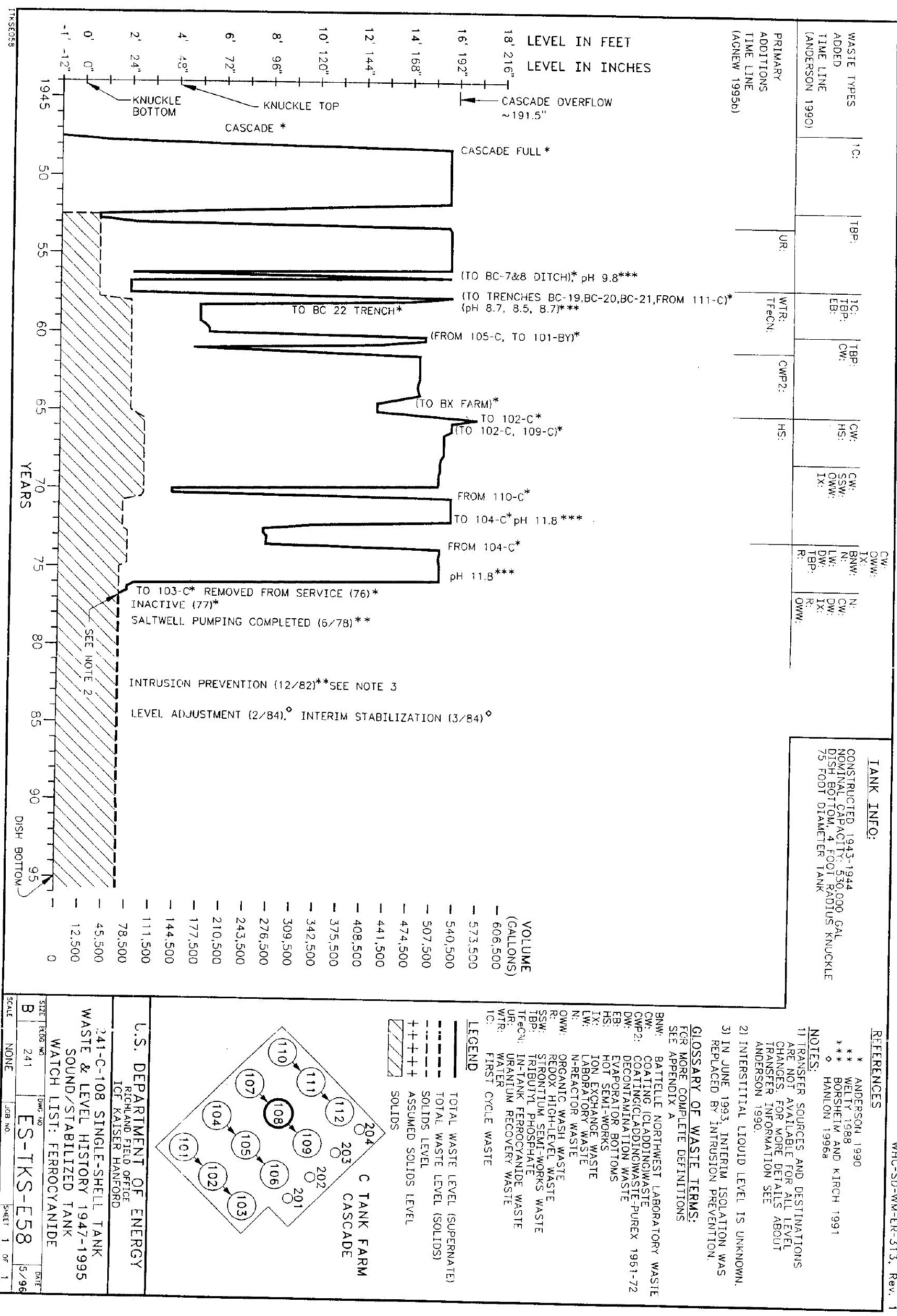




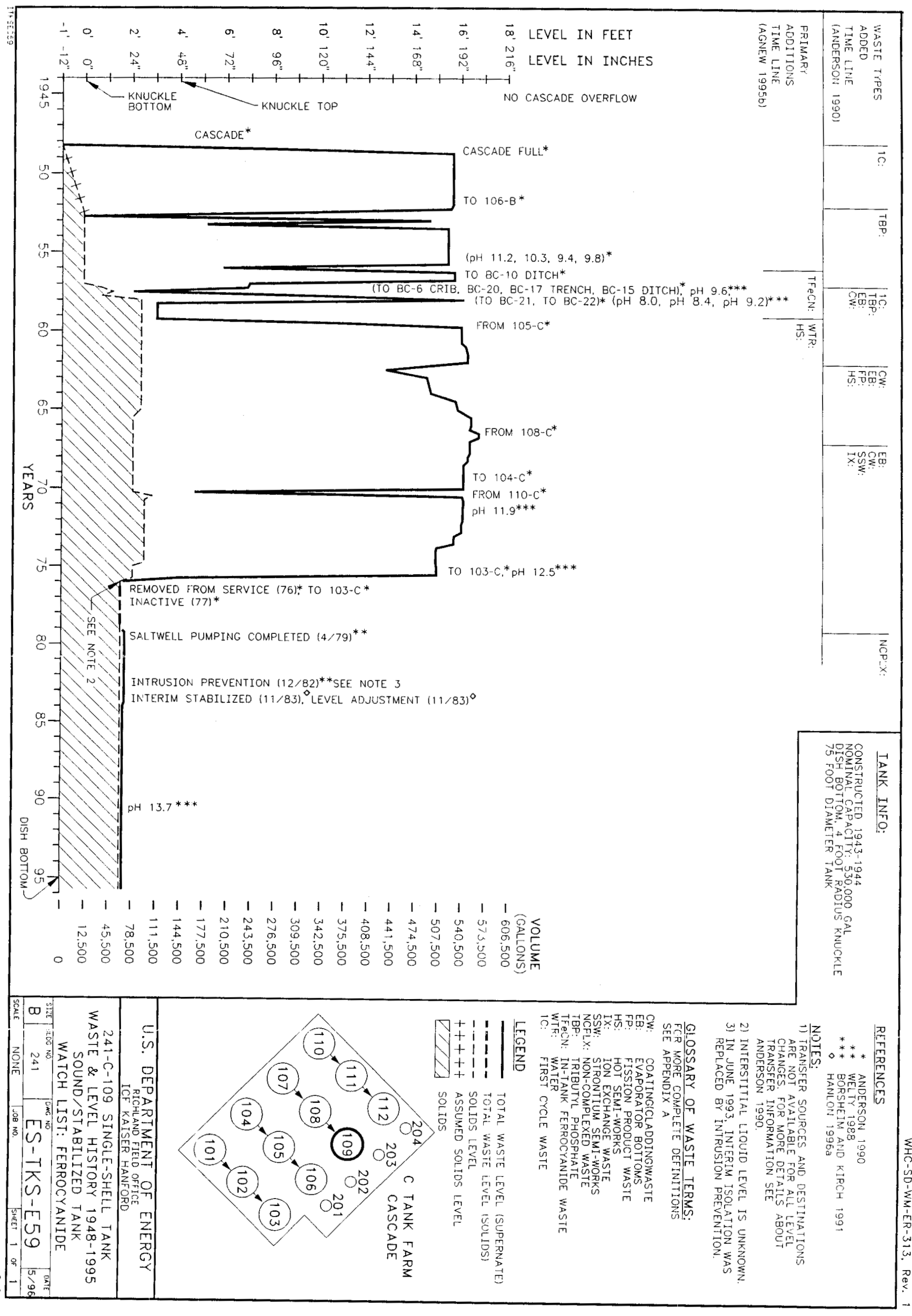




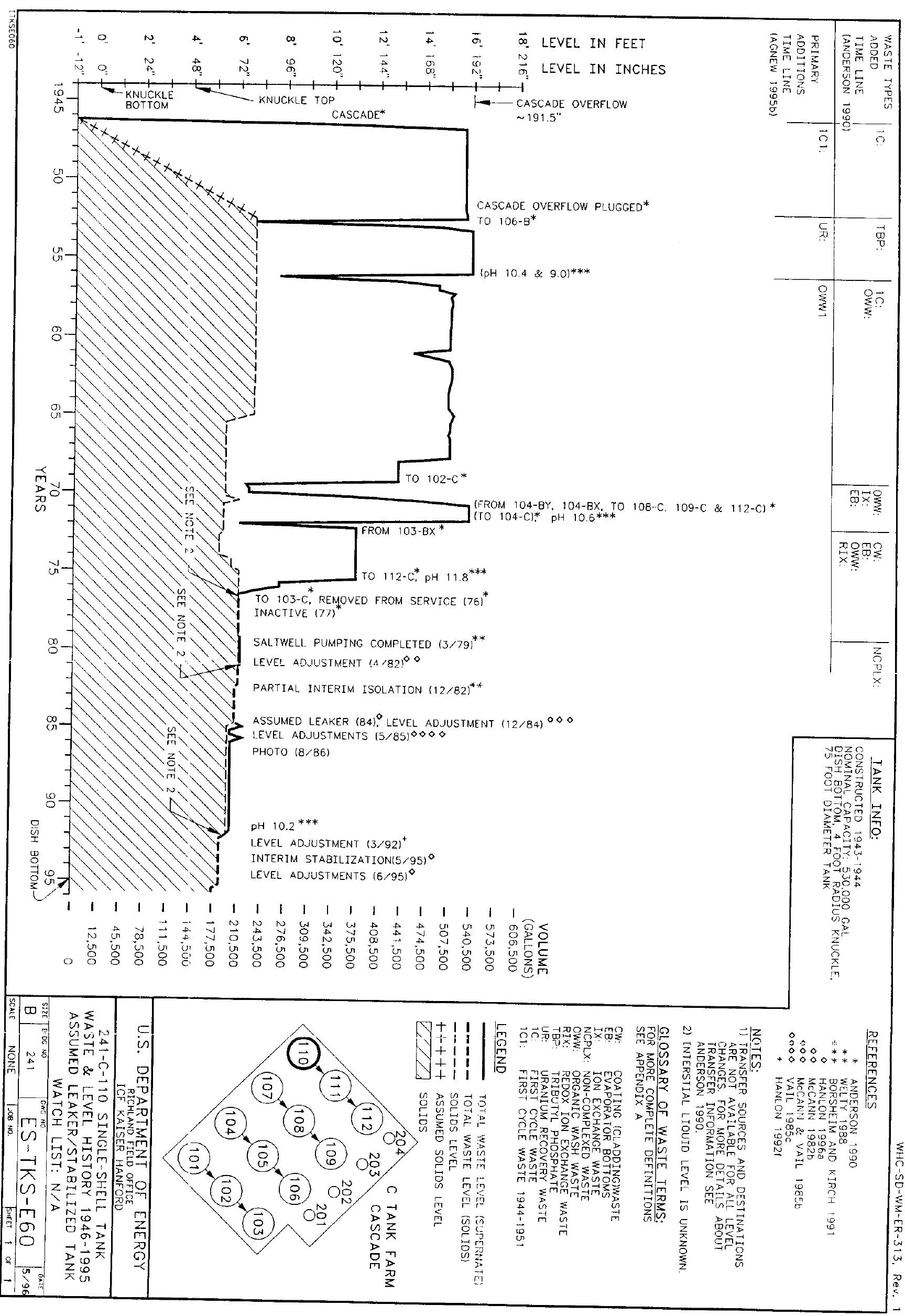




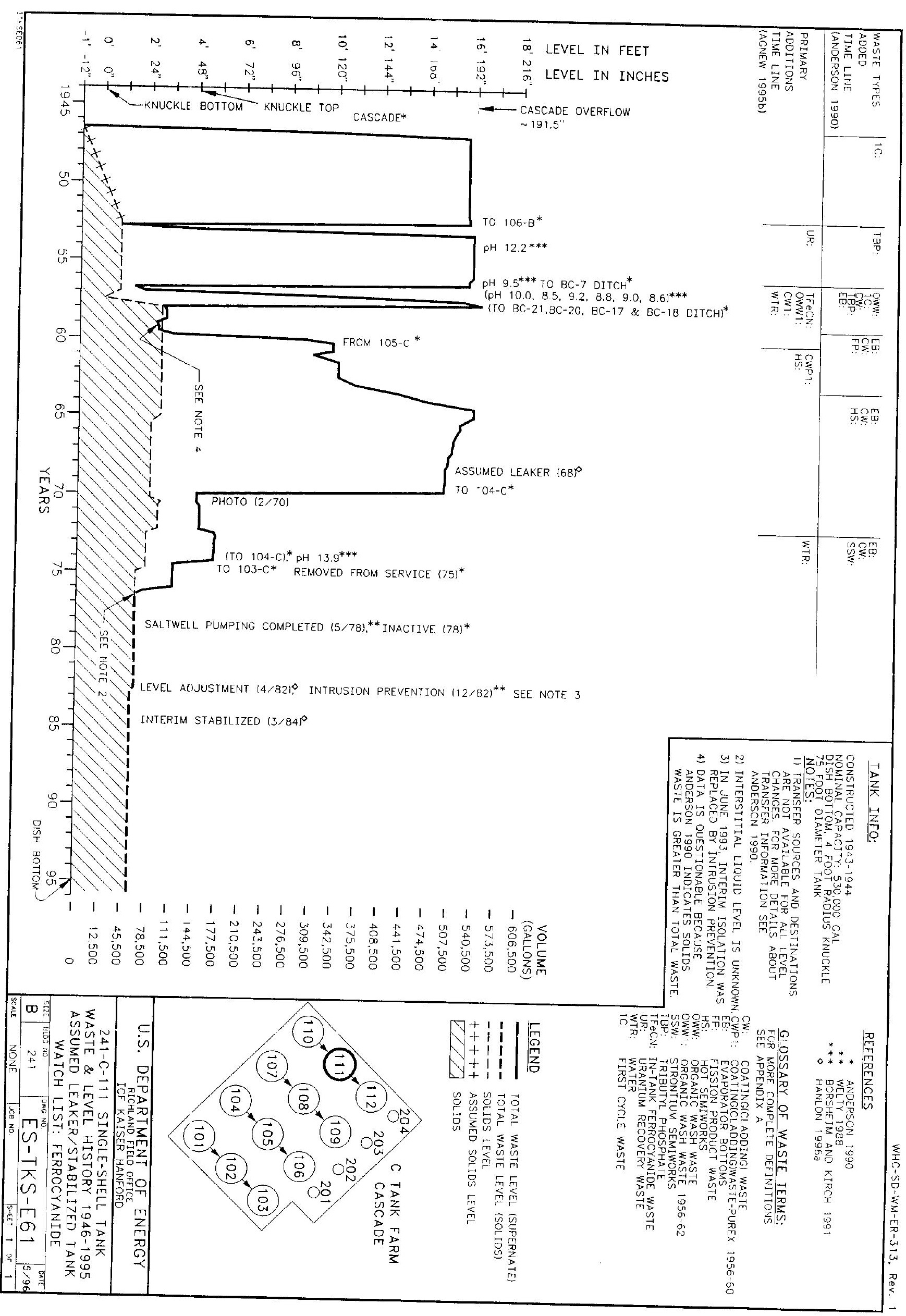




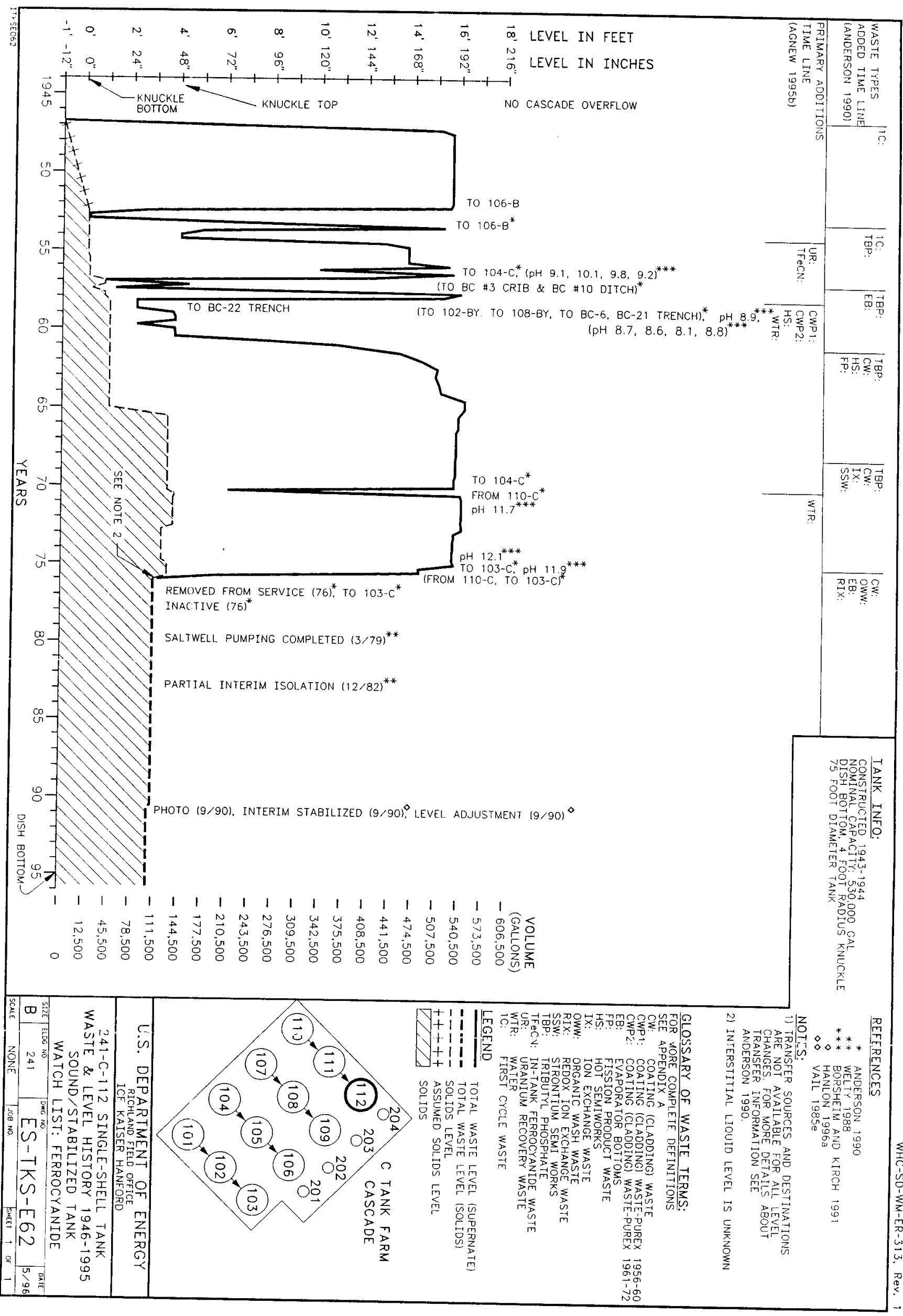




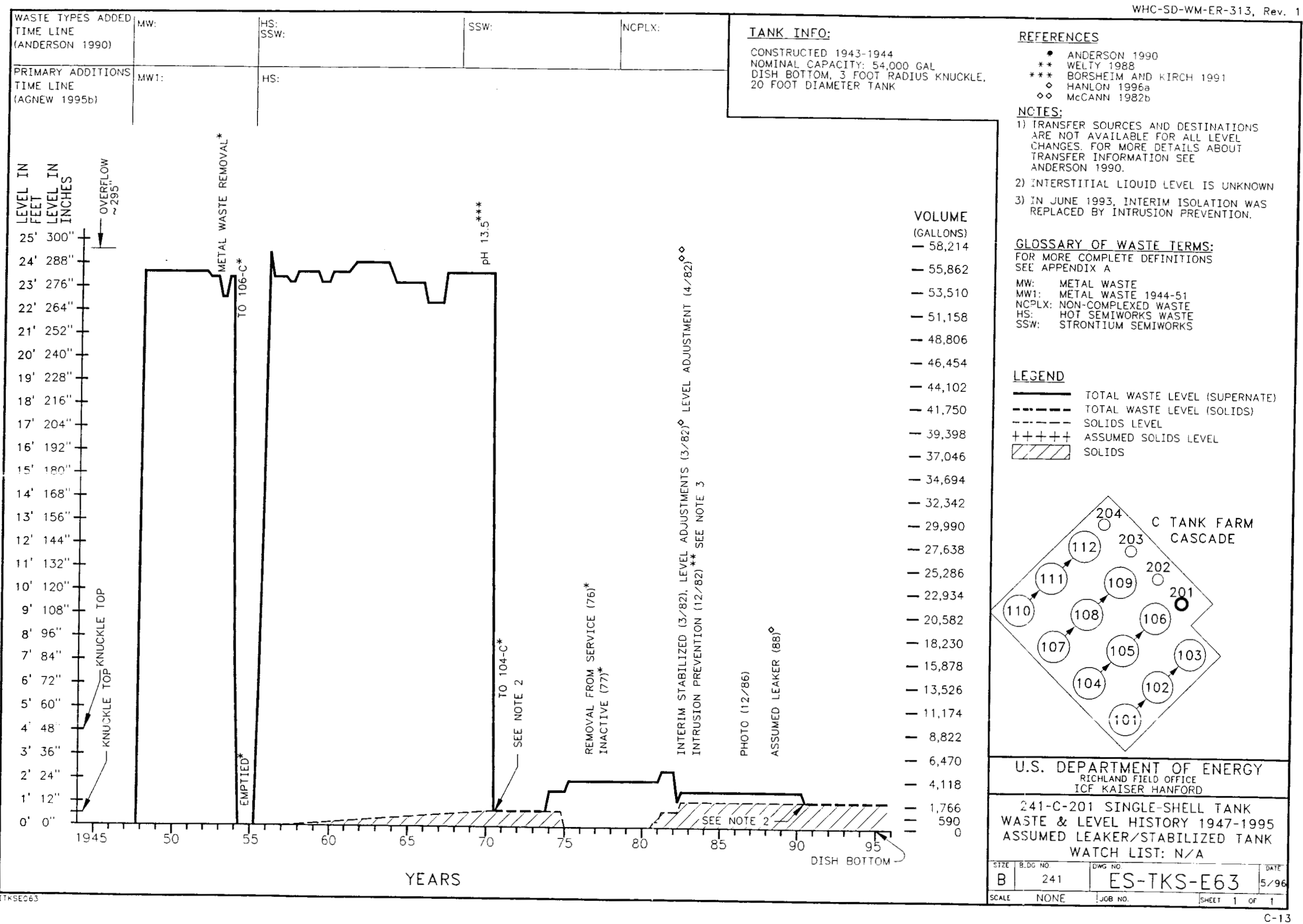


WHC-SD-WM-ER-313, Rev.1

241-C-101 LEVEL HISTORY

\begin{tabular}{|c|c|c|c|c|}
\hline Year & Total & Total & Solids & Solids \\
\hline & [K gal) & (in) & (K gol) & (in) \\
\hline \multirow{2}{*}{\multicolumn{5}{|c|}{1.1944}} \\
\hline & & & & \\
\hline \multicolumn{5}{|l|}{2} \\
\hline \multicolumn{5}{|l|}{3} \\
\hline \multicolumn{5}{|l|}{4} \\
\hline \multicolumn{5}{|l|}{$1-1945$} \\
\hline \multicolumn{5}{|l|}{2} \\
\hline \multicolumn{5}{|l|}{3} \\
\hline \multicolumn{5}{|l|}{4} \\
\hline $1-1946$ & 111 & 36 & & \\
\hline 2 & 528 & 187 & & \\
\hline 3 & 528 & 187 & & \\
\hline 4 & 528 & 187 & & \\
\hline $1-1947$ & 528 & 187 & & \\
\hline 2 & 528 & 187 & & \\
\hline 3 & 528 & 187 & & \\
\hline 4 & 528 & 187 & & \\
\hline $1-1948$ & 528 & 187 & & \\
\hline 2 & 528 & 187 & & \\
\hline 3 & 528 & 187 & & \\
\hline 4 & 528 & 187 & & \\
\hline $1-1949$ & 528 & 187 & & \\
\hline 2 & 528 & 187 & & \\
\hline 3 & 528 & 187 & & \\
\hline 4 & 528 & 187 & & \\
\hline $1-1950$ & 528 & 187 & & \\
\hline 2 & 528 & 187 & & \\
\hline 3 & 528 & 187 & & \\
\hline 4 & 528 & 187 & & \\
\hline $1-1951$ & 528 & 187 & & \\
\hline 2 & 528 & 187 & & \\
\hline 3 & 528 & 187 & & \\
\hline 4 & 528 & 187 & & \\
\hline 1-1952 & 530 & 188 & & \\
\hline 2 & 530 & 188 & & \\
\hline 3 & 530 & 188 & & \\
\hline \multicolumn{5}{|l|}{4} \\
\hline \multicolumn{5}{|l|}{ 1-1953 } \\
\hline 2 & 422 & 149 & & \\
\hline 3 & 222 & 76 & & \\
\hline 4 & 517 & 183 & & \\
\hline $1-1954$ & 510 & 181 & & \\
\hline 2 & 510 & 181 & & \\
\hline 3 & 510 & 181 & & \\
\hline 4 & 510 & 181 & & \\
\hline $1-1955$ & 510 & 181 & & \\
\hline 2 & 510 & 181 & & \\
\hline
\end{tabular}

C-17 
WHC-SD-WM-ER-313, Rev.1

241-C-101 LeVEL HISTORY

\begin{tabular}{|c|c|c|c|c|}
\hline Year & Total & Total & Solids & Solids \\
\hline & (K gol) & (in) & (K gal) & (in) \\
\hline & & & & \\
\hline 3 & 510 & 181 & & \\
\hline 4 & 326 & 114 & & \\
\hline $1-1956$ & 485 & 172 & & \\
\hline 2 & 485 & 172 & & \\
\hline 3 & 161 & 54 & & \\
\hline 4 & 131 & 43 & & \\
\hline 7-1957 & 98 & 31 & & \\
\hline 2 & 483 & 171 & & \\
\hline 3 & 178 & 60 & & \\
\hline 4 & 131 & 43 & & \\
\hline $1-1958$ & 150 & 50 & 98 & 31 \\
\hline 2 & 125 & 41 & 98 & 31 \\
\hline 3 & 125 & 41 & 98 & 31 \\
\hline 4 & 125 & 41 & 98 & 31 \\
\hline $1-1959$ & 125 & 41 & 98 & 31 \\
\hline 2 & 128 & 42 & 98 & 31 \\
\hline 3 & 131 & 43 & 98 & 31 \\
\hline 4 & 131 & 43 & $\overline{98}$ & 31 \\
\hline $1-1960$ & $1 \overline{31}$ & 43 & 98 & 31 \\
\hline 2 & 131 & 43 & 98 & 31 \\
\hline 3 & 131 & 43 & 98 & 31 \\
\hline 4 & 150 & 50 & 98 & 31 \\
\hline \multicolumn{5}{|l|}{ 1-1961 } \\
\hline 2 & 510 & 181 & 98 & 31 \\
\hline \multicolumn{5}{|l|}{3} \\
\hline 4 & 510 & 181 & 98 & 31 \\
\hline \multicolumn{5}{|l|}{ 1-1962 } \\
\hline 2 & 524 & 186 & 98 & 31 \\
\hline \multicolumn{5}{|l|}{3} \\
\hline 4 & 524 & 186 & .98 & 31 \\
\hline \multicolumn{5}{|l|}{$1-1963$} \\
\hline 2 & 524 & 186 & 109 & 35 \\
\hline \multicolumn{5}{|l|}{3} \\
\hline 4 & 370 & 130 & 109 & 35 \\
\hline \multicolumn{5}{|l|}{$1-1964$} \\
\hline 2 & 542 & 193 & 109 & 35 \\
\hline \multicolumn{5}{|l|}{3} \\
\hline 4 & 546 & 194 & 109 & 35 \\
\hline \multicolumn{5}{|l|}{$1-1965$} \\
\hline 2 & 574 & 204 & 51 & 14 \\
\hline 3 & 568 & 202 & 51 & 14 \\
\hline 4 & 565 & 201 & 51 & 14 \\
\hline $1-1966$ & 563 & 200 & 51 & 14 \\
\hline 2 & 571 & 203 & 51 & 14 \\
\hline 3 & 656 & 234 & 51 & 14 \\
\hline 4 & 563 & 200 & 51 & 14 \\
\hline
\end{tabular}


241-C-101 LEVEL HISTORY

\begin{tabular}{|c|c|c|c|c|}
\hline Yoar & Totel & Total & Solids & Solids \\
\hline & (K gal) & (in) & (K gal) & (in) \\
\hline $1-1967$ & 557 & 198 & 51 & 14 \\
\hline 2 & 555 & 197 & 51 & 14 \\
\hline 3 & 555 & 197 & 51 & 14 \\
\hline 4 & 549 & 195 & 51 & 14 \\
\hline $1-1968$ & 545 & 194 & 51 & 14 \\
\hline 2 & 545 & 194 & 51 & 14 \\
\hline 3 & 545 & 194 & 51 & 14 \\
\hline 4 & 541 & 192 & 51 & 14 \\
\hline $1-1969$ & 541 & 192 & 51 & 14 \\
\hline 2 & 538 & 191 & 51 & 14 \\
\hline 3 & 538 & 191 & 106 & 34 \\
\hline 4 & 132 & 43 & 125 & 41 \\
\hline $1-1970$ & 134 & 44 & 87 & 27 \\
\hline 2 & 134 & 44 & 87 & 27 \\
\hline 3 & 136 & 45 & 81 & 25 \\
\hline 4 & 138 & 46 & 81 & 25 \\
\hline $1-1971$ & 131 & 43 & 81 & 25 \\
\hline 2 & 131 & 43 & 81 & 25 \\
\hline 3 & 128 & 42 & 81 & 25 \\
\hline 4 & 127 & 42 & 81 & 25 \\
\hline 1.1972 & 125 & 41 & 81 & 25 \\
\hline 2 & 125 & 41 & 81 & 25 \\
\hline 3 & 124 & 41 & 81 & 25 \\
\hline 4 & 120 & 39 & 81 & 25 \\
\hline $1-1973$ & 121 & 39 & 81 & 25 \\
\hline 2 & 120 & 39 & 81 & 25 \\
\hline 3 & 120 & 39 & 81 & 25 \\
\hline 4 & 131 & 43 & 81 & 25 \\
\hline 1-1974 & 129 & 42 & 81 & 25 \\
\hline 2 & 128 & 42 & 81 & 25 \\
\hline 3 & 81 & 25 & 81 & 25 \\
\hline 4 & 92 & 29 & 62 & 18 \\
\hline $1-1975$ & 92 & 29 & 62 & 18 \\
\hline 2 & 92 & 29 & 62 & 18 \\
\hline 3 & 92 & 29 & 62 & 18 \\
\hline 4 & 92 & 29 & 62 & 18 \\
\hline $1-1976$ & 92 & 29 & 62 & 18 \\
\hline 2 & 73 & 22 & 73 & 22 \\
\hline 3 & 73 & 22 & 73 & 22 \\
\hline 4 & 73 & 22 & 73 & 22 \\
\hline $1-1977$ & 73 & 22 & 73 & 22 \\
\hline 2 & 73 & 22 & 73 & 22 \\
\hline 3 & 73 & 22 & 73 & 22 \\
\hline 4 & 73 & 22 & 73 & 22 \\
\hline $1-1978$ & 73 & 22 & 73 & 22 \\
\hline 2 & 73 & 22 & 73 & 22 \\
\hline
\end{tabular}




\begin{tabular}{|c|c|c|c|c|}
\hline$\angle Z$ & 88 & $\angle Z$ & 88 & $t$ \\
\hline$\angle 2$ & 88 & $\angle 2$ & 88 & $\varepsilon$ \\
\hline$\angle 2$ & 88 & $\angle Z$ & 88 & 2 \\
\hline$\angle Z$ & 88 & $\angle 2$ & 88 & $686 L-L$ \\
\hline$\angle z$ & 88 & $\angle 2$ & 88 & \pm \\
\hline$\angle 2$ & 88 & $\angle 2$ & 88 & $\varepsilon$ \\
\hline$\angle Z$ & 88 & $\angle Z$ & 88 & $z$ \\
\hline$\angle z$ & 88 & $\angle 2$ & 88 & $886 L-L$ \\
\hline$\angle Z$ & 88 & $\angle Z$ & 88 & $t$ \\
\hline$\angle z$ & 88 & $\angle 2$ & 88 & $\varepsilon$ \\
\hline$\angle Z$ & 88 & $\angle Z$ & 88 & $z$ \\
\hline$\angle z$ & 88 & $\angle Z$ & 88 & $\angle 86 L-L$ \\
\hline$\angle Z$ & 88 & $\angle Z$ & 88 & $t$ \\
\hline$\angle Z$ & 88 & $\angle Z$ & 88 & $\varepsilon$ \\
\hline$\angle Z$ & 88 & $\angle Z$ & 88 & $z$ \\
\hline$\angle z$ & 88 & $L Z$ & 88 & $986 L-1$ \\
\hline$\angle 2$ & 88 & $\angle z$ & 88 & $t$ \\
\hline$\angle Z$ & 88 & $L Z$ & 88 & $\varepsilon$ \\
\hline$\angle Z$ & 88 & $\angle Z$ & 88 & $z$ \\
\hline$\angle Z$ & 88 & $\angle Z$ & 88 & $9861-1$ \\
\hline$\angle Z$ & 88 & $\angle Z$ & 88 & $t$ \\
\hline$L Z$ & 88 & $\angle 2$ & 88 & $\varepsilon$ \\
\hline$\angle Z$ & 88 & $\angle Z$ & 88 & 2 \\
\hline$L Z$ & 88 & $\angle 2$ & 88 & t86L-L \\
\hline$\angle 2$ & 88 & $\angle 2$ & 88 & $t$ \\
\hline 82 & 06 & 82 & 06 & $\varepsilon$ \\
\hline 82 & 06 & 82 & 06 & 2 \\
\hline 82 & 06 & 82 & 06 & 886L-L \\
\hline 82 & 06 & 82 & 06 & $t$ \\
\hline 82 & 06 & 82 & 06 & $\varepsilon$ \\
\hline 82 & 06 & 82 & 06 & $\tau$ \\
\hline$Z Z$ & $\varepsilon L$ & $z z$ & $\varepsilon L$ & $286 \mathrm{l}-\mathrm{l}$ \\
\hline$z Z$ & $\varepsilon L$ & $z \tau$ & $\varepsilon L$ & $t$ \\
\hline$z Z$ & $\varepsilon L$ & $2 z$ & $\varepsilon L$ & $\varepsilon$ \\
\hline$z Z$ & $\varepsilon L$ & $z z$ & $\varepsilon L$ & 2 \\
\hline $2 z$ & $\varepsilon$ & 22 & $\therefore L$ & $186 \mathrm{~L}-\mathrm{L}$ \\
\hline $2 Z$ & $\varepsilon L$ & 22 & $\varepsilon L$ & $\rightarrow$ \\
\hline$z \bar{z}$ & $\varepsilon L$ & $2 z$ & $\varepsilon L$ & $\varepsilon$ \\
\hline$z z$ & $\varepsilon L$ & $\tau \bar{z}$ & $\varepsilon L$ & $z$ \\
\hline$z z$ & $\varepsilon L$ & $z z$ & $\varepsilon L$ & $086 l-l$ \\
\hline$z Z$ & $\varepsilon L$ & $z z$ & $\varepsilon L$ & $\nabla$ \\
\hline$Z Z$ & $\varepsilon L$ & $z 2$ & $\varepsilon L$ & $\varepsilon$ \\
\hline$Z Z$ & $\varepsilon L$ & $\tau 2$ & $\varepsilon L$ & 2 \\
\hline$z 2$ & $\varepsilon L$ & $Z z$ & $\varepsilon L$ & $6 \angle 6 L-L$ \\
\hline 22 & $\varepsilon L$ & 22 & $\varepsilon L$ & $t$ \\
\hline$z z$ & $\varepsilon L$ & 22 & $\varepsilon L$ & $\varepsilon$ \\
\hline (UI) & & & & \\
\hline sp!|os & $\frac{(1 \times 0 \times 1)}{501100}$ & (u!n) & $(106 x)$ & \\
\hline & spulos & [E10] & 10701 & Je日A \\
\hline
\end{tabular}


WHC-SD-WM-ER-313, Rev.1

241-C-101 LEVEL HISTORY

\begin{tabular}{|c|c|c|c|c|}
\hline Year & Total & Total & Solids & Solids \\
\hline & (K gal) & (in) & (K gal) & (in) \\
\hline $1-1990$ & 88 & 27 & 88 & 27 \\
\hline 2 & 88 & 27 & 88 & 27 \\
\hline 3 & 88 & 27 & 88 & 27 \\
\hline 4 & 88 & 27 & 88 & 27 \\
\hline $1-1991$ & 88 & 27 & 88 & 27 \\
\hline 2 & 88 & 27 & 88 & 27 \\
\hline 3 & 88 & 27 & 88 & 27 \\
\hline 4 & 88 & 27 & 88 & 27 \\
\hline 1-1992 & 88 & 27 & 88 & 27 \\
\hline 2 & 88 & 27 & 88 & 27 \\
\hline 3 & 88 & 27 & 88 & 27 \\
\hline 4 & 88 & 27 & 88 & 27 \\
\hline 1-1993 & 88 & 27 & 88 & 27 \\
\hline 2 & 88 & 27 & 88 & 27 \\
\hline 3 & 88 & 27 & 88 & 27 \\
\hline 4 & 88 & 27 & 88 & 27 \\
\hline $1-1994$ & 88 & 27 & 88 & 27 \\
\hline 2 & 88 & 27 & 88 & 27 \\
\hline 3 & 88 & 27 & 88 & 27 \\
\hline 4 & 88 & 27 & 88 & 27 \\
\hline 1-1995 & 88 & 27 & 88 & 27 \\
\hline 2 & 88 & 27 & 88 & 27 \\
\hline 3 & 88 & 27 & 88 & 27 \\
\hline
\end{tabular}


241-C-102 LEVEL HISTORY

WHC-SD-WM-ER-313, Rev.1

\begin{tabular}{|c|c|c|c|c|}
\hline Year & Total & Total & Solids & Solids \\
\hline & (K gal) & (in) & (K gal) & (in) \\
\hline \multicolumn{5}{|l|}{$1-1944$} \\
\hline \multicolumn{5}{|l|}{2} \\
\hline \multicolumn{5}{|l|}{3} \\
\hline \multicolumn{5}{|l|}{4} \\
\hline \multicolumn{5}{|l|}{$1-1945$} \\
\hline \multicolumn{5}{|l|}{2} \\
\hline \multicolumn{5}{|l|}{3} \\
\hline \multicolumn{5}{|l|}{4} \\
\hline \multicolumn{5}{|l|}{1.1946} \\
\hline 2 & 195 & 66 & & \\
\hline 3 & 528 & 187 & & \\
\hline 4 & 528 & 187 & & \\
\hline \begin{tabular}{|l|}
$1-1947$ \\
\end{tabular} & 528 & 187 & & \\
\hline 2 & 528 & 187 & & \\
\hline 3 & $5 \overline{28}$ & 187 & & \\
\hline 4 & 528 & 187 & & \\
\hline $1-1948$ & 528 & 187 & & \\
\hline 2 & 528 & 187 & & \\
\hline 3 & 528 & 187 & & \\
\hline 4 & 528 & 187 & & \\
\hline 1.1949 & 528 & 187 & & \\
\hline 2 & 528 & 187 & & \\
\hline 3 & 528 & 187 & & \\
\hline 4 & 528 & 187 & & \\
\hline $1-1950$ & 528 & 187 & & \\
\hline 2 & 528 & 187 & & \\
\hline 3 & 528 & 187 & & \\
\hline 4 & 528 & 187 & & \\
\hline $1-1951$ & 528 & 187 & & \\
\hline 2 & 528 & 187 & & \\
\hline 3 & 528 & 187 & & \\
\hline 4 & 528 & 187 & & \\
\hline $1-1952$ & 530 & 188 & & \\
\hline 2 & 530 & 188 & & \\
\hline 3 & 530 & 188 & & \\
\hline \multicolumn{5}{|l|}{4} \\
\hline \multicolumn{5}{|l|}{$1-1953$} \\
\hline \multicolumn{5}{|l|}{2} \\
\hline 3 & 467 & 165 & & \\
\hline 4 & 508 & 180 & & \\
\hline $1-1954$ & 530 & 188 & & \\
\hline 2 & 530 & 188 & & \\
\hline 3 & 530 & 188 & & \\
\hline 4 & 530 & 188 & & \\
\hline $1-1955$ & 530 & 188 & & \\
\hline 2 & 530 & 188 & & \\
\hline
\end{tabular}


WHC-SD-WM-ER-313. Rev.1

241-C-102 LEVEL HISTORY

\begin{tabular}{|c|c|c|c|c|}
\hline Yoar & Total & Total & I Solids & Solids \\
\hline & (K gal) & (in) & i (K gal) & (in) \\
\hline 3. & 530 & 188 & & \\
\hline 4 & 530 & 188 & & \\
\hline $1-1956$ & 530 & 188 & & \\
\hline 2 & 530 & 188 & & \\
\hline 3 & 530 & 188 & & \\
\hline 4 & 530 & 188 & & \\
\hline 1-1957 & 98 & 31 & & \\
\hline 2 & 48 & 13 & & \\
\hline 3 & 48 & 13 & & \\
\hline 4 & 48 & 13 & & \\
\hline $1-1958$ & 150 & 50 & 98 & 31 \\
\hline 2 & 37 & 9 & & \\
\hline 3 & 37 & 9 & & \\
\hline 4 & 37 & 9 & & \\
\hline $1-1959$ & 37 & 9 & & \\
\hline 2 & 37 & 9 & & \\
\hline 3 & 34 & 8 & & \\
\hline 4 & 34 & 8 & & \\
\hline 1-1960 & 34 & 8 & & \\
\hline 2 & 34 & 8 & & \\
\hline 3 & 378 & 133 & & \\
\hline 4 & 491 & 174 & & \\
\hline \multicolumn{5}{|l|}{$1-1961$} \\
\hline 2 & 521 & 185 & & \\
\hline \multicolumn{5}{|l|}{3} \\
\hline 4 & 519 & 184 & & \\
\hline \multicolumn{5}{|l|}{$1-1962$} \\
\hline 2 & 356 & 125 & & \\
\hline \multicolumn{5}{|l|}{3} \\
\hline 4 & 370 & 130 & & \\
\hline \multicolumn{5}{|l|}{$1-1963$} \\
\hline 2 & 334 & 117 & & \\
\hline \multicolumn{5}{|l|}{3} \\
\hline 4 & 450 & 159 & & \\
\hline \multicolumn{5}{|l|}{$1-1964$} \\
\hline 2 & 407 & 143 & & \\
\hline \multicolumn{5}{|l|}{3} \\
\hline 4 & 442 & 156 & & \\
\hline \multicolumn{5}{|l|}{$1-1965$} \\
\hline 2 & 326 & 114 & 238 & 82 \\
\hline 3 & 447 & 158 & 238 & 82 \\
\hline 4 & 461 & 163 & 238 & 82 \\
\hline 1.1966 & 472 & 167 & 238 & 82 \\
\hline 2 & 472 & 167 & 238 & 82 \\
\hline 3 & 464 & 164 & 238 & 82 \\
\hline 4 & 453 & 160 & 238 & 82 \\
\hline
\end{tabular}


241-C-102 LEVEL HISTORY

WHC-SD-WM-ER-313, Rev.1

\begin{tabular}{|c|c|c|c|c|}
\hline Year & Total & Total & Solids & Solids \\
\hline & (K gal) & (in) & (K gal) & (in) \\
\hline & & & & 82 \\
\hline \begin{tabular}{|l}
$1-1967$ \\
2
\end{tabular} & 499 & $\begin{array}{l}177 \\
172\end{array}$ & 238 & 82 \\
\hline 2 & 486 & 172 & 238 & 82 \\
\hline 3 & 486 & 172 & 238 & 82 \\
\hline 4 & 444 & 157 & 238 & 82 \\
\hline $1-1968$ & 476 & 169 & 238 & 82 \\
\hline 2 & 466 & 165 & 238 & 82 \\
\hline 3 & 455 & 161 & 238 & 82 \\
\hline 4 & 457 & $1 \overline{62}$ & 307 & 107 \\
\hline $1-1969$ & 462 & 163 & 332 & 116 \\
\hline 2 & 458 & 162 & 369 & 130 \\
\hline 3 & 501 & 178 & $\because 1$ & 123 \\
\hline 4 & 486 & 172 & 5 & 121 \\
\hline $1-1970$ & 486 & 172 & 26 & 114 \\
\hline 2 & 486 & 172 & 312 & 109 \\
\hline 3 & 486 & 172 & 299 & 104 \\
\hline 4 & 486 & 172 & 299 & 104 \\
\hline $1-1971$ & 480 & 170 & 299 & 104 \\
\hline 2 & 480 & 170 & 299 & 104 \\
\hline 3 & 480 & 170 & 299 & 104 \\
\hline 4 & 479 & 170 & 299 & 104 \\
\hline 1.1972 & 475 & 168 & 299 & 104 \\
\hline 2 & 477 & 169 & 299 & 104 \\
\hline 3 & 474 & 168 & 299 & 104 \\
\hline 4 & 475 & 168 & 299 & 104 \\
\hline $1-1973$ & 484 & 171 & 299 & 104 \\
\hline 2 & 483 & 171 & 299 & 104 \\
\hline 3 & 465 & 165 & 299 & 104 \\
\hline 4 & 466 & 165 & 299 & 104 \\
\hline $1-1974$ & 467 & 165 & 299 & 104 \\
\hline 2 & 467 & 165 & 299 & 104 \\
\hline 3 & 467 & 165 & 299 & 104 \\
\hline 4 & 466 & 165 & 332 & 116 \\
\hline $1-1975$ & 466 & 165 & 332 & 116 \\
\hline 2 & 466 & 165 & 332 & 116 \\
\hline 3 & 466 & 165 & 332 & 116 \\
\hline 4 & 431 & 152 & 332 & 116 \\
\hline $1-1976$ & 431 & 152 & 62 & 18 \\
\hline 2 & 431 & 152 & 431 & 152 \\
\hline 3 & 431 & 152 & 431 & 152 \\
\hline 4 & 431 & 152 & 431 & 152 \\
\hline $1-1977$ & 431 & 152 & 431 & 152 \\
\hline 2 & 431 & 152 & 431 & 152 \\
\hline 3 & 431 & 152 & 431 & 152 \\
\hline 4 & 431 & 152 & 431 & 152 \\
\hline $1-1979$ & 431 & 152 & 431 & 152 \\
\hline 2 & 439 & 152 & 431 & 152 \\
\hline
\end{tabular}


241-C-102 LEVEL HISTORY

WHC-SD-WM-ER-313, Rev.1

\begin{tabular}{|c|c|c|c|c|}
\hline Year & Total & Total & Solids & Solids \\
\hline & (K gal) & (in) & (K gad) & (in) \\
\hline & & & & \\
\hline 3 & 431 & 152 & 431 & 152 \\
\hline 4 & 431 & 152 & 431 & 152 \\
\hline $1-1979$ & 431 & 152 & 431 & 152 \\
\hline 2 & 431 & $\overline{152}$ & 431 & 152 \\
\hline 3 & 431 & 152 & 431 & 152 \\
\hline 4 & 431 & 152 & 431 & 152 \\
\hline $1-1980$ & 431 & 152 & 431 & 152 \\
\hline 2 & 431 & 152 & 431 & 152 \\
\hline 3 & 431 & 152 & 431 & 152 \\
\hline 4 & 431 & 152 & 431 & 152 \\
\hline 1.1981 & 431 & 152 & 431 & 152 \\
\hline 2 & 431 & 152 & 431 & 152 \\
\hline 3 & 431 & 152 & 431 & 152 \\
\hline 4 & 431 & 152 & 431 & 152 \\
\hline 1-1982 & 431 & 152 & 431 & 152 \\
\hline 2 & 427 & 151 & 424 & 150 \\
\hline 3 & 427 & 151 & 424 & 150 \\
\hline 4 & 427 & 151 & 424 & 150 \\
\hline $1-1983$ & 427 & 151 & 424 & 150 \\
\hline 2 & 427 & 151 & 424 & 150 \\
\hline 3 & 427 & 151 & 424 & 150 \\
\hline 4 & 427 & 151 & 424 & 150 \\
\hline 1-1984 & 427 & 151 & 424 & 150 \\
\hline 2 & 427 & 151 & 424 & 150 \\
\hline 3 & 427 & 151 & 424 & 150 \\
\hline 4 & 427 & 151 & 424 & 150 \\
\hline $1-1985$ & 427 & 151 & 424 & 150 \\
\hline 2 & 427 & 151 & 424 & 150 \\
\hline 3 & 427 & 151 & 424 & 150 \\
\hline 4 & 427 & 151 & 424 & 150 \\
\hline $1-1986$ & 427 & 151 & 424 & 150 \\
\hline 2 & 427 & 151 & 424 & 150 \\
\hline 3 & 427 & 151 & 424 & 150 \\
\hline 4 & 427 & 151 & 424 & 150 \\
\hline $1-1987$ & 427 & 159 & 424 & 150 \\
\hline 2 & 427 & 151 & 424 & 150 \\
\hline 3 & 427 & 151 & 424 & 150 \\
\hline 4 & 427 & 151 & 424 & 150 \\
\hline $1-1988$ & 427 & 151 & 424 & 150 \\
\hline 2 & 427 & 151 & 424 & 150 \\
\hline 3 & 427 & 151 & 424 & 150 \\
\hline 4 & 427 & 151 & 424 & 150 \\
\hline $1-1989$ & 427 & 151 & 424 & 150 \\
\hline 2 & 427 & 151 & 424 & 150 \\
\hline 3 & 427 & 151 & 424 & 150 \\
\hline 4 & 427 & 151 & 424 & 150 \\
\hline
\end{tabular}


241-C-102 LEVEL HISTORY

WHC-SD-WM-ER-313. Rev.1

\begin{tabular}{|l|c|c|c|c|}
\hline Year & Total & Total & Solids & Solids \\
\hline & (K gal) & (in) & (K gal) & (in) \\
\hline $1-1990$ & & & & \\
\hline 2 & 427 & 151 & 424 & 150 \\
\hline 3 & 427 & 151 & 424 & 150 \\
\hline 4 & 427 & 151 & 424 & 150 \\
\hline $1-1991$ & 427 & 151 & 424 & 150 \\
\hline 2 & 427 & 151 & 424 & 150 \\
\hline 3 & 427 & 151 & 424 & 150 \\
\hline 4 & 424 & 150 & 424 & 150 \\
\hline $1-1992$ & 423 & 149 & 423 & 149 \\
\hline 2 & 423 & 149 & 423 & 149 \\
\hline 3 & 423 & 149 & 423 & 149 \\
\hline 4 & 423 & 149 & 423 & 149 \\
\hline $1-1993$ & 423 & 149 & 423 & 149 \\
\hline 2 & 423 & 149 & 423 & 149 \\
\hline 3 & 423 & 149 & 423 & 149 \\
\hline 4 & 423 & 149 & 423 & 149 \\
\hline $1-1994$ & 423 & 149 & 423 & 149 \\
\hline 2 & 423 & 149 & 423 & 149 \\
\hline 3 & 42 & 149 & 423 & 149 \\
\hline 4 & 423 & 149 & 423 & 149 \\
\hline $1-1995$ & 423 & 149 & 423 & 149 \\
\hline 2 & 423 & 149 & 423 & 149 \\
\hline 3 & 316 & 110 & 316 & 110 \\
\hline & & & & \\
\hline
\end{tabular}


241-C-103 LEVEL HISTORY

WHC-SD-WM-ER-313. Rev.1

\begin{tabular}{|c|c|c|c|c|}
\hline Year & Total & Total & Solids & Solids \\
\hline & (K gal) & (in) & (K gal) & (in) \\
\hline & & & & \\
\hline \multicolumn{5}{|l|}{$1-1944$} \\
\hline \multicolumn{5}{|l|}{2} \\
\hline \multicolumn{5}{|l|}{3} \\
\hline \multicolumn{5}{|l|}{4} \\
\hline \multicolumn{5}{|l|}{1.1945} \\
\hline \multicolumn{5}{|l|}{2} \\
\hline \multicolumn{5}{|l|}{3} \\
\hline \multicolumn{5}{|l|}{4} \\
\hline \multicolumn{5}{|l|}{$1-1946$} \\
\hline \multicolumn{5}{|l|}{2} \\
\hline 3 & 333 & 117 & & \\
\hline 4 & 528 & 187 & & \\
\hline $1-1947$ & 528 & 187 & & \\
\hline 2 & 528 & 187 & & \\
\hline 3 & 528 & 187 & & \\
\hline 4 & 528 & 187 & & \\
\hline $1-1948$ & 528 & 187 & & \\
\hline 2 & 528 & 187 & & \\
\hline 3 & 528 & 187 & & \\
\hline 4 & 528 & 187 & & \\
\hline 1.1949 & 528 & 187 & & \\
\hline 2 & 528 & 187 & & \\
\hline 3 & 528 & 187 & & \\
\hline 4 & 528 & 187 & & \\
\hline 1.1950 & 528 & 187 & & \\
\hline 2 & 528 & 187 & & \\
\hline 3 & 528 & 187 & & \\
\hline 4 & 528 & 187 & & \\
\hline $1-1951$ & 528 & 187 & & \\
\hline 2 & 528 & 187 & & \\
\hline 3 & 528 & 187 & & \\
\hline 4 & 528 & 187 & & \\
\hline $1-1952$ & 519 & 184 & & \\
\hline 2 & 519 & 184 & & \\
\hline 3 & 519 & 184 & & \\
\hline \multicolumn{5}{|l|}{4} \\
\hline \multicolumn{5}{|l|}{$1-1953$} \\
\hline 2 & 45 & 12 & & \\
\hline 3 & 508 & 180 & & \\
\hline 4 & 560 & 199 & & \\
\hline $1-1954$ & 560 & 199 & & \\
\hline 2 & 560 & 199 & & \\
\hline 3 & 560 & 199 & & \\
\hline 4 & 560 & 199 & & \\
\hline $1-1955$ & 560 & 199 & & \\
\hline 2 & 560 & 199 & & \\
\hline
\end{tabular}


241-C-103 LEVEL HISTORY

WHC-SD-WM-ER-313. Rev.1

\begin{tabular}{|c|c|c|c|c|}
\hline Year & Total & Total & Solids & Solids \\
\hline & (K gal) & (in) & (K gal) & (in) \\
\hline & & & $\vdots$ & \\
\hline 3 & 560 & 199 & $i$ & \\
\hline 4 & 560 & 199 & 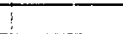 & \\
\hline $1-1956$ & 560 & 199 & & \\
\hline 2 & 560 & 199 & & \\
\hline 3 & 560 & 199 & & \\
\hline 4 & 560 & 199 & & \\
\hline $1-1957$ & 98 & 31 & & \\
\hline 2 & 37 & 9 & & \\
\hline 3 & 329 & 115 & & \\
\hline 4 & 348 & 122 & & \\
\hline \begin{tabular}{|l|}
$1-1958$ \\
\end{tabular} & 62 & 18 & & \\
\hline 2 & 62 & 18 & & \\
\hline 3 & 46 & 12 & & \\
\hline 4 & 46 & 12 & & \\
\hline $1-1959$ & 45 & 12 & & \\
\hline 2 & 48 & 13 & & \\
\hline 3 & 45 & 12 & & \\
\hline 4 & 45 & 12 & & \\
\hline $1-1960$ & 45 & 12 & & \\
\hline 2 & 309 & 108 & & \\
\hline 3 & 416 & 147 & & \\
\hline 4 & 524 & 186 & & \\
\hline \multicolumn{5}{|l|}{$1-1961$} \\
\hline 2 & 557 & 198 & & \\
\hline \multicolumn{5}{|l|}{3} \\
\hline 4 & 563 & 200 & & \\
\hline \multicolumn{5}{|l|}{ 1-1962 } \\
\hline 2 & 227 & 78 & & \\
\hline \multicolumn{5}{|l|}{3} \\
\hline 4 & 57 & 16 & & \\
\hline \multicolumn{5}{|l|}{$1-1963$} \\
\hline 2 & 530 & 188 & & \\
\hline \multicolumn{5}{|l|}{3} \\
\hline 4 & 469 & 166 & & \\
\hline \multicolumn{5}{|l|}{1.1964} \\
\hline 2 & 442 & 156 & & \\
\hline \multicolumn{5}{|l|}{3} \\
\hline 4 & 420 & 148 & & \\
\hline \multicolumn{5}{|l|}{$1-1965$} \\
\hline 2 & 458 & 162 & & \\
\hline 3 & 455 & 161 & & \\
\hline 4 & 222 & 76 & & \\
\hline $1-1966$ & 527 & 187 & & \\
\hline 2 & 497 & 176 & & \\
\hline 3 & 494 & 175 & & \\
\hline 4 & 475 & 168 & & \\
\hline
\end{tabular}


241-C-103 LEVEL HISTORY

\begin{tabular}{|c|c|c|c|c|}
\hline Year & Total & Total & Solids & Solids \\
\hline & (K gal) & (in) & (K gal) & (in) \\
\hline & & & & \\
\hline $1-1967$ & 450 & 159 & & \\
\hline 2 & 439 & 155 & & \\
\hline 3 & 433 & 153 & 35 & 8 \\
\hline 4 & 433 & 153 & 35 & 8 \\
\hline $1-1968$ & 436 & 154 & 35 & 8 \\
\hline 2 & 435 & 154 & 35 & 8 \\
\hline 3 & 433 & 153 & 35 & 8 \\
\hline 4 & 431 & 152 & 35 & 8 \\
\hline $1-1969$ & 431 & 152 & 35 & 8 \\
\hline 2 & 429 & 151 & 35 & 8 \\
\hline 3 & 103 & 33 & 35 & 8 \\
\hline 4 & 103 & 33 & 35 & 8 \\
\hline $1-1970$ & 491 & 174 & 35 & 8 \\
\hline 2 & 109 & 35 & 85 & 26 \\
\hline 3 & 180 & 61 & 99 & 31 \\
\hline 4 & 279 & 97 & 99 & 31 \\
\hline $1-1971$ & 92 & 29 & 92 & 29 \\
\hline 2 & 92 & 29 & 92 & 29 \\
\hline 3 & 90 & 28 & 90 & 28 \\
\hline 4 & 102 & 33 & 102 & 33 \\
\hline $1-1972$ & 102 & 33 & 102 & 33 \\
\hline 2 & 102 & 33 & 102 & 33 \\
\hline 3 & 539 & 191 & 90 & 28 \\
\hline 4 & 92 & 29 & 90 & 28 \\
\hline $1-1973$ & 94 & 30 & 90 & 28 \\
\hline 2 & 239 & 82 & 90 & 28 \\
\hline 3 & 390 & 137 & 90 & 28 \\
\hline 4 & 392 & 138 & 90 & 28 \\
\hline $1-1974$ & 508 & 180 & 90 & 28 \\
\hline 2 & 343 & 120 & 90 & 28 \\
\hline 3 & 107 & 34 & 90 & 28 \\
\hline 4 & 224 & 77 & 73 & 22 \\
\hline $1-1975$ & 516 & 183 & 73 & 22 \\
\hline 2 & 164 & 55 & 73 & 22 \\
\hline 3 & 109 & 35 & 73 & 22 \\
\hline 4 & 106 & 34 & 73 & 22 \\
\hline $1-1976$ & 274 & 95 & 73 & 22 \\
\hline 2 & 288 & 100 & 73 & 22 \\
\hline 3 & 321 & 112 & 73 & 22 \\
\hline 4 & 345 & 121 & 73 & 22 \\
\hline 1-1977 & 384 & 135 & 68 & 20 \\
\hline 2 & 387 & 136 & 68 & 20 \\
\hline 3 & 274 & 95 & 150 & 50 \\
\hline 4 & 422 & 149 & 153 & 51 \\
\hline $1-1978$ & 235 & 81 & 164 & 55 \\
\hline 2 & 260 & 90 & 167 & 56 \\
\hline
\end{tabular}


241-C-103 LEVEL HISTORY

WHC-SD-WM-ER-313. Rev.]

\begin{tabular}{|c|c|c|c|c|}
\hline Year & Total & Total & Solids & Solids \\
\hline & (K gal) & (in) & (K gal) & (in) \\
\hline & & & & \\
\hline 3 & 242 & 83 & 175 & 59 \\
\hline 4 & 296 & 103 & 175 & 59 \\
\hline $1-1979$ & 301 & 105 & 175 & 59 \\
\hline 2 & 307 & 107 & 175 & 59 \\
\hline 3 & 200 & 68 & 175 & 59 \\
\hline 4 & 200 & 68 & 175 & 59 \\
\hline $1-1980$ & 200 & 68 & 175 & 59 \\
\hline 2 & 200 & 68 & 175 & 59 \\
\hline 3 & 200 & 68 & 175 & 59 \\
\hline 4 & 200 & 68 & 175 & 59 \\
\hline $1-1981$ & 200 & 68 & 175 & 59 \\
\hline 2 & 200 & 68 & 175 & 59 \\
\hline 3 & 200 & 68 & 175 & 59 \\
\hline 4 & 200 & 68 & 175 & 59 \\
\hline 1-1982 & 200 & 68 & 175 & 59 \\
\hline 2 & 200 & 68 & 175 & 59 \\
\hline 3 & 200 & 68 & 175 & 59 \\
\hline 4 & 200 & 68 & 175 & 59 \\
\hline $7-1983$ & 200 & 68 & 175 & 59 \\
\hline 2 & 200 & 68 & 175 & 59 \\
\hline 3 & 200 & 68 & 175 & 59 \\
\hline 4 & 200 & 68 & 175 & 59 \\
\hline $1-1984$ & 200 & 68 & 175 & 59 \\
\hline 2 & 200 & 68 & 175 & 59 \\
\hline 3 & 200 & 68 & 175 & 59 \\
\hline 4 & 200 & 68 & 175 & 59 \\
\hline 1-1985 & 200 & 68 & 175 & 59 \\
\hline 2 & 200 & 68 & 175 & 59 \\
\hline 3 & 200 & 68 & 175 & 59 \\
\hline 4 & 200 & 68 & 175 & 59 \\
\hline $1-1986$ & 200 & 68 & 175 & 59 \\
\hline 2 & 200 & 68 & 175 & 59 \\
\hline 3 & 200 & 68 & 175 & 59 \\
\hline 4 & 200 & 68 & 175 & 59 \\
\hline $1-1987$ & 200 & 68 & 175 & 59 \\
\hline 2 & 200 & 68 & 175 & 59 \\
\hline 3 & 200 & 68 & 175 & 59 \\
\hline 4 & 200 & 68 & 175 & 59 \\
\hline $1-1988$ & 200 & 68 & 175 & 59 \\
\hline 2 & 200 & 68 & 175 & 59 \\
\hline 3 & 200 & 68 & 175 & 59 \\
\hline 4 & 200 & 68 & 175 & 59 \\
\hline 1.1989 & 200 & 68 & 175 & 59 \\
\hline 2 & 200 & 68 & 175 & 59 \\
\hline 3 & 200 & 68 & 175 & 59 \\
\hline 4 & 200 & 68 & 175 & 59 \\
\hline
\end{tabular}


241-C-103 LEVEL HISTORY

\begin{tabular}{|c|c|c|c|c|}
\hline Year & Total & Total & Solids & Solids \\
\hline & (K gal) & (in) & (K gal) & (in) \\
\hline $1-1990$ & 200 & 68 & 175 & 59 \\
\hline 2 & 200 & 68 & 175 & 59 \\
\hline 3 & 200 & 68 & 175 & 59 \\
\hline 4 & 195 & 66 & 62 & 18 \\
\hline $1-1991$ & 195 & 66 & 62 & 18 \\
\hline 2 & 195 & 66 & 62 & 18 \\
\hline 3 & 195 & 66 & 62 & 18 \\
\hline 4 & 795 & 66 & 62 & 18 \\
\hline $1-1992$ & 195 & 66 & 62 & 18 \\
\hline 2 & 195 & 66 & 62 & 18 \\
\hline 3 & 195 & 66 & 62 & 18 \\
\hline 4 & 195 & 66 & 62 & 18 \\
\hline 1-1993 & 195 & 66 & 62 & 18 \\
\hline 2 & 195 & 66 & 62 & 18 \\
\hline 3 & 195 & 66 & 62 & 18 \\
\hline 4 & 195 & 66 & 62 & 18 \\
\hline $1-1994$ & 195 & 66 & 62 & 18 \\
\hline 2 & 195 & 66 & 62 & 18 \\
\hline 3 & 195 & 66 & 62 & 18 \\
\hline 4 & 195 & 66 & 62 & 18 \\
\hline $1-1995$ & 195 & 66 & 62 & 18 \\
\hline 2 & 195 & 66 & 62 & 18 \\
\hline 3 & 195 & 66 & 62 & 18 \\
\hline
\end{tabular}


241-C-104 LEVEL HISTORY

WHC-SD-WM-ER-313, Rev.1

\begin{tabular}{|c|c|c|c|c|}
\hline Yoar & Total & Total & Solids & Solids \\
\hline & (K gall) & (in) & (K gal) & (in) \\
\hline \multirow{2}{*}{\multicolumn{5}{|c|}{$1-1944$}} \\
\hline & & & & \\
\hline \multicolumn{5}{|l|}{2} \\
\hline \multicolumn{5}{|l|}{3} \\
\hline \multicolumn{5}{|l|}{4} \\
\hline \multicolumn{5}{|l|}{ 1-1945 } \\
\hline \multicolumn{5}{|l|}{2} \\
\hline \multicolumn{5}{|l|}{3} \\
\hline \multicolumn{5}{|l|}{4} \\
\hline \multicolumn{5}{|l|}{$1-1946$} \\
\hline \multicolumn{5}{|l|}{2} \\
\hline \multicolumn{5}{|l|}{3} \\
\hline 4 & 356 & 125 & & \\
\hline $1-1947$ & 528 & 187 & & \\
\hline 2 & 528 & 187 & & \\
\hline 3 & 528 & 187 & & \\
\hline 4 & 528 & 187 & & \\
\hline $1-1948$ & 528 & 187 & & \\
\hline 2 & 528 & 187 & & \\
\hline 3 & 528 & 187 & & \\
\hline 4 & 528 & 187 & & \\
\hline $1-1949$ & 528 & 187 & & \\
\hline 2 & 528 & 187 & & \\
\hline 3 & 528 & 187 & & \\
\hline 4 & 528 & 187 & & \\
\hline $1-1950$ & 528 & 187 & & \\
\hline 2 & 528 & 187 & & \\
\hline 3 & 528 & 187 & & \\
\hline 4 & 528 & 187 & & \\
\hline 1-1951 & 528 & 187 & & \\
\hline 2 & 528 & 187 & & \\
\hline 3 & 528 & 187 & & \\
\hline 4 & 528 & 187 & & \\
\hline $1-1952$ & 530 & 188 & & \\
\hline 2 & 530 & 188 & & \\
\hline 3 & 530 & 188 & & \\
\hline 4 & 530 & 188 & & \\
\hline $1-1953$ & 530 & 188 & & \\
\hline 2 & 530 & 188 & & \\
\hline 3 & 46 & 12 & & \\
\hline 4 & 0 & -12 & & \\
\hline $1-1954$ & 312 & 109 & & \\
\hline 2 & 323 & 113 & & \\
\hline 3 & 271 & 94 & & \\
\hline 4 & 494 & 175 & & \\
\hline $1-1955$ & 0 & -12 & & \\
\hline 2 & 0 & -12 & 0 & -12 \\
\hline
\end{tabular}


241-C-104 LEVEL HISTORY

WHC-SD-WM-ER-313. Rev.1

\begin{tabular}{|c|c|c|c|c|}
\hline Year & Totel & Total & Solids & Solids \\
\hline & (K gal) & (in) & (K gal) & (in) \\
\hline & & & & \\
\hline 3 & 0 & -12 & 0 & -12 \\
\hline 4 & 420 & 148 & 0 & -12 \\
\hline $1-1956$ & 224 & 77 & 45 & 12 \\
\hline 2 & $4 \overline{39}$ & 155 & 45 & 12 \\
\hline 3 & 176 & 59 & 45 & 12 \\
\hline 4 & 406 & 143 & 45 & 12 \\
\hline $1-1957$ & 464 & 164 & & \\
\hline 2 & 541 & 192 & & \\
\hline 3 & 543 & 193 & 46 & 12 \\
\hline 4 & 535 & 190 & 46 & 12 \\
\hline $1-1958$ & 538 & 191 & 46 & 12 \\
\hline 2 & 535 & 190 & 46 & 12 \\
\hline 3 & 541 & 192 & 46 & 12 \\
\hline 4 & 541 & 192 & 46 & 12 \\
\hline $1-1959$ & 524 & 186 & 46 & 12 \\
\hline 2 & 517 & 183 & 46 & 12 \\
\hline 3 & 524 & 186 & 46 & 12 \\
\hline 4 & 524 & 186 & 46 & 12 \\
\hline 1.1960 & 538 & $19 ?$ & 46 & 12 \\
\hline 2 & 538 & 191 & 46 & 12 \\
\hline 3 & 538 & 191 & 46 & 12 \\
\hline 4 & 538 & 199 & 46 & 12 \\
\hline \multicolumn{5}{|l|}{ 1-1961 } \\
\hline 2 & 538 & 191 & 46 & 12 \\
\hline \multicolumn{5}{|l|}{3} \\
\hline 4 & 541 & 192 & 46 & 12 \\
\hline \multicolumn{5}{|l|}{$1-1962$} \\
\hline 2 & 538 & 191 & 46 & 12 \\
\hline \multicolumn{5}{|l|}{3} \\
\hline 4 & 538 & 191 & 46 & 12 \\
\hline \multicolumn{5}{|l|}{$1-1963$} \\
\hline 2 & 543 & 193 & 101 & 32 \\
\hline \multicolumn{5}{|l|}{3} \\
\hline 4 & 541 & 192 & 101 & 32 \\
\hline \multicolumn{5}{|l|}{$1-1964$} \\
\hline 2 & 539 & 191 & 101 & 32 \\
\hline \multicolumn{5}{|l|}{3} \\
\hline 4 & 539 & 191 & 101 & 32 \\
\hline \multicolumn{5}{|l|}{$1-1965$} \\
\hline 2 & 554 & 197 & 90 & 28 \\
\hline 3 & 560 & 199 & 90 & 28 \\
\hline 4 & 560 & 199 & 90 & 28 \\
\hline $1-1966$ & 560 & 199 & 90 & 28 \\
\hline 2 & 532 & 189 & 90 & 28 \\
\hline 3 & 532 & 189 & 90 & 28 \\
\hline 4 & 532 & 189 & 90 & 28 \\
\hline
\end{tabular}


WHC-SD-WM-ER-313. Rev.1

241-C-104 LEVEL HISTORY

\begin{tabular}{|c|c|c|c|c|}
\hline Year & Total & Total & Solids & Solids \\
\hline & (K gall) & (in) & (K gal) & (in) \\
\hline $1-1967$ & 532 & 189 & 90 & 28 \\
\hline 2 & 532 & 189 & 90 & 28 \\
\hline 3 & 532 & 189 & 90 & 28 \\
\hline 4 & 532 & 189 & 90 & 28 \\
\hline $1-1968$ & 531 & 189 & 90 & 28 \\
\hline 2 & 531 & 189 & 90 & 28 \\
\hline 3 & 530 & 188 & 90 & 28 \\
\hline 4 & 530 & 188 & 90 & 28 \\
\hline $1-1969$ & 530 & 188 & 90 & 28 \\
\hline 2 & 200 & 68 & 90 & 28 \\
\hline 3 & 200 & 68 & 90 & 28 \\
\hline 4 & 246 & 85 & 90 & 28 \\
\hline 1.1970 & 347 & 122 & 96 & 30 \\
\hline 2 & 296 & 103 & 149 & 50 \\
\hline 3 & 480 & 170 & 92 & 29 \\
\hline 4 & 453 & 160 & 132 & 43 \\
\hline $1-1971$ & 481 & 170 & 153 & 51 \\
\hline 2 & 507 & 180 & 153 & 51 \\
\hline 3 & 466 & 165 & $15 \overline{3}$ & 51 \\
\hline 4 & 437 & 154 & $17 \overline{5}$ & 59 \\
\hline 1-1972 & 351 & 123 & 188 & 64 \\
\hline 2 & 366 & 129 & 198 & 67 \\
\hline 3 & 384 & 135 & 198 & 67 \\
\hline 4 & 334 & 117 & 198 & 67 \\
\hline $1-1973$ & 517 & 183 & 198 & 67 \\
\hline 2 & 332 & 116 & 198 & 67 \\
\hline 3 & 483 & 171 & 198 & 67 \\
\hline 4 & 436 & 154 & 274 & 95 \\
\hline $1-1974$ & 439 & 155 & 274 & 95 \\
\hline 2 & 337 & 118 & 274 & 95 \\
\hline 3 & 340 & 119 & 274 & 95 \\
\hline 4 & 351 & 123 & 235 & 81 \\
\hline $1-1975$ & 296 & 103 & 235 & 31 \\
\hline 2 & 417 & 147 & $23=$ & 81 \\
\hline 3 & 299 & 104 & 235 & 81 \\
\hline 4 & 513 & 182 & 235 & 81 \\
\hline $1-1976$ & 362 & 127 & 235 & 81 \\
\hline 2 & 505 & 179 & 235 & 81 \\
\hline 3 & 420 & 148 & 235 & 81 \\
\hline 4 & 373 & 131 & 246 & 85 \\
\hline $1-1977$ & 406 & 143 & 268 & 93 \\
\hline 2 & 453 & 160 & 268 & 93 \\
\hline 3 & 334 & 117 & 274 & 95 \\
\hline 4 & 340 & 119 & 290 & 101 \\
\hline $1-1978$ & 409 & 144 & 304 & 106 \\
\hline 2 & 329 & 115 & 304 & 106 \\
\hline
\end{tabular}


241-C-104 LEVEL HISTORY

WHC-SD-WM-ER-313. Rev.1

\begin{tabular}{|c|c|c|c|c|}
\hline Year & Total & Total & Solids & Solids \\
\hline & (K gal) & (in) & (K gad) & (in) \\
\hline & & & & \\
\hline 3 & 378 & 133 & 304 & 106 \\
\hline 4 & 464 & 164 & 304 & 106 \\
\hline $1-1979$ & 315 & 110 & 304 & 106 \\
\hline 2 & 345 & 121 & 304 & 106 \\
\hline 3 & 365 & 128 & 304 & 106 \\
\hline 4 & 450 & 159 & 304 & 106 \\
\hline $1-1980$ & 315 & 110 & 293 & 102 \\
\hline 2 & 315 & 110 & 293 & 102 \\
\hline 3 & 315 & 110 & 293 & 102 \\
\hline 4 & 315 & 110 & 293 & 102 \\
\hline $1-1981$ & 315 & 110 & 293 & 102 \\
\hline 2 & 315 & 110 & 293 & 102 \\
\hline 3 & 315 & 110 & 293 & 102 \\
\hline 4 & 315 & 110 & 293 & 102 \\
\hline 1-1982 & 315 & 110 & 293 & 102 \\
\hline 2 & 315 & 110 & 304 & 106 \\
\hline 3 & 315 & 110 & 304 & 106 \\
\hline 4 & 315 & 110 & 304 & 106 \\
\hline 1-1983 & 315 & 110 & 304 & 106 \\
\hline 2 & 307 & 107 & 304 & 106 \\
\hline 3 & 307 & 107 & 304 & 106 \\
\hline 4 & 307 & 107 & 304 & 106 \\
\hline $1-1984$ & 307 & 107 & 304 & 106 \\
\hline 2 & 298 & 104 & 295 & 103 \\
\hline 3 & 298 & 104 & 295 & 103 \\
\hline 4 & 298 & 104 & 295 & 103 \\
\hline $1-1985$ & 298 & 104 & 295 & 103 \\
\hline 2 & 298 & 104 & 295 & 103 \\
\hline 3 & 298 & 104 & 295 & 103 \\
\hline 4 & 298 & 104 & 295 & 103 \\
\hline $1-1986$ & 298 & 104 & 295 & 103 \\
\hline 2 & 298 & 104 & 295 & 103 \\
\hline 3 & 298 & 104 & 295 & 103 \\
\hline 4 & 298 & 104 & 295 & 103 \\
\hline 1-1987 & 298 & 104 & 295 & 103 \\
\hline 2 & 298 & 104 & 295 & 103 \\
\hline 3 & 298 & 104 & 295 & 103 \\
\hline 4 & 298 & 104 & 295 & 103 \\
\hline 1-1988 & 295 & 103 & 295 & 103 \\
\hline 2 & 295 & 103 & 295 & 103 \\
\hline 3 & 295 & 103 & 295 & 103 \\
\hline 4 & 295 & 103 & 295 & 103 \\
\hline 1-1989 & 295 & 103 & 295 & 103 \\
\hline 2 & 295 & 103 & 295 & 103 \\
\hline 3 & 295 & 103 & 295 & 103 \\
\hline 4 & 295 & 103 & 295 & 103 \\
\hline
\end{tabular}


241-C-104 LEVEL HISTORY

\begin{tabular}{|c|c|c|c|c|}
\hline Year & Total & Total & Solids & Solids \\
\hline & (K gal) & (in) & (K gal) & (in) \\
\hline $1-1990$ & 295 & 103 & 295 & 103 \\
\hline 2 & 2 & 103 & 295 & 103 \\
\hline$\overline{3}$ & 28 & 103 & 295 & 103 \\
\hline 4 & 295 & 103 & 295 & 103 \\
\hline $1-1991$ & 295 & 103 & 295 & 103 \\
\hline 2 & $29 !$ & 103 & 295 & 103 \\
\hline 3 & $2 \mathrm{c}$ & 103 & 295 & 103 \\
\hline 4 & 295 & 103 & 295 & 103 \\
\hline $1-1992$ & 295 & 103 & 295 & 103 \\
\hline 2 & 295 & 103 & 295 & 103 \\
\hline$\sqrt{3}$ & 295 & 103 & 295 & 103 \\
\hline 4 & 295 & 103 & 295 & 103 \\
\hline $1-1993$ & 295 & 103 & 295 & 103 \\
\hline 2 & 295 & 103 & 295 & 103 \\
\hline 3 & 295 & 103 & 295 & 103 \\
\hline 4 & 295 & 103 & 295 & 103 \\
\hline 1-1994 & 295 & 103 & 295 & 103 \\
\hline 2 & 295 & 103 & 295 & 103 \\
\hline 3 & 295 & 103 & 295 & 103 \\
\hline 4 & 295 & 103 & 295 & 103 \\
\hline $1-1995$ & 295 & 103 & 295 & 103 \\
\hline 2 & 295 & 103 & 295 & 103 \\
\hline 3 & 295 & 103 & 295 & 103 \\
\hline
\end{tabular}


241-C-105 LEVEL HISTORY

WHC-SD-WM-ER-313, Rev.1

\begin{tabular}{|c|c|c|c|c|}
\hline Year & Total & Total & Solids & Solids \\
\hline & (K gal) & (in) & (K gal) & (in) \\
\hline & & & & \\
\hline \multicolumn{5}{|l|}{$1-1944$} \\
\hline \multicolumn{5}{|l|}{2} \\
\hline \multicolumn{5}{|l|}{3} \\
\hline \multicolumn{5}{|l|}{4} \\
\hline \multicolumn{5}{|l|}{ 1-1945 } \\
\hline \multicolumn{5}{|l|}{2} \\
\hline \multicolumn{5}{|l|}{3} \\
\hline \multicolumn{5}{|l|}{4} \\
\hline \multicolumn{5}{|l|}{$1-1946$} \\
\hline \multicolumn{5}{|l|}{2} \\
\hline \multicolumn{5}{|l|}{3} \\
\hline \multicolumn{5}{|l|}{4} \\
\hline $1-1947$ & 208 & 71 & & \\
\hline 2 & 528 & 187 & & \\
\hline 3 & 528 & 187 & & \\
\hline 4 & 528 & 187 & & \\
\hline $1-1948$ & 528 & 187 & & \\
\hline 2 & 528 & 187 & & \\
\hline 3 & 528 & 187 & & \\
\hline 4 & 528 & 187 & & \\
\hline $1-1949$ & 528 & 187 & & \\
\hline 2 & 528 & 187 & & \\
\hline 3 & 528 & 187 & & \\
\hline 4 & 528 & 187 & & \\
\hline $1-1950$ & 528 & 187 & & \\
\hline 2 & 528 & 187 & & \\
\hline 3 & 528 & 187 & & \\
\hline 4 & 528 & 187 & & \\
\hline 1-1951 & 528 & 187 & & \\
\hline 2 & 528 & 187 & & \\
\hline 3 & 528 & 187 & & \\
\hline 4 & 528 & 187 & & \\
\hline 1-1952 & 530 & 188 & & \\
\hline 2 & 530 & 188 & & \\
\hline 3 & 530 & 188 & & \\
\hline 4 & 530 & 188 & & \\
\hline $1-1953$ & 530 & 188 & & \\
\hline 2 & 530 & 188 & & \\
\hline 3 & 202 & 69 & & \\
\hline 4 & 48 & 13 & & \\
\hline $1-1954$ & 453 & 160 & & \\
\hline \multicolumn{5}{|l|}{2} \\
\hline 3 & 546 & 194 & & \\
\hline 4 & 546 & 194 & & \\
\hline 1-1955 & 546 & 194 & & \\
\hline 2 & 546 & 194 & & \\
\hline
\end{tabular}


WHC-SD-WM-ER-313, Rev.1

241-C-105 LEVEL HISTORY

\begin{tabular}{|c|c|c|c|c|}
\hline Year & Total & Total & Solids & Solids \\
\hline & (K gal) & (in) & (K gal) & (in) \\
\hline & & & : & \\
\hline 3 & 546 & 194 & & \\
\hline 4 & 546 & 194 & & \\
\hline $1-1956$ & 252 & 87 & & \\
\hline 2 & 79 & 24 & 15 & 1 \\
\hline 3 & 508 & 180 & 15 & 1 \\
\hline 4 & 508 & 180 & 15 & 1 \\
\hline $1-1957$ & 538 & 191 & & \\
\hline 2 & 406 & 143 & & \\
\hline 3 & 178 & 60 & & \\
\hline 4 & 381 & 134 & & \\
\hline $1-1958$ & 475 & 168 & & \\
\hline 2 & 541 & 192 & & \\
\hline 3 & 541 & 192 & & \\
\hline 4 & 461 & 163 & & \\
\hline $1-1959$ & 271 & 94 & & \\
\hline 2 & 142 & 47 & & \\
\hline 3 & 309 & 108 & & \\
\hline 4 & 431 & 152 & & \\
\hline $1-1960$ & 461 & 163 & & \\
\hline 2 & 529 & 188 & & \\
\hline 3 & 529 & 188 & & \\
\hline 4 & 529 & 188 & & \\
\hline \multicolumn{5}{|l|}{ 1-1961 } \\
\hline 2 & 521 & 185 & & \\
\hline \multicolumn{5}{|l|}{3} \\
\hline 4 & 521 & 185 & & \\
\hline \multicolumn{5}{|l|}{ 1-1962 } \\
\hline 2 & 519 & 184 & & \\
\hline \multicolumn{5}{|l|}{3} \\
\hline 4 & 519 & 184 & & \\
\hline \multicolumn{5}{|l|}{$1-1963$} \\
\hline 2 & 125 & 41 & & \\
\hline \multicolumn{5}{|l|}{3} \\
\hline 4 & 532 & 189 & & \\
\hline \multicolumn{5}{|l|}{$1-1964$} \\
\hline 2 & 522 & 185 & & \\
\hline \multicolumn{5}{|l|}{3} \\
\hline 4 & 516 & 183 & & \\
\hline \multicolumn{5}{|l|}{$1-1965$} \\
\hline 2 & 491 & 174 & 109 & 35 \\
\hline 3 & 491 & 174 & 109 & $3 \overline{5}$ \\
\hline 4 & 483 & 171 & 109 & 35 \\
\hline $1-1966$ & 475 & 168 & 109 & 35 \\
\hline 2 & 450 & 159 & 109 & 35 \\
\hline 3 & 450 & 159 & 109 & 35 \\
\hline 4 & 442 & 156 & 109 & 35 \\
\hline
\end{tabular}


241-C-105 LEVEL HISTORY

WHC-SD-WM-ER-313. Rev.1

\begin{tabular}{|c|c|c|c|c|}
\hline Year & Total & Total & Solids & Solids \\
\hline & (K gal) & (in) & (K gal) & (in) \\
\hline & & & & \\
\hline $1-1967$ & 439 & 155 & 109 & 35 \\
\hline 2 & 435 & 154 & 109 & 35 \\
\hline 3 & 431 & 152 & 109 & 35 \\
\hline 4 & 359 & 126 & 109 & 35 \\
\hline 1-1968 & 542 & 193 & 109 & 35 \\
\hline 2 & 392 & 138 & 109 & 35 \\
\hline 3 & 444 & 157 & 109 & 35 \\
\hline 4 & 384 & 135 & 96 & 30 \\
\hline $1-1969$ & 378 & 133 & 109 & 35 \\
\hline 2 & 490 & 174 & 99 & 31 \\
\hline 3 & 366 & 129 & 139 & 46 \\
\hline 4 & 450 & 159 & 233 & 80 \\
\hline $1-1970$ & 348 & 122 & 123 & 40 \\
\hline 2 & 198 & 67 & 136 & 45 \\
\hline 3 & 497 & 176 & 139 & 46 \\
\hline 4 & 447 & 158 & 156 & 52 \\
\hline $1-1971$ & 211 & 72 & 162 & 54 \\
\hline 2 & 211 & $7 \overline{2}$ & 164 & 55 \\
\hline 3 & 216 & 74 & 164 & 55 \\
\hline 4 & 253 & 87 & 164 & 55 \\
\hline 1-1972 & 510 & 181 & 98 & 31 \\
\hline 2 & 400 & 141 & 98 & 31 \\
\hline 3 & 471 & 167 & 98 & 31 \\
\hline 4 & 411 & 145 & 98 & 31 \\
\hline $1-1973$ & 326 & 114 & 98 & 31 \\
\hline 2 & 227 & 78 & 112 & 36 \\
\hline 3 & 239 & 82 & 112 & 36 \\
\hline 4 & 234 & 81 & 112 & 36 \\
\hline \begin{tabular}{|l|}
1974 \\
\end{tabular} & 447 & 158 & 112 & 36 \\
\hline 2 & 442 & 156 & 112 & 36 \\
\hline 3 & 231 & 79 & 112 & 36 \\
\hline 4 & 279 & 97 & 139 & 46 \\
\hline $1-1975$ & 224 & 77 & 139 & 46 \\
\hline 2 & 233 & 80 & 139 & 46 \\
\hline 3 & 235 & 81 & 139 & 46 \\
\hline 4 & 483 & 171 & 139 & 46 \\
\hline $1-1976$ & 381 & 134 & 139 & 46 \\
\hline 2 & 222 & 76 & 139 & 46 \\
\hline 3 & 367 & 129 & 139 & 46 \\
\hline 4 & 299 & 104 & 139 & 46 \\
\hline 1.1977 & 224 & 77 & 167 & 56 \\
\hline 2 & 224 & 77 & 167 & 56 \\
\hline 3 & 224 & 77 & 167 & 56 \\
\hline 4 & 447 & 158 & 167 & 56 \\
\hline $1-1978$ & 343 & 120 & 167 & 56 \\
\hline 2 & 310 & 108 & 167 & 56 \\
\hline
\end{tabular}


WHC-SD-WM-ER-313. Rev.1

241-C-105 LEVEL HISTORY

\begin{tabular}{|c|c|c|c|c|}
\hline Year & Total & Total & Solids & Solids \\
\hline & (K gal) & (in) & (K gai) & (in) \\
\hline & & & & \\
\hline 3 & 227 & 78 & 167 & 56 \\
\hline 4 & 343 & 120 & 167 & 56 \\
\hline $1-1979$ & 224 & 77 & 167 & 56 \\
\hline 2 & 172 & 58 & 167 & 56 \\
\hline 3 & 172 & 58 & 150 & 50 \\
\hline 4 & 172 & 58 & 150 & 50 \\
\hline $1-1980$ & 172 & 58 & 150 & 50 \\
\hline 2 & 172 & 58 & 150 & 50 \\
\hline 3 & 172 & 58 & 150 & 50 \\
\hline 4 & 172 & 58 & 150 & 50 \\
\hline $1-1981$ & 172 & 58 & 150 & 50 \\
\hline 2 & 172 & 58 & 150 & 50 \\
\hline 3 & 172 & 58 & 150 & 50 \\
\hline 4 & 172 & 58 & 150 & 50 \\
\hline $1-1982$ & 172 & 58 & 150 & 50 \\
\hline 2 & 172 & 58 & 150 & 50 \\
\hline 3 & 172 & 58 & 150 & 50 \\
\hline 4 & 172 & 58 & 150 & 50 \\
\hline $1-1983$ & 172 & 58 & 150 & 50 \\
\hline 2 & 181 & 61 & 150 & 50 \\
\hline 3 & 177 & 60 & 150 & 50 \\
\hline 4 & 177 & 60 & 150 & 50 \\
\hline $1-1984$ & 174 & 59 & 150 & 50 \\
\hline 2 & 174 & 59 & 150 & 50 \\
\hline 3 & 174 & 59 & 150 & 50 \\
\hline 4 & 174 & 59 & 150 & 50 \\
\hline $1-1985$ & 162 & 54 & 150 & 50 \\
\hline 2 & 162 & 54 & 150 & 50 \\
\hline 3 & 162 & 54 & 150 & 50 \\
\hline 4 & 162 & 54 & 150 & 50 \\
\hline $1-1986$ & 162 & 54 & 150 & 50 \\
\hline 2 & 162 & 54 & 150 & 50 \\
\hline 3 & 162 & 54 & 150 & 50 \\
\hline 4 & 162 & 54 & 150 & 50 \\
\hline $9-1987$ & 162 & 54 & 150 & 50 \\
\hline 2 & 162 & 54 & 150 & 50 \\
\hline 3 & 162 & 54 & 150 & 50 \\
\hline 4 & 153 & 51 & 150 & 50 \\
\hline $1-1988$ & 153 & 51 & 150 & 50 \\
\hline 2 & 148 & 49 & 150 & 50 \\
\hline 3 & 146 & 49 & 150 & 50 \\
\hline 4 & 146 & 49 & 150 & 50 \\
\hline $1-1989$ & 150 & 50 & 150 & 50 \\
\hline 2 & 150 & 50 & 150 & 50 \\
\hline 3 & 150 & 50 & 150 & 50 \\
\hline 4 & 150 & 50 & 150 & 50 \\
\hline
\end{tabular}


WHC-SD-WM-ER-313. Rev.1

241-C-105 LEVEL HISTORY

\begin{tabular}{|c|c|c|c|c|}
\hline Year & Total & Total & Solids & Solids \\
\hline & (K gal) & (in) & (K gall) & (in) \\
\hline & & & & \\
\hline $1-1990$ & 150 & 50 & 150 & 50 \\
\hline 2 & 150 & 50 & 150 & 50 \\
\hline 3 & 150 & 50 & 150 & 50 \\
\hline 4 & 150 & 50 & 150 & 50 \\
\hline $1-1991$ & 150 & 50 & 150 & 50 \\
\hline 2 & 150 & 50 & 150 & 50 \\
\hline 3 & 150 & 50 & 150 & 50 \\
\hline 4 & 150 & 50 & 150 & 50 \\
\hline $1-1992$ & 150 & 50 & 150 & 50 \\
\hline 2 & 150 & 50 & 150 & 50 \\
\hline 3 & 150 & 50 & 150 & 50 \\
\hline 4 & 150 & 50 & 150 & 50 \\
\hline 1.1993 & 150 & 50 & 150 & 50 \\
\hline 2 & 150 & 50 & 150 & 50 \\
\hline 3 & 150 & 50 & 150 & 50 \\
\hline 4 & 150 & 50 & 150 & 50 \\
\hline $1-1994$ & 150 & 50 & 150 & 50 \\
\hline 2 & 150 & 50 & 150 & 50 \\
\hline 3 & 135 & 45 & 130 & 43 \\
\hline 4 & 135 & 45 & 130 & 43 \\
\hline 1-1995 & 135 & 45 & 130 & 43 \\
\hline 2 & 135 & 45 & 130 & 43 \\
\hline 3 & 135 & 45 & 130 & 43 \\
\hline
\end{tabular}


241-C-106 LEVEL HISTORY

WHC-SD-WM-ER-313, Rev.1

\begin{tabular}{|c|c|c|c|c|}
\hline Year & Total & Total & Solids & Solids \\
\hline & (K gal) & (in) & (K gol) & (in) \\
\hline \multirow{2}{*}{\multicolumn{5}{|c|}{$1-1944$}} \\
\hline & & & & \\
\hline 2 & & & & \\
\hline \multicolumn{5}{|l|}{3} \\
\hline \multicolumn{5}{|l|}{4} \\
\hline \multicolumn{5}{|l|}{$1-1945$} \\
\hline \multicolumn{5}{|l|}{2} \\
\hline \multicolumn{5}{|l|}{3} \\
\hline \multicolumn{5}{|l|}{4} \\
\hline \multicolumn{5}{|l|}{$1-1946$} \\
\hline \multicolumn{5}{|l|}{2} \\
\hline \multicolumn{5}{|l|}{3} \\
\hline \multicolumn{5}{|l|}{4} \\
\hline \multicolumn{5}{|l|}{$1-1947$} \\
\hline \multicolumn{5}{|l|}{2} \\
\hline 3 & 388 & 137 & & \\
\hline 4 & 528 & 187 & & \\
\hline $1-1948$ & 528 & 187 & & \\
\hline 2 & 528 & 187 & & \\
\hline 3 & 528 & 187 & & \\
\hline 4 & 528 & 187 & & \\
\hline $1-1949$ & 528 & 187 & & \\
\hline 2 & 528 & 187 & & \\
\hline 3 & 528 & 187 & & \\
\hline 4 & $5 \overline{28}$ & 187 & & \\
\hline $1-1950$ & 528 & 187 & & \\
\hline 2 & 528 & 187 & & \\
\hline 3 & 528 & 187 & & \\
\hline 4 & 528 & 187 & & \\
\hline $1-1951$ & 551 & 196 & & \\
\hline 2 & 551 & 196 & & \\
\hline 3 & 551 & 196 & & \\
\hline 4 & 551 & 196 & & \\
\hline $1-1952$ & 519 & 184 & & \\
\hline 2 & 519 & 184 & & \\
\hline 3 & 519 & 184 & & \\
\hline 4 & 519 & 184 & & \\
\hline \multicolumn{5}{|l|}{ 1-1953 } \\
\hline 2 & 76 & 23 & & \\
\hline 3 & 439 & 155 & & \\
\hline 4 & 143 & 47 & & \\
\hline 1-1954 & 50 & 14 & & \\
\hline 2 & 50 & 14 & & \\
\hline 3 & 538 & 191 & & \\
\hline 4 & 538 & 191 & & \\
\hline $1-1955$ & 538 & 191 & 12 & 0 \\
\hline 2 & 538 & 191 & 12 & 0 \\
\hline
\end{tabular}


241-C-106 LEVEL HISTORY

\begin{tabular}{|c|c|c|c|c|}
\hline Year & Total & Total & Solids & Solids \\
\hline & (K gal) & (in) & (K gal) & (in) \\
\hline & & & & \\
\hline 3 & 538 & 191 & 12 & 0 \\
\hline 4 & 538 & 191 & 12 & 0 \\
\hline $1-1956$ & 538 & 191 & 12 & 0 \\
\hline 2 & 538 & 191 & 12 & 0 \\
\hline 3 & 538 & 191 & 12 & 0 \\
\hline 4 & 538 & 191 & 12 & 0 \\
\hline $1-1957$ & 519 & 184 & 12 & 0 \\
\hline 2 & 37 & 9 & 12 & 0 \\
\hline 3 & 524 & 186 & 12 & 0 \\
\hline 4 & 106 & 34 & 29 & 6 \\
\hline $1-1958$ & 106 & 34 & 29 & 6 \\
\hline 2 & 232 & 80 & 29 & 6 \\
\hline 3 & 519 & 184 & 29 & 6 \\
\hline 4 & 535 & 190 & 29 & 6 \\
\hline $1-1959$ & 510 & 181 & 29 & 6 \\
\hline 2 & 510 & 181 & 29 & 6 \\
\hline 3 & 510 & 181 & 29 & 6 \\
\hline 4 & 510 & 181 & 29 & 6 \\
\hline $1-1960$ & 510 & 181 & 29 & 6 \\
\hline 2 & 527 & 187 & 29 & 6 \\
\hline 3 & 527 & 187 & 29 & 6 \\
\hline 4 & 527 & 187 & 29 & 6 \\
\hline \multicolumn{5}{|l|}{$1-1961$} \\
\hline 2 & 527 & 187 & 29 & 6 \\
\hline \multicolumn{5}{|l|}{3} \\
\hline 4 & 527 & 187 & 29 & 6 \\
\hline \multicolumn{5}{|l|}{$1-1962$} \\
\hline 2 & 527 & 187 & 29 & 6 \\
\hline \multicolumn{5}{|l|}{3} \\
\hline 4 & 527 & 187 & 29 & 6 \\
\hline \multicolumn{5}{|l|}{$1-1963$} \\
\hline 2 & 530 & 188 & 24 & 4 \\
\hline \multicolumn{5}{|l|}{3} \\
\hline 4 & 538 & 191 & 24 & 4 \\
\hline \multicolumn{5}{|l|}{$1-1964$} \\
\hline 2 & 522 & 185 & 24 & 4 \\
\hline \multicolumn{5}{|l|}{3} \\
\hline 4 & 505 & 179 & 24 & 4 \\
\hline \multicolumn{5}{|l|}{$1-1965$} \\
\hline 2 & 541 & 192 & 62 & 18 \\
\hline 3 & 546 & 194 & 62 & 18 \\
\hline 4 & 549 & 195 & 62 & 18 \\
\hline $1-1966$ & 549 & 195 & 62 & 18 \\
\hline 2 & 519 & 184 & 62 & 18 \\
\hline 3 & 519 & 184 & 62 & 18 \\
\hline 4 & 527 & 187 & 62 & 18 \\
\hline
\end{tabular}


WHC-SD-WM-ER-313. Rev.1

241-C-106 LEVEL HISTORY

\begin{tabular}{|c|c|c|c|c|}
\hline Year & Total & Total & Solids & Solids \\
\hline & (K gaf) & (in) & (K goll) & (in) \\
\hline & & & & \\
\hline $1-1967$ & 527 & 187 & 62 & 18 \\
\hline 2 & 527 & 187 & 62 & 18 \\
\hline 3 & 527 & 187 & 62 & 18 \\
\hline 4 & 527 & 187 & 62 & 18 \\
\hline$\overline{1-1968}$ & 66 & 19 & 62 & 18 \\
\hline 2 & 72 & 22 & 62 & 18 \\
\hline 3 & 70 & 21 & 62 & 18 \\
\hline 4 & 70 & 21 & 62 & 18 \\
\hline $1-1969$ & 124 & 41 & 62 & 18 \\
\hline 2 & 244 & 84 & 62 & 18 \\
\hline 3 & 293 & 102 & 62 & 18 \\
\hline 4 & 167 & 56 & 57 & 16 \\
\hline $1-1970$ & 222 & 76 & 57 & 16 \\
\hline 2 & 379 & 133 & 57 & 16 \\
\hline 3 & 517 & 183 & 79 & 24 \\
\hline 4 & 530 & 188 & 14.5 & 48 \\
\hline 1-1971 & 212 & 73 & 150 & 50 \\
\hline 2 & 212 & 73 & 150 & 50 \\
\hline$\overline{3}$ & 239 & 82 & $15 \overline{0}$ & 50 \\
\hline 4 & 235 & 81 & 150 & 50 \\
\hline $1-1972$ & 233 & 80 & 150 & 50 \\
\hline 2 & 235 & 81 & 125 & $\overline{41}$ \\
\hline 3 & 244 & 84 & 125 & 41 \\
\hline 4 & 248 & 86 & 125 & 41 \\
\hline $1-1973$ & 255 & 88 & 125 & 41 \\
\hline 2 & 249 & 86 & 125 & 41 \\
\hline 3 & 241 & 83 & 125 & 41 \\
\hline 4 & 238 & 82 & 125 & 41 \\
\hline $1-1974$ & 237 & 82 & 125 & 41 \\
\hline 2 & 250 & 86 & 125 & 41 \\
\hline 3 & 324 & 113 & 125 & 41 \\
\hline 4 & 420 & 148 & 106 & 34 \\
\hline $1-1975$ & 373 & 131 & 106 & 34 \\
\hline 2 & 345 & 121 & 106 & 34 \\
\hline 3 & 469 & 166 & 106 & 34 \\
\hline 4 & 288 & 100 & 106 & 34 \\
\hline $1-1976$ & 329 & 115 & 106 & 34 \\
\hline 2 & 499 & 177 & 106 & 34 \\
\hline 3 & 422 & 149 & 106 & 34 \\
\hline 4 & 233 & 80 & 106 & 34 \\
\hline $1-1977$ & 373 & 131 & 145 & 48 \\
\hline 2 & 480 & 170 & 145 & 48 \\
\hline 3 & 398 & 140 & 145 & 48 \\
\hline 4 & 384 & 135 & 156 & 52 \\
\hline $1-1978$ & 255 & 88 & 156 & 52 \\
\hline 2 & 356 & 125 & 156 & 52 \\
\hline
\end{tabular}


241-C-106 LEVEL HISTORY

WHC-SD-WM-ER-313. Rev.1

\begin{tabular}{|c|c|c|c|c|}
\hline Year & Total & Total & Solids & Solids \\
\hline & (K gal) & (in) & (K gal) & (in) \\
\hline & & & & \\
\hline 3 & 444 & 157 & 156 & 52 \\
\hline 4 & 422 & 149 & 142 & 47 \\
\hline $1-1979$ & 202 & 69 & 197 & 67 \\
\hline 2 & 219 & 75 & 197 & 67 \\
\hline 3 & 219 & 75 & 197 & 67 \\
\hline 4 & 219 & 75 & 197 & 67 \\
\hline 1-1980 & 219 & 75 & 197 & 67 \\
\hline 2 & 219 & 75 & 197 & 67 \\
\hline 3 & 219 & 75 & 197 & 67 \\
\hline 4 & 219 & 75 & 197 & 67 \\
\hline $1-1981$ & 219 & 75 & 197 & 67 \\
\hline 2 & 219 & 75 & 197 & 67 \\
\hline 3 & 219 & 75 & 197 & 67 \\
\hline 4 & 219 & 75 & 197 & 67 \\
\hline $1-1982$ & 219 & 75 & 197 & 67 \\
\hline 2 & 224 & 77 & 197 & 67 \\
\hline 3 & 224 & 77 & 197 & 67 \\
\hline 4 & 224 & 77 & 197 & 67 \\
\hline $1-1983$ & .224 & 77 & 197 & 67 \\
\hline 2 & 224 & 77 & 197 & 67 \\
\hline 3 & 220 & 75 & 197 & 67 \\
\hline 4 & 220 & 75 & 197 & 67 \\
\hline 1.1984 & 220 & 75 & 197 & 67 \\
\hline 2 & 220 & 75 & 197 & 67 \\
\hline 3 & 220 & 75 & 197 & 67 \\
\hline 4 & 220 & 75 & 197 & 67 \\
\hline $1-1985$ & 220 & 75 & 197 & 67 \\
\hline 2 & 220 & 75 & 197 & 67 \\
\hline 3 & 220 & 75 & 197 & 67 \\
\hline 4 & 220 & 75 & 197 & 67 \\
\hline $1-1986$ & 222 & 76 & 197 & 67 \\
\hline 2 & 222 & 76 & 197 & 67 \\
\hline 3 & 222 & 76 & 197 & 67 \\
\hline 4 & 222 & 76 & 197 & 67 \\
\hline $1-1987$ & 222 & 76 & 197 & 67 \\
\hline 2 & 222 & 76 & 197 & 67 \\
\hline 3 & 222 & 76 & 197 & 67 \\
\hline 4 & 222 & 76 & 197 & 67 \\
\hline $1-1988$ & 222 & 76 & 197 & 67 \\
\hline 2 & 226 & 78 & 197 & 67 \\
\hline 3 & 227 & 78 & 197 & 67 \\
\hline 4 & 223 & 77 & 197 & 67 \\
\hline 1.1989 & 229 & 79 & 197 & 67 \\
\hline 2 & 229 & 79 & 197 & 67 \\
\hline 3 & 229 & 79 & 197 & 67 \\
\hline 4 & 229 & 79 & 197 & 67 \\
\hline
\end{tabular}


241-C-106 LEVEL HISTORY

WHC-SD-WM-ER-313. Rev.1

\begin{tabular}{|c|c|c|c|c|}
\hline Year & Total & Total & Solids & Solids \\
\hline & (K gal) & (in) & (K gal) & (in) \\
\hline $1-1990$ & 229 & 79 & 197 & 67 \\
\hline 2 & 229 & 79 & 197 & 67 \\
\hline 3 & 229 & 79 & 197 & 67 \\
\hline 4 & 229 & 79 & 197 & 67 \\
\hline $1-1991$ & 229 & 79 & 197 & 67 \\
\hline 2 & 229 & 79 & 197 & 67 \\
\hline 3 & 229 & 79 & 197 & 67 \\
\hline 4 & 229 & 79 & 197 & 67 \\
\hline 1-1992 & 229 & 79 & 197 & 67 \\
\hline 2 & 229 & 79 & 197 & 67 \\
\hline 3 & 229 & 79 & 197 & 67 \\
\hline 4 & 229 & 79 & 197 & 67 \\
\hline $1-1993$ & 229 & 79 & 197 & 67 \\
\hline 2 & 229 & 79 & 197 & 67 \\
\hline 3 & 229 & 79 & 197 & 67 \\
\hline 4 & 229 & 79 & 197 & 67 \\
\hline $1-1994$ & 229 & 79 & 197 & 67 \\
\hline 2 & 229 & 79 & 197 & 67 \\
\hline 3 & 229 & 79 & 197 & 67 \\
\hline 4 & 229 & 79 & 197 & 67 \\
\hline $1-1995$ & 229 & 79 & 197 & 67 \\
\hline 2 & 229 & 79 & 197 & 67 \\
\hline 3 & 229 & 79 & 197 & 67 \\
\hline
\end{tabular}


241-C-107 LEVEL HISTORY

WHC-SD-WM-ER-313. Rev.1

\begin{tabular}{|c|c|c|c|c|}
\hline Year & Total & Total & Solids & Solids \\
\hline & (K gal) & (in) & (K gad) & (in) \\
\hline & & & & \\
\hline 1-1944 & & & & \\
\hline 2 & & & & \\
\hline \multicolumn{5}{|l|}{3} \\
\hline 4 & & & & \\
\hline \multicolumn{5}{|l|}{$1-1945$} \\
\hline \multicolumn{5}{|l|}{2} \\
\hline \multicolumn{5}{|l|}{3} \\
\hline \multicolumn{5}{|l|}{4} \\
\hline \multicolumn{5}{|l|}{ 1-1946 } \\
\hline 2 & 53 & 15 & & \\
\hline 3 & 53 & 15 & & \\
\hline 4 & 53 & 15 & & \\
\hline $1-1947$ & 53 & 15 & & \\
\hline 2 & 274 & 95 & & \\
\hline 3 & 528 & 187 & & \\
\hline 4 & 528 & 187 & & \\
\hline $1-1948$ & 528 & 187 & & \\
\hline 2 & 528 & 187 & & \\
\hline 3 & 528 & 187 & & \\
\hline 4 & 528 & 187 & & \\
\hline $1-1949$ & 528 & 187 & & \\
\hline 2 & 528 & 187 & & \\
\hline 3 & 528 & 187 & & \\
\hline 4 & 528 & 187 & & \\
\hline $1-1950$ & 528 & 187 & & \\
\hline 2 & 528 & 187 & & \\
\hline 3 & 528 & 187 & & \\
\hline 4 & 528 & 187 & & \\
\hline $1-1951$ & 528 & 187 & & \\
\hline 2 & 528 & 787 & & \\
\hline \multicolumn{5}{|l|}{3} \\
\hline \multicolumn{5}{|l|}{4} \\
\hline $1-1952$ & 399 & 141 & 399 & 141 \\
\hline 2 & 399 & 141 & 399 & 141 \\
\hline 3 & 399 & 141 & 399 & 141 \\
\hline 4 & 547 & 194 & 399 & 141 \\
\hline $1-1953$ & 518 & 184 & 399 & 141 \\
\hline 2 & 519 & 184 & 399 & 141 \\
\hline 3 & 530 & 188 & 399 & 141 \\
\hline 4 & 530 & 188 & 399 & 141 \\
\hline $1-1954$ & 530 & 188 & 399 & 141 \\
\hline 2 & 530 & 188 & 399 & 141 \\
\hline 3 & 530 & 188 & 399 & 141 \\
\hline 4 & 530 & 188 & 399 & 141 \\
\hline $1.195 \overline{5}$ & 530 & 188 & 399 & 141 \\
\hline 2 & 530 & 188 & 399 & 141 \\
\hline
\end{tabular}


WHC-SD-WM-ER-313, Rer.1

241-C-107 LEVEL HISTORY

\begin{tabular}{|c|c|c|c|c|}
\hline Year & Total & Total & Solids & Solids \\
\hline & (K gal) & (in) & (K gal) & (in) \\
\hline 3 & 530 & 188 & 399 & 141 \\
\hline 4 & 530 & 188 & 399 & 141 \\
\hline 1.1956 & 530 & 188 & 399 & 141 \\
\hline 2 & 530 & 188 & 399 & 141 \\
\hline 3 & 530 & 188 & 399 & 141 \\
\hline 4 & 375 & 132 & 375 & 132 \\
\hline $1-1957$ & $37 \overline{6}$ & 132 & 375 & 132 \\
\hline 2 & 381 & 134 & 375 & 132 \\
\hline 3 & 392 & 138 & 375 & 132 \\
\hline 4 & 411 & 145 & 375 & 132 \\
\hline $1-1958$ & 425 & 150 & 375 & 132 \\
\hline 2 & 425 & 150 & 375 & 132 \\
\hline 3 & 422 & 149 & 375 & 132 \\
\hline 4 & 425 & 150 & 375 & 132 \\
\hline $1-1959$ & 425 & 150 & 375 & 132 \\
\hline 2 & 422 & 149 & 375 & 132 \\
\hline 3 & 422 & 149 & 375 & 132 \\
\hline 4 & 422 & 149 & 375 & 132 \\
\hline $1-1960$ & 422 & 149 & 375 & 132 \\
\hline 2 & 422 & 149 & 375 & 132 \\
\hline 3 & 422 & 149 & 375 & 132 \\
\hline 4 & 422 & 149 & 375 & 132 \\
\hline \multicolumn{5}{|l|}{\begin{tabular}{|l|}
1961 \\
\end{tabular}} \\
\hline 2 & 439 & 155 & 375 & 132 \\
\hline \multicolumn{5}{|l|}{3} \\
\hline 4 & 483 & 171 & 375 & 132 \\
\hline \multicolumn{5}{|l|}{$1-1962$} \\
\hline 2 & 384 & 135 & 375 & 132 \\
\hline \multicolumn{5}{|l|}{3} \\
\hline 4 & 384 & 135 & 375 & 132 \\
\hline \multicolumn{5}{|l|}{ 1-1963 } \\
\hline 2 & 384 & 135 & 321 & 112 \\
\hline \multicolumn{5}{|l|}{3} \\
\hline 4 & 381 & 134 & 321 & 112 \\
\hline \multicolumn{5}{|l|}{$1-1964$} \\
\hline 2 & 381 & 134 & 321 & 112 \\
\hline \multicolumn{5}{|l|}{3} \\
\hline 4 & 383 & 135 & 321 & 112 \\
\hline \multicolumn{5}{|l|}{$1-1965$} \\
\hline 2 & 395 & 139 & 225 & 77 \\
\hline 3 & 425 & 150 & 225 & 77 \\
\hline 4 & 466 & 165 & 225 & 77 \\
\hline 1-1966 & 527 & 187 & 255 & 88 \\
\hline 2 & 464 & 164 & 255 & 88 \\
\hline 3 & 486 & 172 & 255 & 88 \\
\hline 4 & 527 & 187 & 255 & 88 \\
\hline
\end{tabular}


WHC-SD-WM-ER-313, Rev.1

241-C-107 LEVEL HISTORY

\begin{tabular}{|c|c|c|c|c|}
\hline Year & Total & Total & Solids & Solids \\
\hline & (K gal) & (in) & (K gal) & (in) \\
\hline & & & & \\
\hline $1-1967$ & 530 & 188 & 255 & 88 \\
\hline 2 & 528 & 187 & 255 & 88 \\
\hline 3 & 528 & 187 & 255 & 88 \\
\hline 4 & 534 & 190 & 255 & 88 \\
\hline $1-1968$ & 534 & 190 & 255 & 88 \\
\hline 2 & 534 & 190 & 255 & 88 \\
\hline 3 & 534 & 190 & 255 & 88 \\
\hline 4 & 528 & 187 & 255 & 88 \\
\hline $1-1969$ & 528 & 187 & 255 & 88 \\
\hline 2 & 525 & 186 & 255 & 88 \\
\hline 3 & 524 & 186 & 255 & 88 \\
\hline 4 & 301 & 105 & 255 & 88 \\
\hline $1-1970$ & 303 & 106 & 255 & 88 \\
\hline 2 & 304 & 106 & 200 & 68 \\
\hline 3 & 547 & 194 & 195 & 66 \\
\hline 4 & 547 & 194 & 195 & 66 \\
\hline \begin{tabular}{|l|}
$1-1971$ \\
\end{tabular} & 546 & 194 & 195 & 66 \\
\hline 2 & 546 & 194 & 197 & 67 \\
\hline 3 & 546 & 194 & 197 & 67 \\
\hline 4 & 541 & 192 & 197 & 67 \\
\hline 1-1972 & 288 & 100 & 197 & 67 \\
\hline 2 & 289 & 101 & 197 & 67 \\
\hline 3 & 289 & 101 & 206 & 70 \\
\hline 4 & 260 & 90 & 206 & 70 \\
\hline $1-1973$ & 260 & 90 & 206 & 70 \\
\hline 2 & 261 & 90 & 206 & 70 \\
\hline 3 & 299 & 104 & 206 & 70 \\
\hline 4 & 513 & 182 & 206 & 70 \\
\hline $1-1974$ & 514 & 182 & 206 & 70 \\
\hline 2 & 514 & 182 & 206 & 70 \\
\hline 3 & 515 & 183 & 206 & 70 \\
\hline 4 & 513 & 182 & 191 & 65 \\
\hline $1-1975$ & 450 & 159 & 191 & 65 \\
\hline 2 & 450 & 159 & 191 & 65 \\
\hline 3 & 255 & 88 & 191 & 65 \\
\hline 4 & 255 & 88 & 191 & 65 \\
\hline $1-1976$ & 257 & 89 & 191 & 65 \\
\hline 2 & 257 & 89 & 191 & 65 \\
\hline 3 & 257 & 89 & 191 & 65 \\
\hline 4 & 257 & 89 & 191 & 65 \\
\hline $1-1977$ & 257 & 89 & 191 & 65 \\
\hline 2 & 249 & 86 & 191 & 65 \\
\hline 3 & 450 & 159 & 191 & 65 \\
\hline 4 & 367 & 129 & 296 & 103 \\
\hline $1-1978$ & 340 & 119 & 337 & 118 \\
\hline 2 & 340 & 119 & 337 & 118 \\
\hline
\end{tabular}




\begin{tabular}{|c|c|c|c|c|}
\hline $81 \mathrm{~L}$ & $\angle \varepsilon \varepsilon$ & 811 & $\angle E E$ & 7 \\
\hline $8 L L$ & $\angle \varepsilon \varepsilon$ & 811 & $\angle \varepsilon \varepsilon$ & $\varepsilon$ \\
\hline $8 L L$ & $\angle \varepsilon \varepsilon$ & 811 & $\angle \varepsilon \varepsilon$ & $z$ \\
\hline $8 L L$ & $\angle \varepsilon \varepsilon$ & 811 & $\angle \varepsilon \varepsilon$ & $686 l-l$ \\
\hline $81 L$ & $\angle \varepsilon \varepsilon$ & 811 & $\angle \varepsilon \varepsilon$ & $t$ \\
\hline 811 & $\angle \varepsilon \varepsilon$ & 811 & LEE & $\varepsilon$ \\
\hline $8 L L$ & $\angle \varepsilon \varepsilon$ & 811 & $\angle E E$ & $z$ \\
\hline 816 & $\angle \varepsilon \varepsilon$ & 811 & $\angle \varepsilon \varepsilon$ & $886 t-1$ \\
\hline 811 & LEE & 811 & $\angle \varepsilon \varepsilon$ & $t$ \\
\hline 811 & $\angle \varepsilon \varepsilon$ & 811 & $\angle \varepsilon \varepsilon$ & $\varepsilon$ \\
\hline 811 & $\angle E E$ & 811 & $\angle E \varepsilon$ & 2 \\
\hline 811 & $\angle \varepsilon \varepsilon$ & 811 & $\angle \varepsilon \varepsilon$ & $\angle 86 \mathrm{~L}-\mathrm{L}$ \\
\hline 811 & $\angle \varepsilon \varepsilon$ & 811 & $\angle E \varepsilon$ & $t$ \\
\hline 811 & $\angle \varepsilon \varepsilon$ & 811 & $\angle E E$ & $\varepsilon$ \\
\hline 811 & $\angle E \varepsilon$ & 811 & $\angle \varepsilon \varepsilon$ & $z$ \\
\hline 811 & $\angle E \varepsilon$ & 811 & $\angle \varepsilon \varepsilon$ & $9861-1$ \\
\hline 811 & $\angle \varepsilon \varepsilon$ & 811 & $\angle \varepsilon \varepsilon$ & $\nabla$ \\
\hline 811 & $\angle \varepsilon \varepsilon$ & 811 & $\angle \varepsilon \varepsilon$ & $\varepsilon$ \\
\hline 811 & $\angle \varepsilon \varepsilon$ & 811 & $\angle \varepsilon E$ & 2 \\
\hline $81 \mathrm{~L}$ & $\angle E \varepsilon$ & 846 & $\angle \varepsilon \varepsilon$ & $986 L-1$ \\
\hline 811 & $\angle \varepsilon \varepsilon$ & 811 & $\angle \varepsilon \varepsilon$ & $D$ \\
\hline 811 & $\angle E \varepsilon$ & 811 & $\angle \varepsilon \varepsilon$ & $\varepsilon$ \\
\hline 811 & $\angle \varepsilon \varepsilon$ & 811 & $\angle \varepsilon \varepsilon$ & 2 \\
\hline $81 \mathrm{~L}$ & $\angle \varepsilon \varepsilon$ & 811 & $\angle \varepsilon \varepsilon$ & $786 l-l$ \\
\hline 811 & $\angle \varepsilon \varepsilon$ & $81 L$ & $\angle \varepsilon \varepsilon$ & $t$ \\
\hline 811 & $\angle E \varepsilon$ & $84 L$ & $\angle \varepsilon \varepsilon$ & $\varepsilon$ \\
\hline 811 & $\angle E \varepsilon$ & 811 & $\angle \varepsilon \varepsilon$ & 2 \\
\hline 811 & $\angle E \varepsilon$ & 811 & $\angle \varepsilon \varepsilon$ & $\varepsilon 86 L-l$ \\
\hline $8 \mathrm{LL}$ & $\angle \varepsilon \varepsilon$ & $81 \mathrm{~L}$ & $\angle \varepsilon \varepsilon$ & $\nabla$ \\
\hline 811 & $\angle \varepsilon \varepsilon$ & 811 & $\angle \varepsilon \varepsilon$ & $\varepsilon$ \\
\hline 811 & $\angle \varepsilon \varepsilon$ & 811 & $\angle \varepsilon \varepsilon$ & 2 \\
\hline 811 & $\angle \varepsilon \varepsilon$ & 811 & $\angle \varepsilon \varepsilon$ & $286 L-L$ \\
\hline 811 & $\angle \varepsilon \varepsilon$ & 811 & $\angle \varepsilon E$ & $t$ \\
\hline 811 & $\angle \varepsilon \varepsilon$ & 811 & $\angle \varepsilon \varepsilon$ & $\varepsilon$ \\
\hline $8 ! 1$ & $\angle \varepsilon \varepsilon$ & 811 & $\angle \varepsilon \varepsilon$ & $z$ \\
\hline 811 & $\angle \varepsilon \varepsilon$ & 811 & $\angle \varepsilon \varepsilon$ & $186 t-1$ \\
\hline 811 & $\angle \varepsilon \varepsilon$ & 811 & $\angle \varepsilon \varepsilon$ & $t$ \\
\hline 811 & $\angle \varepsilon \varepsilon$ & 811 & $\angle \varepsilon \varepsilon$ & $\varepsilon$ \\
\hline 811 & $\angle \varepsilon \varepsilon$ & 811 & $\angle \varepsilon \varepsilon$ & $\tau$ \\
\hline 816 & $\angle \varepsilon \varepsilon$ & 811 & $\angle \varepsilon \varepsilon$ & $086 L-L$ \\
\hline 811 & $\angle \varepsilon \varepsilon$ & 811 & $\angle \varepsilon \varepsilon$ & $t$ \\
\hline 861 & $\angle E \varepsilon$ & glt & $\angle \varepsilon \varepsilon$ & $\varepsilon$ \\
\hline 816 & $\angle \varepsilon \varepsilon$ & 811 & $\angle \varepsilon \varepsilon$ & $z$ \\
\hline 811 & $\angle \varepsilon \varepsilon$ & 811 & $\angle \varepsilon \varepsilon$ & $6 L 6 L-1$ \\
\hline 811 & $\angle \varepsilon E$ & 811 & $\angle \varepsilon \varepsilon$ & $b$ \\
\hline 811 & $\angle E \varepsilon$ & 811 & $\angle \varepsilon \varepsilon$ & $\varepsilon$ \\
\hline & & & & \\
\hline (u!) & $\left(\mathrm{P}^{6} \times{ }^{2}\right)$ & (u!̣) & $(106 \times)$ & \\
\hline sp!los & spyos & 10101 & 10101 & $100 \mathrm{~A}$ \\
\hline
\end{tabular}


241-C-107 LEVEL HISTORY

WHC-SD-WM-ER-313. Rev.1

\begin{tabular}{|c|c|c|c|c|}
\hline Year & Total & Total & Solids & Solids \\
\hline & (K gall) & (in) & (K gal) & (in) \\
\hline & & & & \\
\hline 1-1990 & 337 & 118 & 337 & 118 \\
\hline 2 & 337 & 118 & 337 & 118 \\
\hline 3 & 337 & 118 & 337 & 118 \\
\hline 4 & 337 & 118 & 337 & 118 \\
\hline $1-1991$ & 337 & 118 & 337 & 118 \\
\hline 2 & 337 & 118 & 337 & 118 \\
\hline 3 & 337 & 118 & 337 & 118 \\
\hline 4 & 337 & 118 & 337 & 118 \\
\hline 1-1992 & 275 & 95 & 275 & 95 \\
\hline 2 & 275 & 95 & 275 & 95 \\
\hline 3 & 275 & 95 & 275 & 95 \\
\hline 4 & 275 & 95 & 275 & 95 \\
\hline $7-1993$ & 275 & 95 & 275 & 95 \\
\hline 2 & 275 & 95 & 275 & 95 \\
\hline 3 & 275 & 95 & 275 & 95 \\
\hline 4 & 275 & 95 & 275 & 95 \\
\hline 1-1994 & 275 & 95 & 275 & 95 \\
\hline 2 & 275 & 95 & 275 & 95 \\
\hline 3 & 275 & 95 & 275 & 95 \\
\hline 4 & 275 & 95 & 275 & 95 \\
\hline $1-1995$ & 275 & 95 & 275 & 95 \\
\hline 2 & 275 & 95 & 275 & 95 \\
\hline 3 & 237 & 82 & 237 & 82 \\
\hline
\end{tabular}


WHC-SD-WM-ER-313, Rev.1

241-C-108 LEVEL HISTORY

\begin{tabular}{|c|c|c|c|c|}
\hline Year & Total & Total & Solids & Solids \\
\hline & (K gal) & (in) & (K gal) & (in) \\
\hline \multicolumn{5}{|l|}{$1-1944$} \\
\hline \multicolumn{5}{|l|}{2} \\
\hline \multicolumn{5}{|l|}{3} \\
\hline \multicolumn{5}{|l|}{4} \\
\hline \multicolumn{5}{|l|}{$1-1945$} \\
\hline \multicolumn{5}{|l|}{2} \\
\hline \multicolumn{5}{|l|}{3} \\
\hline \multicolumn{5}{|l|}{4} \\
\hline \multicolumn{5}{|l|}{$1-1946$} \\
\hline \multicolumn{5}{|l|}{2} \\
\hline \multicolumn{5}{|l|}{3} \\
\hline \multicolumn{5}{|l|}{4} \\
\hline \multicolumn{5}{|l|}{1.1947} \\
\hline \multicolumn{5}{|l|}{2} \\
\hline 3 & 53 & 15 & & \\
\hline 4 & 249 & 86 & & \\
\hline $1-1948$ & 528 & 187 & & \\
\hline 2 & 528 & 187 & & \\
\hline 3 & 528 & 187 & & \\
\hline 4 & 528 & 187 & & \\
\hline $1-1949$ & 528 & 187 & & \\
\hline 2 & 528 & 187 & & \\
\hline 3 & 528 & 187 & & \\
\hline 4 & 528 & 187 & & \\
\hline $1-1950$ & 528 & 187 & & \\
\hline 2 & 528 & 187 & & \\
\hline 3 & 528 & 187 & & \\
\hline 4 & 528 & 187 & & \\
\hline 1.1951 & 528 & 187 & & \\
\hline 2 & 528 & 187 & & \\
\hline 3 & 528 & 187 & & \\
\hline \multicolumn{5}{|l|}{4} \\
\hline \multicolumn{5}{|l|}{1.1952} \\
\hline 2 & 34 & 8 & 34 & 8 \\
\hline 3 & 34 & 8 & 34 & 8 \\
\hline 4 & 85 & 26 & 34 & 8 \\
\hline $1-1953$ & 527 & 187 & 34 & 8 \\
\hline 2 & 530 & 188 & 34 & 8 \\
\hline 3 & 530 & 188 & 34 & 8 \\
\hline 4 & 530 & 188 & 34 & 8 \\
\hline $1-1954$ & 530 & 188 & 34 & 8 \\
\hline 2 & 530 & 188 & 34 & 8 \\
\hline 3 & 530 & 188 & 34 & 8 \\
\hline 4 & 530 & 188 & 34 & 8 \\
\hline $1-1955$ & 530 & 188 & 34 & 8 \\
\hline 2 & 530 & 188 & 34 & 8 \\
\hline
\end{tabular}


241-C-108 LEVEL HISTORY

WHC-SD-WM-ER-313, Rev.1

\begin{tabular}{|c|c|c|c|c|}
\hline Year & Total & Total & Solids & Solids \\
\hline & (K gal) & (in) & (K gal) & (in) \\
\hline & & & & \\
\hline 3 & 530 & 188 & 34 & 8 \\
\hline 4 & 530 & 188 & 34 & 8 \\
\hline $1-1956$ & 80 & 25 & 34 & 8 \\
\hline 2 & 530 & 188 & 34 & 8 \\
\hline 3 & 78 & 24 & 34 & 8 \\
\hline 4 & 78 & 24 & 34 & 8 \\
\hline 1-1957 & 78 & 24 & 34 & 8 \\
\hline 2 & 78 & 24 & 34 & 8 \\
\hline 3 & 532 & 189 & 34 & 8 \\
\hline 4 & 472 & 167 & 79 & 24 \\
\hline $1-1958$ & 175 & 59 & 79 & 24 \\
\hline 2 & 175 & 59 & 79 & 24 \\
\hline 3 & 175 & 59 & 79 & 24 \\
\hline 4 & 175 & 59 & 79 & 24 \\
\hline $1-1959$ & 175 & 59 & 79 & 24 \\
\hline 2 & 183 & 62 & 79 & 24 \\
\hline 3 & 188 & 64 & 79 & 24 \\
\hline 4 & 188 & 64 & 79 & 24 \\
\hline $1-1960$ & 494 & 175 & 79 & 24 \\
\hline 2 & 494 & 175 & 79 & 24 \\
\hline 3 & 430 & 152 & 79 & 24 \\
\hline 4 & 166 & 56 & 79 & 24 \\
\hline \multicolumn{5}{|l|}{$1-1961$} \\
\hline 2 & 486 & 172 & 79 & 24 \\
\hline \multicolumn{5}{|l|}{3} \\
\hline 4 & 486 & 172 & 79 & 24 \\
\hline \multicolumn{5}{|l|}{1.1962} \\
\hline 2 & 486 & 172 & $7 \overline{9}$ & 24 \\
\hline \multicolumn{5}{|l|}{3} \\
\hline 4 & 486 & 172 & 79 & 24 \\
\hline \multicolumn{5}{|l|}{$1-1963$} \\
\hline 2 & 483 & 171 & 79 & 24 \\
\hline \multicolumn{5}{|l|}{3} \\
\hline 4 & 486 & 172 & 79 & 24 \\
\hline \multicolumn{5}{|l|}{$1-1964$} \\
\hline 2 & 426 & 150 & 79 & 24 \\
\hline \multicolumn{5}{|l|}{3} \\
\hline 4 & 426 & 150 & 79 & 24 \\
\hline \multicolumn{5}{|l|}{ 1-1965 } \\
\hline 2 & 568 & 202 & 98 & 31 \\
\hline 3 & 532 & 189 & 98 & 31 \\
\hline 4 & 532 & 189 & 98 & 31 \\
\hline $1-1966$ & 532 & 189 & 98 & 31 \\
\hline 2 & 521 & 185 & 98 & 31 \\
\hline 3 & 521 & 185 & 98 & 31 \\
\hline 4 & 521 & 185 & 98 & 31 \\
\hline
\end{tabular}


WHC-SD-WM-ER-313, Rev.1

241-C-108 LEVEL HISTORY

\begin{tabular}{|c|c|c|c|c|}
\hline Year & Total & Total & Solids & Solids \\
\hline & (K gal) & (in) & (K gal) & (in) \\
\hline 1-1967 & 521 & 185 & 98 & 37 \\
\hline 2 & 521 & 185 & 98 & $\overline{31}$ \\
\hline 3 & 521 & 185 & 98 & 31 \\
\hline 4 & 517 & 183 & 98 & 31 \\
\hline 1-1968 & 516 & 183 & 98 & 31 \\
\hline 2 & 516 & 183 & 98 & 31 \\
\hline 3 & 516 & 183 & 98 & 39 \\
\hline 4 & 514 & 182 & 98 & 31 \\
\hline $1-1969$ & 514 & 182 & 98 & 31 \\
\hline 2 & 514 & 182 & 98 & 31 \\
\hline 3 & 513 & 182 & 98 & 31 \\
\hline 4 & 138 & 46 & 98 & 31 \\
\hline $1-1970$ & 138 & 46 & 98 & 31 \\
\hline 2 & 532 & 189 & 95 & 30 \\
\hline 3 & 532 & 189 & 69 & 21 \\
\hline 4 & 532 & 189 & 69 & 21 \\
\hline 1-1971 & 532 & 189 & 69 & 21 \\
\hline 2 & 532 & 189 & 69 & 21 \\
\hline 3 & 532 & 189 & 69 & 21 \\
\hline 4 & 532 & 189 & 69 & 21 \\
\hline \begin{tabular}{|l|}
$1-1972$ \\
\end{tabular} & 334 & 117 & 69 & 21 \\
\hline 2 & 266 & 92 & 69 & 21 \\
\hline 3 & 266 & 92 & 76 & 23 \\
\hline 4 & 271 & 94 & 76 & 23 \\
\hline $1-1973$ & 270 & 94 & 76 & 23 \\
\hline 2 & 270 & 94 & 76 & 23 \\
\hline 3 & 516 & 183 & 76 & 23 \\
\hline 4 & 516 & 183 & 76 & 23 \\
\hline 1-1974 & 515 & 183 & 76 & 23 \\
\hline 2 & 515 & 183 & 76 & 23 \\
\hline 3 & 516 & 183 & 76 & 23 \\
\hline 4 & 516 & 183 & 65 & 19 \\
\hline $1-1975$ & 516 & 183 & 65 & 19 \\
\hline 2 & 516 & 183 & 65 & 19 \\
\hline 3 & 516 & 183 & 65 & 19 \\
\hline 4 & 87 & 27 & 65 & 19 \\
\hline $1-1976$ & 76 & 23 & 65 & 19 \\
\hline 2 & 76 & 23 & 65 & 19 \\
\hline 3 & 65 & 19 & 65 & 19 \\
\hline 4 & 65 & 19 & 65 & 19 \\
\hline $1-1977$ & 65 & 19 & 65 & 19 \\
\hline 2 & 65 & 19 & 65 & 19 \\
\hline 3 & 65 & 19 & 65 & 19 \\
\hline 4 & 65 & 19 & 65 & 19 \\
\hline $1-1978$ & 65 & 19 & 65 & 19 \\
\hline 2 & 65 & 19 & 65 & 19 \\
\hline
\end{tabular}


WHC-SD-WM-ER-313. Rev.1

241-C-108 LEVEL HISTOAY

\begin{tabular}{|c|c|c|c|c|}
\hline Year & Total & Total & Solids & 1 Solids \\
\hline & (K gal) & (in) & (K gol) & (in) \\
\hline & & & & \\
\hline 3 & 65 & 19 & 65 & 19 \\
\hline 4 & 65 & 19 & 65 & 19 \\
\hline $1-1979$ & 65 & 19 & 65 & 19 \\
\hline 2 & 65 & 19 & 65 & 19 \\
\hline 3 & 65 & 19 & 65 & 19 \\
\hline 4 & 65 & 19 & 65 & 19 \\
\hline $1-1980$ & 65 & 19 & 65 & 19 \\
\hline 2 & 65 & 19 & 65 & 19 \\
\hline 3 & 65 & 19 & 65 & 19 \\
\hline 4 & 65 & 19 & 65 & 19 \\
\hline $1-1981$ & 65 & 19 & 65 & 19 \\
\hline 2 & 65 & 19 & 65 & 19 \\
\hline 3 & $\overline{65}$ & 19 & 65 & 19 \\
\hline 4 & 65 & 19 & 65 & 19 \\
\hline $1-1982$ & 65 & 19 & 65 & 19 \\
\hline 2 & 65 & 19 & 65 & 19 \\
\hline 3 & 65 & 19 & 65 & 19 \\
\hline 4 & 65 & 19 & 65 & 19 \\
\hline 1.1983 & 65 & 19 & 65 & 19 \\
\hline 2 & 65 & 19 & 65 & 19 \\
\hline 3 & 65 & 19 & 65 & 19 \\
\hline 4 & 65 & 19 & 65 & 19 \\
\hline 1-1984 & 65 & 19 & 65 & 19 \\
\hline 2 & 65 & 19 & 65 & 19 \\
\hline 3 & 65 & 19 & 65 & 19 \\
\hline 4 & 65 & 19 & 65 & 19 \\
\hline $1-1985$ & 65 & 19 & 65 & 19 \\
\hline 2 & 65 & 19 & 65 & 19 \\
\hline 3 & 65 & 19 & 65 & 19 \\
\hline 4 & 65 & 19 & 65 & 19 \\
\hline $1-1986$ & 65 & 19 & 65 & 19 \\
\hline 2 & 65 & 19 & 65 & 19 \\
\hline 3 & 65 & 19 & 65 & 19 \\
\hline 4 & 65 & 19 & 65 & 19 \\
\hline 1-1987 & 65 & 19 & 65 & 19 \\
\hline 2 & 65 & 19 & 65 & 19 \\
\hline 3 & 65 & 19 & 65 & 19 \\
\hline 4 & 65 & 19 & 65 & 19 \\
\hline $1-1988$ & 65 & 19 & 65 & 19 \\
\hline 2 & 65 & 19 & 65 & 19 \\
\hline 3 & 65 & 19 & 65 & 19 \\
\hline 4 & 65 & 19 & 65 & 19 \\
\hline $1-1989$ & 65 & 19 & 65 & 19 \\
\hline 2 & 65 & 19 & 65 & 19 \\
\hline 3 & 65 & 19 & 65 & 19 \\
\hline 4 & 65 & 19 & 65 & 19 \\
\hline
\end{tabular}


241-C-108 LEVEL HISTORY

\begin{tabular}{|c|c|c|c|c|}
\hline Year & Total & Total & Solids & Solids \\
\hline & (K gal) & (in) & (K gal) & (in) \\
\hline $1-1990$ & 65 & 19 & 65 & 19 \\
\hline 2 & 66 & 19 & 66 & 19 \\
\hline 3 & 66 & 19 & 66 & 19 \\
\hline 4 & 66 & 19 & 66 & 19 \\
\hline 1-1991 & 66 & 19 & 66 & 19 \\
\hline 2 & 66 & 19 & 66 & 19 \\
\hline 3 & 66 & 19 & 66 & 19 \\
\hline 4 & 66 & 19 & 66 & 19 \\
\hline $1-1992$ & 66 & 19 & 66 & 19 \\
\hline 2 & 66 & 19 & 66 & 19 \\
\hline 3 & 66 & 19 & 66 & 19 \\
\hline 4 & 66 & 19 & 66 & 19 \\
\hline $1-1993$ & 66 & 19 & 66 & 19 \\
\hline 2 & 66 & 19 & 66 & 19 \\
\hline 3 & 66 & 19 & 66 & 19 \\
\hline 4 & 66 & 19 & 66 & 19 \\
\hline $1-1994$ & 66 & 19 & 66 & 19 \\
\hline 2 & 66 & 19 & 66 & 19 \\
\hline 3 & 66 & 19 & 66 & 19 \\
\hline 4 & 66 & 19 & 66 & 19 \\
\hline $1-1995$ & 66 & 19 & 66 & 19 \\
\hline 2 & 66 & 19 & $E \Omega$ & 19 \\
\hline 3 & 66 & 19 & & 19 \\
\hline
\end{tabular}


241-C-109 LEVEL HISTORY

WHC-SD-WM-ER-313, Rev.1

\begin{tabular}{|c|c|c|c|c|}
\hline Year & Total & Total & Solids & Solids \\
\hline & (K gal) & (in) & (K gal) & (in) \\
\hline \multirow{2}{*}{\multicolumn{5}{|c|}{$1-1944$}} \\
\hline & & & & \\
\hline \multicolumn{5}{|l|}{2} \\
\hline \multicolumn{5}{|l|}{3} \\
\hline \multicolumn{5}{|l|}{4} \\
\hline \multicolumn{5}{|l|}{ 1-1945 } \\
\hline \multicolumn{5}{|l|}{2} \\
\hline \multicolumn{5}{|l|}{3} \\
\hline \multicolumn{5}{|l|}{4} \\
\hline \multicolumn{5}{|l|}{$1-1946$} \\
\hline \multicolumn{5}{|l|}{2} \\
\hline \multicolumn{5}{|l|}{3} \\
\hline \multicolumn{5}{|l|}{4} \\
\hline \multicolumn{5}{|l|}{$1-1947$} \\
\hline \multicolumn{5}{|l|}{2} \\
\hline \multicolumn{5}{|l|}{3} \\
\hline \multicolumn{5}{|l|}{4} \\
\hline \multicolumn{5}{|l|}{$1-1948$} \\
\hline 2 & 288 & 100 & & \\
\hline 3 & 528 & 187 & & \\
\hline 4 & 528 & 187 & & \\
\hline $1-1949$ & 528 & 187 & & \\
\hline 2 & 528 & 187 & & \\
\hline 3 & 528 & 187 & & \\
\hline 4 & 528 & 187 & & \\
\hline $1-1950$ & 528 & 187 & & \\
\hline 2 & 528 & 187 & & \\
\hline 3 & 528 & 187 & & \\
\hline 4 & 528 & 187 & & \\
\hline $1-1951$ & 528 & 187 & & \\
\hline 2 & 528 & 187 & & \\
\hline 3 & 528 & 187 & & \\
\hline 4 & 528 & 187 & & \\
\hline $1-1952$ & 525 & 186 & & \\
\hline 2 & 311 & 109 & 10 & -1 \\
\hline 3 & 10 & -1 & 10 & -1 \\
\hline 4 & 496 & 176 & 10 & -1 \\
\hline $1-1953$ & 182 & 62 & 10 & -1 \\
\hline 2 & 521 & 185 & 10 & -1 \\
\hline 3 & 521 & 185 & 10 & -1 \\
\hline 4 & 521 & 185 & 10 & -1 \\
\hline $1-1954$ & 521 & 185 & 10 & -1 \\
\hline 2 & 521 & 185 & 10 & -1 \\
\hline 3 & 521 & 185 & 10 & -1 \\
\hline 4 & 521 & 185 & 10 & -1 \\
\hline $1-1955$ & 521 & 185 & 10 & -1 \\
\hline 2 & 521 & 185 & 10 & -1 \\
\hline
\end{tabular}




\section{1-C-109 LEVEL HISTORY}

WHC-SD-WM-ER-313, Rev.1

\begin{tabular}{|c|c|c|c|c|}
\hline Year & Total & Total & Solids & Solids \\
\hline & [K gal] & (in) & (K gal) & (in) \\
\hline & & & & \\
\hline 3 & 521 & 185 & 10 & -1 \\
\hline 4 & 204 & 70 & 10 & -1 \\
\hline $1-1956$ & 530 & 188 & 10 & -1 \\
\hline 2 & 530 & 188 & 10 & -1 \\
\hline 3 & 530 & 188 & 10 & -1 \\
\hline 4 & 241 & 83 & 10 & -1 \\
\hline $1-1957$ & 238 & 82 & 35 & 8 \\
\hline 2 & 79 & 24 & 51 & 14 \\
\hline 3 & 340 & 119 & 35 & 8 \\
\hline 4 & 543 & 193 & 90 & 28 \\
\hline $1-1958$ & 112 & 36 & 90 & 28 \\
\hline 2 & 112 & 36 & 90 & 28 \\
\hline 3 & 112 & 36 & 90 & 28 \\
\hline 4 & 112 & 36 & 90 & 28 \\
\hline $1-1959$ & 112 & 36 & 90 & 28 \\
\hline 2 & 373 & 131 & 90 & 28 \\
\hline$\sqrt{3}$ & 540 & 192 & 90 & 28 \\
\hline 4 & 540 & 192 & 90 & 28 \\
\hline $1-1960$ & 540 & 192 & 90 & 28 \\
\hline 2 & 540 & 192 & 90 & 28 \\
\hline 3 & 540 & 192 & 90 & 28 \\
\hline 4 & 546 & 194 & 90 & 28 \\
\hline \multicolumn{5}{|l|}{$1-1961$} \\
\hline 2 & 549 & 195 & 90 & 28 \\
\hline \multicolumn{5}{|l|}{3} \\
\hline 4 & 549 & 195 & 90 & 28 \\
\hline \multicolumn{5}{|l|}{ 1-1962 } \\
\hline 2 & 433 & 153 & 90 & 28 \\
\hline \multicolumn{5}{|l|}{3} \\
\hline 4 & 491 & 174 & 90 & 28 \\
\hline \multicolumn{5}{|l|}{$1-1963$} \\
\hline 2 & 494 & 175 & 90 & 28 \\
\hline \multicolumn{5}{|l|}{3} \\
\hline 4 & 497 & 176 & 90 & 28 \\
\hline \multicolumn{5}{|l|}{$1-1964$} \\
\hline 2 & 532 & 189 & 90 & 28 \\
\hline \multicolumn{5}{|l|}{3} \\
\hline 4 & 535 & 190 & 90 & 28 \\
\hline \multicolumn{5}{|l|}{$7-1965$} \\
\hline 2 & 554 & 197 & 79 & 24 \\
\hline 3 & 554 & 197 & 79 & 24 \\
\hline 4 & 554 & 197 & 79 & 24 \\
\hline $1-1966$ & 552 & 196 & 79 & 24 \\
\hline 2 & 565 & 201 & 79 & 24 \\
\hline 3 & 565 & 201 & 79 & 24 \\
\hline 4 & 552 & 196 & 79 & 24 \\
\hline
\end{tabular}


241-C-109 LEVEL HISTORY

WHC-SD-WM-ER-313. Rev.1

\begin{tabular}{|c|c|c|c|c|}
\hline Year & Total & Total & Solids & Solids \\
\hline & (K gal) & [in] & (K gal) & (in) \\
\hline $1-1967$ & 552 & & 70 & \\
\hline 2 & 552 & $\frac{196}{196}$ & $\frac{19}{79}$ & $\frac{24}{24}$ \\
\hline 3 & 552 & 196 & 79 & 24 \\
\hline 4 & 549 & 195 & 79 & 24 \\
\hline 1-1968 & 549 & 195 & 79 & 24 \\
\hline 2 & 543 & 193 & 79 & 24 \\
\hline 3 & 543 & 193 & 79 & 24 \\
\hline 4 & 543 & 193 & 79 & 24 \\
\hline $1-1969$ & 543 & 193 & 79 & 24 \\
\hline 2 & 543 & 193 & 79 & 24 \\
\hline 3 & 543 & 193 & 79 & 24 \\
\hline 4 & 543 & 193 & 79 & 24 \\
\hline $1-1970$ & 165 & 55 & 79 & 24 \\
\hline 2 & 541 & 192 & 106 & 34 \\
\hline 3 & 543 & 193 & 95 & 30 \\
\hline 4 & 543 & 193 & 95 & 30 \\
\hline $1-1971$ & 542 & 193 & 95 & 30 \\
\hline 2 & 542 & 193 & 95 & 30 \\
\hline 3 & 542 & 193 & 95 & 30 \\
\hline 4 & 542 & 193 & 95 & 30 \\
\hline $1-1972$ & 540 & 192 & 95 & 30 \\
\hline 2 & 540 & 192 & 95 & 30 \\
\hline 3 & 540 & 192 & 95 & 30 \\
\hline 4 & 530 & 188 & 95 & 30 \\
\hline $1-1973$ & 529 & 188 & 95 & 30 \\
\hline 2 & 529 & 188 & 95 & 30 \\
\hline 3 & 505 & 179 & 95 & 30 \\
\hline 4 & 504 & 179 & 95 & 30 \\
\hline $1-1974$ & 504 & 179 & 95 & 30 \\
\hline 2 & 504 & 179 & 95 & 30 \\
\hline 3 & 504 & 179 & 95 & 30 \\
\hline 4 & 505 & 179 & 79 & 24 \\
\hline $1-1975$ & 505 & 179 & 79 & 24 \\
\hline 2 & 505 & 179 & 79 & 24 \\
\hline 3 & 142 & 47 & 79 & 24 \\
\hline 4 & 62 & 18 & 62 & 18 \\
\hline $1-1976$ & 62 & 18 & 62 & 18 \\
\hline 2 & 62 & 18 & 62 & 18 \\
\hline 3 & 62 & 18 & 62 & 18 \\
\hline 4 & 62 & 18 & 62 & 18 \\
\hline \begin{tabular}{|l|l|}
$1-1977$ \\
\end{tabular} & 62 & 18 & 62 & 18 \\
\hline 2 & 62 & 18 & 62 & 18 \\
\hline 3 & 62 & 18 & 62 & 18 \\
\hline 4 & 62 & 18 & 62 & 18 \\
\hline 1-1978 & 62 & 18 & 62 & 18 \\
\hline 2 & 62 & 18 & 62 & 18 \\
\hline
\end{tabular}


241-C-109 LEVEL HISTORY

WHC-SD-WM-ER-313. Rev.1

\begin{tabular}{|c|c|c|c|c|}
\hline Year & Total & Total & Solids & Solids \\
\hline & (K gal) & (in) & (K gal) & (in) \\
\hline & & & & \\
\hline 3 & 62 & 18 & 62 & 18 \\
\hline 4 & 62 & 18 & 62 & 18 \\
\hline 1.1979 & 68 & 20 & 62 & 18 \\
\hline 2 & 68 & 20 & 62 & 18 \\
\hline 3 & 68 & 20 & 62 & 18 \\
\hline 4 & 68 & 20 & 62 & 18 \\
\hline $1-1980$ & 68 & 20 & 62 & 18 \\
\hline 2 & 68 & 20 & 62 & 18 \\
\hline 3 & 68 & 20 & 62 & 18 \\
\hline 4 & 68 & 20 & 62 & 18 \\
\hline $1-1981$ & 68 & 20 & 62 & 18 \\
\hline 2 & 68 & 20 & 62 & 18 \\
\hline 3 & 68 & 20 & 62 & 18 \\
\hline 4 & 68 & 20 & 62 & 18 \\
\hline $1-1982$ & 68 & 20 & 62 & 18 \\
\hline 2 & 68 & 20 & 62 & 18 \\
\hline 3 & 68 & 20 & 62 & 18 \\
\hline 4 & 68 & 20 & 62 & 18 \\
\hline 1.1983 & 68 & 20 & 62 & 18 \\
\hline 2 & 68 & 20 & 62 & 18 \\
\hline 3 & 68 & 20 & 62 & 18 \\
\hline 4 & 66 & 19 & 62 & 18 \\
\hline $1-1984$ & 66 & 19 & 62 & 18 \\
\hline 2 & 66 & 19 & 62 & 18 \\
\hline 3 & 66 & 19 & 62 & 18 \\
\hline 4 & 66 & 19 & 62 & 18 \\
\hline 1-1985 & 66 & 19 & 62 & 18 \\
\hline 2 & 66 & 19 & 62 & 18 \\
\hline 3 & 66 & 19 & 62 & 18 \\
\hline 4 & 66 & 19 & 62 & 18 \\
\hline 1-1986 & 66 & 19 & 62 & 18 \\
\hline 2 & 66 & 19 & 62 & 18 \\
\hline 3 & 66 & 19 & 62 & 18 \\
\hline 4 & 66 & 19 & 62 & 18 \\
\hline $1-1987$ & 66 & 19 & 62 & 18 \\
\hline 2 & 66 & 19 & 62 & 18 \\
\hline 3 & 66 & 19 & 62 & 18 \\
\hline 4 & 66 & 19 & 62 & 18 \\
\hline $1-1988$ & 66 & 19 & 62 & 18 \\
\hline 2 & 66 & 19 & 62 & 18 \\
\hline 3 & 66 & 19 & 62 & 18 \\
\hline 4 & 66 & 19 & 62 & 18 \\
\hline $1-1989$ & 66 & 19 & 62 & 18 \\
\hline 2 & 66 & 19 & 62 & 18 \\
\hline 3 & 66 & 19 & 62 & 18 \\
\hline 4 & 66 & 19 & 62 & 18 \\
\hline
\end{tabular}


241-C-109 LEVEL HISTORY

\begin{tabular}{|c|c|c|c|c|}
\hline Year & Total & Total & Solids & Solids \\
\hline & (K gal) & (in) & (K gal) & (in) \\
\hline & & & & \\
\hline $1-1990$ & 66 & 19 & 62 & 18 \\
\hline 2 & 66 & 19 & 62 & 18 \\
\hline 3 & 66 & 19 & 62 & 18 \\
\hline 4 & 66 & 19 & 62 & 18 \\
\hline $1-1991$ & 66 & 19 & 62 & 18 \\
\hline 2 & 66 & 19 & 62 & 18 \\
\hline 3 & 66 & 19 & 62 & 18 \\
\hline 4 & 66 & 19 & 62 & 18 \\
\hline $1-1992$ & 66 & 19 & 62 & 18 \\
\hline 2 & 66 & 19 & 62 & 18 \\
\hline 3 & 66 & 19 & 62 & 18 \\
\hline 4 & 66 & 19 & 62 & 18 \\
\hline $1-1993$ & 66 & 19 & 62 & 18 \\
\hline 2 & 66 & 19 & 62 & 18 \\
\hline 3 & 66 & 19 & 62 & 18 \\
\hline 4 & 66 & 19 & 62 & 18 \\
\hline 1-1994 & 66 & 19 & 62 & 18 \\
\hline 2 & 66 & 19 & 62 & 18 \\
\hline 3 & 66 & 19 & 62 & 18 \\
\hline 4 & $6 \overline{6}$ & 19 & 62 & 18 \\
\hline 1-1995 & 66 & 19 & 62 & 18 \\
\hline 2 & 66 & 19 & 62 & 18 \\
\hline 3 & 66 & 19 & 62 & 18 \\
\hline
\end{tabular}


241-C-110 LEVEL HISTORY

WHC-SD-WM-ER-313. Rev.1

\begin{tabular}{|c|c|c|c|c|}
\hline Year & Total & Total & Solids & Solids \\
\hline & (K gal) & (in) & (K gal) & (in) \\
\hline & & & & \\
\hline \multicolumn{5}{|l|}{$1-1944$} \\
\hline \multicolumn{5}{|l|}{2} \\
\hline \multicolumn{5}{|l|}{3} \\
\hline 4 & & & & \\
\hline \multicolumn{5}{|l|}{1.1945} \\
\hline \multicolumn{5}{|l|}{2} \\
\hline \multicolumn{5}{|l|}{3} \\
\hline \multicolumn{5}{|l|}{4} \\
\hline \multicolumn{5}{|l|}{ 1-1946 } \\
\hline 2 & 337 & 118 & & \\
\hline 3 & 528 & 187 & & \\
\hline 4 & 528 & 187 & & \\
\hline $1-1947$ & 528 & 187 & & \\
\hline 2 & 528 & 187 & & \\
\hline 3 & 528 & 187 & & \\
\hline 4 & 528 & 187 & & \\
\hline $1-1948$ & 528 & 187 & & \\
\hline 2 & 528 & 187 & & \\
\hline 3 & 528 & 187 & & \\
\hline 4 & 528 & 187 & & \\
\hline $1-1949$ & 528 & 187 & & \\
\hline 2 & 528 & 187 & & \\
\hline 3 & 528 & 187 & & \\
\hline 4 & 528 & 187 & & \\
\hline $1-1950$ & 528 & 187 & & \\
\hline 2 & 528 & 187 & & \\
\hline 3 & 528 & 187 & & \\
\hline 4 & 528 & 187 & & \\
\hline \begin{tabular}{|l|}
$1-1951$ \\
\end{tabular} & 528 & 187 & & \\
\hline 2 & 528 & 187 & & \\
\hline 3 & 528 & 187 & & \\
\hline 4 & 528 & 187 & & \\
\hline $1-1952$ & 530 & 188 & & \\
\hline 2 & 530 & 188 & 231 & 79 \\
\hline 3 & 231 & 79 & 231 & 79 \\
\hline 4 & 490 & 174 & 231 & 79 \\
\hline 1.1953 & 538 & 191 & 231 & 79 \\
\hline 2 & 538 & 191 & 231 & 79 \\
\hline 3 & 538 & 191 & 231 & 79 \\
\hline 4 & 538 & 191 & 231 & 79 \\
\hline 1.1954 & 538 & 191 & 231 & 79 \\
\hline 2 & 538 & 191 & 231 & 79 \\
\hline 3 & 538 & 191 & 231 & 79 \\
\hline 4 & 538 & 191 & 231 & 79 \\
\hline $1-1955$ & 538 & 191 & 231 & 79 \\
\hline 2 & 538 & 191 & 231 & 79 \\
\hline
\end{tabular}


241-C-110 LEVEL HISTORY

WHC-SD-WM-ER-313. Rev:1

\begin{tabular}{|c|c|c|c|c|}
\hline Year & Total & Total & Solids & Sollds \\
\hline & (K gal) & (in) & (K gal) & (in) \\
\hline 3 & 538 & 191 & 231 & 79 \\
\hline 4 & 538 & 191 & 231 & 79 \\
\hline $1-1956$ & 265 & 92 & 231 & 79 \\
\hline 2 & 436 & 154 & 231 & 79 \\
\hline 3 & 491 & 174 & 231 & 79 \\
\hline 4 & 491 & 174 & 231 & 79 \\
\hline $1-1957$ & 513 & 182 & 231 & 79 \\
\hline 2 & 508 & 180 & 231 & 79 \\
\hline 3 & 510 & 189 & 231 & 79 \\
\hline 4 & 510 & 181 & 231 & 79 \\
\hline $1-1958$ & 508 & 180 & 231 & 79 \\
\hline 2 & 508 & 180 & 231 & 79 \\
\hline 3 & 508 & 180 & 231 & 79 \\
\hline 4 & 508 & 180 & 231 & 79 \\
\hline $1-1959$ & 508 & 180 & 231 & 79 \\
\hline 2 & 507 & 180 & 231 & 79 \\
\hline 3 & 507 & 180 & 231 & 79 \\
\hline 4 & 507 & 180 & 231 & 79 \\
\hline $1-1960$ & 507 & 180 & 231 & 79 \\
\hline 2 & 507 & 180 & 231 & 79 \\
\hline 3 & 507 & 180 & 231 & 79 \\
\hline 4 & 455 & 161 & 231 & 79 \\
\hline \multicolumn{5}{|l|}{ 1-1961 } \\
\hline 2 & 505 & 179 & 231 & 79 \\
\hline \multicolumn{5}{|l|}{3} \\
\hline 4 & 510 & 181 & 231 & 79 \\
\hline \multicolumn{5}{|l|}{$1-1962$} \\
\hline 2 & 510 & 181 & 231 & 79 \\
\hline \multicolumn{5}{|l|}{3} \\
\hline 4 & 508 & 180 & 231 & 79 \\
\hline \multicolumn{5}{|l|}{ 1-1963 } \\
\hline 2 & 505 & 179 & 230 & 79 \\
\hline \multicolumn{5}{|l|}{3} \\
\hline 4 & 505 & 179 & 230 & 79 \\
\hline \multicolumn{5}{|l|}{$1-1964$} \\
\hline 2 & 505 & 179 & 230 & 79 \\
\hline \multicolumn{5}{|l|}{3} \\
\hline 4 & 513 & 182 & 230 & 79 \\
\hline \multicolumn{5}{|l|}{$1-1965$} \\
\hline 2 & 508 & 180 & 191 & 65 \\
\hline 3 & 508 & 180 & 191 & 65 \\
\hline 4 & 508 & 180 & 191 & 65 \\
\hline $1-1966$ & 505 & 179 & 191 & 65 \\
\hline 2 & 508 & 180 & 191 & 65 \\
\hline 3 & 508 & 180 & 191 & 65 \\
\hline 4 & 508 & 180 & 191 & 65 \\
\hline
\end{tabular}




\begin{tabular}{|c|c|c|c|c|}
\hline$Z L$ & $1 . \bar{Z}$ & $z L$ & 112 & 2 \\
\hline$Z L$ & $L L Z$ & $\bar{c}=$ & 112 & $8 \angle 6 L-1$ \\
\hline$Z L$ & 112 & $\overline{Z L}$ & 112 & $t$ \\
\hline$Z L$ & $L L Z$ & $2 L$ & 112 & $\varepsilon$ \\
\hline$Z L$ & 112 & $Z L$ & 112 & 2 \\
\hline$z L$ & $1+2$ & $\overline{Z l}$ & 112 & $\angle L 6 L-1$ \\
\hline$Z L$ & 112 & $Z L$ & LIZ & $t$ \\
\hline $2 L$ & $L L Z$ & $Z L$ & 112 & $\varepsilon$ \\
\hline$Z L$ & $L L Z$ & $z L$ & 112 & 2 \\
\hline$Z L$ & 112 & 08 & $\varepsilon \varepsilon 乙$ & $9 \angle 6 L-1$ \\
\hline $2 L$ & 112 & $\varepsilon 6$ & 892 & $t$ \\
\hline$Z L$ & $L L Z$ & $\varepsilon 6$ & 892 & $\varepsilon$ \\
\hline$Z L$ & $1 L 2$ & Zहl & $9<\varepsilon$ & 2 \\
\hline $2 L$ & 112 & $\tau \varepsilon \downarrow$ & $9 \angle \varepsilon$ & SL6L-L \\
\hline $2 L$ & $1 L Z$ & $z \varepsilon l$ & $9 \angle \varepsilon$ & $t$ \\
\hline 89 & 002 & $\tau \varepsilon \downarrow$ & $9 \angle \varepsilon$ & $\varepsilon$ \\
\hline 89 & 002 & $Z \varepsilon L$ & $9<\varepsilon$ & 2 \\
\hline 89 & $00 z$ & $2 \varepsilon \downarrow$ & $9 \angle \varepsilon$ & $\nabla L \quad x-1$ \\
\hline 29 & $\varepsilon 8 \downarrow$ & $z \varepsilon l$ & $9 \angle \varepsilon$ & $t$ \\
\hline 29 & $\varepsilon 81$ & $2 \varepsilon\llcorner$ & $9 \angle \varepsilon$ & $\varepsilon$ \\
\hline 29 & E8L & टहl & $9 \angle \varepsilon$ & 2 \\
\hline 29 & $\varepsilon 81$ & $Z \varepsilon\llcorner$ & $9 \angle \varepsilon$ & $\varepsilon \angle 6 \downarrow-1$ \\
\hline 29 & $\varepsilon 8 \mathrm{~L}$ & $z \varepsilon L$ & $9 \angle \varepsilon$ & $t$ \\
\hline 29 & E8L & ZEL & $9 \angle \varepsilon$ & $\varepsilon$ \\
\hline 79 & 681 & ZEL & $9 \angle \varepsilon$ & 2 \\
\hline 79 & 681 & $\tau \varepsilon \iota$ & $9 \angle \varepsilon$ & $z \angle 6 L-1$ \\
\hline 79 & 681 & $2 L$ & 162 & $t$ \\
\hline 79 & 681 & 061 & $9 \varepsilon \mathrm{g}$ & $\varepsilon$ \\
\hline 79 & 681 & 061 & $9 \varepsilon 9$ & 2 \\
\hline 79 & 681 & 061 & $9 \varepsilon g$ & $1 \angle 6 L-1$ \\
\hline$\nabla 9$ & 681 & 061 & $9 \varepsilon 9$ & $t$ \\
\hline 79 & 681 & 061 & $9 \varepsilon s$ & $\varepsilon$ \\
\hline$Z L$ & 112 & 991 & $0<t$ & $z$ \\
\hline 99 & $16 L$ & $Z \varepsilon$ & SLE & $0<6 L-1$ \\
\hline 99 & 161 & 4 & $\nabla z z$ & $t$ \\
\hline 99 & $16 !$ & 6 & \pm 22 & $\varepsilon$ \\
\hline 99 & 161 & $g L$ & 022 & 2 \\
\hline 99 & 161 & $\nabla \mathrm{gl}$ & gEt & $696 \mathrm{~L}-\mathrm{L}$ \\
\hline 99 & 161 & $t 9 L$ & GEt & $t$ \\
\hline 99 & $16 L$ & $\nabla 9 l$ & gEt & $\varepsilon$ \\
\hline 99 & 161 & $\forall G_{1}$ & sहt & $z$ \\
\hline 99 & 161 & 691 & SEb & $896 L-1$ \\
\hline 99 & 161 & $\nabla 9 !$ & gEb & $t$ \\
\hline 99 & 161 & 081 & .09 & $\varepsilon$ \\
\hline 99 & $16 \mathrm{~L}$ & $0 ?$ & 809 & 2 \\
\hline 99 & 161 & $\therefore$ & 809 & $\angle 96 \mathrm{l}-\mathrm{l}$ \\
\hline (u!) & $\left(1^{106} \times\right)$ & (u!) & (106 प्र) & \\
\hline sp!pos & sp!los & |R10| & $1030_{1}$ & deed \\
\hline
\end{tabular}


241-C-1 10 LEVEL HISTORY

WHC-SD-WM-ER-313. Rev.1

\begin{tabular}{|c|c|c|c|c|}
\hline Year & Total & Total & Solids & Solids \\
\hline & (K gal) & (in) & (K gal) & (in) \\
\hline 3 & 211 & 72 & 219 & 72 \\
\hline 4 & 211 & 72 & 211 & 72 \\
\hline $1-1979$ & 213 & 73 & 211 & 72 \\
\hline 2 & 213 & 73 & 211 & 72 \\
\hline 3 & 213 & 73 & 211 & 72 \\
\hline 4 & 213 & 73 & 211 & 72 \\
\hline 1.1980 & 213 & 73 & 211 & 72 \\
\hline 2 & 213 & 73 & 211 & 72 \\
\hline 3 & 213 & 73 & 211 & 72 \\
\hline 4 & 213 & 73 & 211 & 72 \\
\hline 1-1981 & 211 & 72 & 211 & 72 \\
\hline 2 & 211 & 72 & 211 & 72 \\
\hline 3 & 211 & 72 & 211 & 72 \\
\hline 4 & 211 & 72 & 211 & 72 \\
\hline $1-1982$ & 211 & 72 & 211 & 72 \\
\hline 2 & 207 & 71 & 206 & 70 \\
\hline 3 & 207 & 71 & 206 & 70 \\
\hline 4 & 207 & 71 & 206 & 70 \\
\hline $1-1983$ & 207 & 71 & 206 & 70 \\
\hline 2 & 207 & 71 & 206 & 70 \\
\hline 3 & 207 & 71 & 206 & 70 \\
\hline 4 & 207 & 71 & 206 & 70 \\
\hline $1-1984$ & 207 & 71 & 206 & 70 \\
\hline 2 & 207 & 71 & 206 & 70 \\
\hline 3 & 207 & 71 & 206 & 70 \\
\hline 4 & 217 & 74 & 196 & 67 \\
\hline $1-1985$ & 200 & 68 & 196 & 67 \\
\hline 2 & 200 & 68 & 196 & 67 \\
\hline 3 & 217 & 74 & 197 & 67 \\
\hline 4 & 201 & 69 & 196 & 67 \\
\hline $1-1986$ & 201 & 69 & 196 & 67 \\
\hline 2 & 201 & 69 & 196 & 67 \\
\hline 3 & 201 & 69 & 196 & 67 \\
\hline 4 & 201 & 69 & 196 & 67 \\
\hline $1-1987$ & 201 & 69 & 196 & 67 \\
\hline 2 & 201 & 69 & 196 & 67 \\
\hline 3 & 201 & 69 & 196 & 67 \\
\hline 4 & 201 & 69 & 196 & 67 \\
\hline $1-1988$ & 201 & 69 & 196 & 67 \\
\hline 2 & 201 & 69 & 196 & 67 \\
\hline 3 & 201 & 69 & 196 & 67 \\
\hline 4 & 201 & 69 & 196 & 67 \\
\hline $1-1989$ & 201 & 69 & 196 & 67 \\
\hline 2 & 201 & 69 & 196 & 67 \\
\hline 3 & 201 & 69 & 196 & 67 \\
\hline 4 & 201 & 69 & 196 & 67 \\
\hline
\end{tabular}


241-C-110 LEVEL HISTORY

WHC-SD-WM-ER-313. Rev.1

\begin{tabular}{|c|c|c|c|c|}
\hline Year & Total & Total & Solids & Solids \\
\hline & (K gel) & (in) & (K gal) & (in) \\
\hline $1-1990$ & 201 & 69 & 196 & 67 \\
\hline 2 & 201 & 69 & 196 & 67 \\
\hline 3 & 201 & 69 & 196 & 67 \\
\hline 4 & 201 & 69 & 196 & 67 \\
\hline 1-1991 & 201 & 69 & 196 & 67 \\
\hline 2 & 201 & 69 & 196 & 67 \\
\hline 3 & 201 & 69 & 196 & 67 \\
\hline 4 & 196 & 67 & 196 & 67 \\
\hline $1-1992$ & 187 & 63 & 187 & 63 \\
\hline 2 & 187 & 63 & 187 & 63 \\
\hline 3 & 187 & 63 & 187 & 63 \\
\hline 4 & 187 & 63 & 197 & 63 \\
\hline 1-1993 & 187 & 63 & 1 & 63 \\
\hline 2 & 187 & 63 & $1=$ & 63 \\
\hline 3 & 187 & 63 & 187 & 63 \\
\hline 4 & 187 & 63 & 187 & 63 \\
\hline 1-1994 & 187 & 63 & 187 & 63 \\
\hline 2 & 187 & 63 & 187 & 63 \\
\hline 3 & 187 & 63 & $a \cdots$ & 63 \\
\hline 4 & 187 & 63 & $71, \ldots$ & 63 \\
\hline $1-1995$ & 187 & 63 & 187 & 63 \\
\hline 2 & 178 & 60 & 177 & 60 \\
\hline 3 & 178 & 60 & 177 & 60 \\
\hline
\end{tabular}


241-C-111 LEVEL HISTOPY

WHC-SD-WM-ER-313, Rev.1

\begin{tabular}{|c|c|c|c|c|}
\hline Year & Total & Total & Solids & Solids \\
\hline & (K gall) & (in) & (K gal) & (in) \\
\hline \multicolumn{5}{|l|}{$1-1944$} \\
\hline \multicolumn{5}{|l|}{2} \\
\hline \multicolumn{5}{|l|}{3} \\
\hline \multicolumn{5}{|l|}{4} \\
\hline \multicolumn{5}{|l|}{$1-1945$} \\
\hline \multicolumn{5}{|l|}{2} \\
\hline \multicolumn{5}{|l|}{3} \\
\hline \multicolumn{5}{|l|}{4} \\
\hline \multicolumn{5}{|l|}{$1-1946$} \\
\hline \multicolumn{5}{|l|}{2} \\
\hline 3 & 331 & 116 & & \\
\hline 4 & 528 & 187 & & \\
\hline $1-1947$ & 528 & 187 & & \\
\hline 2 & 528 & 187 & & \\
\hline 3 & 528 & 187 & & \\
\hline 4 & 528 & 187 & & \\
\hline $1-1948$ & 528 & 187 & & \\
\hline 2 & 528 & 187 & & \\
\hline 3 & 528 & 187 & & \\
\hline 4 & 528 & 187 & & \\
\hline $1-1949$ & 528 & 187 & & \\
\hline 2 & 528 & 187 & & \\
\hline 3 & 528 & 187 & & \\
\hline 4 & 528 & 187 & & \\
\hline $1-1950$ & 528 & 187 & & \\
\hline 2 & 528 & 187 & & \\
\hline 3 & 528 & 187 & & \\
\hline 4 & 528 & 187 & & \\
\hline 1.1951 & 528 & 187 & & \\
\hline 2 & 528 & 187 & & \\
\hline 3 & 528 & 187 & & \\
\hline 4 & 528 & 187 & & \\
\hline 1.1952 & 530 & 188 & & \\
\hline 2 & 530 & 188 & 36 & 9 \\
\hline 3 & 36 & 9 & 36 & 9 \\
\hline 4 & 139 & 46 & 36 & 9 \\
\hline $1-1953$ & 536 & 190 & 36 & 9 \\
\hline 2 & 536 & 190 & 36 & 9 \\
\hline 3 & 536 & 190 & 36 & 9 \\
\hline 4 & 536 & 190 & 36 & 9 \\
\hline $1-1954$ & 536 & 190 & 36 & 9 \\
\hline 2 & 536 & 190 & 36 & 9 \\
\hline 3 & 536 & 190 & 36 & 9 \\
\hline 4 & 536 & 190 & 36 & 9 \\
\hline $1-1955$ & 536 & 190 & 36 & 9 \\
\hline 2 & 536 & 190 & 36 & 9 \\
\hline
\end{tabular}


WHC-SD-WM-ER-313. Rev.1

241-C-111 LEVEL HISTORY

\begin{tabular}{|c|c|c|c|c|}
\hline Year & Total & Total & Solids & Solids \\
\hline & (K gal) & (in) & (K gal) & (in) \\
\hline & & & & \\
\hline 3 & 536 & 190 & 36 & 9 \\
\hline 4 & 536 & 190 & 36 & 9 \\
\hline 1.1956 & 530 & 188 & 36 & 9 \\
\hline 2 & 530 & 188 & 36 & 9 \\
\hline 3 & 56 & 16 & 36 & 9 \\
\hline 4 & 70 & 21 & 36 & 9 \\
\hline 1-1957 & 332 & 116 & & \\
\hline 2 & 521 & 185 & 13 & 0 \\
\hline 3 & 549 & 195 & 54 & 15 \\
\hline 4 & 98 & 31 & 95 & 30 \\
\hline $1-1958$ & 101 & 32 & 95 & 30 \\
\hline 2 & 101 & 32 & 95 & 30 \\
\hline 3 & 101 & 32 & 95 & 30 \\
\hline 4 & 88 & 27 & 95 & 30 \\
\hline $1-1959$ & 90 & 28 & 95 & 30 \\
\hline 2 & 90 & 28 & 95 & 30 \\
\hline 3 & 111 & 36 & 95 & 30 \\
\hline 4 & 298 & 104 & 95 & 30 \\
\hline $1-1960$ & 337 & 118 & 95 & 30 \\
\hline 2 & 337 & 118 & 95 & 30 \\
\hline 3 & 337 & 198 & 95 & 30 \\
\hline 4 & 309 & 108 & 95 & 30 \\
\hline \multicolumn{5}{|l|}{ 1-1961 } \\
\hline 2 & 345 & 121 & 95 & 30 \\
\hline \multicolumn{5}{|l|}{3} \\
\hline 4 & 345 & 121 & 95 & 30 \\
\hline \multicolumn{5}{|l|}{$1-1962$} \\
\hline 2 & 345 & 121 & 95 & 30 \\
\hline \multicolumn{5}{|l|}{3} \\
\hline 4 & 370 & 130 & 95 & 30 \\
\hline \multicolumn{5}{|l|}{$1-1963$} \\
\hline 2 & 431 & 152 & 95 & 30 \\
\hline \multicolumn{5}{|l|}{3} \\
\hline 4 & 472 & 167 & 95 & 30 \\
\hline \multicolumn{5}{|l|}{$1-1964$} \\
\hline 2 & 539 & 191 & 95 & 30 \\
\hline \multicolumn{5}{|l|}{3} \\
\hline 4 & 539 & 191 & 95 & 30 \\
\hline \multicolumn{5}{|l|}{$1-1965$} \\
\hline 2 & 519 & 184 & 81 & 25 \\
\hline 3 & 520 & 185 & 81 & 25 \\
\hline 4 & 516 & 183 & $\overline{81}$ & 25 \\
\hline $1-1966$ & 513 & 182 & 81 & 25 \\
\hline 2 & 510 & 181 & 81 & 25 \\
\hline 3 & 510 & 181 & $\overline{81}$ & 25 \\
\hline 4 & 508 & 180 & 81 & 25 \\
\hline
\end{tabular}


241-C-111 LEVEL hISTOAY

WHC-SD-WM-ER-313. Rev.1

\begin{tabular}{|c|c|c|c|c|}
\hline Year & Total & Total & Solids & I Solids \\
\hline & (K gal) & (in) & (K gal) & (in) \\
\hline $1-1967$ & 508 & 180 & 81 & 25 \\
\hline 2 & 503 & 178 & 81 & 25 \\
\hline 3 & 503 & 178 & 81 & 25 \\
\hline 4 & 502 & 178 & 81 & 25 \\
\hline $1-1968$ & 499 & 177 & 81 & 25 \\
\hline 2 & 499 & 177 & 81 & 25 \\
\hline 3 & 499 & 177 & 81 & 25 \\
\hline 4 & $49 \overline{9}$ & 177 & 81 & 25 \\
\hline $1-1969$ & 498 & 177 & 81 & 25 \\
\hline 2 & 497 & 176 & 81 & 25 \\
\hline 3 & 497 & 176 & 81 & 25 \\
\hline 4 & 147 & 49 & 81 & 25 \\
\hline $1-1970$ & 147 & 49 & 81 & 25 \\
\hline 2 & 146 & 49 & 96 & 30 \\
\hline 3 & 150 & 50 & 92 & 29 \\
\hline 4 & 151 & 50 & 92 & 29 \\
\hline 1-1971 & 151 & 50 & 92 & 29 \\
\hline 2 & 151 & 50 & 92 & 29 \\
\hline 3 & 151 & 50 & 92 & 29 \\
\hline 4 & 151 & 50 & 92 & 29 \\
\hline $1-1972$ & 150 & 50 & 92 & 29 \\
\hline 2 & 172 & 58 & 76 & 23 \\
\hline 3 & 174 & 59 & 76 & 23 \\
\hline 4 & 172 & 58 & 76 & 23 \\
\hline $1-1973$ & 172 & 58 & 76 & 23 \\
\hline 2 & 172 & 58 & 76 & 23 \\
\hline 3 & 172 & 58 & 76 & 23 \\
\hline 4 & 171 & 58 & 76 & 23 \\
\hline $1-1974$ & 171 & 58 & 76 & 23 \\
\hline 2 & 114 & 37 & 76 & 23 \\
\hline 3 & 115 & 37 & 76 & 23 \\
\hline 4 & 114 & 37 & 62 & 18 \\
\hline $1-1975$ & 114 & 37 & 62 & 18 \\
\hline 2 & 114 & 37 & 62 & 18 \\
\hline 3 & 114 & 37 & 62 & 18 \\
\hline 4 & 114 & 37 & 62 & 18 \\
\hline $1-1976$ & 73 & 22 & 62 & 18 \\
\hline 2 & 62 & 18 & 62 & 18 \\
\hline 3 & 62 & 18 & 62 & 18 \\
\hline 4 & 62 & 18 & 62 & 18 \\
\hline $1-1977$ & 62 & 18 & 62 & 18 \\
\hline 2 & 62 & 18 & 62 & 18 \\
\hline 3 & 62 & 18 & 62 & 18 \\
\hline 4 & 62 & 18 & 62 & 18 \\
\hline 1-1978 & 62 & 18 & 62 & 18 \\
\hline 2 & 62 & 18 & 62 & 18 \\
\hline
\end{tabular}


241-C-111 LEVEL HISTORY

WHC-SD-WM-ER-313. Rev.I

\begin{tabular}{|c|c|c|c|c|}
\hline Year & Total & Total & Solids & Solids \\
\hline & (K gal) & (in) & (K gal) & (in) \\
\hline 3 & 62 & 18 & 62 & 18 \\
\hline 4 & 62 & 18 & 62 & 18 \\
\hline $1-1979$ & 62 & 18 & 62 & 18 \\
\hline 2 & 62 & 18 & 62 & 18 \\
\hline 3 & 62 & $\overline{18}$ & 62 & 18 \\
\hline 4 & 62 & 18 & 62 & 18 \\
\hline $1-1980$ & 62 & 18 & 62 & 18 \\
\hline 2 & 62 & 18 & 62 & 18 \\
\hline 3 & 62 & 18 & 62 & 18 \\
\hline 4 & 62 & 18 & 62 & 18 \\
\hline 1-1981 & 62 & 18 & 62 & 18 \\
\hline 2 & 62 & 18 & 62 & 18 \\
\hline 3 & 62 & 18 & 62 & 18 \\
\hline 4 & $\overline{62}$ & 18 & 62 & 18 \\
\hline $1-1982$ & 62 & 18 & 62 & 18 \\
\hline 2 & 62 & 18 & 62 & 18 \\
\hline 3 & 57 & 16 & 57 & 16 \\
\hline 4 & 57 & 16 & 57 & 16 \\
\hline $1-1983$ & 57 & 16 & 57 & 16 \\
\hline 2 & 57 & 16 & 57 & 16 \\
\hline 3 & 57 & 16 & 57 & 16 \\
\hline 4 & 57 & 16 & 57 & 16 \\
\hline $1-1984$ & 57 & 16 & 57 & 16 \\
\hline 2 & 57 & 16 & 57 & 16 \\
\hline 3 & 57 & 16 & 57 & 16 \\
\hline 4 & 57 & 16 & 57 & 16 \\
\hline $1-1985$ & 57 & 16 & 57 & 16 \\
\hline 2 & 57 & 16 & 57 & 16 \\
\hline 3 & 57 & 16 & 57 & 16 \\
\hline 4 & 57 & 16 & 57 & 16 \\
\hline $1-1986$ & 57 & 16 & 57 & 16 \\
\hline 2 & 57 & 16 & 57 & 16 \\
\hline 3 & 57 & 16 & 57 & 16 \\
\hline 4 & 57 & 16 & 57 & 16 \\
\hline $1-1987$ & 57 & 16 & 57 & 16 \\
\hline 2 & 57 & 16 & 57 & 16 \\
\hline 3 & 57 & 16 & 57 & 16 \\
\hline 4 & 57 & 16 & 57 & 16 \\
\hline 1-1988 & 57 & 16 & 57 & 16 \\
\hline 2 & 57 & 16 & 57 & 16 \\
\hline 3 & 57 & 16 & 57 & 16 \\
\hline 4 & 57 & 16 & 57 & 16 \\
\hline 1-1989 & 57 & 16 & 57 & 16 \\
\hline 2 & 57 & 16 & 57 & 16 \\
\hline 3 & 57 & 16 & 57 & 16 \\
\hline 4 & 57 & 16 & 57 & 16 \\
\hline
\end{tabular}


WHC-SD-WM-ER-313. Rev.1

\section{1-C-111 LEVEL HISTORY}

\begin{tabular}{|c|c|c|c|c|}
\hline Year & Total & Total & Solids & Solids \\
\hline & (K gal) & (in) & (K gal) & (in) \\
\hline $1-1990$ & 57 & 16 & 57 & 16 \\
\hline 2 & 57 & 16 & 57 & 16 \\
\hline 3 & 57 & 16 & 57 & 16 \\
\hline 4 & 57 & 16 & 57 & $\overline{16}$ \\
\hline $1-1991$ & 57 & 16 & 57 & 16 \\
\hline 2 & 57 & 16 & 57 & 16 \\
\hline 3 & 57 & 16 & 57 & 16 \\
\hline$\sqrt{4}$ & 57 & 16 & 57 & 16 \\
\hline $1-1992$ & 57 & 16 & 57 & 16 \\
\hline 2 & 57 & 16 & 57 & 16 \\
\hline 3 & 57 & 16 & 57 & 16 \\
\hline 4 & 57 & 16 & 57 & 16 \\
\hline $1-1993$ & 57 & 16 & 57 & 16 \\
\hline 2 & 57 & 16 & 57 & 16 \\
\hline 3 & 57 & 16 & 57 & 16 \\
\hline 4 & 57 & 16 & 57 & 16 \\
\hline $1-1994$ & 57 & 16 & 57 & 16 \\
\hline 2 & 57 & 16 & 57 & 16 \\
\hline 3 & 57 & 16 & 57 & 16 \\
\hline 4 & 57 & 16 & 57 & 16 \\
\hline $1-1995$ & 57 & 16 & 57 & 16 \\
\hline 2 & 57 & 16 & 57 & 16 \\
\hline 3 & 57 & 16 & 57 & 16 \\
\hline
\end{tabular}


WHC-SD-WM-ER-313, Rev.1

241-C-112 LEVEL HISTORY

\begin{tabular}{|c|c|c|c|c|}
\hline Year & Total & Total & Solids & Solids \\
\hline & (K gal) & (in) & (K gal) & (in) \\
\hline & & & & \\
\hline $1-1944$ & & & & \\
\hline 2 & & & & \\
\hline 3 & & & & \\
\hline 4 & & & & \\
\hline 1-1945 & & & & \\
\hline 2 & & & & \\
\hline 3 & & & & \\
\hline 4 & & & & \\
\hline $1-1946$ & & & & \\
\hline 2 & & & & \\
\hline 3 & & & & \\
\hline 4 & 225 & 77 & & \\
\hline $1-1947$ & 512 & 182 & & \\
\hline 2 & 528 & 187 & & \\
\hline 3 & 528 & 187 & & \\
\hline 4 & 528 & 187 & & \\
\hline $1-1948$ & 528 & 187 & & \\
\hline 2 & 528 & 187 & & \\
\hline 3 & 528 & 187 & & \\
\hline 4 & 528 & 187 & & \\
\hline 949 & 528 & 187 & & \\
\hline$E$ & 528 & 187 & & \\
\hline 3 & 528 & 187 & & \\
\hline 4 & 528 & 187 & & \\
\hline $1-1950$ & 528 & 187 & & \\
\hline 2 & 528 & 187 & & \\
\hline 3 & 528 & 187 & & \\
\hline 4 & 528 & 187 & & \\
\hline $1-1951$ & 528 & 187 & & \\
\hline 2 & 528 & 187 & & \\
\hline 3 & 528 & 187 & & \\
\hline 4 & 528 & 187 & & \\
\hline $1-1952$ & 525 & 186 & & \\
\hline 2 & 99 & 31 & 15 & 1 \\
\hline 3 & 17 & 2 & 15 & 1 \\
\hline 4 & 17 & 2 & 15 & 1 \\
\hline $1-1953$ & 249 & 86 & 15 & 1 \\
\hline 2 & 517 & 183 & 15 & 1 \\
\hline 3 & 178 & 60 & 15 & 1 \\
\hline 4 & 145 & 48 & 15 & 1 \\
\hline $1-1954$ & 145 & 48 & 15 & 1 \\
\hline 2 & 433 & 153 & 15 & 1 \\
\hline 3 & 466 & 165 & 15 & 1 \\
\hline 4 & 466 & 165 & 15 & 1 \\
\hline $1-1955$ & 466 & 165 & 15 & 1 \\
\hline 2 & 466 & 165 & 17 & 2 \\
\hline
\end{tabular}


241-C-112 LEVEL HISTORY

WHC-SD-WM-ER-313. Rev.1

\begin{tabular}{|c|c|c|c|c|}
\hline Year & Tota: & Total & Solids & Solids \\
\hline & (K gaf) & (in) & (K gal) & (in) \\
\hline & & & & \\
\hline 3 & 466 & 165 & 17 & 2 \\
\hline 4 & 524 & 186 & 17 & 2 \\
\hline $1-1956$ & 340 & 119 & 17 & 2 \\
\hline 2 & 530 & 188 & 17 & 2 \\
\hline 3 & 417 & 147 & 17 & 2 \\
\hline 4 & 39 & 10 & 39 & 10 \\
\hline 1-1957 & 156 & 52 & 39 & 10 \\
\hline 2 & 54 & 15 & 21 & 3 \\
\hline 3 & 541 & 192 & 39 & 10 \\
\hline 4 & 516 & 183 & 39 & 10 \\
\hline $1-1958$ & 84 & 26 & 46 & 12 \\
\hline 2 & 84 & 26 & 46 & 12 \\
\hline 3 & 84 & 26 & 46 & 12 \\
\hline 4 & 134 & 44 & 46 & 12 \\
\hline $1-1959$ & 137 & 45 & 46 & 12 \\
\hline 2 & 137 & 45 & 46 & 12 \\
\hline 3 & 84 & 26 & 46 & 12 \\
\hline 4 & 136 & 45 & 46 & 12 \\
\hline 1.1960 & 137 & 45 & 46 & 12 \\
\hline 2 & 137 & 45 & 46 & 12 \\
\hline 3 & 263 & 91 & 46 & 12 \\
\hline 4 & 367 & 129 & 46 & 12 \\
\hline \multicolumn{5}{|l|}{$1-1961$} \\
\hline 2 & 455 & 161 & 46 & 12 \\
\hline \multicolumn{5}{|l|}{3} \\
\hline 4 & 486 & 172 & 46 & 12 \\
\hline \multicolumn{5}{|l|}{$1-1962$} \\
\hline 2 & 508 & 180 & 46 & 12 \\
\hline \multicolumn{5}{|l|}{3} \\
\hline 4 & 505 & 179 & 46 & 12 \\
\hline \multicolumn{5}{|l|}{$1-1963$} \\
\hline 2 & 510 & 181 & 46 & 12 \\
\hline \multicolumn{5}{|l|}{3} \\
\hline 4 & 513 & 182 & 46 & 12 \\
\hline \multicolumn{5}{|l|}{$1-1964$} \\
\hline 2 & 547 & 194 & 46 & 12 \\
\hline \multicolumn{5}{|l|}{3} \\
\hline 4 & 547 & 194 & 46 & 12 \\
\hline \multicolumn{5}{|l|}{ 1-1965 } \\
\hline 2 & 538 & 191 & 128 & 42 \\
\hline 3 & 538 & 191 & 128 & 42 \\
\hline 4 & 538 & 191 & 128 & 42 \\
\hline $1-1966$ & 538 & 191 & 128 & 42 \\
\hline 2 & 535 & 190 & 128 & 42 \\
\hline 3 & 535 & 190 & 128 & 42 \\
\hline 4 & 535 & 190 & 128 & 42 \\
\hline
\end{tabular}


WHC-SD-WM-ER-313. Rev.1

241-C-112 LEVEL HISTORY

\begin{tabular}{|c|c|c|c|c|}
\hline "ear & Total & Total & Solids & Solids \\
\hline & (K gal) & (in) & (K gal) & (in) \\
\hline & & & & \\
\hline $1-1967$ & 535 & 190 & 128 & 42 \\
\hline 2 & 535 & 190 & 128 & 42 \\
\hline 3 & 535 & 190 & 128 & 42 \\
\hline 4 & 535 & 190 & 128 & 42 \\
\hline $1-1968$ & 534 & 190 & 128 & 42 \\
\hline 2 & 534 & 190 & 128 & 42 \\
\hline 3 & 534 & 190 & 128 & 42 \\
\hline 4 & 534 & 190 & 128 & 42 \\
\hline $1-1969$ & 534 & 190 & 128 & 42 \\
\hline 2 & 532 & 189 & $12 \overline{8}$ & 42 \\
\hline 3 & $52 ?$ & 189 & 128 & 42 \\
\hline 4 & $5 \approx 2$ & 189 & 128 & 42 \\
\hline $1-1970$ & 213 & 73 & 128 & 42 \\
\hline 2 & 541 & 192 & 138 & 46 \\
\hline 3 & 543 & 193 & 136 & 45 \\
\hline 4 & 543 & 193 & 136 & 45 \\
\hline $1-1971$ & 543 & 193 & 136 & 45 \\
\hline 2 & 543 & 193 & 136 & 45 \\
\hline 3 & 543 & 193 & 136 & 45 \\
\hline 4 & 543 & 193 & 136 & 45 \\
\hline 1-1972 & 542 & 193 & 136 & 45 \\
\hline 2 & 543 & 193 & 136 & 45 \\
\hline 3 & 543 & 193 & 120 & 39 \\
\hline 4 & 532 & 189 & 120 & 39 \\
\hline $1-1973$ & 532 & 189 & 120 & 39 \\
\hline 2 & 531 & 189 & 120 & 39 \\
\hline 3 & 531 & 189 & 120 & 39 \\
\hline 4 & 531 & 189 & 120 & 39 \\
\hline 7-1974 & 530 & 188 & 120 & 39 \\
\hline 2 & 530 & 188 & 120 & 39 \\
\hline 3 & 530 & 188 & 120 & 39 \\
\hline 4 & 532 & 189 & 128 & 42 \\
\hline $1-1975$ & 483 & 171 & 128 & 42 \\
\hline 2 & 483 & 171 & 128 & 42 \\
\hline 3 & 194 & 66 & 128 & 42 \\
\hline 4 & 109 & 35 & 109 & 35 \\
\hline $1-1976$ & 109 & 35 & 109 & 35 \\
\hline 2 & 109 & 35 & 109 & 35 \\
\hline 3 & 109 & 35 & 109 & 35 \\
\hline 4 & 109 & 35 & 109 & 35 \\
\hline $1-1977$ & 109 & 35 & 109 & 35 \\
\hline 2 & 109 & 35 & 109 & 35 \\
\hline 3 & 109 & 35 & 109 & 35 \\
\hline 4 & 109 & 35 & 109 & 35 \\
\hline $1-1978$ & 109 & 35 & 109 & 35 \\
\hline 2 & 109 & 35 & 109 & 35 \\
\hline
\end{tabular}


WHC-SD-WM-ER-313, Rev. 1

241-C-112 LEVEL HISTORY

\begin{tabular}{|c|c|c|c|c|}
\hline Year & Total & Total & Solids & Solids \\
\hline & (K gal) & (in) & (K gal) & (in) \\
\hline & & & & \\
\hline 3 & 109 & 35 & 109 & 35 \\
\hline 4 & 109 & 35 & 109 & 35 \\
\hline 1-1979 & 109 & 35 & 109 & 35 \\
\hline 2 & 109 & 35 & 109 & 35 \\
\hline 3 & 109 & 35 & 109 & 35 \\
\hline 4 & 109 & 35 & 109 & 35 \\
\hline $1-1980$ & 109 & 35 & 109 & 35 \\
\hline 2 & 109 & 35 & 109 & 35 \\
\hline 3 & 109 & 35 & 109 & 35 \\
\hline 4 & 109 & 35 & 109 & 35 \\
\hline 1-1981 & 109 & 35 & 109 & 35 \\
\hline 2 & 109 & 35 & 109 & 35 \\
\hline 3 & 109 & 35 & 109 & 35 \\
\hline 4 & 109 & 35 & 109 & 35 \\
\hline $1-1982$ & 109 & 35 & 109 & 35 \\
\hline 2 & 109 & 35 & 109 & 35 \\
\hline 3 & 109 & 35 & 109 & 35 \\
\hline 4 & 109 & 35 & 109 & 35 \\
\hline $1-1983$ & 109 & 35 & 109 & 35 \\
\hline 2 & 109 & 35 & 109 & 35 \\
\hline 3 & 109 & 35 & 109 & 35 \\
\hline 4 & 109 & 35 & 109 & 35 \\
\hline $1-1984$ & 109 & 35 & 109 & 35 \\
\hline 2 & 109 & 35 & 109 & 35 \\
\hline 3 & 109 & 35 & 109 & 35 \\
\hline 4 & 109 & 35 & 109 & 35 \\
\hline \begin{tabular}{|l|}
$1-1985$ \\
\end{tabular} & 109 & 35 & 109 & 35 \\
\hline 2 & 109 & 35 & 109 & 35 \\
\hline 3 & 109 & 35 & 109 & 35 \\
\hline 4 & 109 & 35 & 109 & 35 \\
\hline $1-1986$ & 109 & 35 & 109 & 35 \\
\hline 2 & 109 & 35 & 109 & 35 \\
\hline 3 & 109 & 35 & 109 & 35 \\
\hline 4 & 109 & 35 & 109 & 35 \\
\hline $1-1987$ & 109 & 35 & 109 & 35 \\
\hline 2 & 109 & 35 & 109 & 35 \\
\hline 3 & 109 & 35 & 109 & 35 \\
\hline 4 & 109 & 35 & 109 & 35 \\
\hline $1-1988$ & 109 & 35 & 109 & 35 \\
\hline 2 & 109 & 35 & 109 & 35 \\
\hline 3 & 109 & 35 & 109 & 35 \\
\hline 4 & 109 & 35 & 109 & 35 \\
\hline 1-1989 & 109 & 35 & 109 & 35 \\
\hline 2 & 109 & 35 & 109 & 35 \\
\hline 3 & 109 & 35 & 109 & 35 \\
\hline 4 & 109 & 35 & 109 & 35 \\
\hline
\end{tabular}


241-C-112 LEVEL HISTORY

WHC-SD-WM-ER-313, Rev.1

\begin{tabular}{|c|c|c|c|c|}
\hline Year & Total & I Total & Solids & Solids \\
\hline & (K gal) & (in) & (K gal) & (in) \\
\hline & & & & $\mathrm{i}$ \\
\hline $1-1990$ & 109 & 35 & 09 & 35 \\
\hline 2 & 109 & 35 & 109 & 35 \\
\hline 3 & 104 & 33 & 104 & 33 \\
\hline 4 & 104 & 33 & 104 & 33 \\
\hline $1-1991$ & 104 & 33 & $10 \overline{4}$ & 33 \\
\hline 2 & 104 & 33 & 104 & 33 \\
\hline 3 & 104 & 33 & 104 & 33 \\
\hline 4 & 104 & 33 & 104 & 33 \\
\hline 1-1992 & 74 & 33 & 104 & 33 \\
\hline 2 & 104 & 33 & 104 & 33 \\
\hline 3 & 104 & 33 & 104 & $\overline{33}$ \\
\hline 4 & 104 & 33 & 104 & 33 \\
\hline 1-1993 & & 33 & 104 & 33 \\
\hline 2 & .4 & 33 & 104 & 33 \\
\hline 3 & 104 & 33 & 104 & 33 \\
\hline 4 & 104 & 33 & 104 & 33 \\
\hline $1-1994$ & 104 & 33 & 104 & 33 \\
\hline 2 & 104 & 33 & 104 & 33 \\
\hline 3 & 104 & 33 & 104 & 33 \\
\hline 4 & 104 & 33 & 104 & 33 \\
\hline 1.1995 & 104 & 33 & 104 & 33 \\
\hline 2 & 104 & 33 & 104 & 33 \\
\hline 3 & 104 & 33 & 104 & 33 \\
\hline
\end{tabular}


241-C-201 LEVEL HISTORY

WHC-SD-WM-ER-313, Rev.1

\begin{tabular}{|c|c|c|c|c|}
\hline Year & Total & Total & Solids & Solids \\
\hline & (K gal) & (in) & (K gal) & (in) \\
\hline \multicolumn{5}{|l|}{$1-1947$} \\
\hline \multicolumn{5}{|l|}{2} \\
\hline \multicolumn{5}{|l|}{3} \\
\hline 4 & 55 & 284 & & \\
\hline $1-1948$ & 55 & 284 & & \\
\hline 2 & 55 & 284 & & \\
\hline 3 & 55 & 284 & & \\
\hline 4 & 55 & 284 & & \\
\hline $1-1949$ & 55 & 284 & & \\
\hline 2 & 55 & 284 & & \\
\hline 3 & 55 & 284 & & \\
\hline 4 & 55 & 284 & & \\
\hline $1-1950$ & 55 & 284 & & \\
\hline 2 & 55 & 284 & & \\
\hline 3 & 55 & 284 & & \\
\hline 4 & 55 & 284 & & \\
\hline 1.1951 & 55 & 284 & & \\
\hline 2 & 55 & 284 & & \\
\hline 3 & 55 & 284 & & \\
\hline 4 & 55 & 284 & & \\
\hline $1+1952$ & 54.5 & 281 & & \\
\hline 2 & 54.5 & 281 & & \\
\hline 3 & 54.5 & 281 & & \\
\hline 4 & 52.5 & 271 & & \\
\hline $1-1953$ & 52.5 & 271 & & \\
\hline 2 & 54.5 & 281 & & \\
\hline 3 & 54.5 & 281 & & \\
\hline 4 & 15.7 & 83 & & \\
\hline $1-1954$ & 0 & 0 & 0 & 0 \\
\hline 2 & 0 & 0 & 0 & 0 \\
\hline 3 & 0 & 0 & 0 & 0 \\
\hline 4 & 0 & 0 & 0 & 0 \\
\hline $1-1955$ & 0 & 0 & 0 & 0 \\
\hline 2 & 13 & 69 & 0 & 0 \\
\hline 3 & 30 & 156 & 0 & 0 \\
\hline 4 & 57 & 294 & 0 & 0 \\
\hline $1-1956$ & 54.5 & 281 & 0 & 0 \\
\hline 2 & 54.5 & 281 & 0 & 0 \\
\hline 3 & 54.5 & 281 & 0 & 0 \\
\hline 4 & 54.5 & 281 & 0 & 0 \\
\hline $1-1957$ & 54 & 279 & & \\
\hline 2 & 54 & 279 & & \\
\hline 3 & 55 & 284 & & \\
\hline 4 & 55 & 284 & & \\
\hline $1-1958$ & 55 & 284 & & \\
\hline 2 & 55 & 284 & & \\
\hline
\end{tabular}


WHC-SD-WM-ER-313, Rev.1

241-C-201 LEVEL HISTORY

\begin{tabular}{|c|c|c|c|c|}
\hline Year & Total & Total & Solids & Solids \\
\hline & (K gal) & (in) & (K gal) & (in) \\
\hline & & & & \\
\hline 3 & 55 & 284 & & \\
\hline 4 & 55 & 284 & & \\
\hline $1-1959$ & 54 & 279 & & \\
\hline 2 & 54 & 279 & & \\
\hline 3 & 54 & 279 & & \\
\hline 4 & 55 & 284 & & \\
\hline $7-1960$ & 55 & 284 & & \\
\hline 2 & 55 & 284 & & \\
\hline 3 & 55 & 284 & & \\
\hline 4 & 55 & 284 & & \\
\hline \multicolumn{5}{|l|}{ 1-1961 } \\
\hline 2 & 56 & 289 & & \\
\hline \multicolumn{5}{|l|}{3} \\
\hline 4 & 56 & 289 & & \\
\hline \multicolumn{5}{|l|}{$1-1962$} \\
\hline 2 & 56 & 289 & & \\
\hline \multicolumn{5}{|l|}{3} \\
\hline 4 & 56 & 289 & & \\
\hline \multicolumn{5}{|l|}{$1-1963$} \\
\hline 2 & 56 & 289 & & \\
\hline \multicolumn{5}{|l|}{3} \\
\hline 4 & 54 & 279 & & \\
\hline \multicolumn{5}{|l|}{$1-1964$} \\
\hline 2 & 54 & 279 & & \\
\hline \multicolumn{5}{|l|}{3} \\
\hline 4 & 54 & 279 & & \\
\hline \multicolumn{5}{|l|}{$1-1965$} \\
\hline 2 & 54 & 279 & & \\
\hline 3 & 54 & 279 & & \\
\hline 4 & 52 & 268 & & \\
\hline $1-1966$ & 52 & 268 & & \\
\hline 2 & 52 & 268 & & \\
\hline 3 & 52 & 268 & & \\
\hline 4 & 52 & 268 & & \\
\hline $1-1967$ & 55 & 284 & & \\
\hline 2 & 55 & 284 & & \\
\hline 3 & 55 & 284 & & \\
\hline 4 & 55 & 284 & & \\
\hline 1.1968 & 55 & 284 & & \\
\hline 2 & 55 & 284 & & \\
\hline 3 & 55 & 284 & & \\
\hline 4 & 55 & 284 & & \\
\hline $1-1969$ & 55 & $2 \overline{84}$ & & \\
\hline 2 & 55 & 284 & & \\
\hline 3 & 55 & 284 & & \\
\hline 4 & 55 & 284 & & \\
\hline
\end{tabular}


WHC-SD-WM-ER-313, Rev.1

241-C-201 LEVEL HISTORY

\begin{tabular}{|c|c|c|c|c|}
\hline Year & Total & Total & Solids & Solids \\
\hline & (K gol) & (in) & (K gall) & (in) \\
\hline & & & & \\
\hline $1-1970$ & 55 & 284 & 1 & 8 \\
\hline 2 & 1 & 8 & 1 & 8 \\
\hline 3 & 1 & 8 & 1 & 8 \\
\hline 4 & 1 & 8 & 1 & 8 \\
\hline $1-1971$ & 1 & 8 & 1 & 8 \\
\hline 2 & 1 & 8 & 1 & 8 \\
\hline 3 & 1 & 8 & 1 & 8 \\
\hline 4 & 1 & 8 & 1 & 8 \\
\hline 1.1972 & 1 & 8 & 1 & 8 \\
\hline 2 & 1 & 8 & 1 & 8 \\
\hline 3 & 1 & 8 & 1 & 8 \\
\hline 4 & 1 & 8 & 1 & 8 \\
\hline $1-1973$ & 1 & 8 & 1 & 8 \\
\hline 2 & 1 & 8 & 1 & 8 \\
\hline 3 & 1 & 8 & 1 & $\overline{8}$ \\
\hline 4 & 3 & 18 & 1 & 8 \\
\hline $1-1974$ & 3 & 18 & 1 & 8 \\
\hline 2 & 3 & 18 & 1 & 8 \\
\hline 3 & 3 & 18 & 1 & $\overline{8}$ \\
\hline 4 & 3 & 18 & 0 & 0 \\
\hline $1-1975$ & 4 & 23 & 0 & 0 \\
\hline 2 & 4 & 23 & 0 & 0 \\
\hline 3 & 4 & 23 & 0 & 0 \\
\hline 4 & 4 & 23 & 0 & 0 \\
\hline $1-1976$ & 4 & 23 & 0 & 0 \\
\hline 2 & 4 & 23 & 0 & 0 \\
\hline 3 & 4 & 23 & 0 & 0 \\
\hline 4 & 4 & 23 & 0 & 0 \\
\hline $1-1977$ & 4 & 23 & 0 & 0 \\
\hline 2 & 4 & 23 & 0 & 0 \\
\hline 3 & 4 & 23 & 0 & 0 \\
\hline 4 & 4 & 23 & 0 & 0 \\
\hline $1-1978$ & 4 & 23 & 0 & 0 \\
\hline 2 & 4 & 23 & 0 & 0 \\
\hline 3 & 4 & 23 & 0 & 0 \\
\hline 4 & 4 & 23 & 0 & 0 \\
\hline $1-1979$ & 4 & 23 & 0 & 0 \\
\hline 2 & 4 & 23 & 0 & 0 \\
\hline 3 & 4 & 23 & 0 & 0 \\
\hline 4 & 4 & 23 & 0 & 0 \\
\hline $1-1980$ & 4 & 23 & 0 & 0 \\
\hline 2 & 4 & 23 & 0 & 0 \\
\hline 3 & 4 & 23 & 0 & 3 \\
\hline 4 & 4 & 23 & 0 & 3 \\
\hline $1-1981$ & 5 & 29 & 1 & 8 \\
\hline 2 & 5 & 29 & 1 & 8 \\
\hline
\end{tabular}


241-C-201 LEVEL HISTORY

WHC-SD-WM-ER-313, Rev.1

\begin{tabular}{|c|c|c|c|c|}
\hline Year & Total & Total & Solids & $\therefore \quad$ Solids \\
\hline & (K gal) & (in) & (K gal) & (in) \\
\hline & & & & 1 \\
\hline 3 & 5 & 29 & 1 & 8 \\
\hline 4 & 5 & 29 & 1 & 8 \\
\hline $1-1982$ & 2 & 13 & 1 & 8 \\
\hline 2 & 3 & 18 & 2 & 13 \\
\hline 3 & 3 & 18 & 2 & 13 \\
\hline 4 & 3 & 18 & 2 & 13 \\
\hline $1-1983$ & 3 & 18 & 2 & 13 \\
\hline 2 & 3 & 18 & 2 & 13 \\
\hline 3 & 3 & 18 & 2 & 13 \\
\hline 4 & 3 & 18 & 2 & 13 \\
\hline $1-1984$ & 3 & 18 & 2 & 13 \\
\hline 2 & 3 & 18 & 2 & 13 \\
\hline 3 & 3 & 18 & 2 & 13 \\
\hline 4 & 3 & 18 & 2 & 13 \\
\hline $1-1985$ & 3 & 18 & 2 & 13 \\
\hline 2 & 3 & 18 & 2 & 13 \\
\hline 3 & 3 & 18 & 2 & 13 \\
\hline 4 & 3 & 18 & 2 & 13 \\
\hline $1-1986$ & 3 & 18 & 2 & 13 \\
\hline 2 & 3 & 18 & 2 & 13 \\
\hline 3 & 3 & 18 & 2 & 13 \\
\hline 4 & 3 & 18 & 2 & 13 \\
\hline $1-1987$ & 3 & 18 & 2 & 13 \\
\hline 2 & 3 & 18 & 2 & 13 \\
\hline 3 & 3 & 18 & 2 & 13 \\
\hline 4 & 3 & 18 & 2 & 13 \\
\hline $1-1988$ & 3 & 18 & 2 & 13 \\
\hline 2 & 3 & 18 & 2 & 13 \\
\hline 3 & 3 & 18 & 2 & 13 \\
\hline 4 & 3 & 18 & 2 & 13 \\
\hline $1-1989$ & 3 & 18 & 2 & 13 \\
\hline 2 & 3 & 18 & $?$ & 13 \\
\hline 3 & 3 & 18 & 2 & 13 \\
\hline 4 & 3 & 18 & 2 & 13 \\
\hline $1-1990$ & 3 & 18 & 2 & 13 \\
\hline 2 & 2 & 13 & 2 & 13 \\
\hline 3 & 2 & 13 & 2 & 13 \\
\hline 4 & 2 & 13 & 2 & 13 \\
\hline 1-1991 & 2 & 13 & 2 & 13 \\
\hline 2 & 2 & 13 & 2 & 13 \\
\hline 3 & 2 & 13 & 2 & 13 \\
\hline 4 & 2 & 13 & 2 & 13 \\
\hline $1-1992$ & 2 & 13 & 2 & 13 \\
\hline 2 & 2 & 13 & 2 & 13 \\
\hline 3 & 2 & 13 & 2 & 13 \\
\hline 4 & 2 & 13 & 2 & 13 \\
\hline
\end{tabular}


241-C-201 LEVEL HISTOAY

\begin{tabular}{|l|c|c|c|c|}
\hline Year & Total & Total & Solids & Solids \\
\hline & (K gal) & lin) & (K gal) & (in) \\
\hline $1-1993$ & & & & \\
\hline 2 & 2 & 13 & 2 & 13 \\
\hline 3 & 2 & 13 & 2 & 13 \\
\hline 4 & 2 & 13 & 2 & 13 \\
\hline $1-1994$ & 2 & 13 & 2 & 13 \\
\hline 2 & 2 & 13 & 2 & 13 \\
\hline 3 & 2 & 13 & 2 & 13 \\
\hline 4 & 2 & 13 & 2 & 13 \\
\hline $1-1995$ & 2 & 13 & 2 & 13 \\
\hline 2 & 2 & 13 & 2 & 13 \\
\hline 3 & 2 & 13 & 2 & 13 \\
\hline
\end{tabular}


WHC-SD-WM-ER-313, Rev.1

241-C-202 LEVEL HISTORY

\begin{tabular}{|c|c|c|c|c|}
\hline Yoar & Total & Total & Solids & Solids \\
\hline & (K gal) & (in) & (K gal) & (in) \\
\hline & & & & \\
\hline \multicolumn{5}{|l|}{$1-1947$} \\
\hline \multicolumn{5}{|l|}{2} \\
\hline \multicolumn{5}{|l|}{3} \\
\hline 4 & 55 & 284 & & \\
\hline $1-1948$ & 55 & 284 & & \\
\hline 2 & 55 & 284 & & \\
\hline 3 & 55 & 284 & & \\
\hline 4 & 55 & 284 & & \\
\hline $1-1949$ & 55 & 284 & & \\
\hline 2 & 55 & 284 & & \\
\hline 3 & 55 & 284 & & \\
\hline 4 & 55 & 284 & & \\
\hline $1-1950$ & 55 & 284 & & \\
\hline 2 & 55 & 284 & & \\
\hline 3 & 55 & 284 & & \\
\hline 4 & 55 & 284 & & \\
\hline $1-1951$ & 55 & 284 & & \\
\hline 2 & 55 & 284 & & \\
\hline 3 & 55 & 284 & & \\
\hline 4 & 55 & 284 & & \\
\hline 1.1952 & 54.5 & 281 & & \\
\hline 2 & 54.5 & 281 & & \\
\hline 3 & 54.5 & 281 & & \\
\hline 4 & 54.5 & 281 & & \\
\hline 1-1953 & 54.5 & 281 & & \\
\hline 2 & 8 & 44 & & \\
\hline 3 & 8 & 44 & & \\
\hline 4 & 43.7 & 226 & & \\
\hline $1-1954$ & 0 & 0 & 0 & 0 \\
\hline 2 & 0 & 0 & 0 & 0 \\
\hline 3 & 0 & 0 & 0 & 0 \\
\hline 4 & 0 & 0 & 0 & 0 \\
\hline $1-1955$ & 0 & 0 & 0 & 0 \\
\hline 2 & 0 & 0 & 0 & 0 \\
\hline 3 & 0 & 0 & 0 & 0 \\
\hline 4 & 6 & 34 & 0 & 0 \\
\hline 1.1956 & 23.5 & 123 & 0 & 0 \\
\hline 2 & 54.5 & 281 & 0 & 0 \\
\hline 3 & 54.5 & 281 & 0 & 0 \\
\hline 4 & 54.5 & 281 & 0 & 0 \\
\hline $1-1957$ & 56 & 289 & & \\
\hline 2 & 56 & 289 & & \\
\hline 3 & 56 & 289 & & \\
\hline 4 & 56 & 289 & & \\
\hline 1.1958 & 56 & 289 & & \\
\hline 2 & 56 & 289 & & \\
\hline
\end{tabular}


WHC-SD-WM-ER-313, Rev.1

241-C-202 LEVEL HISTORY

\begin{tabular}{|c|c|c|c|c|}
\hline Year & Total & Total & Solids & Solids \\
\hline & (K gal) & (in) & (K gal) & (in) \\
\hline 3 & 56 & 289 & & \\
\hline 4 & 55 & 284 & & \\
\hline $1-1959$ & 55 & 284 & & \\
\hline 2 & 55 & 284 & & \\
\hline 3 & 55 & 284 & & \\
\hline 4 & 55 & 284 & & \\
\hline $1-1960$ & 55 & 284 & & \\
\hline 2 & 55 & 284 & & \\
\hline 3 & 55 & 284 & & \\
\hline 4 & 55 & 284 & & \\
\hline \multicolumn{5}{|l|}{$1-1961$} \\
\hline 2 & 56 & 289 & & \\
\hline \multicolumn{5}{|l|}{3} \\
\hline 4 & 56 & 289 & & \\
\hline \multicolumn{5}{|l|}{$1-1962$} \\
\hline 2 & 56 & 289 & & \\
\hline \multicolumn{5}{|l|}{3} \\
\hline 4 & 56 & 289 & & \\
\hline \multicolumn{5}{|l|}{$1-1963$} \\
\hline 2 & 56 & 289 & & \\
\hline \multicolumn{5}{|l|}{3} \\
\hline 4 & 57 & 294 & & \\
\hline \multicolumn{5}{|l|}{$1-1964$} \\
\hline 2 & 55 & 284 & & \\
\hline \multicolumn{5}{|l|}{3} \\
\hline 4 & 55 & 284 & & \\
\hline \multicolumn{5}{|l|}{$1-1965$} \\
\hline 2 & 55 & 284 & & \\
\hline 3 & 55 & 284 & & \\
\hline 4 & 55 & 284 & & \\
\hline $1-1966$ & 55 & 284 & & \\
\hline 2 & 55 & 284 & & \\
\hline 3 & 55 & 284 & & \\
\hline 4 & 55 & 284 & & \\
\hline 1-1967 & 55 & 284 & & \\
\hline 2 & 55 & 284 & & \\
\hline 3 & 55 & 284 & & \\
\hline 4 & 55 & 284 & & \\
\hline $1-1968$ & 55 & 284 & & \\
\hline 2 & 55 & 284 & & \\
\hline 3 & 55 & 284 & & \\
\hline 4 & 55 & 284 & & \\
\hline $1-1969$ & 55 & 284 & & \\
\hline 2 & 55 & 284 & & \\
\hline 3 & 55 & 284 & & \\
\hline 4 & 55 & 284 & & \\
\hline
\end{tabular}


WHC-SD-WM-ER-313. Rel.1

241-C-202 LEVEL HISTORY

\begin{tabular}{|c|c|c|c|c|}
\hline Year & Total & Total & Solids & Solids \\
\hline & (K gall) & (in) & (K gal) & (in) \\
\hline $1-1970$ & 55 & 284 & & \\
\hline 2 & 0 & 0 & & \\
\hline 3 & 0 & 0 & & \\
\hline 4 & 0 & 0 & & \\
\hline $1-1971$ & 0 & 0 & & \\
\hline 2 & 0 & 0 & & \\
\hline 3 & 0 & 0 & & \\
\hline 4 & 0 & 0 & & \\
\hline $1-1972$ & 0 & 0 & & \\
\hline 2 & 0 & 0 & & \\
\hline 3 & 0 & 0 & & \\
\hline 4 & 0 & 0 & & \\
\hline 1-1973 & 0 & 0 & 0 & 0 \\
\hline 2 & 0 & 0 & 0 & 0 \\
\hline 3 & 0 & 0 & 0 & 0 \\
\hline 4 & 1 & 8 & 0 & 0 \\
\hline $1-1974$ & 1 & 8 & 0 & 0 \\
\hline 2 & 2 & 13 & 0 & 0 \\
\hline 3 & 2 & 13 & 0 & 0 \\
\hline 4 & 2 & 13 & $\overline{0}$ & 0 \\
\hline 1-1975 & 2 & 13 & 0 & 0 \\
\hline 2 & 2 & 13 & 0 & 0 \\
\hline 3 & 2 & 13 & 0 & 0 \\
\hline 4 & 2 & 13 & 0 & 0 \\
\hline $1-1976$ & 2 & 13 & 0 & 0 \\
\hline 2 & 2 & 13 & 0 & 0 \\
\hline 3 & 2 & 13 & 0 & 0 \\
\hline 4 & 2 & 13 & 0 & 0 \\
\hline $1-1977$ & 2 & 13 & 0 & 0 \\
\hline 2 & 2 & 13 & 0 & 0 \\
\hline 3 & 2 & 13 & 0 & 0 \\
\hline 4 & 2 & 13 & 0 & 0 \\
\hline $1-1978$ & 2 & 13 & 0 & 0 \\
\hline 2 & 2 & 13 & 0 & 0 \\
\hline 3 & 2 & 13 & 0 & 0 \\
\hline 4 & 2 & 13 & 0 & 0 \\
\hline $1-1979$ & 2 & 13 & 0 & 0 \\
\hline 2 & 2 & 13 & 0 & 0 \\
\hline 3 & 2 & 13 & 0 & 0 \\
\hline 4 & 2 & 13 & 0 & 0 \\
\hline 1.1980 & 2 & 13 & 0 & 0 \\
\hline 2 & 2 & 13 & 0 & 0 \\
\hline 3 & 3 & 18 & 1 & 8 \\
\hline 4 & 1 & 8 & 1 & 8 \\
\hline $1-1981$ & 1 & 8 & 1 & 8 \\
\hline 2 & 1 & 8 & 1 & 8 \\
\hline
\end{tabular}




\begin{tabular}{|c|c|c|c|c|}
\hline 8 & $\downarrow$ & 8 & $\mathrm{l}$ & $t$ \\
\hline 8 & 1 & 8 & 1 & $\varepsilon$ \\
\hline 8 & $\mathbf{L}$ & 8 & $l$ & 2 \\
\hline 8 & 1 & 8 & $t$ & $266 L-1$ \\
\hline 8 & 1 & 8 & $L$ & $t$ \\
\hline 8 & 1 & 8 & $t$ & $E$ \\
\hline 8 & 1 & 8 & 1 & 2 \\
\hline 8 & 1 & 8 & $L$ & $166 L-L$ \\
\hline 8 & 1 & 8 & 1 & $t$ \\
\hline 8 & 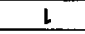 & 8 & $L$ & $\varepsilon$ \\
\hline 8 & 1 & 8 & 1 & 2 \\
\hline 8 & $\mathrm{I}$ & 8 & 1 & $066 l-l$ \\
\hline 8 & 1 & 8 & 1 & $t$ \\
\hline 8 & 1 & 8 & 1 & $\varepsilon$ \\
\hline 8 & 1 & 8 & 1 & 2 \\
\hline 8 & 1 & 8 & 1 & $6861-1$ \\
\hline 8 & $I$ & 8 & 1 & $\nabla$ \\
\hline 8 & 1 & 8 & 1 & $\varepsilon$ \\
\hline 8 & 1 & 8 & 1 & 2 \\
\hline 8 & 1 & 8 & 1 & $886 L-L$ \\
\hline 8 & 1 & 8 & 1 & $t$ \\
\hline 8 & 1 & 8 & 1 & $\varepsilon$ \\
\hline 8 & 1 & 8 & 1 & 2 \\
\hline 8 & 1 & 8 & $b$ & $\angle 86 L-l$ \\
\hline 8 & 1 & 8 & 1 & $t$ \\
\hline 8 & 1 & 8 & 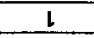 & $\varepsilon$ \\
\hline 8 & 6 & 8 & 1 & 2 \\
\hline 8 & 1 & 8 & $l$ & $986 L-L$ \\
\hline 8 & $\mathbf{L}$ & 8 & 1 & $t$ \\
\hline 8 & 1 & 8 & 1 & $\varepsilon$ \\
\hline 8 & 1 & 8 & 1 & 2 \\
\hline 8 & 1 & 8 & 1 & $986 L-L$ \\
\hline 8 & 1 & 8 & 1 & $t$ \\
\hline 8 & 1 & 8 & 1 & $\varepsilon$ \\
\hline 8 & 1 & 8 & 1 & 2 \\
\hline 8 & 1 & 8 & 1 & $586 t-1$ \\
\hline 8 & 1 & 8 & 1 & $t$ \\
\hline 8 & 1 & 8 & 1 & $\varepsilon$ \\
\hline 8 & 1 & 8 & $l$ & 2 \\
\hline 8 & 1 & 8 & 1 & EB6L-L \\
\hline 8 & 1 & 8 & 1 & $t$ \\
\hline 8 & 1 & 8 & 1 & $\varepsilon$ \\
\hline 8 & 1 & 8 & 1 & $z$ \\
\hline 8 & $L$ & 8 & 1 & $286 L-1$ \\
\hline 8 & $L$ & 8 & $\downarrow$ & $t$ \\
\hline 8 & $l$ & 8 & $\downarrow$ & $\varepsilon$ \\
\hline (볘) & 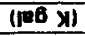 & (u!) & $(f 06 x)$ & \\
\hline spy|os & spyjos & 10101 & 10201 & de0h \\
\hline
\end{tabular}


241-C-202 LEVEL HISTORY

\begin{tabular}{|l|c|c|c|c|}
\hline \multicolumn{1}{|c|}{ Yoar } & Total & Total & Solids & Solids \\
\hline & (K gal) & (in) & (K gal) & (in) \\
\hline $1-1993$ & 1 & & & \\
\hline 2 & 1 & 8 & 1 & 8 \\
\hline 3 & 1 & 8 & 1 & 8 \\
\hline 4 & 1 & 8 & 1 & 8 \\
\hline $1-1994$ & 1 & 8 & 1 & 8 \\
\hline 2 & 1 & 8 & 1 & 8 \\
\hline 3 & 1 & 8 & 1 & 8 \\
\hline 4 & 1 & 8 & 1 & 8 \\
\hline $1-1995$ & 1 & 8 & 1 & 8 \\
\hline 2 & 1 & 8 & 1 & 8 \\
\hline 3 & 1 & 8 & 1 & 8 \\
\hline
\end{tabular}


241-C-203 LEVEL HISTORY

WHC-SD-WM-ER-313, Rev.1

\begin{tabular}{|c|c|c|c|c|}
\hline Year & Total & Total & Sollids & Solids \\
\hline & (K gal) & (in) & (K gal) & (in) \\
\hline \multirow{2}{*}{\multicolumn{5}{|c|}{$1-1947$}} \\
\hline \multirow{2}{*}{\multicolumn{5}{|c|}{2}} \\
\hline & & & & \\
\hline \multicolumn{5}{|l|}{$\overline{3}$} \\
\hline 4 & 41 & 212 & & \\
\hline $1-1 \overline{948}$ & 55 & 284 & & \\
\hline 2 & 55 & 284 & & \\
\hline 3 & 55 & 284 & & \\
\hline 4 & 55 & 284 & & \\
\hline $1-1949$ & 55 & 284 & & \\
\hline 2 & 55 & 284 & & \\
\hline 3 & 55 & 284 & & \\
\hline 4 & 55 & 284 & & \\
\hline $1-1950$ & 55 & 284 & & \\
\hline 2 & 55 & 284 & & \\
\hline 3 & 55 & 284 & & \\
\hline 4 & 55 & 284 & & \\
\hline 1.1951 & 55 & 284 & & \\
\hline 2 & 55 & 284 & & \\
\hline 3 & 55 & 284 & & \\
\hline 4 & 55 & 284 & & \\
\hline $1-1952$ & 54.5 & 281 & & \\
\hline 2 & 54.5 & 281 & & \\
\hline 3 & 54.5 & 281 & & \\
\hline 4 & 54.5 & 281 & & \\
\hline $1-1953$ & 54.5 & 281 & & \\
\hline 2 & 54.5 & 281 & & \\
\hline 3 & 54.5 & 281 & & \\
\hline 4 & 14.8 & 79 & & \\
\hline $1-1954$ & 0 & 0 & 0 & 0 \\
\hline 2 & 0 & 0 & 0 & 0 \\
\hline 3 & 0 & 0 & 0 & 0 \\
\hline 4 & 0 & 0 & 0 & 0 \\
\hline 1.1955 & 0 & 0 & 0 & 0 \\
\hline 2 & 0 & 0 & 0 & 0 \\
\hline 3 & 0 & 0 & 0 & 0 \\
\hline 4 & 5 & 29 & 0 & 0 \\
\hline $1-1956$ & 5 & 29 & 0 & 0 \\
\hline 2 & 5 & 29 & 0 & 0 \\
\hline 3 & 22 & 115 & 0 & 0 \\
\hline 4 & 34.5 & 179 & 0 & 0 \\
\hline $1-1957$ & 36 & 187 & & \\
\hline 2 & 35 & 182 & & \\
\hline 3 & 35 & 182 & & \\
\hline 4 & 35 & 182 & & \\
\hline 1.1958 & 35 & 182 & & \\
\hline 2 & 35 & 182 & & \\
\hline
\end{tabular}


241-C-203 LEVEL HISTORY

WHC-SD-WM-ER-313. Rev.1

\begin{tabular}{|c|c|c|c|c|}
\hline Year & Total & Total & Solids & Solids \\
\hline & (K gal) & (in) & (K gal) & (in) \\
\hline & & & & \\
\hline 3 & 35 & 182 & & \\
\hline 4 & 35 & 182 & & \\
\hline 1-1959 & 34 & 176 & & 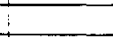 \\
\hline 2 & 34 & 176 & & 3 \\
\hline 3 & 34 & 176 & & \\
\hline 4 & 34 & 176 & & \\
\hline 1-1960 & 34 & 176 & & \\
\hline 2 & 34 & 176 & & \\
\hline 3 & 34 & 176 & & \\
\hline 4 & 34 & 176 & & \\
\hline \multicolumn{5}{|l|}{ 1-1961 } \\
\hline 2 & 34 & 176 & & \\
\hline \multicolumn{5}{|l|}{3} \\
\hline 4 & 34 & 176 & & \\
\hline \multicolumn{5}{|l|}{$1-1962$} \\
\hline 2 & 34 & 176 & & \\
\hline \multicolumn{5}{|l|}{3} \\
\hline 4 & 34 & 176 & & \\
\hline \multicolumn{5}{|l|}{$1-1963$} \\
\hline 2 & 34 & 176 & & \\
\hline \multicolumn{5}{|l|}{3} \\
\hline 4 & 35 & 182 & & \\
\hline \multicolumn{5}{|l|}{$1-1964$} \\
\hline 2 & 35 & 182 & & \\
\hline \multicolumn{5}{|l|}{3} \\
\hline 4 & 35 & 182 & & \\
\hline \multicolumn{5}{|l|}{$1-1965$} \\
\hline 2 & 33 & 171 & & \\
\hline 3 & 33 & 171 & & \\
\hline 4 & 33 & 171 & & \\
\hline $1-1966$ & 33 & 171 & & \\
\hline 2 & 33 & 171 & & \\
\hline 3 & 33 & 171 & & \\
\hline 4 & 33 & 171 & & \\
\hline 1-1967 & 34 & 176 & & \\
\hline 2 & 34 & 176 & & \\
\hline 3 & 34 & 176 & & \\
\hline 4 & 34 & 176 & & \\
\hline $1-1968$ & 34 & 176 & & \\
\hline 2 & 34 & 176 & & \\
\hline 3 & 34 & 176 & & \\
\hline 4 & 34 & 176 & & \\
\hline $1-1969$ & 34 & 176 & & \\
\hline 2 & 34 & 176 & & \\
\hline 3 & 34 & 176 & & \\
\hline 4 & 34 & 176 & & \\
\hline
\end{tabular}


WHC-SD-WM-ER-313, Rev.1

241-C-203 LEVEL HISTORY

\begin{tabular}{|c|c|c|c|c|}
\hline Year & Total & Totel & Solids & Solids \\
\hline & (K gal) & (in) & (K gal) & (in) \\
\hline $1-1970$ & 18 & 95 & 5 & 29 \\
\hline 2 & 6 & 34 & 5 & 29 \\
\hline 3 & 6 & 34 & 5 & 29 \\
\hline 4 & 6 & 34 & 5 & 29 \\
\hline 1-1971 & 6 & 34 & 5 & 29 \\
\hline 2 & 6 & 34 & 5 & 29 \\
\hline 3 & 6 & 34 & 5 & 29 \\
\hline 4 & 6 & 34 & 5 & 29 \\
\hline $1-1972$ & 6 & 34 & 3 & 18 \\
\hline 2 & 6 & 34 & 3 & 18 \\
\hline 3 & 6 & 34 & 3 & 18 \\
\hline 4 & 6 & 34 & 3 & 18 \\
\hline $1-1973$ & 6 & 34 & 3 & 18 \\
\hline 2 & 6 & 34 & 3 & 18 \\
\hline 3 & 6 & 34 & 3 & 18 \\
\hline 4 & 7 & 39 & 3 & 18 \\
\hline $1-1974$ & 7 & 39 & 3 & 18 \\
\hline 2 & 8 & 44 & 3 & 18 \\
\hline 3 & 8 & 44 & 3 & 18 \\
\hline 4 & 7 & 39 & 3 & 18 \\
\hline \begin{tabular}{|l|}
$1-1976$ \\
\end{tabular} & 7 & 39 & 3 & 18 \\
\hline 2 & 8 & 44 & 3 & 18 \\
\hline 3 & 8 & 44 & 3 & 18 \\
\hline 4 & 8 & 44 & 3 & 18 \\
\hline 1.1976 & 8 & 44 & 3 & 18 \\
\hline 2 & 8 & 44 & 3 & 18 \\
\hline 3 & 8 & 44 & 3 & 18 \\
\hline 4 & 8 & 44 & 3 & 18 \\
\hline $1-1977$ & 8 & 44 & 3 & 18 \\
\hline 2 & 8 & 44 & 3 & 18 \\
\hline 3 & 8 & 44 & 3 & 18 \\
\hline 4 & 8 & 44 & 4 & 23 \\
\hline $1-1978$ & 8 & 44 & 4 & 23 \\
\hline 2 & 8 & 44 & 4 & 23 \\
\hline 3 & 8 & 44 & 4 & 23 \\
\hline 4 & 8 & 44 & 4 & 23 \\
\hline 1.1979 & 8 & 44 & 4 & 23 \\
\hline 2 & 8 & 44 & 4 & 23 \\
\hline 3 & 8 & 44 & 4 & 23 \\
\hline 4 & 8 & 44 & 4 & 23 \\
\hline $1-1980$ & 8 & 44 & 4 & 23 \\
\hline 2 & 8 & 44 & 4 & 23 \\
\hline 3 & 9 & 49 & 5 & 29 \\
\hline 4 & 9 & 49 & 5 & 29 \\
\hline 1-1981 & 9 & 49 & 5 & 29 \\
\hline 2 & 9 & 49 & 5 & 29 \\
\hline
\end{tabular}


WHC-SD-WM-ER-313, Rev.1

241-C-203 LEVEL HISTORY

\begin{tabular}{|c|c|c|c|c|}
\hline Year & Total & Total & Solids & Solids \\
\hline & (K gal) & (in) & i (K gal) & (in) \\
\hline & & & $i$ & \\
\hline 3 & 9 & 49 & 5 & 29 \\
\hline 4 & 9 & 49 & 5 & 29 \\
\hline $1-1982$ & 5 & 29 & 5 & 29 \\
\hline 2 & 5 & 29 & 4 & 23 \\
\hline 3 & 5 & 29 & 5 & 29 \\
\hline 4 & 5 & 29 & 5 & 29 \\
\hline $1-1983$ & 5 & 29 & 5 & 29 \\
\hline 2 & 5 & 29 & 5 & 29 \\
\hline 3 & $\overline{5}$ & 29 & 5 & 29 \\
\hline 4 & 5 & 29 & 5 & 29 \\
\hline $1-1984$ & 5 & 29 & 4 & 23 \\
\hline 2 & 5 & 29 & 5 & 29 \\
\hline 3 & 5 & 29 & 5 & 29 \\
\hline 4 & 5 & 29 & 5 & 29 \\
\hline $1-1985$ & 5 & 29 & 5 & 29 \\
\hline 2 & 5 & 29 & 5 & 29 \\
\hline 3 & 5 & 29 & 5 & 29 \\
\hline 4 & 5 & 29 & 5 & 29 \\
\hline $1-1986$ & 5 & 29 & 5 & 29 \\
\hline 2 & 5 & 29 & 5 & 29 \\
\hline 3 & 5 & 29 & 5 & 29 \\
\hline 4 & 5 & 29 & 5 & 29 \\
\hline $1-1987$ & 5 & 29 & 5 & 29 \\
\hline 2 & 5 & 29 & 5 & 29 \\
\hline 3 & 5 & 29 & 5 & 29 \\
\hline 4 & 5 & 29 & 5 & 29 \\
\hline $1-1988$ & 5 & 29 & 5 & 29 \\
\hline 2 & 5 & 29 & 5 & 29 \\
\hline 3 & 5 & 29 & 5 & 29 \\
\hline 4 & 5 & 29 & 5 & 29 \\
\hline $1-1989$ & 5 & 29 & 5 & 29 \\
\hline 2 & 5 & 29 & 5 & 29 \\
\hline 3 & 5 & 29 & 5 & 29 \\
\hline 4 & 5 & 29 & 5 & 29 \\
\hline $1-1990$ & 5 & 29 & 5 & 29 \\
\hline 2 & 5 & 29 & 5 & 29 \\
\hline 3 & 5 & 29 & 5 & 29 \\
\hline 4 & 5 & 29 & 5 & 29 \\
\hline $4-1991$ & 5 & 29 & 5 & 29 \\
\hline 2 & 5 & 29 & 5 & 29 \\
\hline 3 & 5 & 29 & 5 & 29 \\
\hline 4 & 5 & 29 & 5 & 29 \\
\hline $1-1992$ & 5 & 29 & 5 & 29 \\
\hline 2 & 5 & 29 & 5 & 29 \\
\hline 3 & 5 & 29 & 5 & 29 \\
\hline 4 & 5 & 29 & 5 & 29 \\
\hline
\end{tabular}


241-C-203 LEVEL HISTORY

\begin{tabular}{|l|c|c|c|c|}
\hline Year & Total & Total & Solids & Solids \\
\hline & (K gal) & (in) & (K gal) & (in) \\
\hline & & & & \\
\hline $1-1993$ & 5 & 29 & 5 & 29 \\
\hline 2 & 5 & 29 & 5 & 29 \\
\hline 3 & 5 & 29 & 5 & 29 \\
\hline 4 & 5 & 29 & 5 & 29 \\
\hline $1-1994$ & 5 & 29 & 5 & 29 \\
\hline 2 & 5 & 29 & 5 & 29 \\
\hline 3 & 5 & 29 & 5 & 29 \\
\hline 4 & 5 & 29 & 5 & 29 \\
\hline $1-1995$ & 5 & 29 & 5 & 29 \\
\hline 2 & 5 & 29 & 5 & 29 \\
\hline 3 & 5 & 29 & 5 & 29 \\
\hline
\end{tabular}


WHC-SD-WM-ER-313. Rev.!

241-C-204 LEVEL HISTORY

\begin{tabular}{|c|c|c|c|c|}
\hline Year & Total & Total & Solids & Solids \\
\hline & (K gal) & (in) & (K gal) & (in) \\
\hline \multirow{2}{*}{\multicolumn{5}{|c|}{$1-1947$}} \\
\hline & & & & \\
\hline \multicolumn{5}{|l|}{2} \\
\hline \multicolumn{5}{|l|}{3} \\
\hline \multicolumn{5}{|l|}{4} \\
\hline 1-1948 & 55 & 284 & & \\
\hline 2 & 55 & 284 & & \\
\hline 3 & 55 & 284 & & \\
\hline 4 & 55 & 284 & & \\
\hline $1-1949$ & 55 & 284 & & \\
\hline 2 & 55 & 284 & & \\
\hline 3 & 55 & 284 & & \\
\hline 4 & 55 & 284 & & \\
\hline $1-1950$ & 55 & 284 & & \\
\hline 2 & 55 & 284 & & \\
\hline 3 & 55 & 284 & & \\
\hline 4 & 55 & 284 & & \\
\hline 1-1951 & 55 & 284 & & \\
\hline 2 & 55 & 284 & & \\
\hline 3 & 55 & 284 & & \\
\hline 4 & 55 & 284 & & \\
\hline $1-1952$ & 54.5 & 281 & & \\
\hline 2 & 54.5 & 281 & & \\
\hline 3 & 54.5 & 281 & & \\
\hline 4 & 54.5 & 281 & & \\
\hline $1-1953$ & 54.5 & 281 & & \\
\hline 2 & 54.5 & 281 & & \\
\hline 3 & 54.5 & 281 & & \\
\hline 4 & 15.2 & 81 & & \\
\hline $1-1954$ & 51 & 263 & 19 & 59 \\
\hline 2 & 51 & 263 & 11 & 59 \\
\hline 3 & 51 & 263 & 11 & 59 \\
\hline 4 & 47 & 243 & 11 & 59 \\
\hline $1-1955$ & 0 & 0 & 0 & 0 \\
\hline 2 & 0 & 0 & 0 & 0 \\
\hline 3 & 0 & 0 & 0 & 0 \\
\hline 4 & 5 & 29 & 0 & 0 \\
\hline $1-1956$ & 5 & 29 & 0 & 0 \\
\hline 2 & 34 & 176 & 0 & 0 \\
\hline 3 & 34 & 176 & 0 & 0 \\
\hline 4 & 34.5 & 179 & 0 & 0 \\
\hline $1-1957$ & 54 & 279 & & \\
\hline 2 & 33 & 171 & & \\
\hline 3 & 32 & 166 & & \\
\hline 4 & 32 & 166 & & \\
\hline 1.1958 & 34 & 176 & & \\
\hline 2 & 34 & 176 & & \\
\hline
\end{tabular}


WHC-SD-WM-ER-3 [3. Rev.1

241-C-204 LEVEL HISTORY

\begin{tabular}{|c|c|c|c|c|}
\hline Year & Total & Total & Solids & Solids \\
\hline & (K gal) & (in) & (K gal) & (in) \\
\hline & & & & \\
\hline 3 & 34 & 176 & & \\
\hline 4 & 34 & 176 & & \\
\hline $1-1959$ & 33 & 171 & & \\
\hline 2 & 33 & 171 & & \\
\hline 3 & 33 & 171 & & \\
\hline 4 & 36 & 187 & & \\
\hline $1-1960$ & 36 & 187 & & \\
\hline 2 & 36 & 187 & & \\
\hline 3 & 36 & 187 & & \\
\hline 4 & 36 & 187 & & \\
\hline \multicolumn{5}{|l|}{ 1-1961 } \\
\hline 2 & 37 & 192 & & \\
\hline \multicolumn{5}{|l|}{3} \\
\hline 4 & 37 & 192 & & \\
\hline \multicolumn{5}{|l|}{$1-1962$} \\
\hline 2 & 37 & 192 & 11 & 59 \\
\hline \multicolumn{5}{|l|}{3} \\
\hline 4 & 37 & 192 & 11 & 59 \\
\hline \multicolumn{5}{|l|}{$1-1963$} \\
\hline 2 & 37 & 192 & 11 & 59 \\
\hline \multicolumn{5}{|l|}{3} \\
\hline 4 & 36 & 187 & 11 & 59 \\
\hline \multicolumn{5}{|l|}{$1-1964$} \\
\hline 2 & 36 & 187 & 11 & 59 \\
\hline \multicolumn{5}{|l|}{3} \\
\hline 4 & 36 & 187 & 11 & 59 \\
\hline \multicolumn{5}{|l|}{$1-1965$} \\
\hline 2 & 36 & 187 & 11 & 59 \\
\hline 3 & 36 & 187 & 11 & 59 \\
\hline 4 & 36 & 187 & 11 & 59 \\
\hline $1-1966$ & 36 & 187 & 11 & 59 \\
\hline 2 & 36 & 187 & 11 & 59 \\
\hline 3 & 36 & 187 & 11 & 59 \\
\hline 4 & 36 & 187 & 11 & 59 \\
\hline $1-1967$ & 36 & 187 & 11 & 59 \\
\hline 2 & 36 & 187 & 11 & 59 \\
\hline 3 & 36 & 187 & 11 & 59 \\
\hline 4 & 57 & 294 & 11 & 59 \\
\hline $1-1968$ & 57 & 294 & 11 & 59 \\
\hline 2 & 57 & 294 & 11 & 59 \\
\hline 3 & 57 & 294 & 11 & 59 \\
\hline 4 & 57 & 294 & 11 & 59 \\
\hline $1-1969$ & 57 & 294 & 11 & 59 \\
\hline 2 & 57 & 294 & 11 & 59 \\
\hline 3 & 57 & 294 & 11 & 59 \\
\hline 4 & 57 & 294 & 11 & 59 \\
\hline
\end{tabular}


WHC-SL-WM-ER-313. Rev.1

241-C-204 LEVEL HISTORY

\begin{tabular}{|c|c|c|c|c|}
\hline Year & Total & Total & Solids & Solids \\
\hline & (K gal) & (in) & (K gal) & (in) \\
\hline & & & & \\
\hline $1-1970$ & 57 & 294 & 2 & 13 \\
\hline 2 & 43 & 222 & 2 & 13 \\
\hline 3 & 42 & 217 & 2 & 13 \\
\hline 4 & 42 & 217 & 2 & 13 \\
\hline $1-1971$ & 42 & 217 & 2 & 13 \\
\hline 2 & 42 & 217 & 2 & 13 \\
\hline 3 & 42 & 217 & 2 & 13 \\
\hline 4 & 42 & 217 & 2 & 13 \\
\hline 1-1972 & 42 & 217 & 1 & 8 \\
\hline 2 & 42 & 217 & 1 & 8 \\
\hline 3 & 42 & 217 & 1 & 8 \\
\hline 4 & 42 & 297 & 1 & 8 \\
\hline $1-1973$ & 42 & $\bar{F}$ & 1 & 8 \\
\hline 2 & 42 & -7 & 1 & 8 \\
\hline 3 & 42 & $2^{\circ}$ & 1 & 8 \\
\hline 4 & 44 & 227 & 1 & 8 \\
\hline $1-1974$ & 44 & 227 & 1 & 8 \\
\hline 2 & 44 & 227 & 1 & 8 \\
\hline 3 & 44 & 227 & 1 & 8 \\
\hline 4 & 44 & 227 & 0 & 0 \\
\hline $1-1975$ & 44 & 227 & 0 & 0 \\
\hline 2 & 44 & 227 & 0 & 0 \\
\hline 3 & 44 & 227 & 0 & 0 \\
\hline 4 & 44 & 227 & 0 & 0 \\
\hline $1-1976$ & 44 & 227 & 0 & 0 \\
\hline 2 & 44 & 227 & 0 & 0 \\
\hline 3 & 44 & 227 & 0 & 0 \\
\hline 4 & 44 & 227 & 0 & 0 \\
\hline $1-1977$ & 44 & 227 & 0 & 0 \\
\hline 2 & 44 & 227 & 0 & 0 \\
\hline 3 & 3 & 18 & 0 & 0 \\
\hline 4 & 3 & 18 & 0 & 0 \\
\hline \begin{tabular}{|l|l|}
1978 \\
\end{tabular} & 3 & 18 & 0 & 0 \\
\hline 2 & 3 & 18 & 0 & 0 \\
\hline 3 & 3 & 18 & 0 & 0 \\
\hline 4 & 3 & 18 & 0 & 0 \\
\hline \begin{tabular}{|l|}
$1-1979$ \\
\end{tabular} & 3 & 18 & 0 & 0 \\
\hline 2 & 3 & 18 & 0 & 0 \\
\hline 3 & 3 & 18 & 0 & 0 \\
\hline 4 & 3 & 18 & 0 & 0 \\
\hline $1-1980$ & 3 & 18 & 0 & 0 \\
\hline 2 & 3 & 18 & 0 & 0 \\
\hline 3 & 3 & 18 & 1 & 8 \\
\hline 4 & 3 & 18 & 1 & 8 \\
\hline $1-1981$ & 3 & 18 & 1 & 8 \\
\hline 2 & 3 & 18 & 1 & 8 \\
\hline
\end{tabular}


WHC-SD-WM-ER-313. Rev.1

241-C-204 LEVEL HISTORY

\begin{tabular}{|c|c|c|c|c|}
\hline Year & Total & Total & Solids & Solids \\
\hline & (K gal) & (in) & (K gal) & (in) \\
\hline & & & & \\
\hline$\frac{3}{4}$ & $\frac{3}{3}$ & $\frac{18}{18}$ & $\frac{1}{1}$ & 8 \\
\hline$\frac{4}{1-1982}$ & 3 & 18 & 1 & 8 \\
\hline $1-1982$ & 3 & 18 & 1 & 8 \\
\hline 2 & 3 & 18 & 3 & 18 \\
\hline 3 & 3 & 18 & 3 & 18 \\
\hline 4 & 3 & 18 & 3 & 18 \\
\hline $1-1983$ & 3 & 18 & 3 & 18 \\
\hline 2 & 3 & 18 & 3 & 18 \\
\hline 3 & 3 & 18 & 3 & 18 \\
\hline 4 & 3 & 18 & 3 & 18 \\
\hline $1-1984$ & 3 & 18 & 3 & 18 \\
\hline 2 & 3 & 18 & 3 & 18 \\
\hline 3 & 3 & 18 & 3 & 18 \\
\hline 4 & 3 & 18 & 3 & 18 \\
\hline $1-1985$ & 3 & 18 & 3 & 18 \\
\hline 2 & 3 & 18 & 3 & 18 \\
\hline 3 & 3 & 18 & 3 & 18 \\
\hline 4 & 3 & 18 & 3 & 18 \\
\hline $1-1986$ & 3 & 18 & 3 & 18 \\
\hline 2 & 3 & 18 & 3 & 18 \\
\hline 3 & 3 & 18 & 3 & 18 \\
\hline 4 & 3 & 18 & 3 & 18 \\
\hline $1-1987$ & 3 & 18 & 3 & 18 \\
\hline 2 & 3 & 18 & 3 & 18 \\
\hline 3 & 3 & 18 & 3 & 18 \\
\hline 4 & 3 & 18 & 3 & 18 \\
\hline $1-1988$ & 3 & 18 & 3 & 18 \\
\hline 2 & 3 & 18 & 3 & 18 \\
\hline 3 & 3 & 18 & 3 & 18 \\
\hline 4 & 3 & 18 & 3 & 18 \\
\hline 1-1989 & 3 & 18 & 3 & 18 \\
\hline 2 & 3 & 18 & 3 & 18 \\
\hline 3 & 3 & 18 & 3 & 18 \\
\hline 4 & 3 & 18 & 3 & 18 \\
\hline $1-1990$ & 3 & 18 & 3 & 18 \\
\hline 2 & 3 & 18 & 3 & 18 \\
\hline 3 & 3 & 18 & 3 & 18 \\
\hline 4 & 3 & 18 & 3 & 18 \\
\hline 1.1991 & 3 & 18 & 3 & 18 \\
\hline 2 & 3 & 18 & 3 & 18 \\
\hline 3 & 3 & 18 & 3 & 18 \\
\hline 4 & 3 & 18 & 3 & 18 \\
\hline 1-1992 & 3 & 18 & 3 & 18 \\
\hline 2 & 3 & 18 & 3 & 18 \\
\hline 3 & 3 & 18 & 3 & 18 \\
\hline 4 & 3 & 18 & 3 & 18 \\
\hline
\end{tabular}


241-C-204 LEVEL HISTORY

\begin{tabular}{|l|c|c|c|c|}
\hline Year & ial & Total & Solids & Solids \\
\hline & (K gal) & (in) & (K gal) & (in) \\
\hline & & & & \\
\hline $1-1993$ & 3 & 18 & 3 & 18 \\
\hline 2 & 3 & 18 & 3 & 18 \\
\hline 3 & 3 & 18 & 3 & 18 \\
\hline 4 & 3 & 18 & 3 & 18 \\
\hline $1-1994$ & 3 & 18 & 3 & 18 \\
\hline 2 & 3 & 18 & 3 & 18 \\
\hline 3 & 3 & 18 & 3 & 18 \\
\hline 4 & 3 & 18 & 3 & 18 \\
\hline $1-1995$ & 3 & 18 & 3 & 18 \\
\hline 2 & 3 & 18 & 3 & 18 \\
\hline 3 & 3 & 18 & 3 & 18 \\
\hline
\end{tabular}




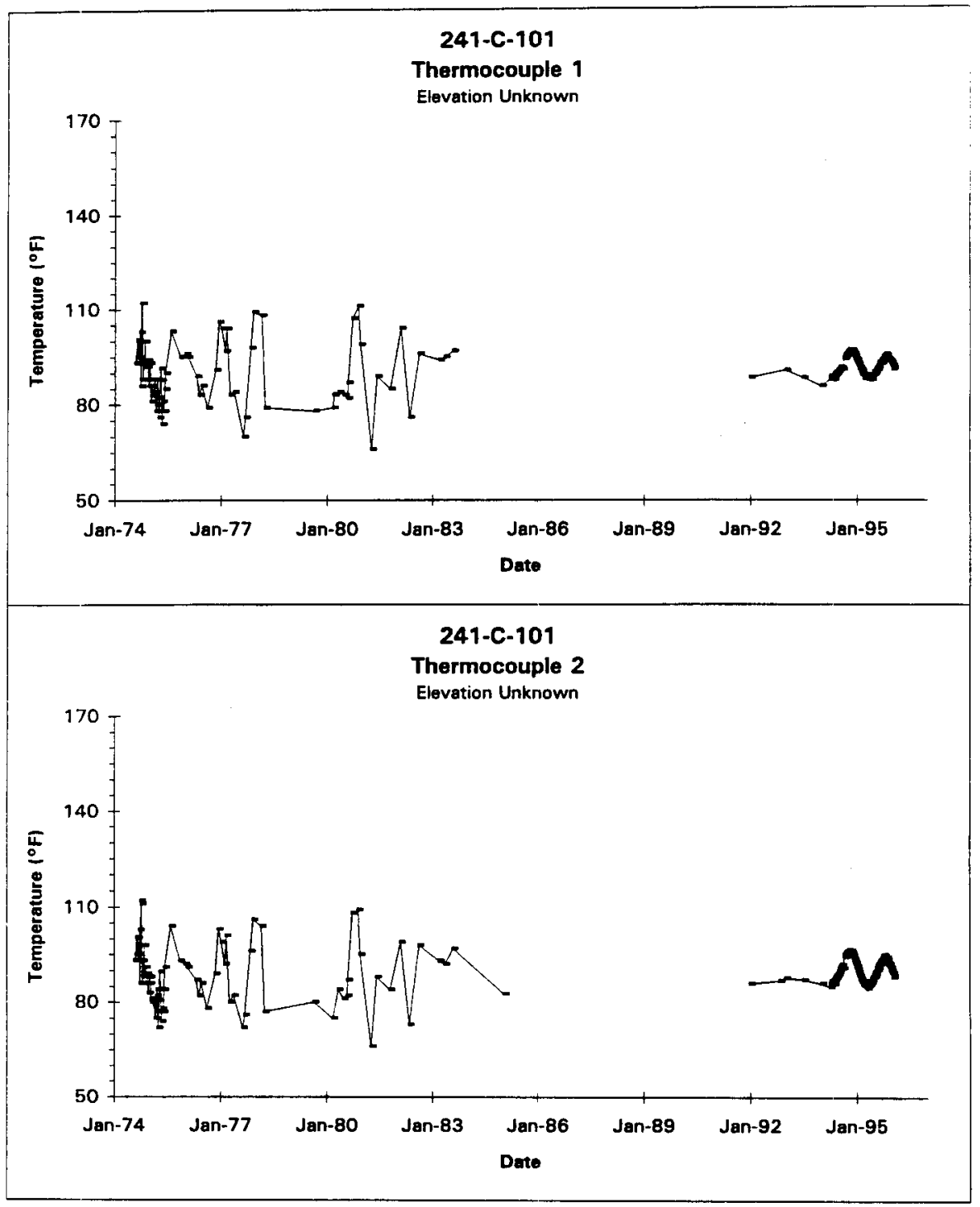

Data obtained from WHC Surveillance Analysis Computer System (SACS), Jan 9, 1996.

D-1 


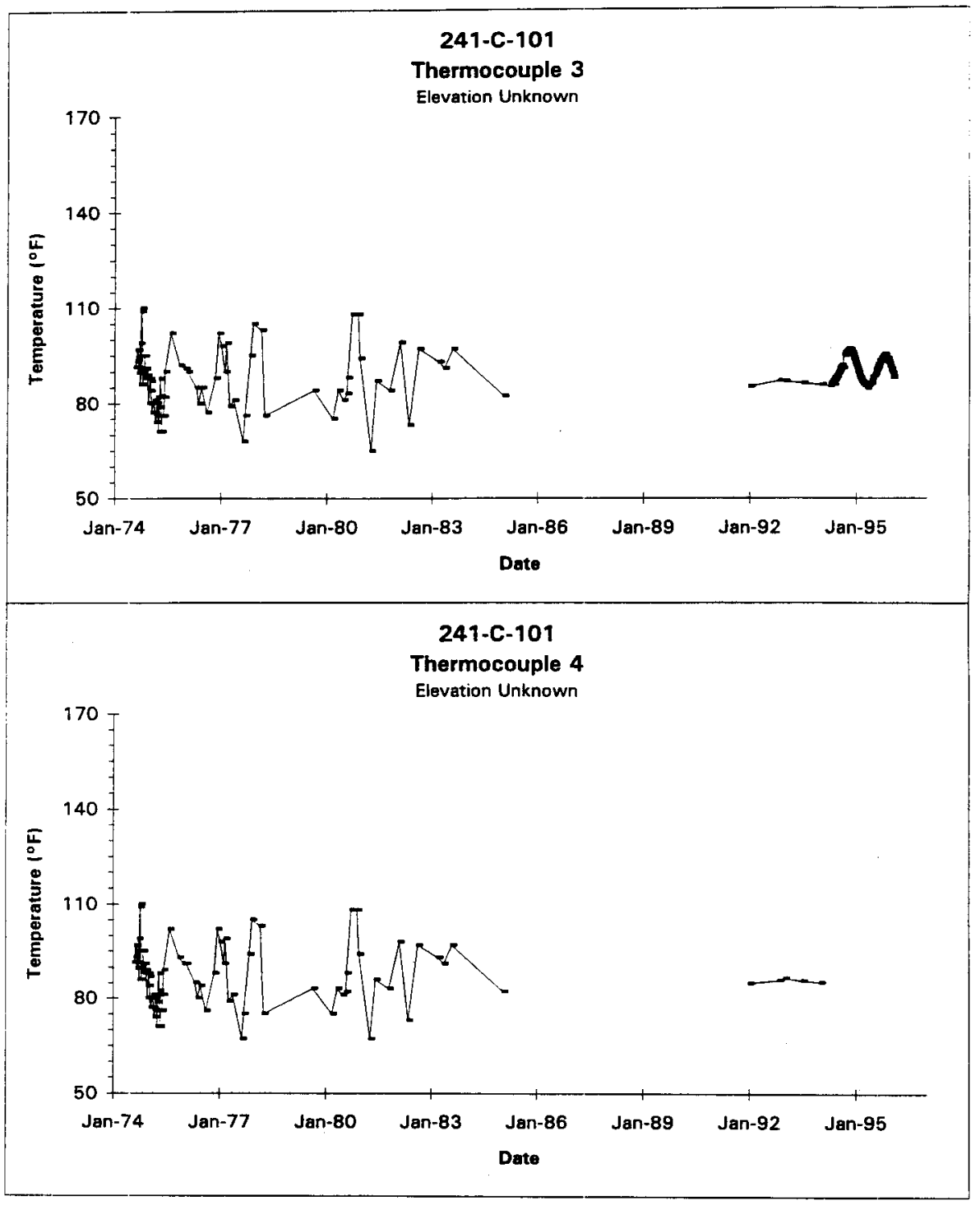

Data obtained from WHC Surveillance Analysis Computer System (SACS), Jan 9, 1996.

D-2 


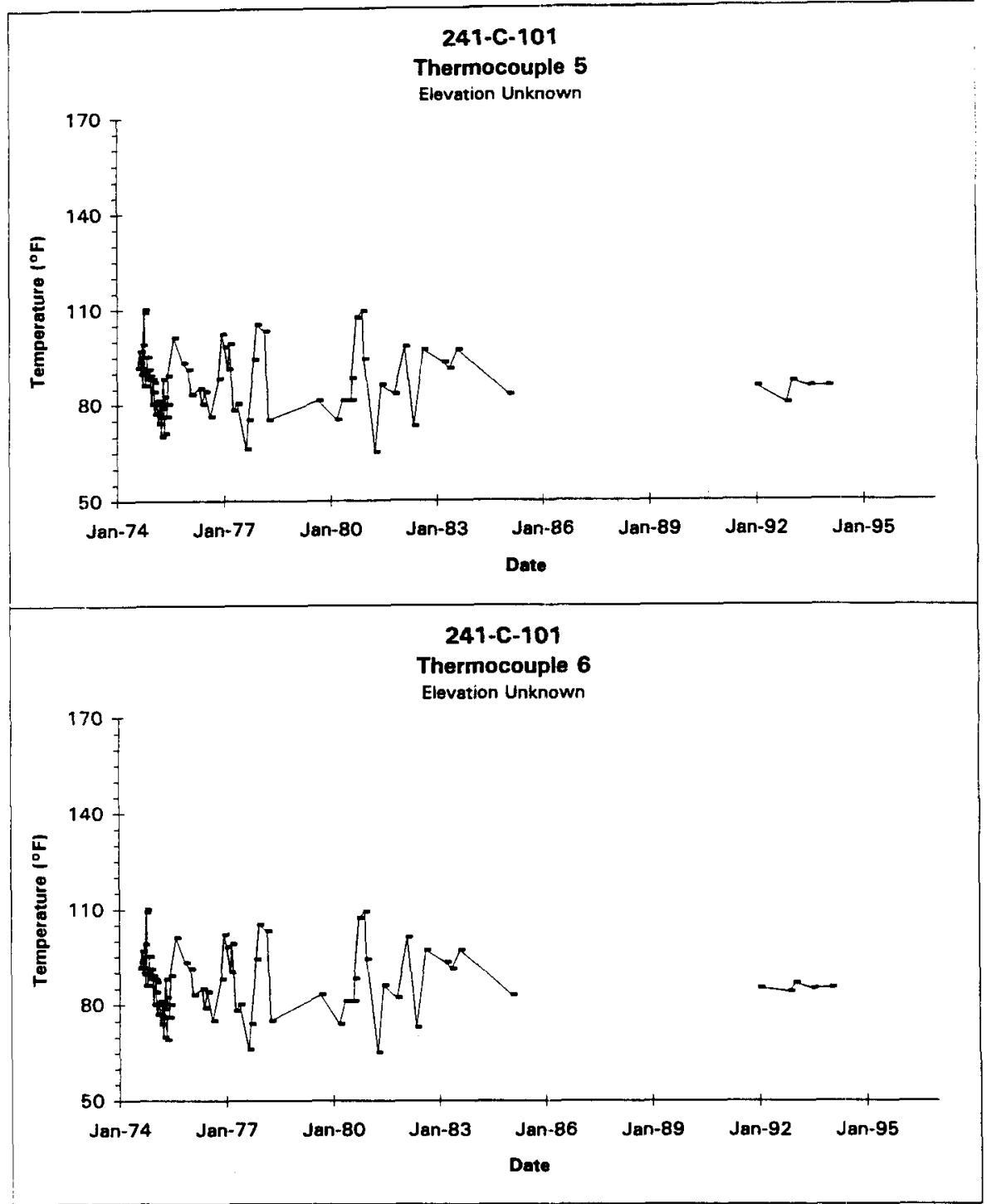

Data obtained from WHC Surveillance Analysis Computer System (SACS), Jan 9, 1996.

D-3 


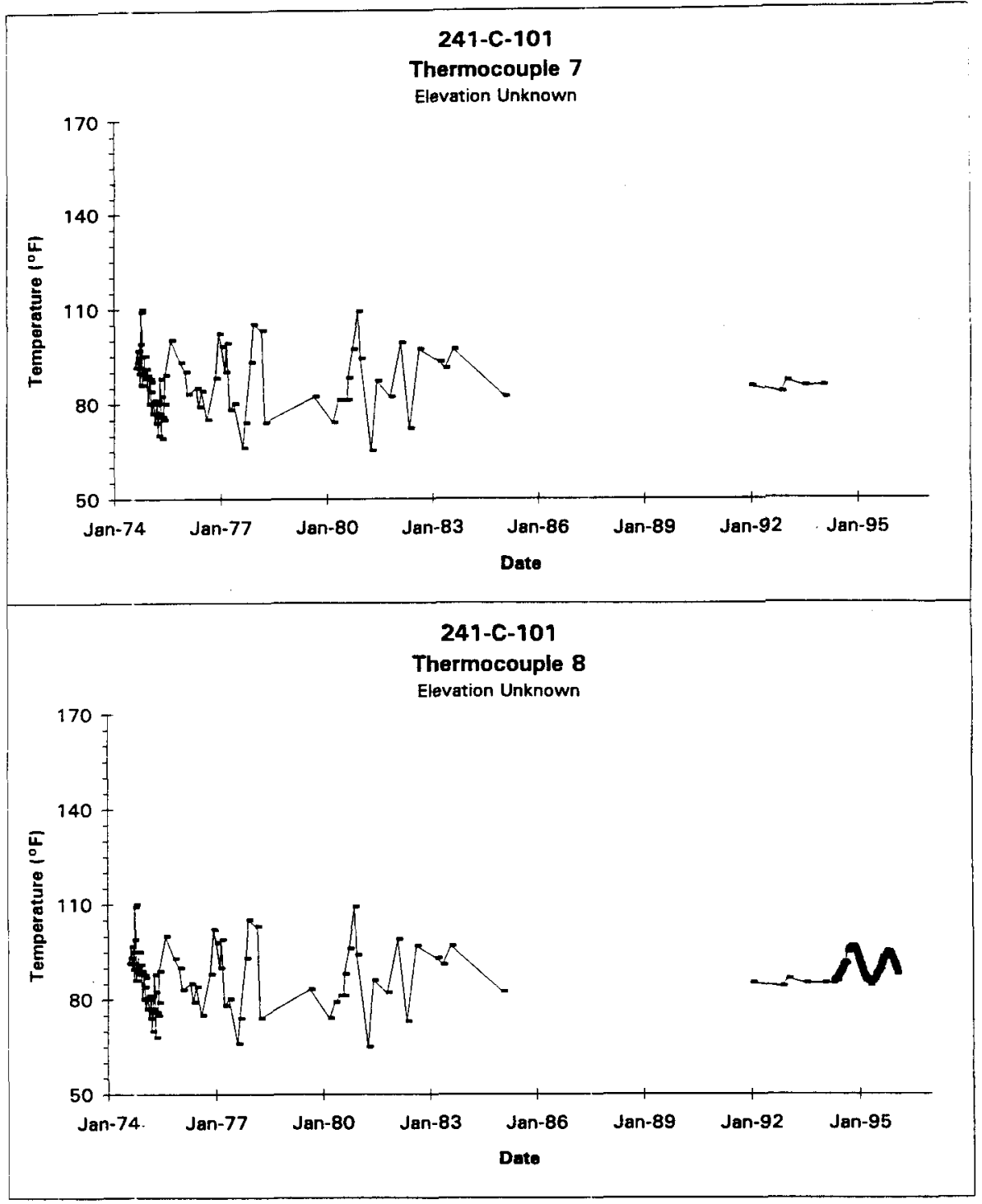

Data obtained from WHC Surveillance Analysis Computer System (SACS), Jan 9, 1996.

D-4 


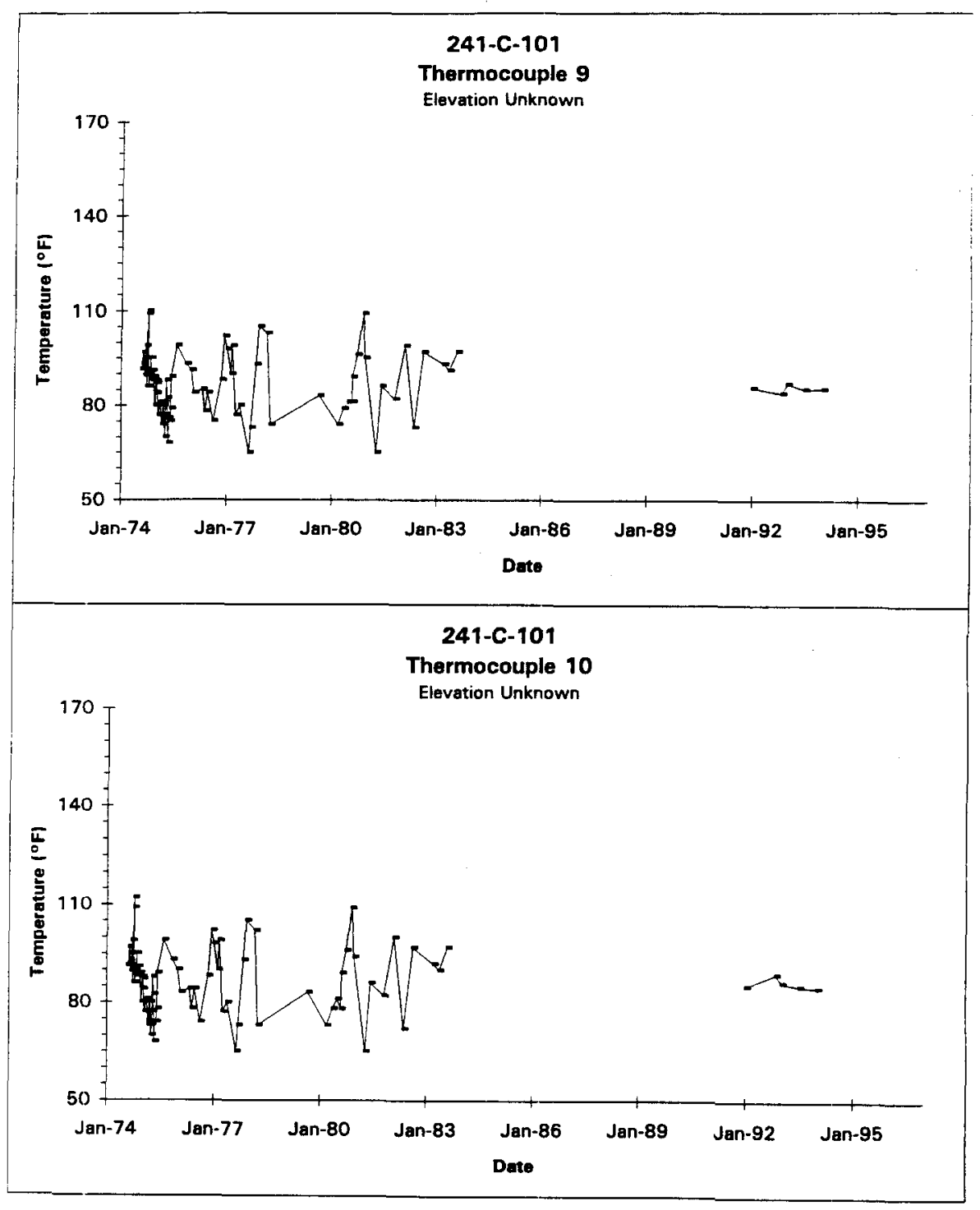

Data obtained from WHC Surveillance Analysis Computer System (SACS), Jan 9, 1996. D-5 


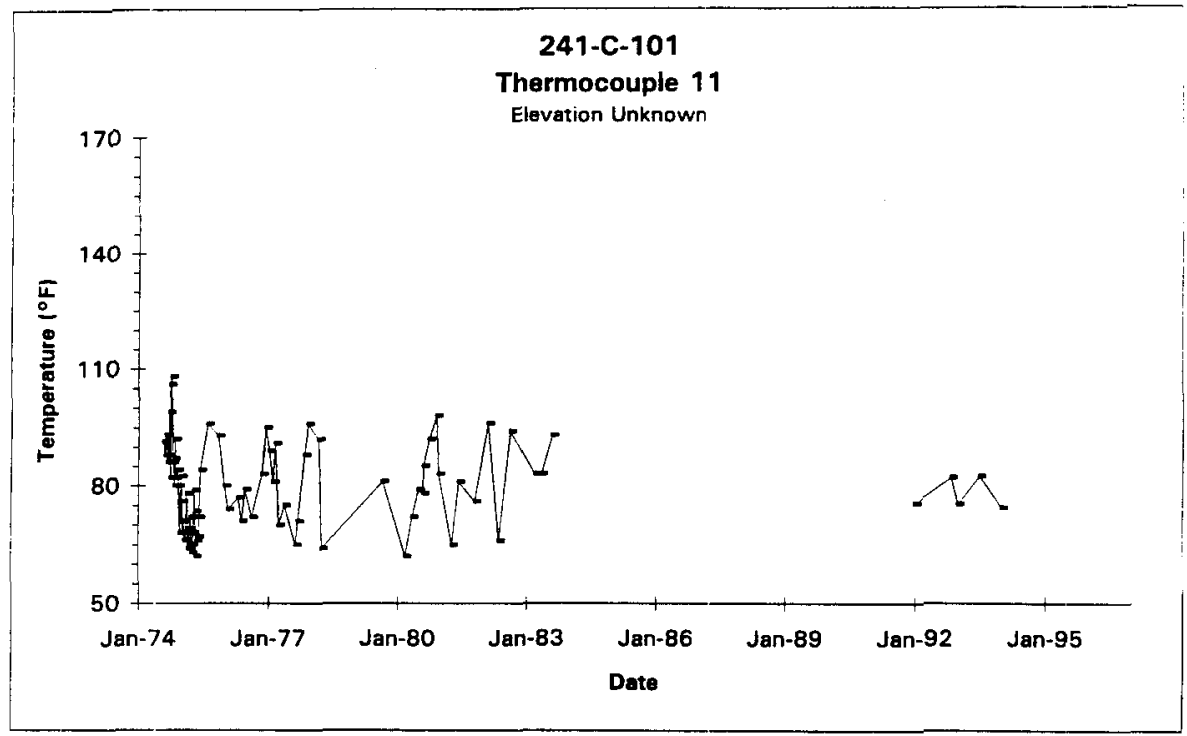

Data obtained from WHC Surveillance Analysis Computer System (SACS), Jan 9, 1996.

D-6 


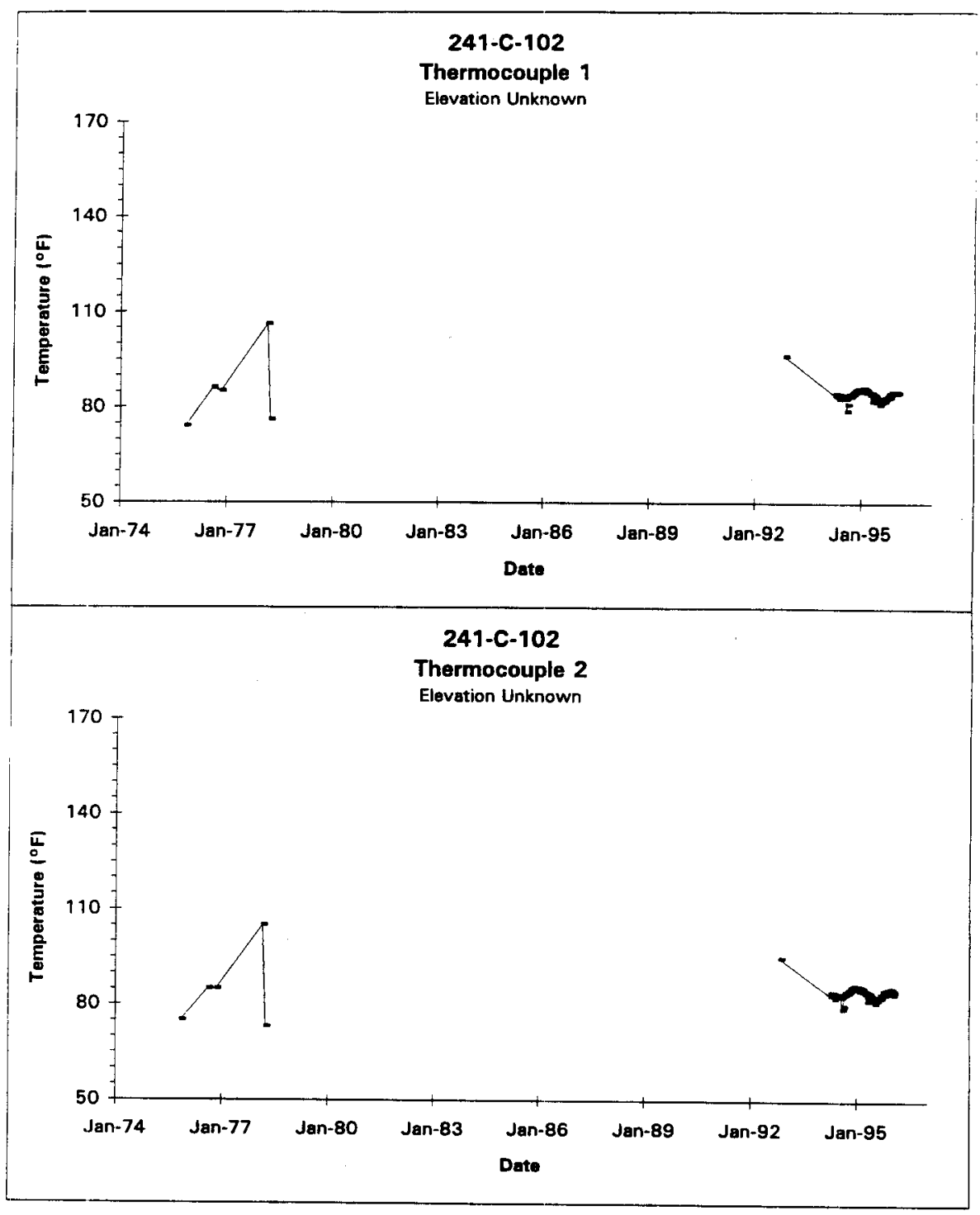

Data obtained from WHC Surveillance Analysis Computer System (SACS), Jan 9, 1996.

D-7 


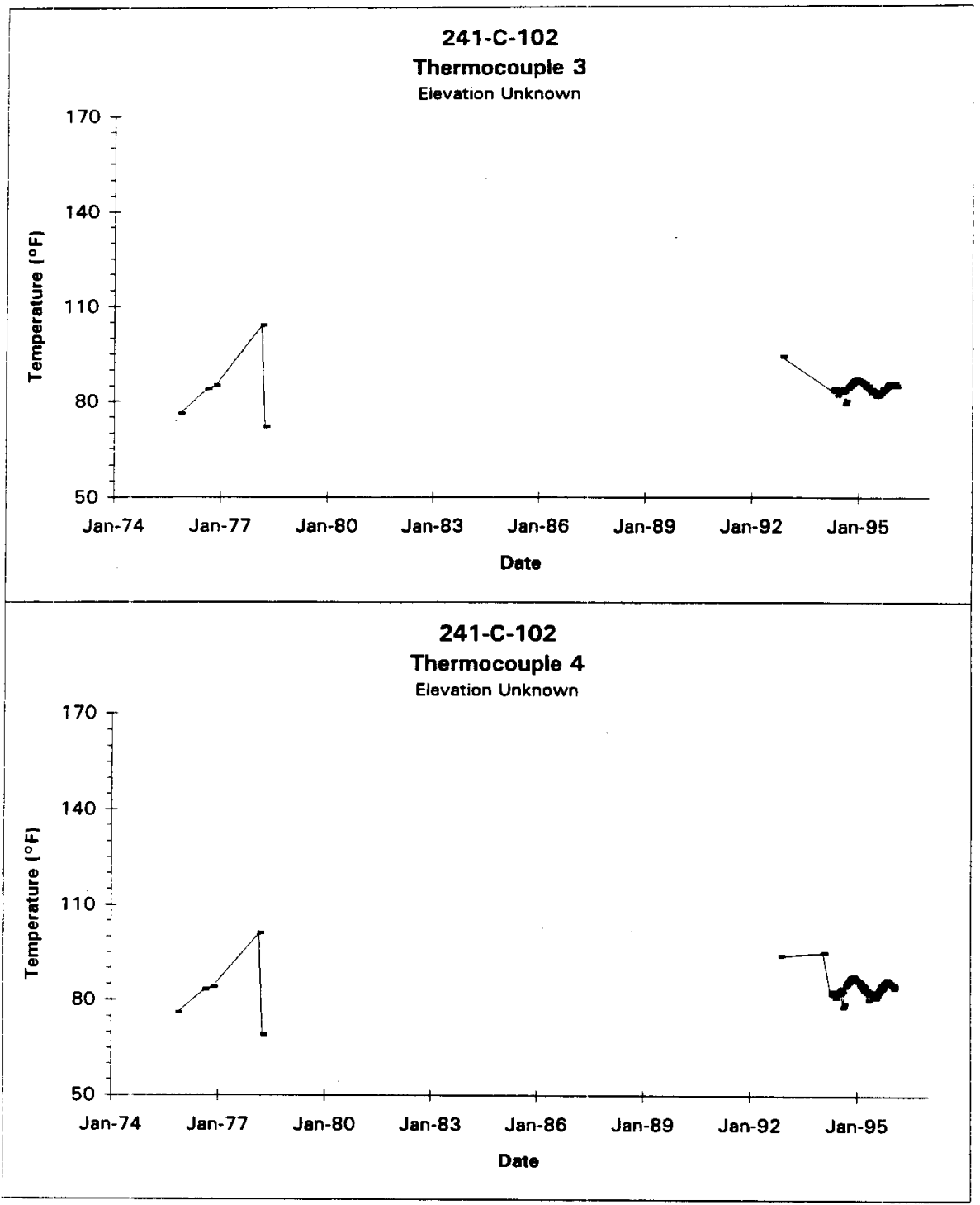

Data obtained from WHC Surveillance Analysis Computer System (SACS), Jan 9, 1996.

D-8 


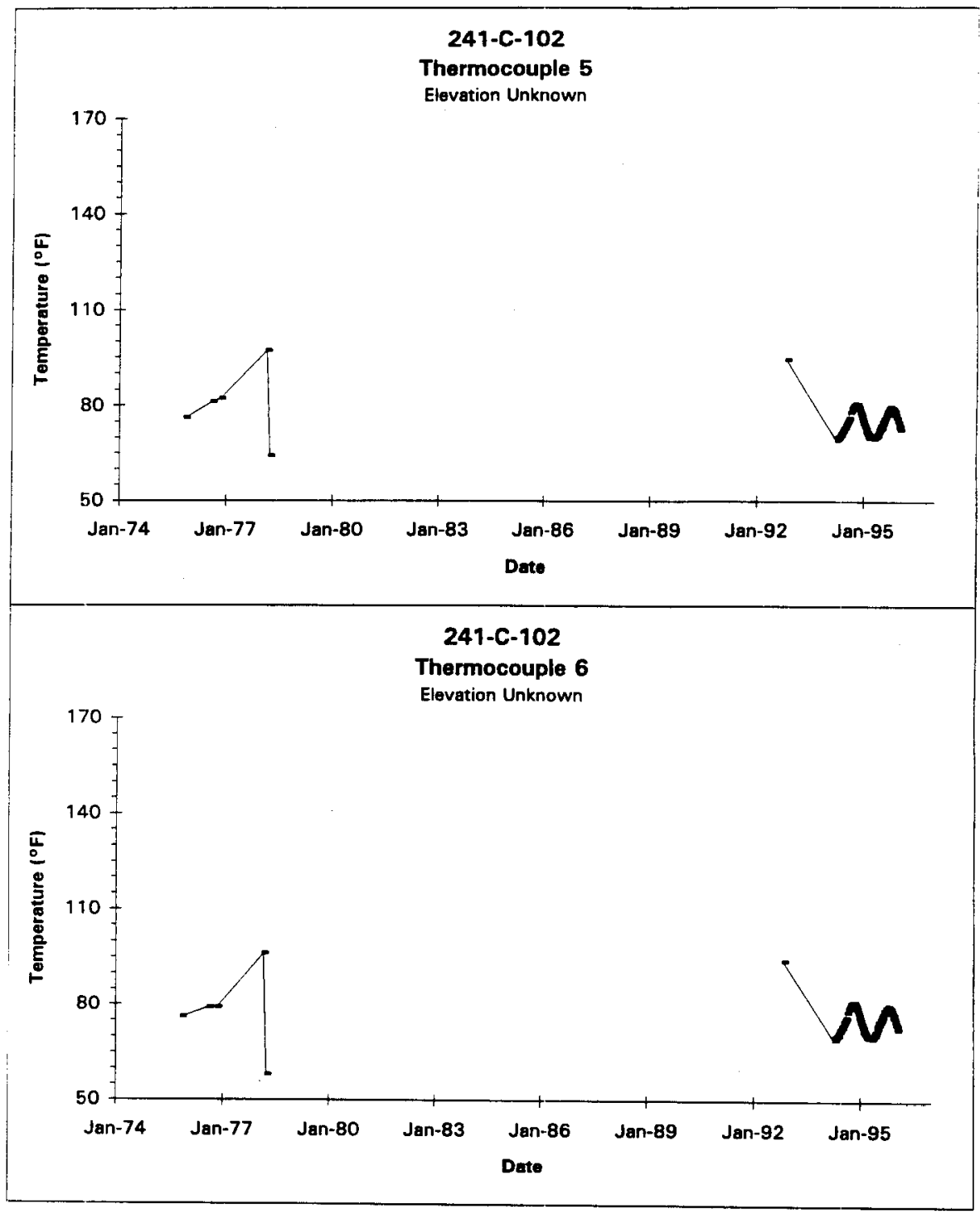

Data obtained from WHC Surveillance Analysis Computer Systern (SACS), Jan 9, 1996. 


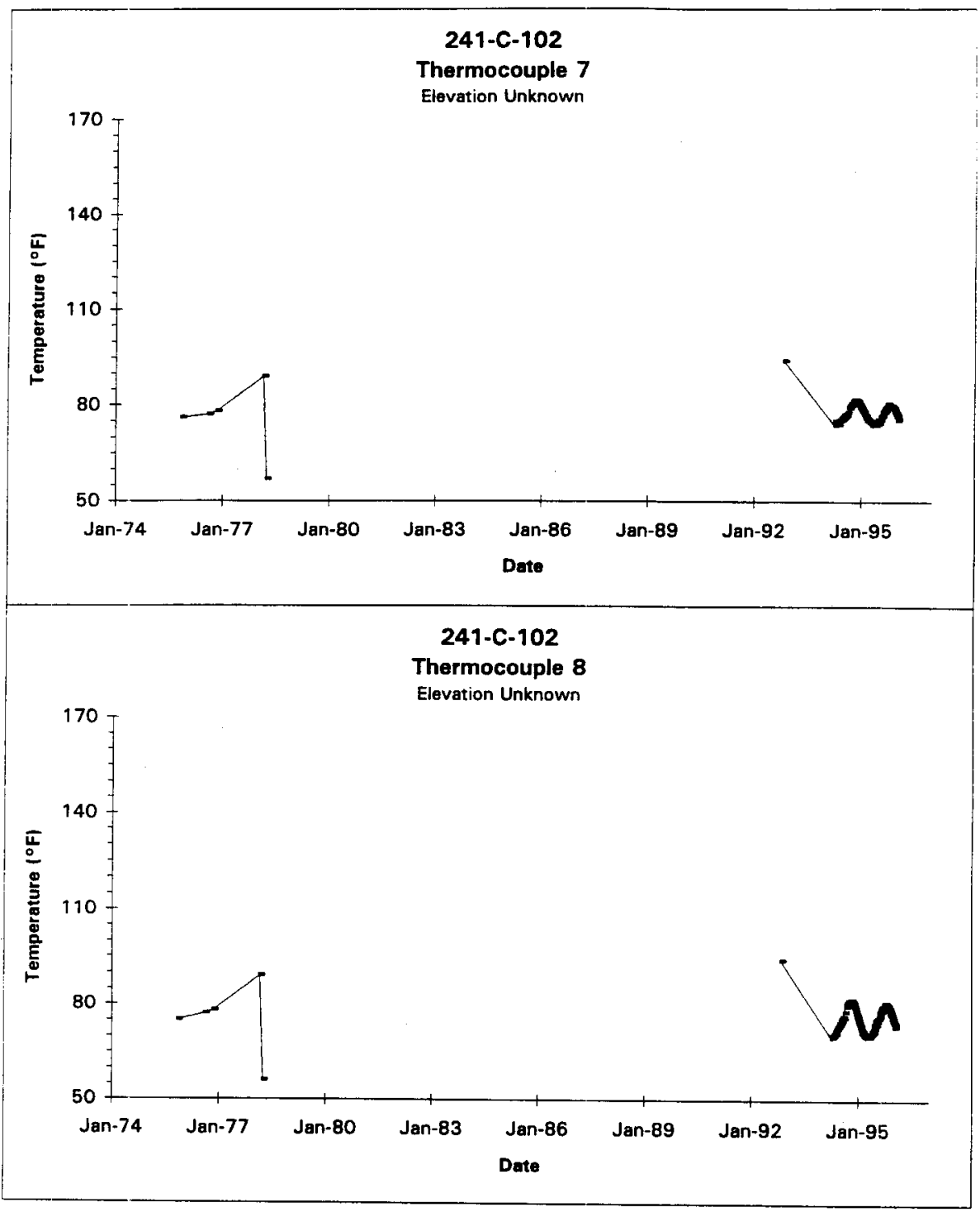

Data obtained from WHC Surveillance Analysis Computer System (SACS), Jan 9, 1996.

D-10 


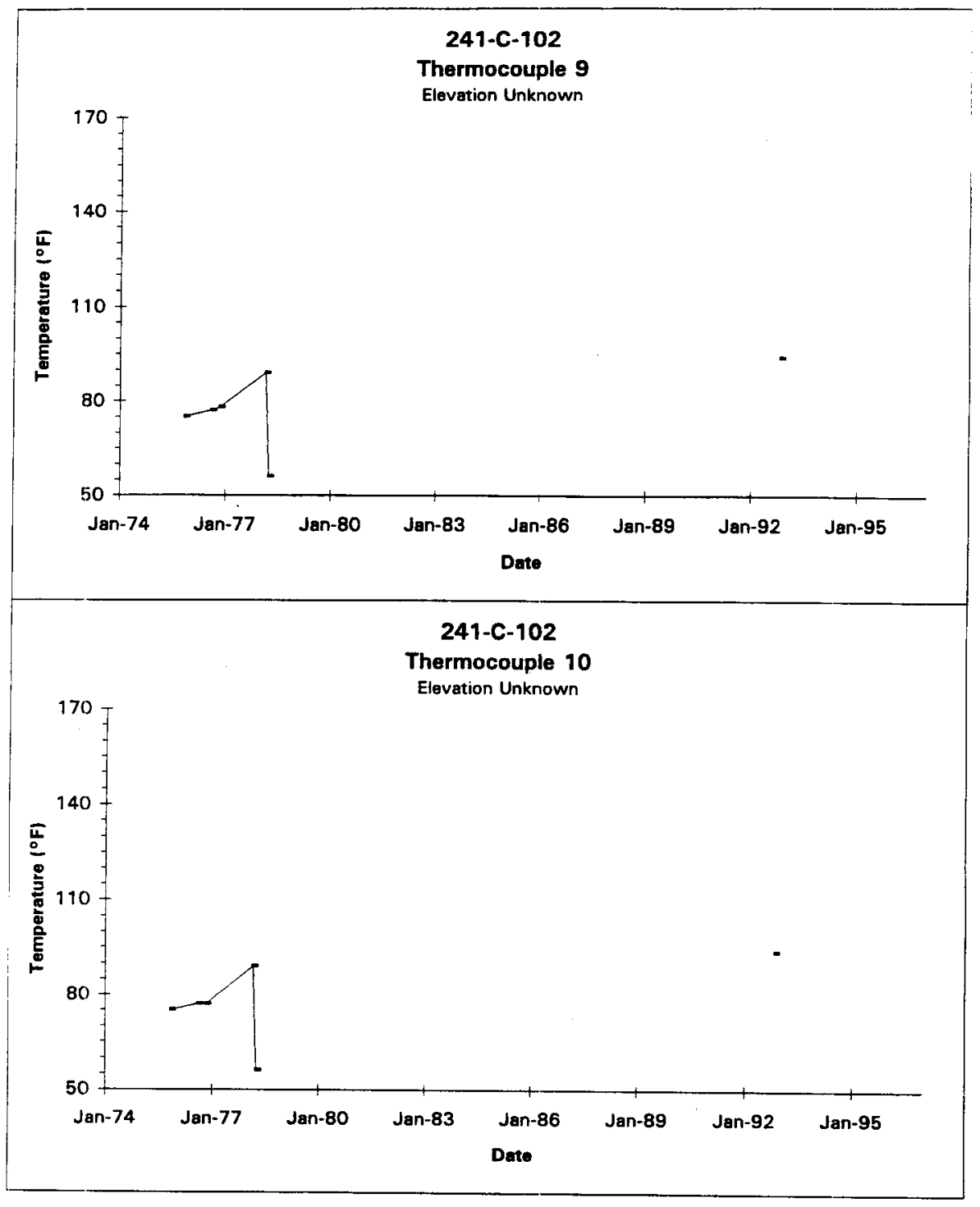

Data obtained from WHC Surveillance Analysis Computer System (SACS), Jan 9, 1996. D-11 


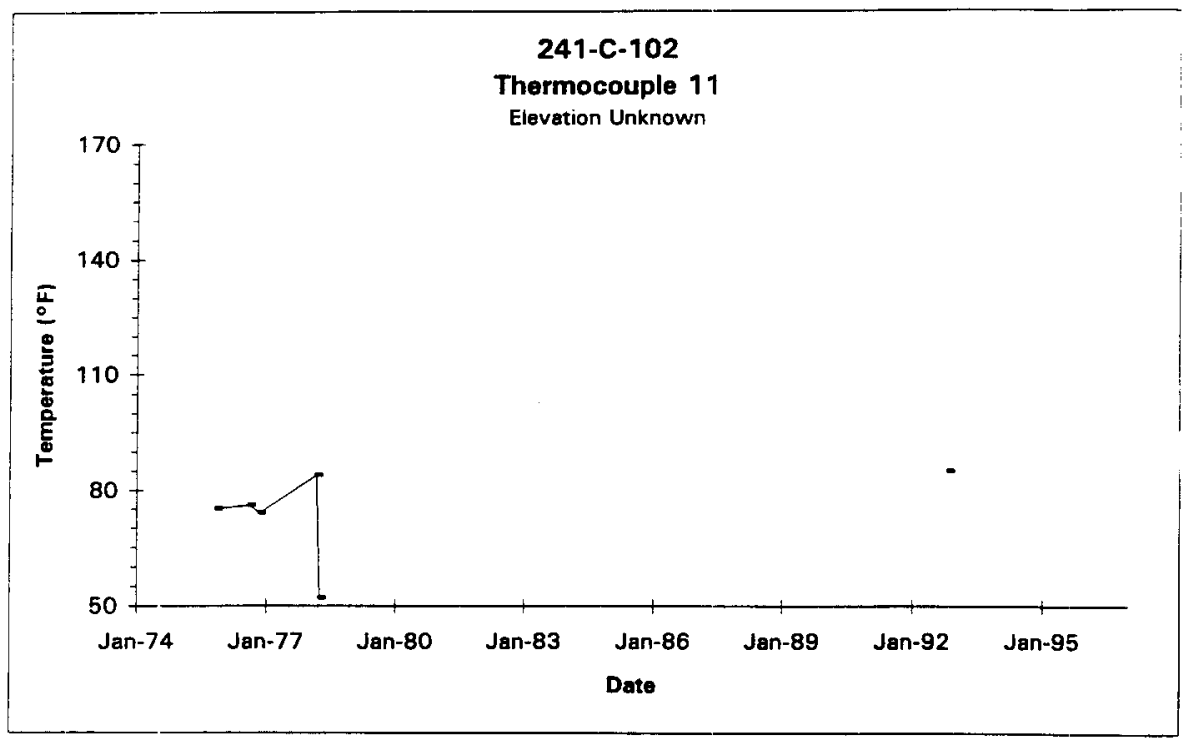

Data obtained from WHC Surveillance Analysis Computer System (SACS), Jan 9, 1996.

D-12 


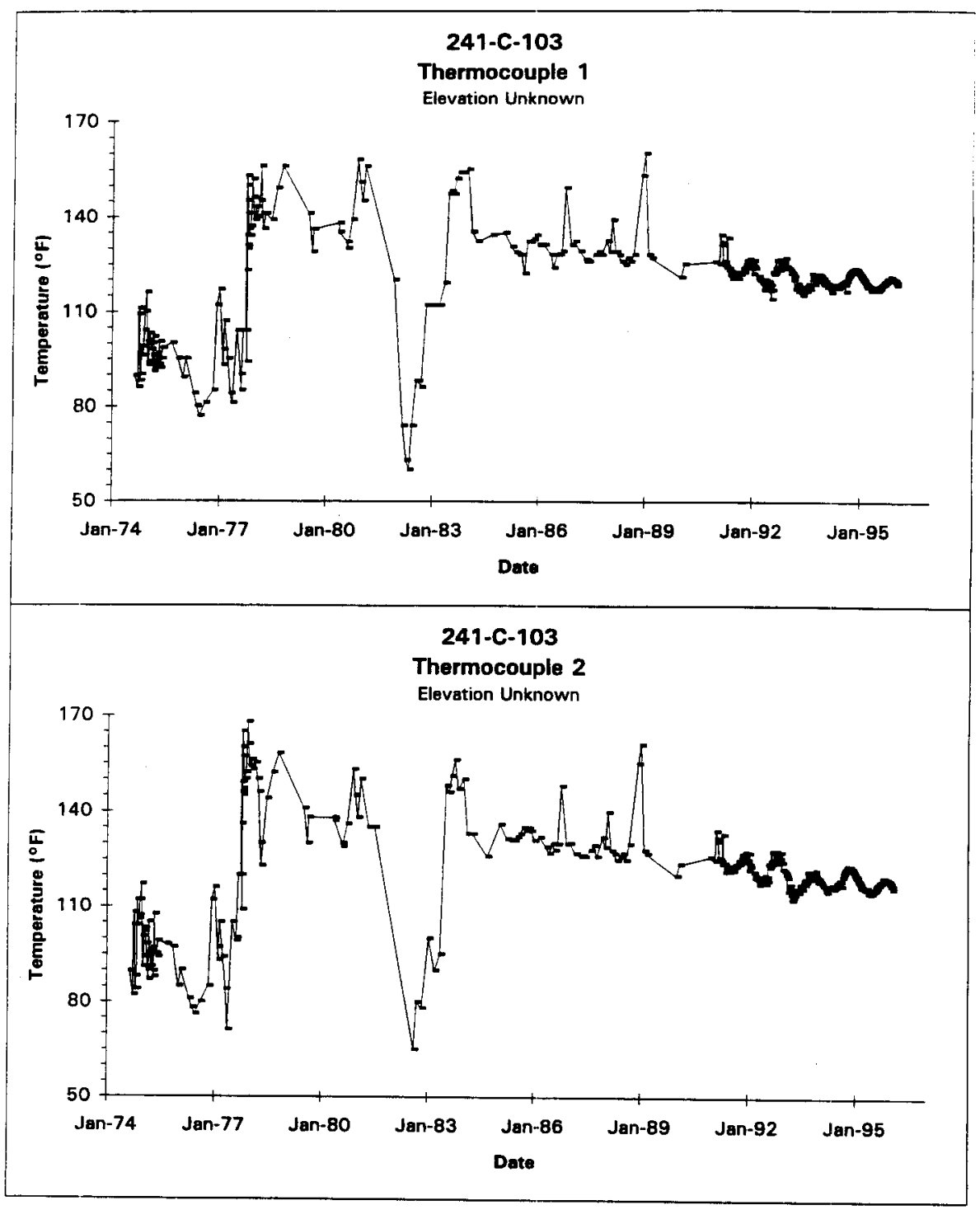

Data obtained from WHC Surveillance Analysis Computer System (SACS), Jan 9, 1996.

D-13 


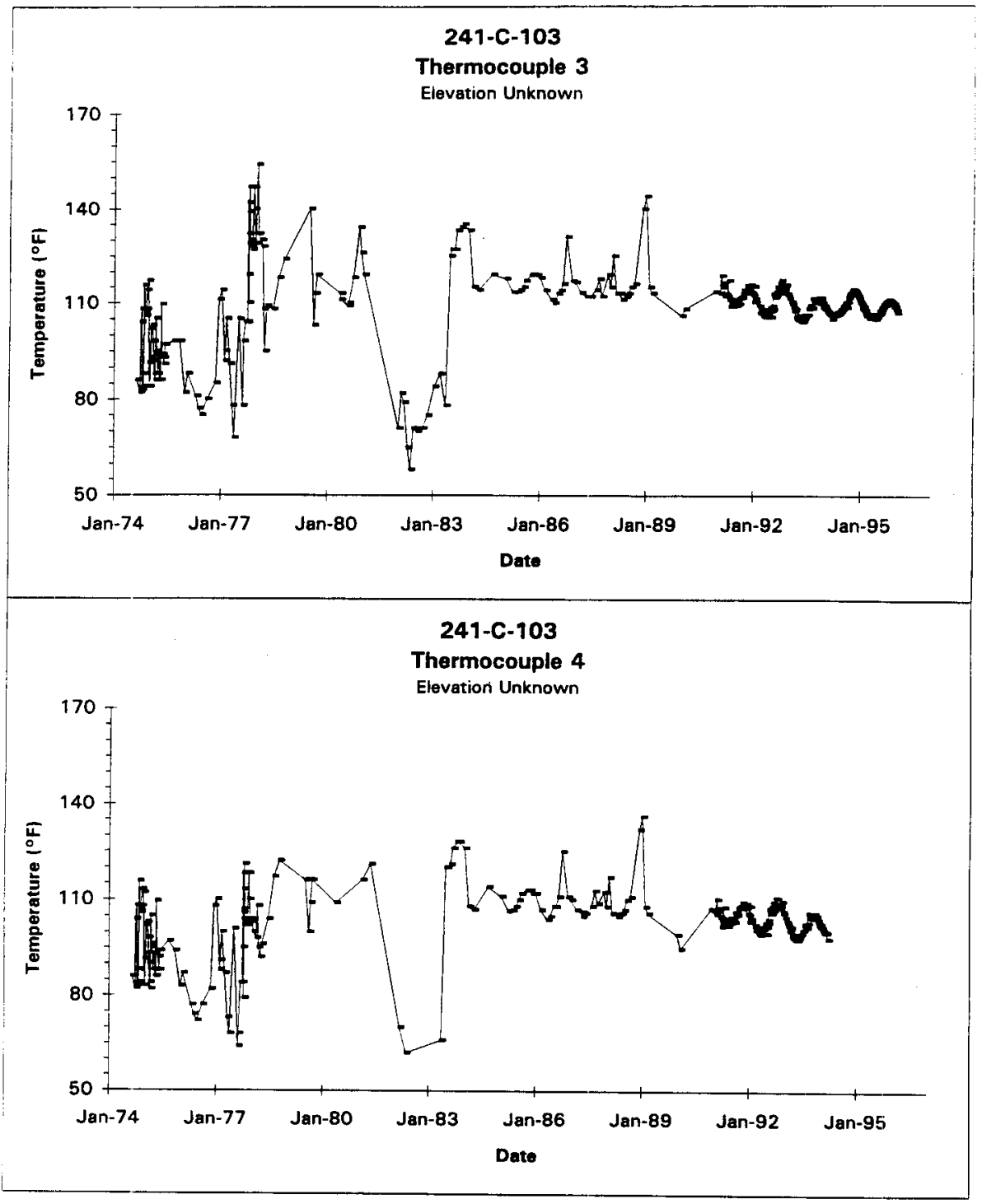

Data obtained from WHC Surveillance Analysis Computer System (SACS), Jan 9, 1996.

\section{D-14}




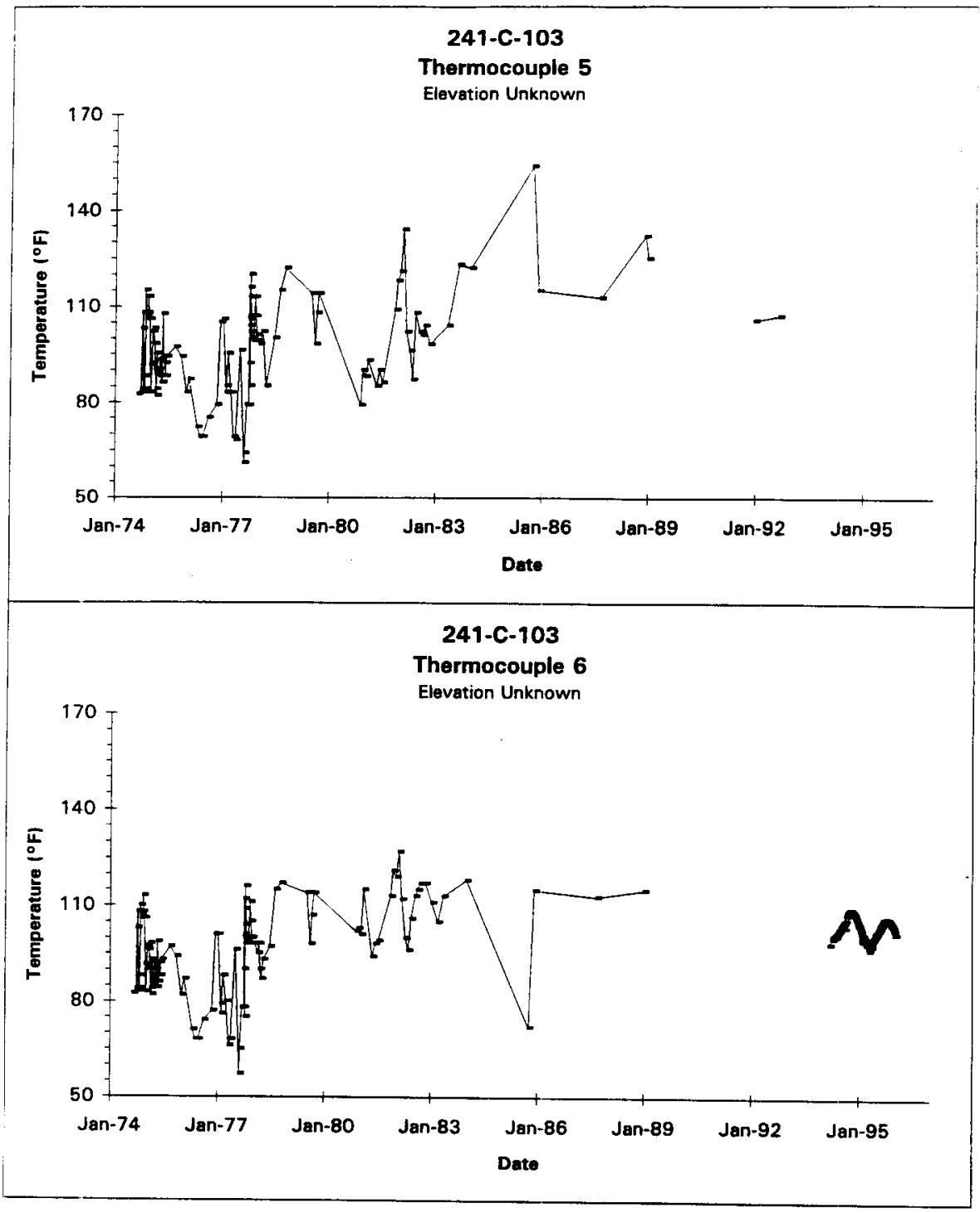

Data obtained from WHC Surveillance Analysis Computer System (SACS), Jan 9, 1996.

D-15 


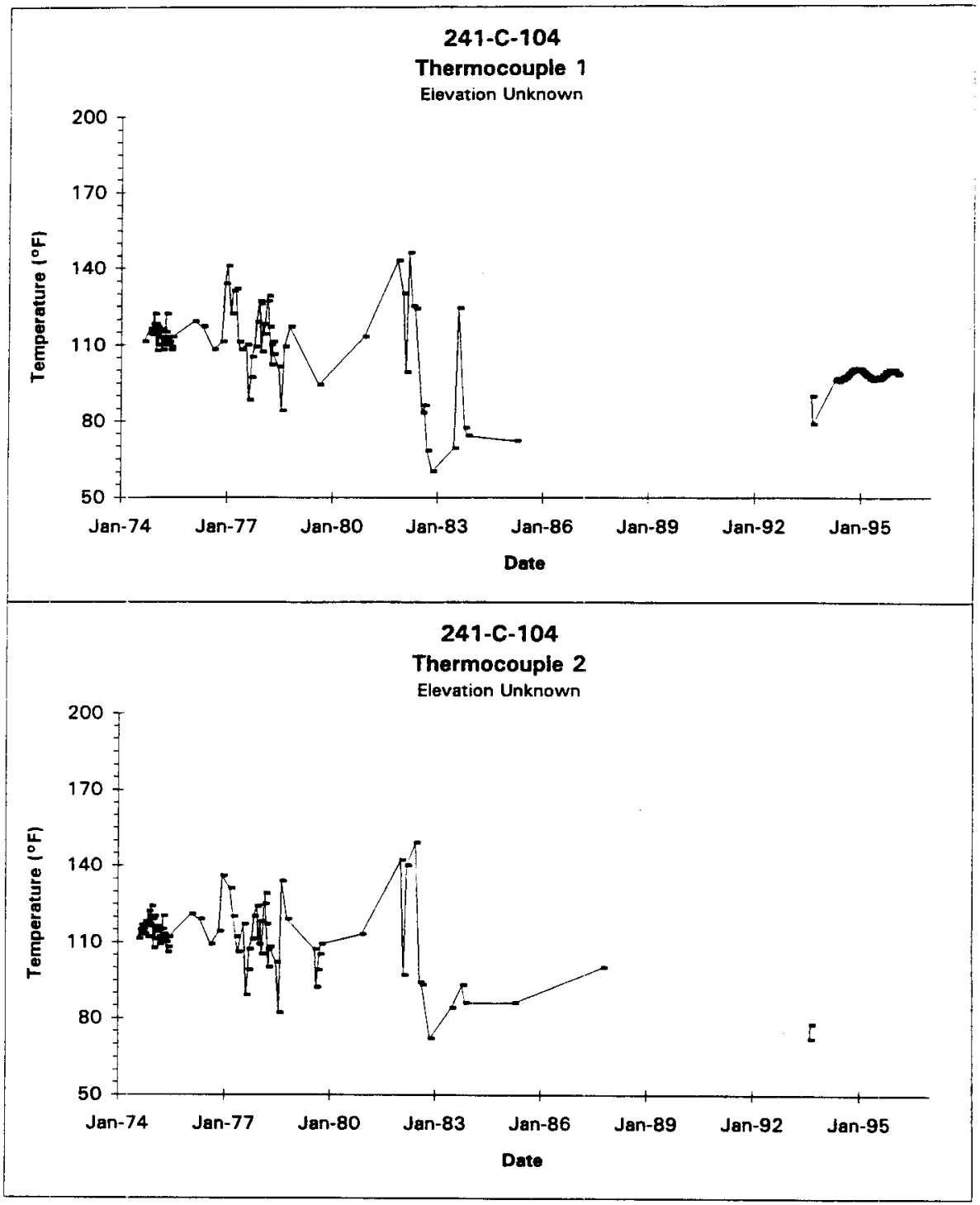

Data obtained from WHC Surveillance Axalysis Computer System (SACS), Jan 9, 1996.

D-16 


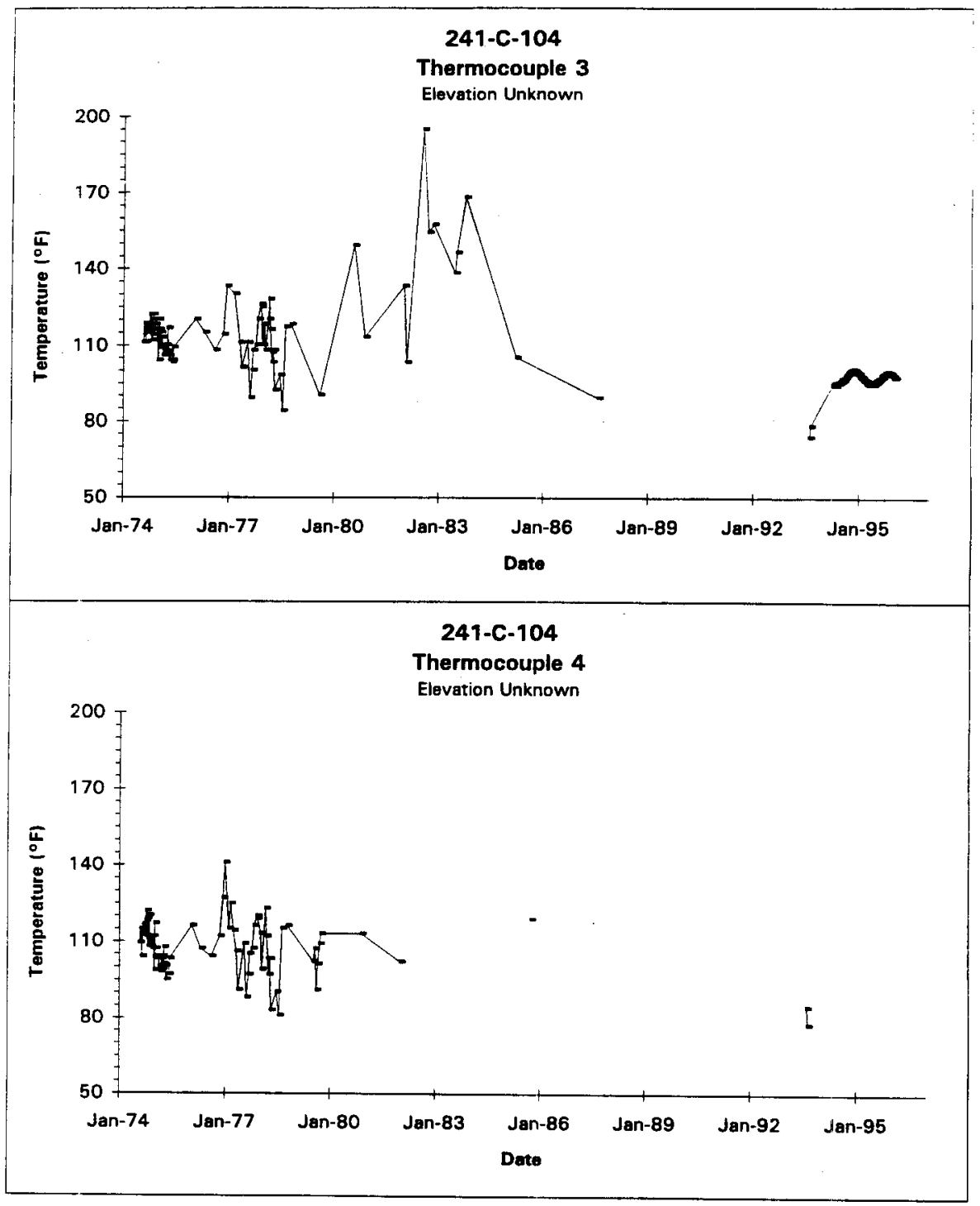

Data obtained from WHC Surveillance Analysis Computer System (SACS), Jan 9, 1996.

D-17 


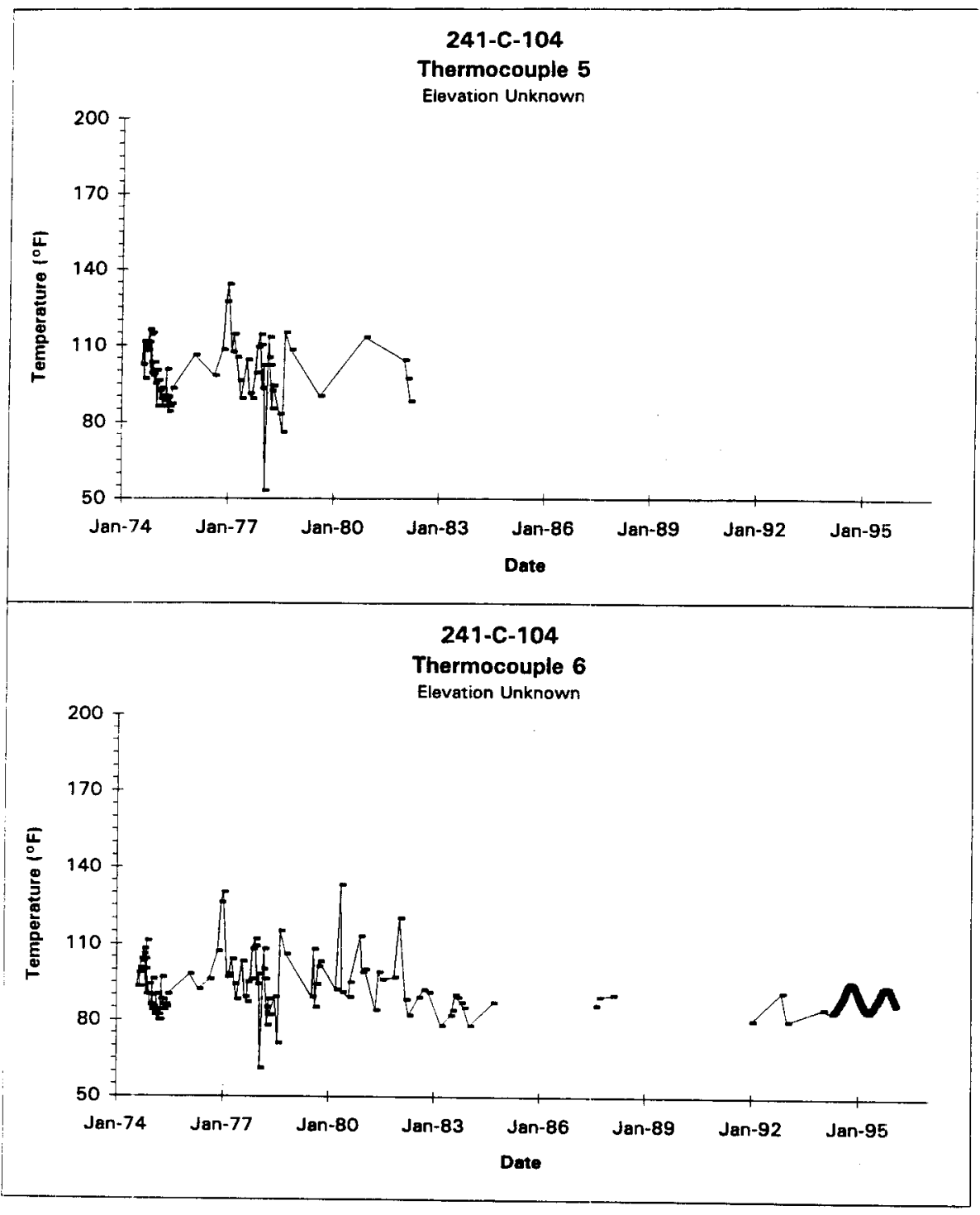

Data obtained from WHC Surveillance Analysis Computer System (SACS), Jan 9, 1996.

D.18 


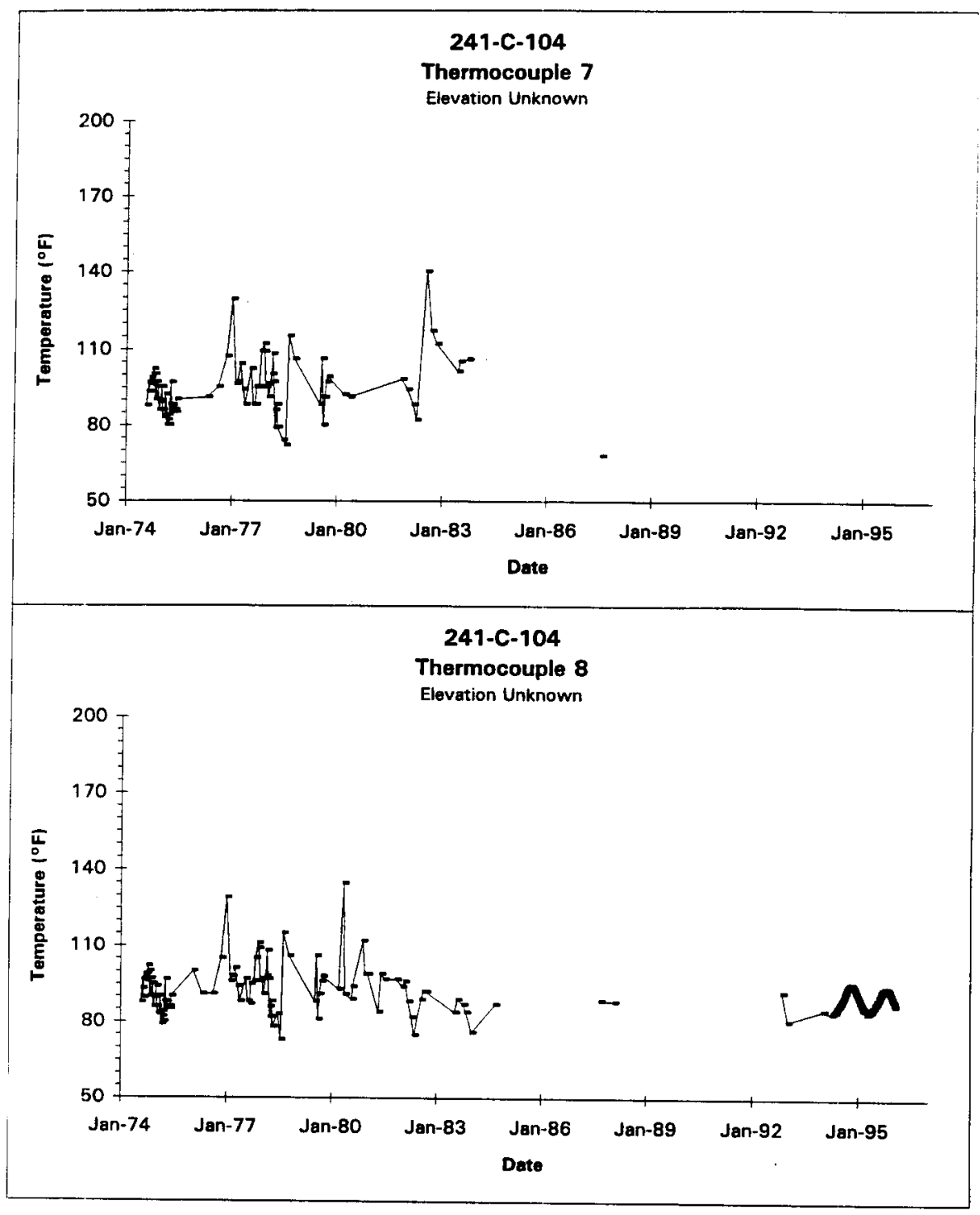

Data obtained from WHC Surveillance Analysis Computer System (SACS), Jan 9, 1996.

D-19 


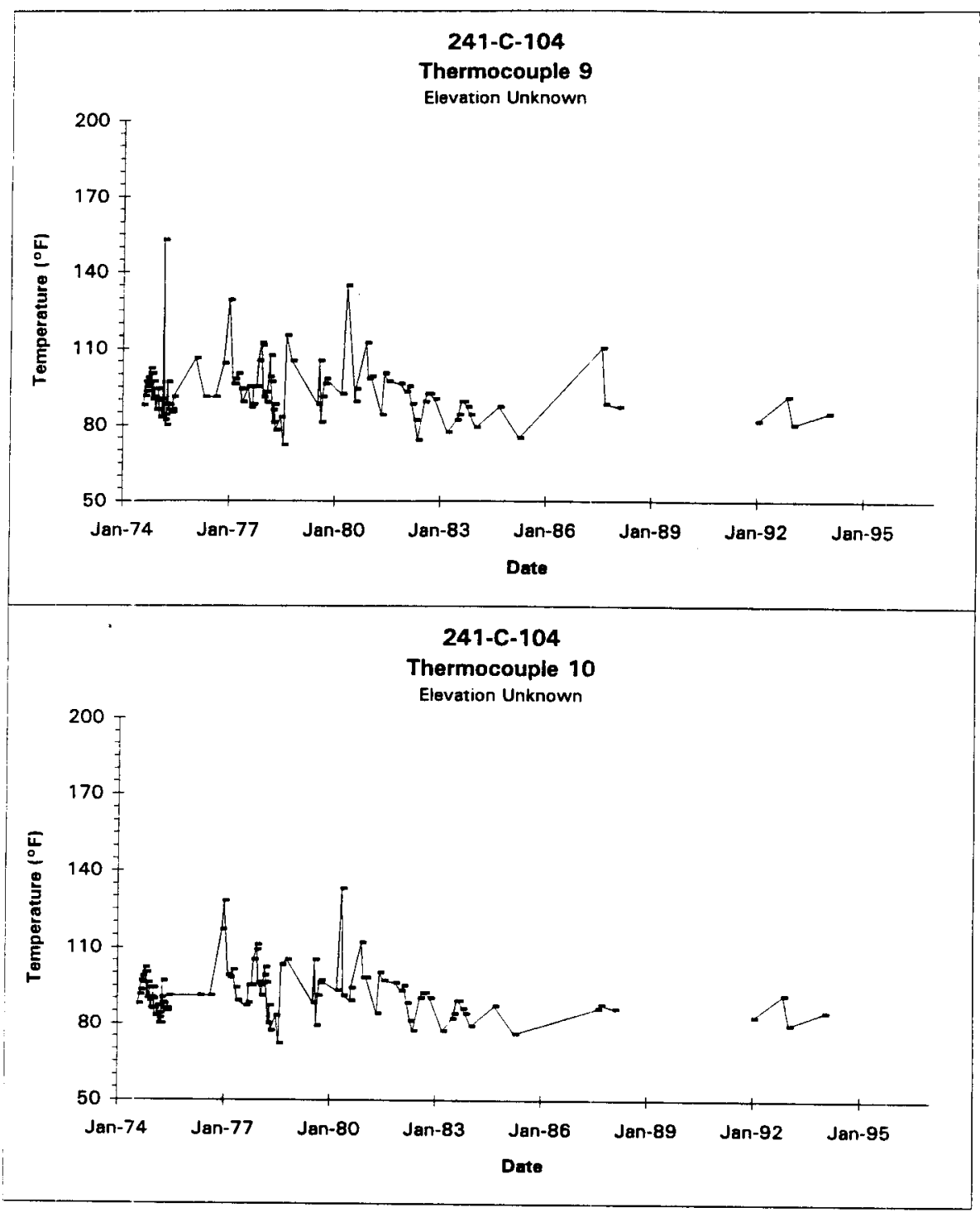

Data obtained from WHC Surveillance Analysis Computer System (SACS), Jan 9, 1996.

$$
\text { D-20 }
$$




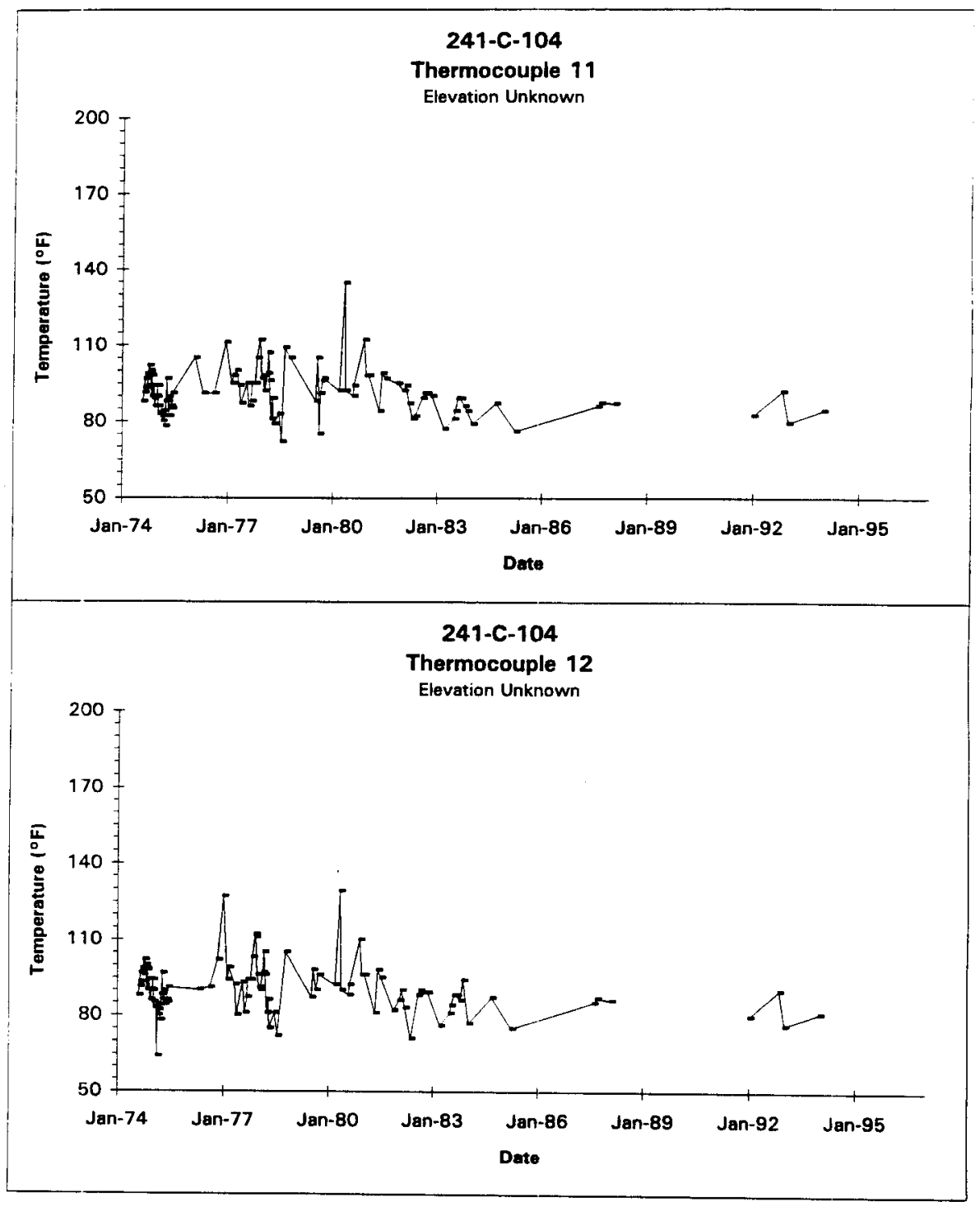

Data obtained from WHC Surveillance Analysis Computer System (SACS), Jan 9, 1996. 


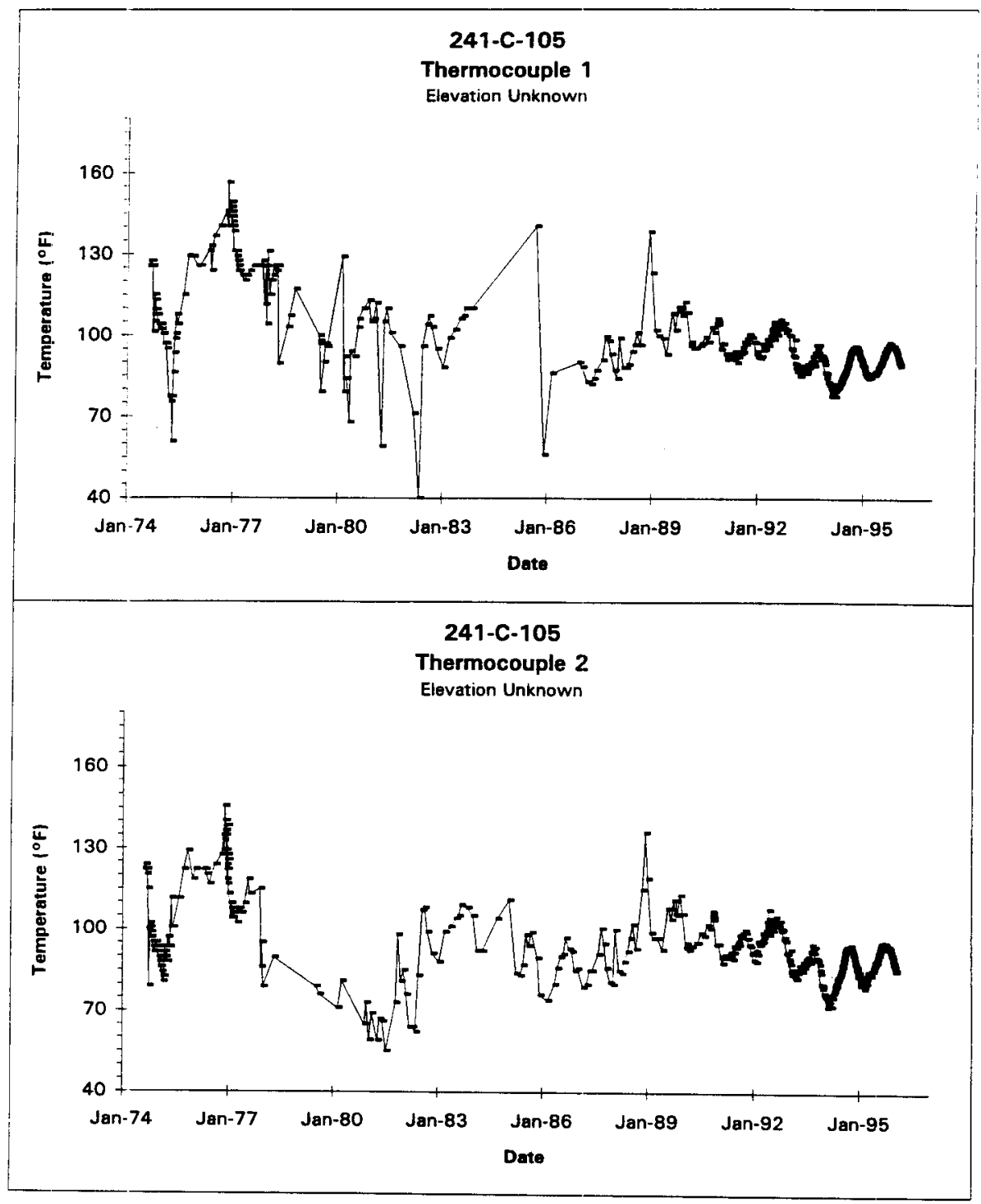

Data obtained from WHC Surveillance Analysis Computer System (SACS), Jan 9, 1996. 


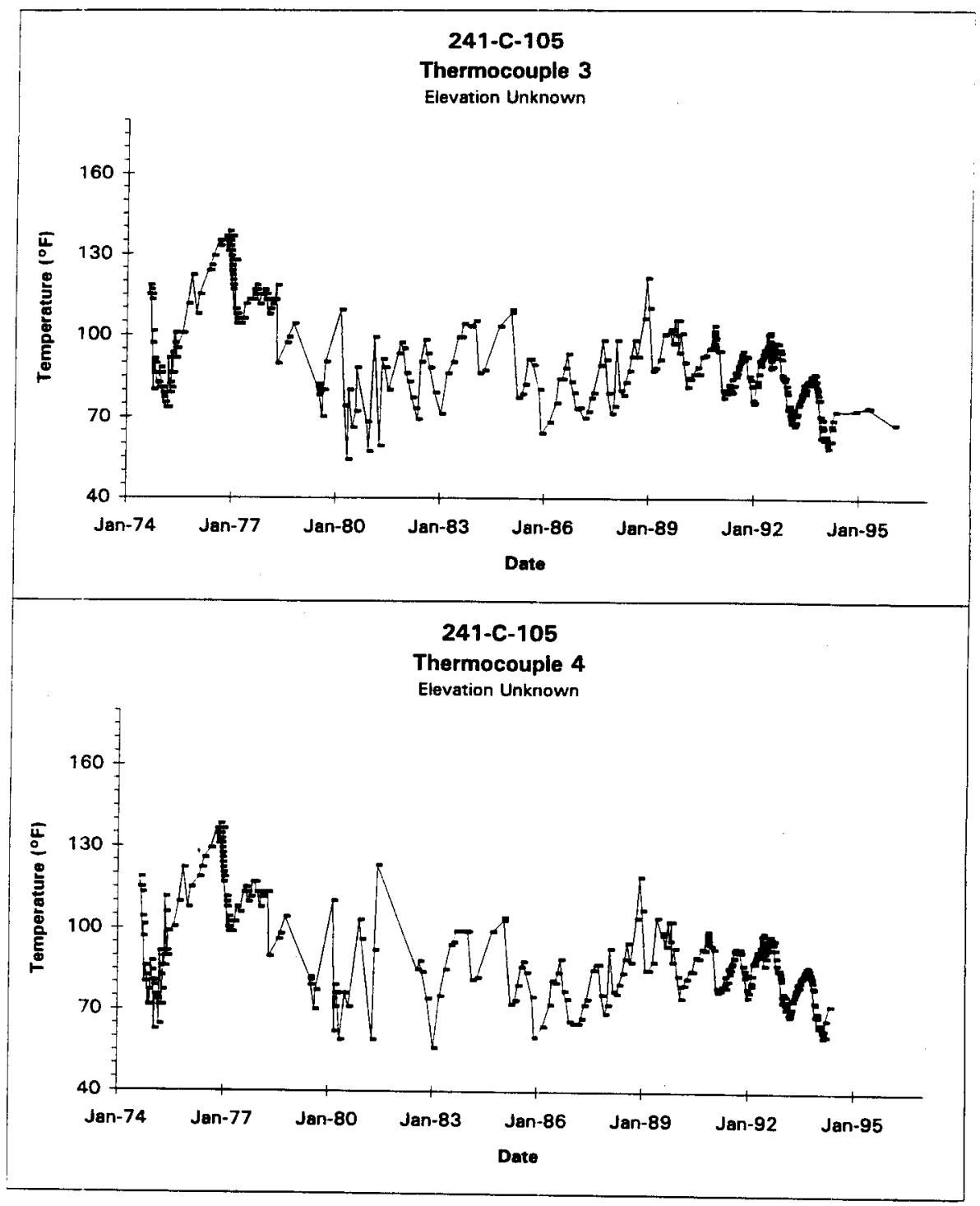

Data obtained from WHC Surveillance Analysis Computer System (SACS), Jan 9, 1996.

D-23 


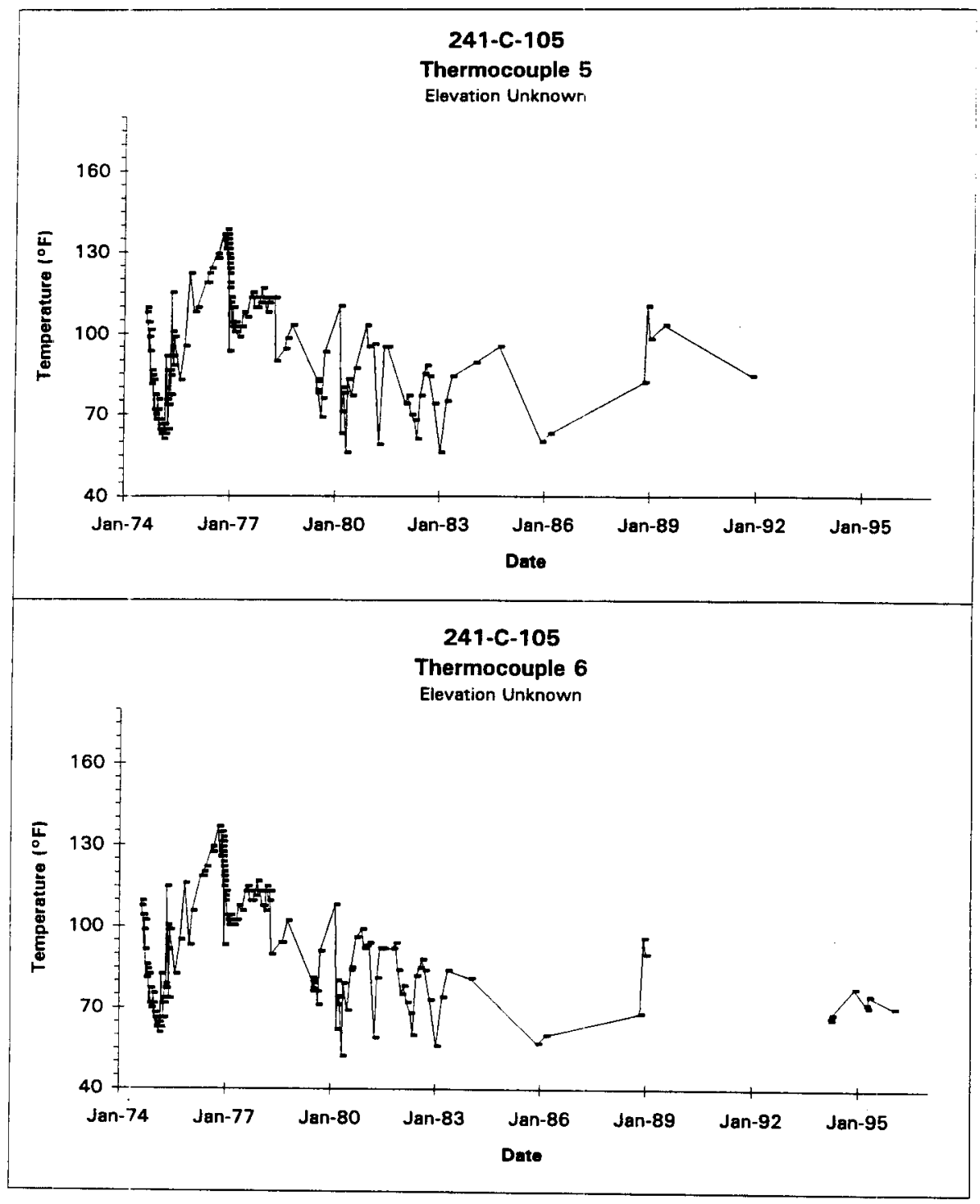

Data obtained from WHC Surveillance Analysis Computer System (SACS), Jan 9, 1996. 


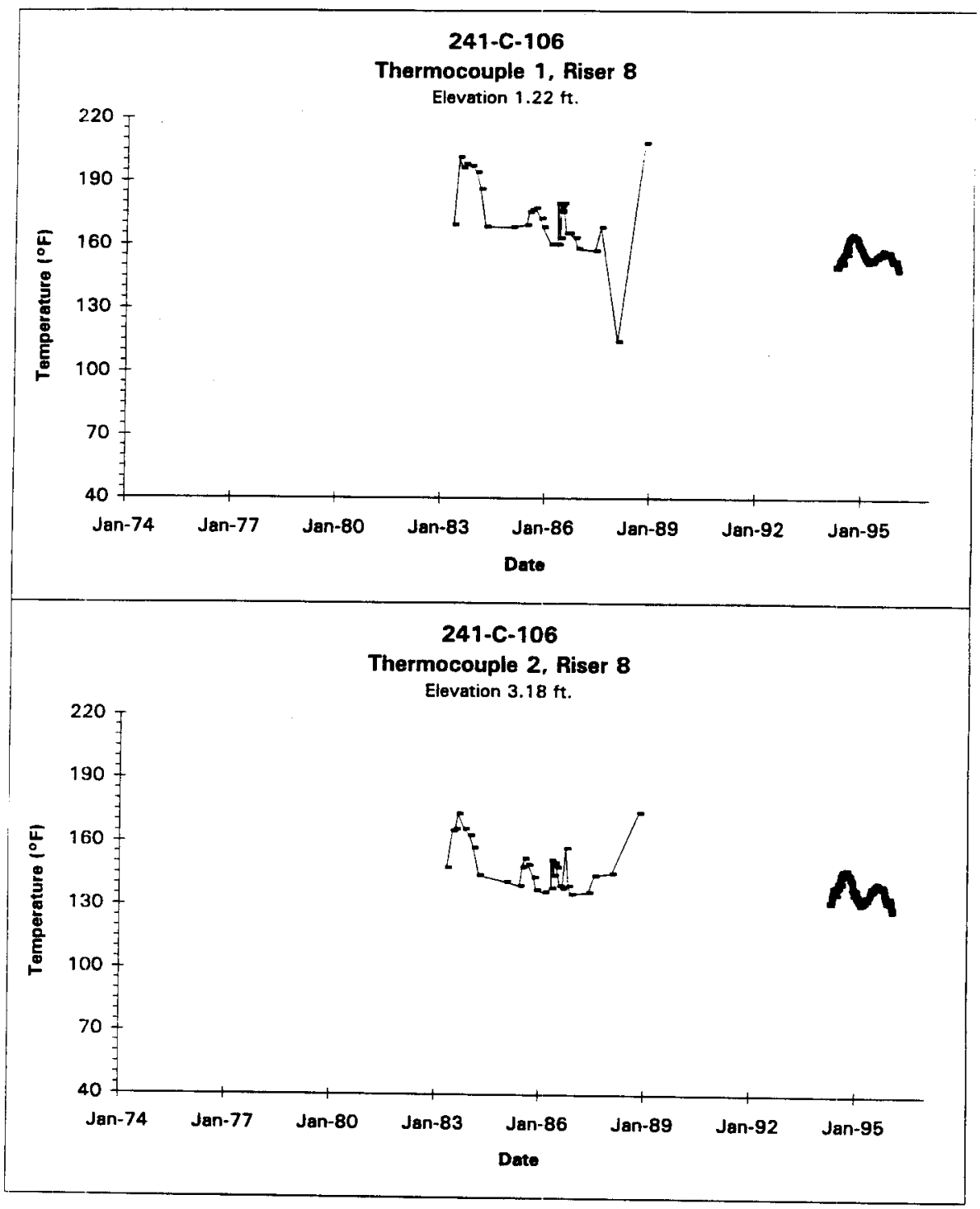

Data obtained from WHC Surveillance Analysis Computer System (SACS), Jan 9, 1996. 


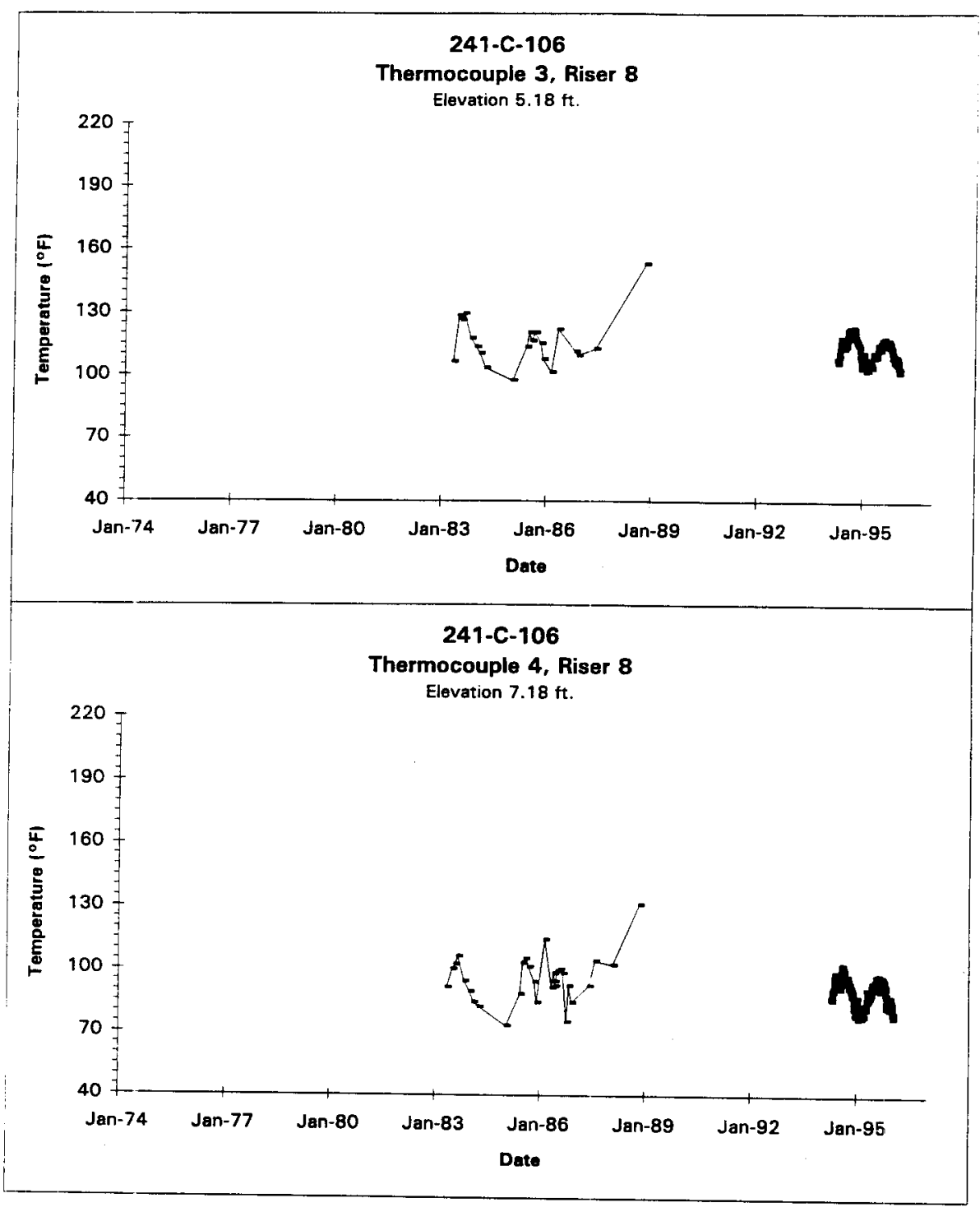

Data obtained from WHC Surveillance Analysis Computer System (SACS), Jan 9, 1996. 


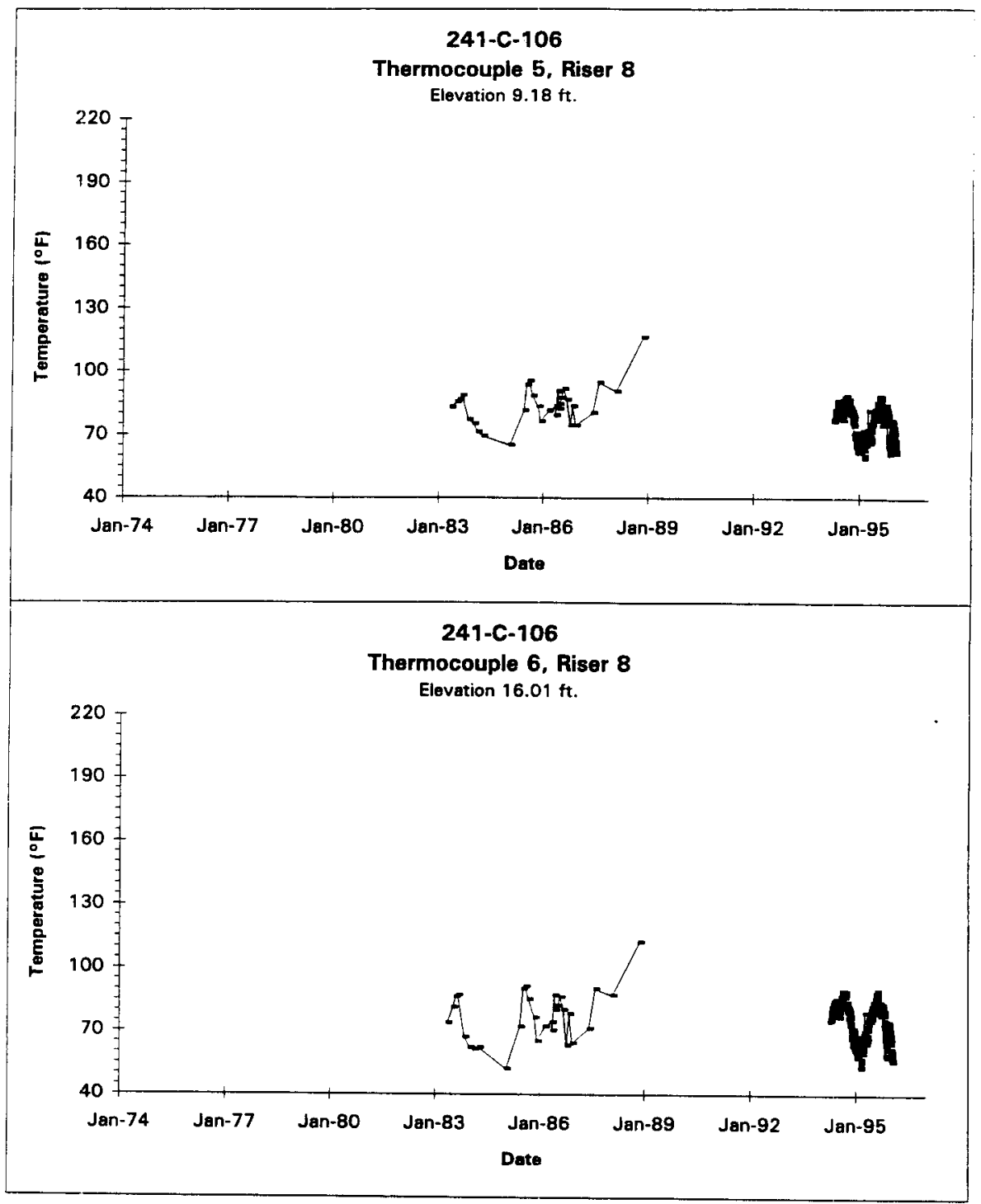

Data obtained from WHC Surveillance Analysis Computer System (SACS), Jan 9, 1996.

D-27 


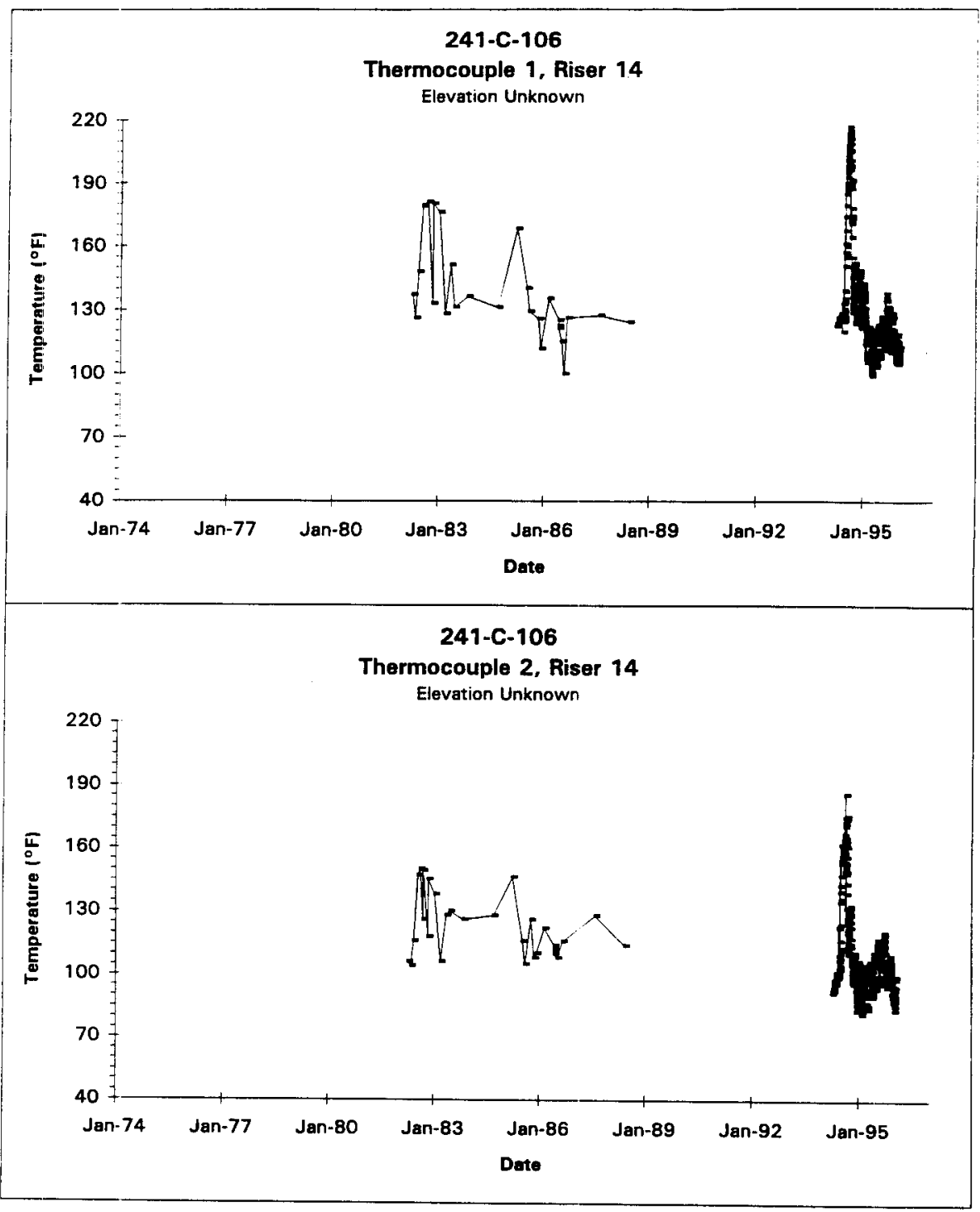

Data obtained from WHC Surveillance Analysis Computer System (SACS), Jan 9, 1996. D-28 


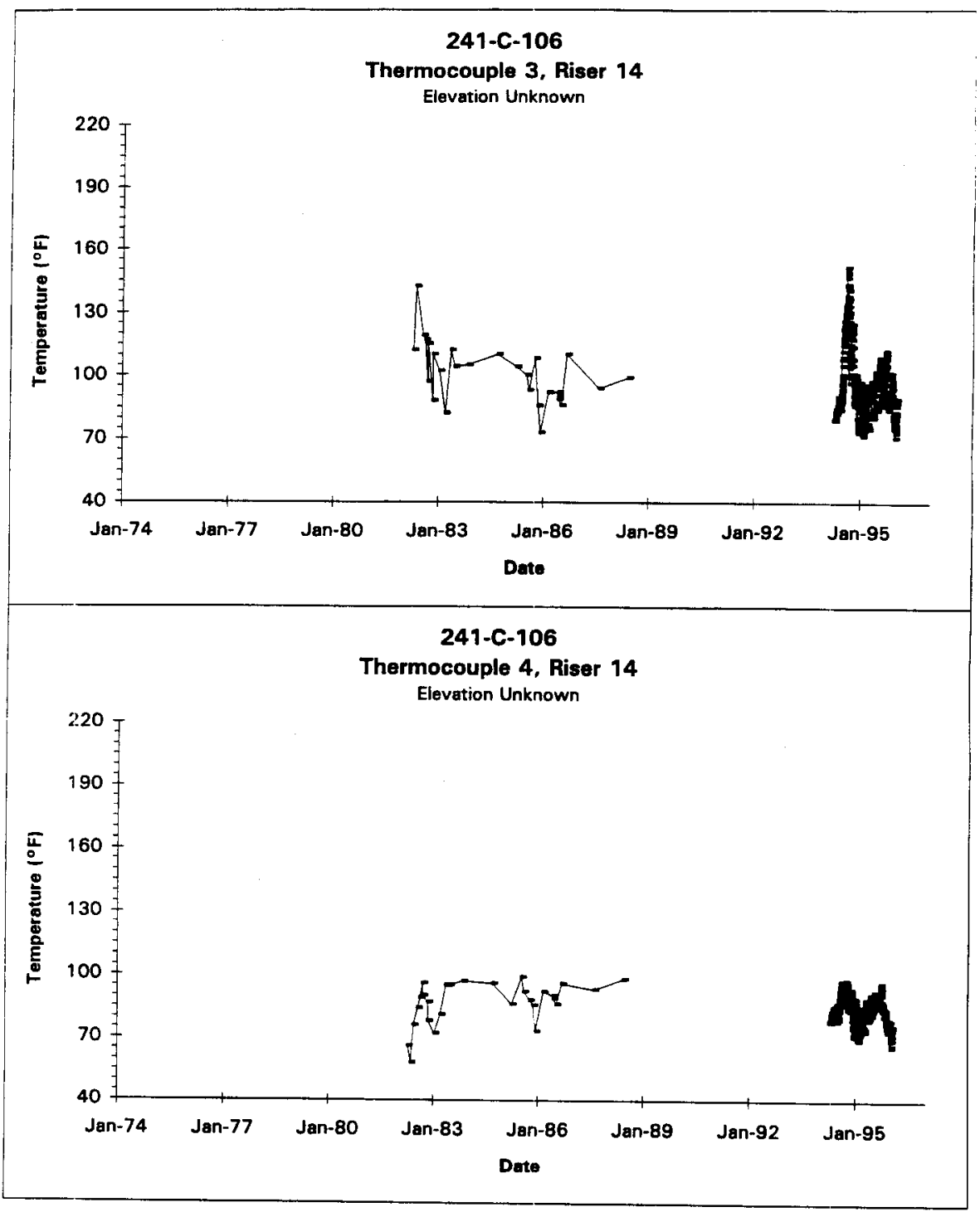

Data obtained from WHC Surveillance Analysis Computer System (SACS), Jan 9, 1996.

D-29 


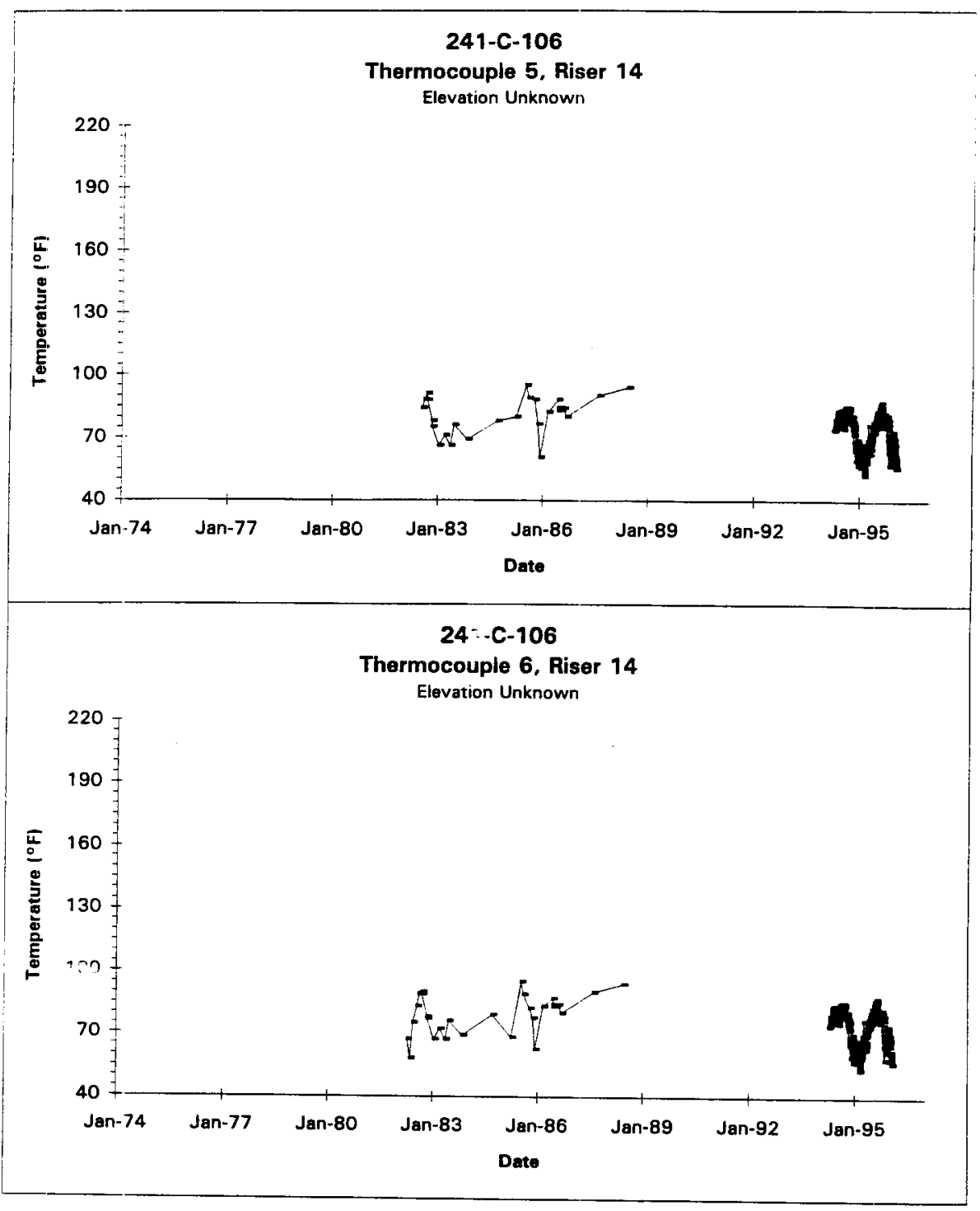

Data obtained from WHC Surveillance Analysis Computer System (SACS), Jan 9, 1996.

$$
\text { D-30 }
$$




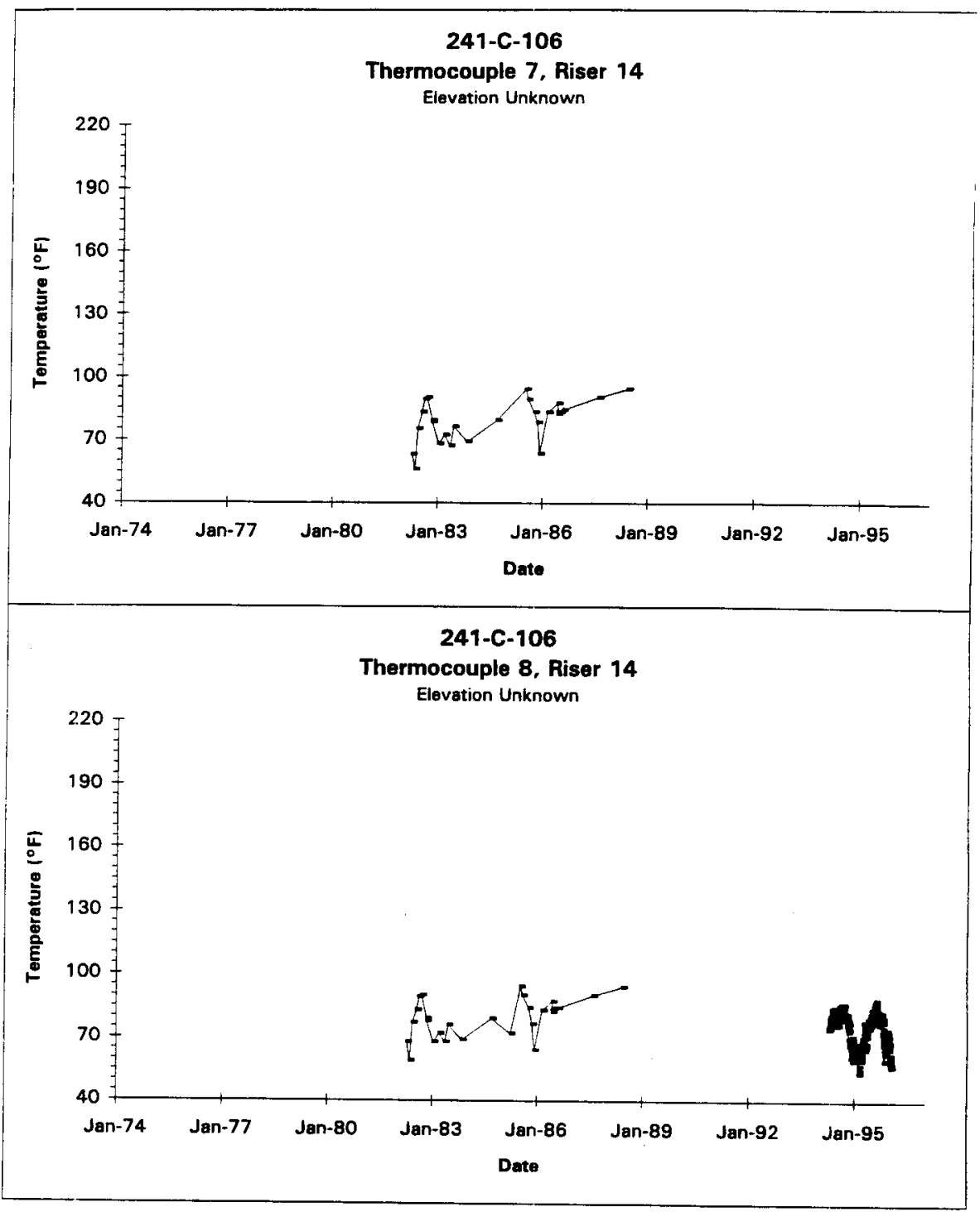

Data obtained from WHC Surveillance Analysis Computer System (SACS), Jan 9, 1996.

D-31 


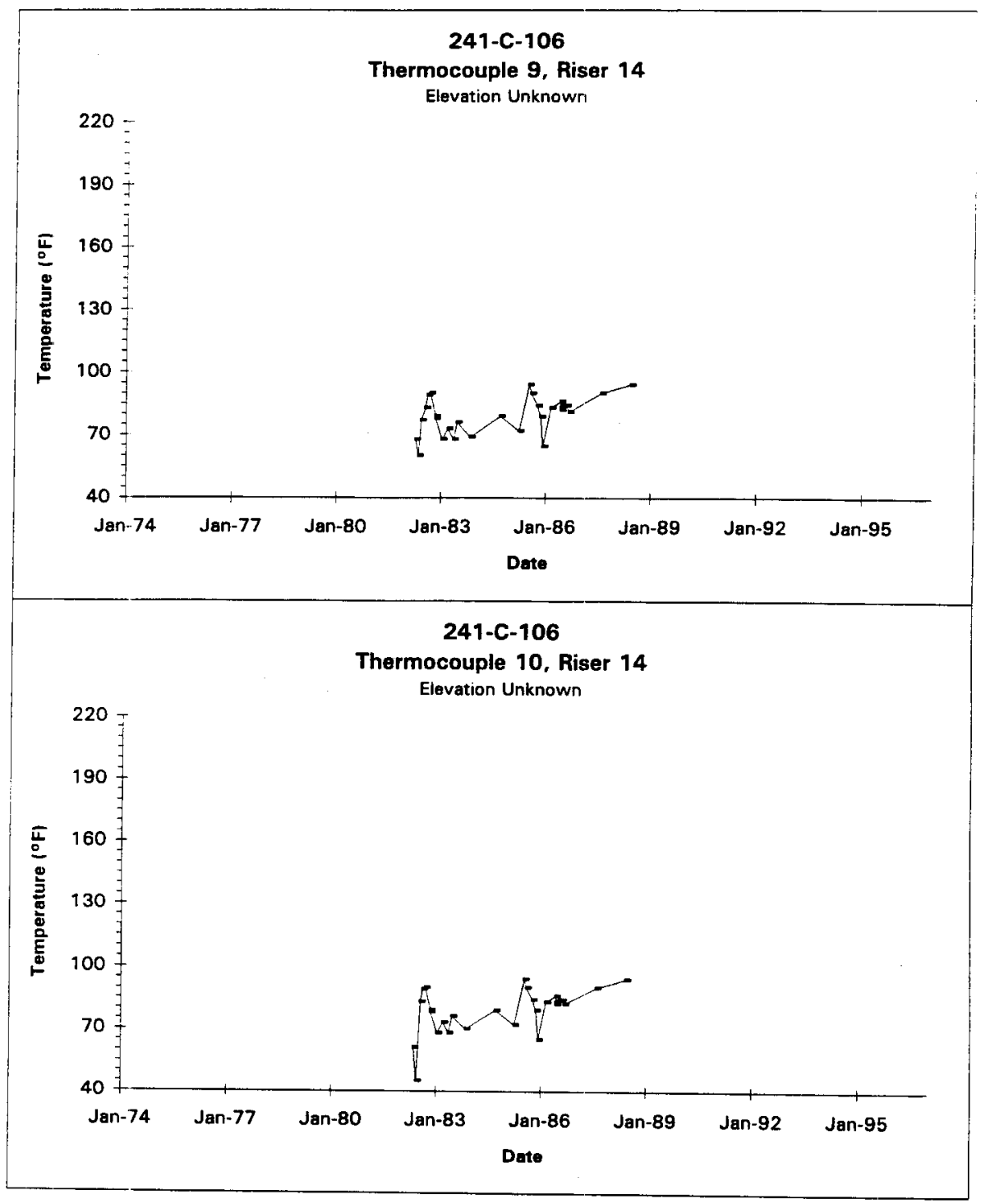

Data obtained from WHC Surveillance Analysis Computer System (SACS), Jan 9, 1996.

$$
\text { D-32 }
$$




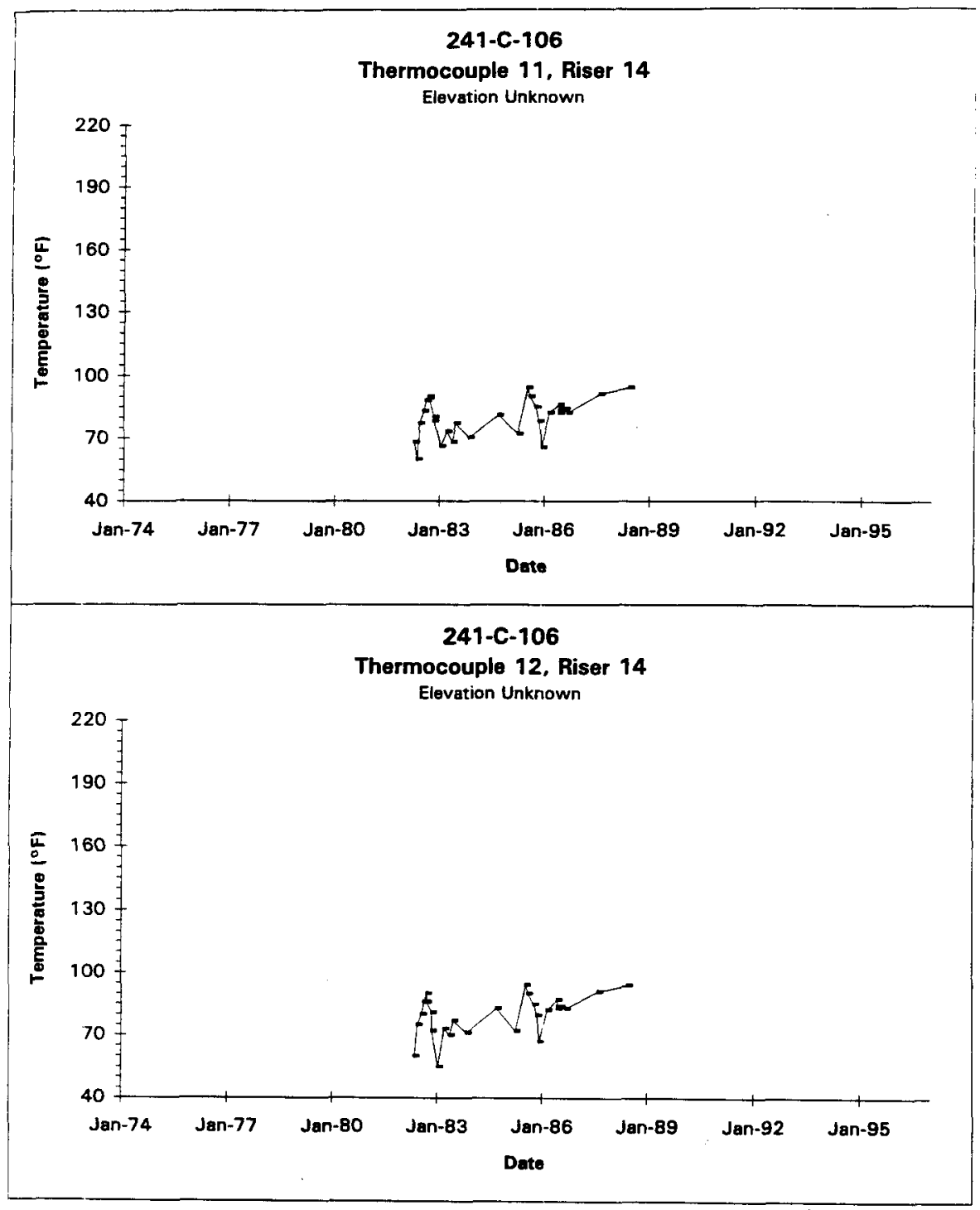

Data obtained from WHC Surveillance Analysis Computer System (SACS), Jan 9, 1996. 


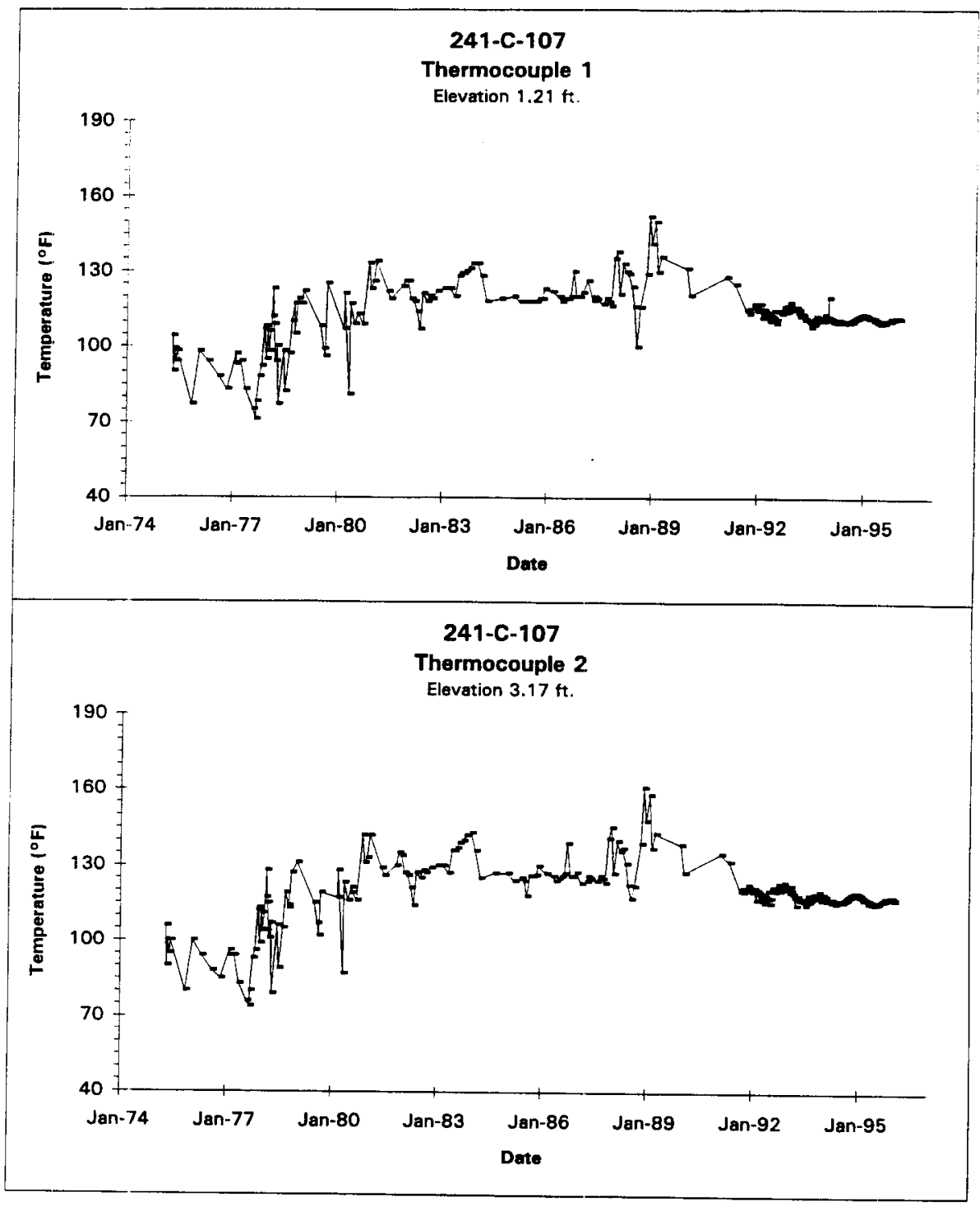

Data obtained from WHC Surveillance Analysis Computer System (SACS), Jan 9, 1996.

D-34 


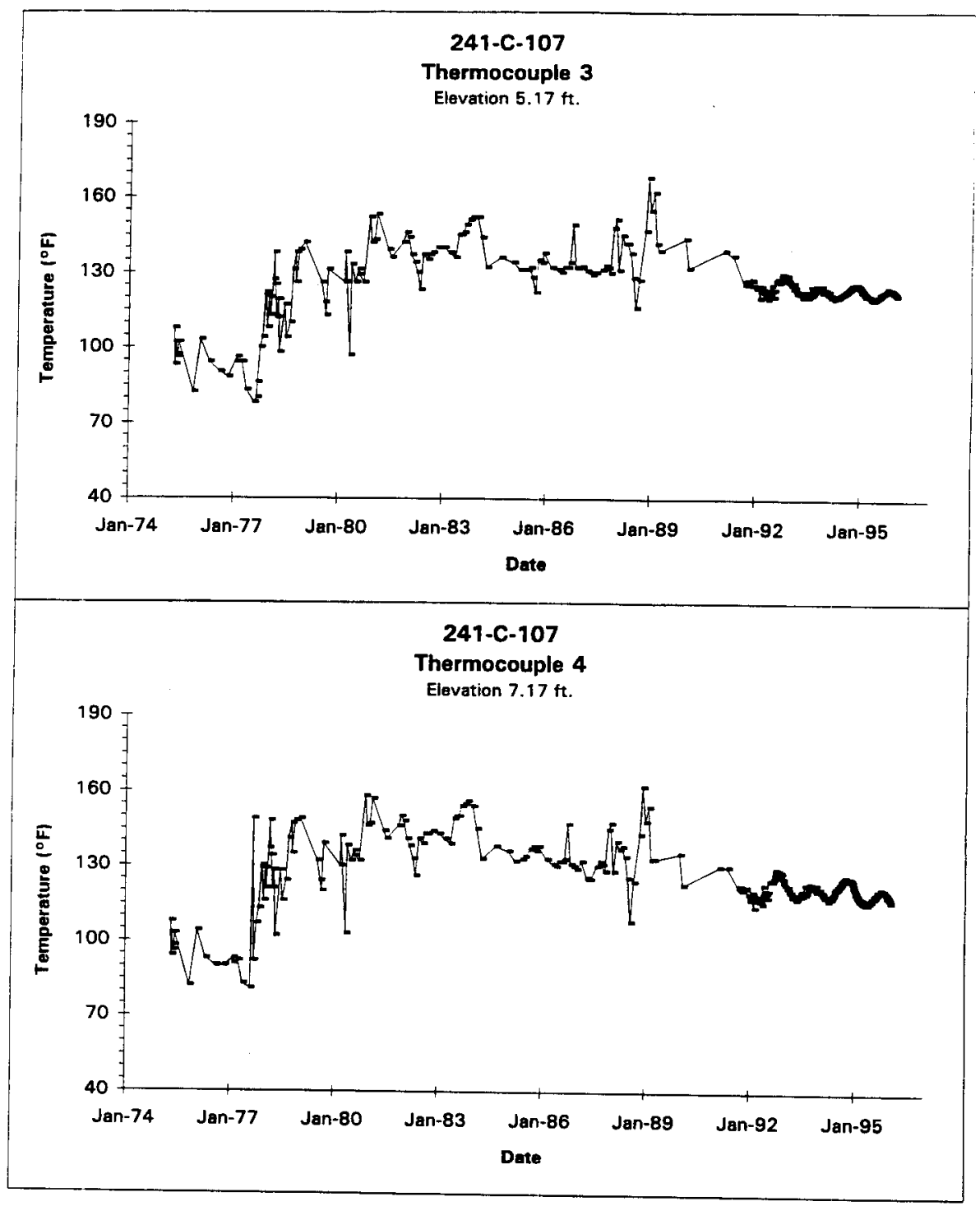

Data obtained from WHC Surveillance Analysis Computer System (SACS), Jan 9, 1996.

D-35 


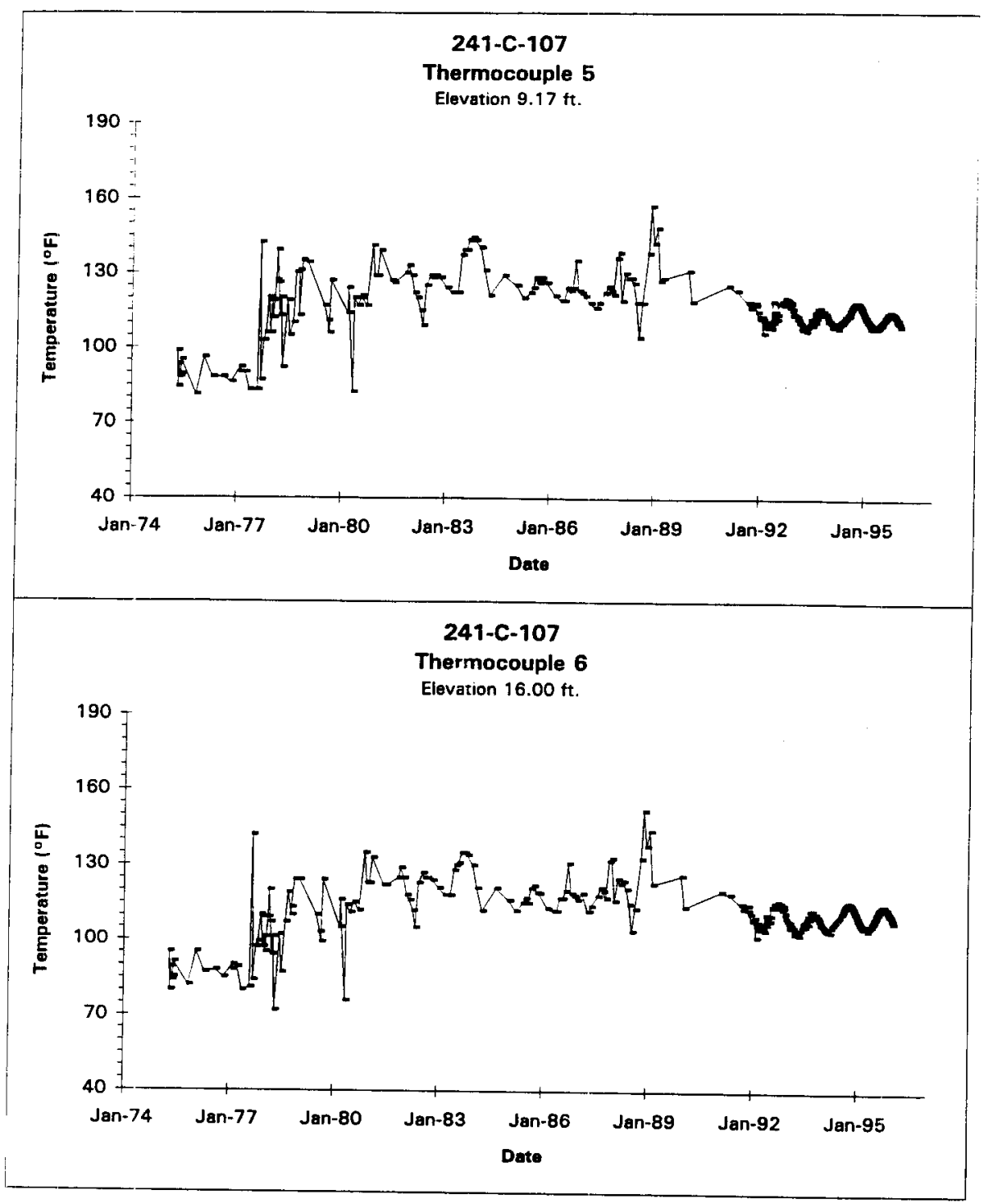

Data obtained from WHC Surveillance Analysis Computer System (SACS), Jan 9, 1996. 


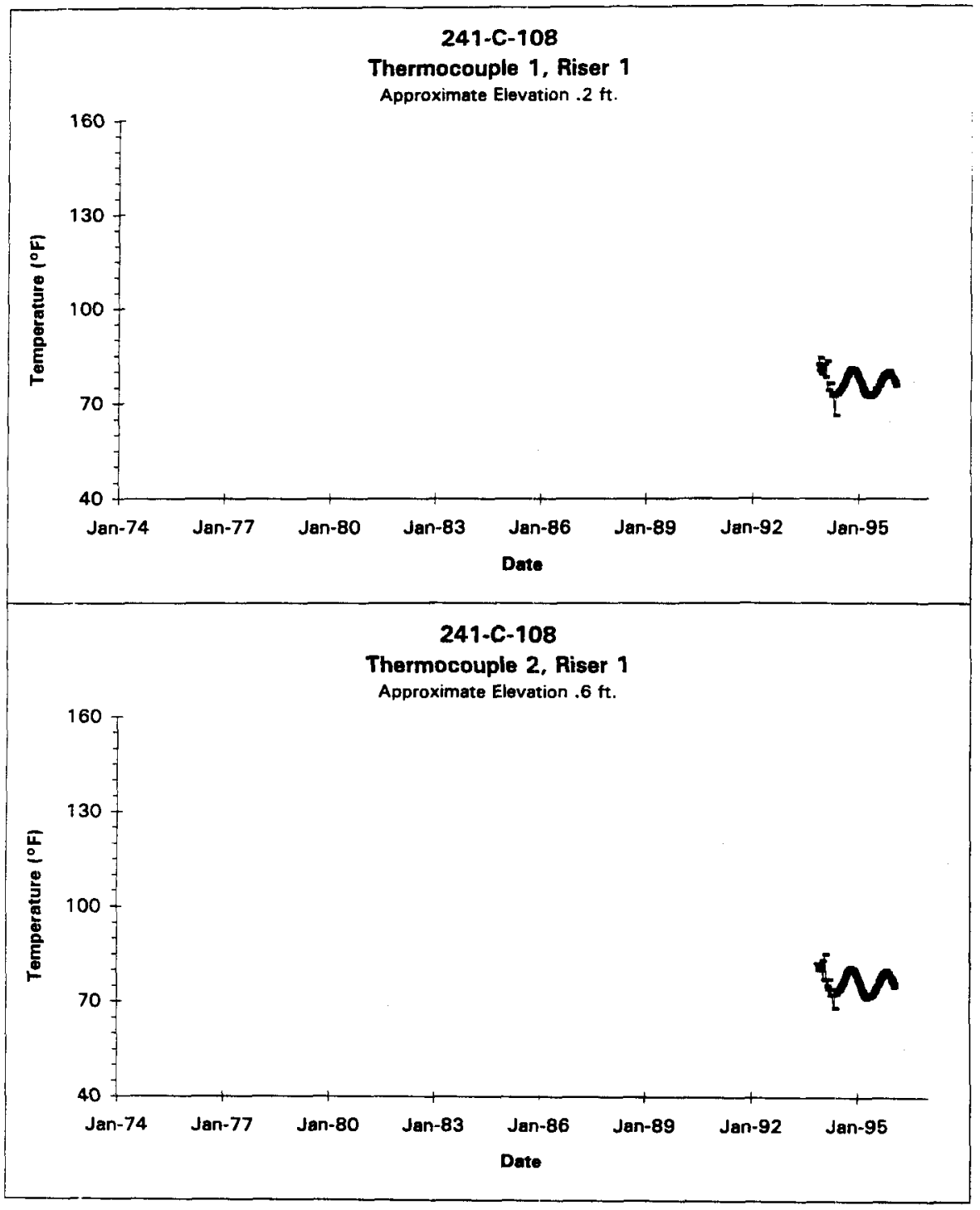

Data obtained from WHC Surveillance Analysis Computer System (SACS), Jan 9, 1996.

D-37 


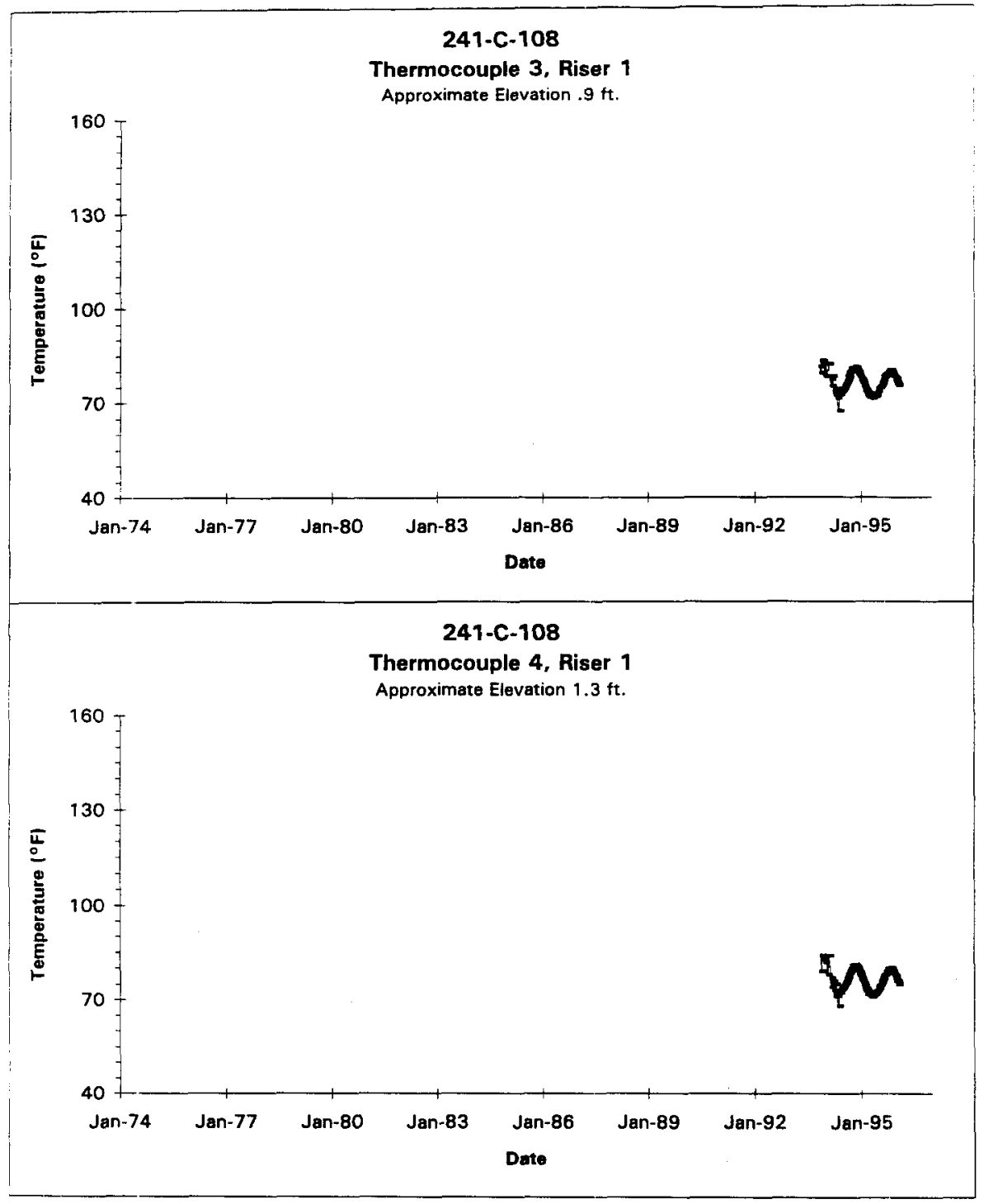

Data obtained from WHC Surveillance Analysis Computer System (SACS), Jan 9, 1996.

D-38 


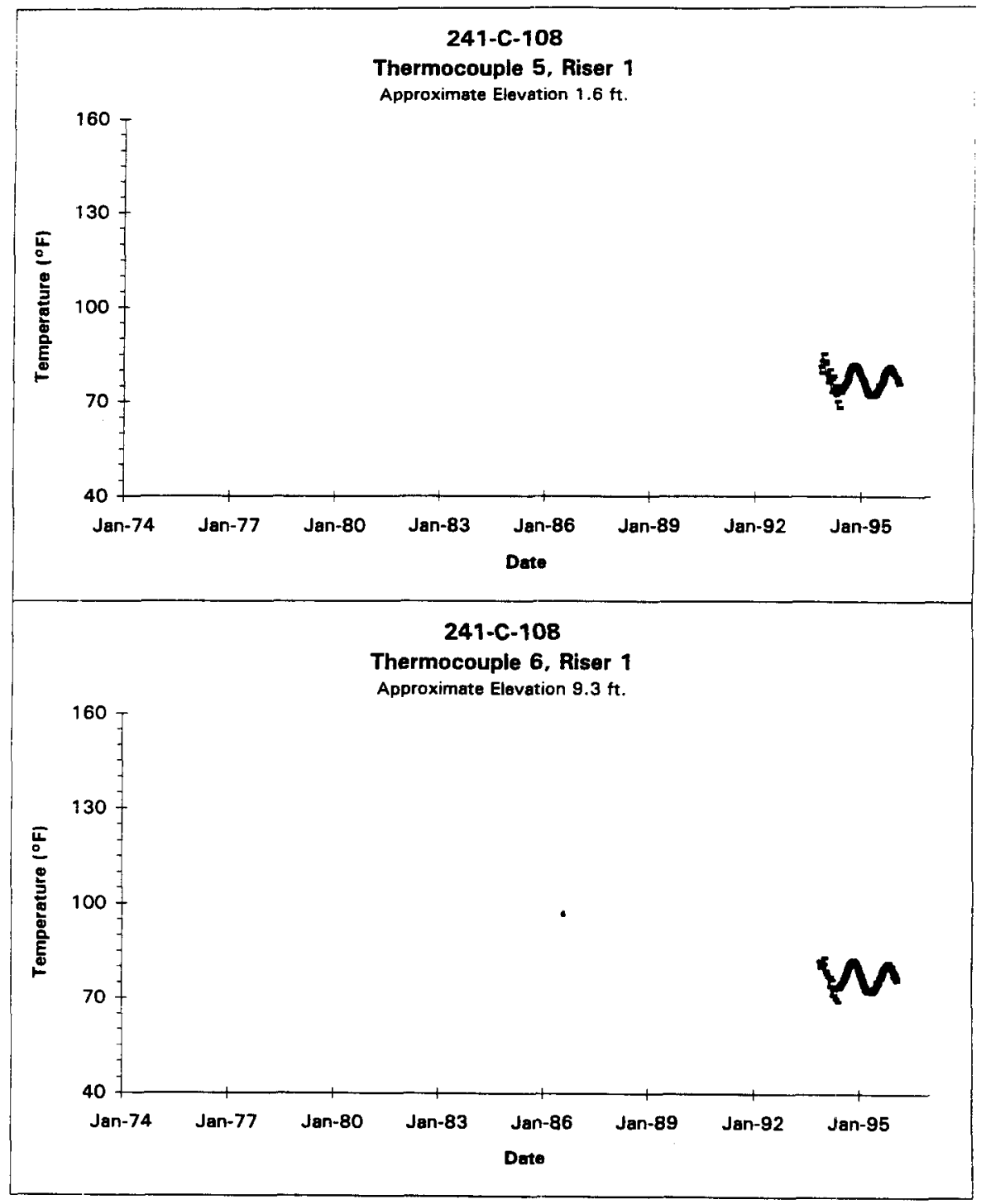

Data obtained from WHC Surveillance Analysis Computer System (SACS), Jan 9, 1996. 


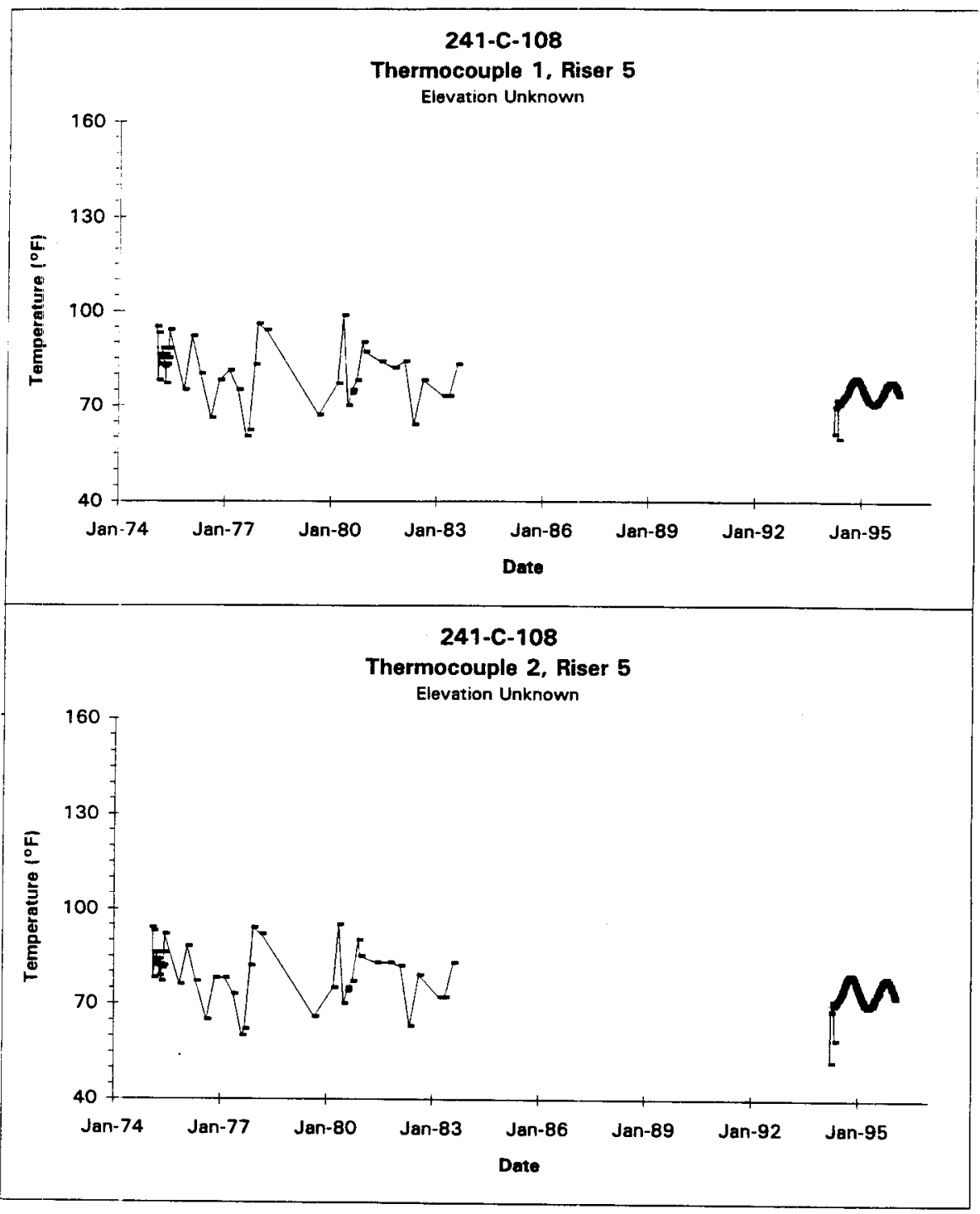

Data obtained from WHC Surveillance Analysis Computer System (SACS), Jan 9, 1996. 


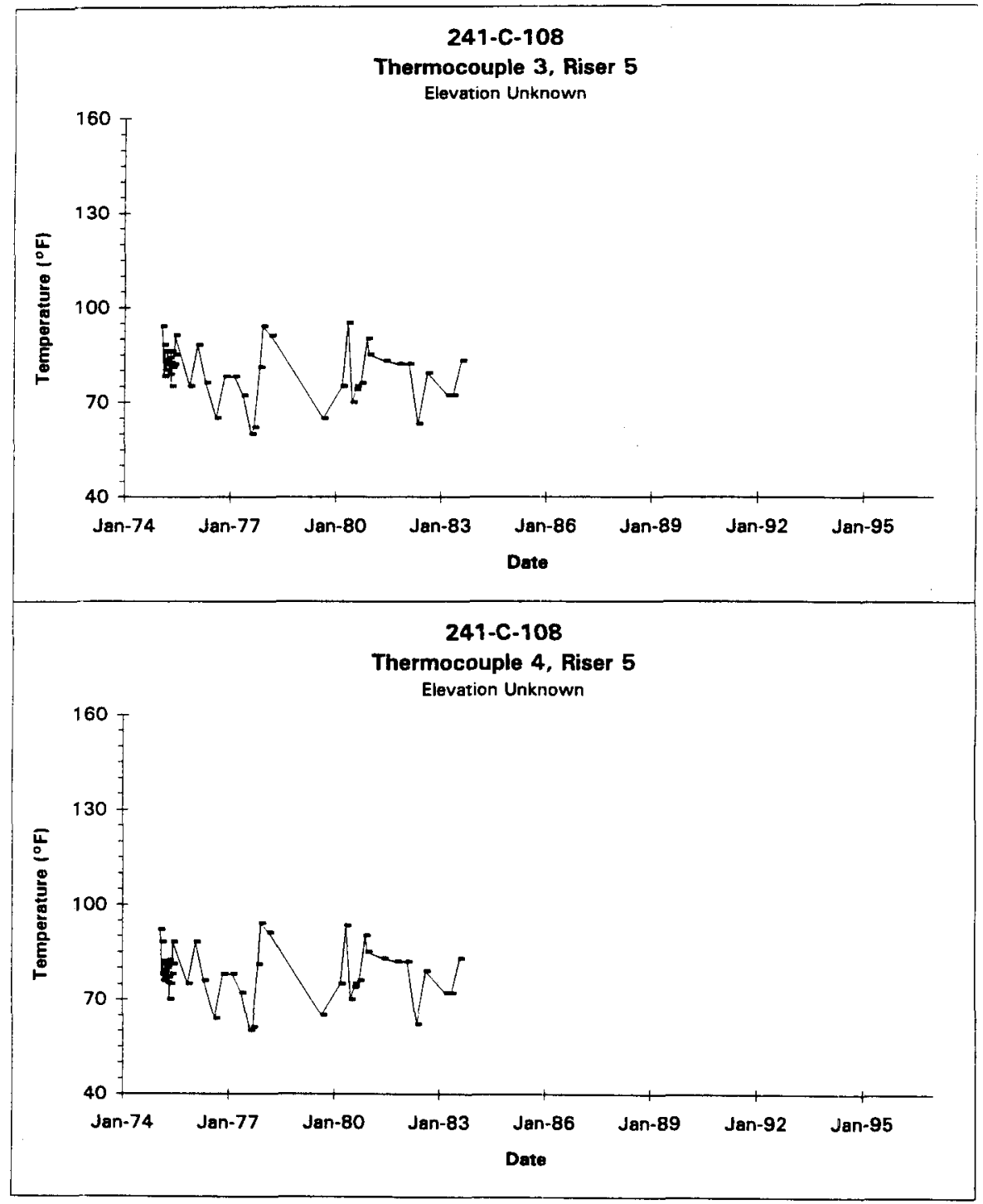

Data obtained from WHC Surveillance Analysis Computer System (SACS), Jan 9, 1996. 


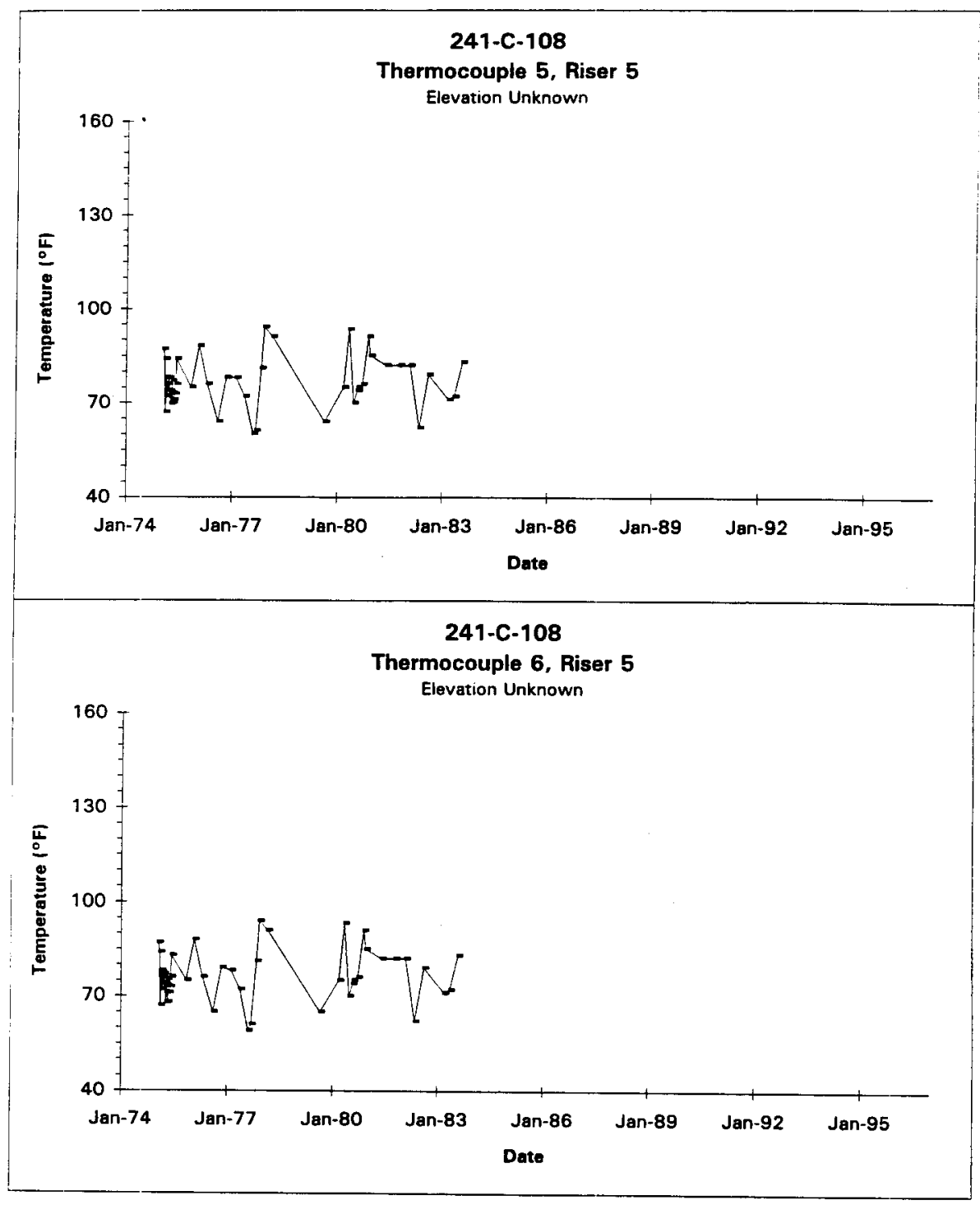

Data obtained from WHC Surveillance Analysis Computer System (SACS), Jan 9, 1996. 


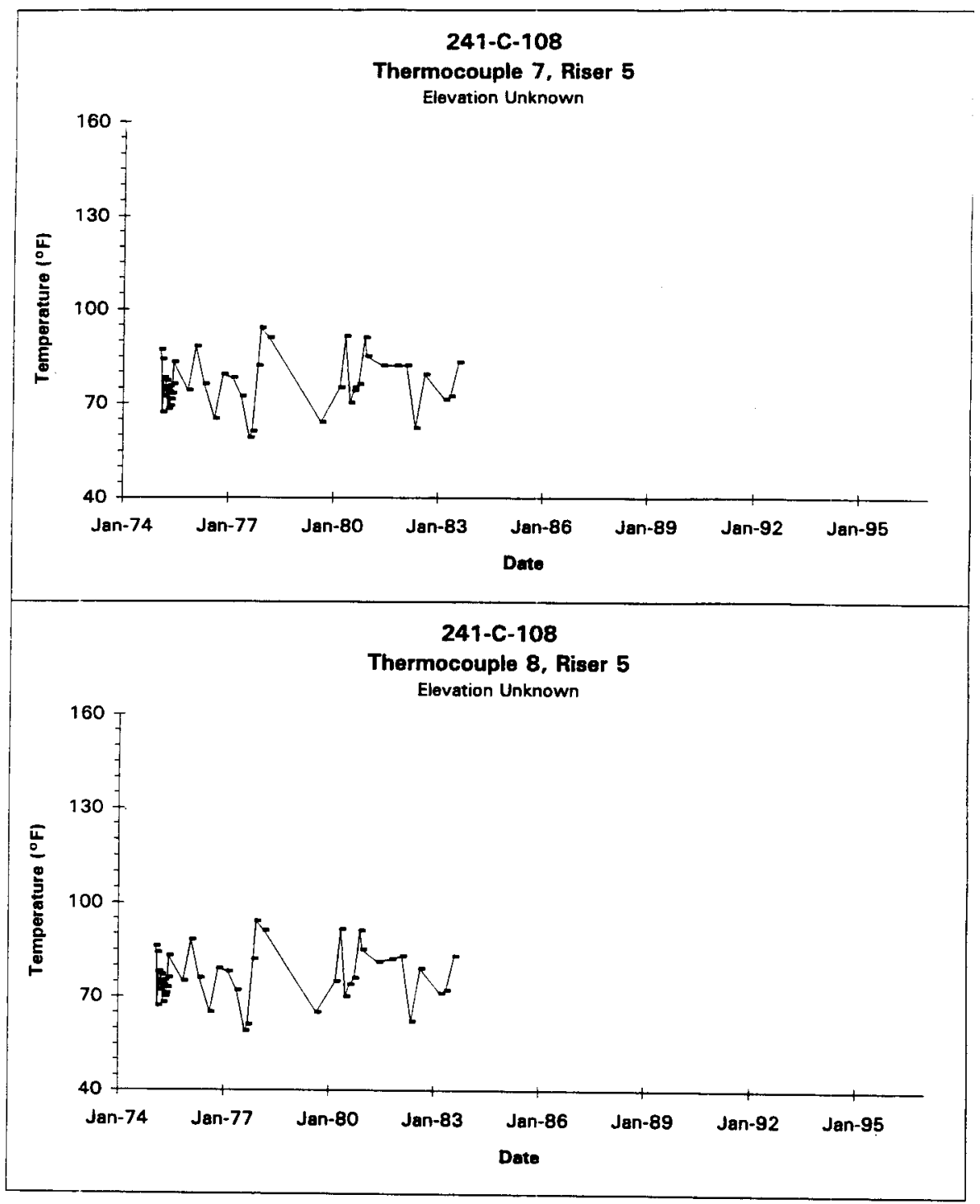

Data obtained from WHC Surveillance Analysis Computer System (SACS), Jan 9, 1996. 


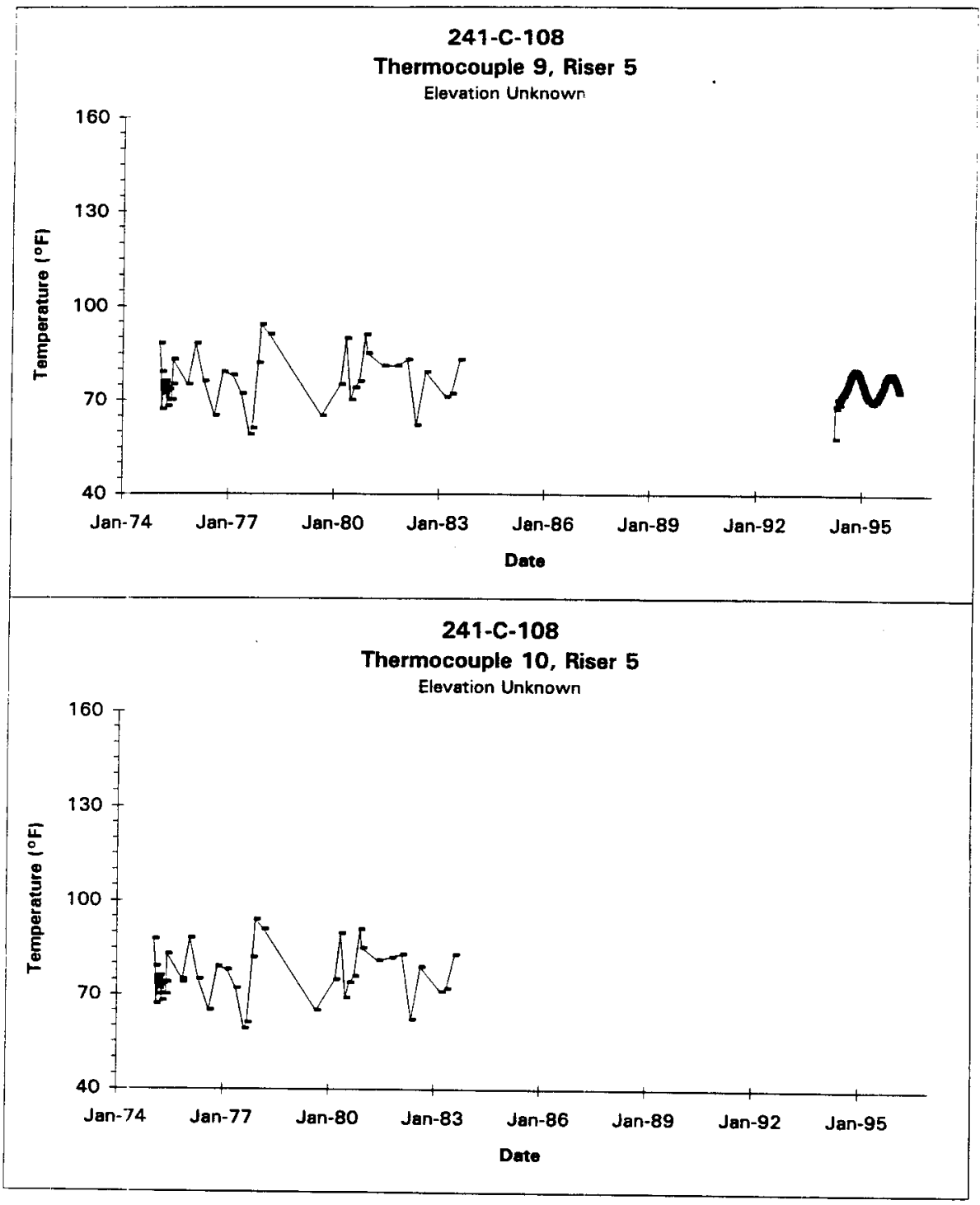

Data obtained from WHC Surveillance Analysis Computer System (SACS), Jan 9, 1996. 


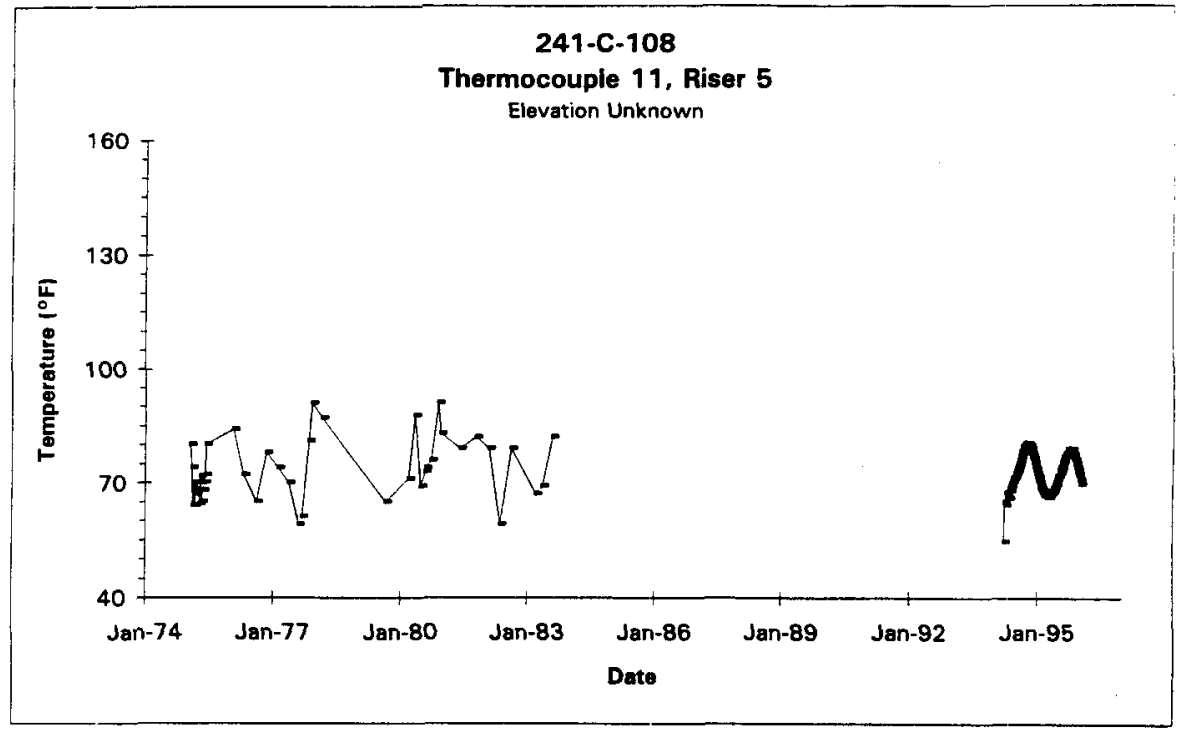

Data obtained from WHC Surveillance Analysis Computer System (SACS), Jan 9, 1996.

$$
\text { D-45 }
$$




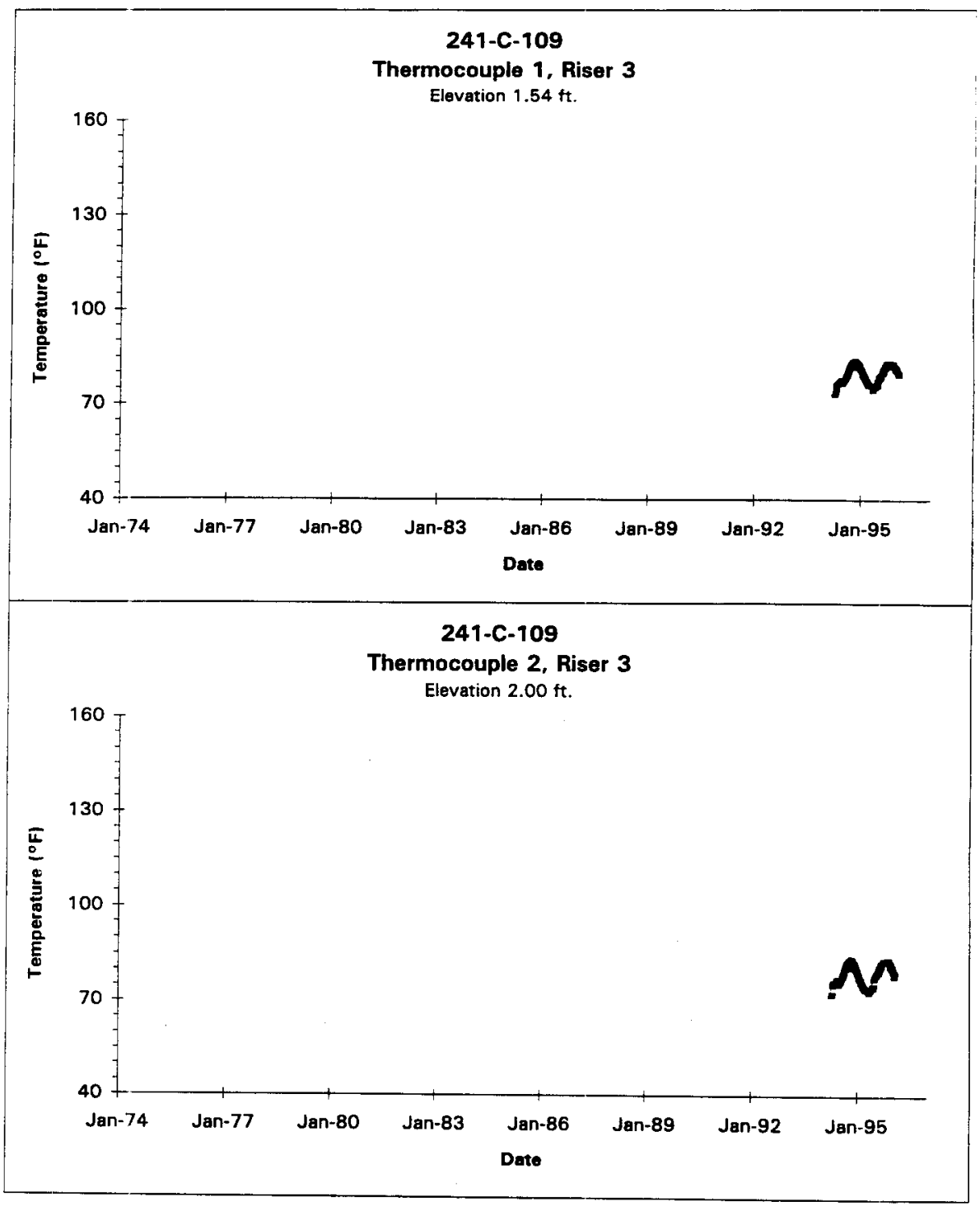

Data obtained from WHC Surveillance Analysis Computer System (SACS), Jan 9, 1996. 


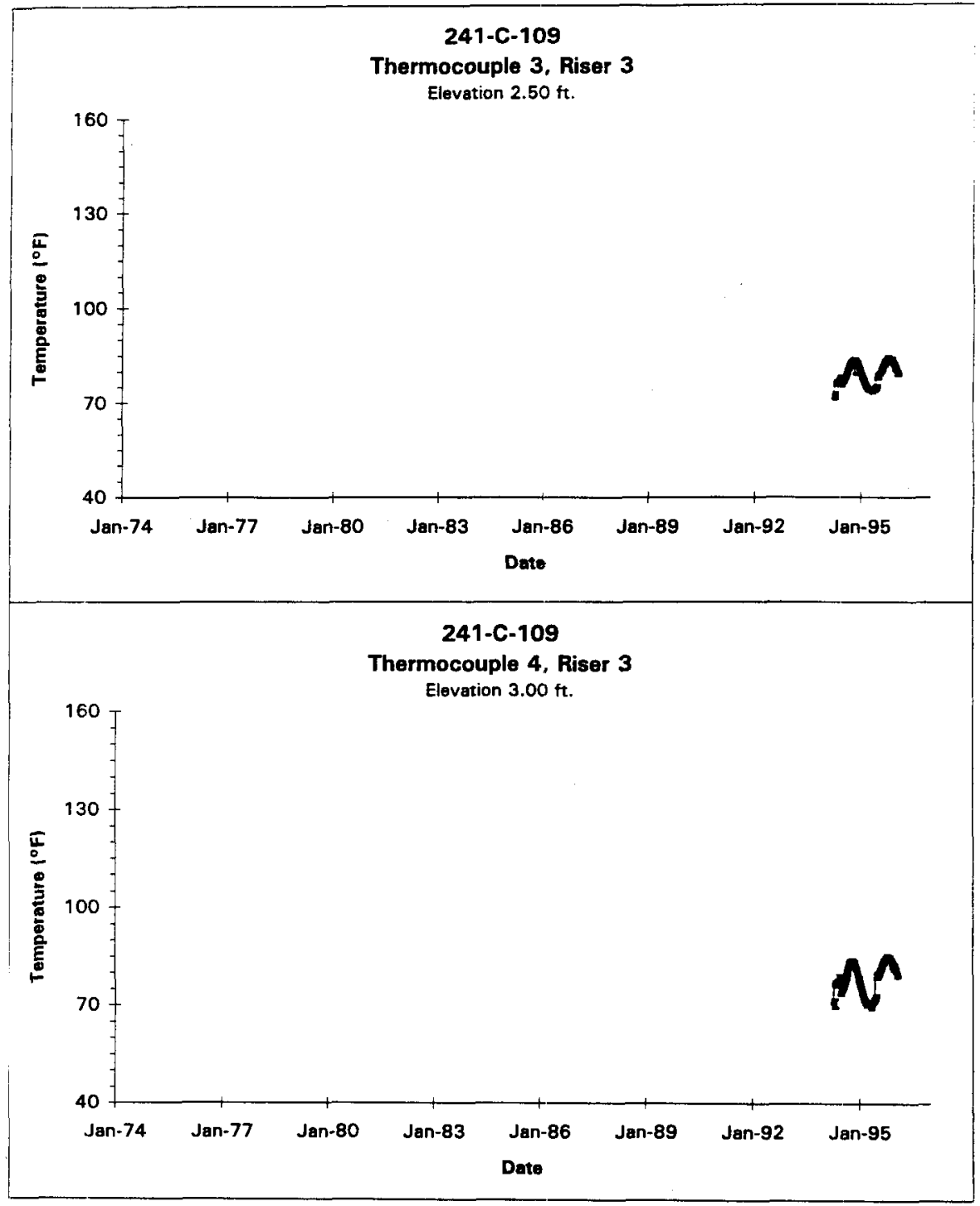

Data obtained from WHC Surveillance Analysis Computer System (SACS), Jan 9, 1996. 


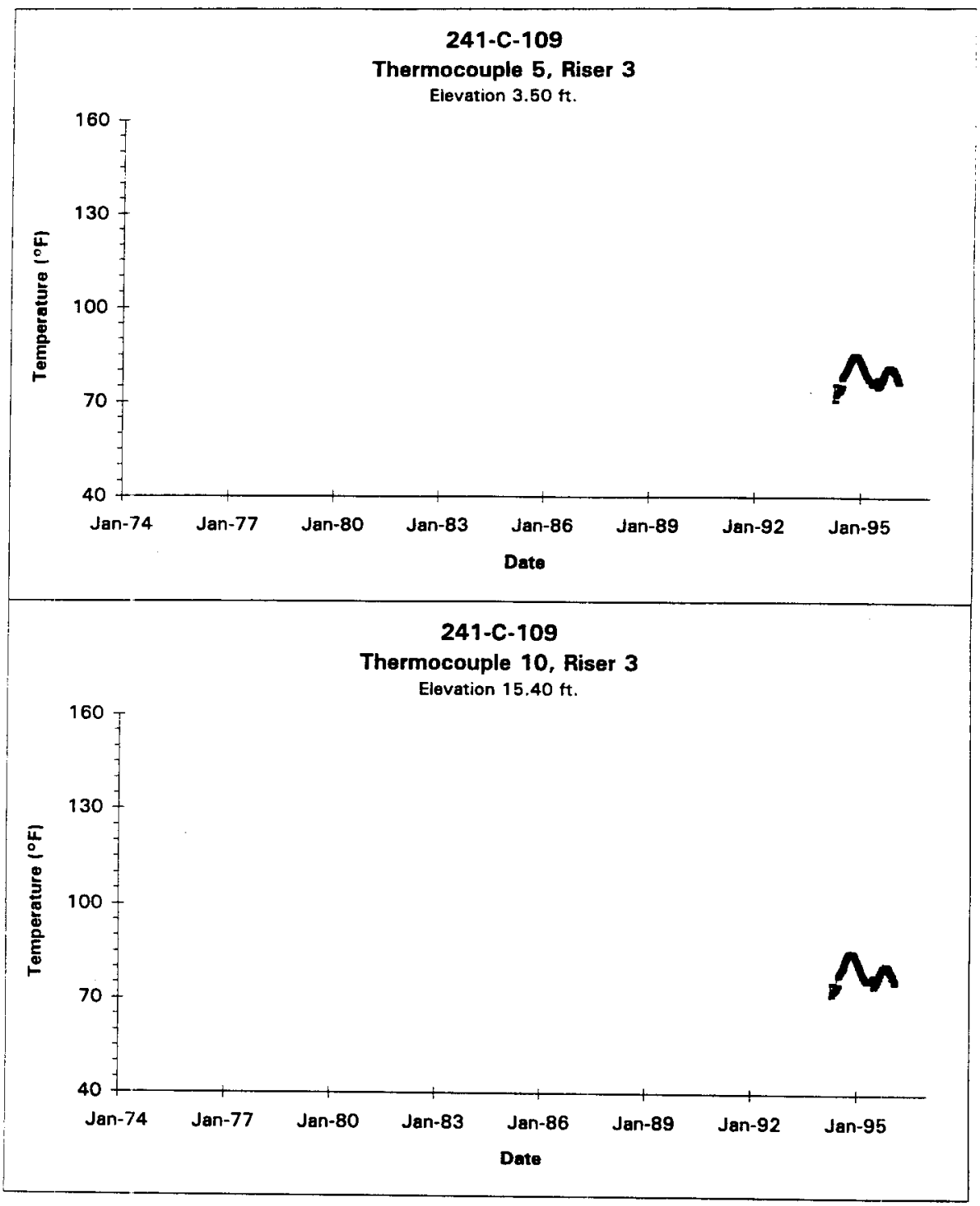

Data obtained from WHC Surveillance Analysis Computer System (SACS), Jan 9, 1996. 


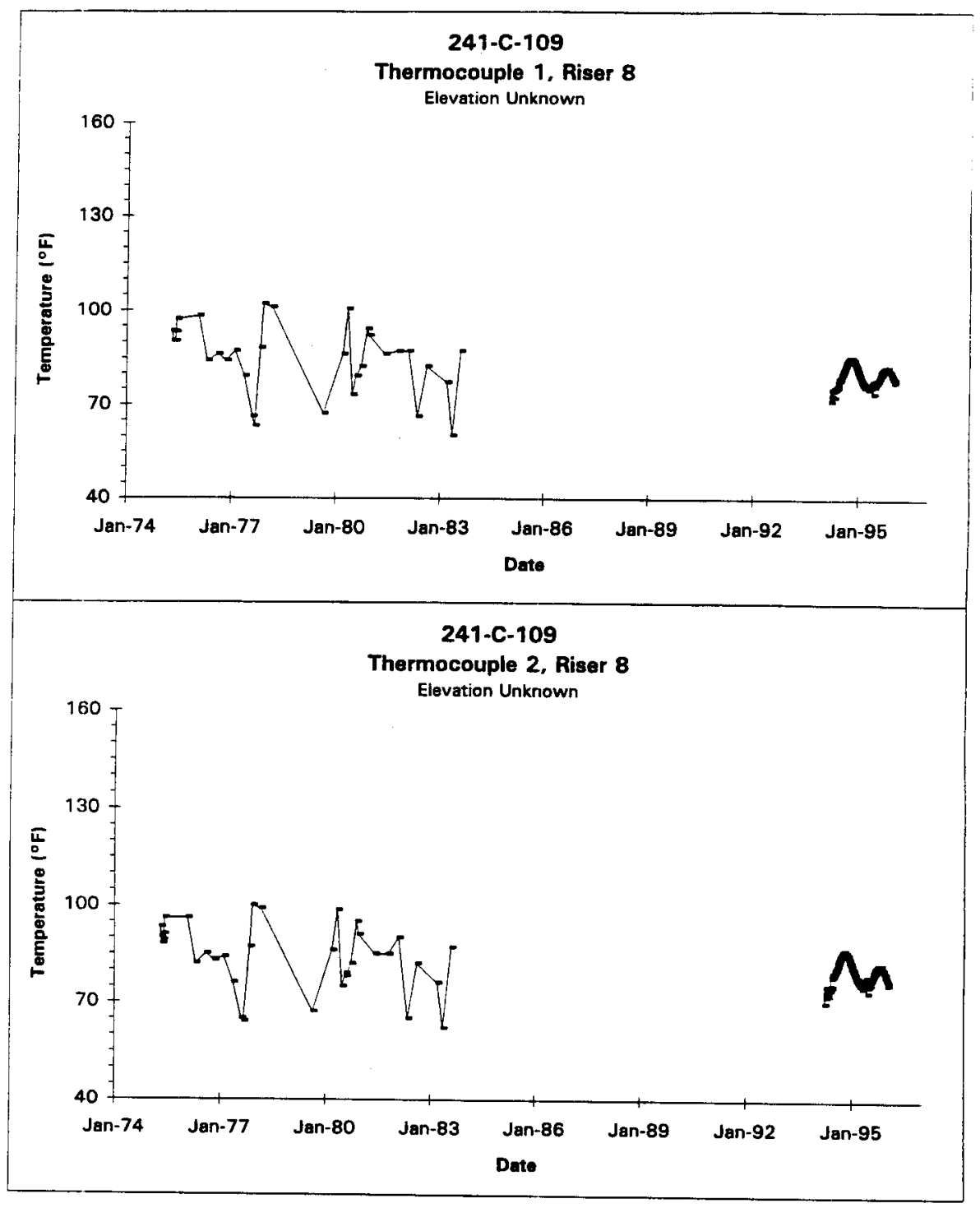

Data obtained from WHC Surveillance Analysis Computer System (SACS), Jan 9, 1996. 


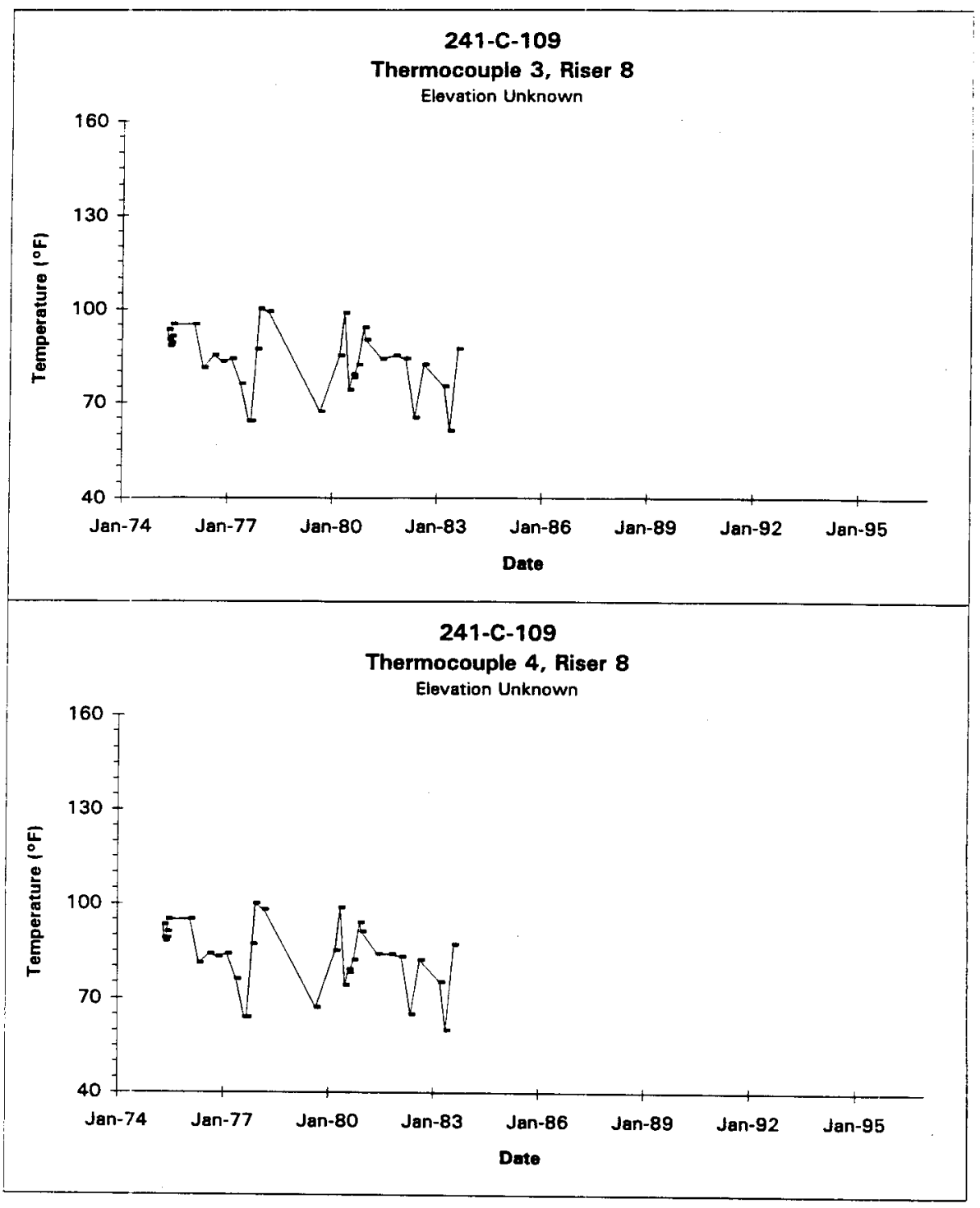

Data obtained from WHC Surveillance Analysis Computer System (SACS), Jan 9, 1996. 


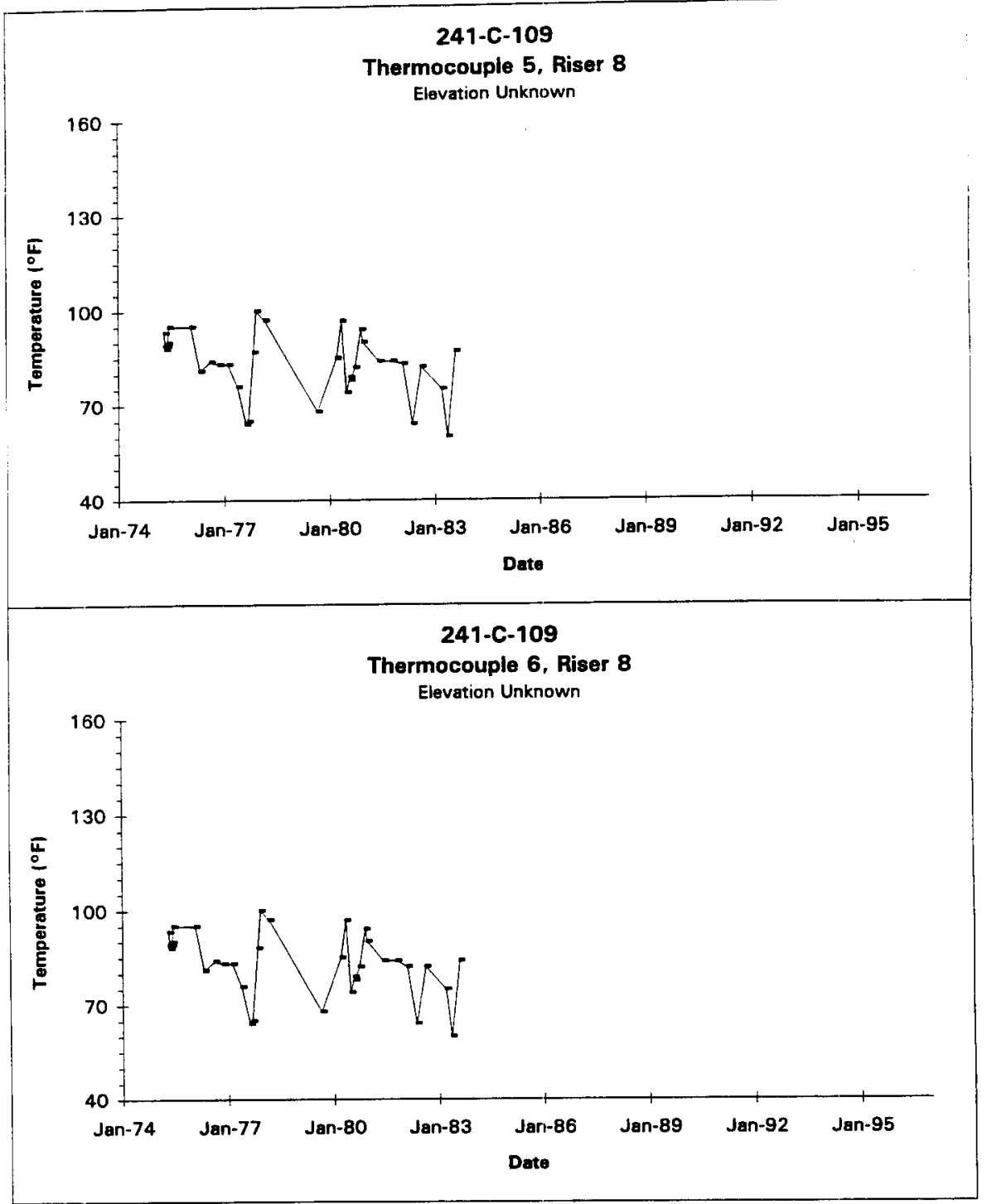

Data obtained from WHC Surveillance Analysis Computer System (SACS), Jan 9, 1996. 


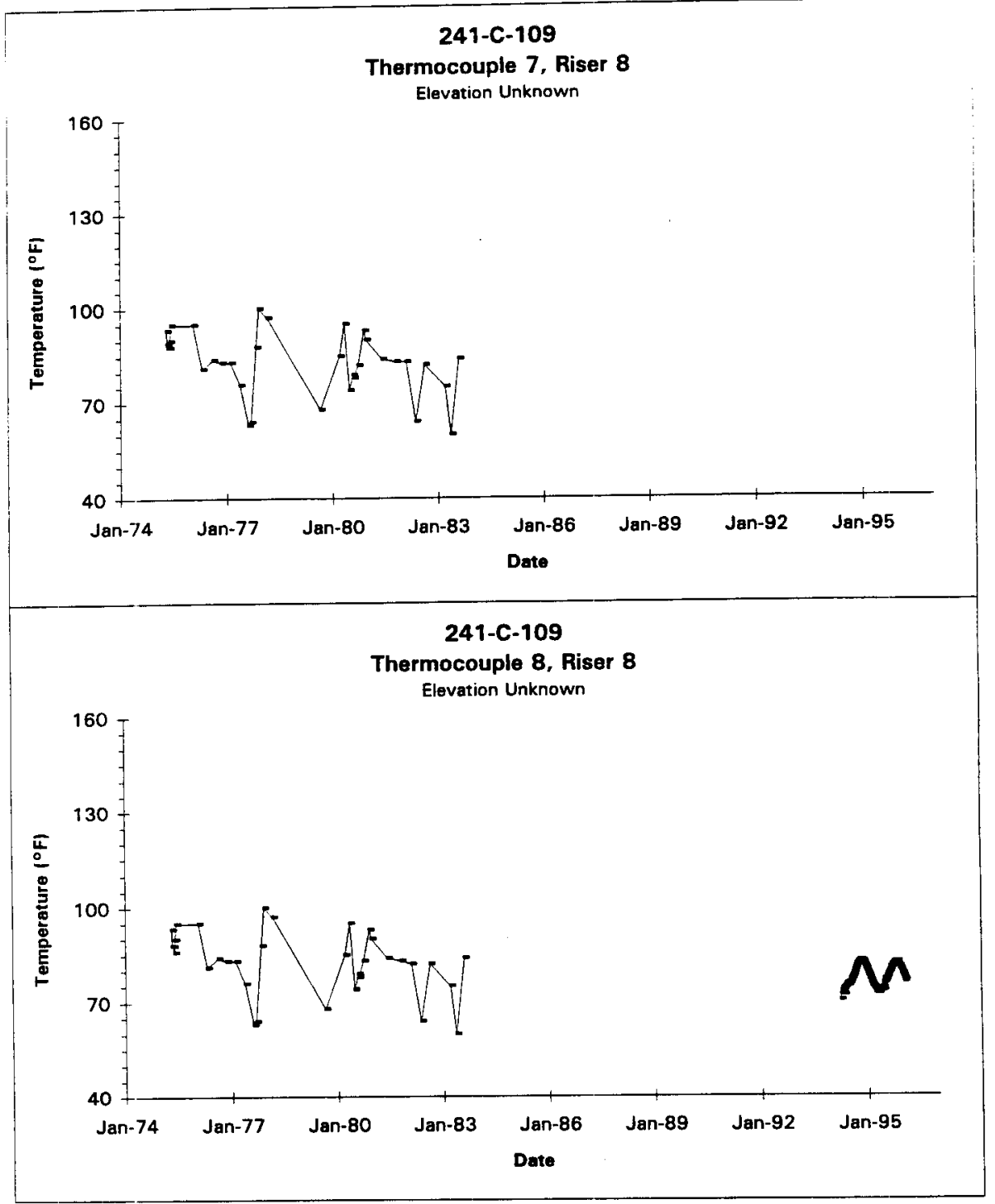

Data obtained from WHC Surveillance Analysis Computer System (SACS), Jan 9, 1996.

D-52 


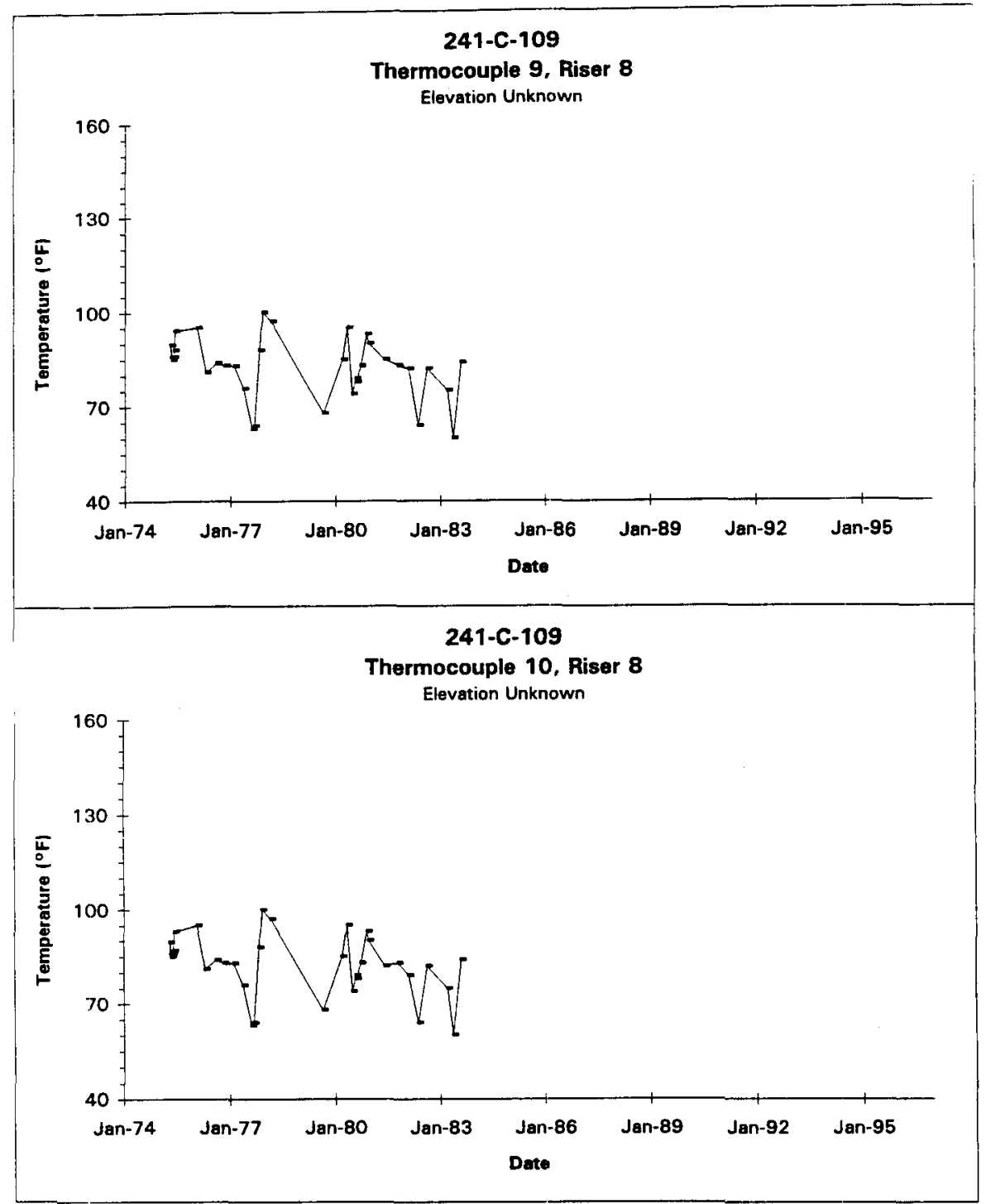

Data obtained from WHC Surveillance Analysis Computer System (SACS), Jan 9, 1996. 
WHC-SD-WM-ER-313, Rev. 1

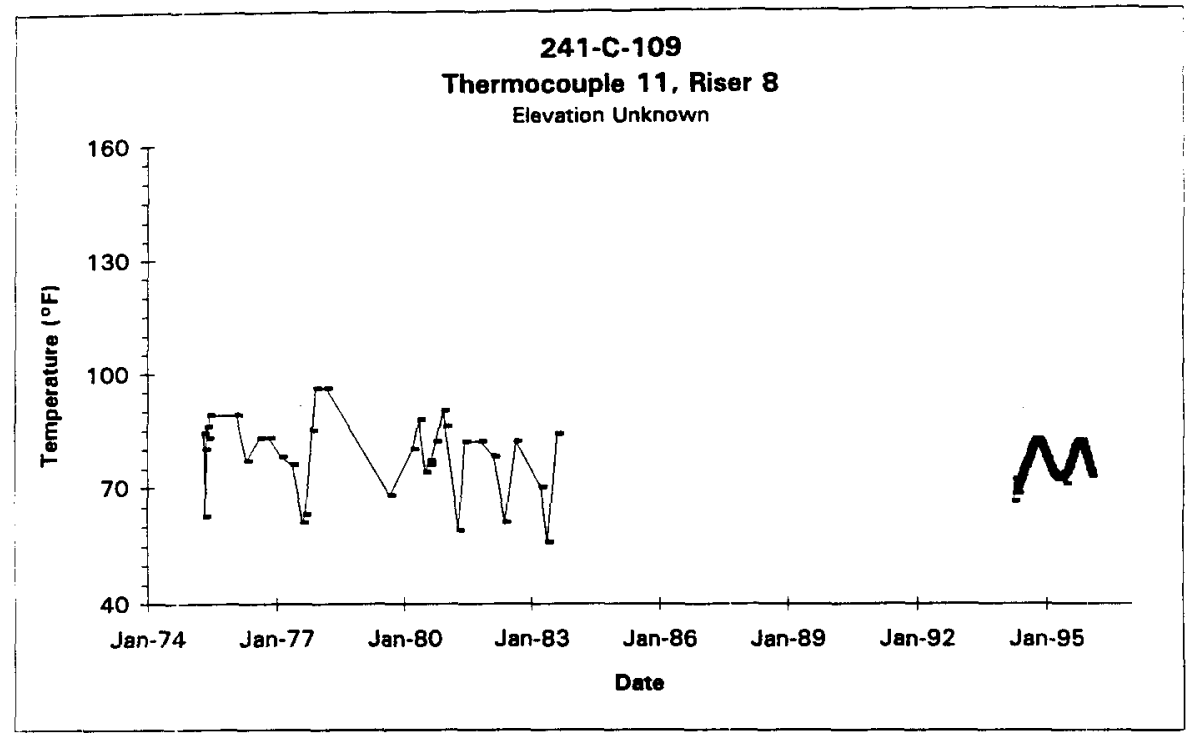

Data obtained from WHC Surveillance Analysis Computer System (SACS), Jan 9, 1996.

D-54 


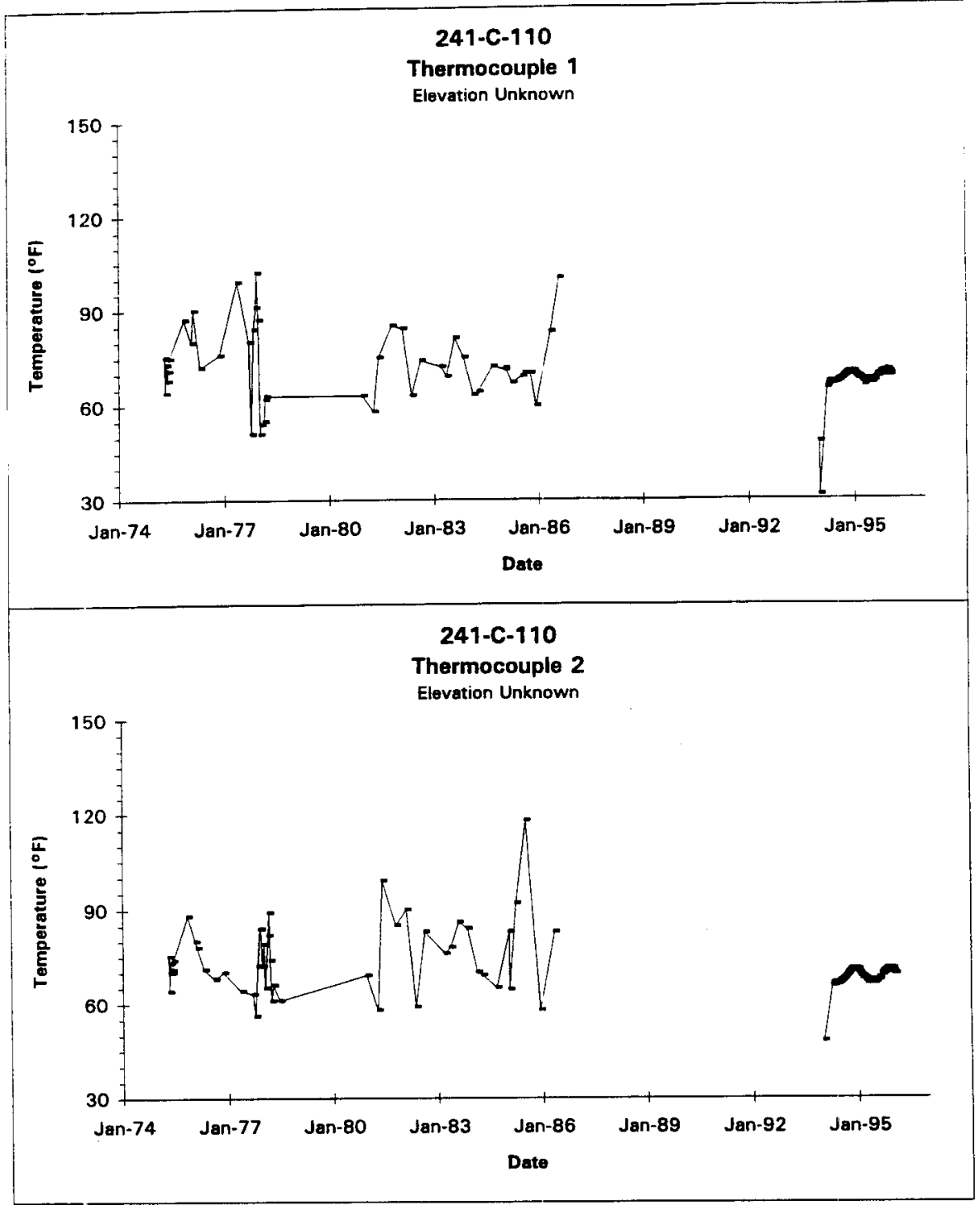

Data obtained from WHC Surveillance Analysis Computer System (SACS), Jan 9, 1996.

$$
\text { D-55 }
$$




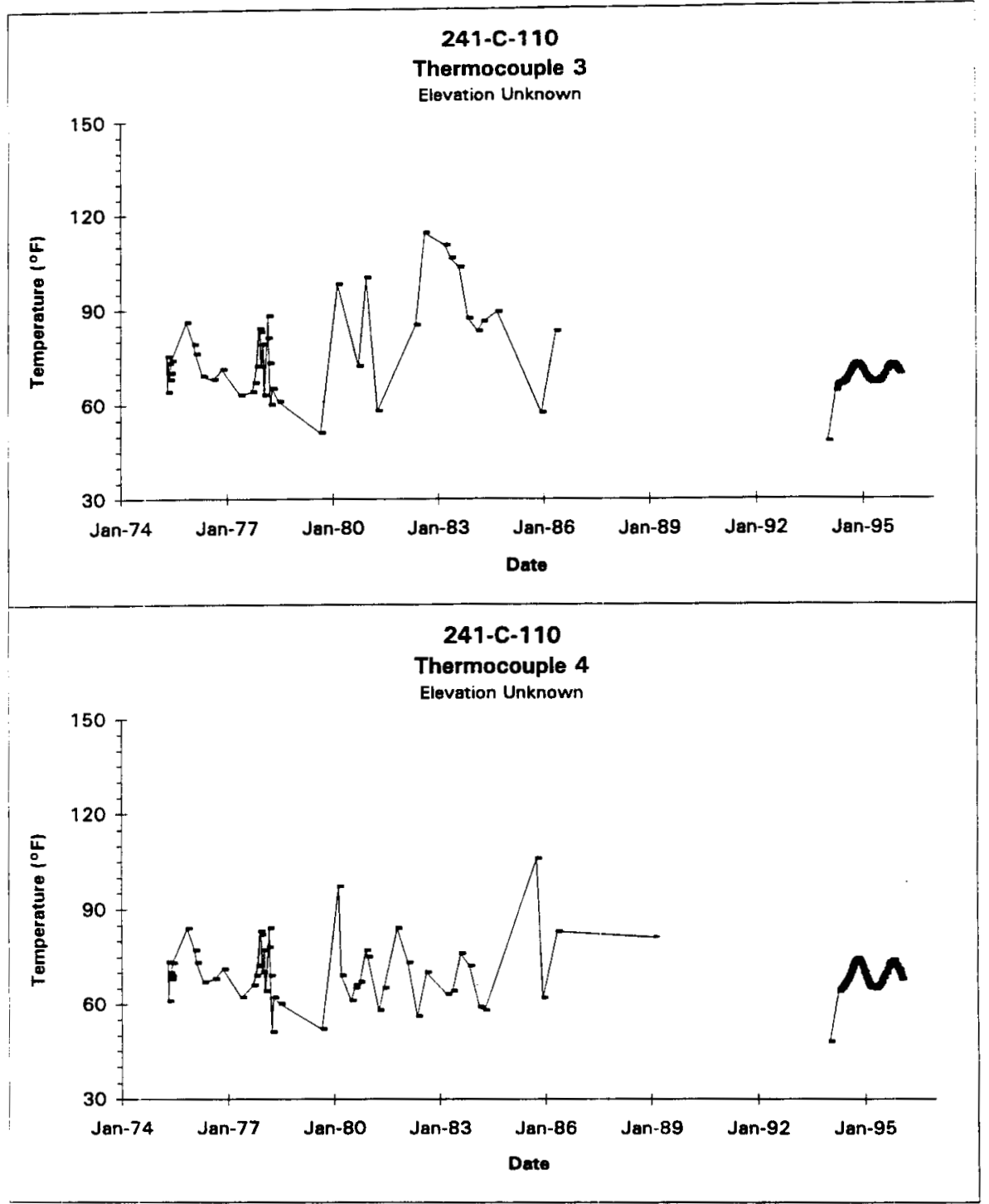

Data obtained from WHC Surveillance Analysis Computer System (SACS), Jan 9, 1996.

D-56 


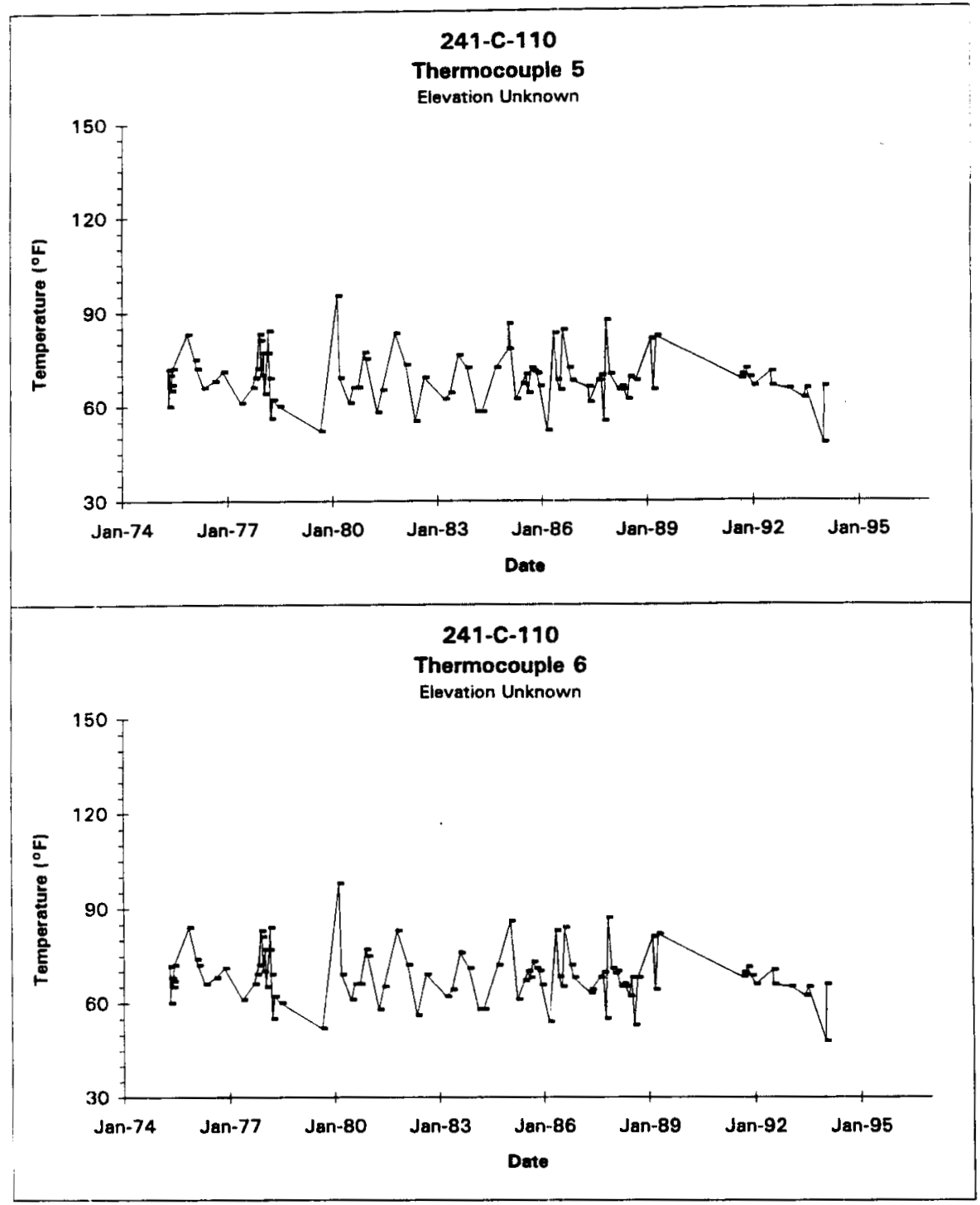

Data obtained from WHC Surveillance Analysis Computer System (SACS), Jan 9, 1996. 


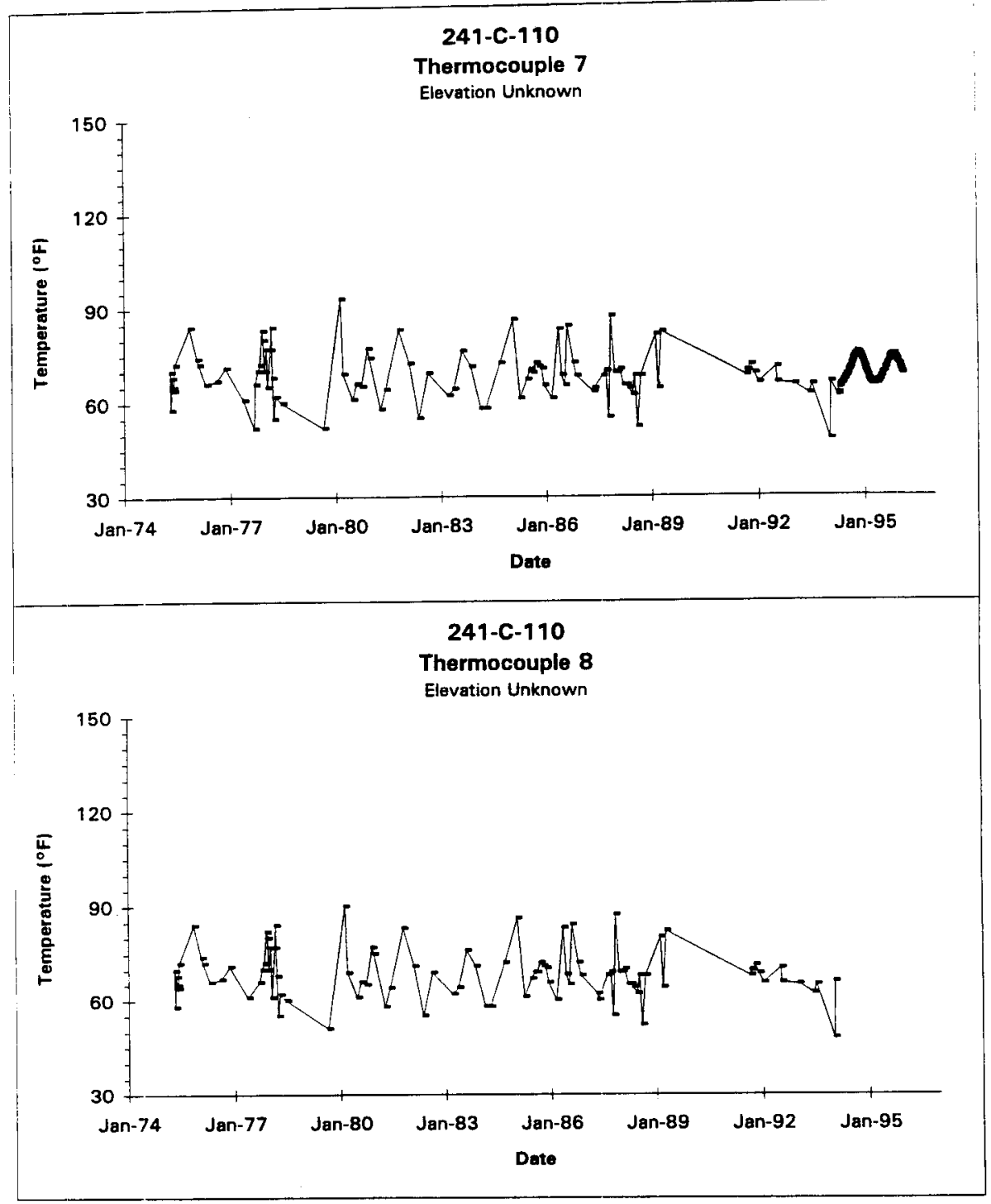

Data obtained from WHC Surveillance Analysis Computer System (SACS), Jan 9, 1996.

D-58 


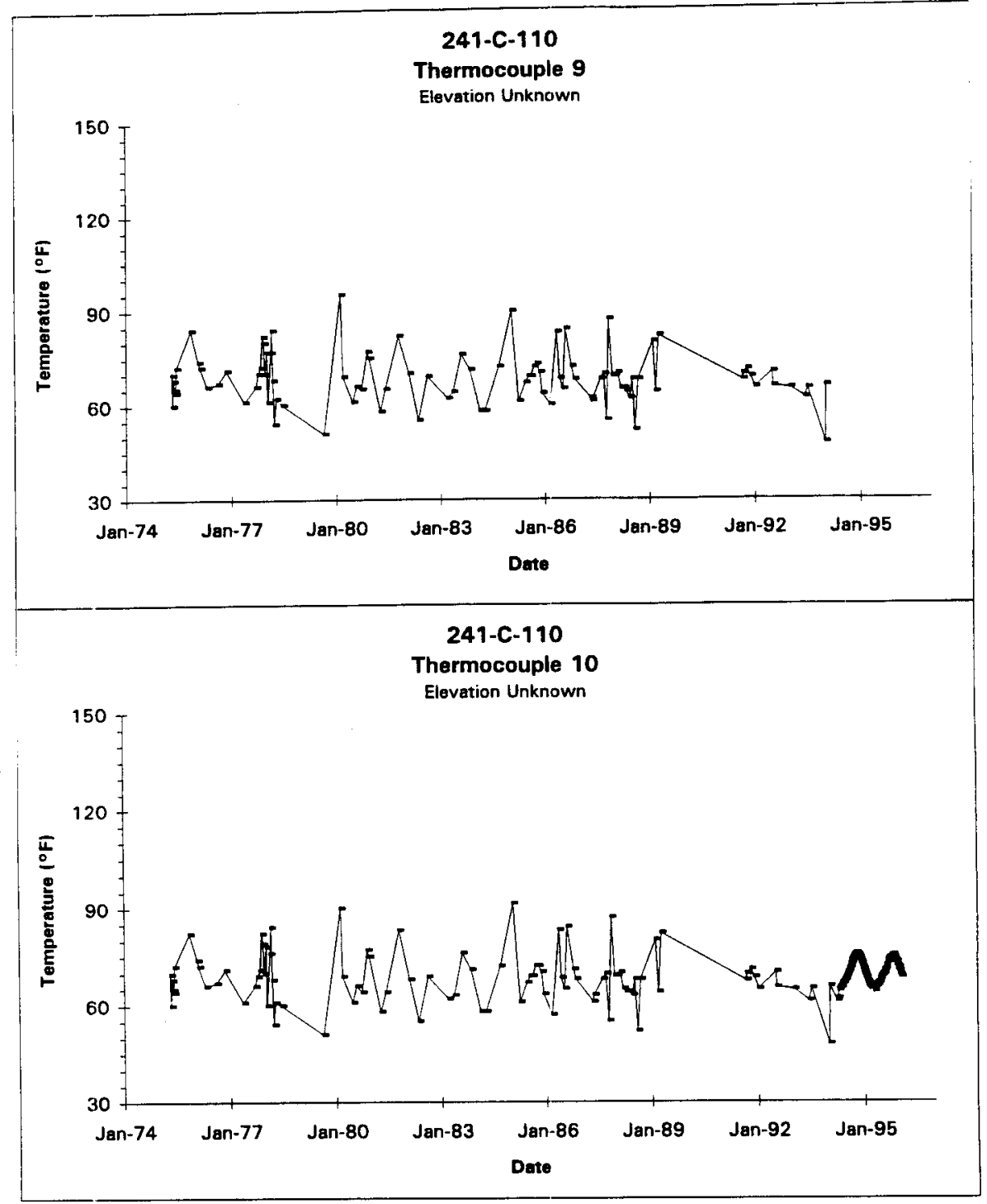

Data obtained from WHC Surveillance Analysis Computer System (SACS), Jan 9, 1996.

D-59 


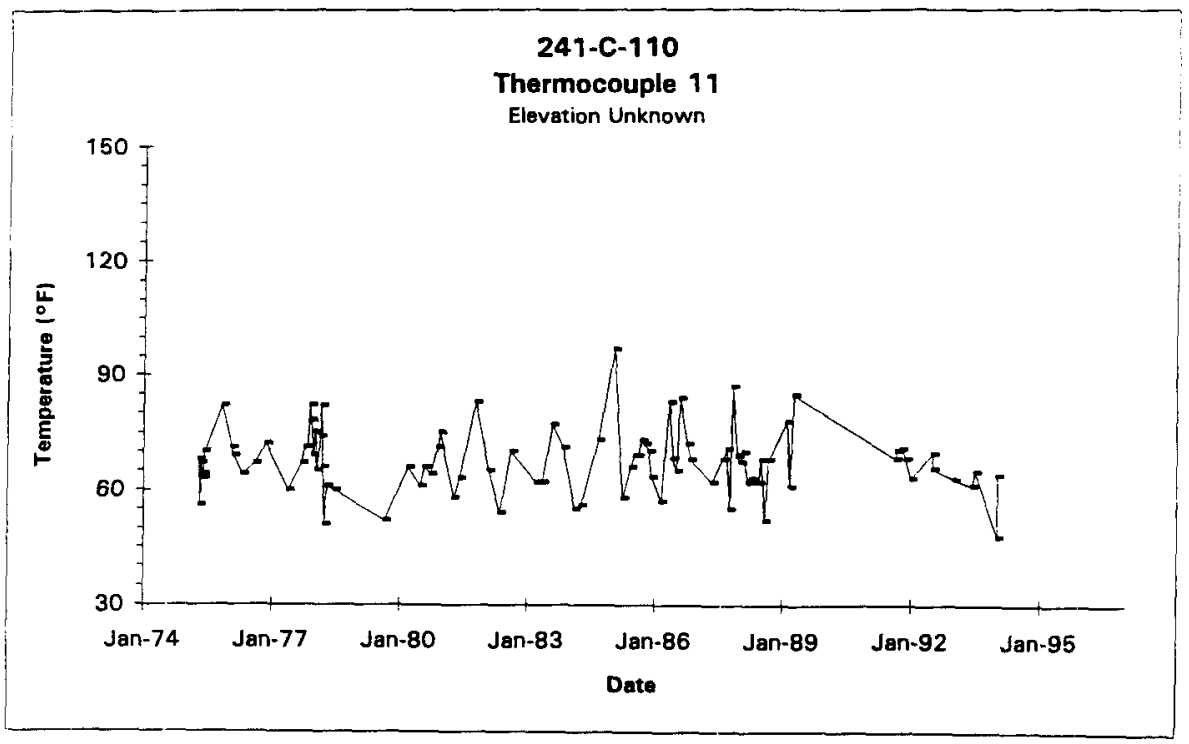

Data obtained from WHC Surveillance Analysis Computer System (SACS), Jan 9, 1996. 


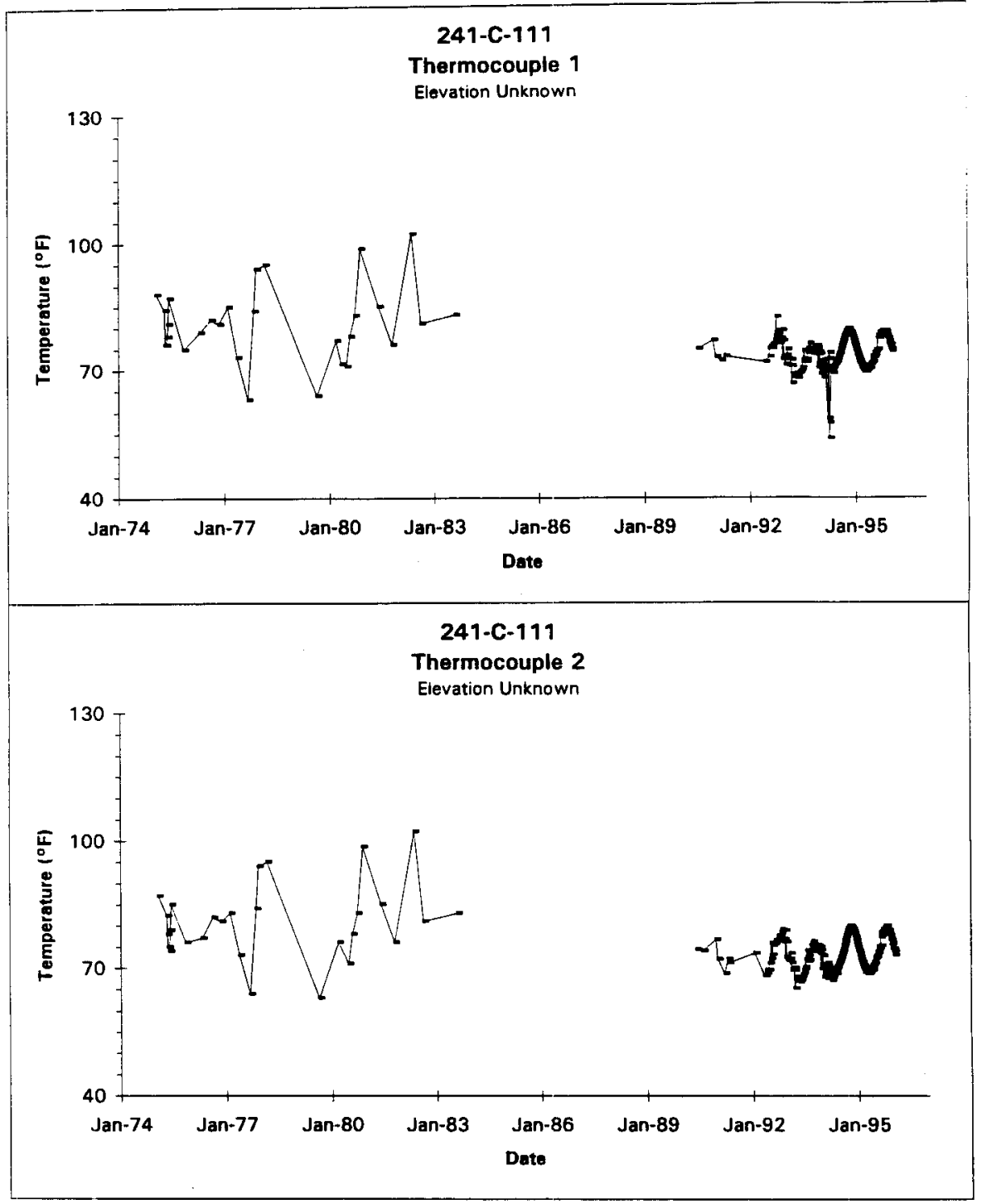

Data obtained from WHC Surveillance Analysis Computer System (SACS), Jan 9, 1996. 


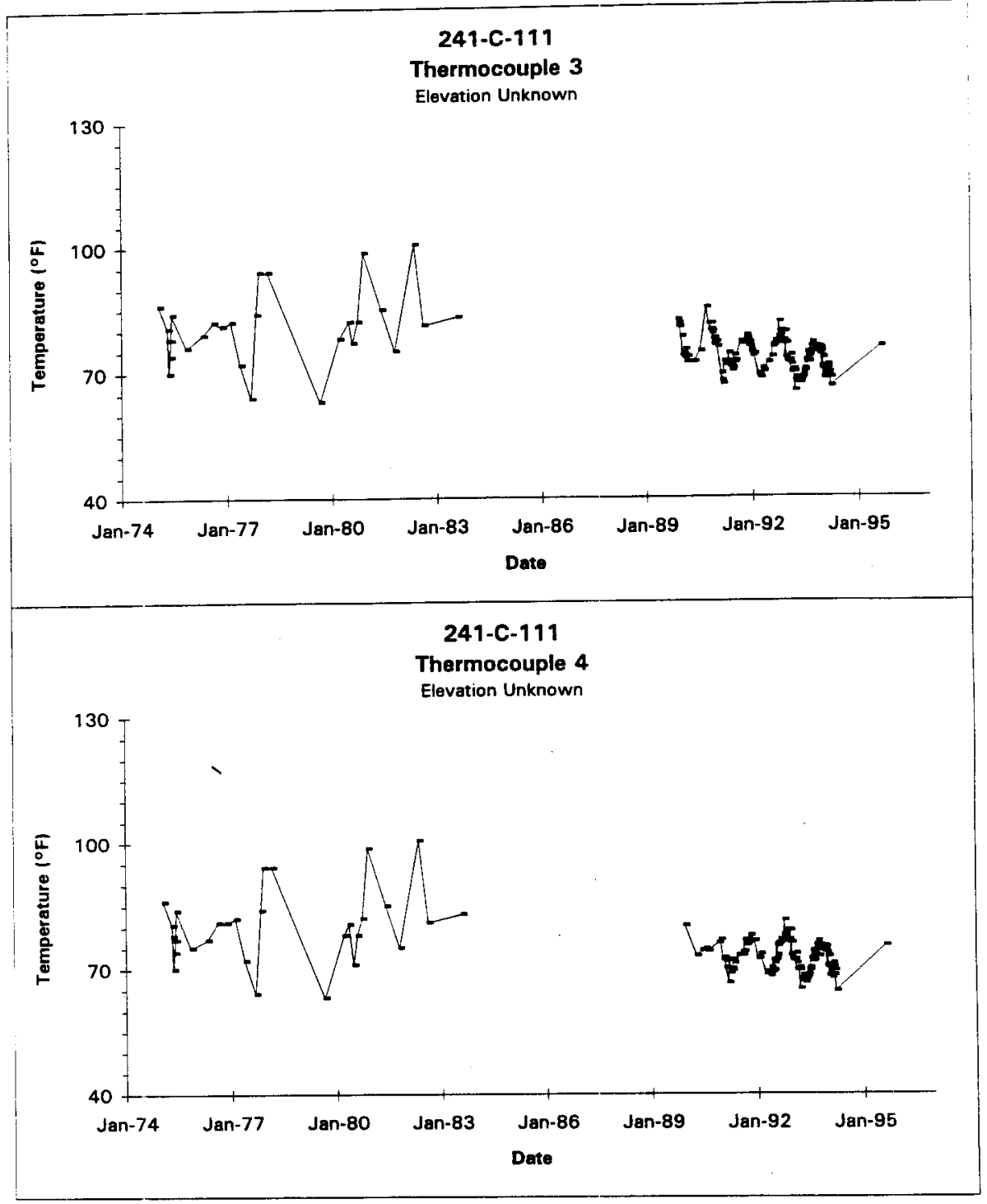

Data obtained from WHC Surveillance Analysis Computer System (SACS), Jan 9, 1996. 


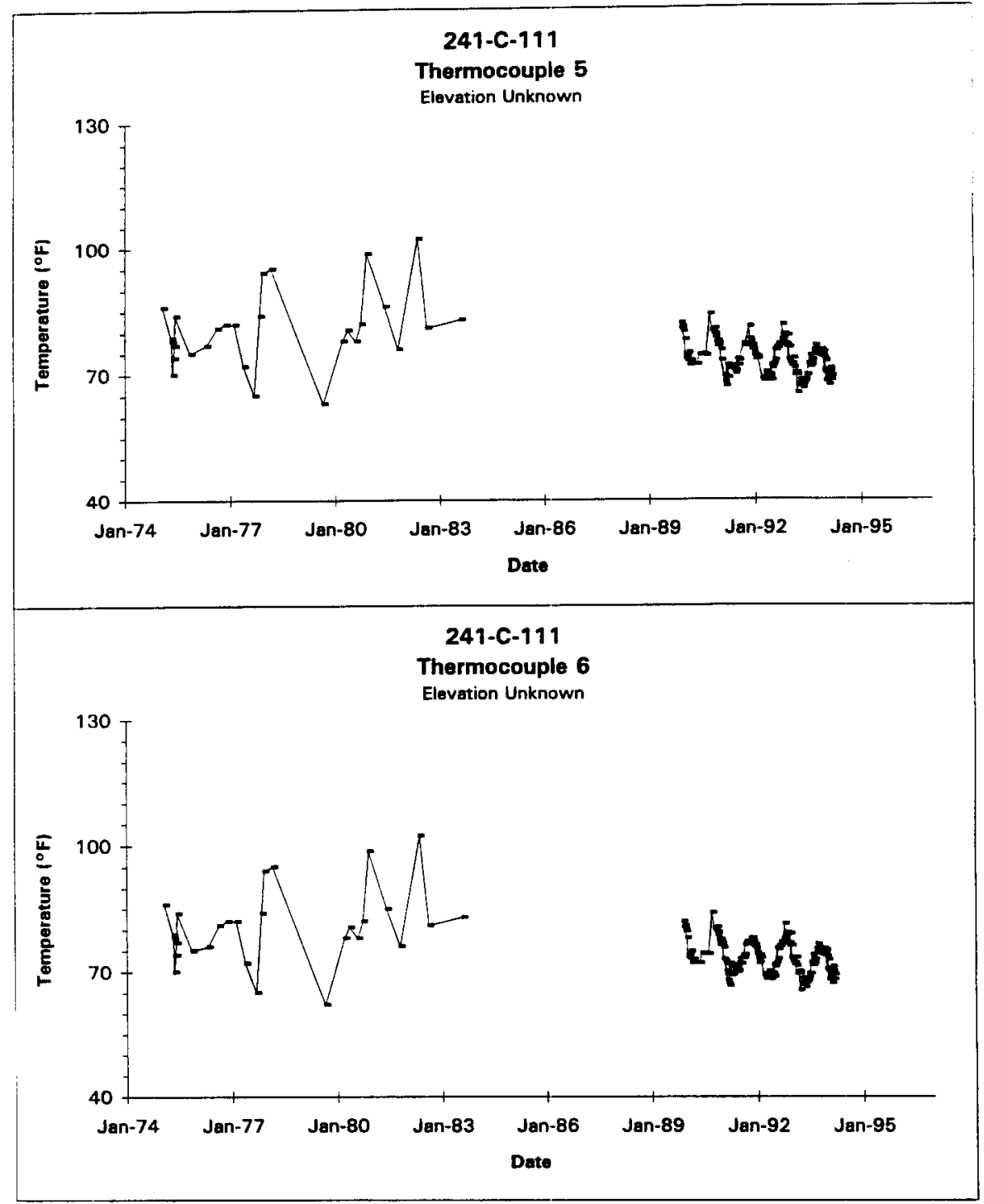

Data obtained from WHC Surveillance Analysis Computer System (SACS), Jan 9, 1996. 


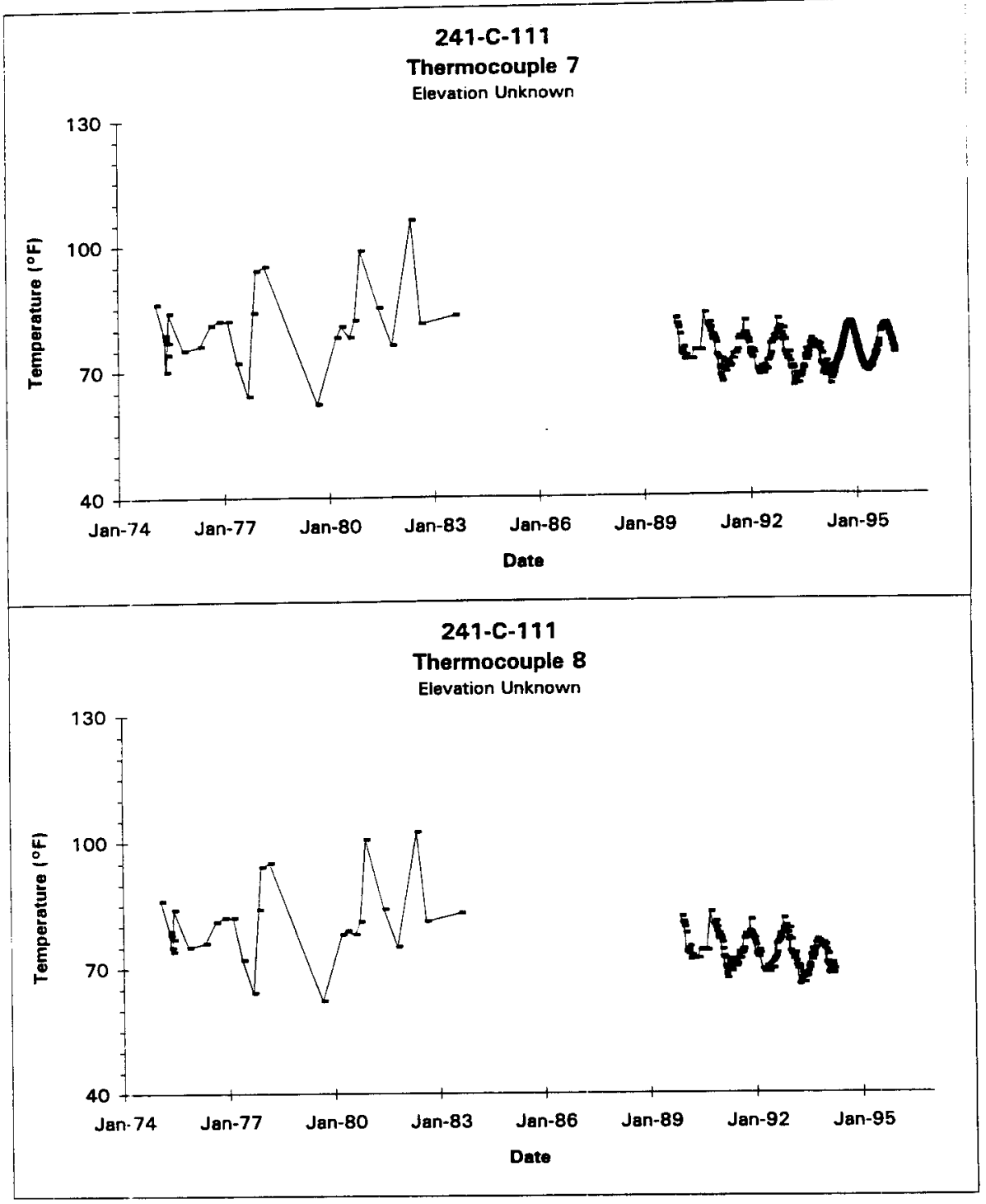

Data obtained from WHC Surveillance Analysis Computer System (SACS), Jan 9, 1996. 


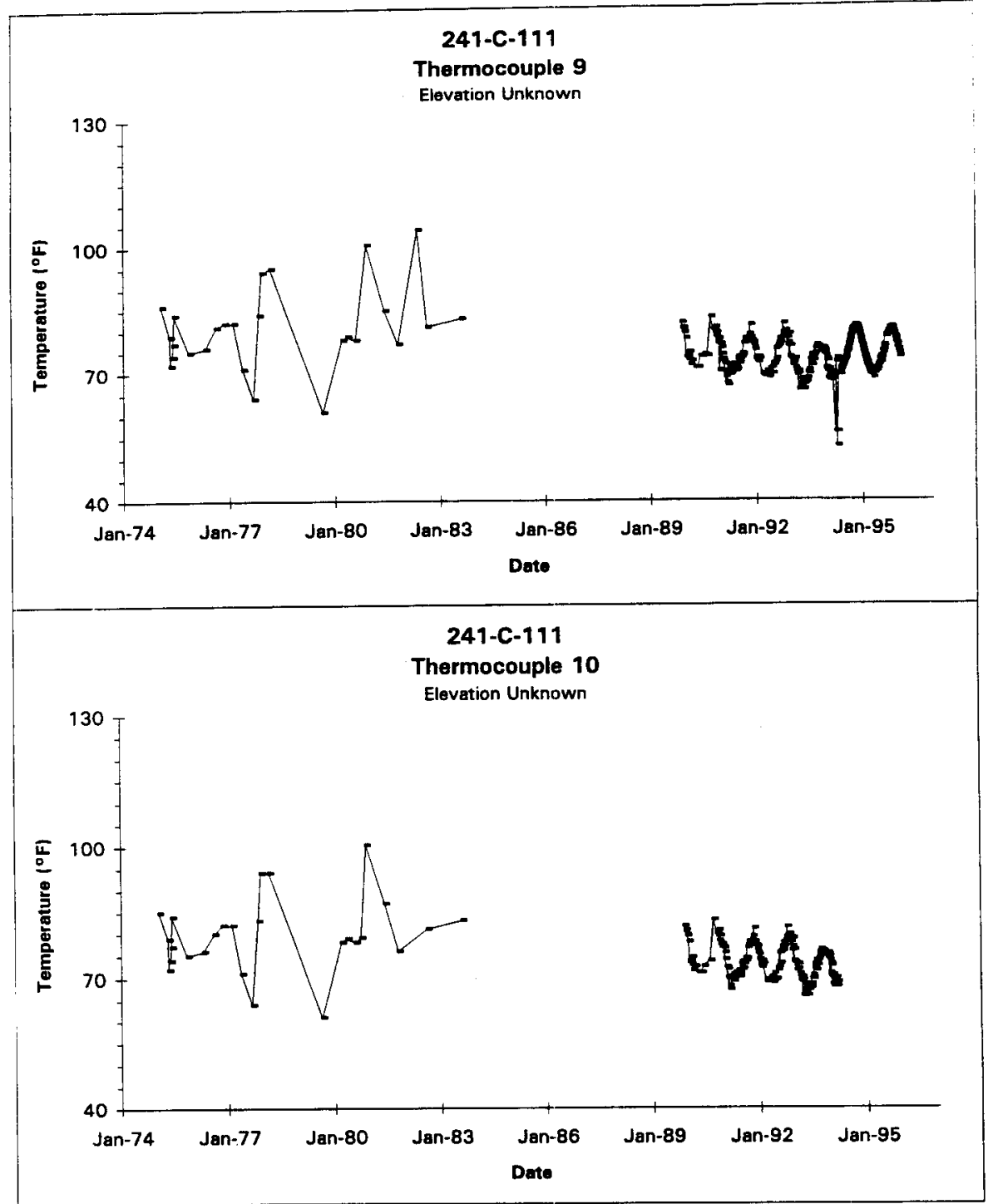

Data obtained from WHC Surveillance Analysis Computer System (SACS), Jan 9, 1996. 


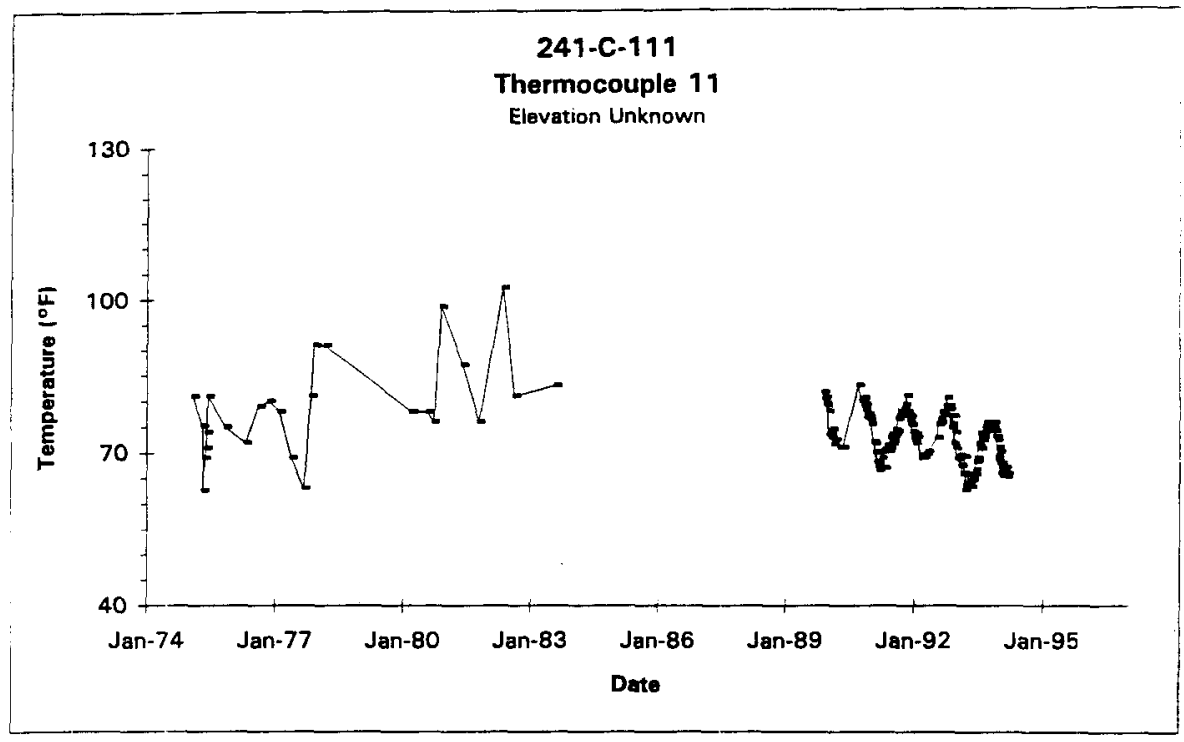

Data obtained from WHC Surveillance Analysis Computer System (SACS), Jan 9, 1996. 


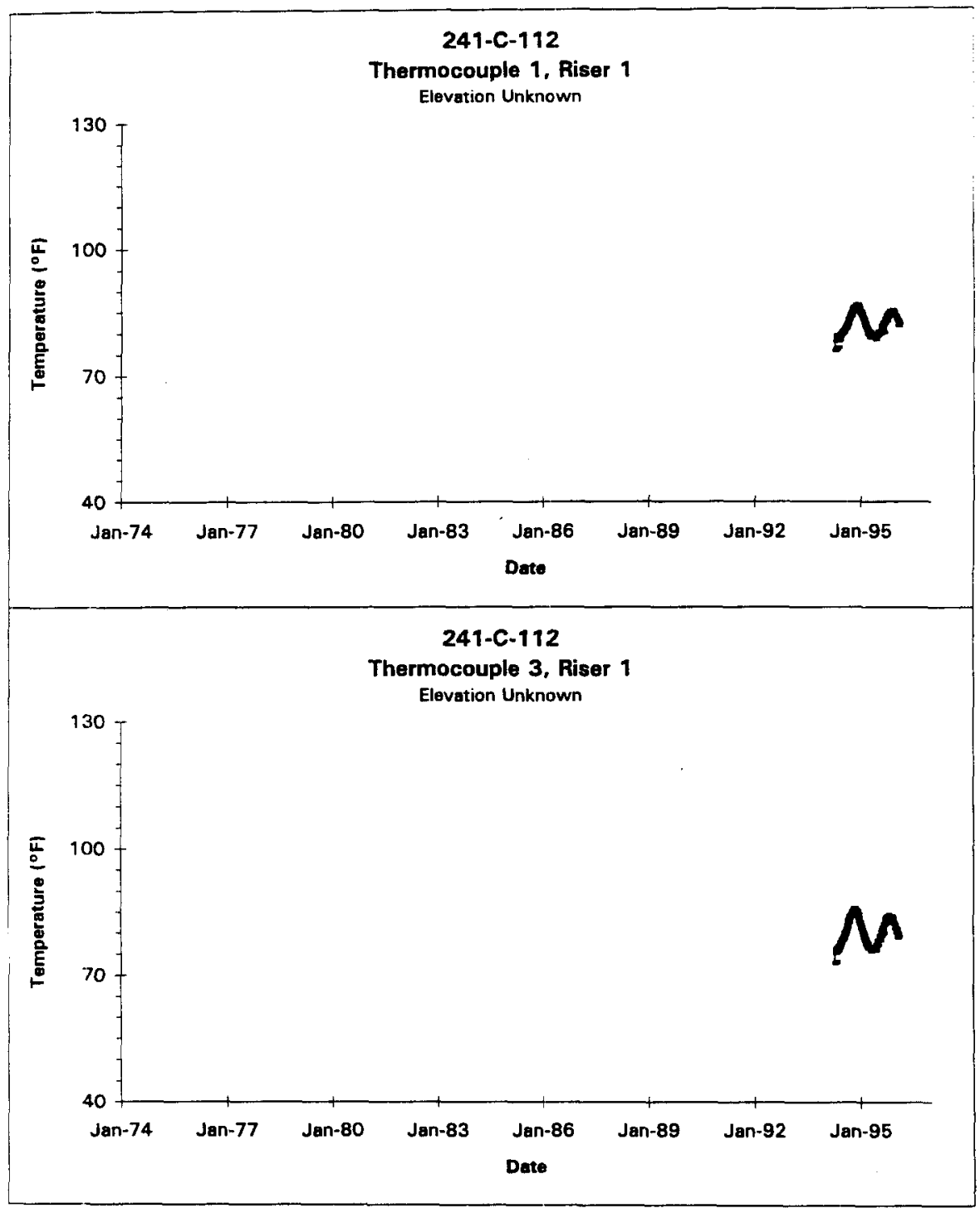

Data obtained from WHC Surveillance Analysis Computer System (SACS), Jan 9, 1996. 


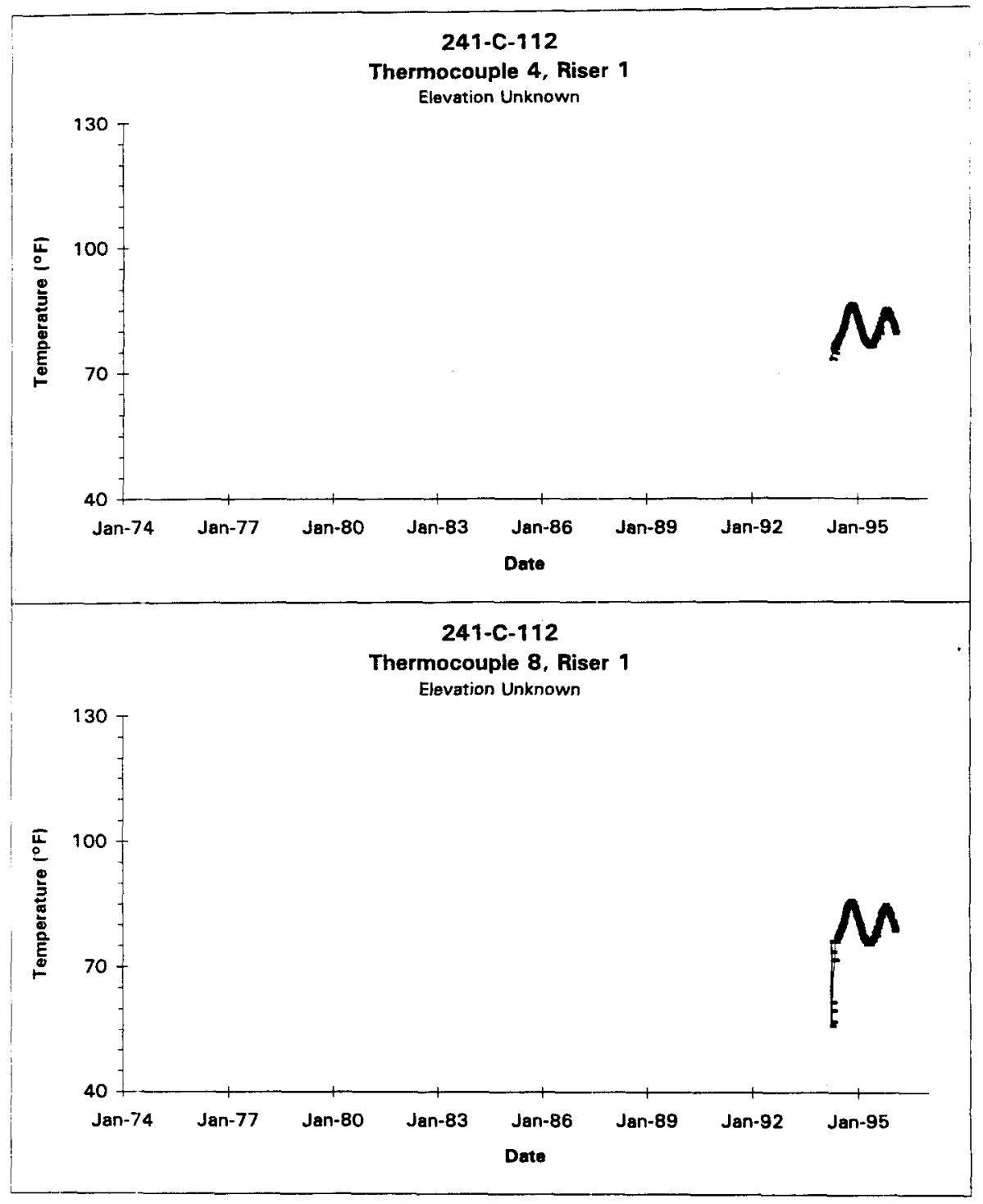

Data obtained from WHC Surveillance Analysis Computer System (SACS), Jan 9, 1996. 


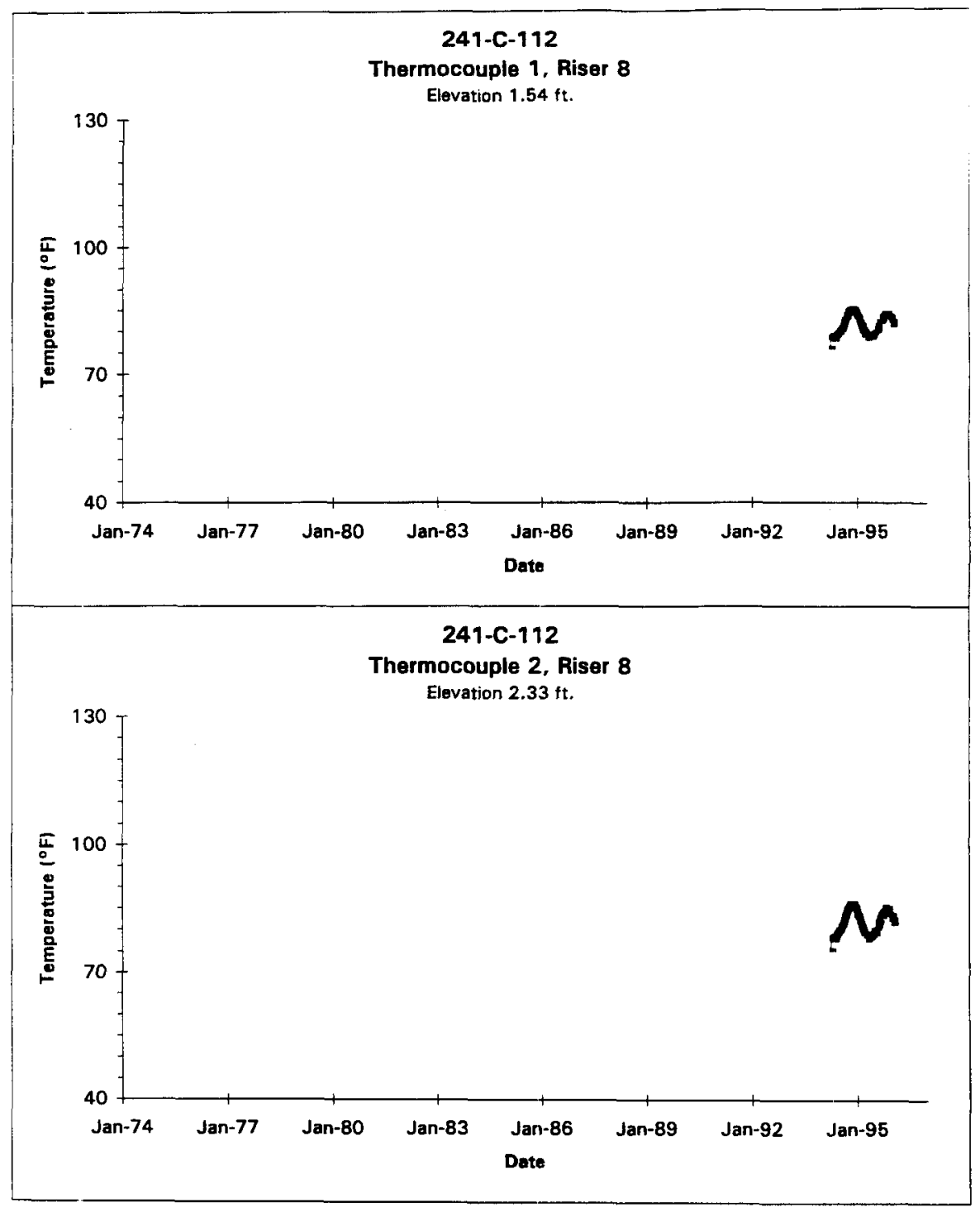

Data obtained from WHC Surveillance Analysis Computer System (SACS), Jan 9, 1996.

D-69 


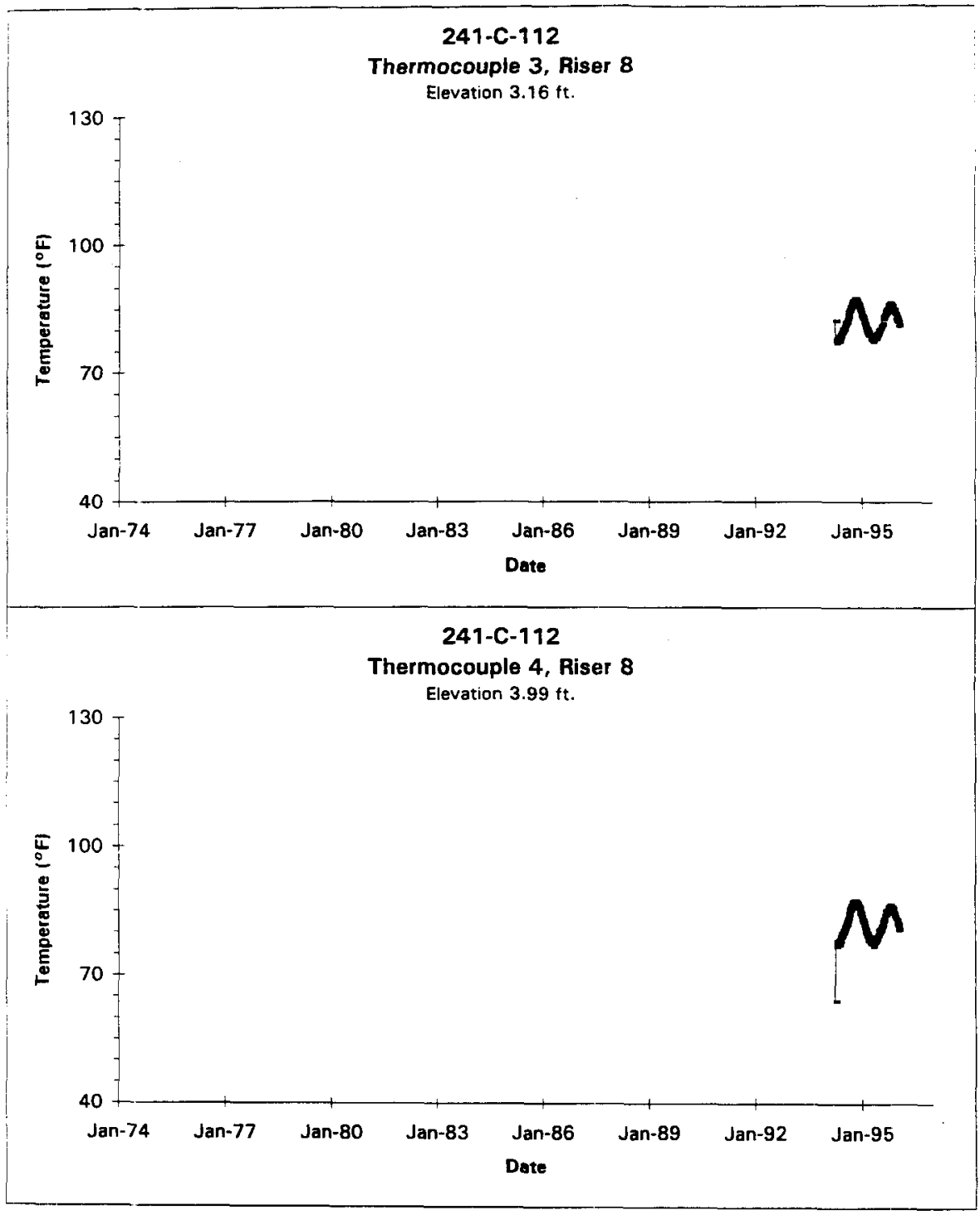

Data obtained from WHC Surveillance Analysis Computer System (SACS), Jan 9, 1996.

$$
\text { D-70 }
$$




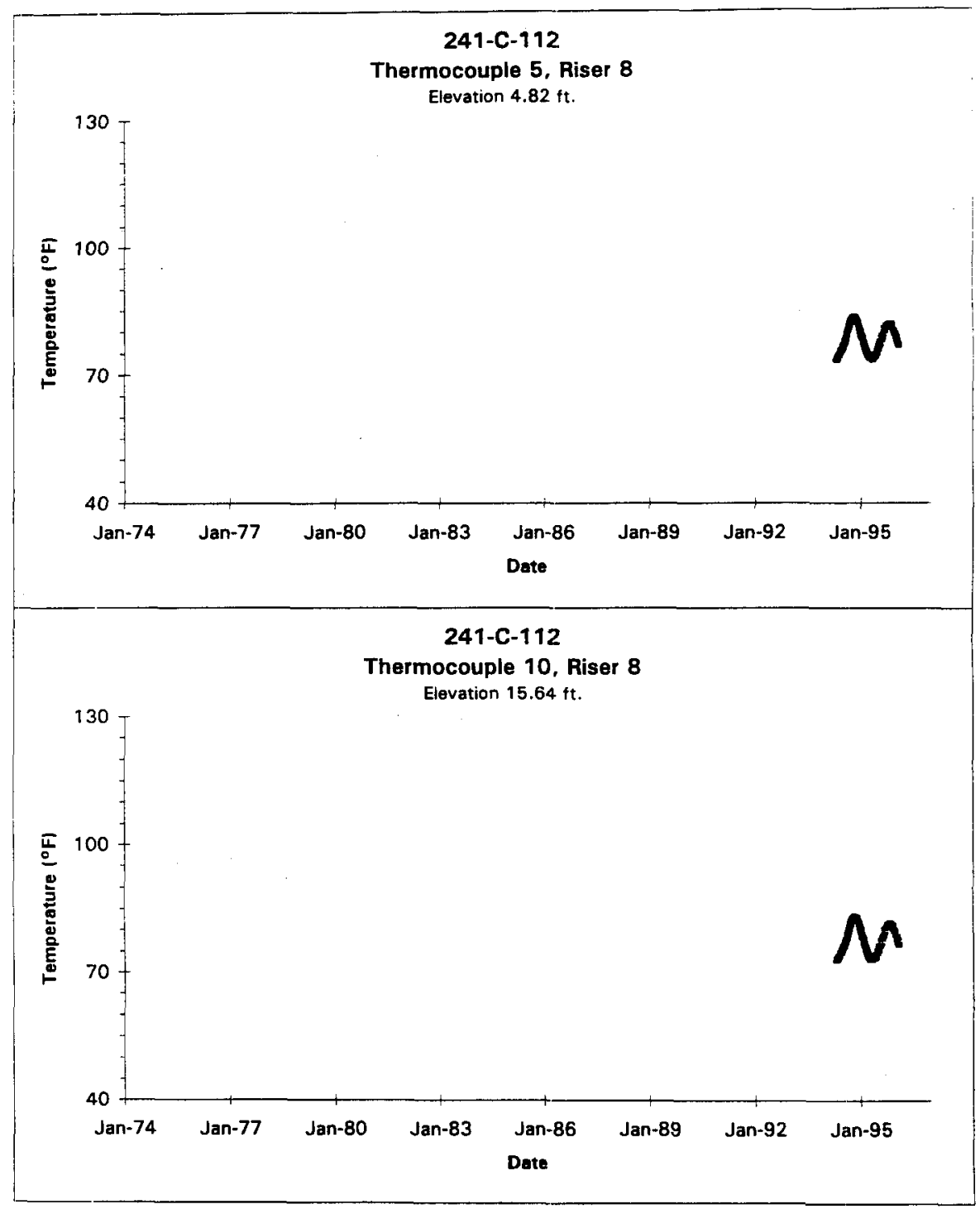

Data obtained from WHC Surveillance Analysis Computer System (SACS), Jan 9, 1996.

D-71 


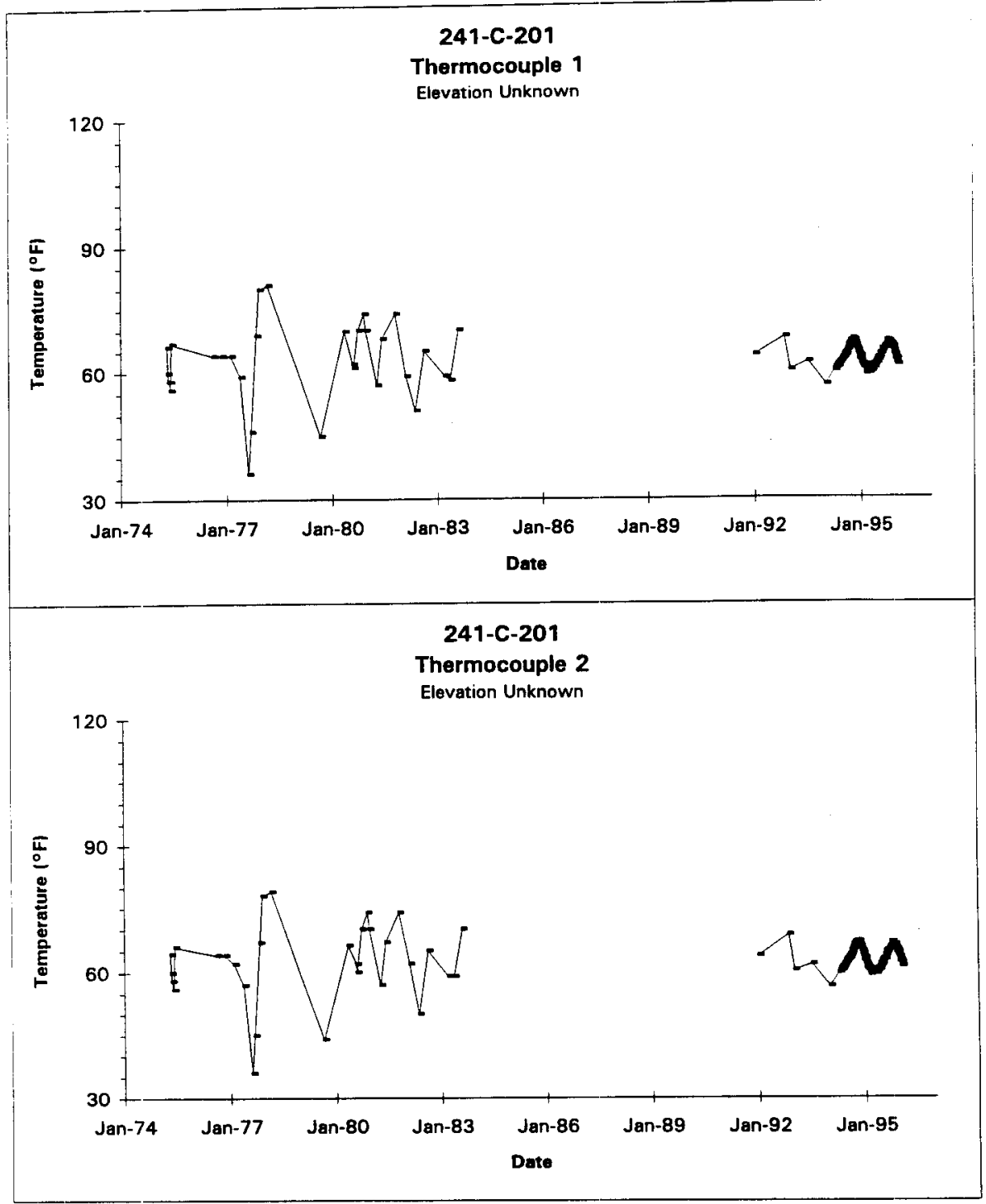

Data obtained from WHC Surveillance Analysis Computer System (SACS), Jan 9, 1996.

D-72 


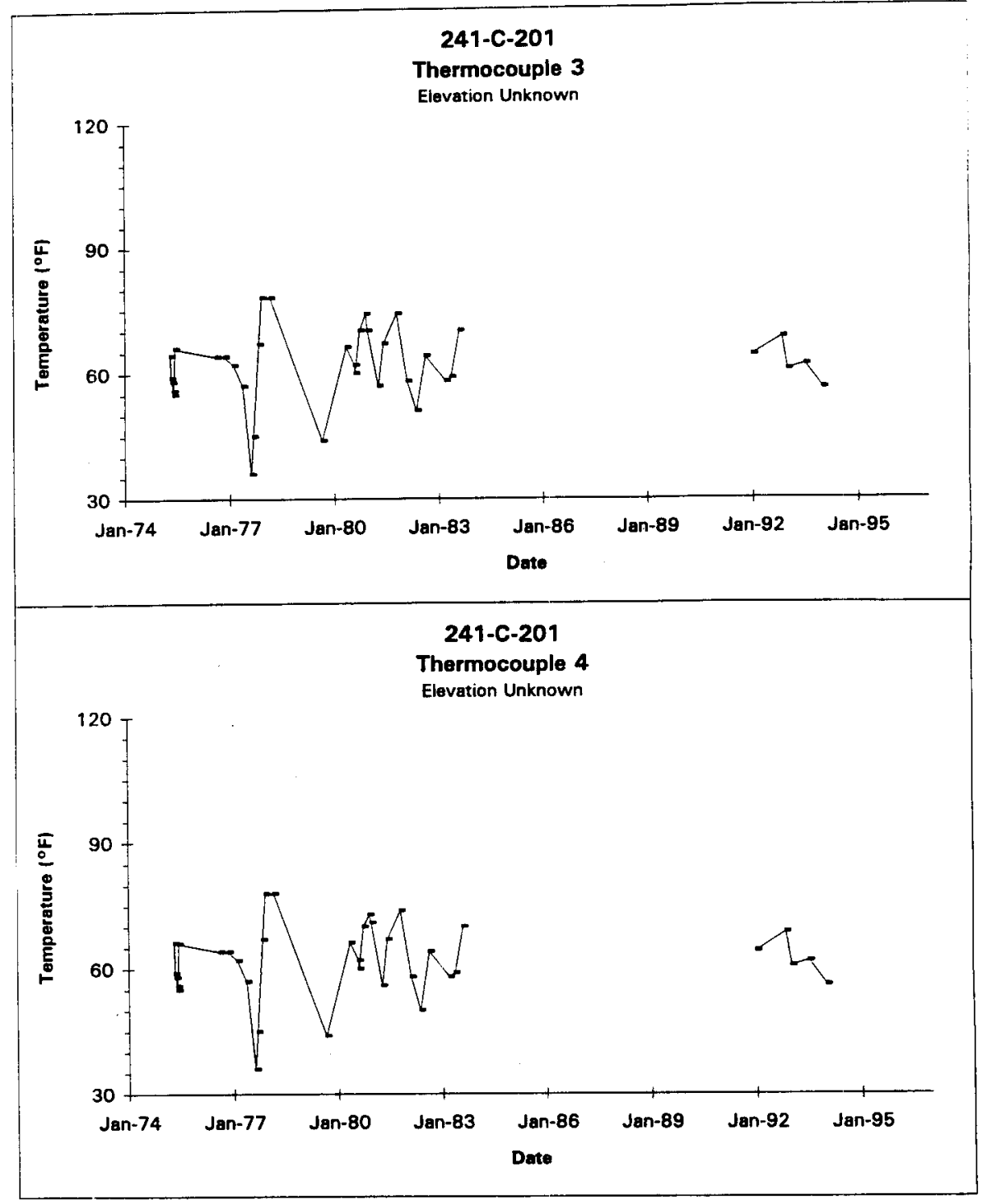

Data obtained from WHC Surveillance Analysis Computer System (SACS), Jan 9, 1996.

D-73 


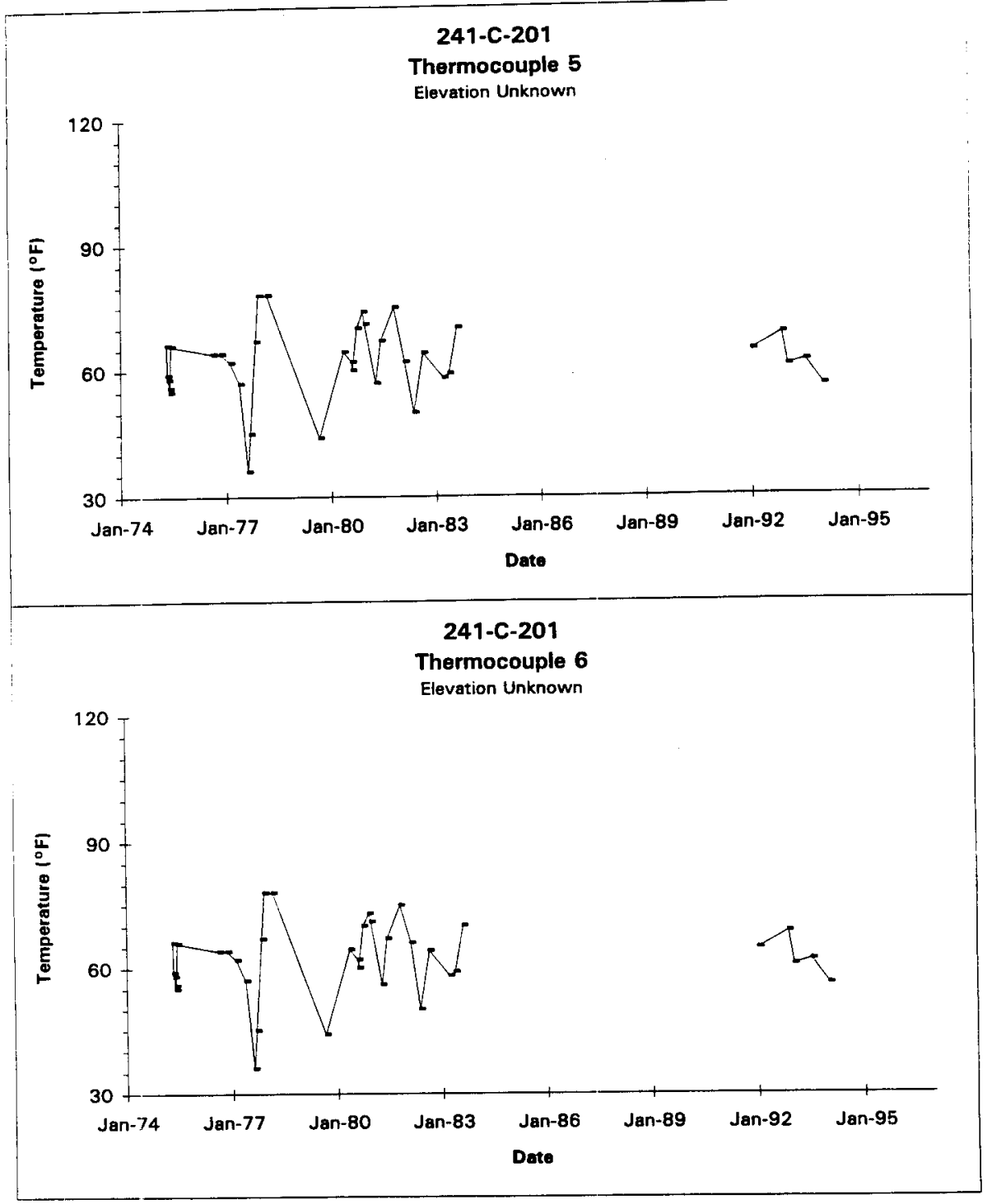

Data obtained from WHC Surveillance Analysis Computer System (SACS), Jan 9, 1996.

D-74 


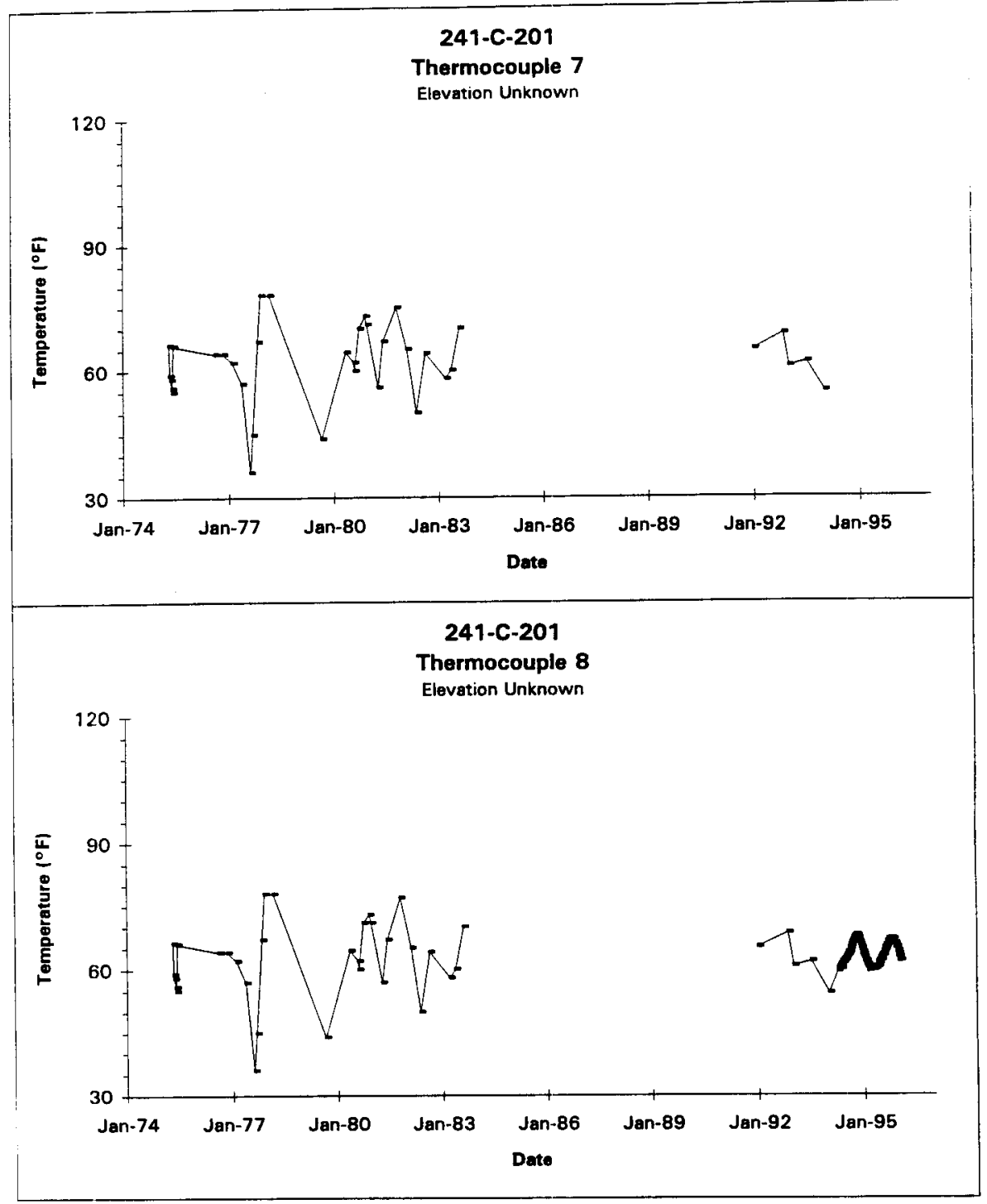

Data obtained from WHC Surveillance Analysis Computer System (SACS), Jan 9, 1996.

D-75 


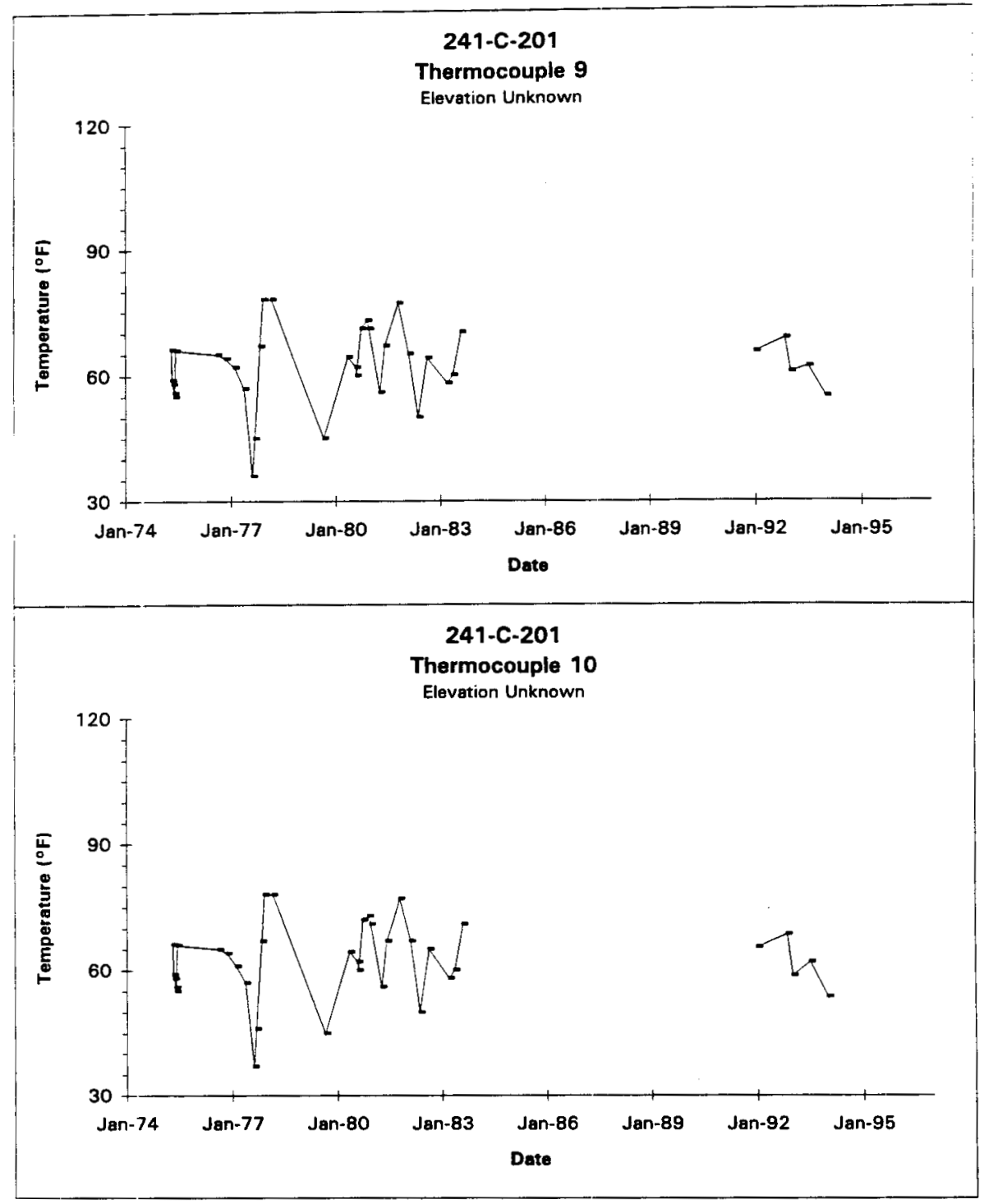

Data obtained from WHC Surveillance Analysis Computer System (SACS), Jan 9, 1996. 


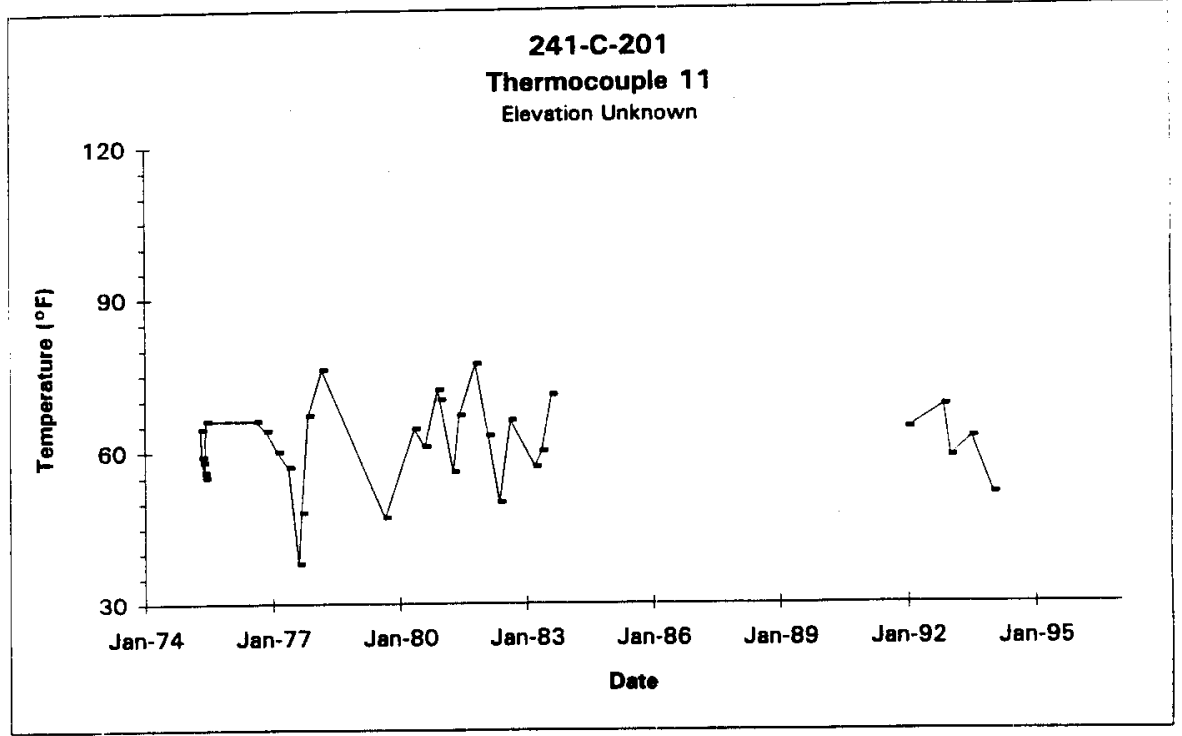

Data obtained from WHC Surveillance Analysis Computer System (SACS), Jan 9, 1996. 


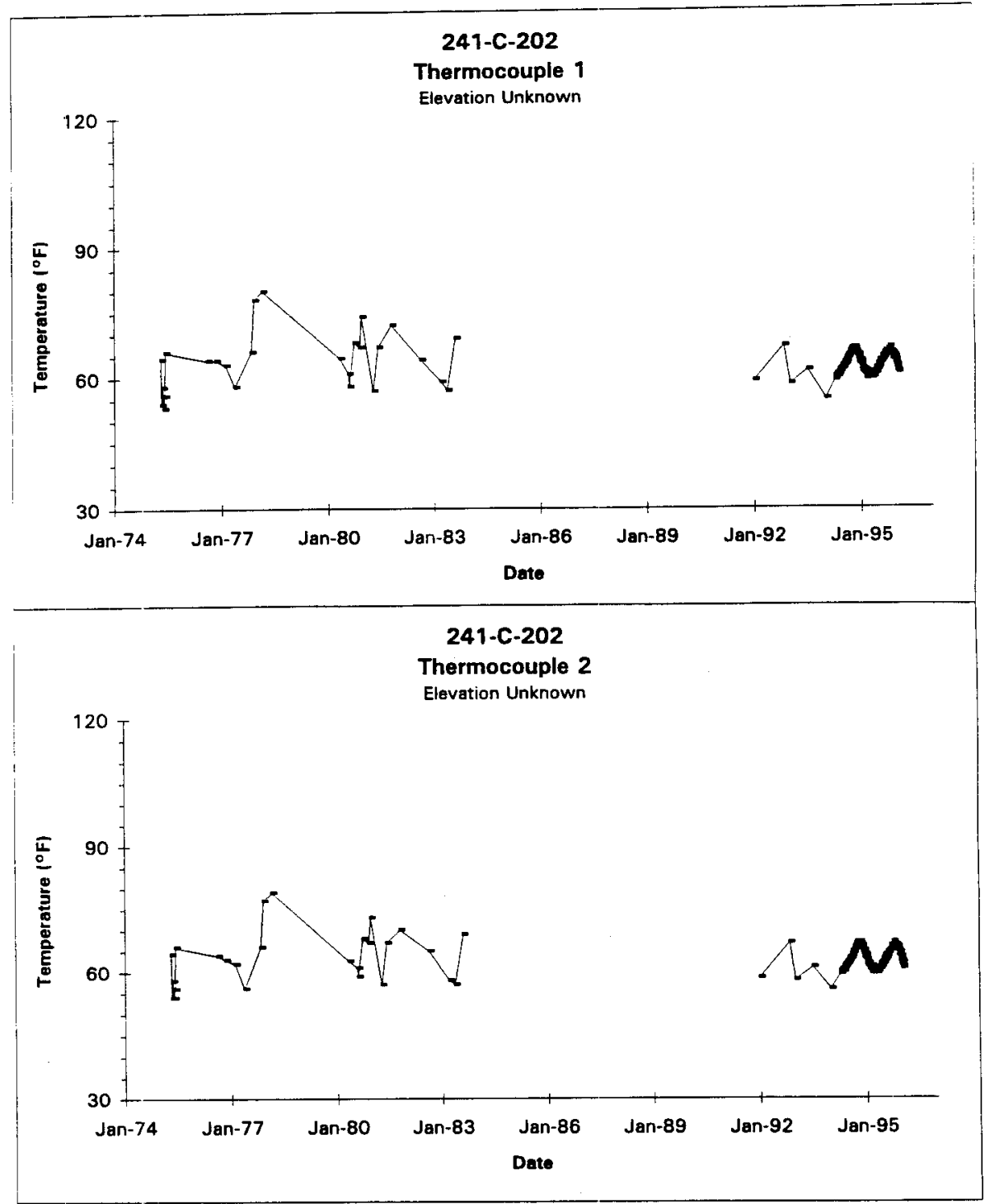

Data obtained from WHC Surveillance Analysis Computer System (SACS), Jan 9, 1996.

D-78 


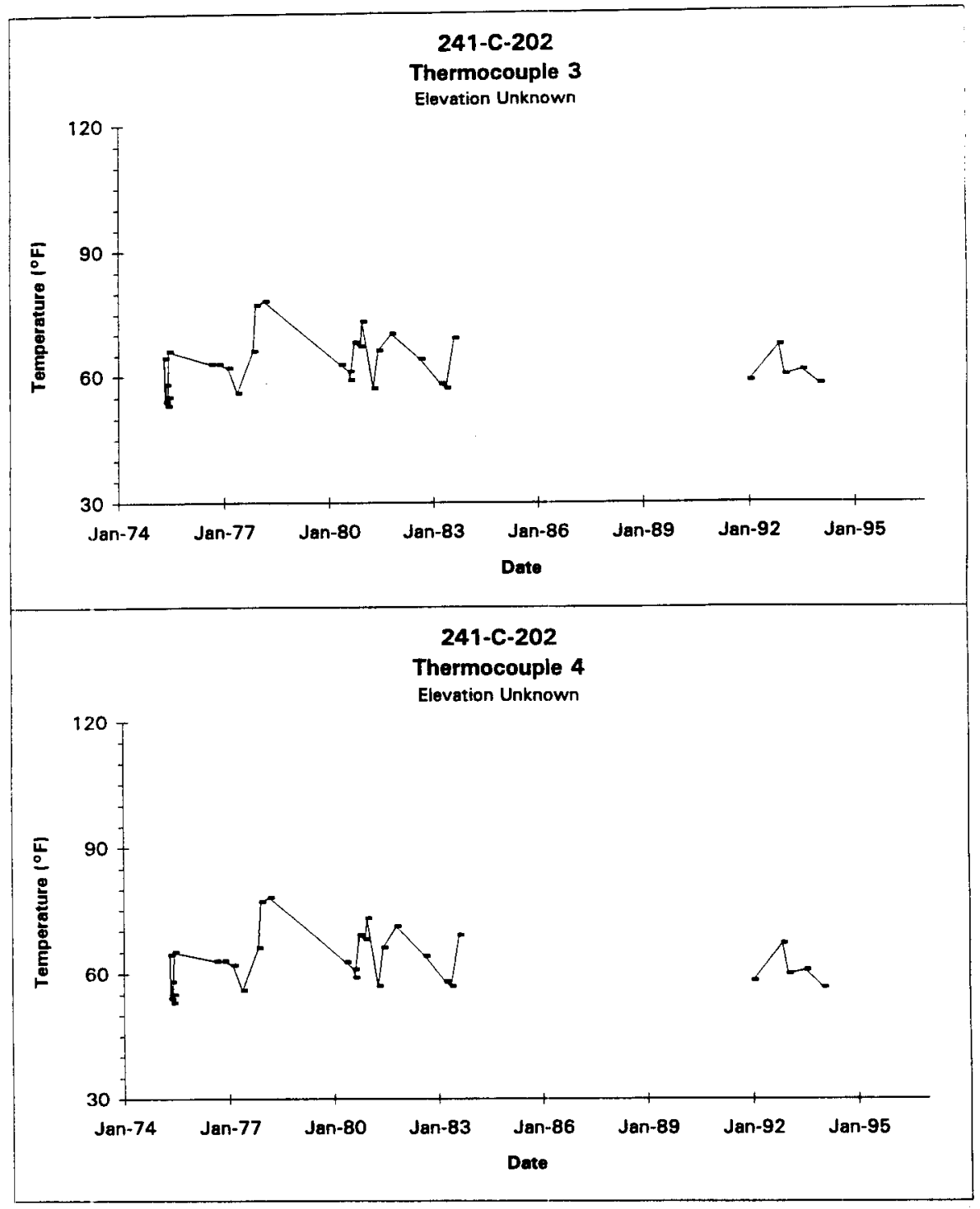

Data obtained from WHC Surveillance Analysis Computer System (SACS), Jan 9, 1996.

D-79 


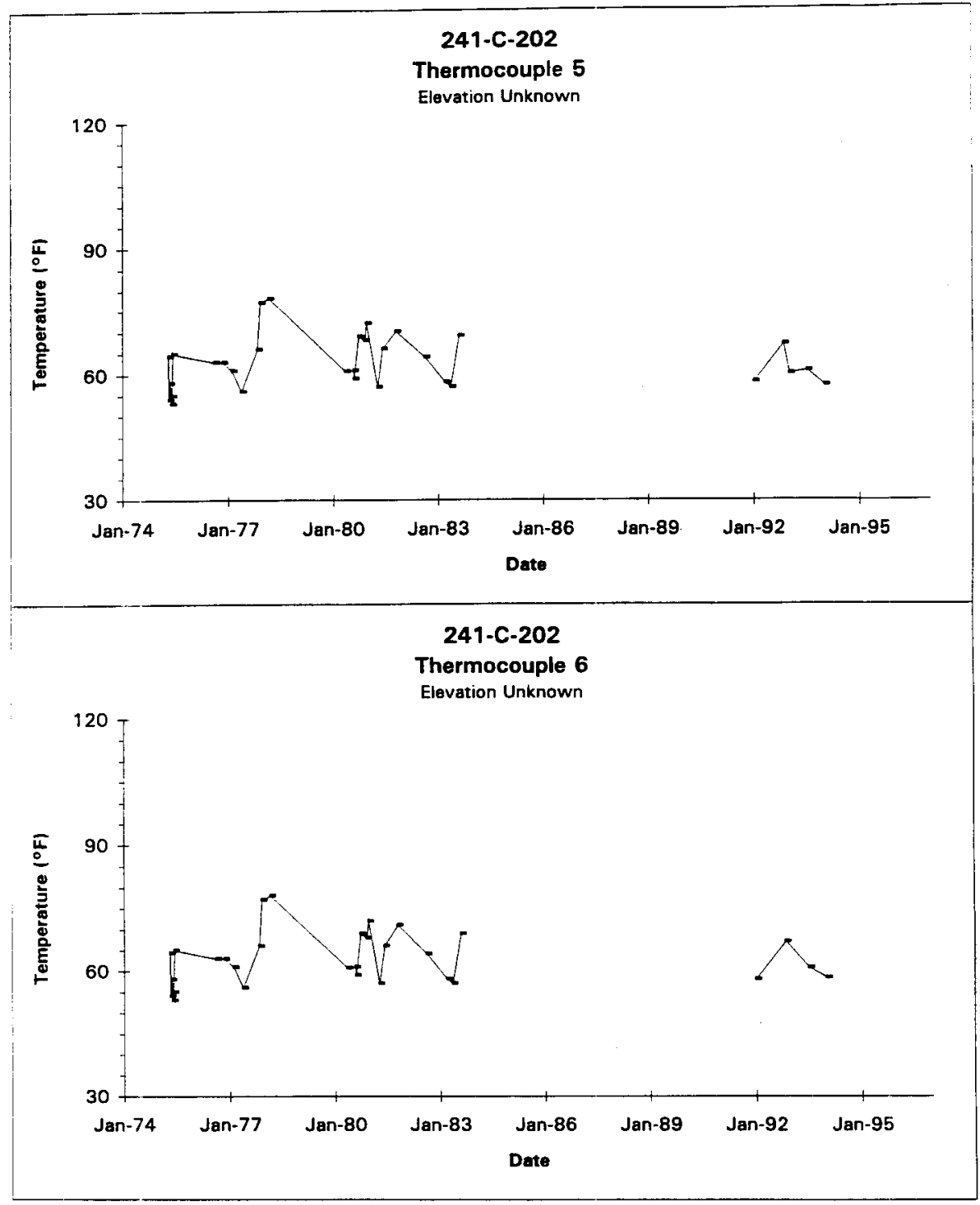

Data obtained from WHC Surveillance Analysis Compurer System (SACS), Jan 9, 1996.

D-80 


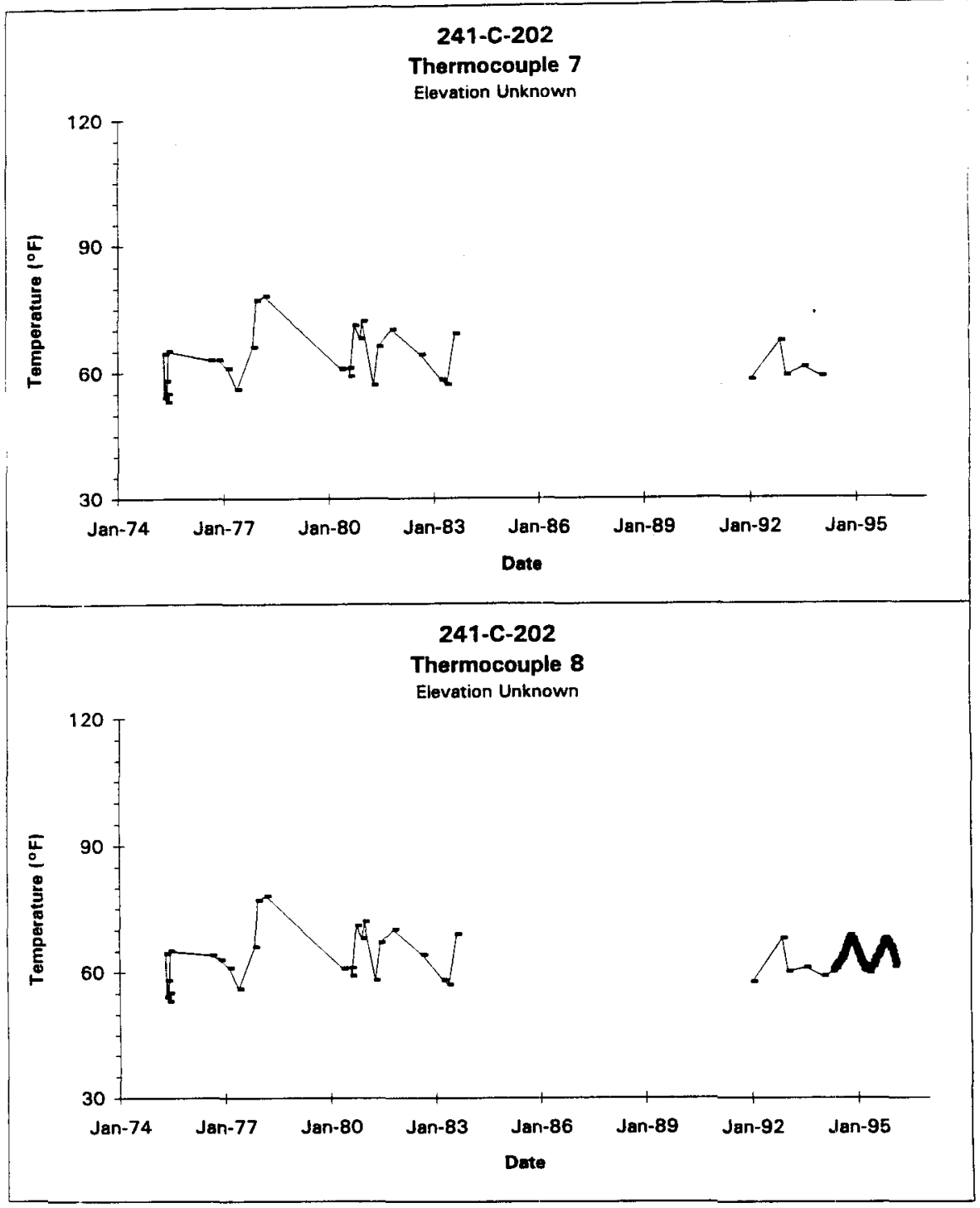

Data obtained from WHC Surveillance Analysis Computer System (SACS), Jan 9, 1996. 


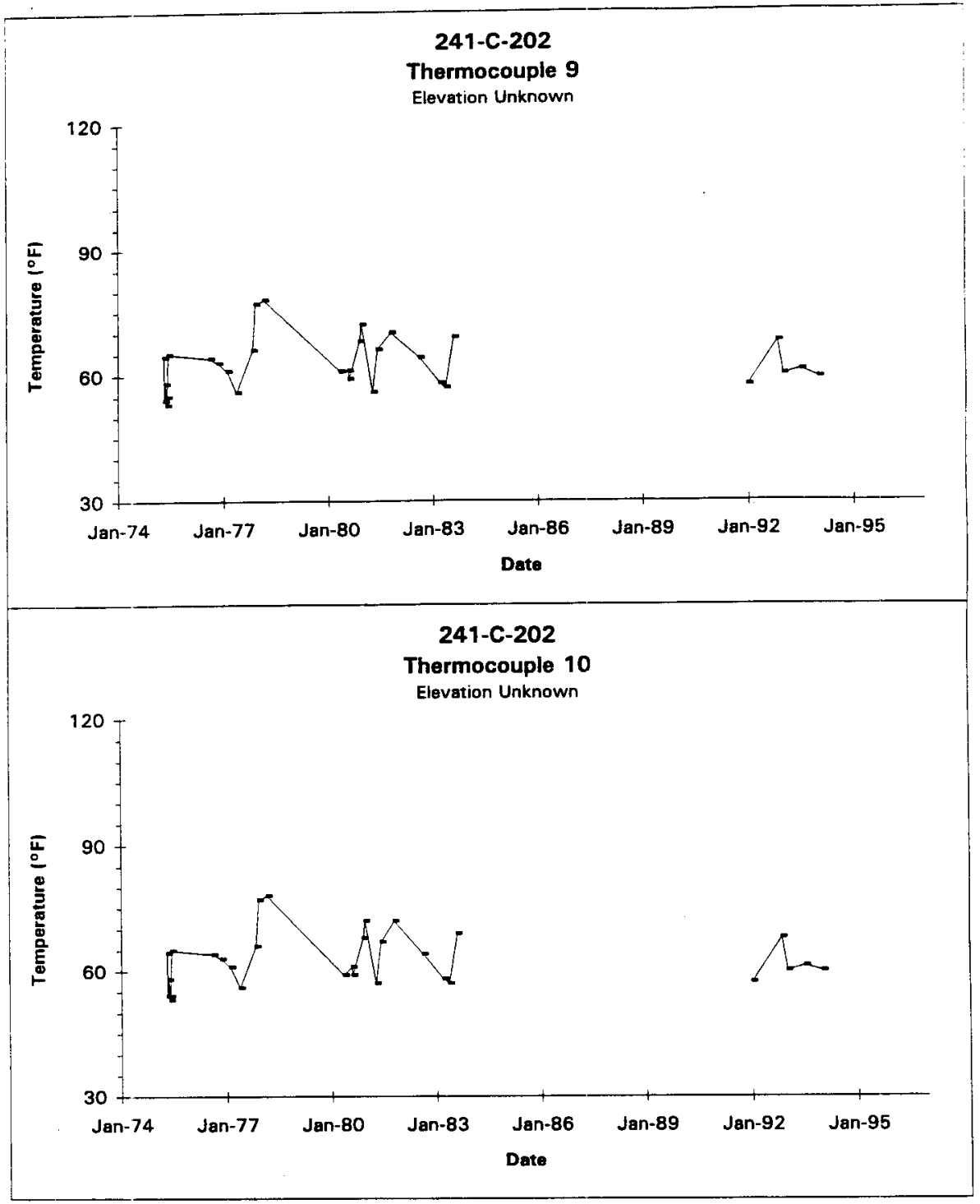

Data obtained from WHC Surveillance Analysis Computer System (SACS), Jan 9, 1996. 


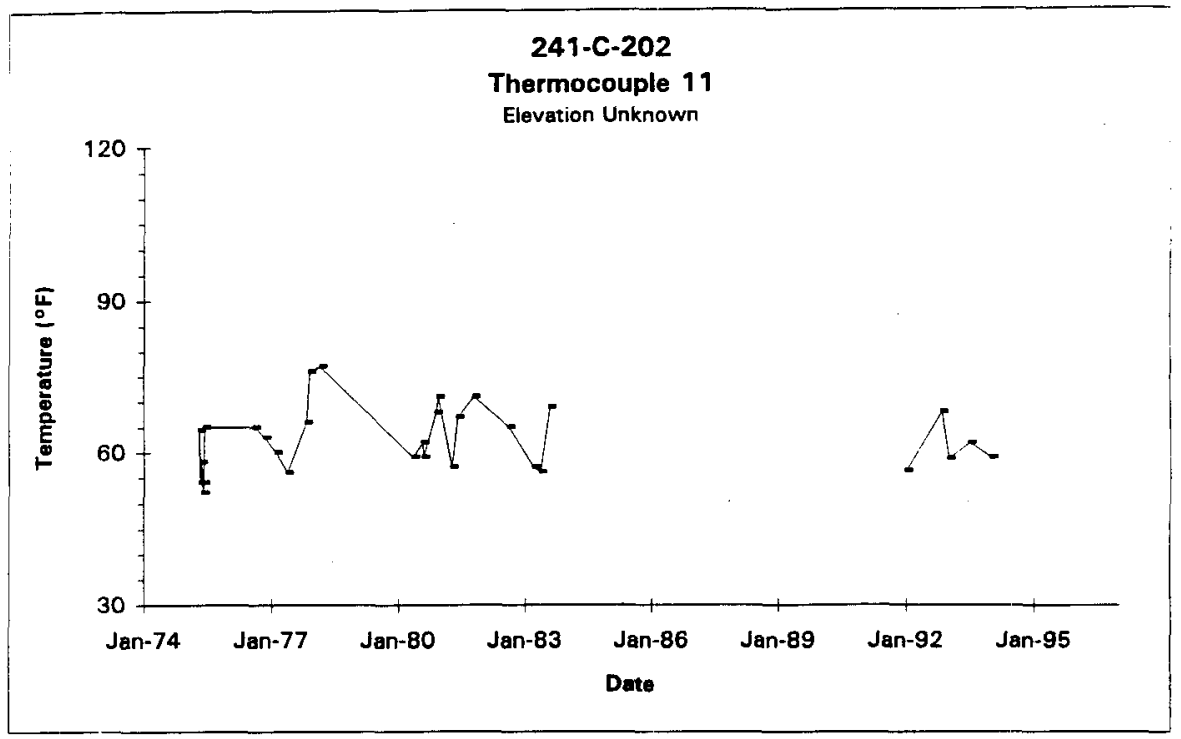

Data obtained from WHC Surveillance Analysis Computer System (SACS), Jan 9, 1996. 


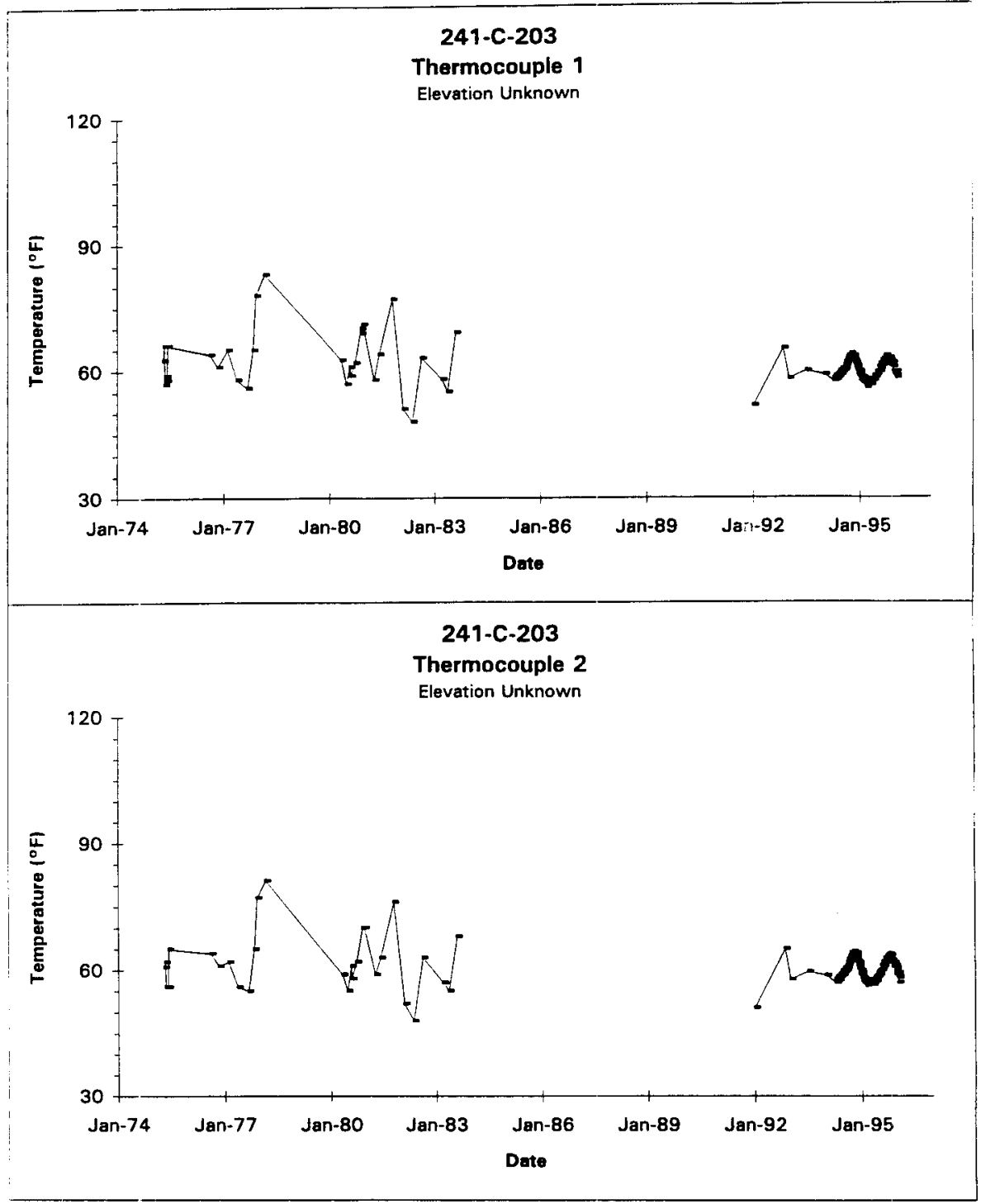

Data obtained from WHC Surveillance Analysis Computer System (SACS), Jan 9, 1996.

\section{D-84}




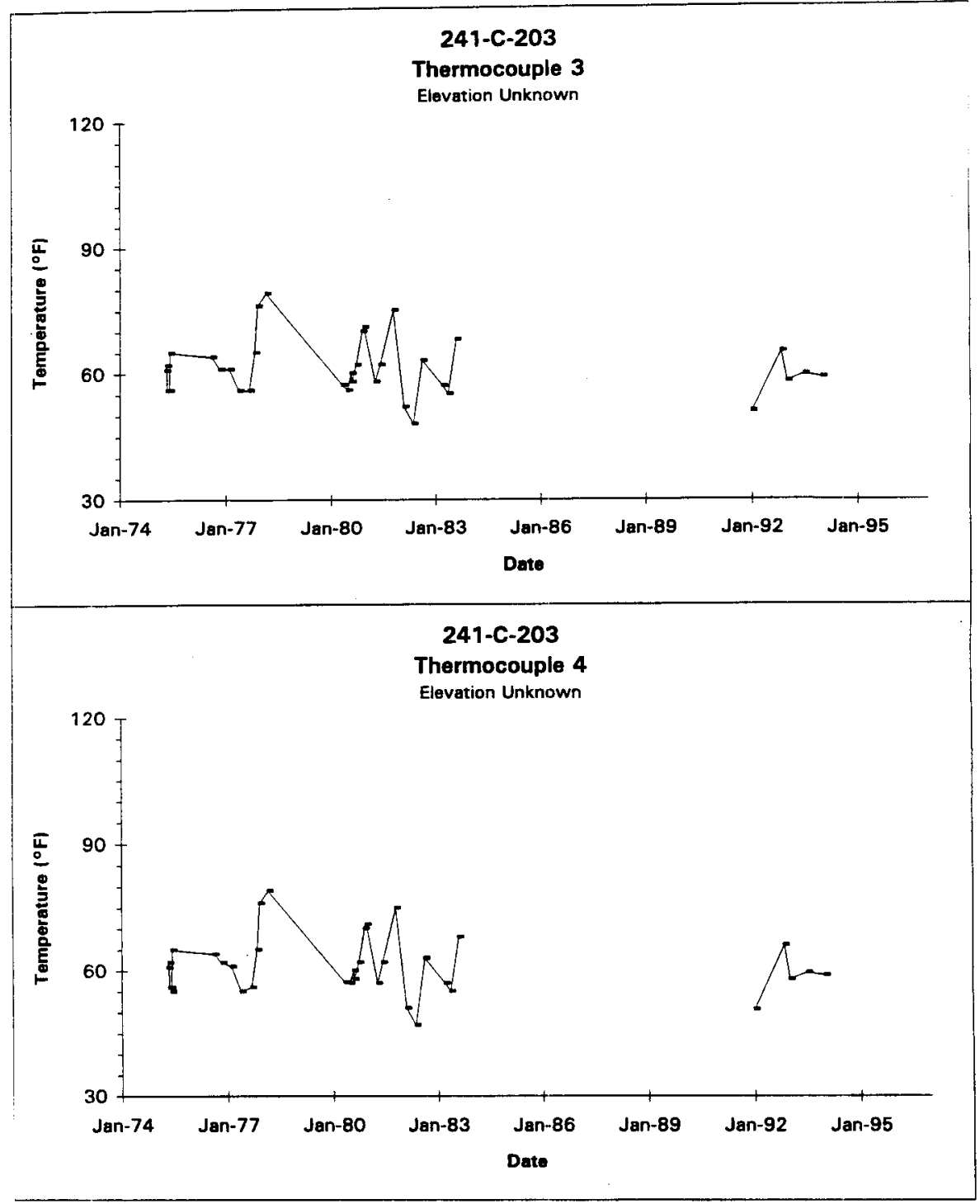

Data obtained from WHC Surveillance Analysis Computer System (SACS), Jan 9, 1996. 


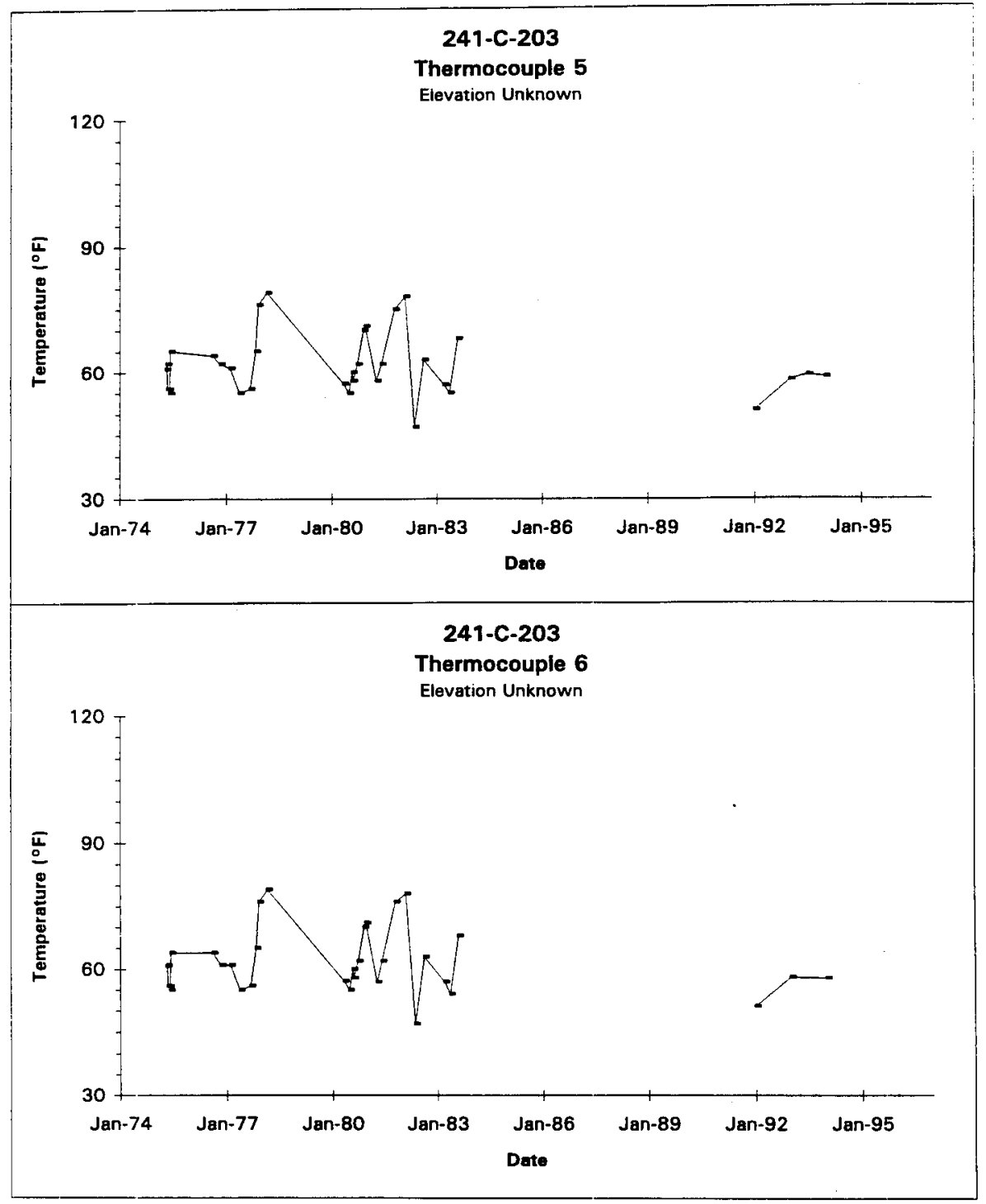

Data obtained from WHC Surveillance Analysis Computer System (SACS), Jan 9, 1996. 


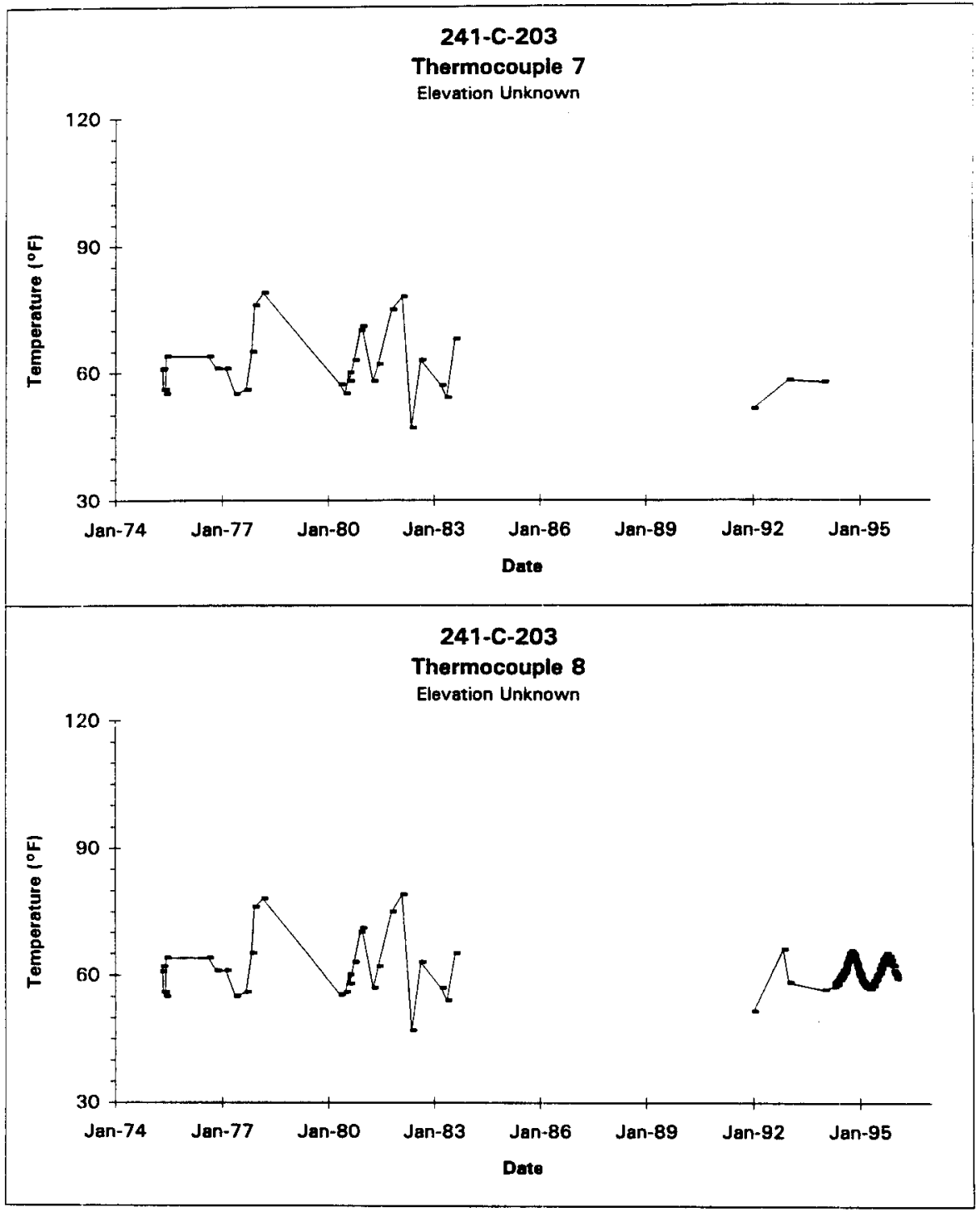

Data obtained from WHC Surveillance Analysis Computer System (SACS), Jan 9, 1996. 


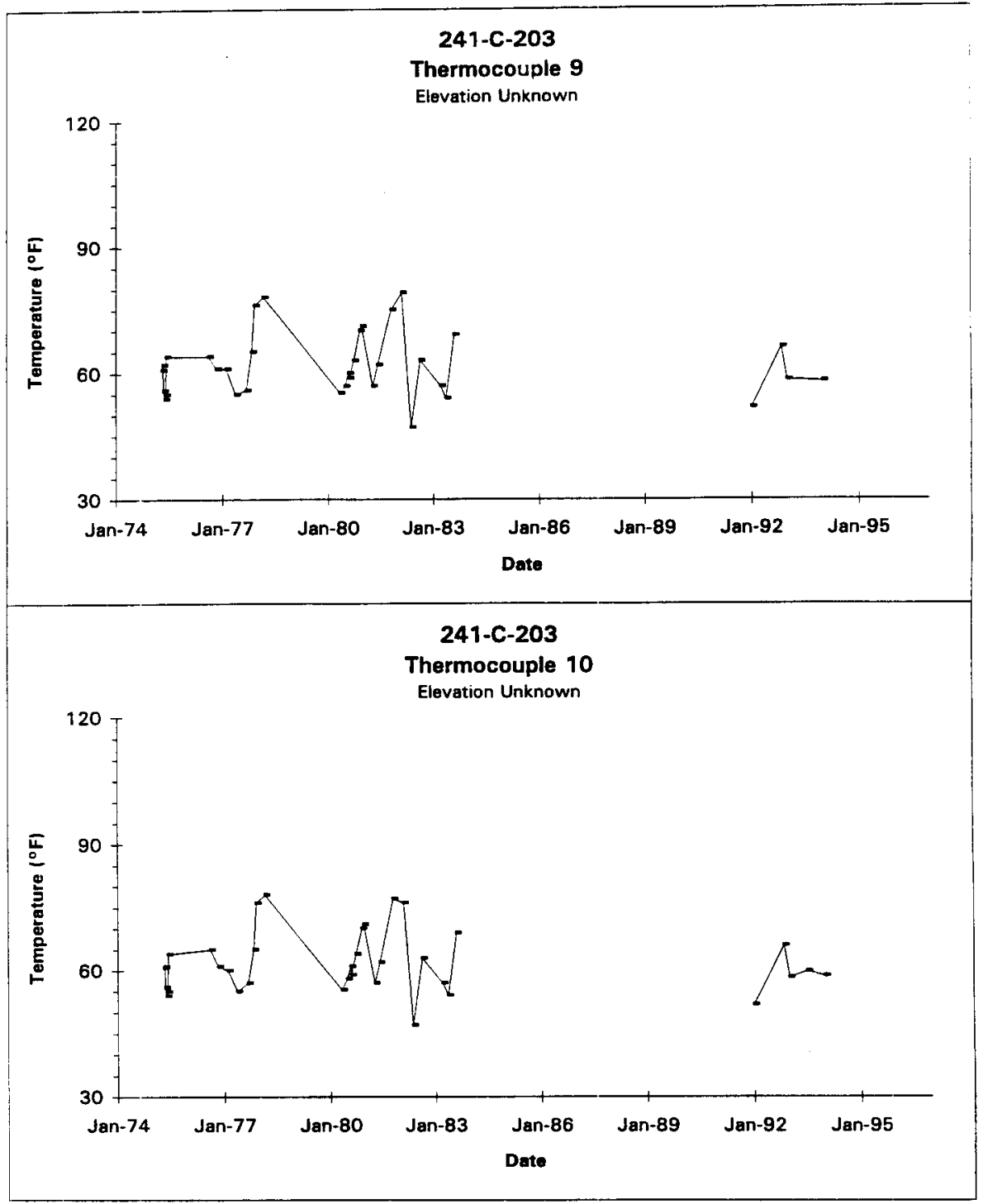

Data obtained from WHC Surveillance Analysis Computer System (SACS), Jan 9, 1996. 
WHC-SD-WM-ER-313, Rev. 1

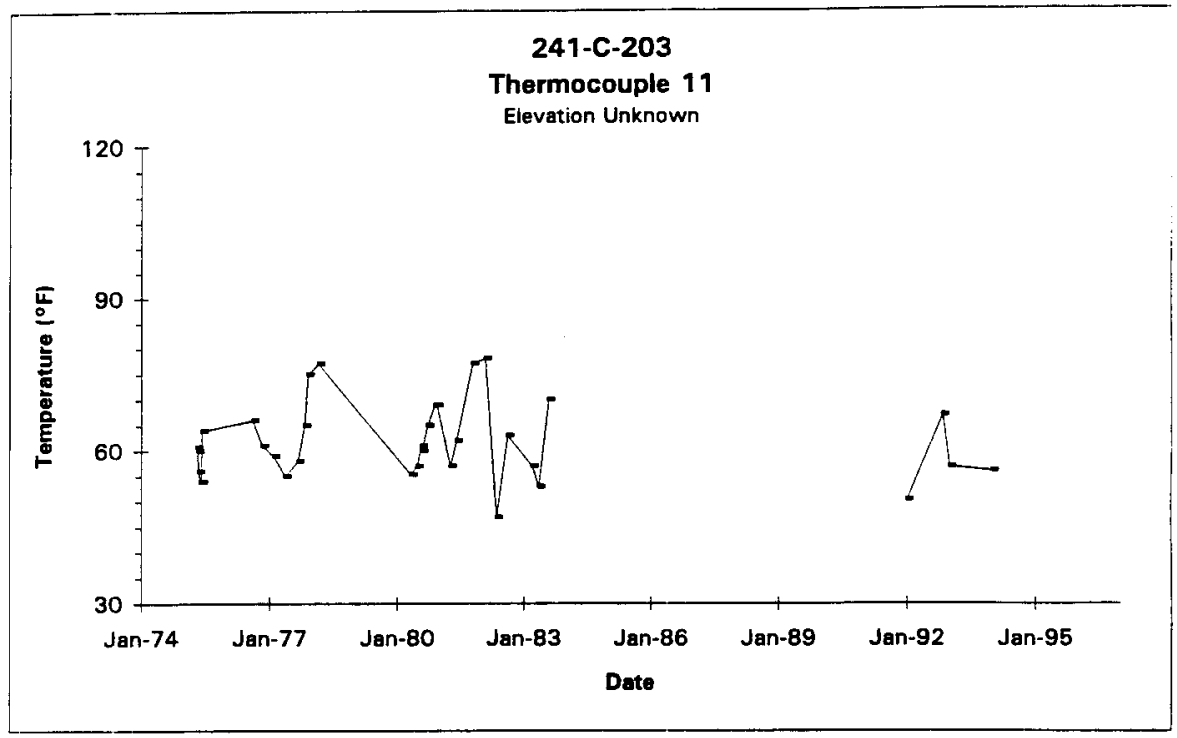

Data obtained from WHC Surveillance Analysis Computer System (SACS), Jan 9, 1996.

D-89 
WHC-SD-WM-ER-313, Rev 1

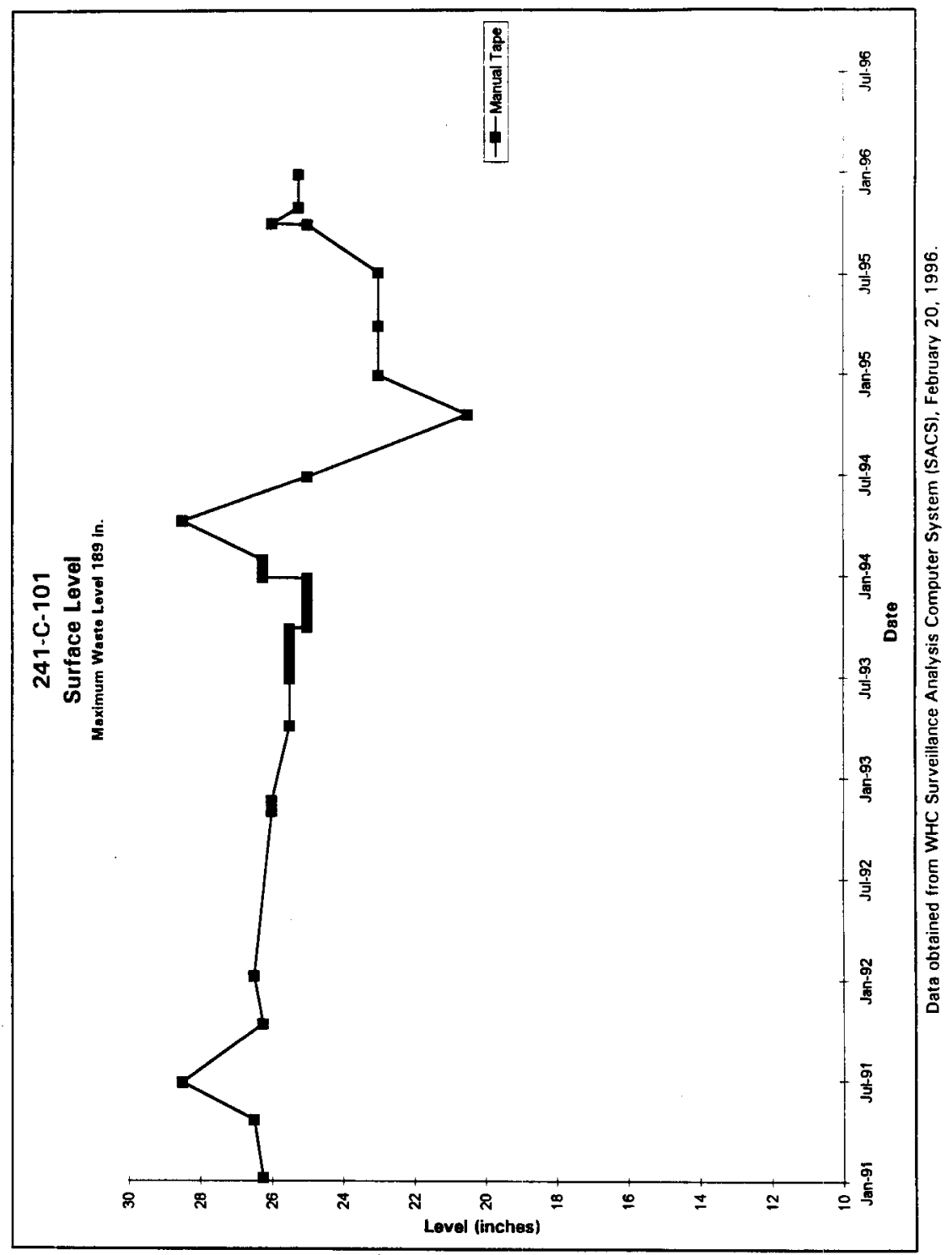

E-1 
WHC-SD-WM-ER-313. Rev. 1

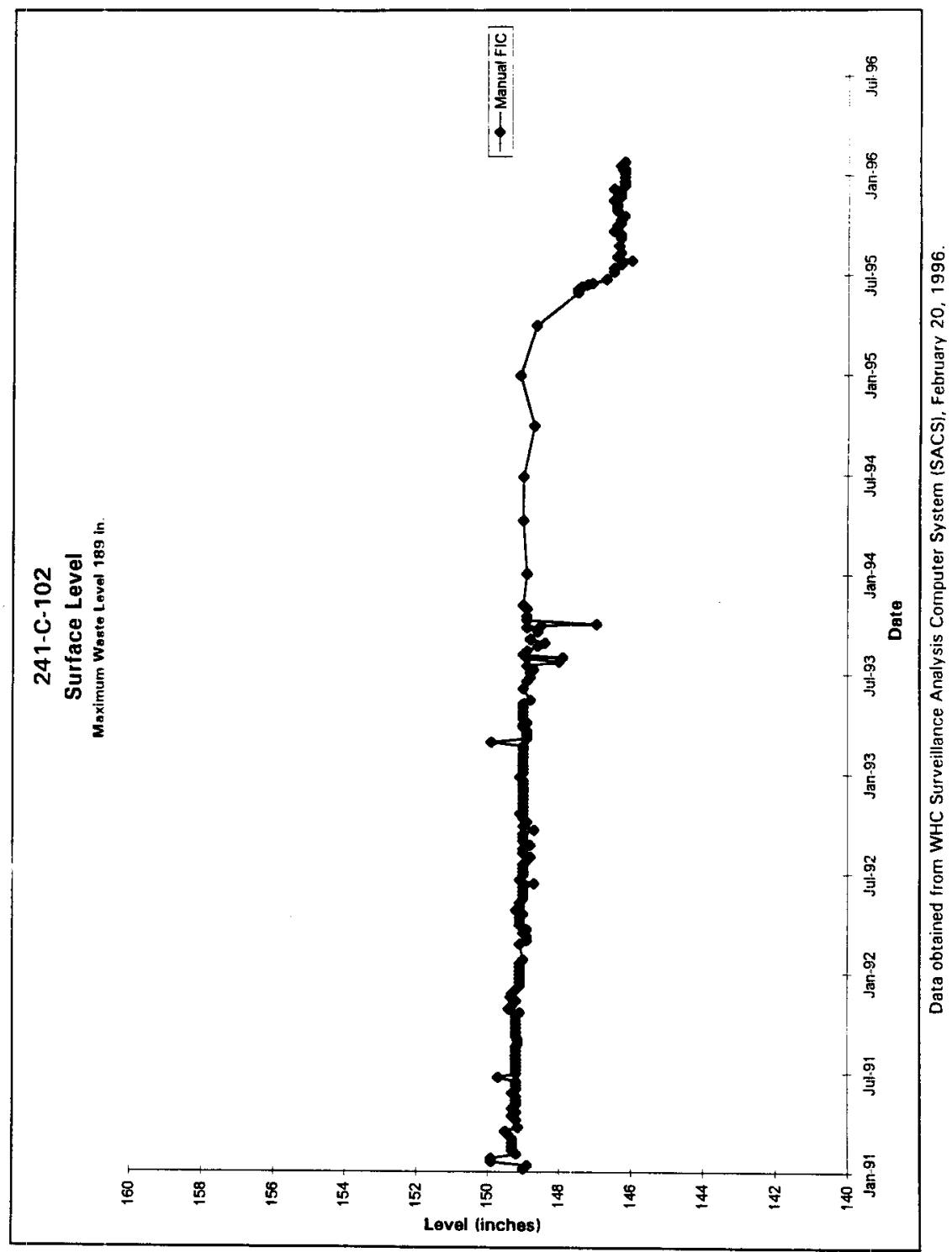

E-2 
WHC-SD-WM-ER-313, Rer. 1

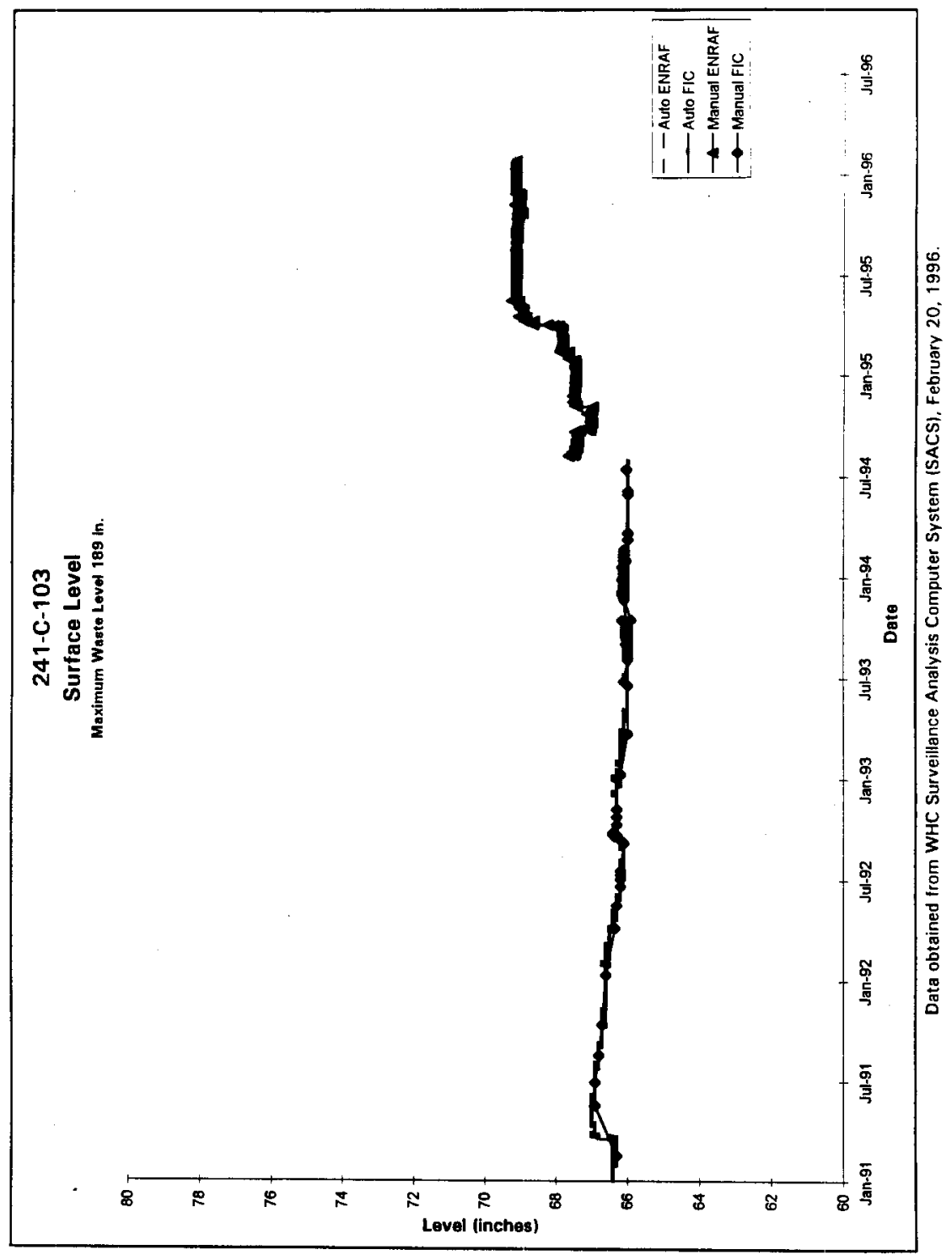




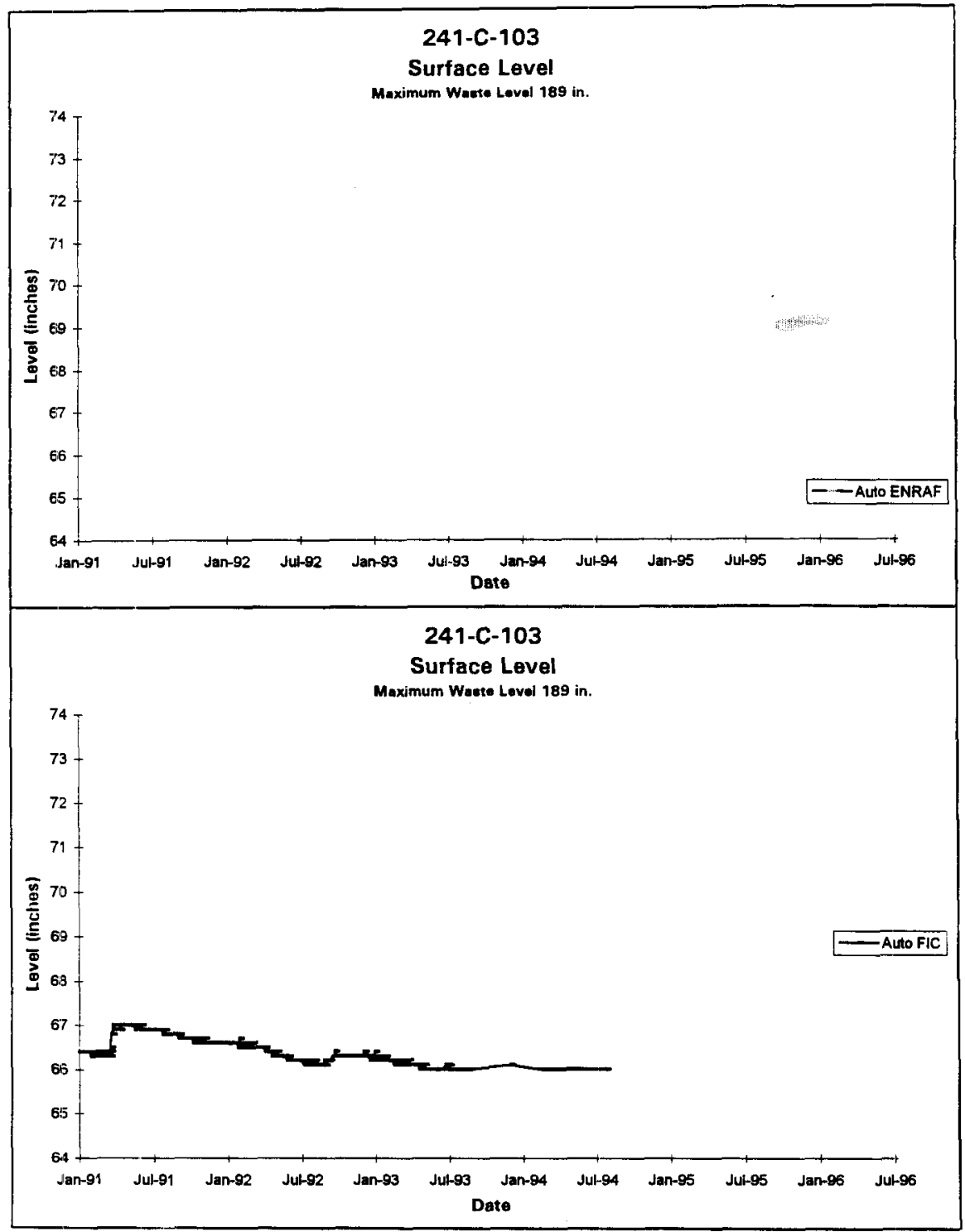

Data obtinined from WHC Surveillance Analysis Computer System (SACS), February 20, 1996. 


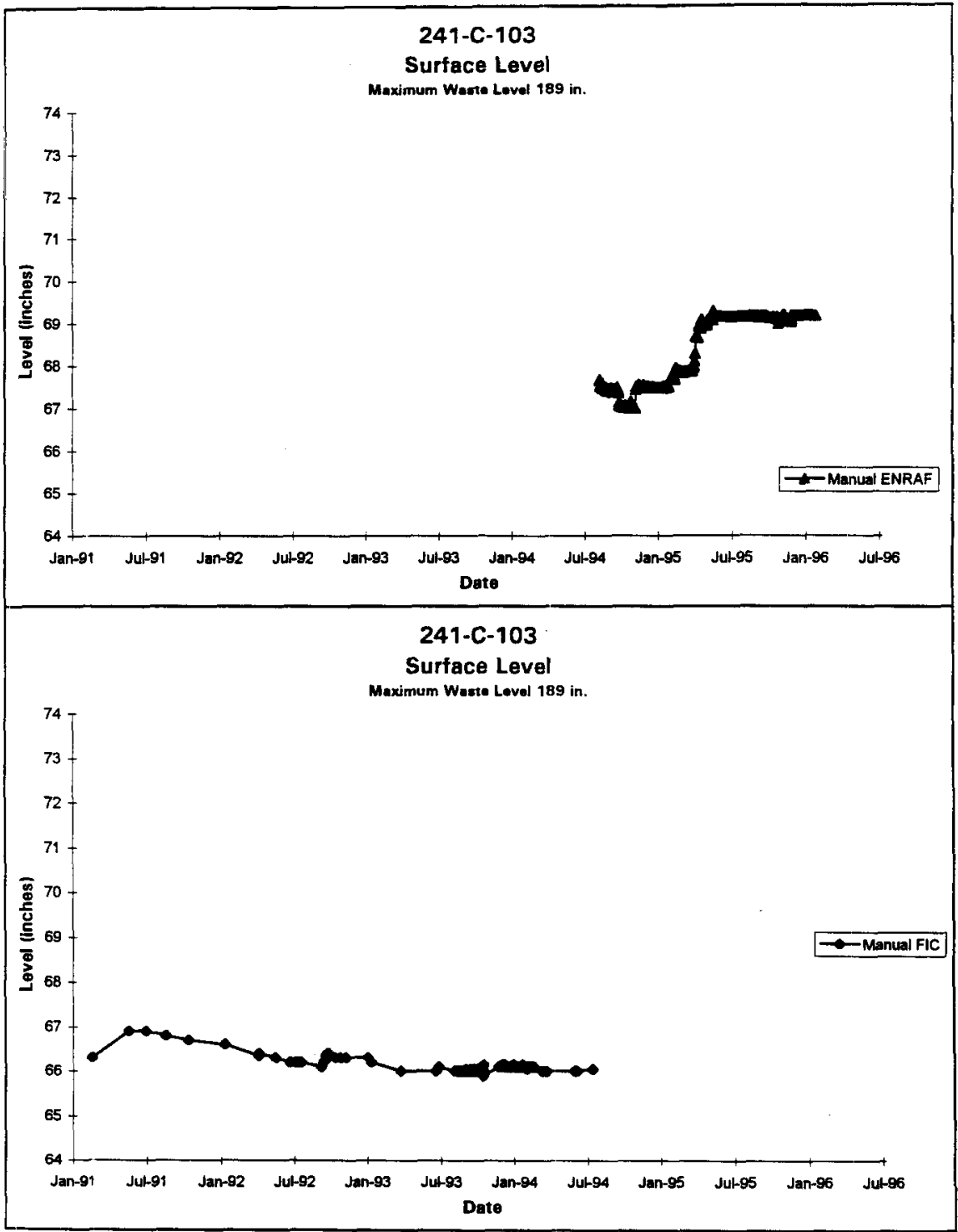

Data obtained from WHC Surveillance Analysis Computer System (SACS), February 20, 1996. 
WHC-SD-WM-ER-313, Rev I

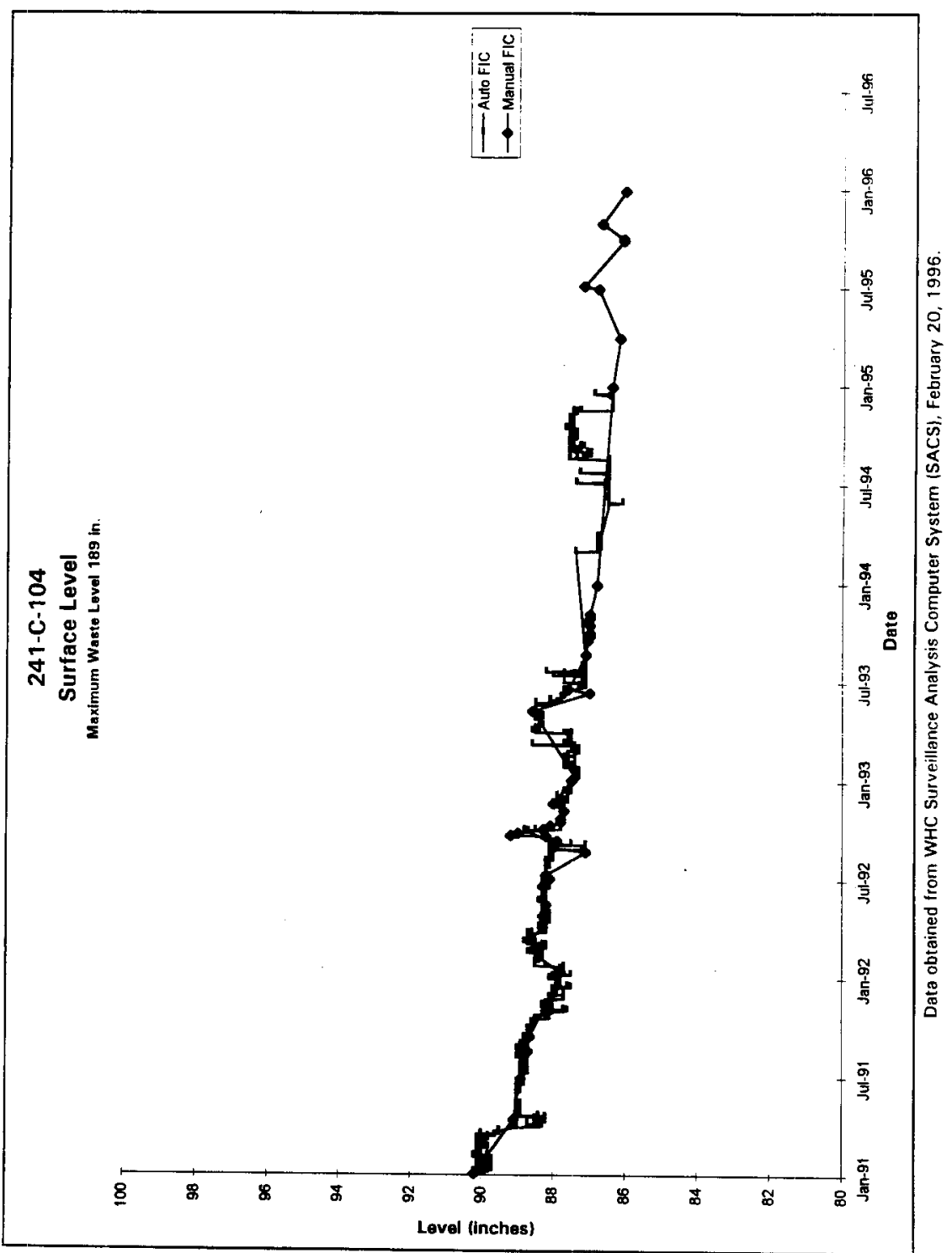




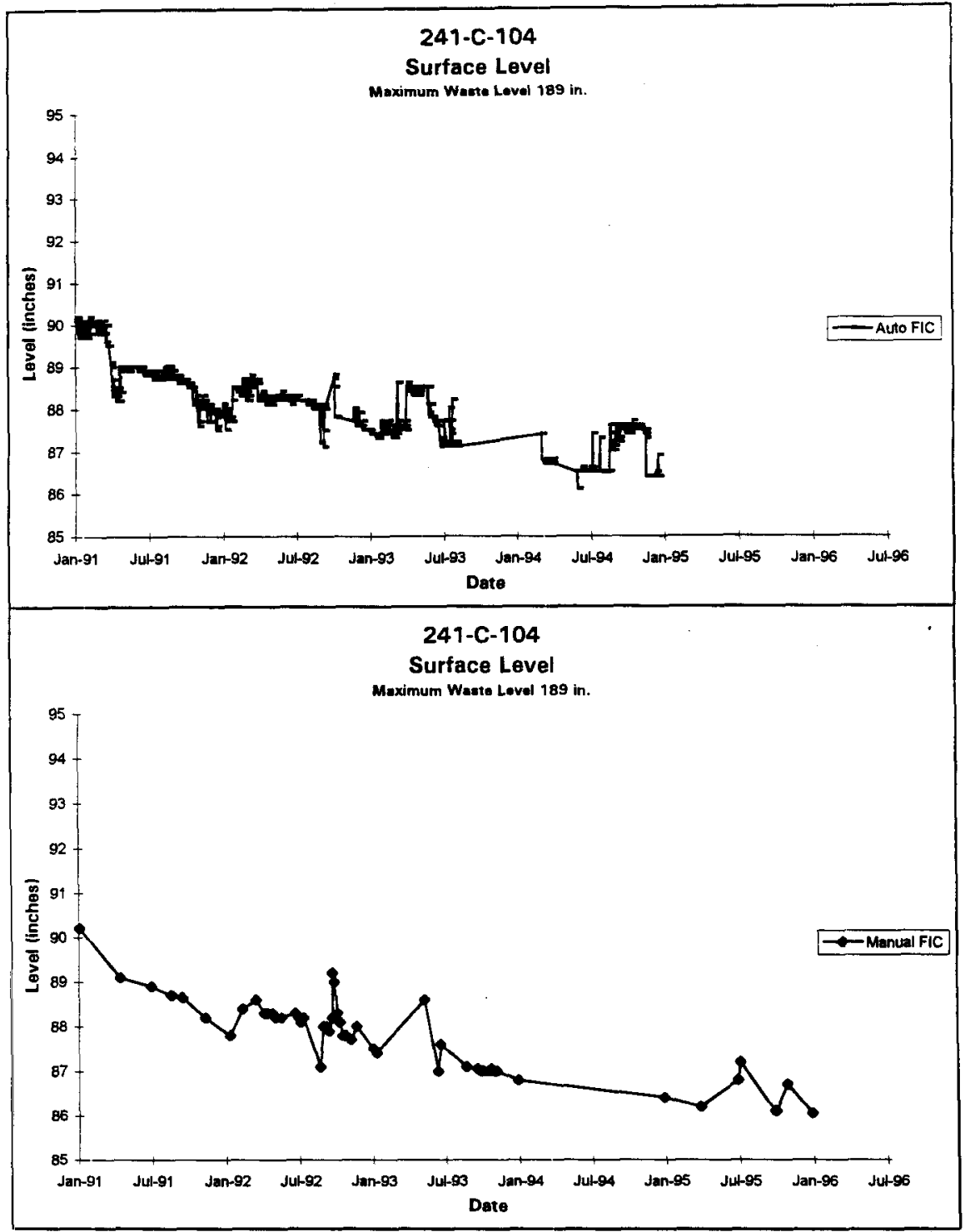

Data obtained from WHC Surveillance Analysis Computer System (SACS), February 20, 1996. 


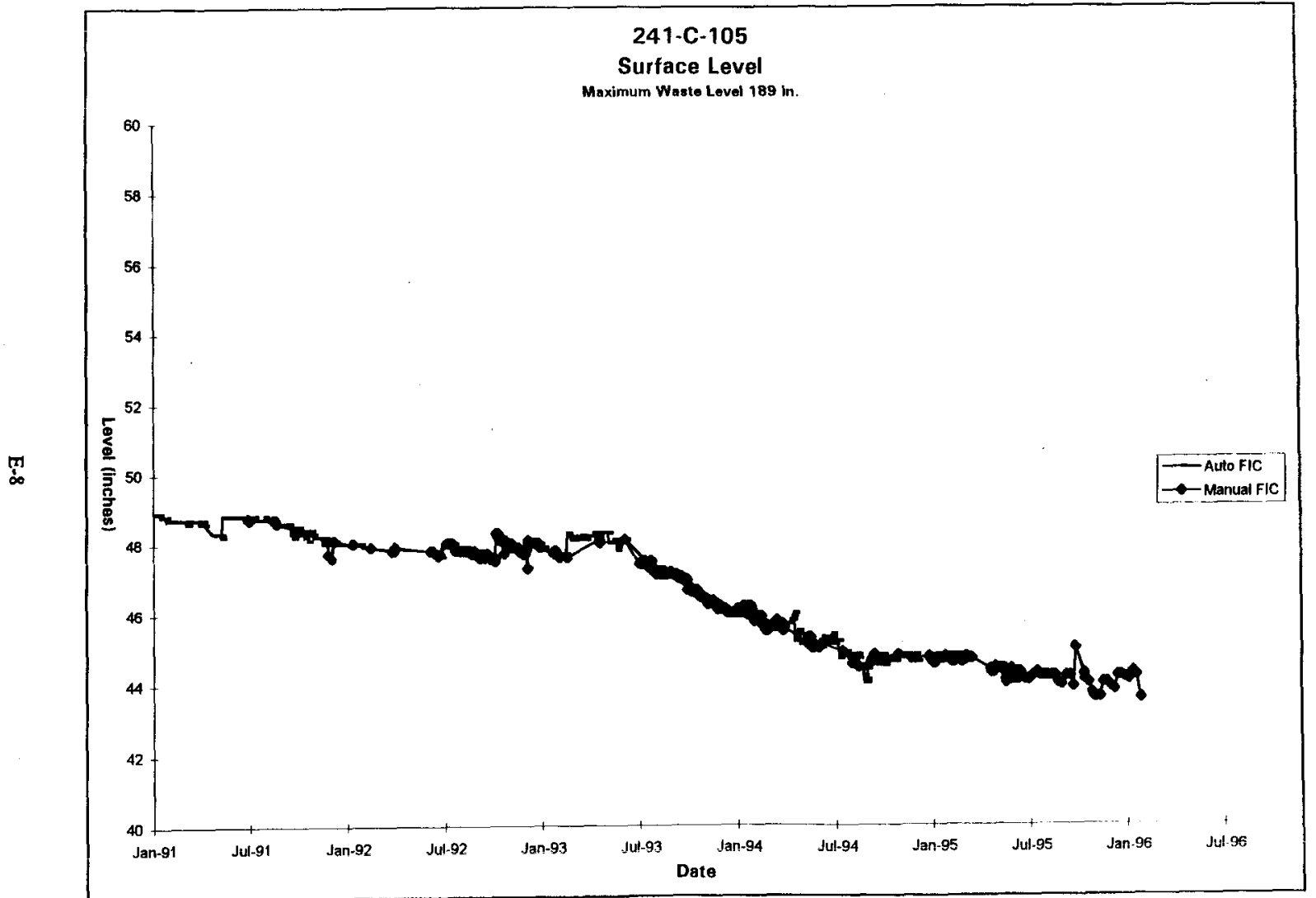

Data obtained from WHC Surveillance Analysis Computer System (SACS), February 20, 1996. 


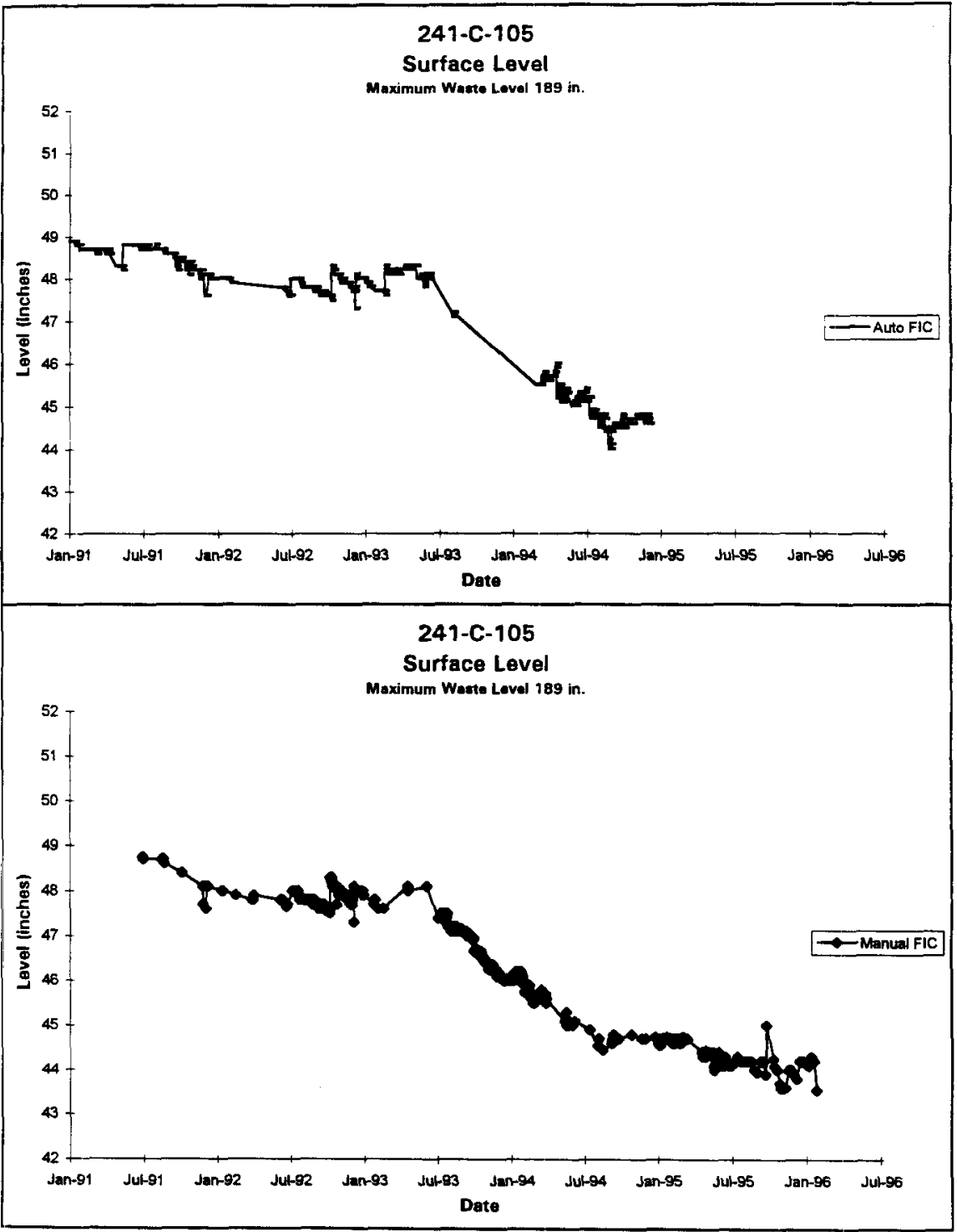

Data obtained from WHC Surveillance Analysis Computer System (SACS), February 20, 1996. 
WHC-SD-WM-ER-313, Rev. 1

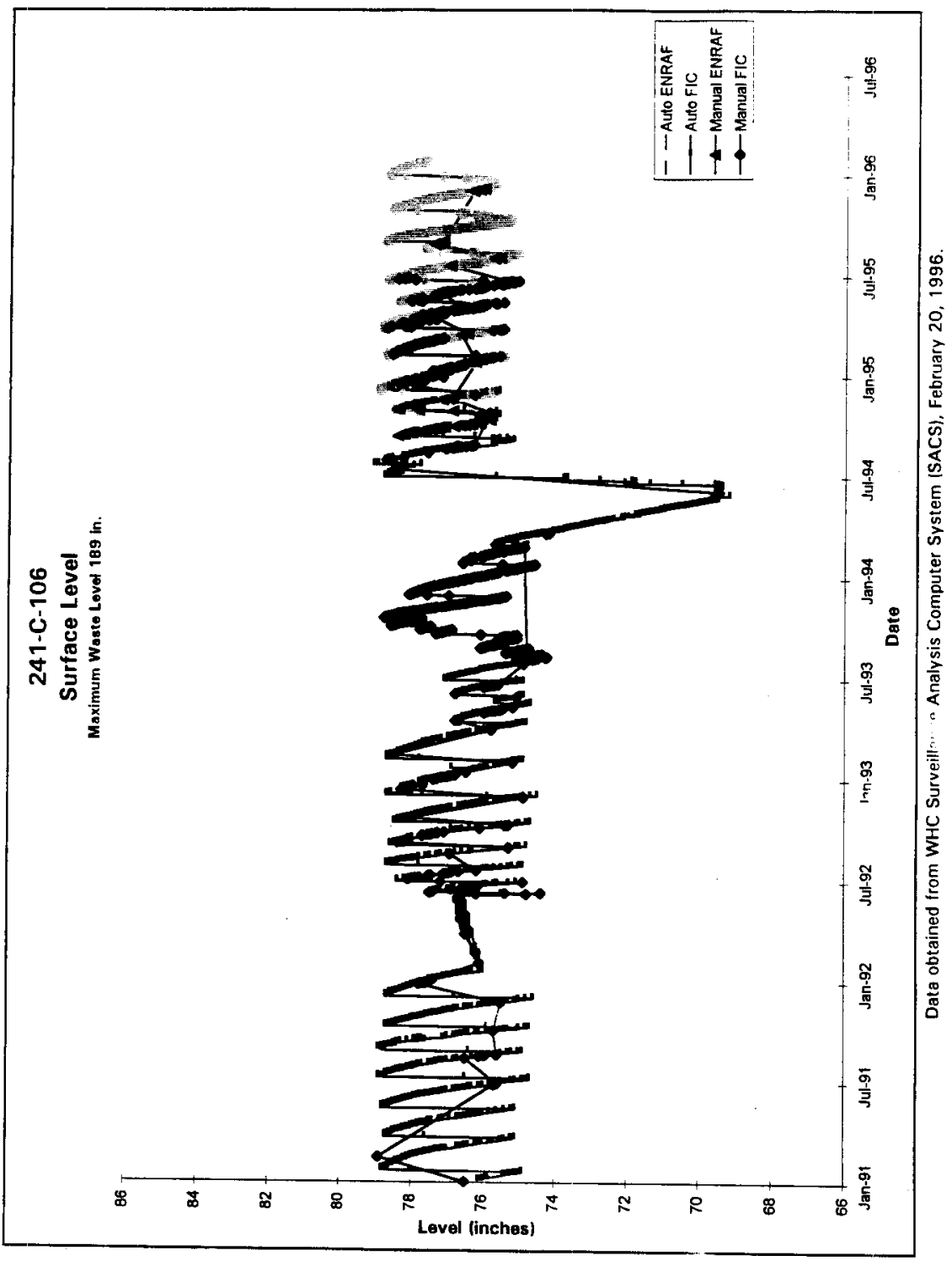




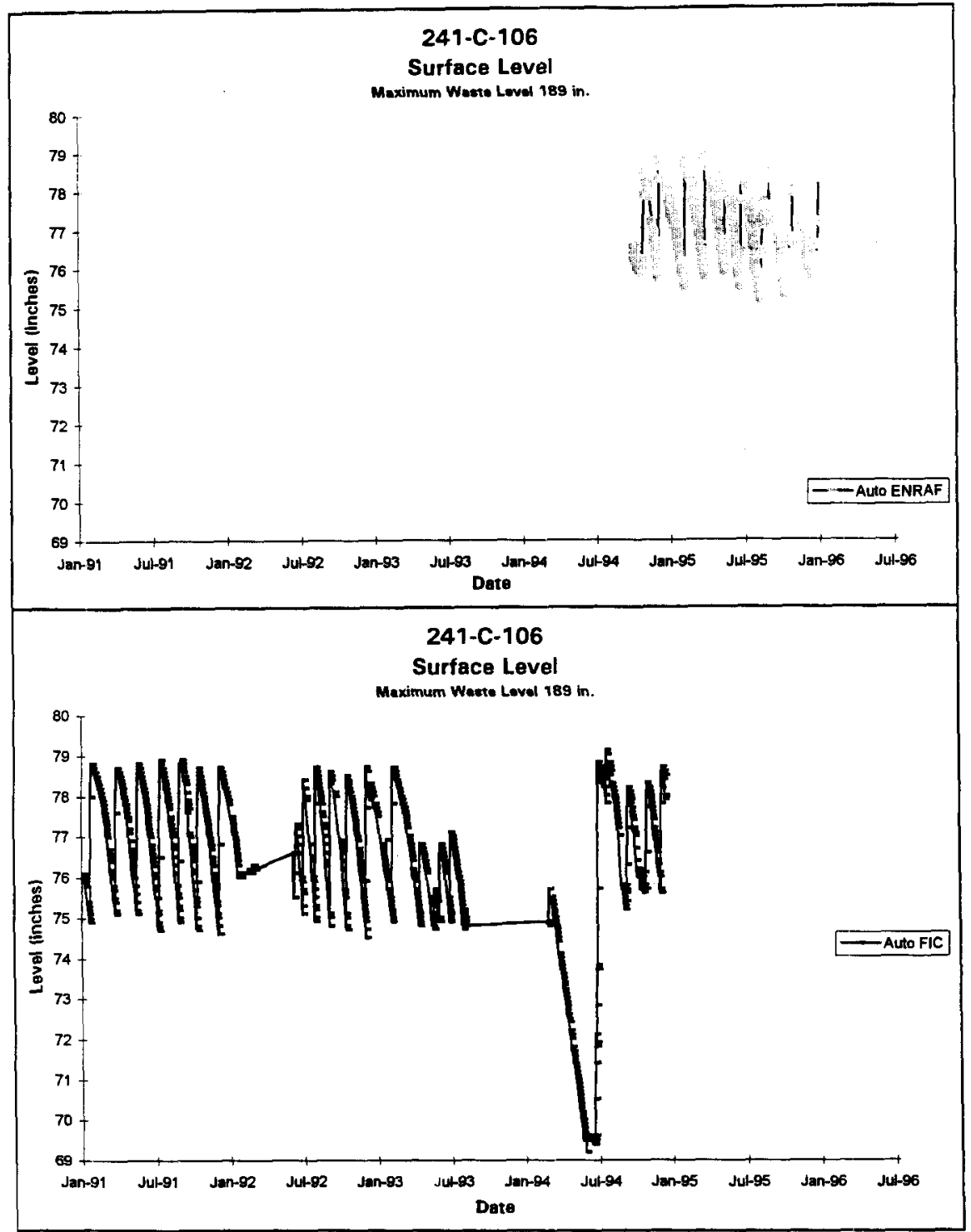

Data obtained from WHC Surveillance Analysis Computer System (SACS), February 20, 1996. 


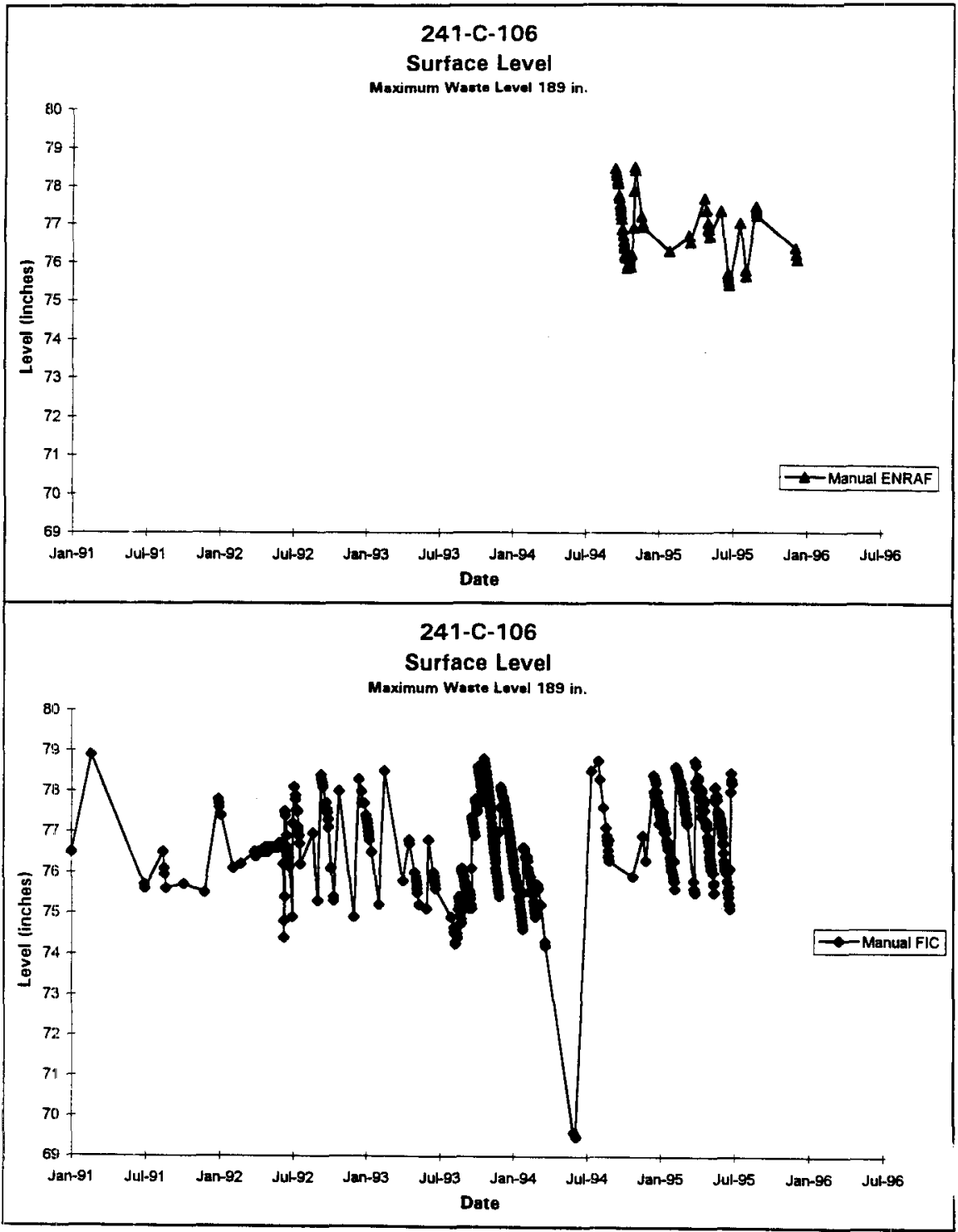

Data obtained from WHC Surveillance Analysis Computer System (SACS), February 20, 1996.

E-12 
WHC-SD-WM-ER-3̈13. Rev. 1

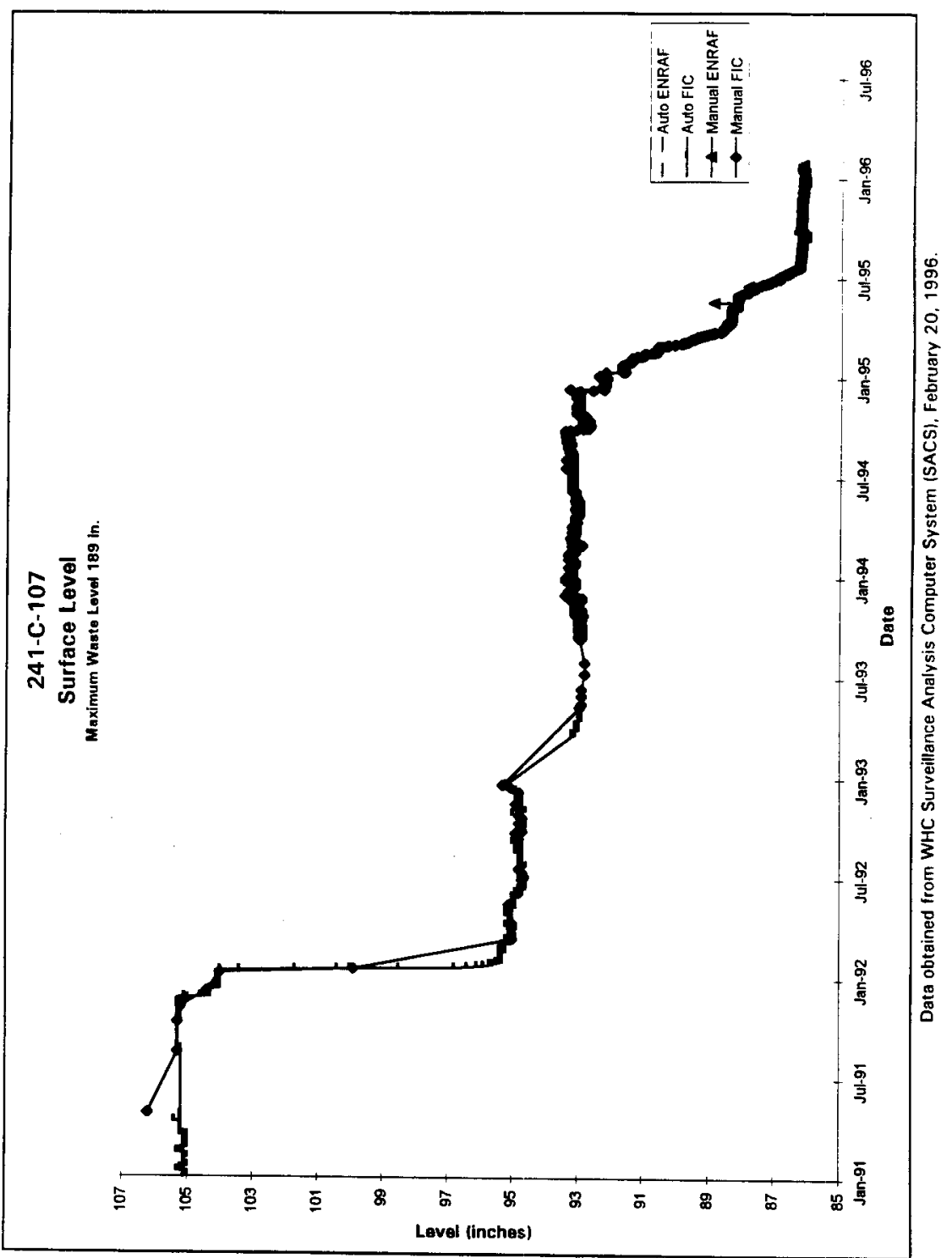

E-13 


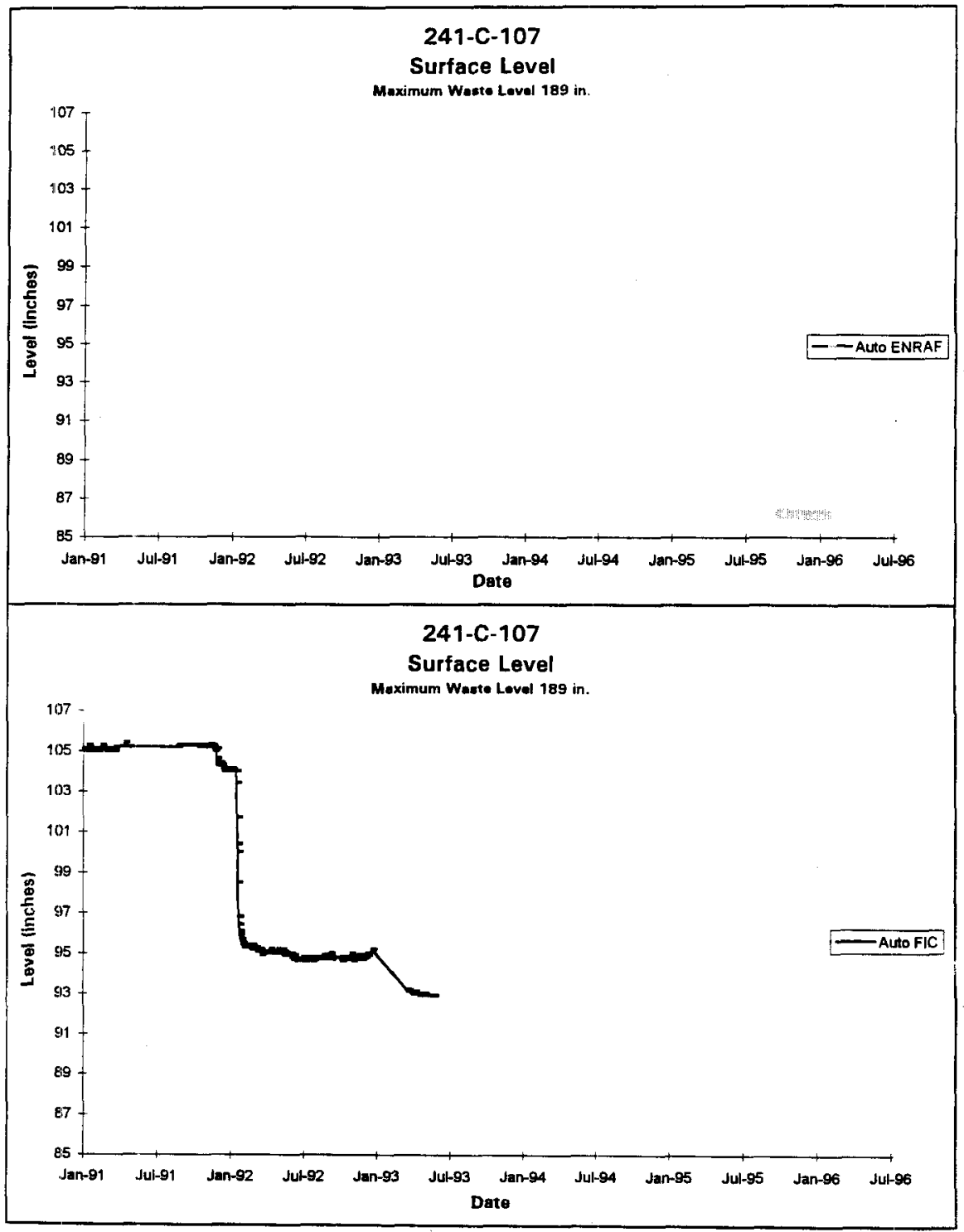

Data obtained from WHC Surveillance Analysis Computer System (S.ACS), February 20, 1996. 


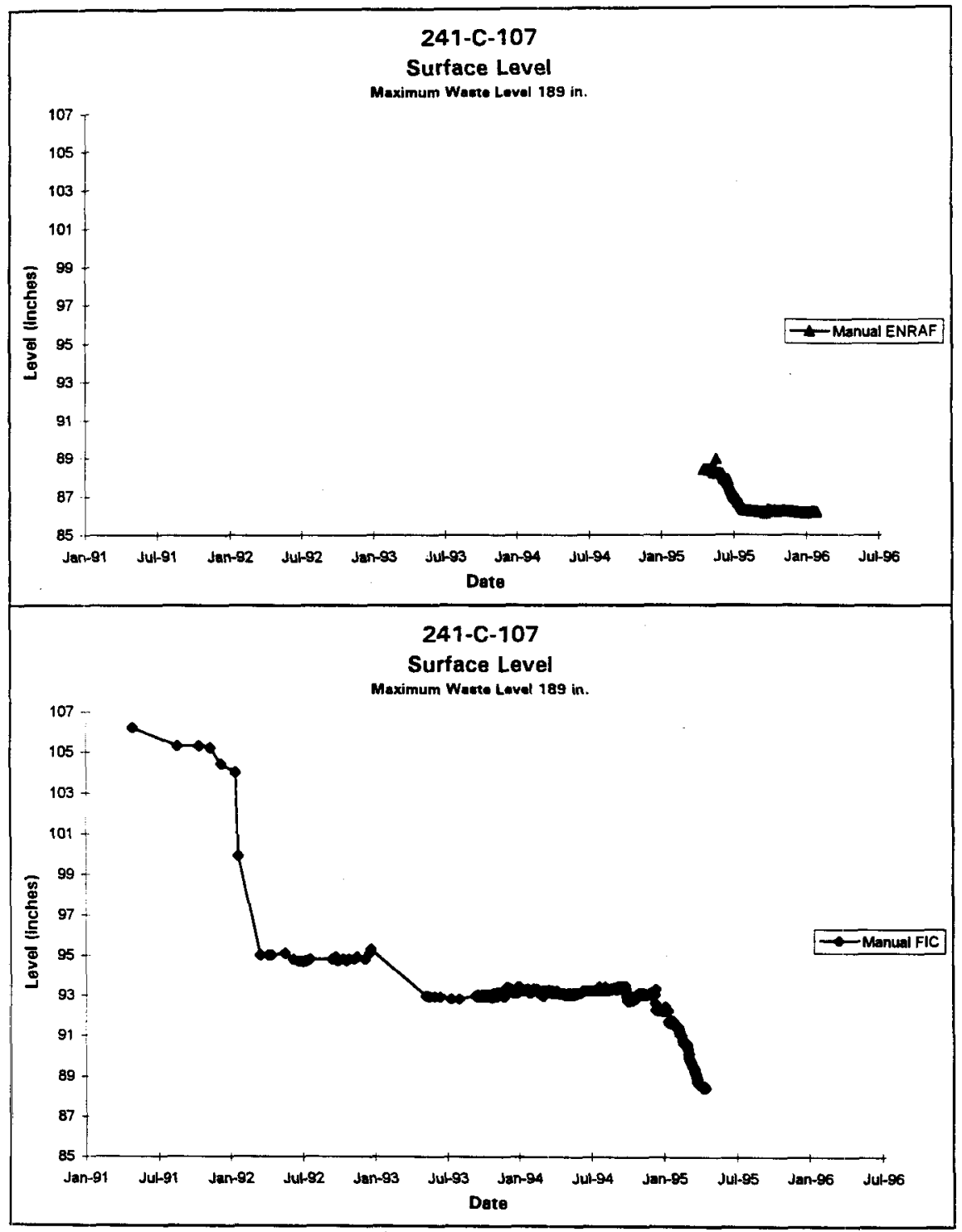

Data obtained from WHC Surveillance Analysis Computer System (SACS), February 20, 1996. 
WHC-SD-WM-ER-313. Rev. 1

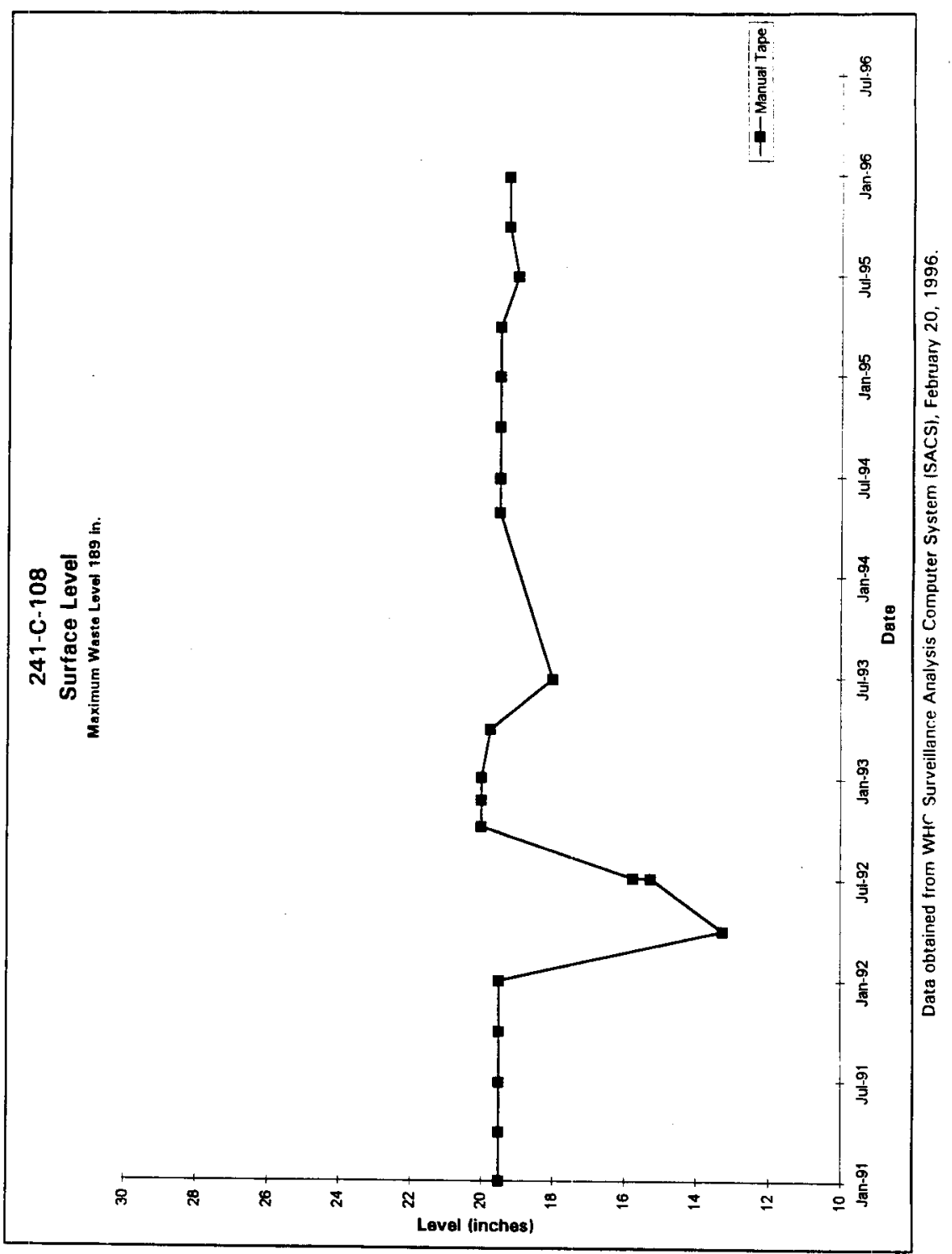

E-16 
WHC-SD-WM-ER-313. Rer. 1

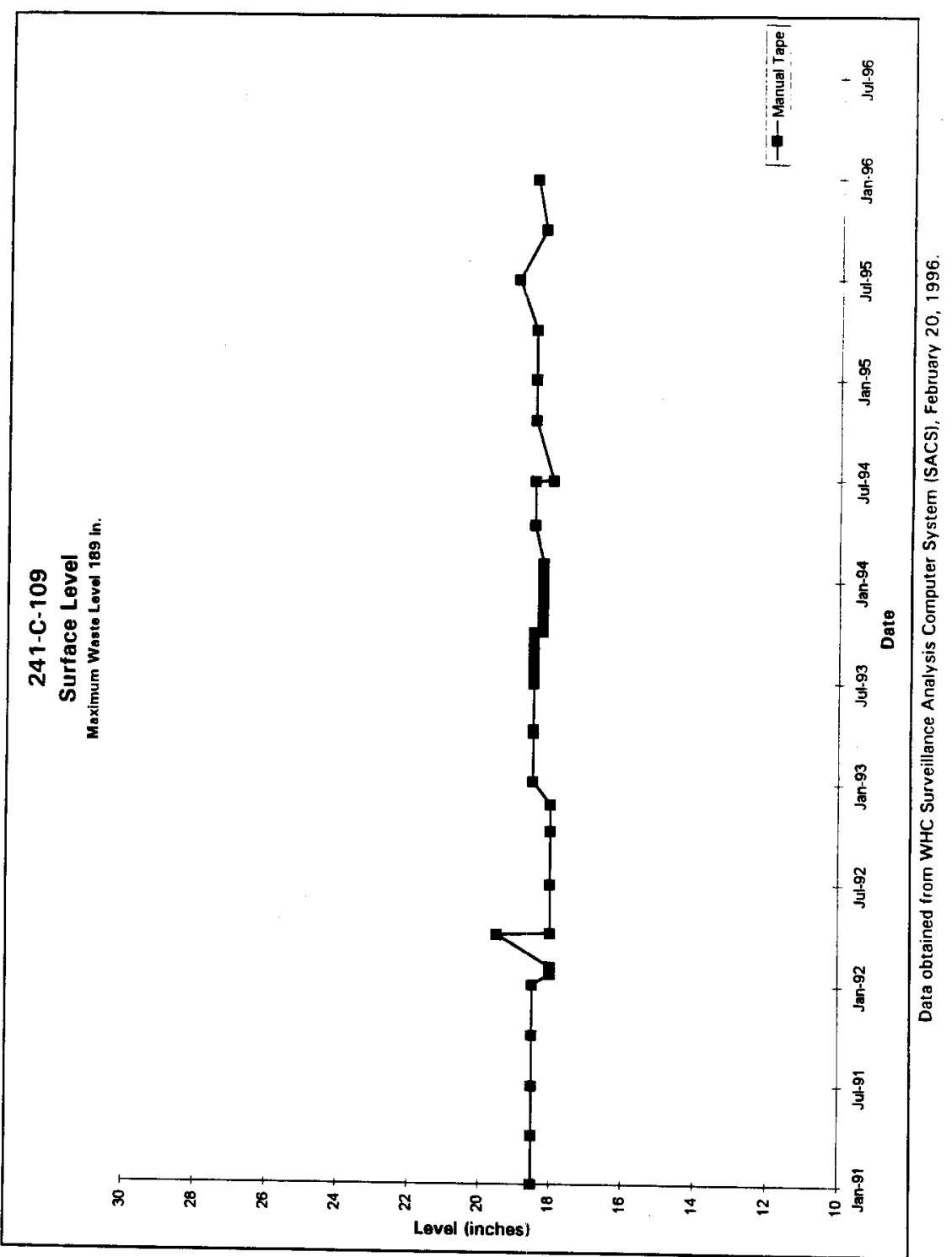

E-17 
WHC-SD-WM-ER-313, Rev. 1

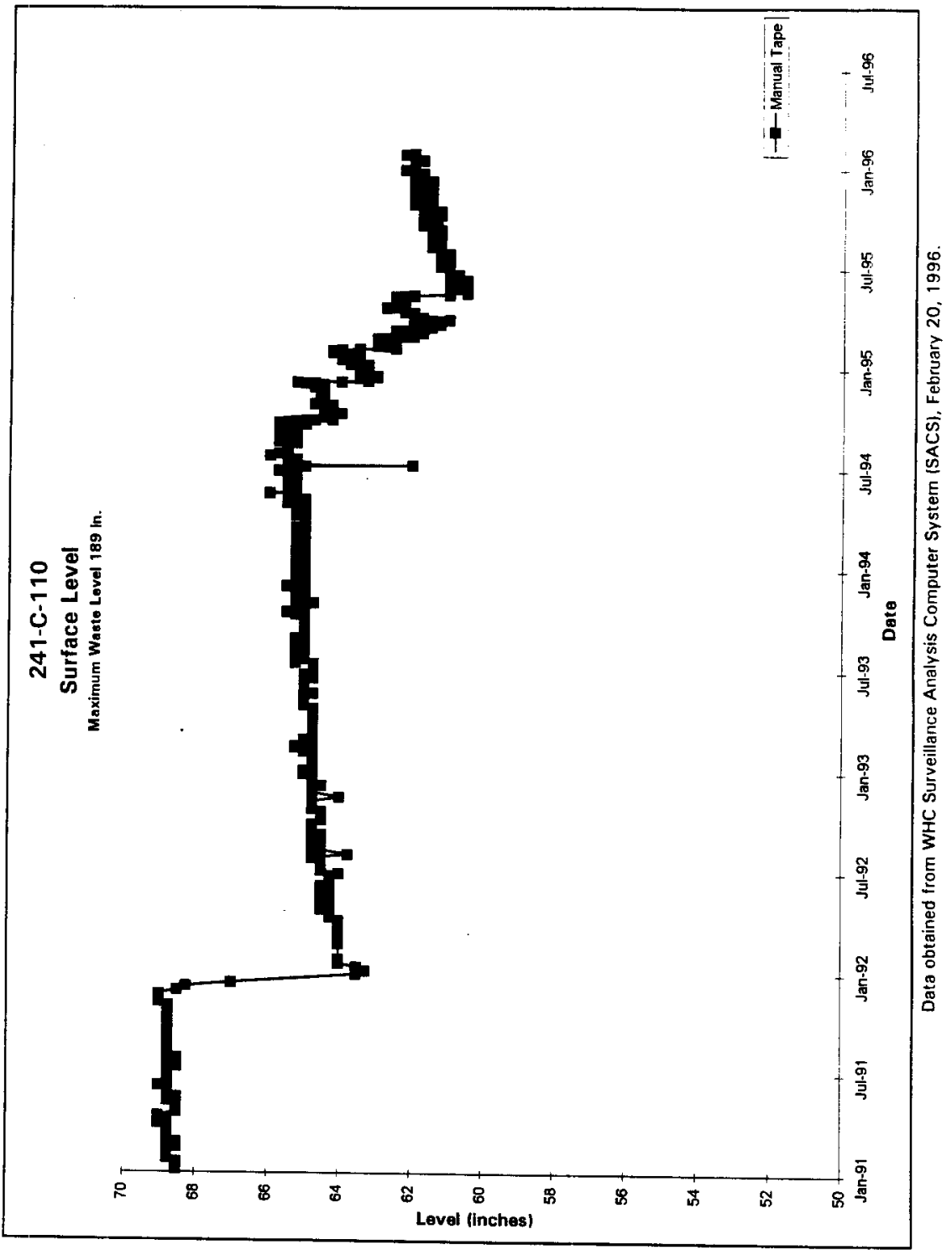


WHC-SD-WM-ER-313, Rev. 1

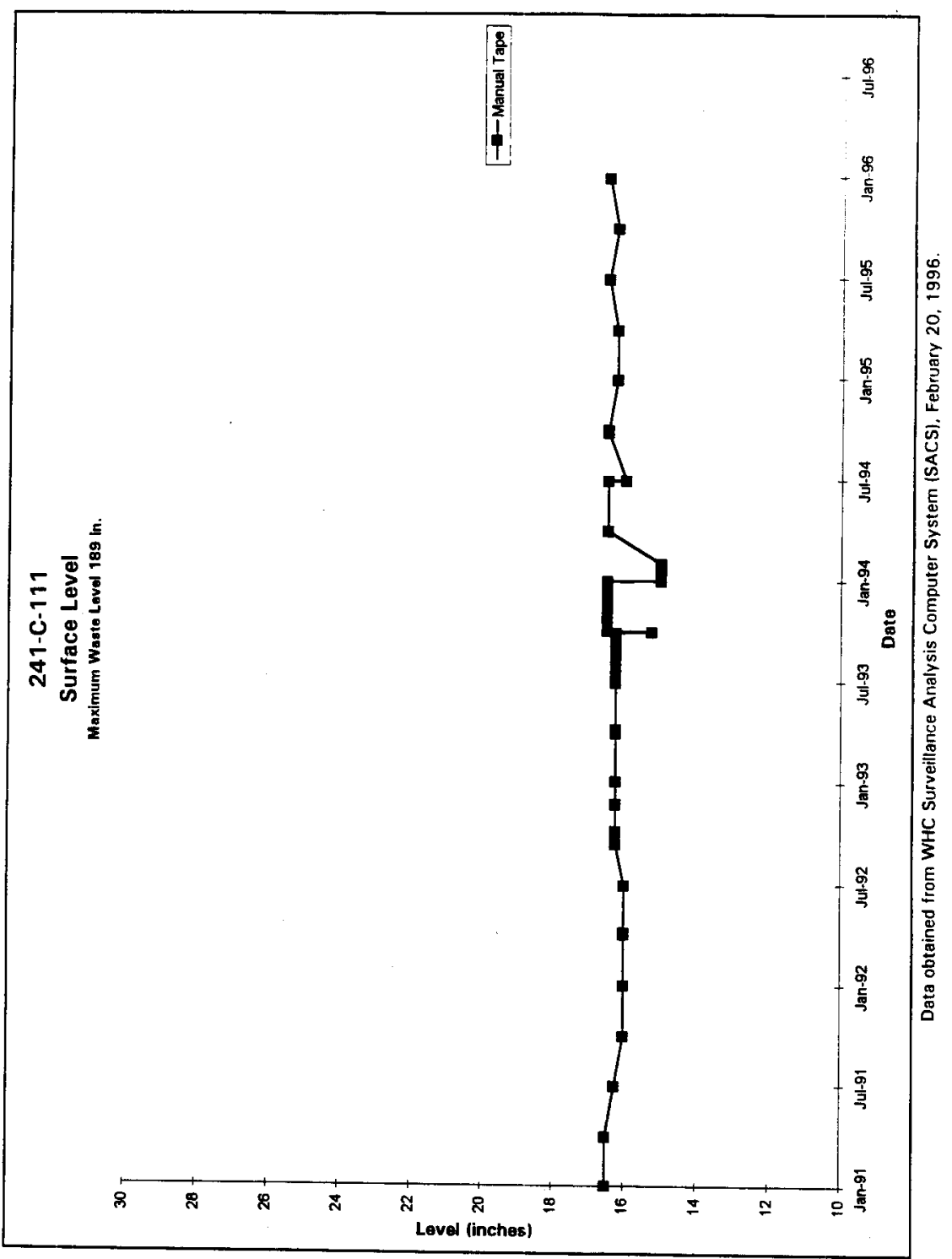




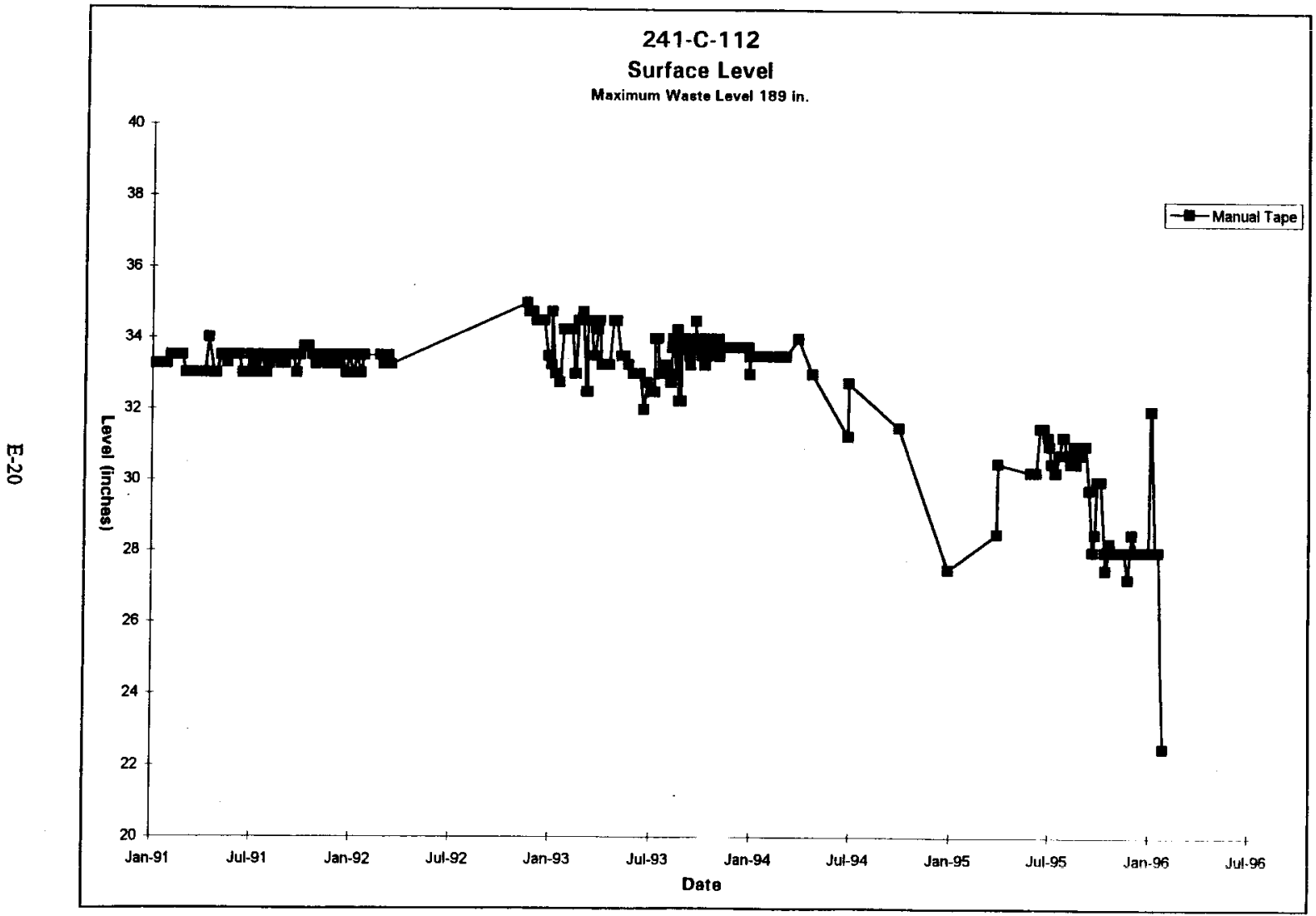

Data obtained from WHC Surveillance Analysis Computer System (SACS), February 20, 1996. 


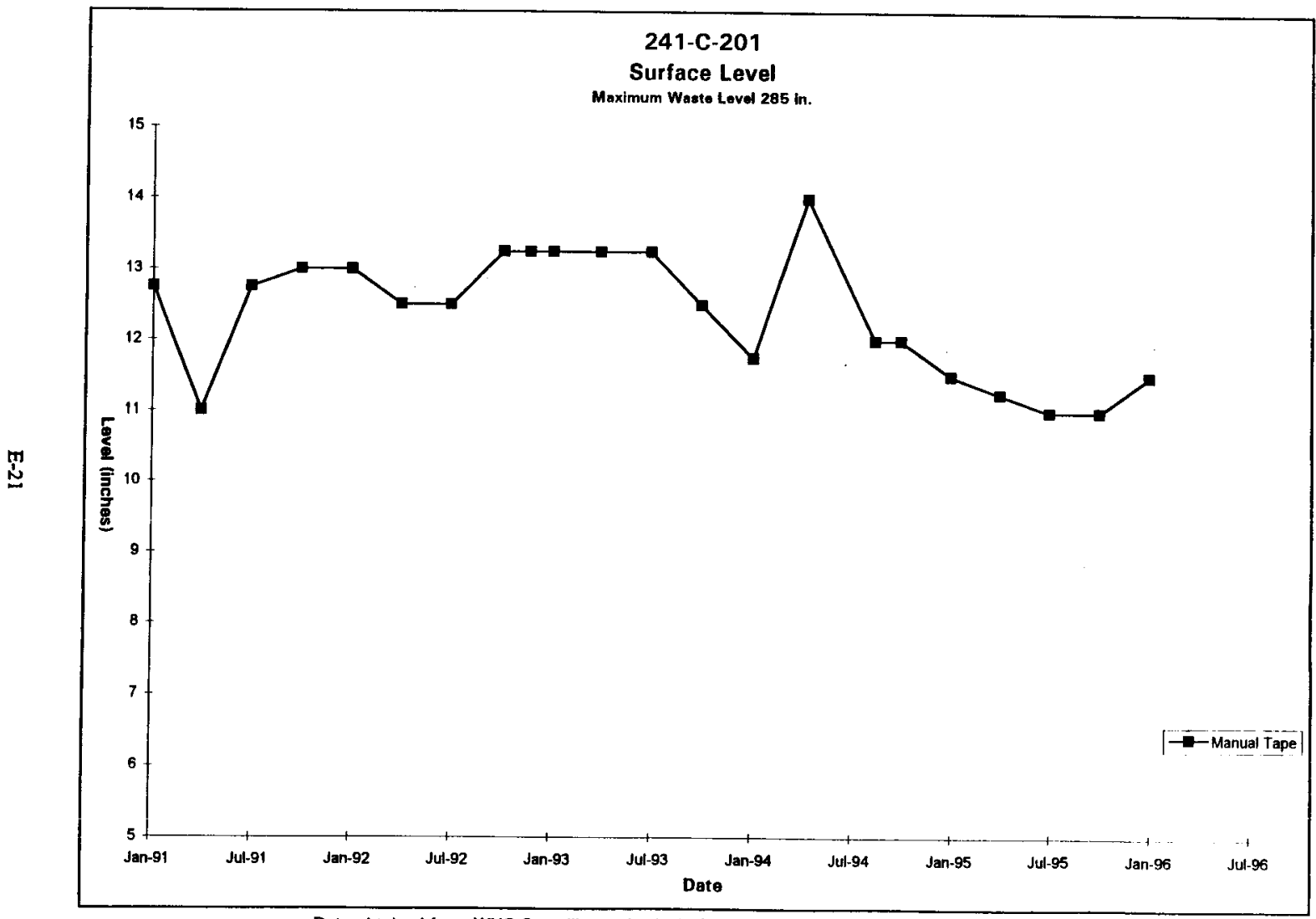

Data obtained from WHC Surveillance Analysis Computer System (SACSI, February 20, 1996. 
WHC-SD-WM-ER-31j, Rev. 1

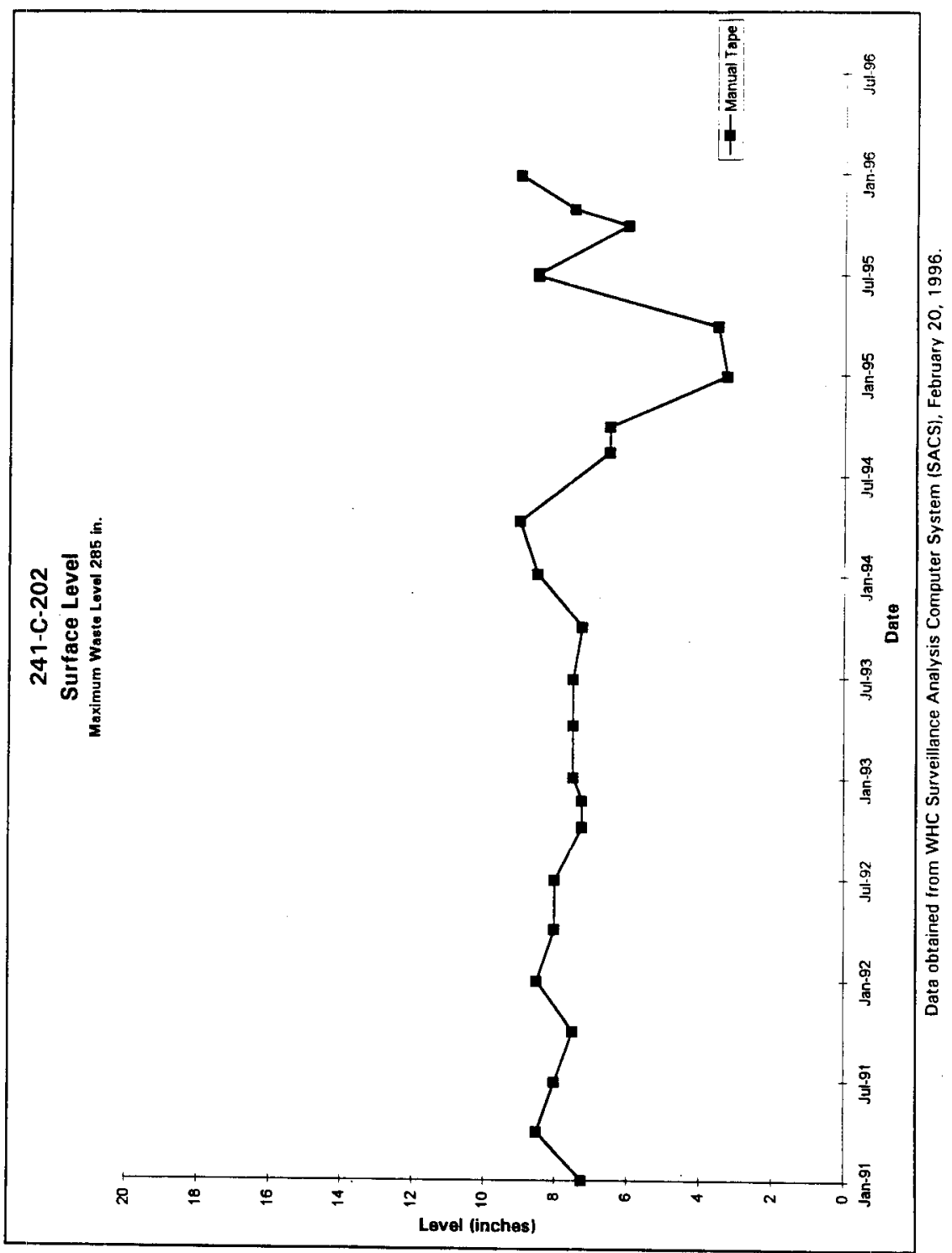

E-22 
WHC-SD-WM-ER-313. Rev. 1

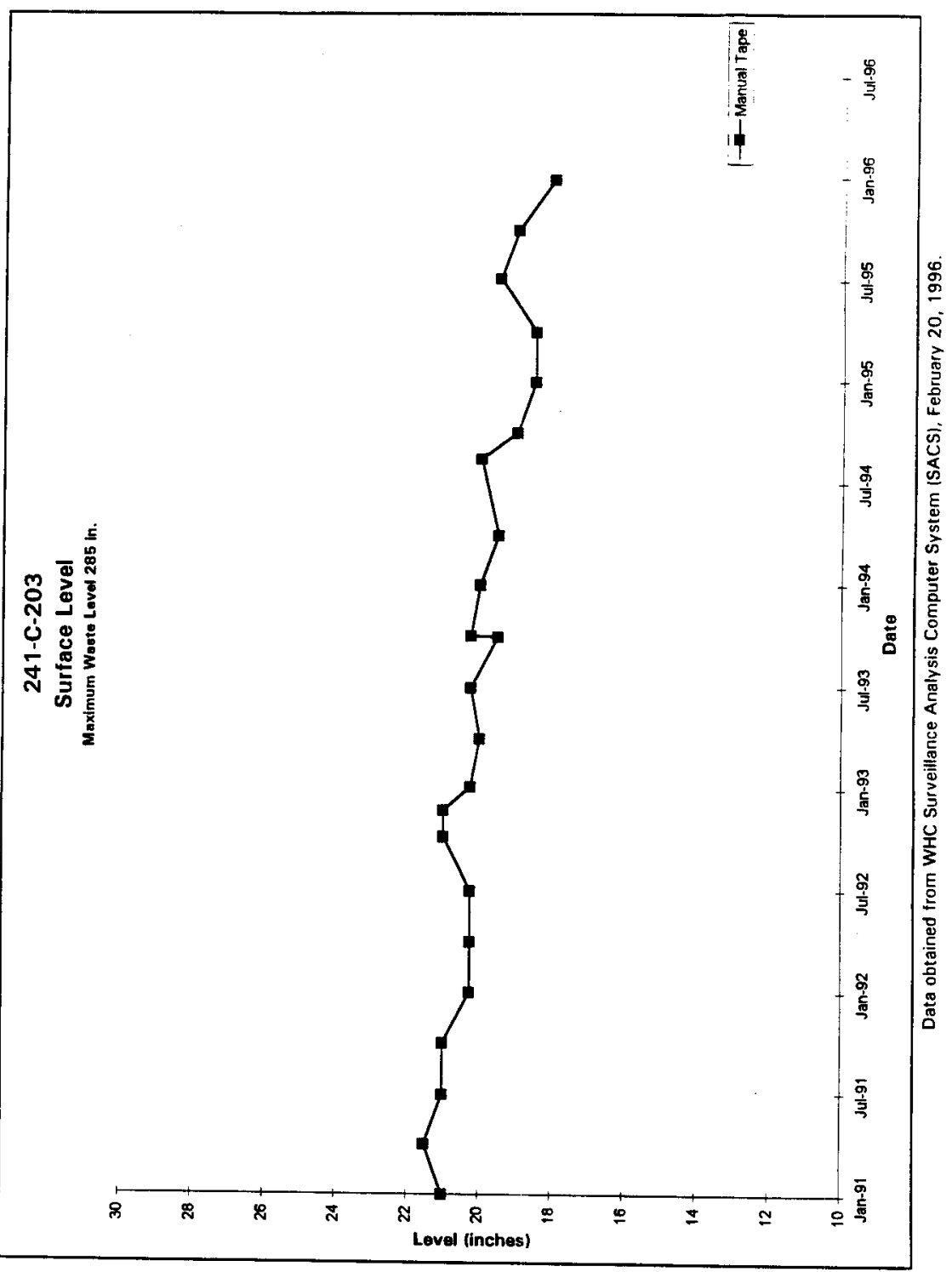




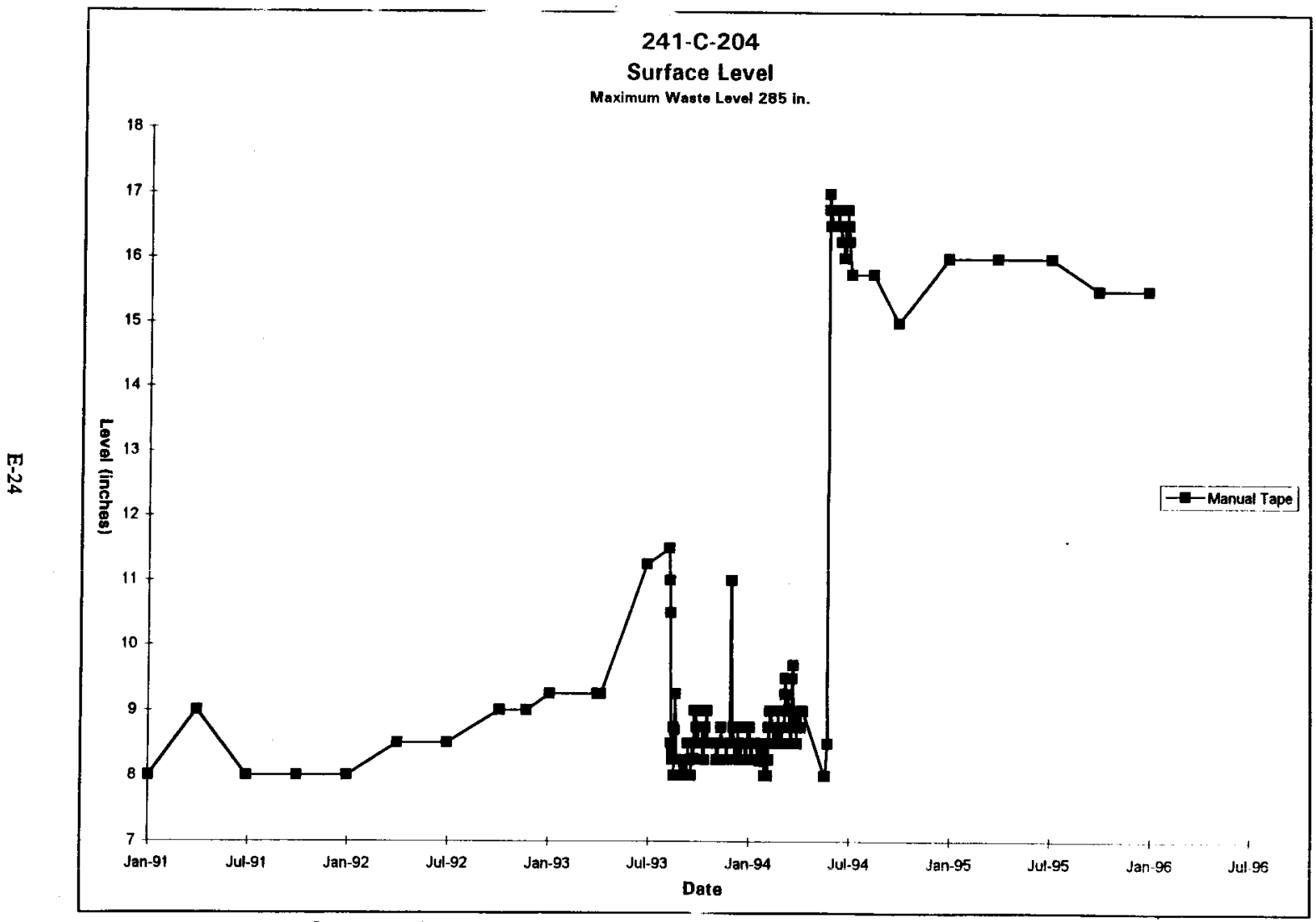

Data obtained from WHC Surveillance Analysis Computer System (SACS), February 20, 1996. 
WHC-SD-WM-ER-313. Rev. I

Intentionally left blank.

F-1 


\section{$241-C-101$ \\ 2.006.300 Liters \\ [530,000 Gallons]}

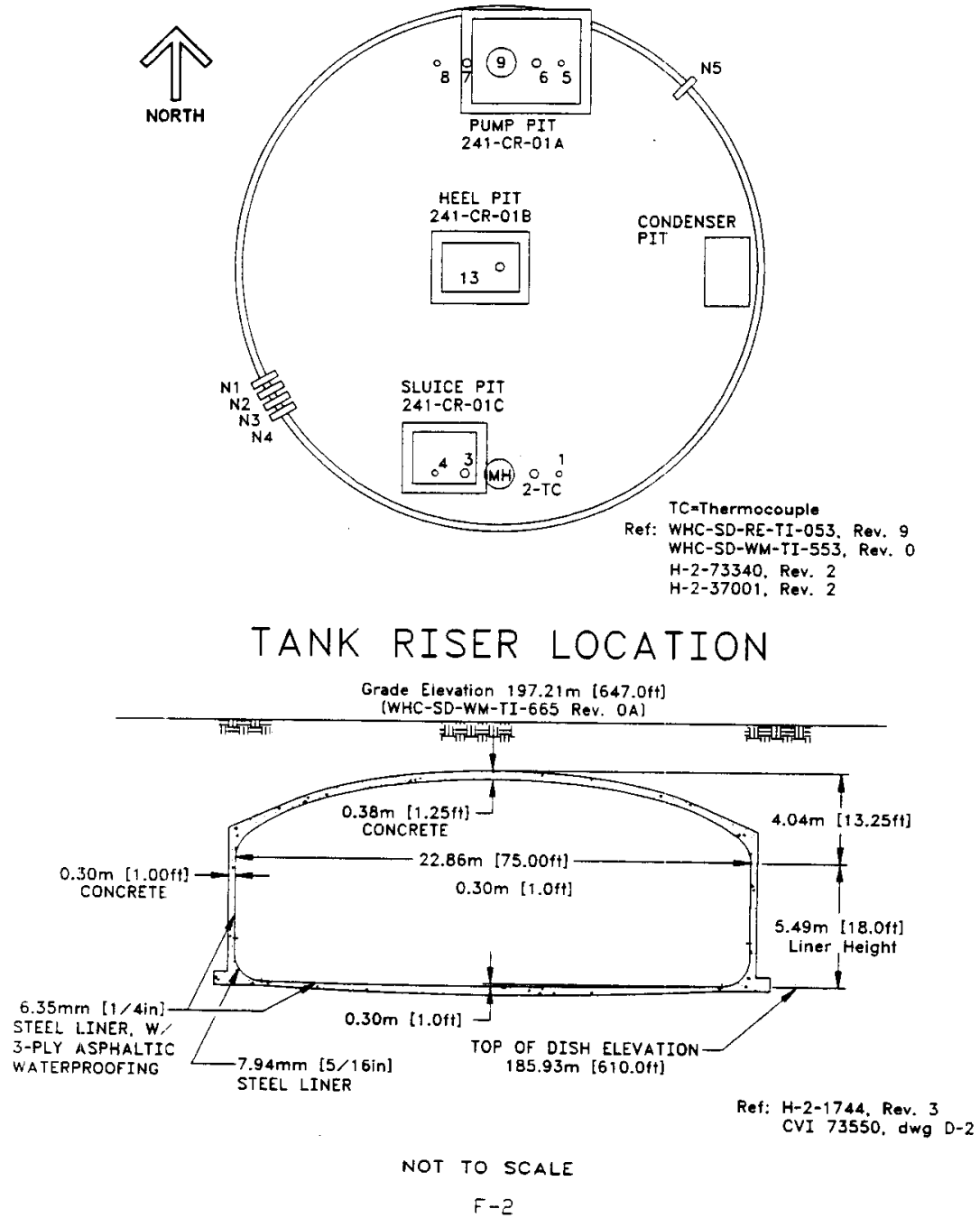




\begin{tabular}{|c|c|c|c|}
\hline No. & DIA. & SAMPLING : & DESCRIPTION AND COMMENTS \\
\hline 1 & 4" & $x$ & FLANGE [BM CEO-36922 12/11/86] \\
\hline 2 & $12^{\prime \prime}$ & & LIOUID LEVEL REEL AND TEMPERATURE PAOBE \\
\hline 3 & $12^{n}$ & & SLUICING NOZZLE, WC \\
\hline 4 & 4" & & DRAIN, WC \\
\hline 5 & $4^{\prime \prime}$ & & DRAIN, WC \\
\hline 6 & $12^{\prime \prime}$ & & PUMP, WC \\
\hline 7 & $12^{\prime \prime}$ & $\bar{x}$ & B-222 OBSV PORT \\
\hline 8 & $4^{\prime \prime}$ & $x$ & $\begin{array}{l}\text { BAEATHER FILTER IVAPOR ASSEMBLY/BREATHER FILTER } \\
\text { OFFSET ADAPTER ECN-618483 01/10/95] } \\
\text { [SPARE/BREATHER FILTER W/ OFFSET ADAPTER ECN- } \\
62082105 / 02 / 95]\end{array}$ \\
\hline 13 & $12^{*}$ & & PUMP, WC \\
\hline 9 & $42^{*}$ & & PUMP \\
\hline N1 & $3^{n}$ & & SPARE, PLUGGED \\
\hline N2 & $3^{n}$ & & SPARE, PLUGGED \\
\hline N3 & $3^{n}$ & & LINE V102, SEALED IN DIVERSION BOX 241-C-151 \\
\hline N4 & 3" & & LINE V104, SEALED IN DIVERSION BOX 241-C-151 \\
\hline N5 & $3^{n}$ & & OVERFLOW \\
\hline
\end{tabular}

Ref: WHC-SD-RE-TI-053, Rev.9 "WHC-SD-WM-TH-710, Rev.2 WHC-SD-WM-TI-553, Rev.O H-2-73340, Rev. 2

If there was a discrepancy between the documents and the drawings, the drawings shall take precedence.

Comments placed in II denote Engineering Change Notices (ECN) made against the reference drawings.

- Denotes risers tentatively available for sampling (Lipnicki 1995) 


\section{$241-C-102$ \\ 2.006.300 Liters \\ [530,000 Gallons]}

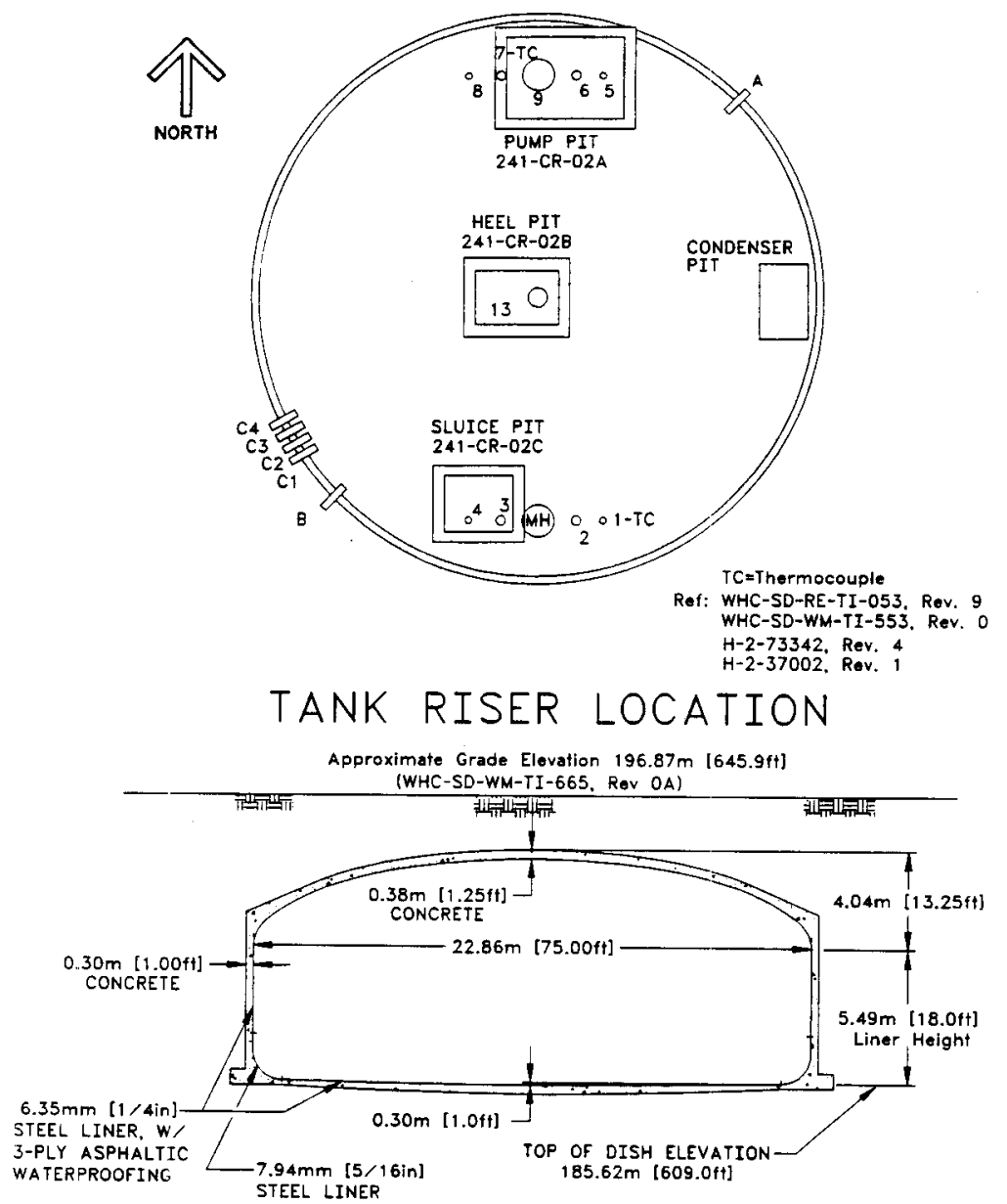

Ref: H-2-1744, Rev. 3

CVI 73550. owg D-2

NOT TO SCALE

$$
F-4
$$




\begin{tabular}{|c|c|c|c|}
\hline No. & DIA. & SAMPLING* & DESCRIPTION AND COMMENTS \\
\hline 1 & 4" & & $\begin{array}{l}\text { UNUSED TEMPERATURE PROBE, FLANGE I BM CEO-36922 } \\
12 / 11 / 86 \text { ] }\end{array}$ \\
\hline 2 & $12^{\prime \prime}$ & $\mathrm{x}$ & FIC IOBSV PORT ECN-625939 10/05/95] \\
\hline 3 & $12^{\prime \prime}$ & $\mathrm{x}$ & $\begin{array}{l}\text { B-222 OBSV PORT/BREATHER FILTER IENRAF } 854 \text { ECN- } \\
625939 \quad 10 / 05 / 95]\end{array}$ \\
\hline 4 & 4" & & RECIRCULATING DIP LEG, WC \\
\hline 5 & 4" & & RECIRCULATING DIP LEG, WC \\
\hline 6 & $12^{*}$ & & SLUICING ACCESS, WC \\
\hline 7 & $12^{n}$ & & TEMPERATURE PROBE, FLANGE \\
\hline 8 & $4^{\prime \prime}$ & & LOW \\
\hline 9 & 42" & & SLUDGE PUMP, WC \\
\hline 13 & $26^{\prime \prime}$ & & SALTWELL SCREEN \\
\hline A & 3" & & OVERFLOW OUTLET TO TANK 241-C-103 \\
\hline B & $3^{n}$ & & OVERFLOW INLET FROM TANK 241-C-101 \\
\hline $\mathrm{Cl}$ & $3^{n}$ & & SPARE INLET, CAPPED \\
\hline $\mathrm{C} 2$ & 3" & & SPARE INLET, CAPPED \\
\hline C3 & $3^{\prime \prime}$ & & SPARE INLET, CAPPED \\
\hline $\mathrm{C4}$ & $3^{n}$ & & SPARE INLET, CAPPED \\
\hline
\end{tabular}

Ref:

WHC-SD-RE-TI-053, Rev.9 "WHC-SD-WM-TH-710, Rev.2

WHC-SD-WM-TI-553, Rev.O H-2-73342, Rev. 4

If there was a discrepancy between the documents and the drawings, the drawings shall take precedence.

Comments placed in [] denote Engineering Change Notices (ECN) made against the reference drawings.

- Denotes risers tentatively available for sampling (Lipnicki 1995) 


\section{$241-C-103$ \\ 2.006.300 Liters [530,000 Gallons]}
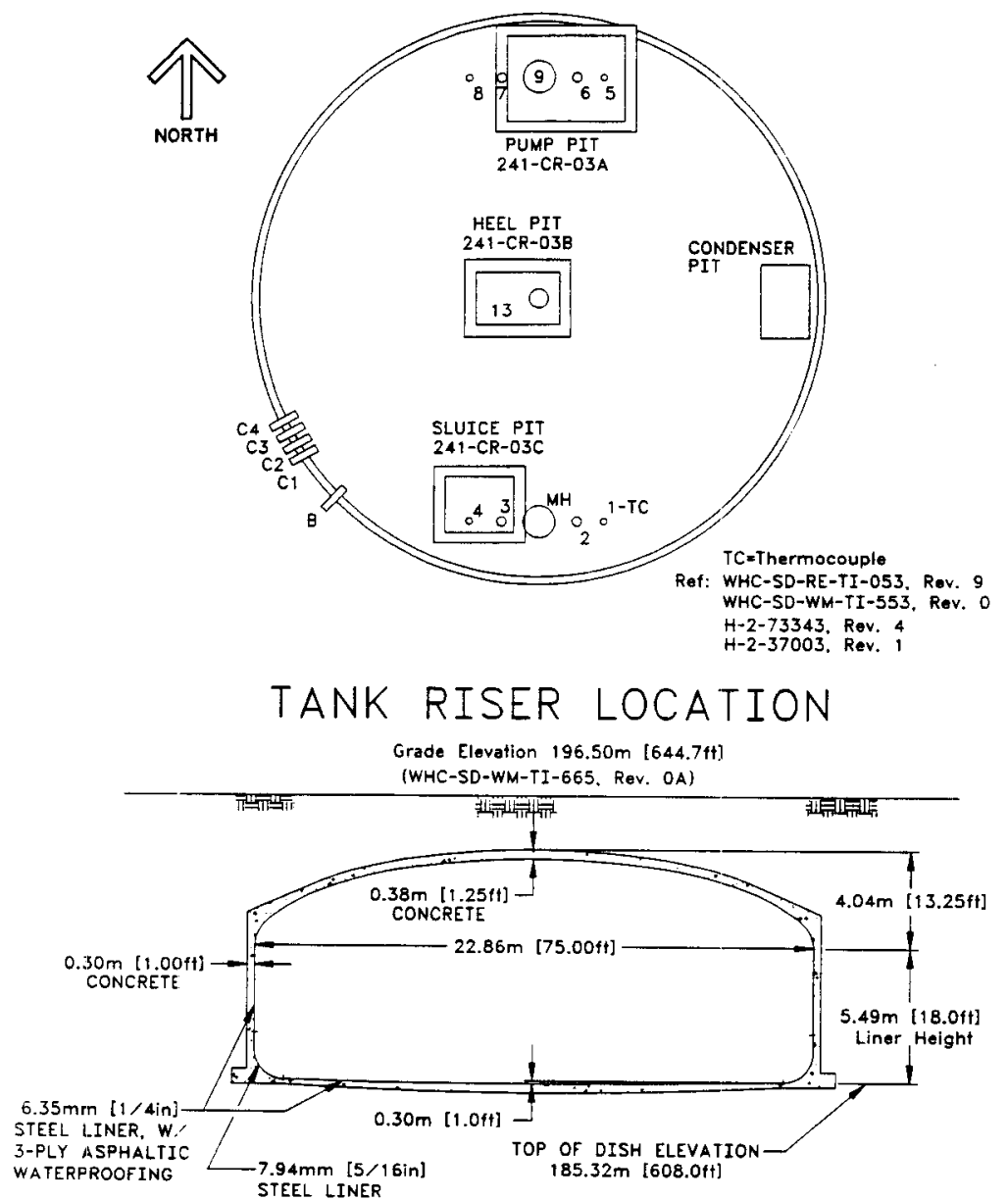

Ref: $H-2-1744$, Rev. 3

CVI 73550. dwg D-2

nOt to scale

$F-6$ 


\begin{tabular}{|c|c|c|c|}
\hline NO. & DIA. & SAMPLING * & DESCRIPTION AND COMMENTS \\
\hline 1 & 4" & & TEMPERATURE PROBE [ BM CEO-36922 12/11/86] \\
\hline 2 & $12^{n}$ & $x$ & $\begin{array}{l}\text { BREATHER FILTER IFLEX TUBING TO ULTRA LOW } \\
\text { FLOWMETER ECN-608894L 04/05/95] [AIR FILTER W/ } \\
\text { VAPOR MIXING SYSTEM ECN-620758 05/11/95] }\end{array}$ \\
\hline 3 & $12^{\prime \prime}$ & & SLUICING ACCESS, WC \\
\hline 4 & $4^{n}$ & & RECIRCULATING DIP LEG, WC \\
\hline 5 & 4" & & RECIRCULATING DEP LEG, WC \\
\hline 6 & $12^{\prime \prime}$ & & SLUICING ACCESS, WC \\
\hline 7 & $12^{\prime \prime}$ & $x$ & $\begin{array}{l}\text { BLANK [AEROSOL SAMPLING FLANGE ECN-190882 } \\
04 / 15 / 93]\end{array}$ \\
\hline 8 & 4" & & FIC [ENRAF 854 ECN-608131 $06 / 08 / 94]$ \\
\hline 9 & 42" & & SPECIAL PROBE, WC \\
\hline 13 & $26^{\prime \prime}$ & & SALTWELL SCREEN \\
\hline B & 3" & & OVERFLOW INLET \\
\hline C1 & $3^{n}$ & & SPARE INLET, CAPPED \\
\hline $\mathrm{C2}$ & 3" & & SPARE INLET, CAPPED \\
\hline $\mathrm{C3}$ & $3^{\prime \prime}$ & & SPARE INLET, CAPPED \\
\hline $\mathrm{C} 4$ & 3" & & SPARE INLET, CAPPED \\
\hline
\end{tabular}

Ref:

WHC-SD-RE-TI-053, Rev.9

"WHC-SD-WM-TI-710, Rev.2

WHC-SD-WM-TI-553, Rev.0

H-2-73343, Rev. 3

If there was a discrepancy between the documents and the drawings, the drawings shall take precedence.

Comments placed in [] denote Engineering Change Notices (ECN) made against the reference drawings.

- Denotes risers tentatively available for sampling (Lipnicki 1995) 


\section{$241-C-104$ \\ 2,006.300 Liters \\ [530,000 Gallons]}

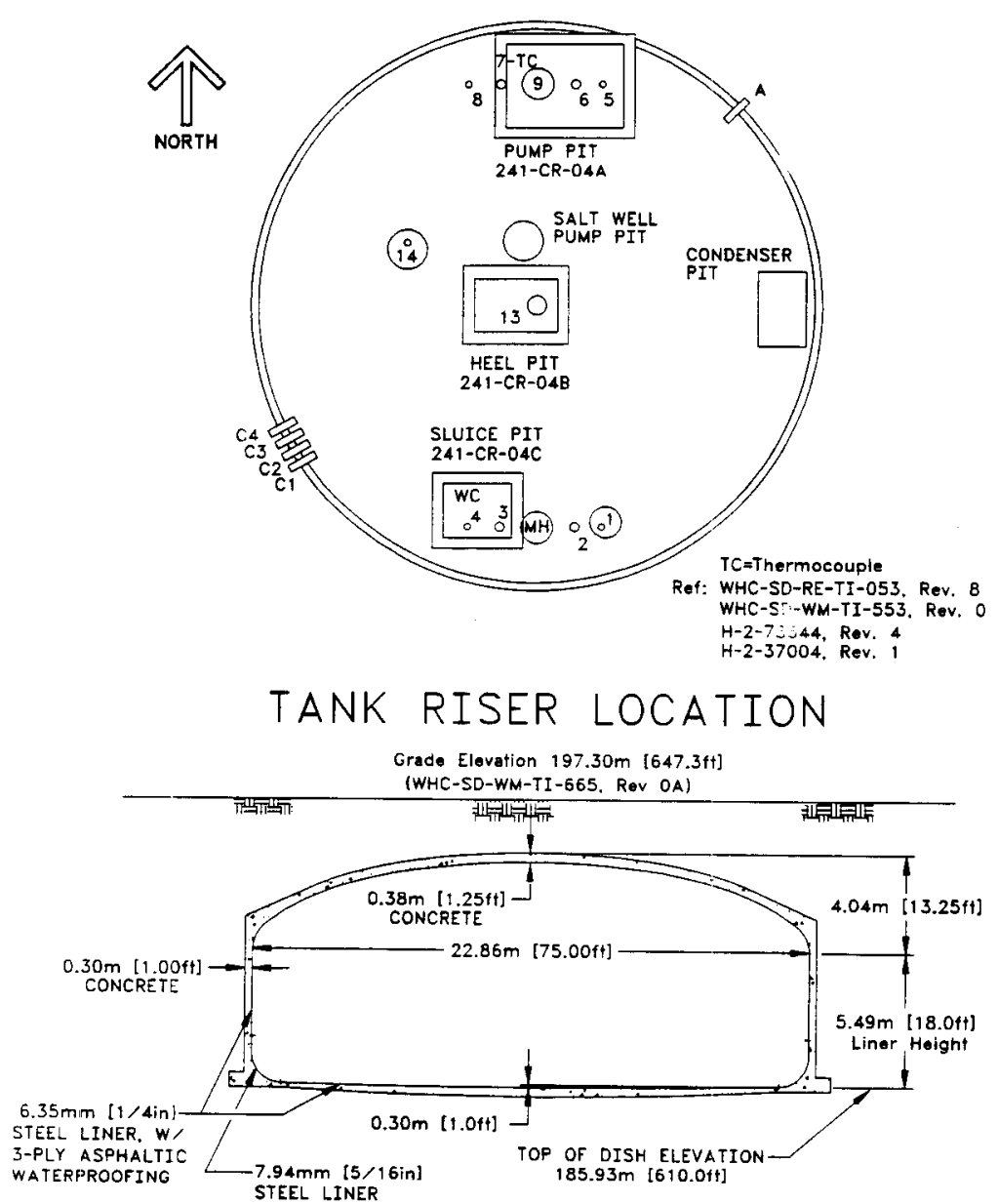

Ref: H-2-1744, Rev. 3

CVI 73550. dwg D-2

NOT TO SCALE

$$
F-8
$$




\begin{tabular}{|c|c|c|c|}
\hline NO. & DIA. & SAMPLING * & DESCRIPTION AND COMMENTS \\
\hline 1 & $4^{\prime \prime}$ & & LIQUID LEVEL WELL "B" \\
\hline 2 & $10^{\prime \prime}$ & $x$ & 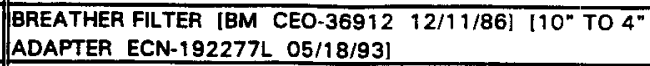 \\
\hline 3 & $12^{\prime \prime}$ & $x$ & B-222 OBSV PORT \\
\hline 4 & $4^{\prime \prime}$ & & RECIRCULATING DIP LEG, WC \\
\hline 5 & $4^{\prime \prime}$ & & RECIRCULATING DIP LEG, WC \\
\hline 6 & $12^{\prime \prime}$ & & SLUICING ACCESS, WC \\
\hline 7 & $12^{\prime \prime}$ & & TEMPERATURE PROBE, FLANGE \\
\hline 8 & $4^{\prime \prime}$ & & FIC \\
\hline 9 & $42^{n}$ & & SLUDGE PUMP, WC \\
\hline 13 & $26^{*}$ & & SALTWELL RISER \\
\hline 14 & & & LIQUID LEVEL WELL "A" \\
\hline$\vec{A}$ & 3" & & OVERFLOW OUTLET \\
\hline C1 & 3" & & FILL LINE V150 \\
\hline $\mathrm{C2}$ & $3^{n}$ & & FILL LINE V149, SEALED IN DIVERSION BOX $241-C-153$ \\
\hline C3 & $3^{n}$ & & FILL LINE V148, SEALED IN DIVERSION BOX 241-C-153 \\
\hline $\mathrm{C4}$ & 3" & & SPARE, CAPPED \\
\hline
\end{tabular}

Ref:

$$
\begin{array}{ll}
\text { WHC-SD-RE-TI-053, Rev.9 } & \text { "WHC-SD-WM-TI-710, Rev.2 } \\
\text { WHC-SD-WM-TI-553, Rev.0 } & \text { H-2-73344, Rev. } 4
\end{array}
$$

If there was a discrepancy between the documents and the drawings, the drawings shall take precedence.

Comments placed in [] denote Engineering Change Notices (ECN) made against the reference drawings.

- Denotes risers tentatively available for sampling (Lipnicki 1995) 


\section{$241-C-105$ \\ 2.006.300 Liters \\ [530.000 Gallons]}

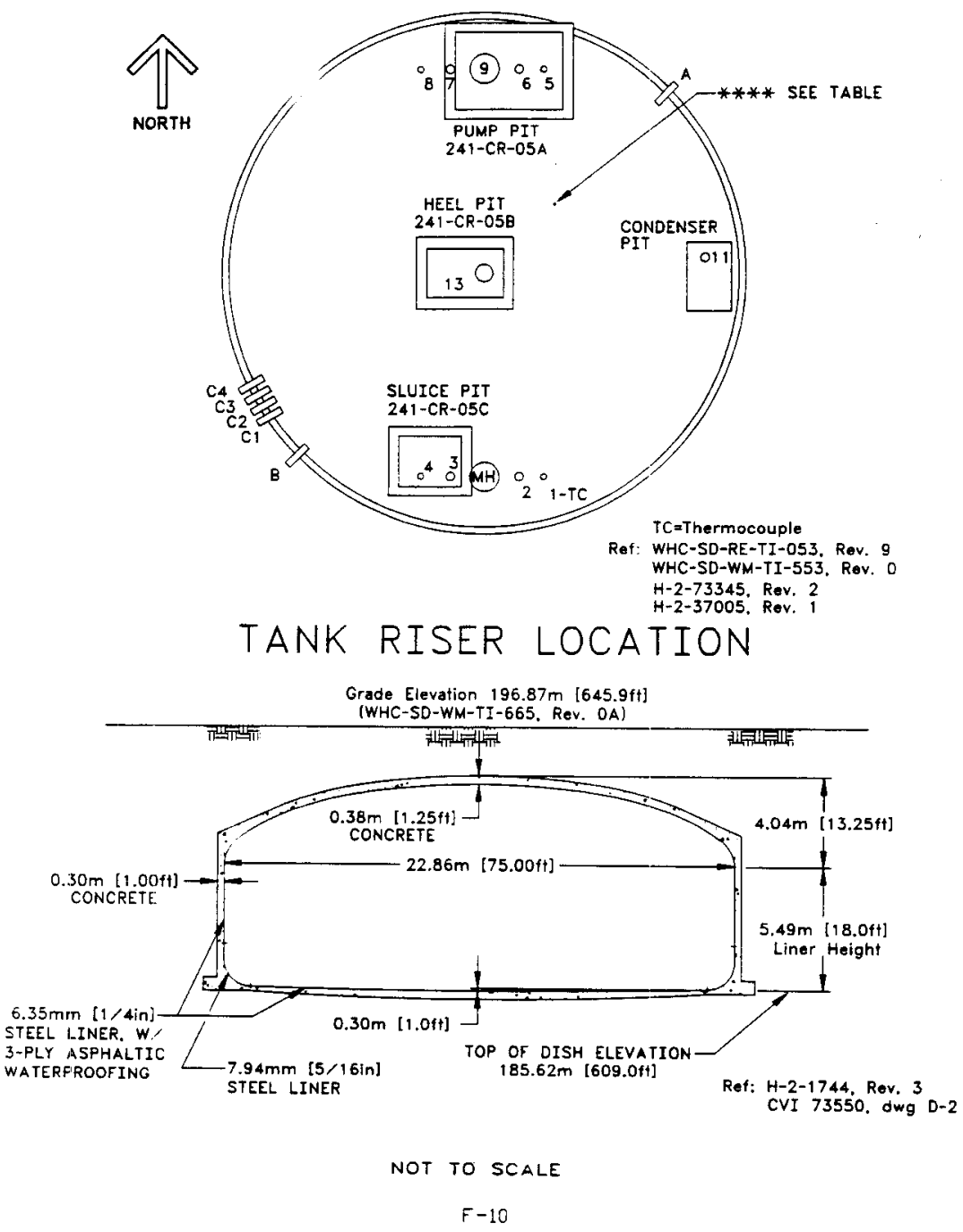




\begin{tabular}{|c|c|c|c|}
\hline No. & DIA. & SAMPLING* & DESCRIPTION AND COMMENTS \\
\hline 1 & 4" & & $\begin{array}{l}\text { TEMPERATURE PROBE, B-221 [MULTI-FUNCTIONAL } \\
\text { INSTRUMENT TREE ECN-107980 06/03/91]! BM CEO- } \\
36922 \quad 12 / 11 / 86 \text { ] }\end{array}$ \\
\hline 2 & $12^{\prime \prime}$ & $\mathbf{x}$ & $\begin{array}{l}\text { VENT LINE [AIR INLET FILTER ECN-101611 } 04 / 17 / 8 B \quad \& \\
\text { ECN-103736 } 11 / 30 / 88 \text { ] }\end{array}$ \\
\hline 3 & $12^{*}$ & & BLANK, WC \\
\hline 4 & 4" & & RECIRCULATING DIP LEG, WC \\
\hline 5 & $4^{n}$ & & AECIRCULATING DIP LEG, WC \\
\hline 6 & $12^{\prime \prime}$ & & $\begin{array}{l}\text { SLUICING ACCESS/WEATHER CAP, WC ITEMPERATURE } \\
\text { PROBE ECN-101611 } 04 / 17 / 88 \text { ] }\end{array}$ \\
\hline 7 & $12^{n}$ & & LEAD COVEREDWC \\
\hline 8 & 4" & $\mathbf{x}$ & $\begin{array}{l}\text { FIC IFIC/PRESSURE GUAGE ECN-103736 } 11 / 30 / 88 \text { ] [ENRAF } \\
854 \text { ECN-619367 03/16/95] }\end{array}$ \\
\hline 9 & $42^{\prime \prime}$ & & SLUDGE PUMP, WC \\
\hline $11 \cdots$ & $12^{\prime \prime}$ & & EXHAUSTER PORT ECN-103736 $111 / 30 / 88$ \\
\hline 13 & $26^{\prime \prime}$ & & DISTAIBUTOR JET, WC \\
\hline$\#$ & $4^{\prime \prime}$ & & [ADD NEW 4" RISER FCN-54902 05/14/81] \\
\hline A & 3" & & OVERFLOW OUTLET \\
\hline $\mathbf{B}$ & 3" & & OVEAFLOW INLET \\
\hline C1 & $3^{*}$ & & INLET LINE V103, SEALED IN DIVERSION BOX 241-C-151 \\
\hline $\mathrm{C} 2$ & $3^{n}$ & & SPARE INLET, CAPPED \\
\hline $\mathrm{C3}$ & 3" & & SPARE INLET, CAPPED \\
\hline $\mathrm{C} 4$ & $3^{\prime \prime}$ & & SPARE INLET, CAPPED \\
\hline
\end{tabular}

Ref:

WHC-SD-RE-TI-053, Rev.9 "WHC-SD-WM-TI-710, Rev.2

WHC-SD-WM-TI-553, Rev.O H-2.73345, Rev. 2

H-2-72352, Rev. $O$

If there was a discrepancy between the documents and the drawings, the drawings shall take precedence.

Comments placed in [] denote Engineering Change Notices (ECN) made against the reference drawings.

- Denotes risers tentatively available for sampling (Lipnicki 1995)

* Created by ECN-103736.

* * * Created by FCN-54902 and H-2-72352; however, this was not mentioned in isolation drawing. 


\section{$241-C-106$ \\ 2,006.300 Liters \\ [530.000 Gallons]}
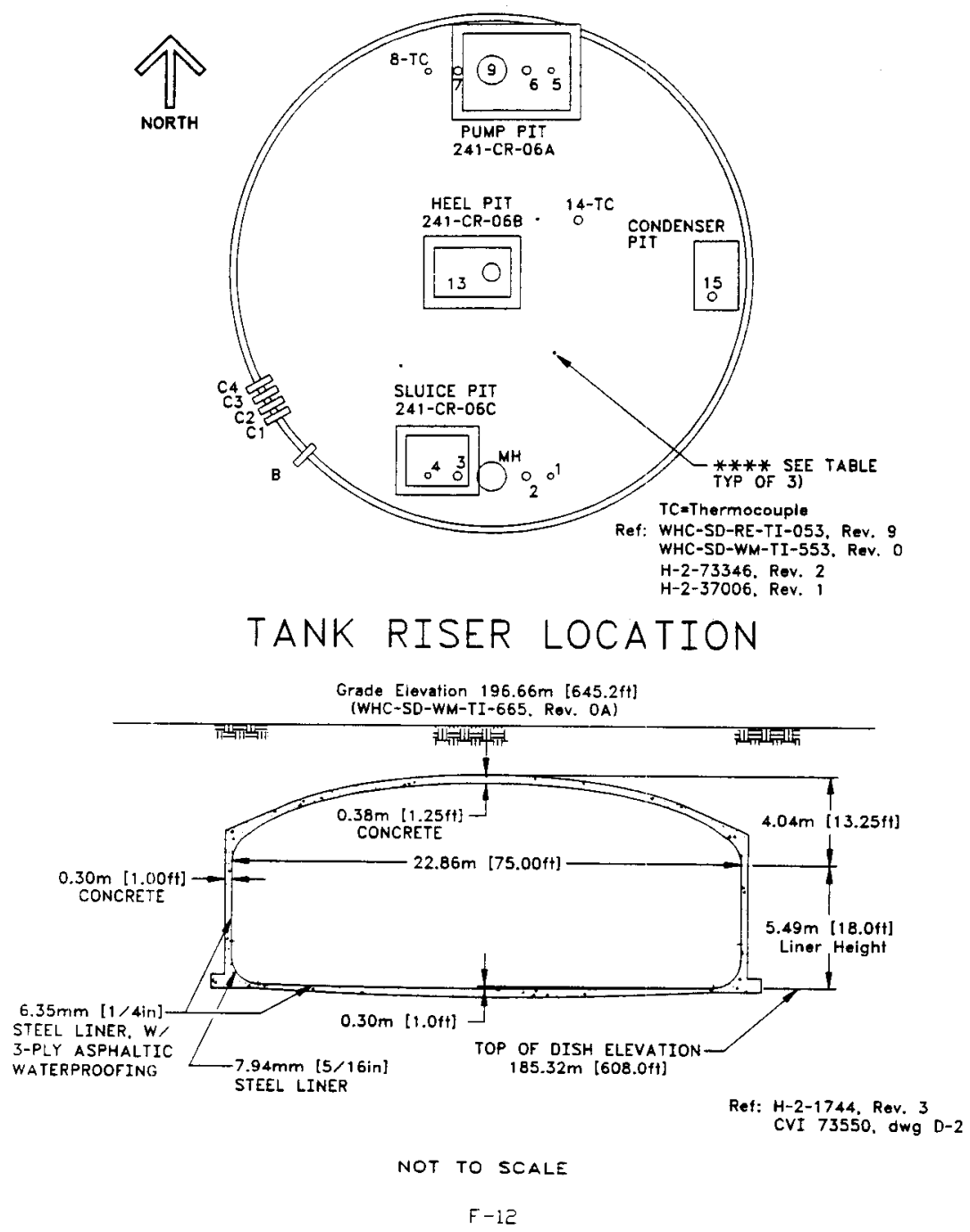


\begin{tabular}{|c|c|c|c|}
\hline NO. & DIA. & SAMPLING & DESCAIPTION AND COMMENTS \\
\hline 1 & 4" & $x$ & $\begin{array}{l}\text { FIC I BM CEO-36922 12/11/86] [ENRAF } 854 \text { ECN-629511 } \\
01 / 25 / 96]\end{array}$ \\
\hline 2 & $12^{n}$ & & EXHAUSTER PORT \\
\hline 3 & $12^{\prime \prime}$ & & BLANK, WC \\
\hline 4 & $4^{\prime \prime}$ & & RECIRCULATING DIP LEG, WC \\
\hline 5 & $4^{\prime \prime}$ & & RECIRCULATING DIP LEG, WC \\
\hline 6 & $12^{*}$ & & SLUICING ACCESS \\
\hline 7 & $12^{n}$ & $x$ & $\begin{array}{l}\text { B-222 OBSV PORT IMULTI-PORT RISER ADAPTER ECN- } \\
613184 \text { O8/11/94] [TEMPERATURE PROBE ECN-613207L } \\
09 / 15 / 94 \text { ] [ENRAF AND PRESSURE GAUGE ECN-629512L } \\
01 / 30 / 96 \text { ] }\end{array}$ \\
\hline 8 & 4" & & TEMPERATURE PAOBE \\
\hline 9 & $42^{*}$ & & SLUDGE PUMP \\
\hline 13 & $26^{\prime \prime}$ & & DISTRIBUTOR JET, WC \\
\hline 14 & 4" & & SPARE \\
\hline $15^{* * *}$ & $12^{n}$ & & [INLET FILTER ECN-103653 10/24/88] \\
\hline$* * *$ & & & $\begin{array}{l}\text { [ADD NEW 4" RISEA FCN-54902 05/14/81] [ADD } 2 \text { NEW 4" } \\
\text { RISERS FCN-50547' 10/16/79] }\end{array}$ \\
\hline B & 3" & & OVERFLOW INLET \\
\hline C1 & 3* & & SPARE INLET, CAPFED \\
\hline $\mathrm{C2}$ & 3" & & SPARE INLET, CAPPED \\
\hline $\mathrm{C3}$ & $3 "$ & & SPARE INLET, CAPF'ED \\
\hline $\mathrm{C} 4$ & $3^{n}$ & & SPARE INLET, CAPFED \\
\hline
\end{tabular}

Ref:

WHC-SD-RE-TI-053, Rev.9 *WHC-SD-WM-TI-710, Rev.2

WHC-SD-WM-TI-553, Rev.0 H-2-73346, Rev. 2

H-2-72352, Rev. 0

If there was a discrepancy between the documents and the drawings, the drawings shall take precedence.

Comments placed in [] denote Engineering Change Notices (ECN) made against the reference drawings.

\footnotetext{
- Denotes risers tentatively available for sampling (Lipnicki 1995)

** Created by ECN-103653.

* * * Created by FCN-50547 written against H-2-7/2352 rev. O. and FCN-54902.
} 


\section{$241-C-107$ \\ 2,006,300 Liters \\ [530,000 Gallons]}
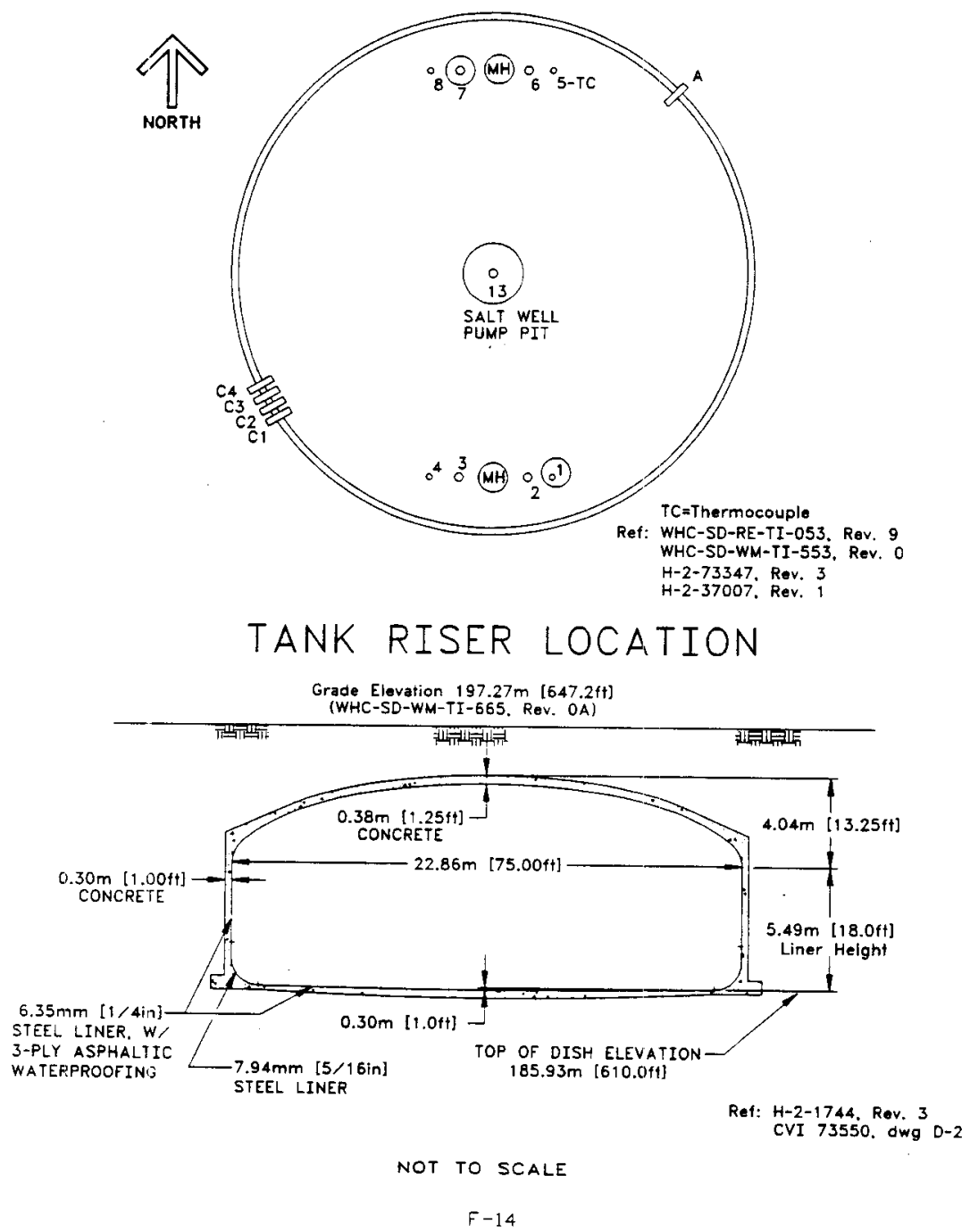


\begin{tabular}{|c|c|c|c|}
\hline NO. & DIA. & SAMPLING* & DESCRIPTION AND COMMENTS \\
\hline 1 & $4^{n}$ & & LIQUID LEVEL WELL_. "B" \\
\hline 2 & $12^{\prime \prime}$ & $x$ & FLANGE [BM CEO.37761 $12 / 11 / 86]$ \\
\hline 3 & $12^{\prime \prime}$ & $x$ & $\begin{array}{l}\text { B-221 OVSV PORT IHEATED VAPOR ASSEMBLY ON } 12^{\prime \prime} \text { TO } \\
4^{*} \text { ADAPTER ECN-613544 O9/23/94] }\left(12^{*} \text { BLIND FLANGE }\right. \\
\text { ECN-618245 O2/OB/95] [MULTI-PORT ADAPTER W/VAPOR } \\
\text { PROBE ECN-626623 } 12 / 11 / 95)\end{array}$ \\
\hline 4 & 4" & $x$ & $\begin{array}{l}\text { 8REATHER FILTER [BREATHER FILTER W/ OFFSET ADAPTER } \\
\text { ECN-613544 } 09 / 23 / 94 \text { ] }\end{array}$ \\
\hline 5 & 4" & & TEMPERATURE PROBE \\
\hline $6 *$ & $12^{n}$ & & LIQUID LEVEL WELL. "A" \\
\hline $7 *$ & $12^{\prime \prime}$ & $\bar{x}$ & SPARE \\
\hline 8 & 4" & & FIC \\
\hline 13 & $12^{\prime \prime}$ & & SALTWELL SCREEN \\
\hline $\bar{A}$ & $33^{\prime \prime}$ & & OVERFLOW OUTLET \\
\hline $\mathrm{C}_{1}$ & $3^{\prime \prime}$ & & FILL LINE, SEALED IN DIVERSION BOX 241-C-153 \\
\hline $\mathrm{C2}$ & 3" & & FILL LINE, SEALED IN DIVERSION BOX 241-C-153 \\
\hline $\mathrm{C3}$ & $3^{n}$ & & FILL LINE, SEALED IN DIVERSION BOX 241-C-153 \\
\hline $\mathrm{C4}$ & 3" & & SPARE, PLUGGED \\
\hline
\end{tabular}

Ref:

WHC-SD-RE-TI-053, Rev.9

"WHC-SD-WM-TI-710, Rev.2

WHC-SD-WM-TH-553, Rev.0

H-2-73347, Rev. 3

If there was a discrepancy between the documents and the drawings, the drawings shall take precedence.

Comments placed in [] denote Engineering Change Notices (ECN) made against the reference drawings.

$*$

Denotes risers tentatively available for sampling (Lipnicki 1995)

* Figure on H-2-73347 Rev. 3 shows riser 7 as Liquid Level Well "A" \& table shows riser 6 as Liquid Level Well "A" and riser 7 as spare. For this document, the table was chosen as the discription for risers 6 and 7 . The table is from revision 2 and the figure from revision 1 . 


\section{$241-C-108$}

2,006.300 Liters

[530,000 Gallons]
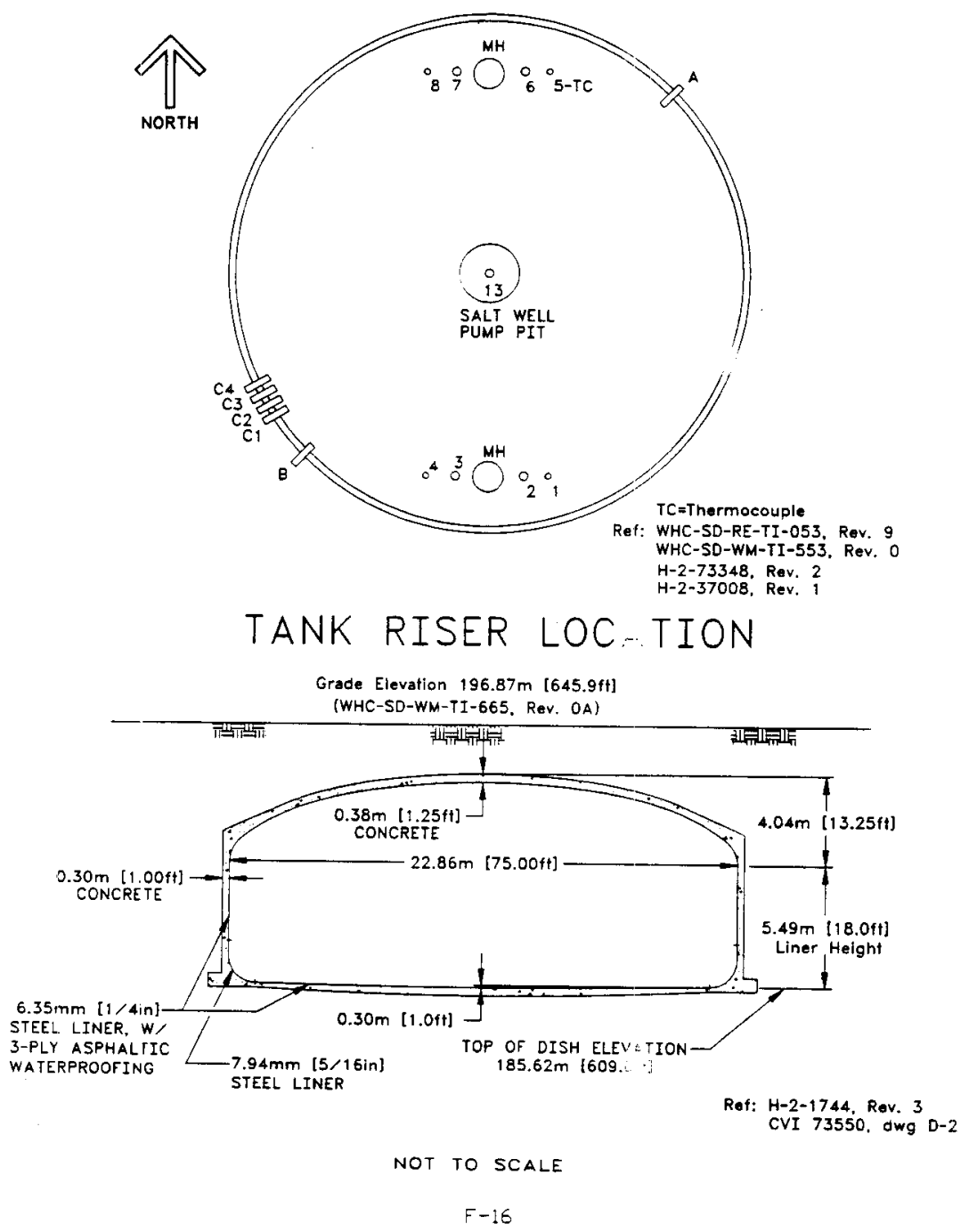


\begin{tabular}{|c|c|c|c|}
\hline No. & DIA. & SAMPLING* & DESCRIPTION AND COMMENTS \\
\hline 1 & $4^{\prime \prime}$ & & $\begin{array}{l}\text { LLQUID LEVEL REEL [THERMOCOUPLE ECN-190138 } \\
\text { [03/29/93] }\end{array}$ \\
\hline 2 & $12 "$ & $x$ & $\begin{array}{l}\text { BLANK [BM CEO-40213 } 12 / 08 / 86 \& \text { ECN-614184 } \\
10 / 31 / 94]\end{array}$ \\
\hline 3 & $12^{\prime \prime}$ & $x$ & SPARE \\
\hline 4 & 4" & $x$ & $\begin{array}{l}\text { BREATHER FILTER [VAPOR ASSEMBLY/BREATHER FILTER } \\
\text { OFFSET ADAPTER ECN-618483 01/10/95] [BREATHER } \\
\text { FILTER W/ OFFSET ADAPTER ECN-620822 O5/02/95] }\end{array}$ \\
\hline 5 & $4^{n}$ & & TEMPERATURE PROBE \\
\hline 6 & $12^{*}$ & $\bar{x}$ & SPARE \\
\hline 7 & $12^{\prime \prime}$ & $\bar{x}$ & B-222 OBSV PORT \\
\hline 8 & $4^{\prime \prime}$ & & $\begin{array}{l}\text { FLOW INDICATOR ILIOUID LEVEL REEL ECN-190138 } \\
03 / 29 / 93 \text { ] [BM ECN-614184 10/31/94] }\end{array}$ \\
\hline 13 & $12^{\prime \prime}$ & & SALTWELL SCAEEN, WC \\
\hline A & $3^{n}$ & & OVERFLOW OUTLET \\
\hline B & $3^{\prime \prime}$ & & OVERFLOW INLET \\
\hline $\mathrm{Cl}$ & $3^{n}$ & & SPARE, CAPPED \\
\hline $\mathrm{C2}$ & 3" & & SPARE, CAPPED \\
\hline $\mathrm{C3}$ & 3" & & SPARE, CAPPED \\
\hline $\mathrm{C4}$ & $3 n$ & & SPARE, CAPPED \\
\hline
\end{tabular}

Ref:

WHC-SD-RE-TI-053, Rev.9 *WHC-SD-WM-TI-710, Rev.2

WHC-SD-WM-TI-553, Rev.0 H-2-73348, Rev. 2

If there was a discrepancy between the documents and the drawings, the drawings shall take precedence.

Comments placed in [] denote Engineering Change Notices (ECN) made against the reference drawings.

- Denotes risers tentatively available for sampling (Lipnicki 1995) 


\section{$241-C-109$ \\ 2.006,300 Liters \\ [530.000 Gallons]}

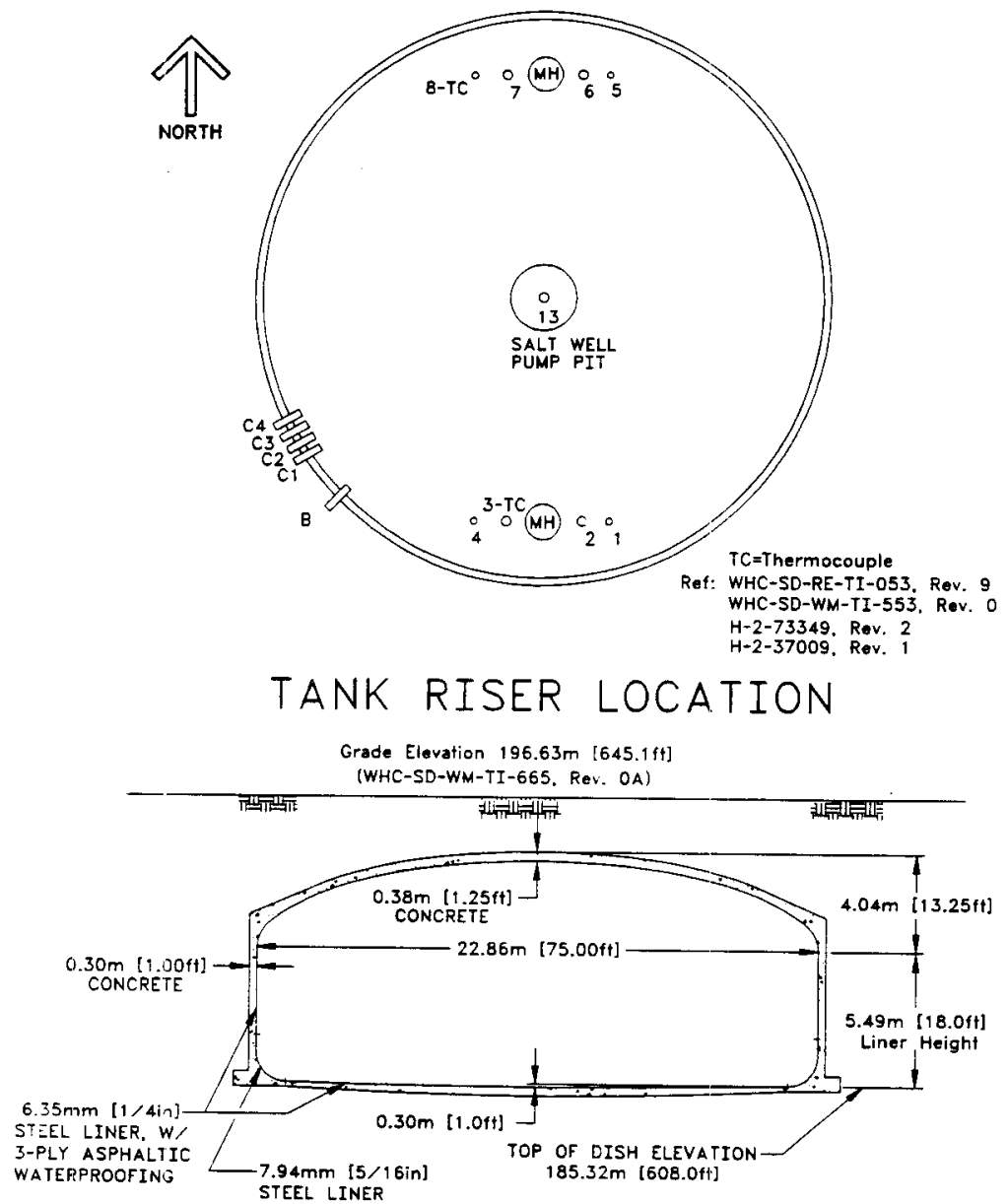

Ref: $\mathrm{H}-2-1744$, Rev. 3

CVI 73550, dwg D-2

$$
\begin{gathered}
\text { NOT TO SCALE } \\
\mathrm{F}-18
\end{gathered}
$$




\begin{tabular}{|c|c|c|c|}
\hline No. & DIA. & SAMPLING * & DESCRIPTION AND COMMENTS \\
\hline 1 & $4^{n}$ & & LIQUID LEVEL REEL \\
\hline 2 & $12^{\prime \prime}$ & $x$ & BLANK [BM CEO-37763 12/08/86] \\
\hline 3 & $12^{\prime \prime}$ & $x$ & BLANK \\
\hline 4 & 4" & $\mathbf{x}$ & $\begin{array}{l}\text { BREATHER FILTER [VAPOR ASSEMBLY/BREATHER FILTER } \\
\text { OFFSET AOAPTER ECN-618483 O1/10/95] [BLIND FLANGE } \\
\text { ECN-618481 06/09/95] }\end{array}$ \\
\hline 5 & $4^{n}$ & & DRY WELL \\
\hline 6 & $12^{\prime \prime}$ & $x$ & SPAAE \\
\hline 7 & $12^{*}$ & $x$ & B-222 OBSV POAT \\
\hline 8 & $4^{n}$ & & TEMPERATURE PROBE \\
\hline 13 & $12^{\prime \prime}$ & & SALTWELL PUMP, WC \\
\hline B & $3^{n}$ & & OVERFLOW INLET \\
\hline $\mathrm{Cl}_{1}$ & $3^{\prime \prime}$ & & SPARE, CAPPED \\
\hline $\mathrm{C2}$ & $3^{\prime \prime}$ & & SPARE, CAPPED \\
\hline C3 & 3" & & SPARE, CAPPED \\
\hline $\mathrm{C4}$ & $3^{\prime \prime}$ & & SPARE, CAPPED \\
\hline
\end{tabular}

Ref:

WHC-SD-RE-TI-053, Rev.9 *WHC-SD-WM-TI-710, Rev.2

WHC-SD-WM-TI-553, Rev.O H-2-73349, Rev. 2

If there was a discrepancy between the documents and the drawings, the drawings shall take precedence.

Comments placed in [] denote Engineering Change Notices (ECN) made against the reference drawings.

- Denotes risers tentatively available for sampling (Lipnicki 1995) 


\section{$241-C-110$ \\ 2.006,300 Liters \\ [530.000 Gallons]}
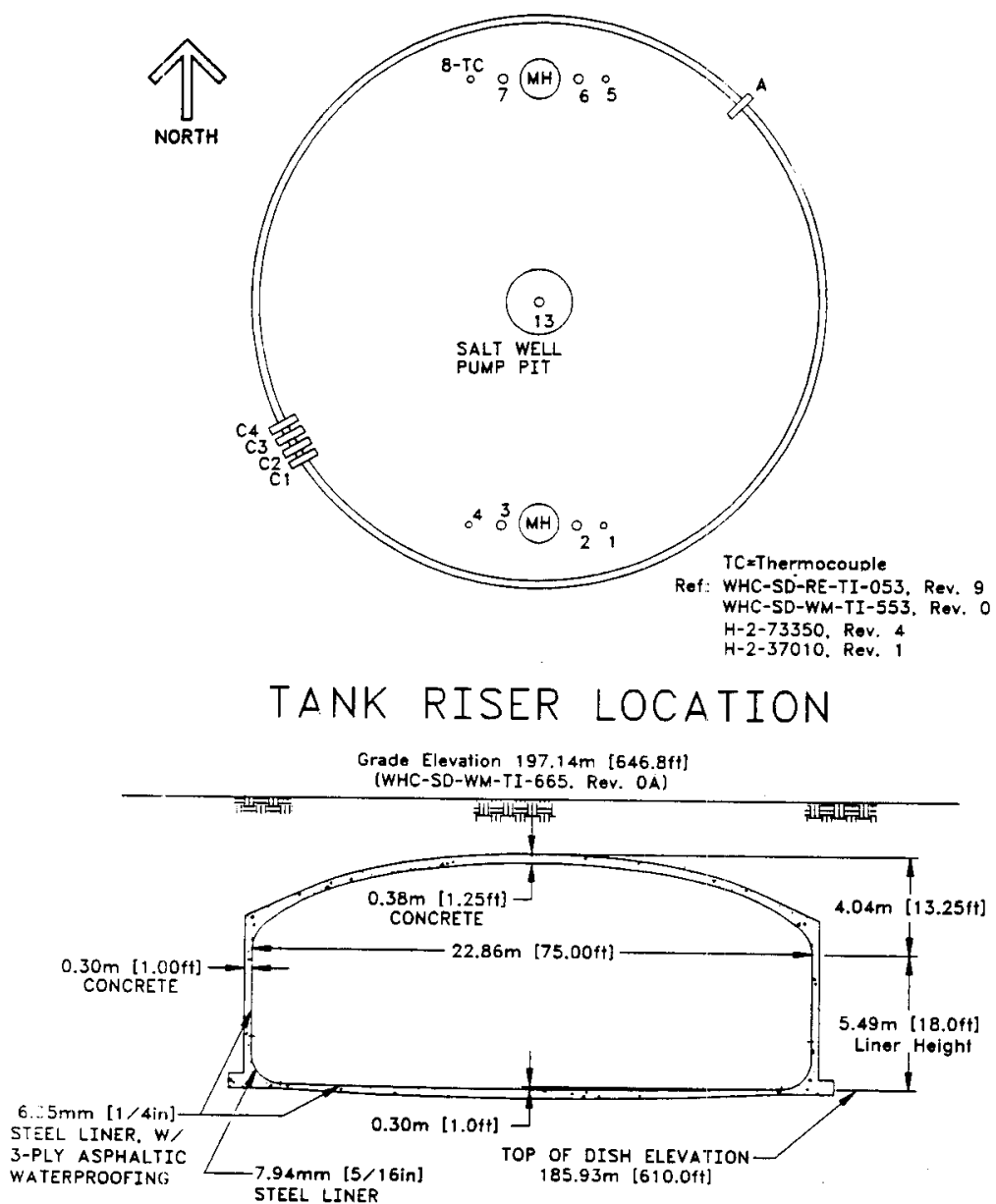

STEEL LINER, W/ 3-PLY ASPHALTIC STEEL LINER

Ref: H-2-1744. Rev. 3 CVI 73550. dwg $\mathrm{D}-2$

$$
\begin{gathered}
\text { NOT TO SCALE } \\
F-20
\end{gathered}
$$




\begin{tabular}{|c|c|c|c|}
\hline No. & DIA. & SAMPLING* & DESCRIPTION AND COMMENTS \\
\hline 1 & $4^{*}$ & $x$ & $\begin{array}{l}\text { SPARE [THIS SHOULD BE VAPOR ASSEMBLY/ NOW IS BLIND } \\
\text { FLANGE ECN-618484 06/09/95] }\end{array}$ \\
\hline 2 & $12^{\prime \prime}$ & $\mathrm{x}$ & $\begin{array}{l}\text { BLANK [BM CEO-40212 } 12 / 11 / 86] \text { [BM ECN-614184 } \\
10 / 31 / 94]\end{array}$ \\
\hline 3 & $12^{\prime \prime}$ & $\mathbf{x}$ & $\begin{array}{l}\text { BREATHER FILTER IVAPOR ASSEMBLY ECN-618483 } \\
01 / 10 / 95 \text { ] }\end{array}$ \\
\hline 4 & $4^{\prime \prime}$ & & LIQUID LEVEL REEL \\
\hline 5 & 4" & $x$ & FLANGE [BM ECN-614184 $10 / 31 / 94]$ \\
\hline 6 & $12^{-}$ & $\mathrm{x}$ & BLANK \\
\hline 7 & $12^{\prime \prime}$ & $x$ & B-222 OBSV PORT \\
\hline 8 & 4" & & TEMPERATURE PROBE \\
\hline 13 & $12^{\prime \prime}$ & & SALTWELL PUMP PIT, WC \\
\hline A & $3^{n}$ & & OVERFLOW OUTLET \\
\hline $\mathrm{Cl}$ & $3^{n}$ & & FILL LINE, SEALED IN DIVERSION BOX 241-C-153 \\
\hline C2 & $3^{n}$ & & FILL LINE, SEALED IN DIVERSION BOX 241-C-153 \\
\hline $\mathrm{C3}$ & $3^{\prime \prime}$ & & FILL LINE, SEALED IN DIVERSION BOX 241-C.153 \\
\hline $\mathrm{C4}$ & 3" & & SPARE, CAPPED \\
\hline
\end{tabular}

Ref: WHC-SD-RE-TI-053, Rev.9 WHC-SD-WM-TI-710, Rev.2 WHC-SD-WM-TI-553, Rev.0 H-2-73350, Rev. 4

If there was a discrepancy between the documents and the drawings, the drawings shell take precedence.

Comments placed in [] denote Engineering Change Notices (ECN) made against the reference drawings.

- Denotes risers tentatively available for sampling (Lipnicki 1995) 


\section{$241-C-111$ \\ 2,006.300 Liters \\ [530,000 Gallons]}

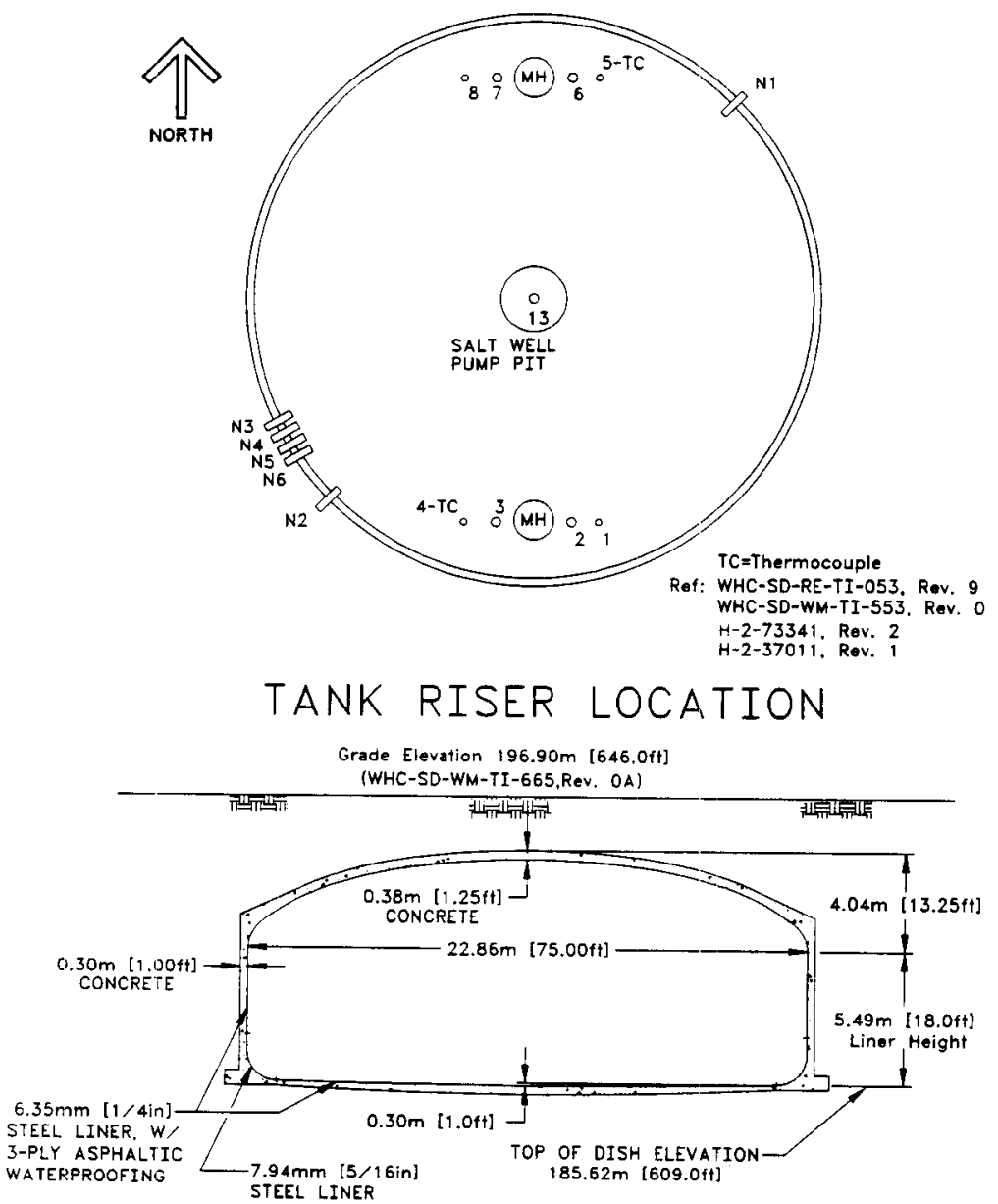

Ref: $H-2-1744$, Rev. 3

CVI 73550, dwg D-2

NOT TO SCALE

$$
F-22
$$




\begin{tabular}{|c|c|c|c|}
\hline No. & DIA. & SAMPLING* & DESCRIPTION AND COMMENTS \\
\hline 1 & 4" & $x$ & |BREATHER FILTER IBLIND FLANGE ECN-620824 05/02/95] \\
\hline 2 & $12^{\prime \prime}$ & $x$ & BLIND FLANGE [BM CEO-37762 12/08/86] \\
\hline 3 & $12^{\prime \prime}$ & $x$ & $\begin{array}{l}\text { SPARE [BREATHER FILTER CEO-41103 07/20/87] } \\
\text { [SPARE/BREATHER FILTER W/ OFFSET ADAPTER ECN- } \\
62076607 / 25 / 95 \text { ] }\end{array}$ \\
\hline 4 & $4^{\prime \prime}$ & $\mathrm{x}$ & FLANGE \\
\hline 5 & $4^{n}$ & & TEMPERATURE PROBE \\
\hline 6 & $12^{\prime \prime}$ & $x$ & $\begin{array}{l}\text { B-222 OBSV PORT [TEMPERATUAE VAPOR PROBE W/ } \\
\text { ADAPTER ECN-620766 O7/25/95] [SPARE/BREATHER FILTER } \\
\text { W/ DUAL PORT ADAPTER ECN-620824 05/02/95] }\end{array}$ \\
\hline 7 & $12^{n}$ & $x$ & $\begin{array}{l}\text { EXHAUSTER INLET [PORTABLE EXHAUSTER CEO-41103 } \\
07 / 20 / 87]\end{array}$ \\
\hline 8 & 4" & & LIQUID LEVEL REEL \\
\hline 13 & $12^{\prime \prime}$ & & PUMP PIT, WC \\
\hline N1 & $3^{n}$ & & OVERFLOW OUTLET \\
\hline N2 & $3^{\prime \prime}$ & & OVERFLOW INLET \\
\hline N3 & $3^{\prime \prime}$ & & SPARE NOZZLE, CAPPED \\
\hline $\mathrm{N} 4$ & $3^{\prime \prime}$ & & SPARE NOZZLE, CA.PPED \\
\hline N5 & 3" & & SPARE NOZZLE, CAPPED \\
\hline N6 & 3" & & FILL LINE V137, SEALED IN DIVERSION BOX 241-C-153 \\
\hline
\end{tabular}

Ref:

WHC-SD-RE-TI-053, Rev.9

-WHC-SD-WM-TI-710, Rev.2

WHC-SD-WM-TI-553, Rev.0

H-2-73341, Rev. 2

If there was a discrepancy between the documents and the drawings, the drawings shall take precedence.

Comments placed in [] denote Engineering Change Notices (ECN) made against the reference drawings.

- Denotes risers tentatively available for sampling (l.ipnicki 1995) 


\section{$241-\mathrm{C}-112$ \\ 2.006.300 Liters \\ [530,000 Gallons]}

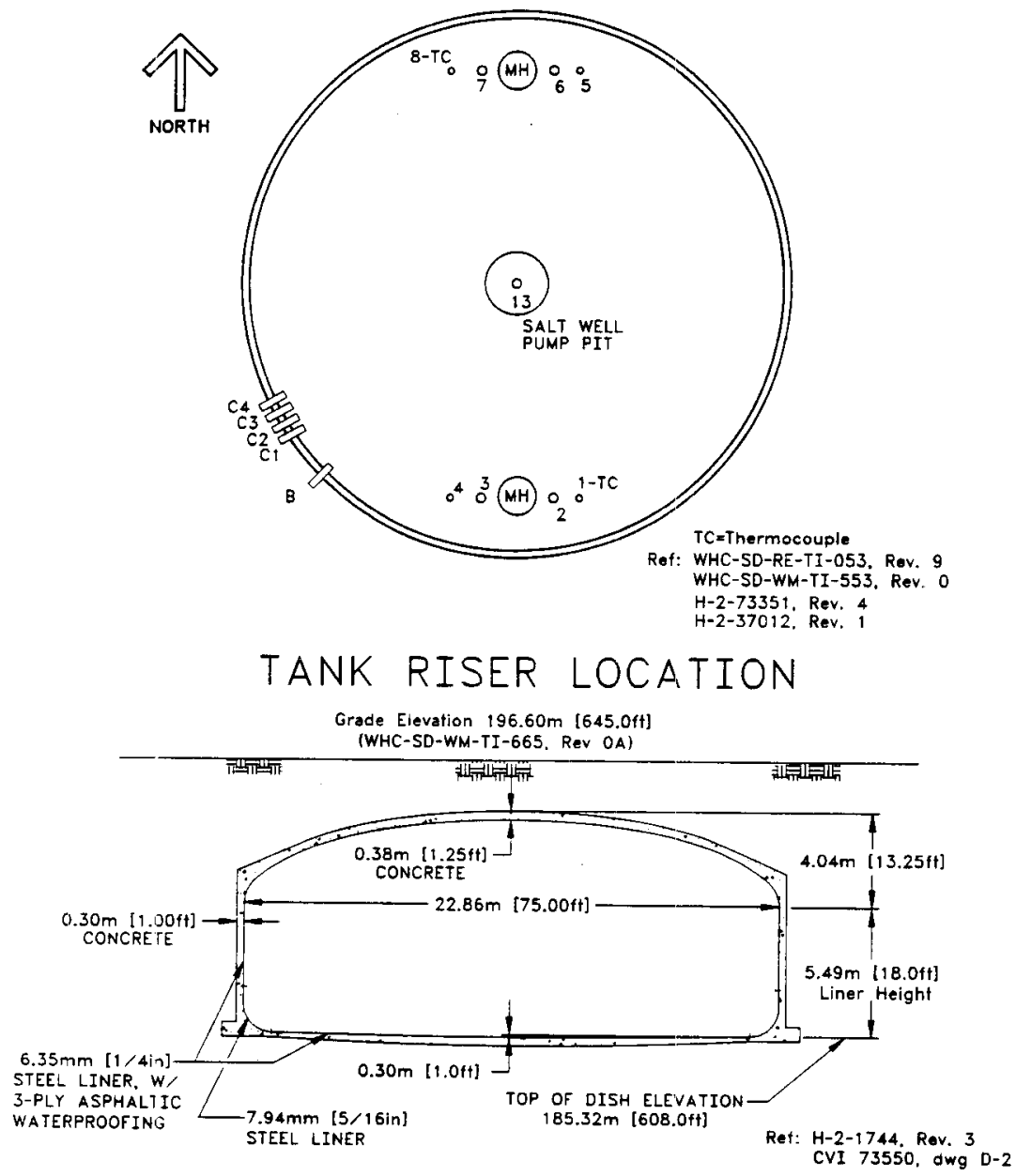

NOT TO SCALE

$F-24$ 


\begin{tabular}{|c|c|c|c|}
\hline No. & DIA. & SAMPLING * & DESCRIPTION AND COMMENTS \\
\hline 1 & 4" & & TEMPERATURE PROBE \\
\hline 2 & $12^{n}$ & $x$ & BLANK [BM CEO-37538 12/11/86] \\
\hline 3 & $12^{n}$ & $x$ & BLANK \\
\hline 4 & $4^{\prime \prime}$ & $x$ & $\begin{array}{l}\text { BREATHER FILTER IVAPOR ASSEMBLY/BREATHER FILTER } \\
\text { OFFSET ADAPTER ECN-618483 O1/10/95] IVAPOR PROBE } \\
\text { REMOVED AND REPLACED W/ BLIND FLANGE ECN-618481 } \\
06 / 09 / 95 \text { ] }\end{array}$ \\
\hline 5 & $4^{\prime \prime}$ & & $\begin{array}{l}\text { FIC [THEAMOCOUPLE ECN-169038 09/10/92] [MANUAL } \\
\text { TAPE ECN-175521 10/30/92] [ENAAF } 854 \text { ECN-623211 } \\
\text { 06/08/95] }\end{array}$ \\
\hline 6 & $12^{\prime \prime}$ & $x$ & SPARE \\
\hline 7 & $12^{n}$ & $x$ & B-222 OBSV POAT \\
\hline 8 & 4" & & $\begin{array}{l}\text { LIOUID LEVEL REEL IINSTRUMENT TREE ECN-175521 } \\
10 / 30 / 92 \text { ] }\end{array}$ \\
\hline 13 & $12^{\prime \prime}$ & & SALTWELL PUMP PIT, WC \\
\hline B & $3^{n}$ & & OVERFLOW INLET \\
\hline $\mathrm{C} 1$ & $3^{n}$ & & SPARE, CAPPED \\
\hline $\mathrm{C}_{2}$ & $3^{\prime \prime}$ & & SPARE, CAPPED \\
\hline C3 & $3^{\prime \prime}$ & & SPARE, CAPPED \\
\hline $\mathrm{C} 4$ & $3^{n}$ & & SPARE, CAPPED \\
\hline
\end{tabular}

Ret:

WHC-SD-RE-TI-053, Rev.9 "WHC-SD-WM-TI-710, Rev.2

WHC-SD-WM-TI-553, Rev.O H-2-73351, Rev.4

If there was a discrepancy between the documents and the drawings, the drawings shalt take precedence.

Comments placed in [] denote Engineering Change Notices (ECN) made against the reference drawings.

- Denotes risers tentatively available for sampling (L.ipnicki 1995) 


\section{$241-C-201$}

208,200 Liters

AN [55.000 Gallons]

NORTH

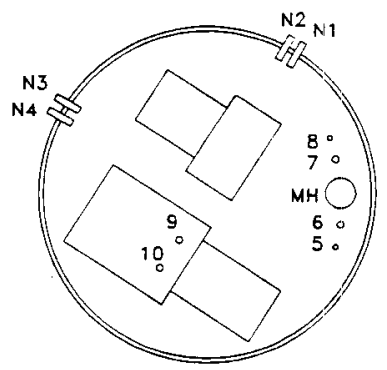

Ref: WHC-SD-RE-TI-053, Rev. 9

WHC-SD-WM-TI-553, Rev. 0

H-2-73352, Rev. 2

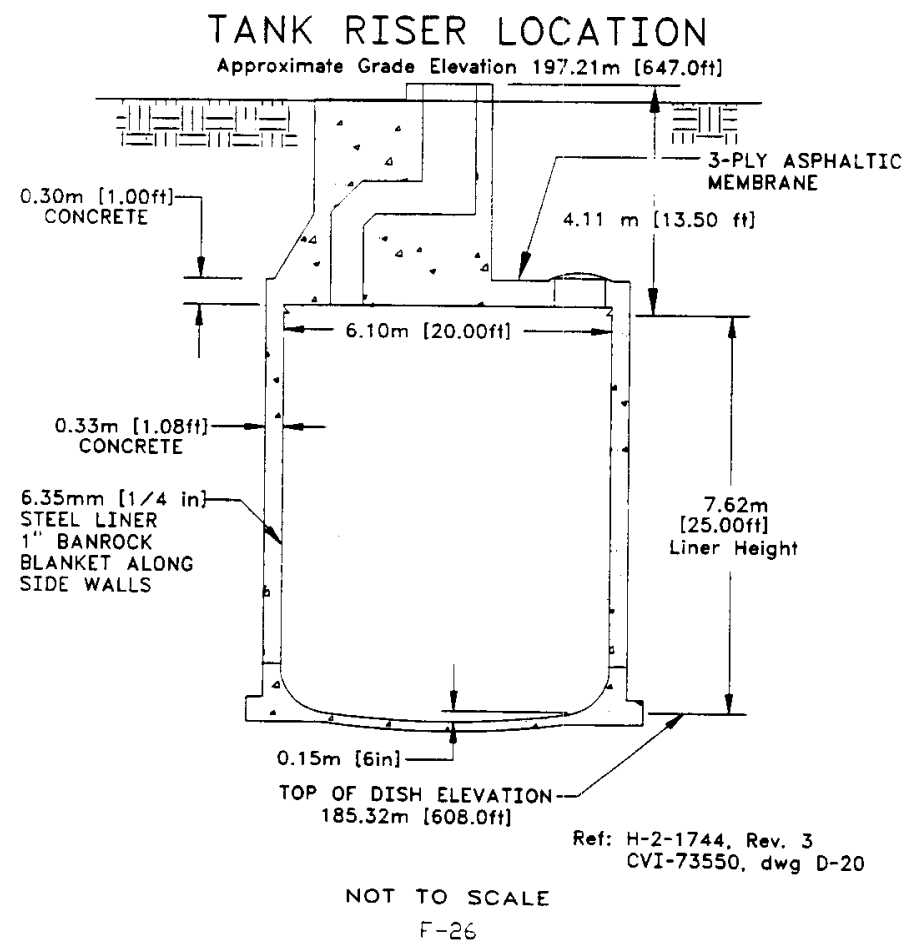




\begin{tabular}{|c|c|c|c|}
\hline NO. & DIA. & SAMPLING* & DESCRIPTION AND COMMENTS \\
\hline 5 & $4^{\prime \prime}$ & & LIQUID LEVEL REEL \\
\hline 6 & $12^{n}$ & & TEMPERATURE \\
\hline 7 & $12^{n}$ & $\bar{x}$ & B-222 OBSV PORT \\
\hline 8 & $4^{*}$ & $\bar{x}$ & BREATHER FILTER \\
\hline 9 & $12^{\prime \prime}$ & & WC \\
\hline 10 & $12^{\circ}$ & & $W C$ \\
\hline $\mathbf{N} 1$ & $3^{n}$ & & SPARE INLET, CAPPED \\
\hline N2 & $3^{-}$ & & SPARE INLET, CAPPED \\
\hline N3 & $3^{n}$ & & INLET LINE V157, SEALED IN DIVERSION BOX $241-C-252$ \\
\hline N4 & $3^{n}$ & & INLET LINE V156, SEALED IN DIVERSION BOX 241-C-252 \\
\hline
\end{tabular}

Ref:

WHC-SD-RE-TI-053, Rev.9 "WHC-SD-WM-TI-710, Rev.2

WHC-SD-WM-TI-553, Rev.0 H-2-73352, Rev. 2

If there was a discrepancy between the documents and the drawings, the drawings shall take precedence.

Comments placed in [] denote Engineering Change Notices (ECN) made against the reference drawings.

- Denotes risers tentatively available for sampling (Lipnicki 1995) 


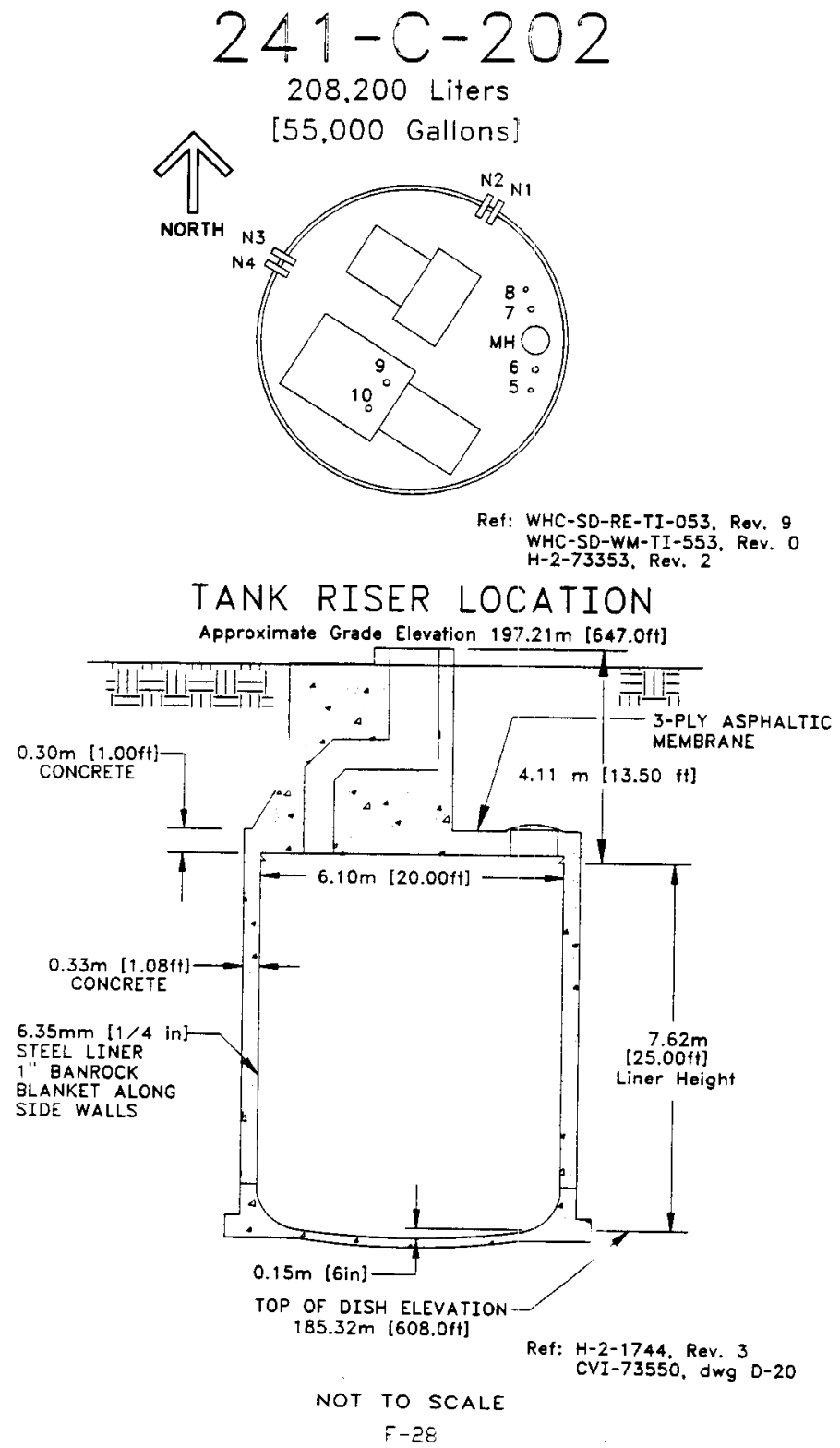




\begin{tabular}{|c|c|c|c|}
\hline NO. & DIA. & SAMPLING * & DESCRIPTION AND COMMENTS \\
\hline 5 & 4" & & LIQUID LEVEL AEEL \\
\hline 6 & $12^{\prime \prime}$ & & TEMPERATURE \\
\hline 7 & $12^{n}$ & $x$ & B-222 OBSV PORT \\
\hline 8 & $4^{n}$ & $\bar{x}$ & BREATHER FILTER \\
\hline 9 & $12^{*}$ & & SLUDGE JET ACCESS, WC \\
\hline 10 & $12^{\prime \prime}$ & & SLUDGE JET ACCESS, WC \\
\hline N1 & 3" & & SPARE INLET, CAPPED \\
\hline N2 & $3^{\prime \prime}$ & & SPARE INLET, CAPPED \\
\hline N3 & 3" & & INLET LINE V159, SEALED IN DIVERSION BOX $241-C-252$ \\
\hline N4 & $3^{\prime \prime}$ & & INLET LINE V158, SEALED IN DIVERSION BOX $241 \cdot C \cdot 252$ \\
\hline
\end{tabular}

$\begin{array}{ll}\text { Ref: } & \text { WHC-SD-RE-TI-053, Rev.9 } \\ \text { WHC-SD-WM-TI-553, Rov.0 } & \text { H-2-73353, Rev. } 2\end{array}$

If there was a discrepancy between the documents and the drawings, the drawings shall take precedence.

Comments placed in [] denote Engineering Change Notices (ECN) made against the reference drawings.

- Denotes risers tentatively available for sampling (Lipnicki 1995) 


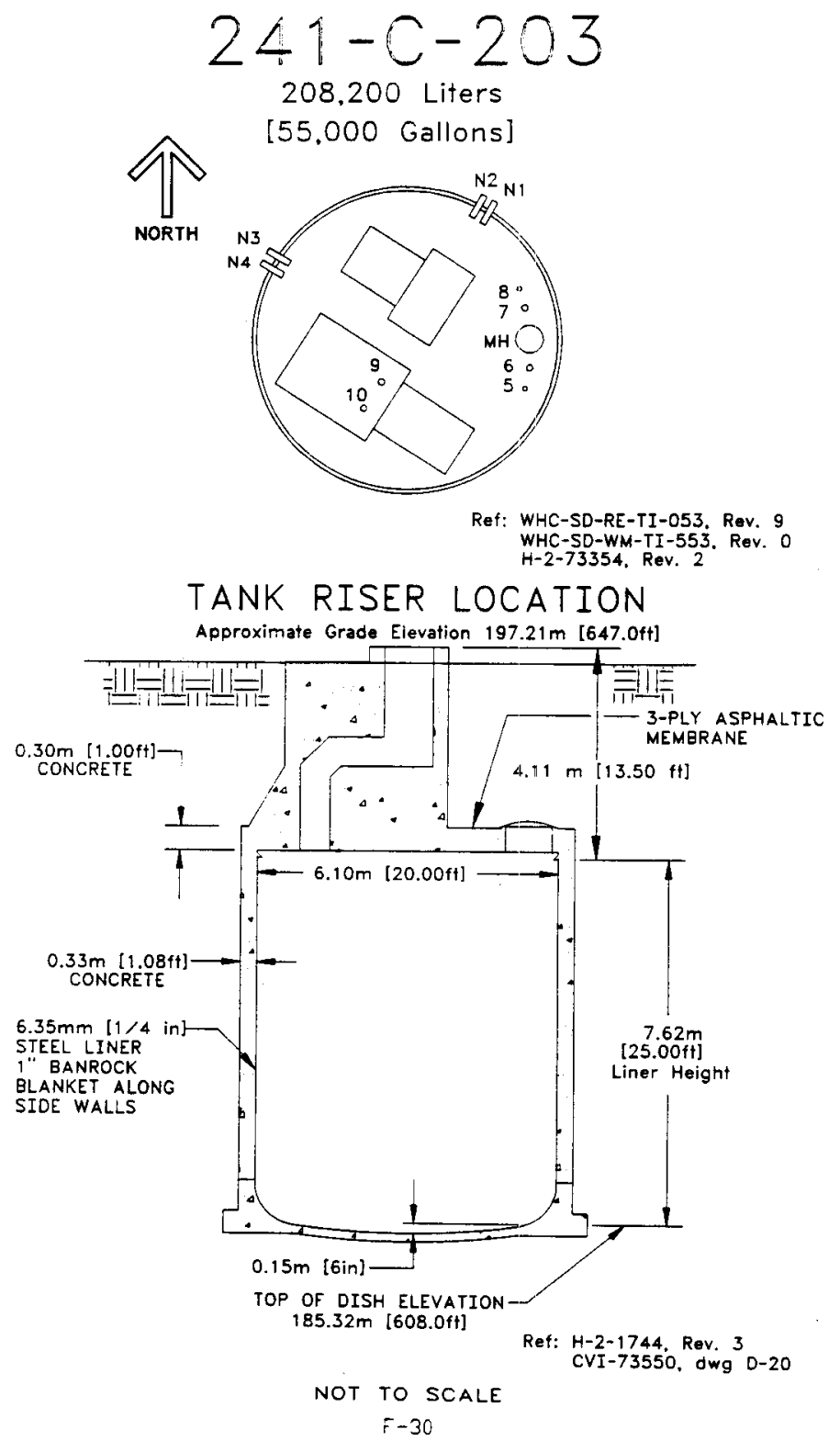




\begin{tabular}{|c|c|c|c|}
\hline No. & DIA. & SAMPLING * & DESCRIPTION AND COMMENTS \\
\hline 5 & 4" & & LIQUID LEVEL REEL \\
\hline 6 & $12^{\prime \prime}$ & & TEMPERATURE \\
\hline 7 & $12^{\prime \prime}$ & $x$ & B-222 OBSV PORT \\
\hline 8 & $4^{\prime \prime}$ & $x$ & BREATHER FILTER \\
\hline 9 & $12^{\prime \prime}$ & & SLUDGE JET ACCESS, WC \\
\hline 10 & $12^{\prime \prime}$ & & SLUICING ACCESS, WC \\
\hline N1 & $3^{n}$ & & SPARE INLET, CAPPED \\
\hline N2 & 3" & & SPARE INLET, CAPPED \\
\hline N3 & $3^{n}$ & & INLET LINE V161, SEALED IN DIVERSION BOX 241-C-252 \\
\hline N4 & $3^{n}$ & & INLET LINE V160, SEALED IN DIVERSION BOX 241-C-252 \\
\hline
\end{tabular}

Ref:

WHC-SD-RE-TI-053, Rev.9 *WHC-SD-WM-TI-710, Rev.2

WHC-SD-WM-TI-553, Rev.0 H-2-73354, Rev. 2

If there was a discrepancy between the documents and the drawings, the drawings shall take precedence.

Comments placed in [] denote Engineering Change Notices (ECN) made against the reference drawings.

* Denotes risers tentatively available for sampling (Lipnicki 1995) 


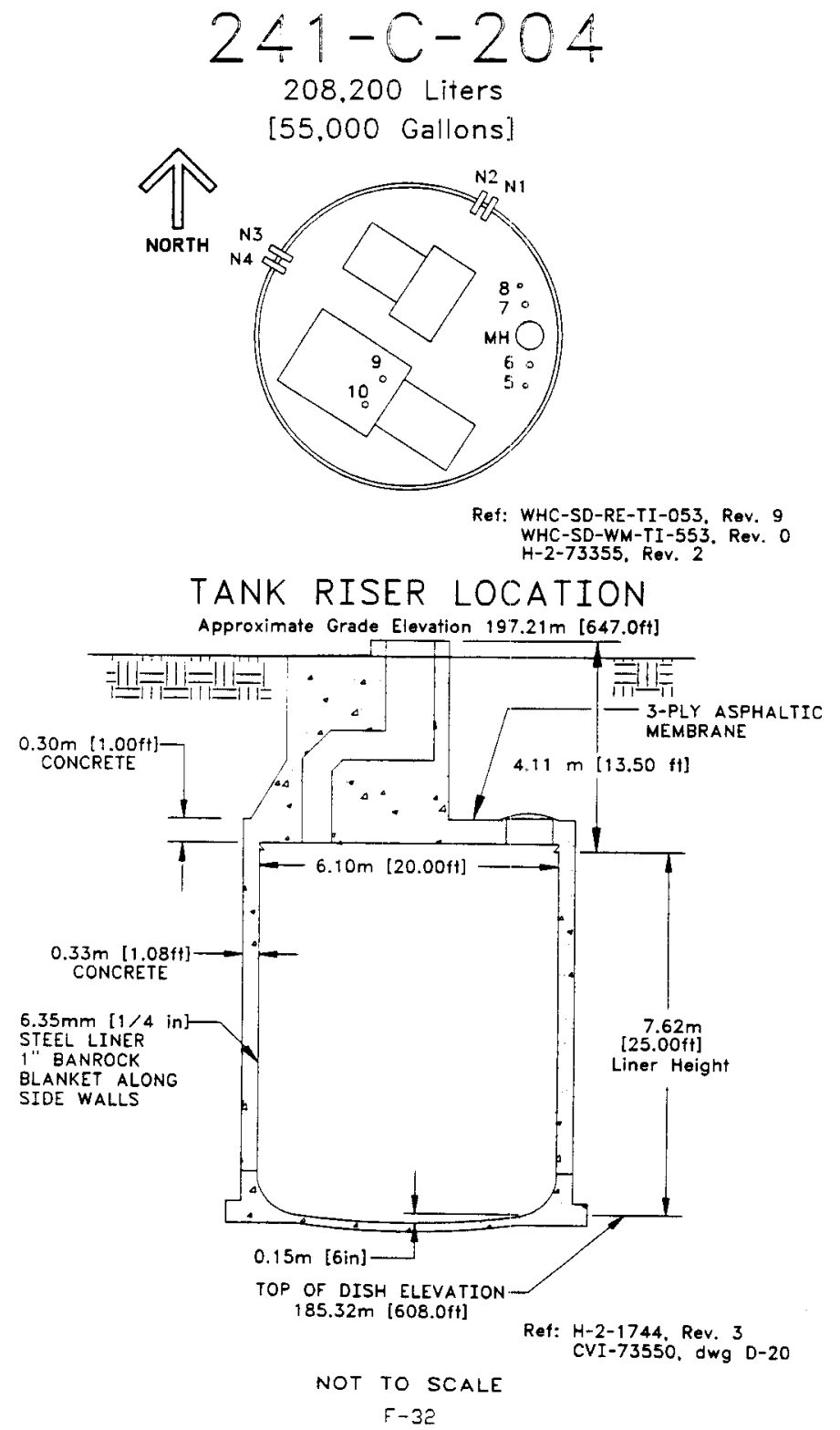




\begin{tabular}{|c|c|c|c|}
\hline No. & DIA. & SAMPLING* & DESCRIPTION AND COMMENTS \\
\hline 5 & $4^{\prime \prime}$ & & LIQUID LEVEL REEL \\
\hline 6 & $12^{\prime \prime}$ & & TEMPERATURE \\
\hline 7 & $12^{\prime \prime}$ & $\mathrm{x}$ & B-222 OBSV PORT \\
\hline 8 & 4" & $\mathrm{x}$ & BREATHER FILTER \\
\hline 9 & $12^{\prime \prime}$ & & SLUDGE JET ACCESS, WC \\
\hline 10 & $12^{\prime \prime}$ & & SLUICING ACCESS, WC \\
\hline N1 & 3" & & SPARE INLET, CAPPED \\
\hline N2 & 3" & & SPARE INLET, CAPPED \\
\hline N3 & $3^{\prime \prime}$ & & INLET LINE V163, SEALED IN DIVERSION BOX 241-C-252 \\
\hline N4 & 3" & & INLET LINE V162, SEALED IN DIVERSION BOX 241-C-252 \\
\hline
\end{tabular}

Ref:

WHC-SD-RE-TI-053, Rev.9 "WHC-SD-WM-TI-710, Rev.2

WHC-SD-WM-TI-553, Rev.O H-2-73355, Rev. 2

If there was a discrepancy between the documents and the drawings, the drawings shall take precedence.

Comments placed in [] denote Engineering Change Notices (ECN) made against the reference drawings.

- Denotes risers tentatively available for sampling (Lipnicki 1995) 
C TANK FARM PHOTOS

\begin{tabular}{|c|c|c|c|}
\hline 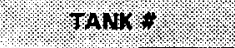 & MONHAB & ORIGNAL PHOTO SET H & DATE \\
\hline C Farm Aerial Photo & N/A & $93030994-292 \mathrm{CN}$ & N/A \\
\hline $241-C-101$ & $94011379-40 \mathrm{CN}$ & $87-06971$ & $11 / 17 / 87$ \\
\hline $241-C-102$ & $94011379-39 \mathrm{CN}$ & 76.4705 & $5 / 18 / 76$ \\
\hline $241-C-103$ & $94011379-38 \mathrm{CN}$ & $87-04421$ & $7 / 28 / 87$ \\
\hline 241-C-104 & $94011379-37 \mathrm{CN}$ & $90-071805$ & $7 / 25 / 90$ \\
\hline 241-C-105 & $94011379-36 \mathrm{CN}$ & $88-01714$ & $4 / 1 / 88$ \\
\hline $241 \cdot C-106$ & $94011379-15 \mathrm{CN}$ & 86242 & $4 / 5 / 79$ \\
\hline $241-C-107$ & No Photos Availabie. & No Photos Available. & \\
\hline $241-C-108$ & No Photos Available. & No Photos Available. & \\
\hline 241-C-109 & $94011379-16 \mathrm{CN}$ & $74-7641$ & $12 / 9 / 74$ \\
\hline $241-C-110$ & $94011379.17 \mathrm{CN}$ & 86-05264 & $8 / 12 / 86$ \\
\hline $247-C-111$ & $94011379-18 \mathrm{CN}$ & $70-0906$ & $2 / 25 / 70$ \\
\hline 241-C-112 & $94011379-19 \mathrm{CN}$ & $90-091810$ & $9 / 18 / 90$ \\
\hline 241-C-201 & $94011379-58 \mathrm{CN}$ & $86-07869$ & $12 / 2 / 86$ \\
\hline $241-C-202$ & $94011379-57 \mathrm{CN}$ & $86-08029$ & $12 / 9 / 86$ \\
\hline $241-C-203$ & $94011379-56 \mathrm{CN}$ & $86-08030$ & $12 / 9 / 86$ \\
\hline $241-C-204$ & $94011379-55 \mathrm{CN}$ & $86-08031$ & $12 / 9 / 86$ \\
\hline
\end{tabular}


C Tank Farm

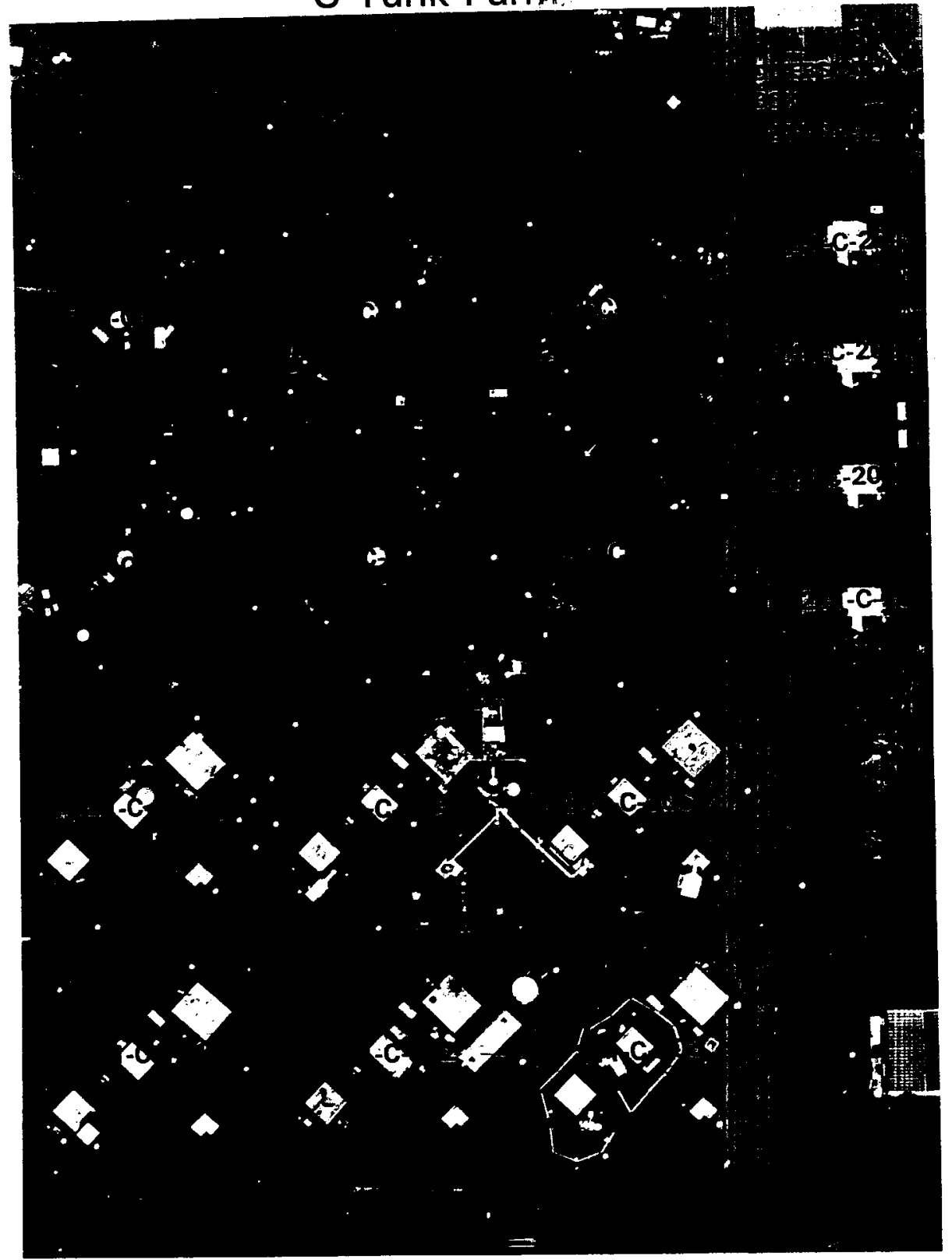




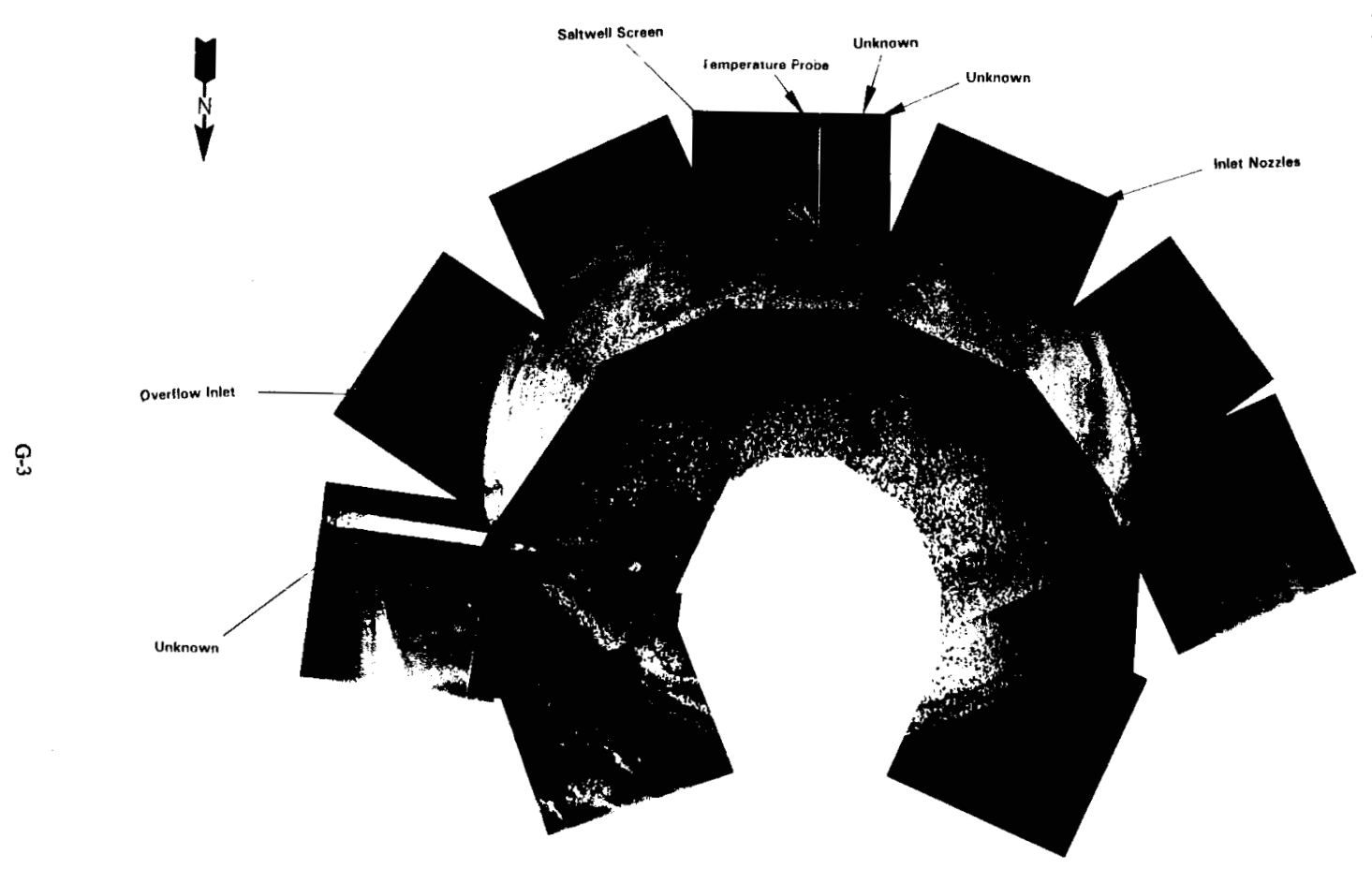

BEST AVAILABLE COPY

241-C-101

Phow date: $11-17-87$ 


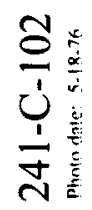

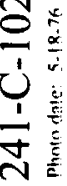

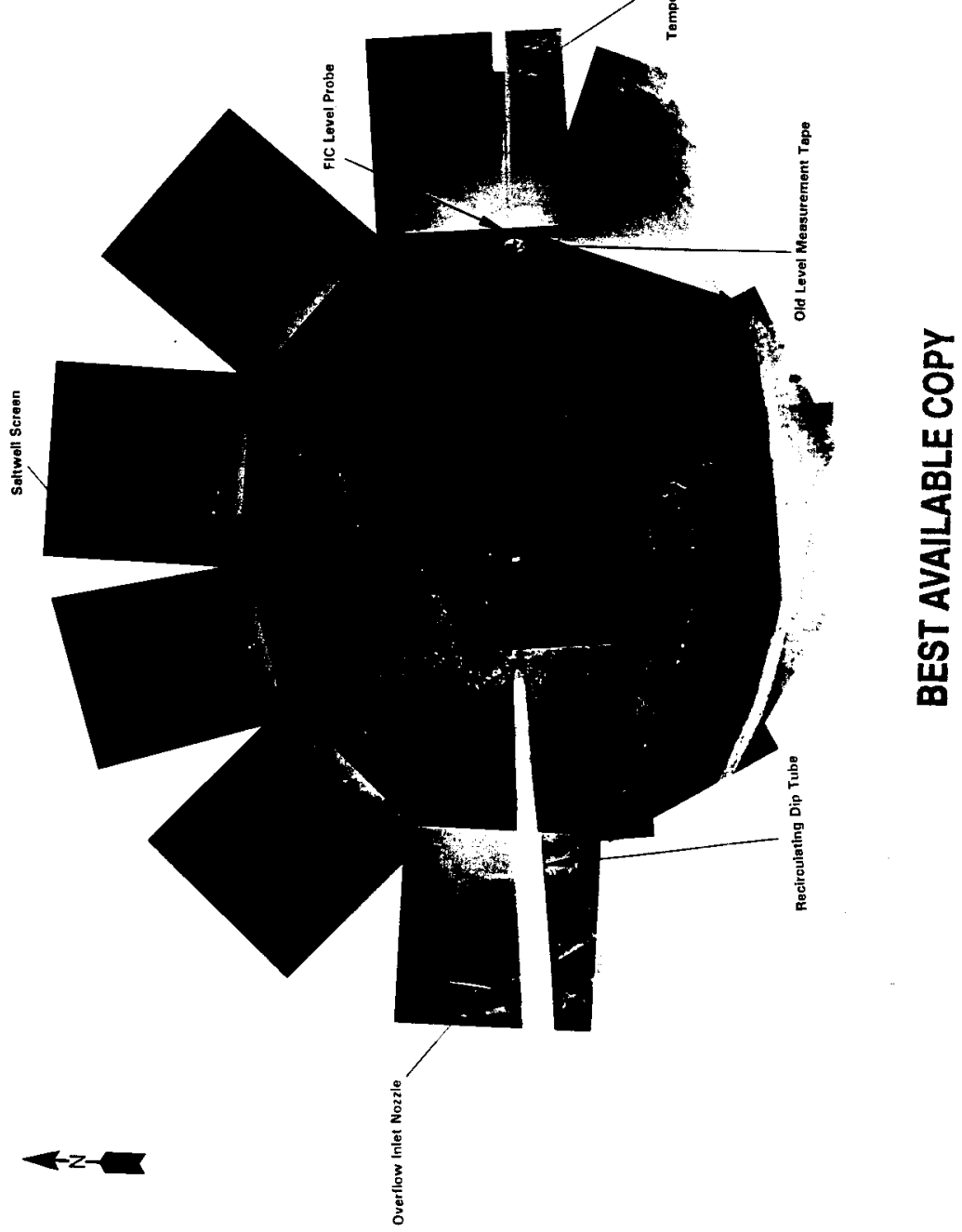


$\frac{8}{\frac{1}{3}}$

(1)

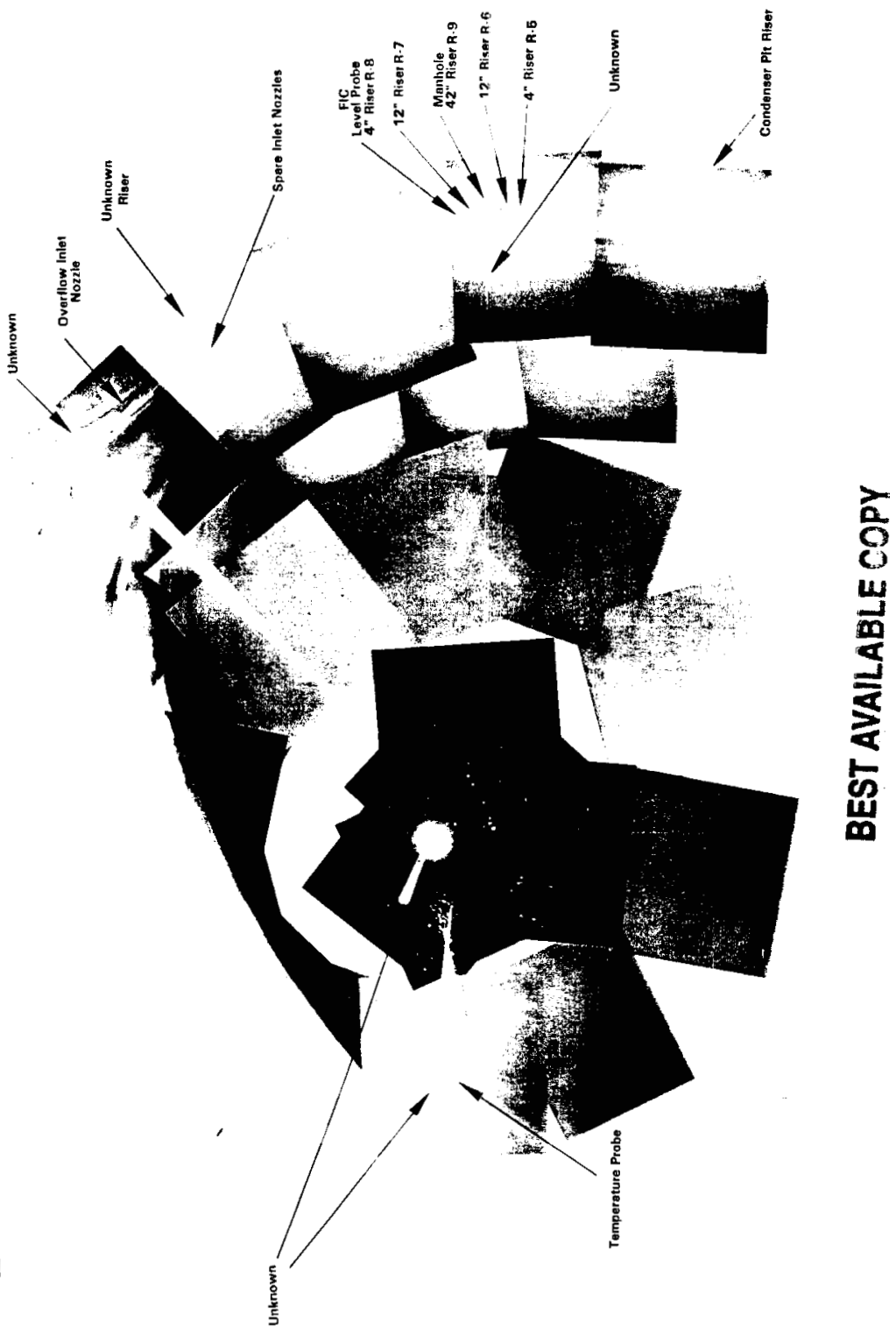




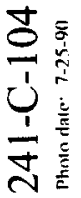
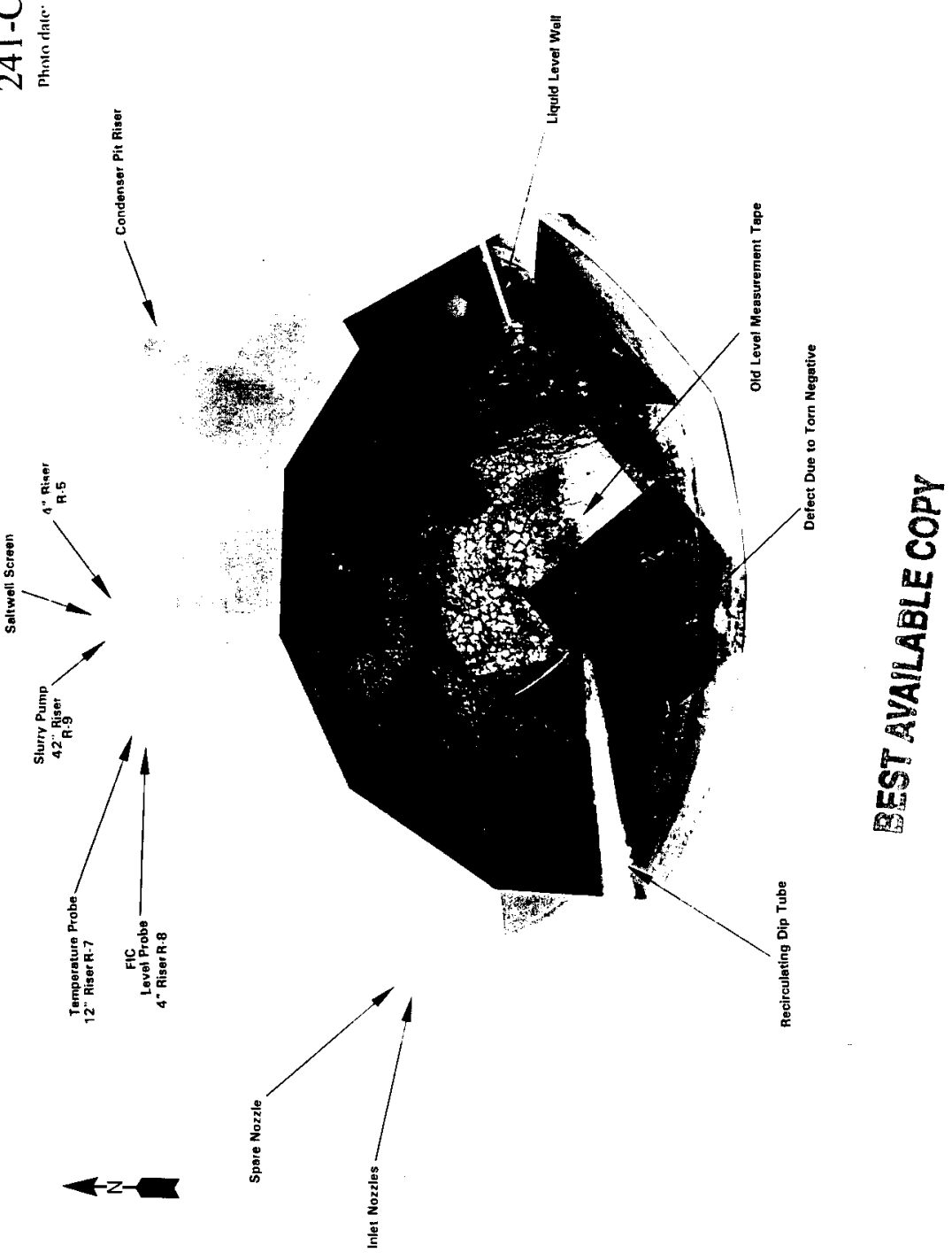

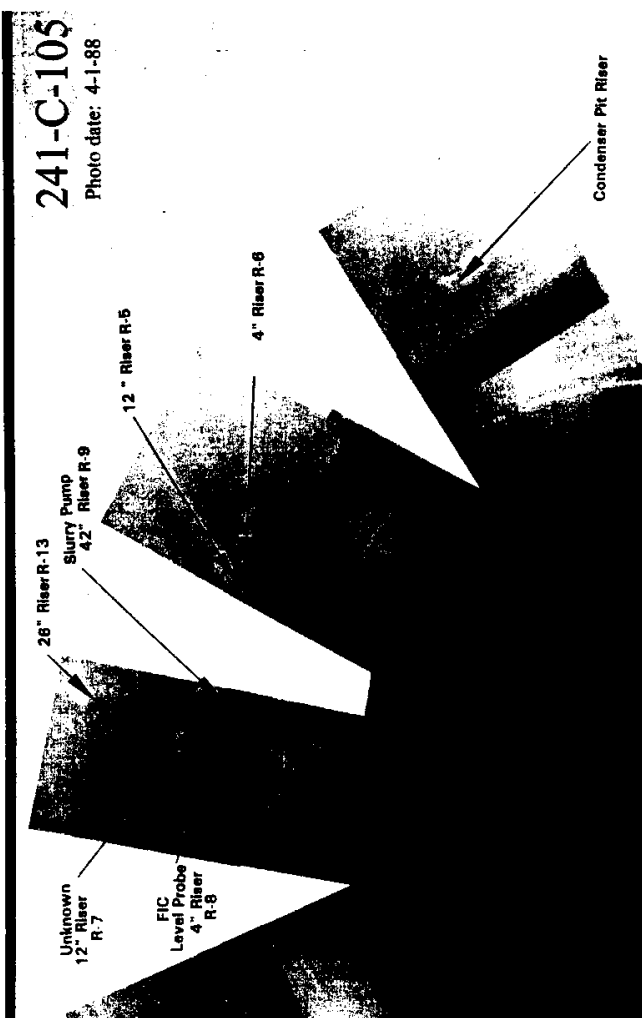

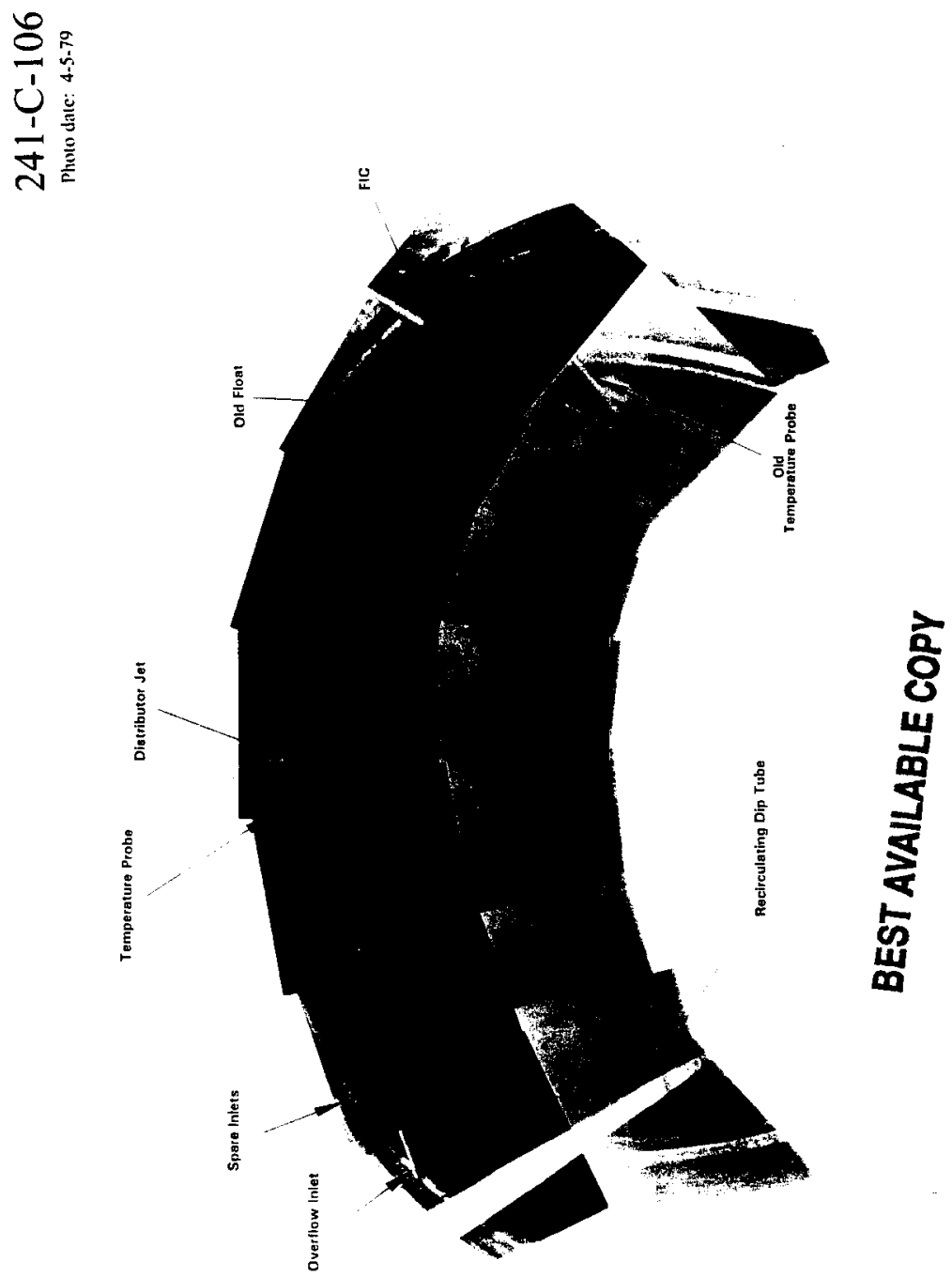


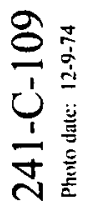

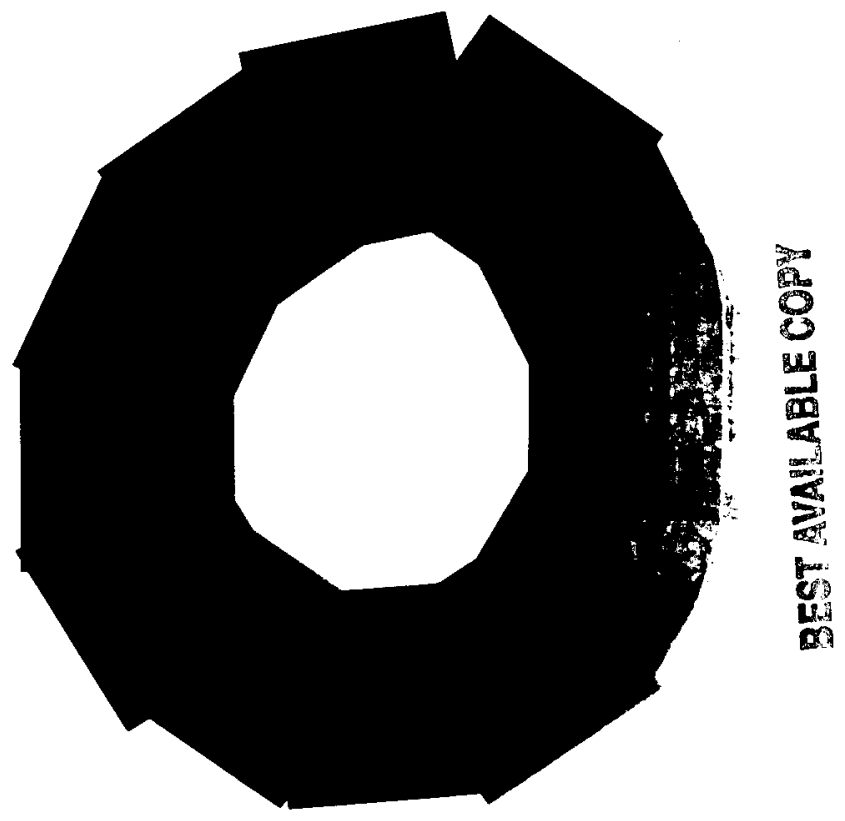


WHC-SD-WM-ER-313, Rev. 1

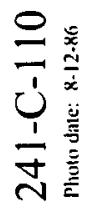
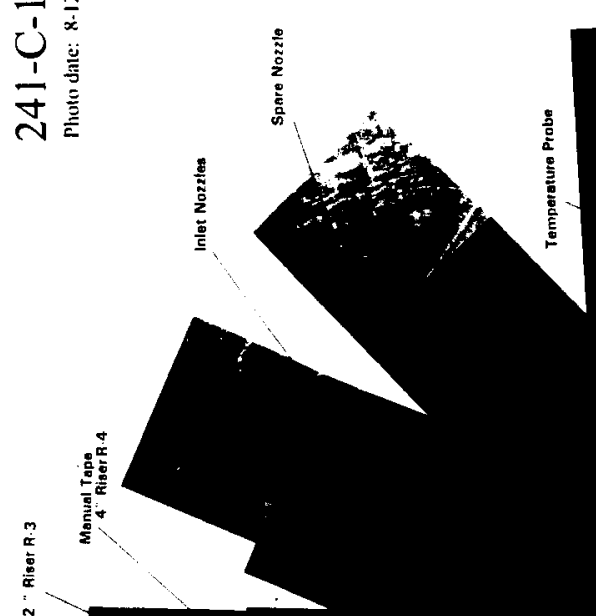

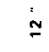

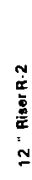
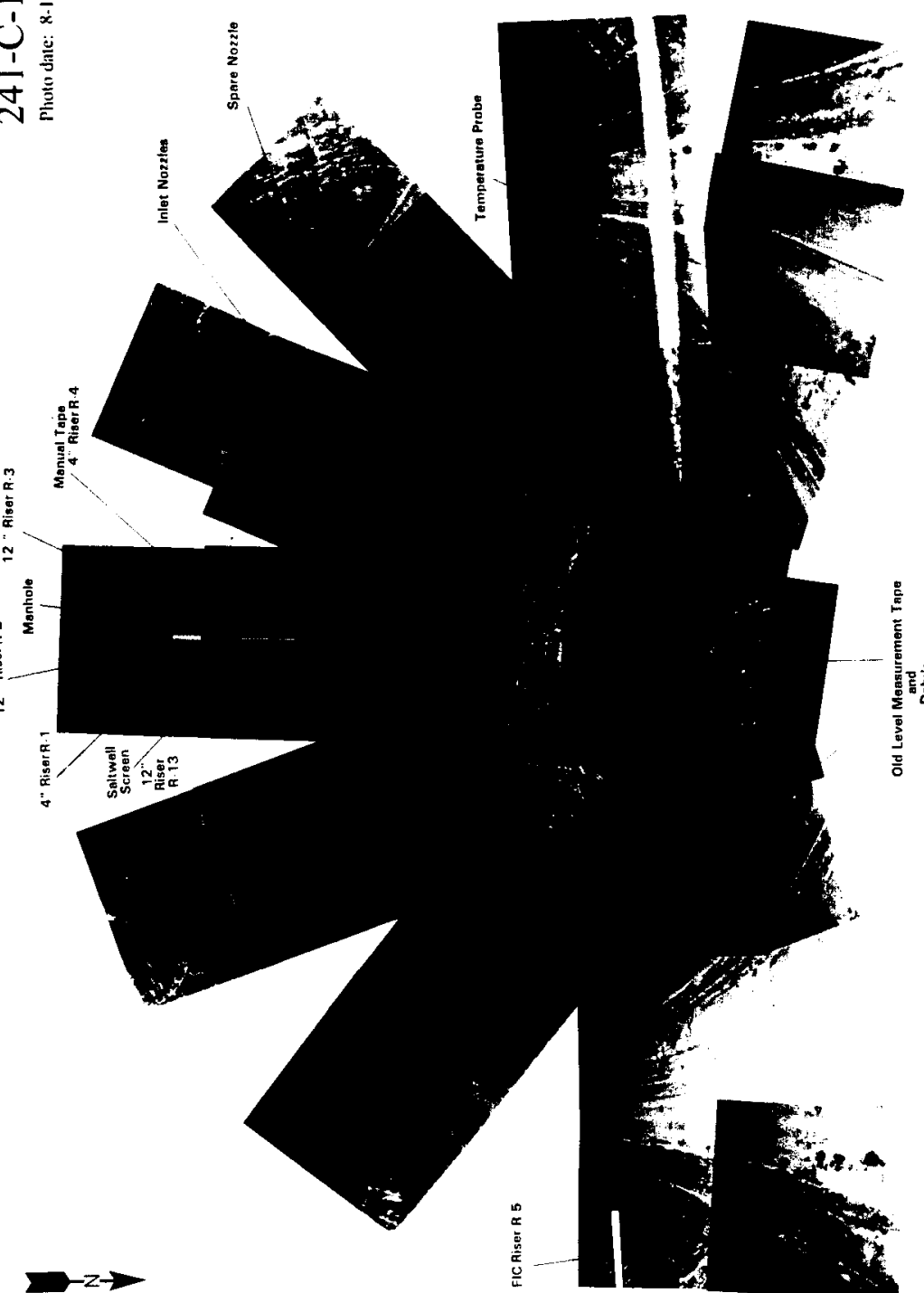


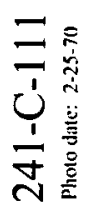

$$
\underbrace{\frac{5}{\alpha}}_{0}
$$

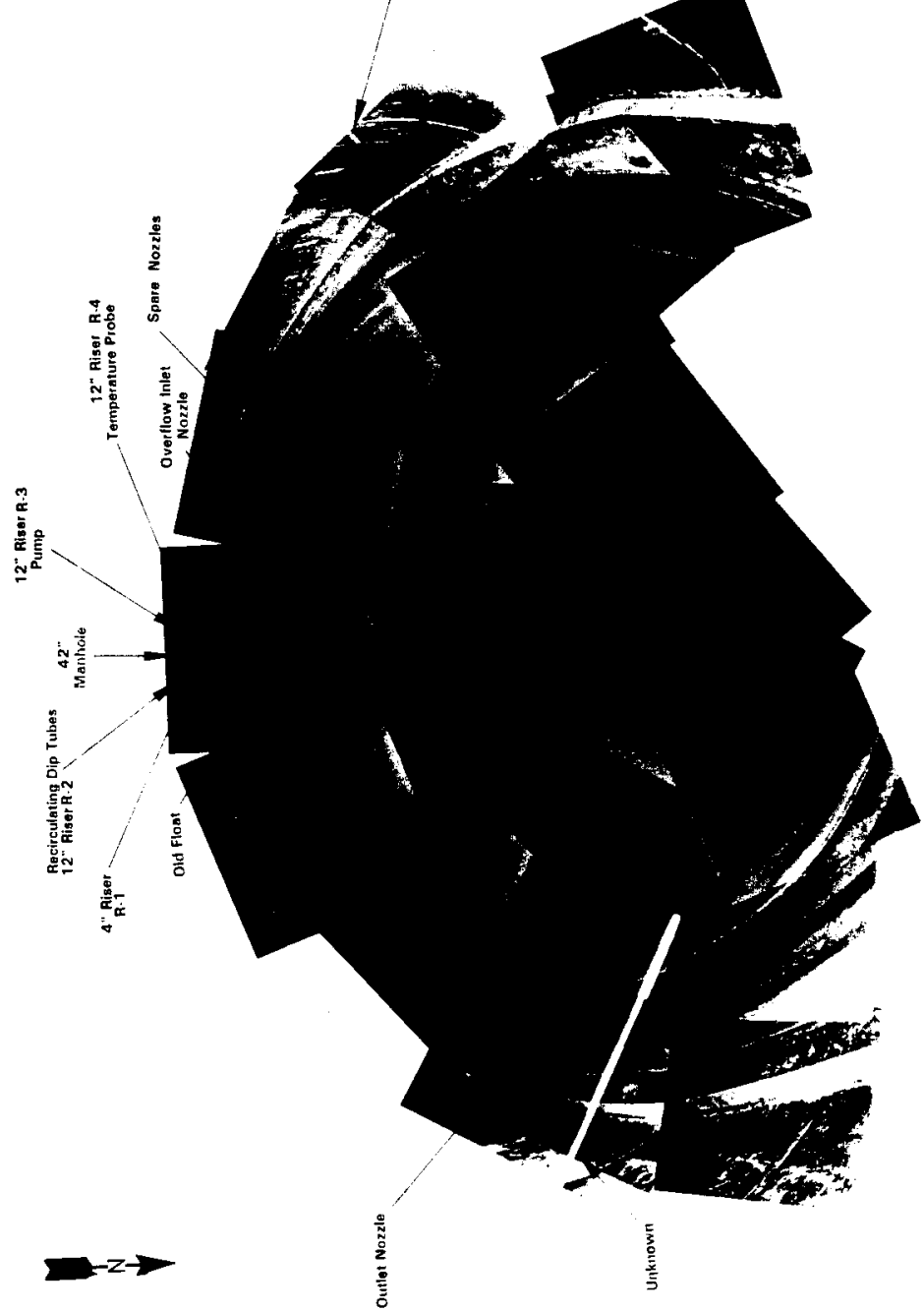




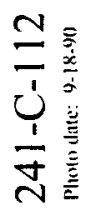

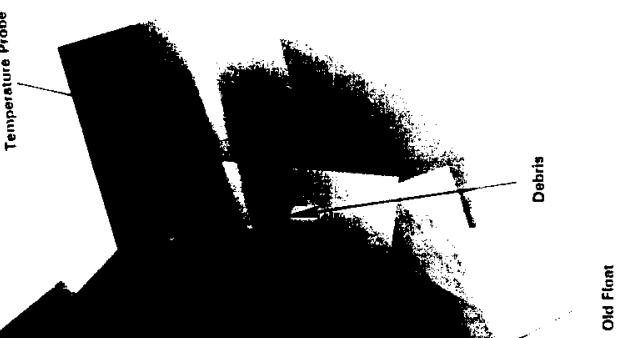




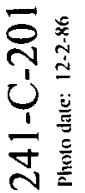

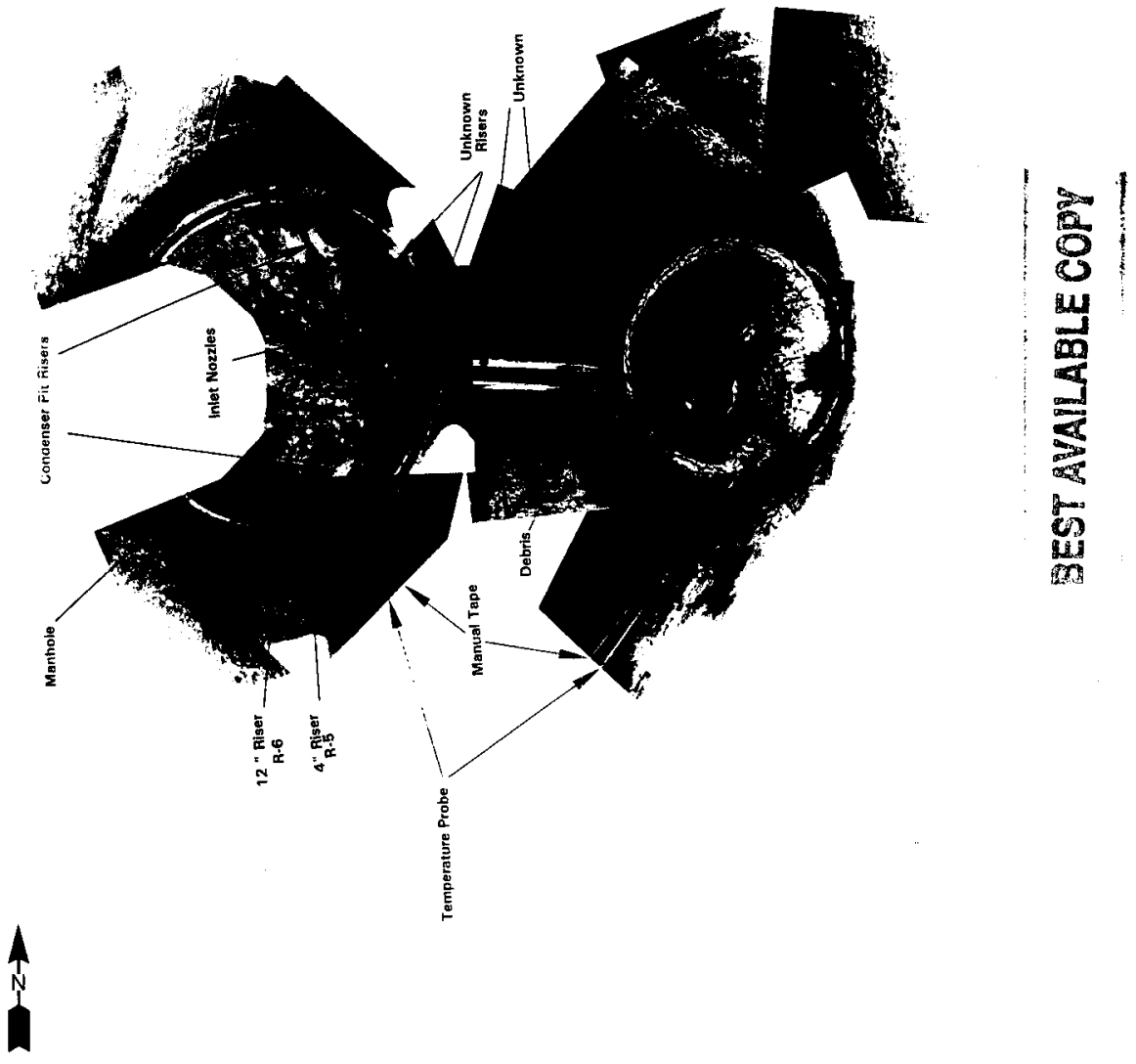




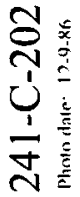
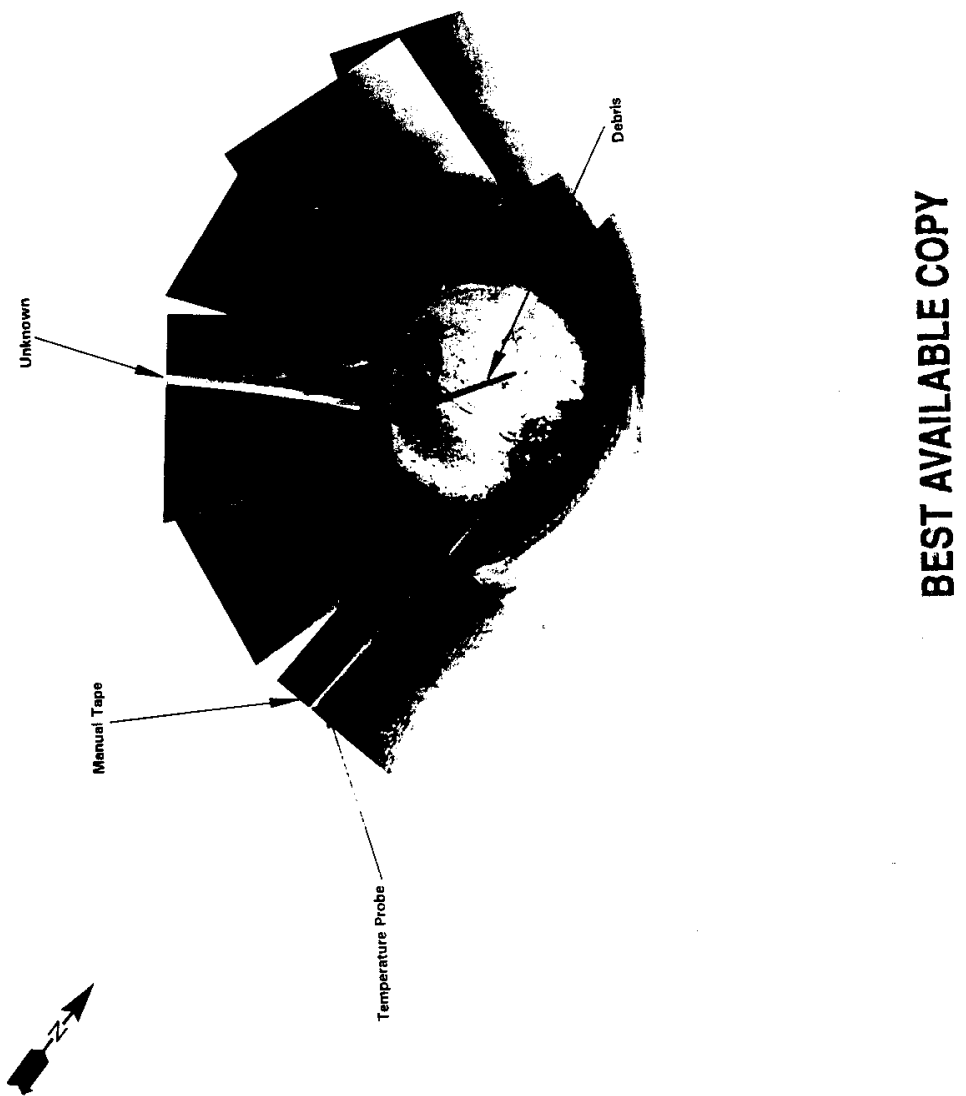

ᄀ 


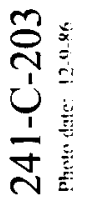

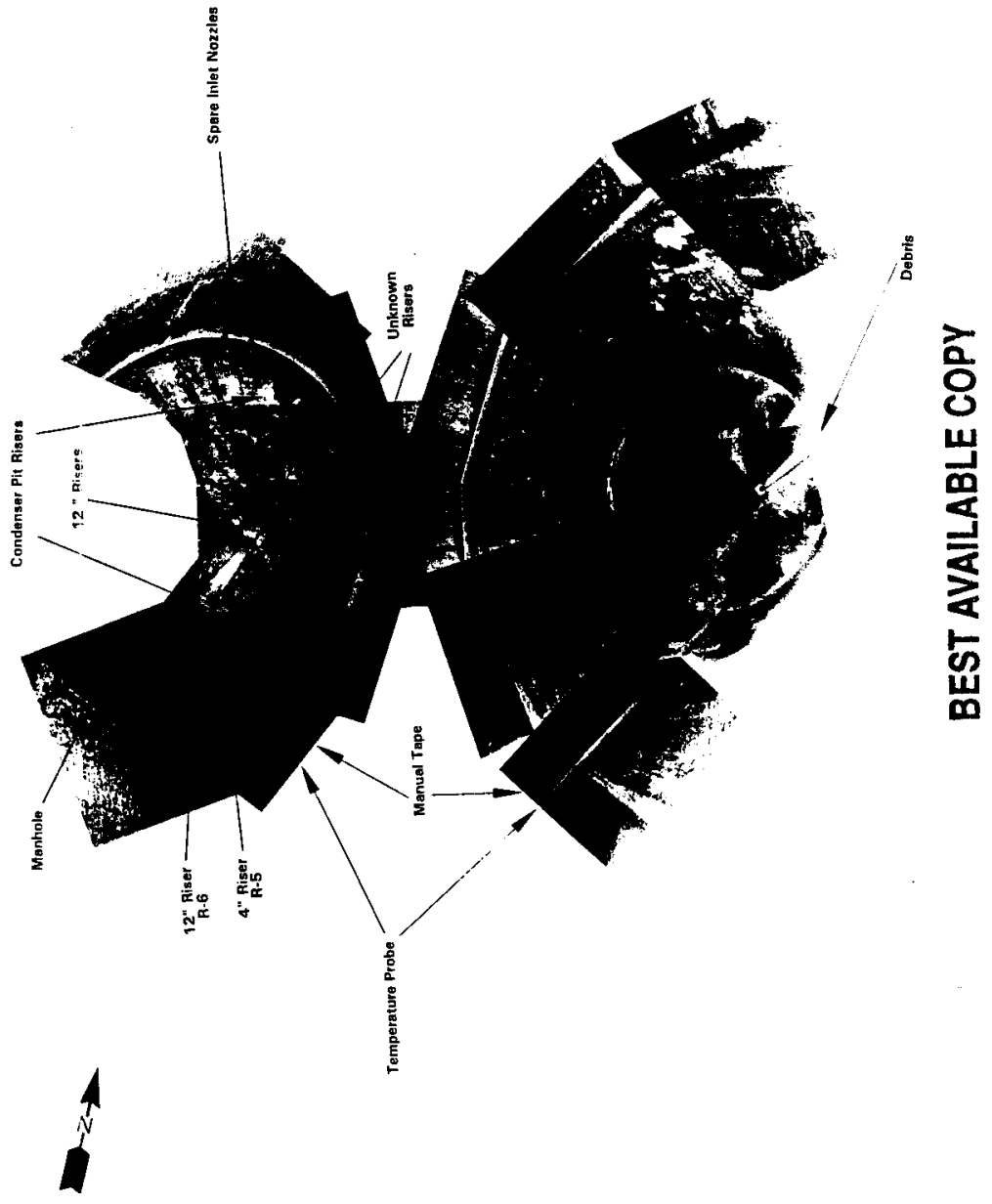




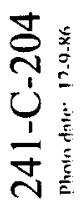

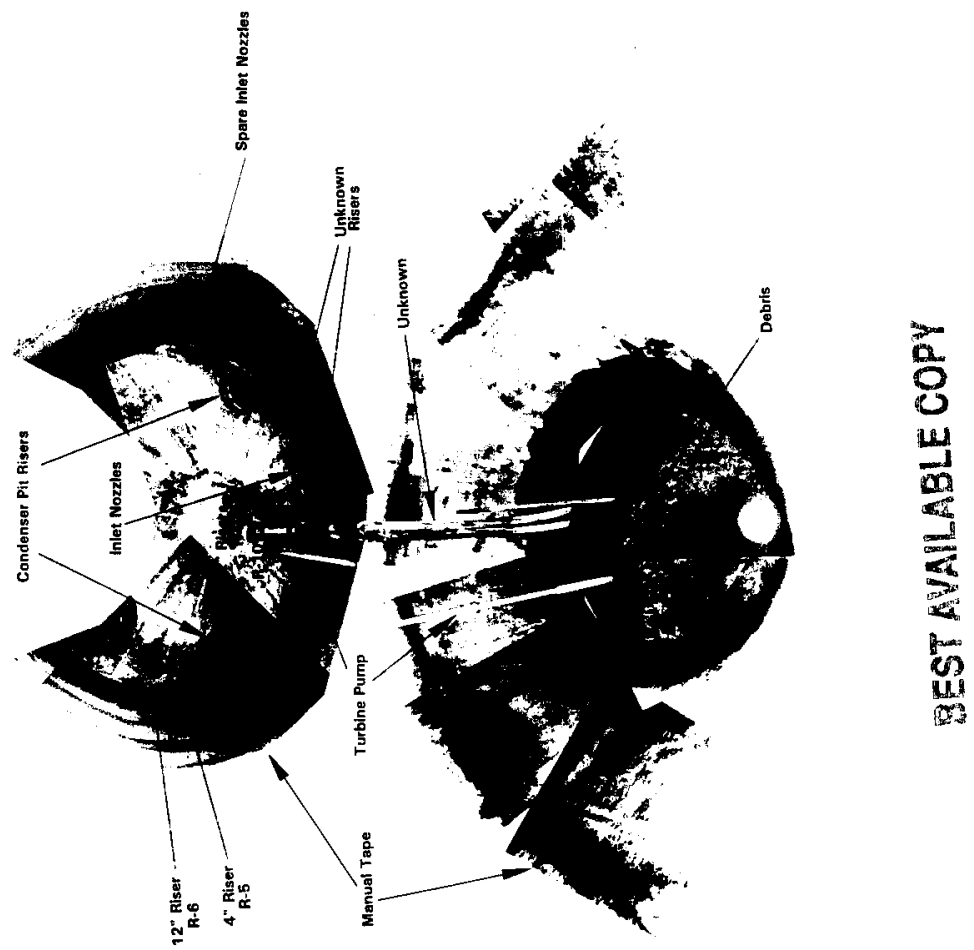

1 


\title{
Hanford Tank Chemical and Radionuclide Inventories: HDW Model Rev. 3
}

\author{
Stephen F. Agnew \\ James Boyer \\ Robert A. Corbin \\ Tomasita B. Duran \\ John R. FitzPatrick \\ Kenneth A. Jurgensen \\ Theodore P. Ortiz \\ Bonnie L. Young \\ Chemical Science and Technology Division \\ Los Alamos National Laboratory \\ Los Alamos, NM 87545
}

May 1996

\section{Executive Summary}

This estimate for the chemical and radionuclide compositions of the 177 Hanford High Level Waste storage tanks is the third major revision in a developing model called the Hantord Defined Waste (HDW) model. This model is composed of four parts:

1) a compilation of transaction records for all the tanks called the Waste Status and Transaction Record Summary (WSTRS);

2) a derivation called the Tank Layer Model (TLM) of solids histories for each tank based on primary additions of waste;

3) a calculation of supernatant blending and concentration with the Supernatant Mixing Model (SMM); and

4) a combination of process information along with some transaction information to derive compositions for about fitty Hanford Defined Wastes (HDW's), each of which has both sludge and supematant layers.

Alf of this information is combined together in a spreadsheet to produce total chemical and radionuclide compositions for each tank's waste as well as a composition for its TLM and SMM blends. Furthermore, each tank's inventory is also represented by a linear combination of TLM sludges and SMM supernatants, each expressed in kgal of original waste. Thus, the genealogy of each tank's waste carl be traced back to the plant and process from which it derived. These estimates comprise some 33 non-radioactive species and 4 radionuclides, Pu-239, U-238, Cs-137, and $\mathrm{Sr}-90$. The 33 non-radioactive species in the model are $\mathrm{Na}, \mathrm{Al}, \mathrm{Fe}, \mathrm{Cr}, \mathrm{Bi}, \mathrm{La}, \mathrm{Hg}, \mathrm{Zr}, \mathrm{Pb}, \mathrm{Ni}, \mathrm{Sr}(\mathrm{stable}), \mathrm{Mn}, \mathrm{Ca}, \mathrm{K}, \mathrm{OH}$, nitrate, nitrite, carbonate, phosphate, sulfate, silicate, F, Cl, citrate, EDTA, HEDTA, glycolate, acetate, oxalate, DBP. butanol, ammonia, and ferrocyanide.

Also reported are total site inventories for DST's, SST's, as well as the total inventory of waste placed into cribs and trenches from the waste tanks during the history of Hanford. These estimates do not cover all waste additions to cribs since many streams went into the cribs directly from the plants. Such streams as stack scrubbing and process condensates were often sent directly to cribs from the plants.

Tank leaks represent a very small amount of the total waste. Many "leaks" are not actually measured volumes and are only assumed to have occurred at some nominal vatue. This is because ground activity occurred in the vicinity of a tank even though there was no measurable change in its inventory. HDW estimated leak inventory, then, does not provide for leaks that did not have a measurable effect on inventory. Only those leaks that actually resulted in a measurable volume loss from a tank are included in the leak estimate. 


\section{Background}

One of the most important tasks involving the Hanford waste tanks is the estimation of those tank's contents. Such estimates are very important for three reasons: first, to establish safety limits during intrusive activities associated with these tanks; second, to establish a planning basis for future disposal; and third, to allow assays from one tank's waste to be used to validate, compare, and assess hazards among other tank's with similar waste inventories.

It is clear that direct assays of tank wastes will always be an important and ongoing need for the Hanford tanks. However, it is equally clear that it will be very difficult if not impossible to adequately address all issues with respect to waste tanks by sampling and assay alone. Representative sampling is undoubtedly the most difficult aspect of deriving tank inventories from assays alone. Both the extremely heterogeneous nature of tank waste and the limited access provided by riser pathways to waste in these seventy-five foot diameter underground tanks contribute to difficulties in using assays abone to derive tank inventories. Furthermore, there are safety issues, such as elevated amounts of soluble organic in dry nitrate waste, that are difficult to address by sampling alone since they could involve relatively small inaccessibie regions of waste within a tank.

Finally, in order to make sense out of the highly variable results that chen come from a tank's waste assays, it is necessary to couch those results in terms of the particular process and storage history of that tank. The HDW model estimates provide just such a needed sitewide framework for each of the 177 Hanford tanks.

\section{Approach}

The HDW model is described schematically in Fig. 1 . The model benins with a process and transaction dataset that derives from a variety of sources. From this dataset, a balanced ank-by-:ank quarterly summary transaction spreadsheet is derived called the Waste Status and Transaction Record Summary (WSTRS). At the end of each quarter, all tanks' volumes are reconciled with their reported status at that time and in the process, unknown transactions are recorded to accommodate otherwise unexplained gains or losses at the end of each quarter.

Using these fill records, the Tank Layer Model (TLM) provides a definition of the sludge and salt cake layers within each tank. The TLM is a volumetric and chronological description of tank inventory based on a defined set of waste solids layers. Each solids layer is attributed to a particular waste addition or process, and any solids layers that have unknown origin are assigned as such and contribute to the uncertainty of that tank's inventory. The TLM simply associates each layer of sludge within a tank with a process waste addition. As indicated in Fig. 1, the TLM analysis depends only on information from WSTRS.

The Supernatant Mixing Model (SMM) is an algorithm written in $\mathrm{C}++$ and installed as a spreadsheet macro that describes the supernatant and concentrates within each of the tanks. The SMM uses information from both WSTRS and the TLM and describes supematants and concentrates in terms of $\mathrm{kgal}$ ( $1 \mathrm{kgal}=1,000 \mathrm{gal}$ ) of each of the process waste additions.

Together the WSTRS, TLM, and SMM define each tank's waste in terms of a linear combination of HDW sludges and supematants. In order to provide information on the elemental composition of each tank, the Hanford Defined Wastes (HDW's) compositions describes each of the HDW's based on process historical intormation. Each HDW has both supematant and sludge layers, its total amount of waste set by WSTRS, and its sludge volume determined by the TLM. Thus, the HDW compositions depend on all prior model components-process/transaction dataset, WSTRS, TLM, and SMM.

Each tank's total inventory is calculated as

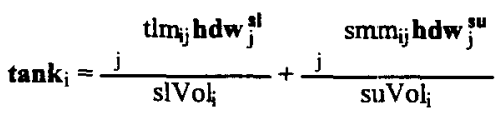


WHC-SD-WM-ER-313, Rev. 1

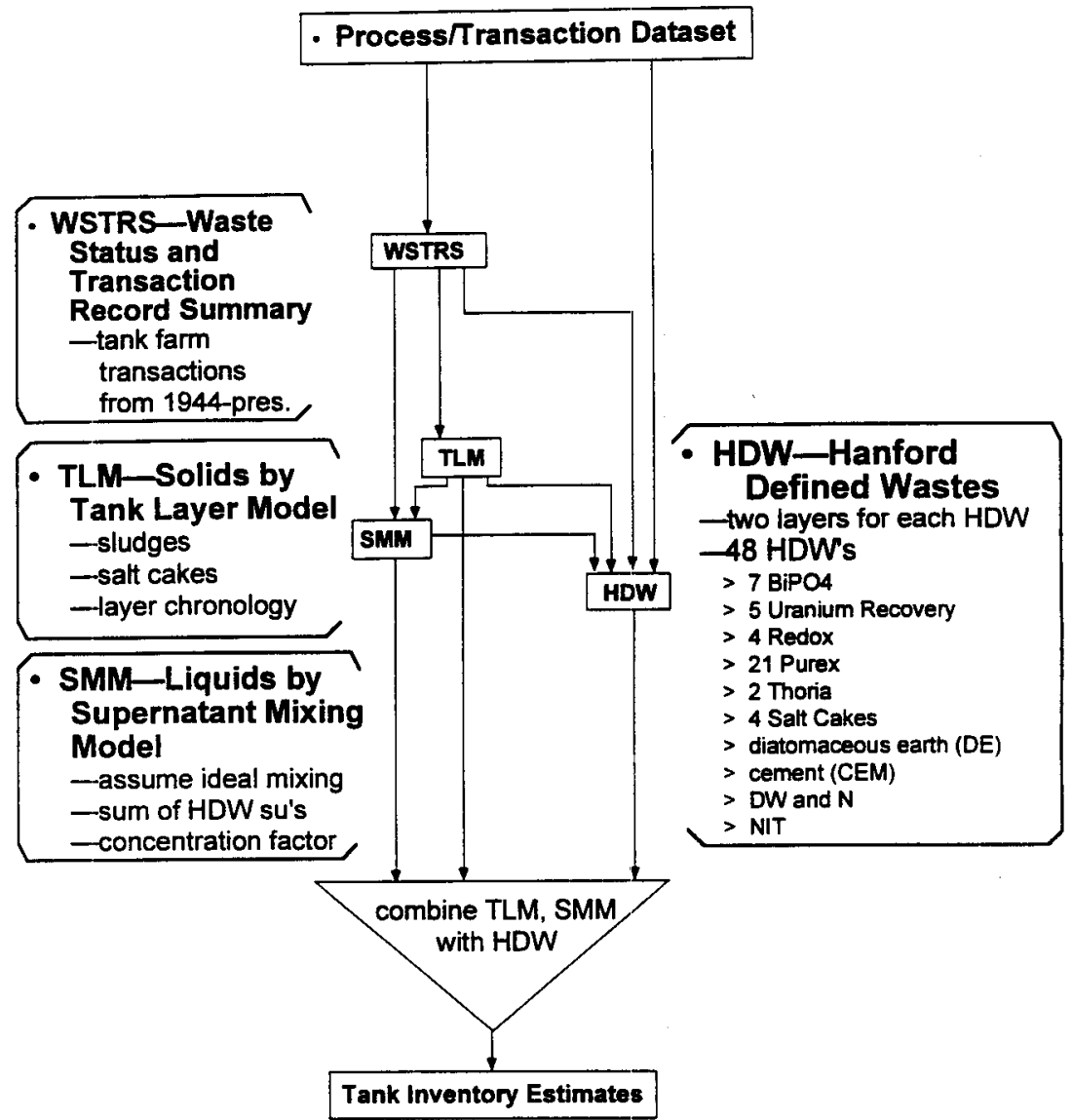

Fig. 1. Schematic of overall strategy.

where

$$
\begin{aligned}
& \text { tanky = composition vector for tank } \mathrm{i} \\
& h d w]^{s !}=\text { composition vector for HDW sludge } j \\
& h d w_{j} \mathbf{* u}=\text { composition vector for HDW supernatant } j \\
& \mathrm{tim}_{\mathrm{ij}} \quad=\mathrm{kgal} \text { of hdw sludge } \mathrm{j} \text { for tank } \mathrm{i} \\
& \mathrm{smm}_{\mathrm{ij}} \quad=\mathrm{kgal} \text { of hdw supernatant } \mathrm{j} \text { for tank } \mathrm{i} \\
& \text { siVoli } \quad=\text { sludge kgal tor tank } \mathrm{i} \\
& \text { suVoli } \quad=\text { supernatant concentrate kgal for tank } i \text {. }
\end{aligned}
$$


The first term is the TLM solids inventory and is reported as

$$
\operatorname{tank}_{i}^{s !}=\frac{j^{\operatorname{thm}_{i j} h d w_{j}^{s !}}}{\text { slVol }_{i}}
$$

while the second term is the SMM inventory reported as

$$
\operatorname{tank}_{\mathrm{i}}^{\mathrm{su}}=\frac{\mathbf{j}}{\operatorname{smVol}_{\mathrm{ij}} \mathbf{s m d w _ { j } ^ { s u }}} .
$$

These inventory estimates for each tank also appear in the Historical Tank Content Estimate reports for each of four quadrants. ${ }^{1}$

\section{Ila. Approach-Waste Status and Transaction Record Summary}

The WSTRS is a spreadsheet of qualifie: : ill records ${ }^{2}$ with intormation extracted from Jungfleisch- $83^{3}$ and Anderson- $91^{4}$, and checked b: Ogden Environmental and LANL against quarterly summary reports. The WSTRS reports, although largely representative of the waste histories of the tanks, are nevertheless incomplete in that there are a number of unrecorded transactions that have occurred for many tanks. Included within the WSTRS report, then, is a comparison of the tank volume that is calculated based on the fill records that are present in WSTFS with the measured volume of each tank. This comparison is made for each quarter to record any unknown waste additions or removals that may have occurred during that quarter.

The Rev. 3 estimates include new information from the Logbook Dataset ${ }^{5}$ and have extensive revisions in the latter four evaporator campaigns: 242-S (S1 and S2) and 242-A (A1 and A2). The Logbook Dataset contains extremely detailed tank level information from about 1975 to 1992 and has allowed Rev. 3 to accomodate the blending that occurred during these campaigns. In Rev. 1 , each campaign's waste was blended over many years of operation, then concentrated in one single step and distributed over all the bottoms receivers. In contrast, Rev. 3 blends the evaporator concentrates on about a quarterly basis thereby providing much better representation of these evaporator campaigns.

${ }^{1}$ Brevick, C. H., et al., "Historical Tank Content Estimate of the Northeast (Southwest, Northwest, Southeast) Quadrant of the Hantord 200 East Area," WHC-SD-WM-ER-349 thru 352, Rev. 0, June 1994.

2 (a) Agnew, S. F., et al., "Waste Status and Transaction Record Summary tor the NE Ouadrant" WHC-SD-WM-TI-615, Rev. 1, October 1994. (b) Agnew, S. F., et al. "Waste Status and Transaction Record Summary for the SW Quadrant, "WHC-SDWM-TI-614, Rev. 1, October 1994. (c) Agnew, S. F., et al. "Waste Status and Transaction Record Summary for the NW Quadrant," WHC-SD-WM-TI-669, Rev. 1, October 1994.

3(a) Jungfleisch, F. M. "Hanford High-Level Defense Waste Characterization-A Status Report," RH-CD-1019, Juły 1980. (b) Jungfleisch, F. M. "Supplementary information for the Preliminary Estination of Waste Tank Inventories in Hanford Tanks through 1980," SD-WM-TI-058, June 1983. (c) Jungfleisch, F. M. "Preliminary Estimation of Waste Tank Inventories in Hantord Tanks through 1980," SD-WM-TI-057, March 1984.

${ }^{4}$ Anderson, J. D. "A History of the 200 Area Tank Farms," WHC-MR-0132. June 1990.

5Brevick and Gaddis, "Tank Farm Logbook Dataset," in preparation. 
Transactions were added to WSTRS to resolve the many unknown level changes for each quarter according to a set of rules resulting in an updated WSTRS that is known as Rev. 3. This unknown transaction resolution was only completed for all unknowns larger than $50 \mathrm{kgal}$, although many smaller transaction unknowns were accommodated as well. The following rules were used for unknown transaction resolution for the various tank categories.

\section{Evaporator feed and bottoms receivers:}

During an evaporator campaign, unknown waste transfers at the end of each quarter are resolved by sending wastes to or receiving wastes from an evaporator feed tank for tanks identified as either bottoms receivers or feed tanks for those campaigns.

\section{Self-concentrating tanks:}

Certain tanks in S, SX, A, and AX farms were allowed to self concentrate. Any losses or additions to these tanks are assigned to condensate or water, respectively.

\section{Sluicing receivers:}

For tanks associated with a sluicing campaign (either UR or SRR), unknown transactions are resolved by either sending or receiving from the sluicing receiver tank for that campaign. Unassigned losses from the sluicing receivers, then, are sent directly to the process.

\section{Salt-well pumping and stabilization:}

If an unknown loss occurs during salt well pumping stabilization of a tank, then the unknown is resolved by sending waste to the active salt well receiver at that time.

\section{Historical use of tank:}

If none of the above rules apply, then the historical use of the tank is used to assign the transaction. For example, C-105 was used as a supernatant feed tank for the CSR campaign and supplied $-1,500 \mathrm{kgal}$ per quarter for several years. However, there is one quarter (1971q2) where C-105 loses $1,748 \mathrm{kgal}$ without an assigned transaction. Because of C-105's process history, this transaction is assigned to CSR feed. Likewise, there are a number of large supernatant losses in $A$ and $A X$ Farms during sluicing for siudge recovery. These supernatant losses are assigned as feed to AR, which are the slurries transferred to AR Vault for solids separation, washing, dissolution, and feed to SRR.

The transaction data set has sometimes an arbitrary and non-unique order for transactions within each quarter. This transaction order has been largely resolved for the period 1975-present, but not for all of the remaining tanks for this estimate. Thus, a certain "historical" error is present in these DST estimates that is largely related to transaction ordering errors from 1945-1975. These errors are not very serious for the DST's, since much blending has occurred since 1981, butthis transaction ordering should be completed for the entire history of Hanford in order to determine how it will affect tank inventories.

\section{Ilb. Approach-Tank Layer Model (TLM)}

The TLM a solids layer model that uses the past fill history of each tank to derive an estimate of the types of solids that reside within those tanks. The TLM ${ }^{6,7}$ is generated by reconciling the reported solids levels from WSTRS

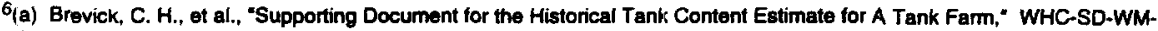
ER-308, Rev. 0, June 1994. Likewise, reports and numbers for each farm are as follows: $A X$ is $309, B$ is $310, B X$ is $311, B Y$ is $312, \mathrm{C}$ is $313, \mathrm{~S}$ is $323, \mathrm{SX}$ is 324 , and $\mathrm{U}$ is 325 . These supporting documents contain much of the detailed information for each tank fam in a concise format, all released as Rev. 0 in June 1994.
}

${ }^{7}$ Agnew, S. F., el al. "Tank Layer Model (TLM) for Northeast, Southwest, and Northwest Quadrants," LA-UR-94-4269, February 1995. 
for each tank (as shown in App. C) with the solids volume per cent expected for each primary waste addition (see App. A). Note that a solid's model has already been extensively used at Hanford to estimate siudge and salt cake accumulation, the results of which are reported $d^{8}$ monthly.

There are some tanks that the HDW model assumes a different waste inventory than that reported in Hanlon. This differences come aboutbecause of the difficulties that are often encountered in determining the remaining inventory in tanks with large surface heterogeneities. Also shown in App. C, then, are a list of tanks for with their Hanion volumes and their adjusted volumes used for the HDW estimates. The sources of these discrepancies are a series of reports about stabilized tanks. ${ }^{9}$

The TLM is a volumetric and chronological description of tank inventory based on the HDW sludges and salt cakes. Each solids layer is attributed to a particular waste addition or process, and any solids layers that have unknown origin are assigned as such and contribute to the uncertainty' of that tank's inventory. The TLM simply associates layers of solids within each tank with a waste addition or a process campaign.

The TLM us: : the information obtained from the transaction history for each tank to predict solids accumulations. Thes e predictions are made for three categories of waste tanks. The first category involves primary waste additions, which are the waste additions from process plants directly into a waste tank. The primary waste transactions are used along with solids volume reports for each tank to derive an average volume per cent solids for each HDW type. The solids accumulations are, then, also assigned to a particular HDW for the tanks where the solids information is missing or inconsistent.

A second category of waste is that where solids accumulate as a result of evaporative concentration of supernatants. All solids that accumulate in such tanks occur after they have been designated as "bottoms" receivers. These solids are assigned to one of four salt cakes, which are defined as blends over entire evaporator campaigns. The four salt cakes are BSHCK, T1SItCk, BYSItCk and RSHCk, are all defined as HDW's. The latter five evaporator campaigns $\mathrm{T2}, \mathrm{S1}, \mathrm{S2}, \mathrm{A1}$, and A2 all result in waste concentrates that are defined differently for each tank within the SMM.

The third category of waste is that where solids accumulate due to tank to tank transfers of solids. This category allows solids to cascade from tank to tank, for example, or accounts for solids lost during routine transfers, as was common with decladding wastes CWR and CWP, $1 \mathrm{C}$, or FeCN sludges.

The results of the TLM analysis are a description of each tank's solids in terms of sludge and salt cake layers. Although interstitial liquid is incorporated within the composition for sludges and salt cakes, any residual supernatants that reside in these tanks above the solids are described by the SMM. The output of the TLM, then, can only be used to predict the inventory of the sludges and each of four salt cakes that reside within waste tanks. These TLM results are inserted into the WSTRS record and are used by the SMM in considering excluded volumes for mixing of waste supernatants.

Not all of the transactions that have occurred in the past are faithfully recorded by the WSTRS data set. Theretore, WSTRS is an incomplete document with many missing transactions. However, the two critical pieces of information that are used in the TLM analysis are the primary waste additions and the solids level measurements, both of which are well represented in WSTRS.

\footnotetext{
8Hanton. B. M. "Tank Farm Surveillance and Waste Status and Summary Report for November 1993, "WHC-EP-0182-68, February 1994, published monthly.
}

9 (a) Swaney. S. L. Waste Level Discrepancies between Manual Level Readings and Current Waste Inventory for SingleShell Tanks," Internal Memo 7C242-93-038, Dec. 10, 1993. (b) Boyles, V. C. Boyles "Single Shell Tank Stabilization Record," SD-RE-TI-178 Rev. 3, July 1992. (c) Wetty, R. K. "Waste Storage Tank Status and Leak Detection Criteria," SDWM-TI-356, September 1988. 
The missing transactions largely involve tank-to-tank trarısfers within WSTRS. These missing transactions, which are salt cake, salt slurry, and supematant, do lead to a larger uncertainty for the compositions of the concentrated products from evaporator operations. As many as $25 \%$ of all transactions may be missing from this data set, perhaps as many as $60-80 \%$ of these missing transactions are associated with the evaporator operations. Although this information might be recovered in the future, the HDW model strategy at this time resolves as many of these unknown transactions as possible with the rules stated above.

\section{Sludge Accumulation from Primary Waste}

The TLM analysis associates a solids volume percent (vol\%) with each primary waste stream. These solids vol\% are those that are consistent with the solids volumes reported in Anderson-91 by comparing those solids accumulations with the primary waste additions that are recorded in WSTRS. The result of this analysis is a solids volume percent for each waste type with a range of uncertainty associaled with the inherent variability of the process.

Not all of the waste types have adequate solids reports associated with them. For these waste types. a nominal value is assigned based on similarity to other waste types where there exists a solids vol\%. For example, a total of $810 \mathrm{kgal}$ of Hot Semi-Works waste (HS) was added to several tanks in C Farm, but these additions only constituted a small fraction of the total solids present in any of these tanks. Therefore, a nominal 5 vol\% solids is assigned for that waste type.

Each TLM spreadsheet table shows the primary waste additions and the solids from those additions based on the characteristic vol\% for that waste type. The TLM compares this prediction with the solids level reported for the tank and indicates either an unknown gain or loss for this tank. Once a layer is "set" in the tank, its volume appears in "Pred. layer" and type in "Layer type", thus comprising a chronological layer order trom the bottom of a tank to the top, where each layer is described in terms of a volume and a type. Note that lateral variations are not accounted for in this model, and therefore this model only derives an average layer thickness. The TLM does not include any lateral distribution of those layers, which can in some cases can be quite extreme.

There are two main sources for variations in the solids vol\% for each waste type. First, there is an inherent variability in each process stream, which is largely attributable to process variations. Second, solids can be added to or removed from tanks by inadvertent (or purposeful) entrainment during other supernatant transfers. In addition to these sources of variation, there are a number of other minor sources of solids changes such as compaction, subsidence following removal of salt well liquid, and dissolution of soluble salts by later dilute waste additions. Other solids variations may be due to metathesis and other chemical reactions within the tanks, such as degradation of organic complexants over time.

The TLM assigns solids changes to variability when they fall within the range established. If a change in solids falls outside of this range, the TLM associates the gain or loss of solids with a waste transfer to or from another tank or to dissolution of soluble salts in the upper existing solids layers.

\section{Diatomaceous Earth/Cement}

Diatomaceous Earth, an effective and efficient waste sorbent material, was added to the following waste storage tanks BX-102 (1971), SX-113 (1972), TX-116 (1970), TX-117 (1970), TY-106 (1972), and U-104 (1972). The additions of diatomaceous earth were used to immobilize residual supematant liquid in tanks where the liquid removal by pumping was not feasible. The conversion factor in the TLM for Diatomaceous Earth (DE) is 0.16 $\mathrm{kgal} /$ ton and Cement (CEM) or (CON) is $0.12 \mathrm{kgal} / \mathrm{ton}$. The CEM waste was only added to one tank, BY-105 (1977).

\section{Salt Cake Accumulation}


Once a tank becomes a "bottoms" receiver, the TLM assumes from that point on that any solids that accumulate are salt cake or salt slurry. Salt cake can be any one of four different types, depending on which evaporator campaign created it. These are B (242-B), T1 (early 242-T). BY (ITS \#1 and \#2 in BY Farm), and R (Redox self-concentrating tanks). Table 2 describes the various evaporator campaigns that resulted in concentration of waste and precipitation of solids at Hanford. For salt cake accumulation, the TLM assumes that all of the solids reported are salt cake. Two other minor evaporation campaigns involved use of Redox and $B$ Plant evaporators for tank wastes. These minor campaigns have been associated with $\mathrm{T} 2$ or $\mathbf{S} 1$ campaigns, respectively.

The HDW model assigns waste of the five later campaigns for 242-T, 242-S, and 242-A evaporators as concentrates within the SMM. These later concentrates correspond roughly to what is known as double-shell slurry (DSS) or double-shell slurry feed (DSSF), although their early concentrates are often referred to as salt cake as well.

\section{Ilc. Approach-Supernatant Mixing Model (SMM)}

The third step is to describe the composition of supematants and concentrates within each of the tanks (note that interstitial liquid is part of the TLM sludge and salt cake definitions, not the supernatant). To accomplish this, an ideal mixing model has been developed, called the Supernatant Mixing Model. This model describes supernatants in terms of original $\mathrm{kgal}$ ( $1 \mathrm{kgal}=1,000 \mathrm{gal}$ ) of each of the $\mathrm{HDW}$ supernatants. The SMM is a very critical part of the definition of waste in double-shell tanks (DST's) where a large fraction of the waste supernatants now reside. For single-shell tanks, the SMM contributes largely to the composition of concentrated wastes. A block diagram of the SMM approach is shown in Fig. 2. The fundamental assumptions used for this model are ideal mixing of each tank's free supernatant volume throughout its history. In particular, the volume of solids layers within each tank defined by the TLM are excluded from mixing with any supematant additions. In addition, all evaporator feed to and from 242-A, 242-S, and the latter 242-T operations are treated as free supernatant in all tank transactions.

The SMM calculation reads transaction information from WSTFIS, sorts it to a date order, and performs a transaction by transaction accounting of all of the tank waste transactions for the history of Hanford. This afgorithm accounts for residual solids accumulation as per the TLM above.

The SMM provides a description of each tank's free supernatant and supernatant concentrate based on a linear combination of Hanford Defined Waste (HDW) supematants. The HDW supematants have been reported in the Waste Status and Transaction Record Summaries for that tank. This linear combination of HDW supernatants represents a total volume that is usually larger (sometimes smaller) than the actual volume of free supernatant within each tank. This is because active evaporation (or dilution) of the waste during its history.

Each tank's SMM waste vector is expressed in terms of a linear combination of HDW supernatants, which in tum are used to predict a chemical and radionuclide inventory with compositions provided by the HDW (or other sources). The SMM does not allow mixing with TLM solids that have precipitated from primary waste streams. However, those solids that resulted from the later concentrator operations 242-A, 242-S, and latter 242-T, are treated as supernatants within the SMM.

\section{SMM and TLM Output Tables}

The output of the Supernatant Mixing Model is a table whose column headings are the HDW's and auxiliary wastes and whose rows are the waste tanks and processes. The auxiliary wastes are water, unk, swliq, and gas and do not appear on the HDW waste list. These auxiliary wastes are used for tracking of unknowns, evaporator runs, and gas retention in waste concentrates. The SMM table's columns (see App. D) show the HDW distribution among the tanks and processes for a particular time. These are given in kgal of original HDW supernatant. The linear combination of HDW supematants represerit a total volume that is usually larger (but sometimes smaller) than the actual volume of free supernatant or concentrate within each tank. The reason that the SMM volume differs from the tank volume is because of active evaporation or dilution of a tank's waste. 
The TLM tables are also shown in App. C and follow roughly the same format as the SMM tabies. There is no concentration effect with the TLM solids and so the row sum of the TLM for each tank is equal to the TLM volume for that tank.

\section{Ild. Approach-Hanford Defined Wastes (HDW)}

The fourth step in the strategy is to provide chemical and radionuclide concentrations for each of the Hanford Defined Wastes ${ }^{10}$ (HDW's). The HDW's begin with inputs of radionuclide and stable chemicals, both of which are used to define the total species in each waste stream (see Fig. 3, campaign and chemicals added). These total species are then separated into two layers, a sludge and a supernatant, that result in different concentrations of species for the two layers.

Each species is precipitated according to a single point solubility and ions precipitated in more than one salt are simply successively precipitated. Thus, the solids that precipitate are merely representative of the actual solids and are not meant to reflect the actual solids distribution. Because the supernatant is also present in the interstices of the sludge layer, this "supematant" is included within the sludge composition. The solubility of each species is set by a macro that, when run on the HDW spreadsheet, adjusts the fraction precipitated parameter so that the supernatant concentration is equal to or less than the target solubility.

The sludge and supematant compositions are each expressed in moln for the stable chemicals, with water and TOC as wt\% and radionuclides in $\mu \mathrm{Ci} / g$ and $\mathrm{Ci} /$, respectively. Each waste is kept in ion balance according to the oxidation states assumed for that species. The sludge and supernatant layers are also expressed in terms of ppm composition, for which are kept a mass balance as well. However, the

\footnotetext{
${ }^{10}$ Agnew, S. F., et al., "Hantord Defined Wastes: Chemical and Radionuclide Compositions," LA-UR-94-2657, Rev. 2, September 1995.
} 


\section{Supernatant Mixing Model Block Diagram}

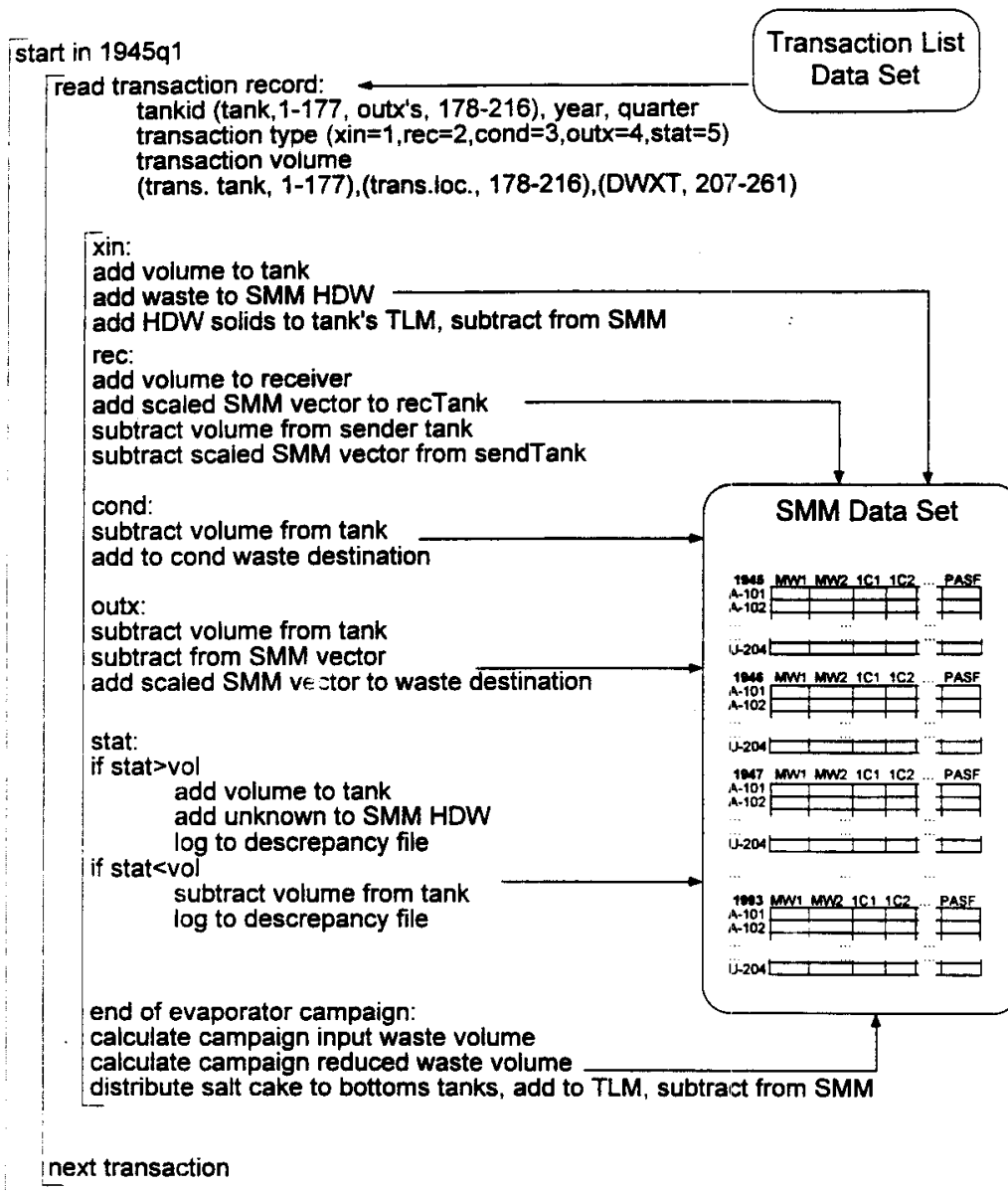

end in 1993q4

Fig. 2. Block Diagram of SMM algorithm.

mass balances are limited by differences among water, oxide, and hydroxide with the various solids to only within $\pm 2 \%$. 


\section{Block Diagram of HDW Spreadsheet}

Campaign Information, pp. $1 *-3$

-fuel processed

-exposure

- total waste

-average waste rate

-Pu extraction efficiency

-nuclide source terms

- solids vol\%

- CSR input

Chemicals Added, pp. 4-6

-mostly based on tons fuel

-others concentration

$-\mathrm{NaOH}$ added to neutralize

"p. 1 refers to Appendix pages with HDW spreadsheets.

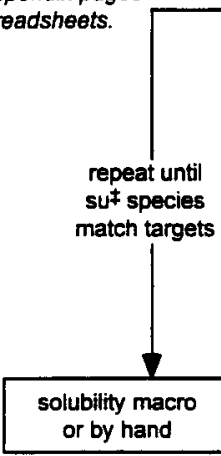

Supermatant (mol/L), pp. 13-15

Sludge (mol/L), pp. 10-12

Species Total (mol/h), pp. 7-9

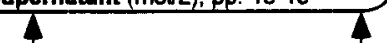

Solids Volume (cC/L), pp. 19-21

Solids Conc (molll), pp. 16-18

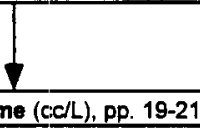

( $\$$ su $=$ supernatant)

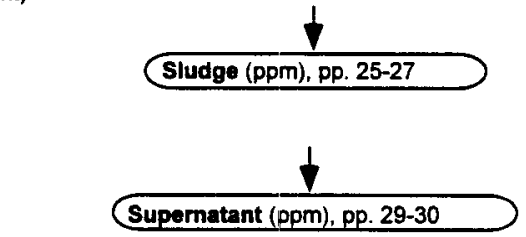

calculate blends

as weighted averages of HDW su's

Supernatant to Evaporator Campaigns,

Nitrate to Nitrite to Ammonia Radiolysis,

$A R$ and CSR Waste Blends, pp. 31-33

Fig. 3. Block Diagram of HDW spreadsheet . 


\section{Results and History of Revisions}

Appendix $E$ shows the composition and inventory for each of the 177 Hanford Waste tanks. Each tank is described by three tables and each table comprises three columns of information. Two columns describe the analyte concentrations as moll and ppm and the third column expresses the tank inventory in $\mathrm{kg}$ or $\mathrm{MCi}(1 \mathrm{MCi}=1 \mathrm{e} 6 \mathrm{Ci}$ ). The three tables represent TLM solids blend, SMM liquids blend, and total somposite tank concentrations and inventories. The TLM solids composition and inventory represents the volume average blend of all of the TLM solids layers. Note that among the TLM solids definitions are four salt cake concentrates: B, T1, A, and BY. Therefore, the TLM solids inventory definition includes sludges and some salt cake.

The second table for each tank represen:s the SMM composite inventory for liquids and concentrates. This table represents inventories from evaporator concentrates termed T2, S1, S2, A1, and A2. Note that these concentrates actually include a lot of solids but are treated nevertheless as homogeneous mixtures that can be pumped, blended, and moved to other tanks as though they were liquid.

The HDW model provided its first estimates in June of 1994 as: Rev. 0 for the NE and SW quadrants. This early revision was based on single waste types for satt cake and salt slurry for the entire site. Revision 1 was actually the first complete site inventory and was completed in Fall of 1994 for the three SST quadrants, NE, SW, and NW, while Rev. 1 for the DST SE quadrant was completed in March 1995. These estimates included many bug fixes and other corrections and as 0 included additions tor process vessel corrosion source terms (adds $\mathrm{Fe}, \mathrm{Cr}$, and $\mathrm{Ni}$ ) as well as a hard water $\mathrm{Ca}$ source term. However, the $\mathrm{Cs}-137$ and $\mathrm{Sr}-90$ inventories were calculated too high by about $20 \%$ and all evaporator campaigns were blended into multi-year composites. These evaporator blends were an improvement over the single waste types for salt cake and salt slurry in Rev. O, but still represented an approximation for individual tanks. Essentially, these evaporator blends were excellent representations of the total waste into a campaign and its total volume reduction, but were distributed across perhaps ten or twenty different slurry receivers that were involved in each campaign.

The next step with the HDW Estimates, Rev. 2, was an attempt to express the five later evaporator campaigns on a tank by tank basis. The SMM provided the waste concentrate nistory step by step throughout each of the evaporator campaigns. Revision 2.1 represents a bug fix in the spreadsheet that incorrectly calculated water and TOC and another problem with miscalculatior in SX Farm. This revision was based on the HDW Rev. 2 compositions, which had improved the $\mathrm{Cs}-137$ and $\mathrm{Sr}-90$ inventory calculation and had included chloride and potassium source terms that piggyback on the $\mathrm{NaOH}$ additions. Various other bug fixes and changes and additions were a mercury source term used in the decladding process, adjustments on the wastes from UR (U ranium Recovery), slight realignments of 1C and $2 \mathrm{C}$ waste campaigns, and other minor changes. Revision 2 also reduced the process vessel corrosion source term $(\mathrm{Fe}, \mathrm{Ni}, \mathrm{Cr}$ ) for early BiPO4 wastes and decladding wastes consistent with the fact that these processes were much less corrosive than either Purex or Redox.

The Rel . 2.1 estimates nevertheless had some problems. The most significant problem was ne incomplete transaction records for the later evaporator campaigns caused incorrect distribution of waste concentrates. In particular, some tanks were impossibly over concentrated ( $\mathrm{Na}$ in excess of 16-17 moll), while other slurry receivers were more dilute than they should have been. It was clear that there were severe problems in waste misdirection with Rev. 2.

To correct these problems, the Rev. 3 estimates have extensively modified WSTAS by adjusting the evaporator transactions to blend on a per quarter basis and for some quarters, wastes have been blended on an even finer time scale. This improvement in the transaction record was largely accomplished by use of a draft version of the Logbook Datase ${ }^{5}$, constructed by ICF Kaiser for WHC and not yet published. Also used is an extensive set of reports from evaporator operations for 242-S and 242-T. Unfortunately, there was a lack of detailed information about the 242-T evaporator operation.

The overall inventories for the analytes have not changed significantly except for lead, manganese, and oxalate. Lead site inventories increased dramatically in Rev. 3 since these estimates included the lead coating that 
WHC-SD-WM-ER-313, Rev. 1

covered each fuel slug. This tums out to be a major source of lead in the waste tanks and the total lead inventory increased trom 3 to $280 \mathrm{mT}$. There was also an error in the concentration of manganese in OWW2, which upon correction lowered the manganese site inventory from 219 to $39 \mathrm{mT}$. The oxalate inventory increased from 23 to $69 \mathrm{mT}$ because of a decrease in its solubility limit. Since 224 waste supematant was all cribbed, decreasing oxalate solubility retains more in the waste tanks and this was the only oxalate source term.

\section{Uses and Limitations of HDW Model Estimates}

The HDW Model Rev. 3 estimates represent a Hanford site inventory based on process history that is compatible with the waste types, compositions, and processing history of the site. The total site estimates will not change appreciably in the future unless the wastse source terms for the various waste streams change, but it is still possible that changes in the transaction record will alter the inventory estimates of individual tanks. All estimates are valid as of 1-1-94 and Sr-90 and Cs-137 are both decayed to the same date. Therefore, these estimates do not account for the latest evaporator campaign in '95-'96, which moved and blended large amounts of waste supernatants in the DST's.

The HDW estimates are the first complete, total, ion and mass balanced inventory estimates yet provided on a per tank basis. As such, they have immediately shown that: site sodium inventory has been traditionally overestimated by about one third. Whereas previous site estimates for sodium were around $71,000 \mathrm{mT}$ (mT = metric tonnes), the HDW estimate show only $40,000 \mathrm{mT}$ are actually now in either the DST's or the SST's. This difference is largely due to the large amount of waste supernatant that was sent to crib, some $20,000 \mathrm{mT}$, but is aiso due to more subtle double counting of waste stream chemicals that has occurred in the past.

These estimates have also shown an increase in the iron inventory, which the HDW model now estimates at $1,830 \mathrm{mT}(1,610$ in the SST's and 220 in the DST's) as compared to previous estimates of $710-730 \mathrm{mT}$. These total site estimates are shown in App. E along with estimates for individual tanks.

The site inventory estimates include totals for waste sent to the cribs as well as totals for leaks with measurable volume losses. Note that the leaks from waste tanks are only a small fraction of the total inventory sent to the ground, constituting only $10 \%$ of the $2.2 \mathrm{MCi}$ of Cs/Sr activity and only $2 \%$ of the $48 \mathrm{~kg}$ of Pu that was sent to the soil column. Thus, the amount of activity intentionally sent to the soil column dwarts the activity inadvertently placed into the ground by leaks and spills.

There are still problems with these estimates. The evaporator blending and SMM approach naturally produce blending averages for waste supernatants that were processed during each quarter. The actual blending that occurred during these quarters may not be exactly represented in this approximation. This blending error then contributes to the overall variability in the waste predictions.

Another problem with the HDW model is that precipitated solids from waste concentration do not remain in the slurry receiver during evaporator runs. That is, liquid that is drawn from each bottoms tank following cooling is always removed as a blend of the total concentrate. This leads to an under concentration of the boftoms receiver and correspondingly an over concentration of tanks that receive and further blend and concentrate the recycled liquors. This effect systematically shifts concentrate from early receivers to later receivers and therefore increases the variability of the estimates by introducing a systematic bias in early versus late concentrates.

\section{Uncertainty for the HDW Estimates}

There are two main origins of variability within the HDW model-process variability (results in variability of hdw's) and transaction variability (results in variability in t/m and smm factors). Since process variability affects the HDW compositions and transaction variability affects the SMM/TLM factors, these two variabilities will be additive in the final inventory estimates. 
WHC-SD-WM-ER-313, Rev. 1

\section{Quantification of Process Variability}

Starting with the hypothesis that the waste rate variability is the most direct measure of process variability and therefore of HDW compositional variability, the two sources of waste rate variability are:

1) Rework processing. For a given amount of fuel processed during a campaign, early batches needed to be reworked more otten than later batches because the separations failed to achieve the necessary decontamination or separation factors. Note that for rework, the chemicals in the waste scale linearly with the waste volume but the radionuclides will be diluted by increas ng reworik;

2) Ancillary processing resulting in primary waste dilution. There are many ancillary waste streams that derive from various cell cleanup and vessel cleanout activities. These activities by and large add very little or no chemicals or radionuclides to the waste stream. Therefore, to a first approximation, this variability simpiy dilutes or concentrates the waste stream. This dilution or concentration simply changes the relative supernatant and sludge inventories of each component.

This approach completely neglects chemical source term variability, which derives from measurement errors during processing. This variability is in the range 3-5\% and will therefore be bounded by the two main sources noted above.

The variability of every process waste rate will actually be a combination of rework and anciliary processing and there is little information about what this combination is. Assuming that the amount of chemicals used scales linearly with the volume of the waste produced for rework processing, the waste compositions within each tank will actually be independent of the amount of process rework (radionuclides, however, will be reduced in concentration by the increase in rework.)

This approach subtracts a linear trend from each waste rate due to rework over the period of a campaign and makes the assumption that the resultant variability of the waste composition is wholly attributable to ancillary processing. This results in waste composition variabilities that should be equal to or greater than the true waste composition variabilities. In principle, the HDW model would need more information to assign the correct fraction of waste rate variability to process rework.

With these assumptions in hand, an uncertainty for each HDW (Hanford Defined Waste) can be derived by resolving each HDW analyte for its upper and lower limits. An RSD (F:elative Standard Deviation) for each HDW results in a set of upper and lower compositions for each component of each HDW. Note that these relative variabilities will be different in g: neral from the overall RSD for each HDW. This is because of the fact that the solution concentrations of semi-soluble species are directly linked to their sludge inventories.

Finally, there is a fundamental correspondence that relates a tank's waste volume to a corresponding waste stream variability. That is, if a tank contains $75 \mathrm{kgal}$ of : waste siudge, then the waste rate variability must be calculated for the time that it took to deposit that $75 \mathrm{kgal}$ of sludge.

This is a very important point. A manifestation of waste heterogeneity within a tank is that the larger the waste sample taken from a tank, the more representative that sample will be to the mean value for that waste type. The waste rate variability quantitates that relationship. It means that the smaller the sample of waste in an assay, the less representative that assay will be for tha tank contents and therefore a larger margin will occur for comparison of that assay to the HDW estimates. Conversely, the larger the amount of waste sampled, the better it will represent the tank's waste and the smaller will be the margin for HDW estimate comparisons.

There are fourteen tanks in S and SX Farms that hold nearly all of the R1 sludge, averaging 75 kgal each. Thus, each tank's sludge represents about two quarters worth of accumulation, and the variability is $12 \%$, ranging trom $10-16 \%$ depending on exactly how much sludge is in a given tank. 
WHC-SD-WM-ER-3 13, Rev. 1

Most of the R2 waste sludge is on average distributed $30 \mathrm{kgal}$ each among 7 tanks. At $30 \mathrm{kgal}$, the variability will be $13 \%$, and will range from $10-16 \%$ for that set of tanks as well. It is interesting to note that despite the very different Redox campaigns, the waste rate variabilities are very similar.

There are two basic parameters from this variability analysis; a waste rate variability and a waste rate trend. The waste rate variability represents a dilution of all species while the waste rate trend does not change the chemical composition at all, since chemicals added remain proportional to waste volume. On the other hand, there will be a bias in the radionuclide concentration through a campaign as a result of the waste rate trend. Radionuclides will be more dilute early in the campaign and more concentrated late in the campaign. Thus, there is an extra source of variability for radionuclides within each campaign that is tied to the waste rate trend parameter.

For example, the waste rate trend for $\mathrm{R} 1$ is $\pm 73 \%$ of the mean over the campaign, which places an effective RSD for the radionuclides at $\pm 50 \%$. Thus, while the chemical cornposition variability for these tanks is within an RSD of $\pm 12 \%$, the radionuclides vary with an RSD of $\pm 50 \%$.

Quantification of Transaction Variability

There are three contributions to transaction variability; evaporator blending, concentrate carryover, and of course, inaccurate transaction information. As regards to inaccurate information, it is not possible to derive meaningful uncertainty estimates about what is not known. Therefore, variability estimates are only possible for the first two contributions.

Evaporator blending and concentrate carryover are now both approximations used within the HDW model. Evaporator blending assumes that all of the waste feed for a given time can be blended together and reduced in volume as a biend and then transferred to a bottoms receiver. In reality, this process was continuous feed and continuous volume reduction.

Concentrate carryover is an approximation within the HDW model whereby all liquids that are removed and recycled to the evaporator from a bottoms receiver are assumed to be homogeneous mixtures of the entire concentrate inventory of each tank. This approximation is valid for dilute wastes but increasingly invalid as wastes are concentrated. That is, waste concentrates are returned to the tariks from the evaporator and allowed to cool, sediment, and gel. Then, residual liquid is removed from these tanks and often reblended and further concentrated. The HDW model allows concentrated waste to be "carried over" into later receivers because of its assumptions and limitations. This represents a second major source of variability within the model, but it only affects concentrates.

Although these arguments provide a basis for transaction variability esimates, the task is not yet completed and therefore are not yet included in HDW Rev. 3 estimates.

\section{Summary}

The HDW Rev. 3 estimates are the latest in a developing model of the tank waste inventories at Hanford. The HDW model variability estimates are not yet complete and the comparison of HDW estimates with analytical assays is also in progress. Both of these tasks are ongoing and represent the "bottom line" for the model validity.

Note, though, that comparison of HDW model results with assay data is more complex than just comparing one estimate with another. To derive a tank inventory from assay data for waste samples from within a tank is not a trivial task in and of itself. The extremely heterogeneous wastes within each tank make representative sampling problematic and this is compounded by limited access to the tank waste. Therefore, when comparing inventory estimates based on waste assays with the HDW model, one is actually comparing one model with another model and both models have significant uncertainties. Therefore, comparisons are often more effective if they are made among tank groups with similar process histories. Such grouping strategies can be very important in comparisons between assay data and HDW predictions. 
Appendix C.

TLM Working Spreadsheet

May 1996

The TLM (Tank Layer Model) is a volumetric and chronological description of tank inventory based on the HDW sludges and salt cakes. Each solids layer is attributed to a particular waste addition or process, and any solids layers that have unknown origin are assigned as such and contribute to the uncertainty of that tank's inventory. Many of these unknown layers are assigned as per the history of each tank and such assignments are included in the TLM table in parentheses. The TLM for each tank simply associates layers of solids within each tank with a waste addition or a process campaign. Each tank's history is summarized by rows and its primary waste additions are all indicated.

The bolded entry in the Pred. layer column is the volume in kgal of each residual layer and the Layer Type column has information on the HDW assignment for that layer. This is the information that is used in WSTRS, which adds TLM solids layers to each tank accordingly. These result, then, also appear in the SMMTLM tables in App. D. The TLM working spreadsheets are grouped by quadrant, which is a roughly geographical grouping of tanks that has been useful in the HDW model development.

The level discrepancies between the HDW Model-TLM and the Hanion report are listed at the end of the appendix. These are given for volume differences greater than $10 \mathrm{kgals}$. Volume differences greater that 50 $\mathrm{kgais}$ were changed in the HDW Model and the new value is listed. This is further described in the Approach section (TLM) of the main text.

NE Quadrant (A, AX, B, BX, BY, C)

Table C1. TLM Working Spreadsheet Column Descriptions.

\begin{tabular}{l|l}
\hline Column Headings & Descriptions \\
\hline Tank & tank number \\
\hline Year & year of transaction \\
\hline Otr & quarter of transaction \\
\hline Meas. solids & reported solids from Anderson-91 in kgal \\
\hline Solids change & $\begin{array}{l}\text { calculated solids based on primary fill record or difference } \\
\text { between solids records }\end{array}$ \\
\hline Pred. Jayer & kgal predicted layer now in tank \\
\hline Layer type & Defined Waste Type for that layer \\
\hline Waste volume & $\begin{array}{l}\text { summation of primary waste additions calculated for this } \\
\text { time period }\end{array}$ \\
\hline Comments & various details of each calculation
\end{tabular}




\begin{tabular}{|c|c|c|c|c|c|c|c|c|}
\hline Tank & Year & Qtr & $\begin{array}{l}\text { Meas. } \\
\text { solids }\end{array}$ & $\begin{array}{c}\text { Solids } \\
\text { change }\end{array}$ & Pred laver & Layer type & $\begin{array}{c}\text { Waste } \\
\text { volume }\end{array}$ & comments \\
\hline C-101 & 1946 & 4 & & 190 & 3 & MW & 1590 & 12 vol \% \\
\hline C-101 & 1953 & 4 & & 30 & 30 & UR & 1055 & $2.8 \mathrm{vol} \%$ \\
\hline$\overline{\mathbf{C}-101}$ & 1957 & 4 & 0 & .220 & & & & sluicing tank \\
\hline C.-101 & 1958 & 1 & $9 \overline{8}$ & & 28 & (CWP1) & & ignore, unk assign to CWP1, tank drawn to 61 \\
\hline C-101 & 1960 & 4 & & 2 & 2 & CWP1 & 19 & B.1 vol \% \\
\hline C-101 & 1962 & 2 & & 19 & 19 & CWP2 & 637 & 2.90 vol \% \\
\hline C.101 & 1963 & 2 & 109 & 88 & & & & unk gain \\
\hline C-101 & 1965 & 2 & & $\mathbf{0}$ & & $\overline{D W}$ & 28 & 1 vol $\%$ \\
\hline C-101 & 1965 & 2 & 51 & .58 & & & & unk loss, sent to $B$ farm \\
\hline C-101 & $1 \overline{969}$ & $\overline{3}$ & 106 & 55 & & _. & & washed out \\
\hline C.101 & 1969 & 4 & 125 & 19 & & & & unk gain \\
\hline C-101 & 1970 & $i$ & 87 & -38 & & & & unk loss \\
\hline C-101 & 1970 & 3 & 81 & & & & & \\
\hline $\bar{c}-101$ & 1974 & 4 & 62 & & & & & ignore \\
\hline C-101 & 1976 & 2 & 73 & & & & & \\
\hline C-101 & 1993 & $\overline{2}$ & 88 & & & & & \\
\hline C.101 & 1993 & 4 & 88 & 1 & 6 & (CWP2) & & unk gain, assign to CWP2 \\
\hline C-102 & 1952 & $\overline{4}$ & & & & MW & & \\
\hline C-102 & 1954 & 1 & & 5 & 5 & $M W$ & -530 & \begin{tabular}{|l} 
SL C-103 \\
smail sludge heel
\end{tabular} \\
\hline C-102 & 1954 & $i$ & & 16 & 16 & UR & 552 & 2.8 vol $\dot{\%}$ \\
\hline $\mathrm{c}-102$ & 1958 & 1 & 98 & & & & 552 & ignore Questionable stat record \\
\hline C-102 & 1960 & 4 & & 33 & 33 & CWP1 & 401 & $8.10 \mathrm{vol} \%$ \\
\hline C- 102 & 1965 & 2 & 238 & $\overline{184}$ & & & & unk gain, AEC from C-105 and C-108 \\
\hline C- 102 & 1966 & $i$ & & 200 & & CWP2 & 6892 & 2.9 vol \% \\
\hline C-102 & 1966 & 2 & & 26 & 26 & TH1 1 & 443 & 5.8 vol $\%$ \\
\hline$\overline{\mathbf{C}}-102$ & 1968 & 3 & & 125 & 252 & CWP2 & 4320 & 2.9 vol $\%$ \\
\hline$\underline{\mathbf{C}} \cdot \mathbf{1 0 2}$ & 1968 & 4 & 307 & & & & & still settling \\
\hline$\overline{\mathbf{C}}-10 \overline{2}$ & 1969 & 1 & $\overline{332}$ & .257 & & & & numerous xfers-wash out \\
\hline C.102 & 1969 & 2 & & 25 & & CWP2 & 872 & 2.9 vol $\%$ \\
\hline C. 102 & 1969 & 2 & 369 & 12 & & & & unk gain, REC from C-110 and C-104 \\
\hline C-102 & 1969 & 3 & & 14 & & OWw3 & 2262 & 0.6 vol\% \\
\hline c- 102 & 1969 & 3 & 351 & -18 & & & & unk loss \\
\hline C.102 & 1969 & 4 & & 16 & & CWPIZR & 550 & 2.9 vol $\%$ \\
\hline C-102 & 1969 & 4 & 345 & -22 & 13 & CWPIZ & & washed out \\
\hline C.102 & 1970 & i & 326 & & & & & \\
\hline c-102 & 1970 & 2 & 312 & & & & & \\
\hline c-102 & 1970 & 3 & 299 & & & & & \\
\hline C-102 & 1974 & 4 & 332 & & & & & \\
\hline C. 102 & 1976 & 1 & 62 & & & & & ignore \\
\hline C. 102 & $19 \overline{6}$ & 2 & 431 & & & & & \\
\hline
\end{tabular}




\begin{tabular}{|c|c|c|c|c|c|c|c|c|}
\hline Tank & Year & atr & $\begin{array}{l}\text { Meas. } \\
\text { solids }\end{array}$ & $\begin{array}{c}\text { Solids } \\
\text { change }\end{array}$ & Pred layer & Layer type & $\begin{array}{c}\text { Waste } \\
\text { volumb }\end{array}$ & comments \\
\hline $\bar{C}-102$ & 1993 & 2 & 423 & & & & & \\
\hline$c-102$ & 1993 & 4 & 423 & 78 & 78 & (CWP2) & & $\begin{array}{l}\text { unk gain. unk assign to CWP2. pic shows studge wi } \\
\text { challow pools liquid }\end{array}$ \\
\hline$\overline{C-103}$ & 1952 & : & & & & & 1060 & SL C-102, C-101 \\
\hline C-103 & 1953 & i & & & & & -1687 & SL UR \\
\hline C-103 & 1953 & 2 & & & & & & Prob MW left after sluicing \\
\hline C-103 & 1953 & 3 & & & & & & UR from C-101 \\
\hline C-103 & 1960 & 4 & & 39 & & $\overline{C W P 1}$ & 479 & 8.1 vol $\%$ \\
\hline c-103 & 1967 & 3 & 35 & -4 & 37 & CWP1 & & Unk loss \\
\hline c- 103 & 1970 & $\overline{\underline{2}}$ & $\overline{85}$ & 50 & & & & unk gain, REC from BX-101 \\
\hline C. 103 & 1970 & 3 & 99 & 25 & 25 & AR & & secondary transfer of AR solids from C-106 \\
\hline$\overline{\mathbf{c}}-10 \overline{3}$ & $197 !$ & 1 & 92 & -7 & & & & unk loss to $\mathrm{C}-106$ \\
\hline $\bar{c}-103$ & $197 i$ & 3 & 90 & & & & & \\
\hline$\overline{c-103}$ & 1971 & 4 & 102 & & & & & ignore \\
\hline$\overline{C-103}$ & 1972 & 3 & 90 & & & & & 年 \\
\hline $\bar{c} \cdot 10 \overline{3}$ & 1974 & 4 & 73 & -19 & & & & some xfer to C-104? \\
\hline c.103 & 1977 & 1 & $6 \overline{8}$ & -5 & & & & washed out \\
\hline C-103 & 1977 & 3 & 150 & & & & & solids continue to increase \\
\hline c-103 & 1977 & 4 & 153 & 85 & & & & unk gain, Evap B plant recovery \\
\hline C-103 & 1978 & 1 & 164 & 11. & & & & unk gain, REC from C-107 \\
\hline C-103 & 1978 & 2 & 167 & & & & & solids continue to increase \\
\hline $\mathrm{C}-103$ & 1978 & $\frac{7}{3}$ & 175 & 11 & & & & unk gain \\
\hline$c-103$ & 1393 & $\overline{2}$ & 82 & & & & & \\
\hline \multirow[t]{2}{*}{$\mathrm{c}-103$} & 1993 & $\overline{4}$ & 62 & -113 & & & & unk loss, Prob CWP1 or $\bar{A} \bar{A}$ \\
\hline & & & & & & & & Note: unaccounted solids from core $30 \mathrm{kgal}$ \\
\hline$\overline{c-104}$ & 1947 & 4 & & 190 & 3 & $\mathbf{M W}$ & 1590 & 12 vol \% \\
\hline C-104 & 1953 & 2 & & & & & -530 & SLC- 106 \\
\hline c. 104 & 1955 & 2 & 0 & -190 & & & & \\
\hline c. 104 & 1956 & 1 & 45 & & & & & ignore \\
\hline C-104 & 1957 & 3 & 46 & & & & & ignore \\
\hline C-104 & 1958 & $\overline{2}$ & & 103 & 98 & CWP1 & 1269 & 8.1 vol $\%$ \\
\hline $\mathrm{c}-104$ & 1963 & 2 & 101 & .2 & & & & unknown loss \\
\hline c.104 & 1965 & 2 & 90 & -11 & & & & unknown loss \\
\hline$c-104$ & 1970 & 1 & & 16 & & CWP2 & 535 & 2.9 vol $\%$ \\
\hline c-104 & 1970 & 1 & 96 & -10 & & & & unknown loss \\
\hline$\overline{c-104}$ & 1970 & 2 & 149 & & & & & ignore \\
\hline$\overline{C-104}$ & 1970 & 3 & & 17 & & $\overline{\text { CWP2 }}$ & 581 & $2.9 \mathrm{vol} \%$ \\
\hline C-104 & 1970 & 3 & & 29 & & THL & 499 & 5.8 vol \\
\hline$\vec{c}:: i$ & 1970 & 3 & 92 & -50 & & & & $\therefore$ ignore \\
\hline $\bar{c}-104$ & 1970 & 4 & & $\overline{8}$ & & CWP2 & 279 & $2.9 \mathrm{vol} \%$ \\
\hline
\end{tabular}




\begin{tabular}{|c|c|c|c|c|c|c|c|c|}
\hline C. 104 & 1970 & 4 & & 24 & 24 & TH70 & 413 & $5.8 \mathrm{vol} \%$ \\
\hline$\overline{\mathbf{c}}-\overline{104}$ & 1970 & 4 & 132 & $\overline{4}$ & & & & unk gian, probably CWP uncertainty \\
\hline C-104 & 1971 & 1 & & 5 & & CWP2 & 189 & 2.9 vol \% \\
\hline C-104 & 1971 & $\overline{4}$ & 175 & .22 & & & & unknown loss \\
\hline C-104. & 1972 & 1 & & 11 & & CWP2 & 364 & 2.9 vol $\%$ \\
\hline C-104 & 1972 & 1 & 188 & 2 & & & & CWP2 \\
\hline C-104. & $1 \overline{972}$ & 2 & & 8 & 66 & CWP2 & 281 & $2 . \overline{9}$ vol $\%$ \\
\hline$\overline{\mathbf{C}}-\overline{104}$ & 1972 & 2 & $1 \overline{98}$ & $\overline{2}$ & & & & CWP2 \\
\hline C.104 & $1 \overline{972}$ & 3 & & 31 & 31 & oww3 & 5163 & 0.6 vol\% \\
\hline C-104 & 1973 & 4 & 274 & & & & & \\
\hline C.104 & 1974 & 1 & & 1 & & P2 & 27 & 3.9 vol $\%$ \\
\hline C-104 & $1 \overline{974}$ & 1 & & 1 & & $\overline{\mathrm{DW}}$ & 90 & 1 vol\% \\
\hline c-104 & 1974 & 4 & & 1 & & $\mathrm{PL}$ & 37 & 2.2 vol $\%$ \\
\hline C-104 & 1974 & 4 & 235 & -42 & & & & Unk loss \\
\hline C-104 & 1975 & 2 & & 1 & 1 & $P 2$ & 33 & 3.9 vol $\%$ \\
\hline C-104 & 1976 & $\overline{2}$ & & 6 & 6 & $\mathbf{P L}$ & 261 & $2 . \overline{2}$ vol $\%$ \\
\hline C- 104 & 1976 & 2 & & 7 & & SRR & & SAR solids from A-101 \\
\hline C-104 & 1976 & 4 & 246 & & & & & \\
\hline C-104 & 1977 & 1 & 268 & & & & & \\
\hline C-104 & 1977 & 3 & 274 & & & & & $\div$ \\
\hline c. 104 & 1977 & 4 & 290 & 44 & 11 & (S̄ÁA) & & unk gain Purex Waste Storege??, unk assign to SRR \\
\hline $\mathbf{C - 1 0 5}$ & 1956 & 2 & 15 & 0 & & & & \\
\hline $\bar{c} \cdot \overline{105}$ & 1960 & 2 & & 255 & $\mathbf{8 1}$ & CWP1 & 3151 & 8.1 vol $\%$ \\
\hline C-105 & 1965 & 2 & 109 & & & & & \\
\hline C-105 & 1966 & 4 & & & & & 250 & SL A-103 \\
\hline C-105 & $1 \overline{9} 6$ & 4 & 98 & .174 & & & & unk loss \\
\hline$\overline{\mathbf{C}}-10 \overline{5}$ & $1 \overline{9} 69$ & $1]$ & 109 & & & & & \\
\hline
\end{tabular}




\begin{tabular}{|c|c|c|c|c|c|c|c|c|}
\hline Tank & Year & Qtr & $\begin{array}{c}\text { Meas. } \\
\text { solids }\end{array}$ & $\begin{array}{c}\text { Solids } \\
\text { change }\end{array}$ & Pred layer & Layer type & $\begin{array}{r}\text { Waste } \\
\text { volume }\end{array}$ & comments \\
\hline C- $-10 \overline{5}$ & 1969 & 2 & 99 & 3 & 3 & (CWP1) & & unk gain, assign to CWP1 \\
\hline $\bar{C}-105$ & 1969 & 3 & 139 & & & & & various rec eventually washed out \\
\hline $\mathrm{C}-105$ & 1969 & 4 & 233 & & & & & various rec eventually washed out \\
\hline $\bar{c}-10 \bar{b}$ & 1970 & 1 & 123 & & & & & various rec eventually washed out \\
\hline c-105 & 1970 & $\underline{2}$ & 136 & & & & & various rec eventually washed out \\
\hline C- 105 & 1970 & 3 & 139 & & & & & various rec eventually washed out \\
\hline C. 105 & 1970 & 4 & 156 & & & & & various rec eventually washed out \\
\hline C. 105 & 1971 & 1 & 162 & & & & & various rec eventually washed out \\
\hline c-105 & 1971 & 2 & 164 & & & & & various rec eventually washed out \\
\hline $\mathrm{C}-105$ & 1972 & 1 & 98 & & & & & various rec eventually washed out \\
\hline C-105 & 1973 & $\overrightarrow{2}$ & 112 & & & & & unknown loss \\
\hline$\overline{c-105}$ & 1974 & 3 & & & & & 48 & SL A-103, A-102 \\
\hline C-105 & 1974 & 4 & 139 & & & & & \\
\hline C-105 & 1977 & 1 & 167 & 68 & & & & unk gain \\
\hline C-105 & 1977 & 3 & & & & & 39 & SL AX-103, AX-101, AX-102 \\
\hline C.105 & 1979 & $\underline{3}$ & 150 & -17 & & & & unk loss \\
\hline $\bar{c} \cdot \overline{105}$ & 1993 & $\overline{2}$ & $15 \overline{0}$ & & & & & \\
\hline $\bar{c}-105$ & $19 \overline{993}$ & 4 & 150 & & E1 & (CWP1) & & unk assign to CWP1 \\
\hline$\overline{\mathrm{C}-106}$ & 1953 & 2 & & & & & 1060 & SL C-104, C-1105 \\
\hline C.106 & 1954 & 1 & & & & & -1906 & SL UR \\
\hline C.106 & 1954 & 3 & & 15 & & UR & 538 & 2.8 vol $\overline{\%}$ \\
\hline c-106 & 1955 & 1 & 12 & & $1 \overline{5}$ & UR & & ignore \\
\hline C-106. & 1957 & 4 & 29 & 14 & & $\overline{\mathbf{P}}$ & & $x$ fer from $A-101$ and $A-102$ \\
\hline C-106 & 1960 & 2 & & 34 & 34 & CWP1 & 420 & 8.1 vol $\%$ \\
\hline$\overline{\mathrm{C}}-\overline{106}$ & 1963 & 2 & 24 & & & & & ignore \\
\hline $\bar{c} \cdot 106$ & 1965 & 1 & & 0 & & DW & 36 & 1 vol\% \\
\hline $\mathrm{C} \cdot 106$ & 1965 & $\overline{2}$ & 62 & -1 & & & & \\
\hline c-106 & 1969 & 4 & & 11 & & AR & 276 & 4.0 vol\% \\
\hline C.106 & 1969 & 4 & 57 & -16 & & & & unk loss \\
\hline C-106 & 1970 & 3 & & 17 & & AR & 432 & $4.0 \mathrm{vol} \%$ \\
\hline C-106 & 1970 & $\overline{3}$ & $\overline{79}$ & 5 & & & & unk gain \\
\hline C-106 & 1970 & 4 & & 14 & & $\overline{A A}$ & 311 & 4.0 vol $\%$ \\
\hline C-106 & 1970 & 4 & 145 & 52 & & & & unk gain \\
\hline c.106 & $19 \overline{1}$ & 1 & 150 & & & & & \\
\hline C-106 & 1972 & 2 & & 6 & & AR & 151 & $4.0 \mathrm{vol} \%$ \\
\hline C.106 & 1972 & 2 & 125 & -26 & 64 & $\bar{A} \bar{A}$ & & unk loss, more AR cascaded from $\mathrm{C}=103$ \\
\hline C-106 & 1974 & 4 & & 20 & & $\overline{B L}$ & 789 & $2.50 \mathrm{vol} \%$ \\
\hline$\overline{C-106}$ & 1974 & 4 & 106 & +39 & & & & unk loss \\
\hline C-106 & 1976 & 2 & & $5 \overline{4}$ & 20 & BL & 2148 & 2.50 vol $\%$ \\
\hline C.106 & 1977 & 1 & 145 & & & & & \\
\hline
\end{tabular}




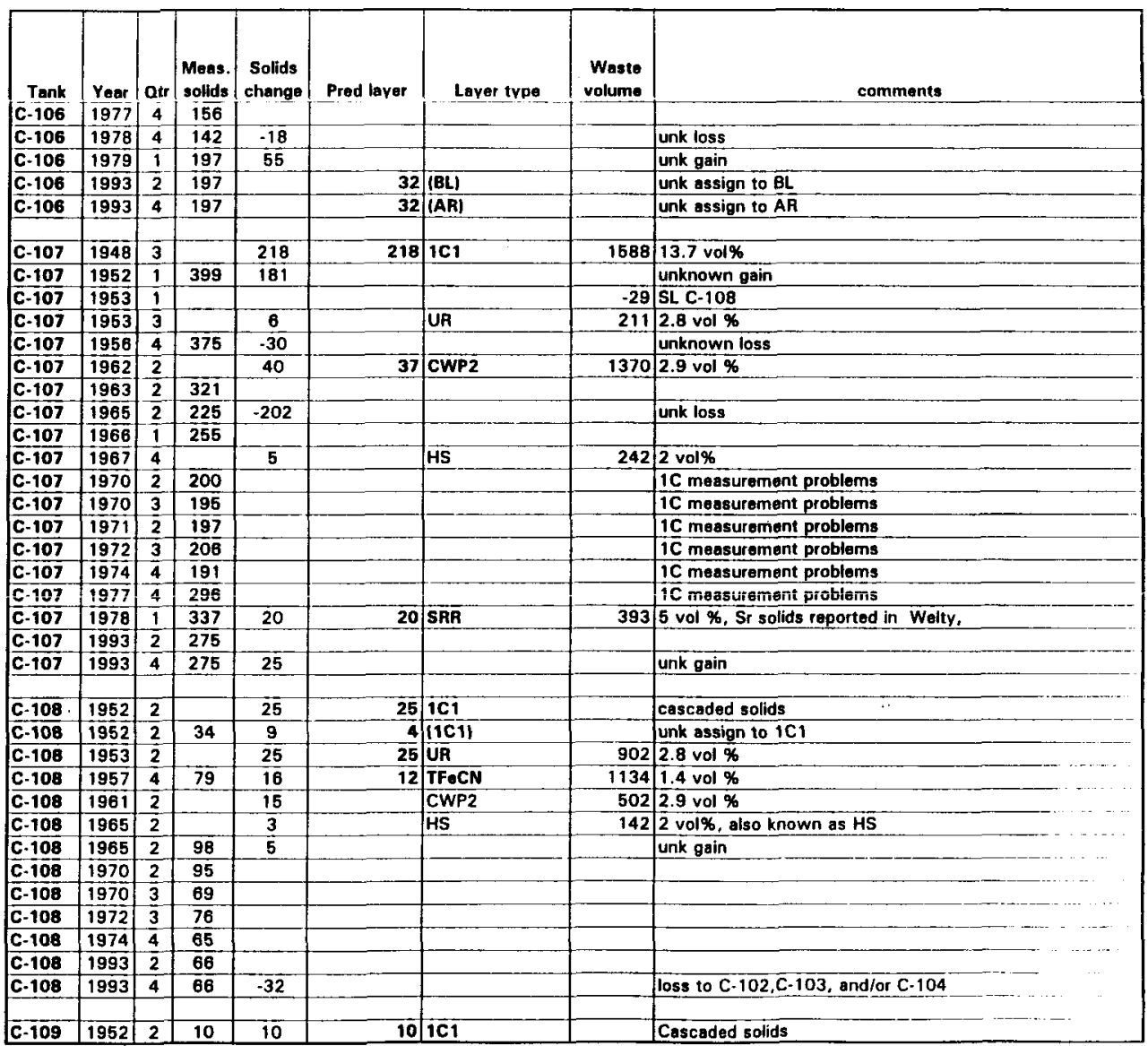




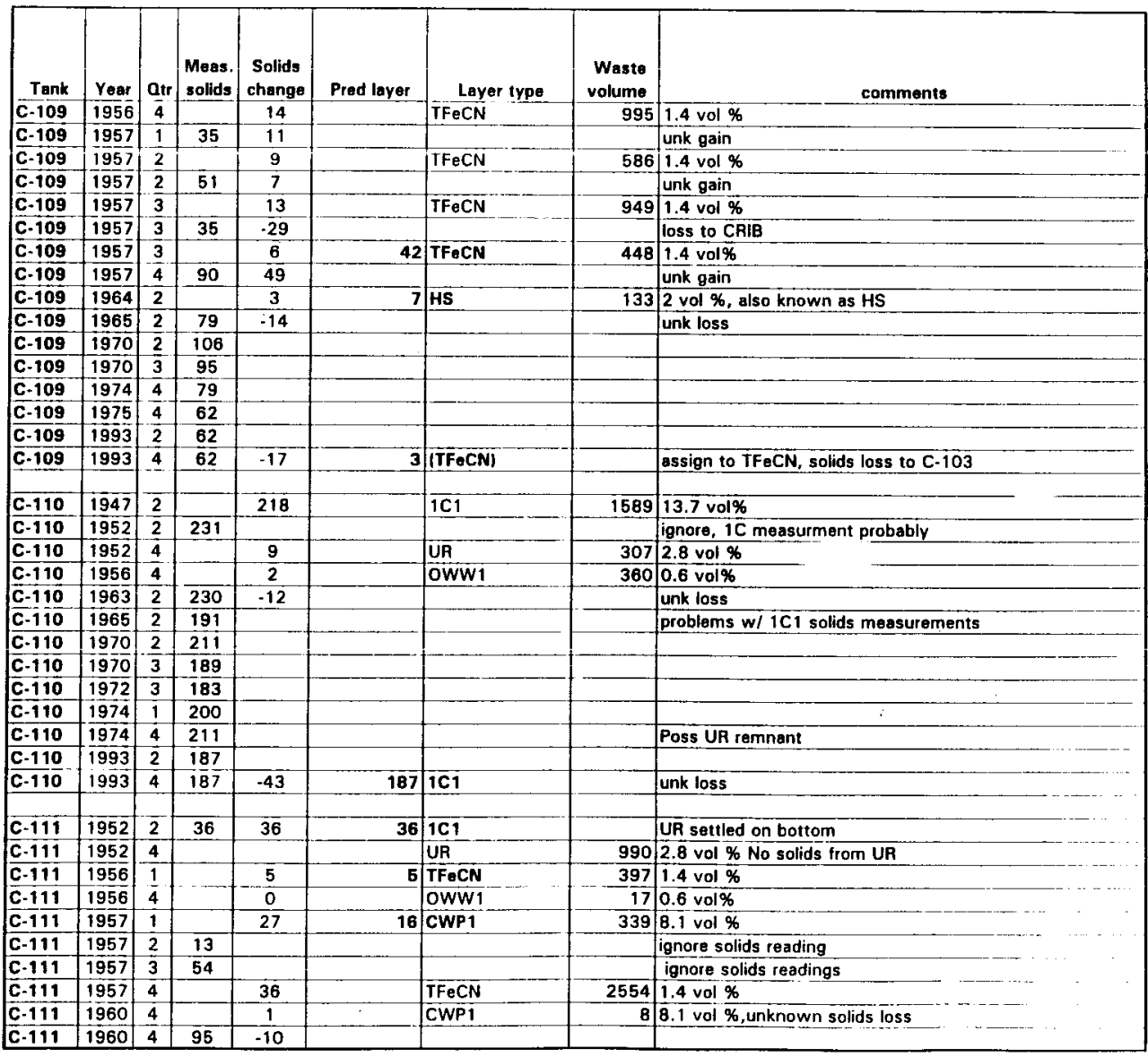




\begin{tabular}{|c|c|c|c|c|c|c|c|c|}
\hline Tank & Year & atr & $\begin{array}{c}\text { Meas. } \\
\text { solids }\end{array}$ & $\begin{array}{c}\text { Solids } \\
\text { change }\end{array}$ & Pred layer & Layer type & $\begin{array}{c}\text { Waste } \\
\text { volume }\end{array}$ & comments \\
\hline c-111 & 1964 & $\underline{2}$ & & 5 & & HS & 228 & 2 vol\% \\
\hline C.111 & 1965 & 2 & 81 & & & & & unknown loss \\
\hline $\mathrm{C}-111$ & 1970 & 2 & 96 & & & & & \\
\hline C-111 & 1970 & 3 & 92 & & & & & washed out \\
\hline C.111 & 1972 & 2 & 76 & & & & & \\
\hline C-111 & 1974 & 4 & 62 & & & & & \\
\hline c-111 & 1993 & $\overline{2}$ & 57 & & & & & \\
\hline c-111 & 1993 & 4 & 57 & .43 & & & & $\begin{array}{l}\text { solids loss to C-104 and C-103, lost } 12 \mathrm{HS}, 29 \mathrm{TFeCN} \text {, and } \\
11 \mathrm{CWP}\end{array}$ \\
\hline C-112 & $\overline{1952}$ & 2 & 15 & 15 & & $\overline{1 \mathrm{C1}}$ & & \\
\hline $\bar{c}-112$ & 1954 & 3 & & & & UR & 321 & $5.0 \mathrm{vol} \%$. No solids from UA? \\
\hline C-112 & 1955 & 2 & 17 & & & & & ignore \\
\hline c-112 & 1956 & $\overline{4}$ & & $\overline{25}$ & & IFeCN & 1811 & 1.4 vol $\%$ \\
\hline C-112 & 1956 & 4 & 39 & -1 & & & & unknown loss \\
\hline C-112 & 1957 & $\overline{2}$ & 21 & & & & & ignore \\
\hline $\bar{c}-11 \overline{2}$ & 1957 & 3 & 39 & & & & & ignore solids volume \\
\hline $\bar{C}-112$ & 1957 & 4 & & 38 & 68 & IFoCN & 2728 & 1.4 vol $\%$ \\
\hline $\bar{c}-11 \overline{2}$ & 1958 & 1. & 48 & & & & & ignore \\
\hline $\bar{c} \cdot \overline{112}$ & 1960 & 4 & & $\overline{13}$ & 13 & CWP1 & 166 & 8.1 vol $\%$ \\
\hline c-112 & 1961 & 2 & & 3 & 3 & CWP2 & 88 & 2.9 vol \% \\
\hline C.112 & 1962 & 2 & & $i$ & 9 & $\mu \mathrm{s}$ & 53 & 2 yo! $\%$ \\
\hline C-112 & 1965 & 2 & 128 & 34 & & & & unknown gain \\
\hline C.112 & 1970 & 2 & 138 & & & & & \\
\hline C.112 & 1970 & 3 & 136 & & & & & - \\
\hline c.112 & 1972 & 3 & 120 & & & & & - \\
\hline c-112 & 1974 & 4 & 128 & & & & & ...... \\
\hline $\bar{c}-\overline{112}$ & 1975 & 4 & 109 & & & & & \\
\hline C-112 & 1993 & 2 & 104 & & & & & \\
\hline C-112 & 1993 & 4 & 104 & -24 & 4 & (TFOCN) & & Unk loss to $\mathrm{C}-103$, unk assign to TFeCN \\
\hline C-201 & 1948 & 1 & & 26 & & $\overline{M W}$ & 220 & $12 \mathrm{vol} \%$ \\
\hline $\bar{c} \cdot 201$ & 1954 & 1 & 0 & -26 & & & & \\
\hline C-201 & 1954 & 4 & & & & & 53 & SL C-204 \\
\hline C-201 & 1955 & 4 & & 1 & 1 & HS & 57 & 2 vol\%, also known as ssw \\
\hline C.201 & 1970 & $\overline{1}$ & 1 & & & & & - . \\
\hline C-201 & 1974 & 4 & $\underline{0}$ & & & & & \\
\hline C.201 & 1993 & 2 & 2 & & & & & \\
\hline c-201 & 1993 & 4 & 2 & 2 & 1 & MW & & MW heel \\
\hline $\mathrm{C}-202$ & $|\overline{1954}|$ & 1 & 0 & 0 & & & & $--\square-\cdots \cdots \cdot+\cdot \cdot$ \\
\hline
\end{tabular}




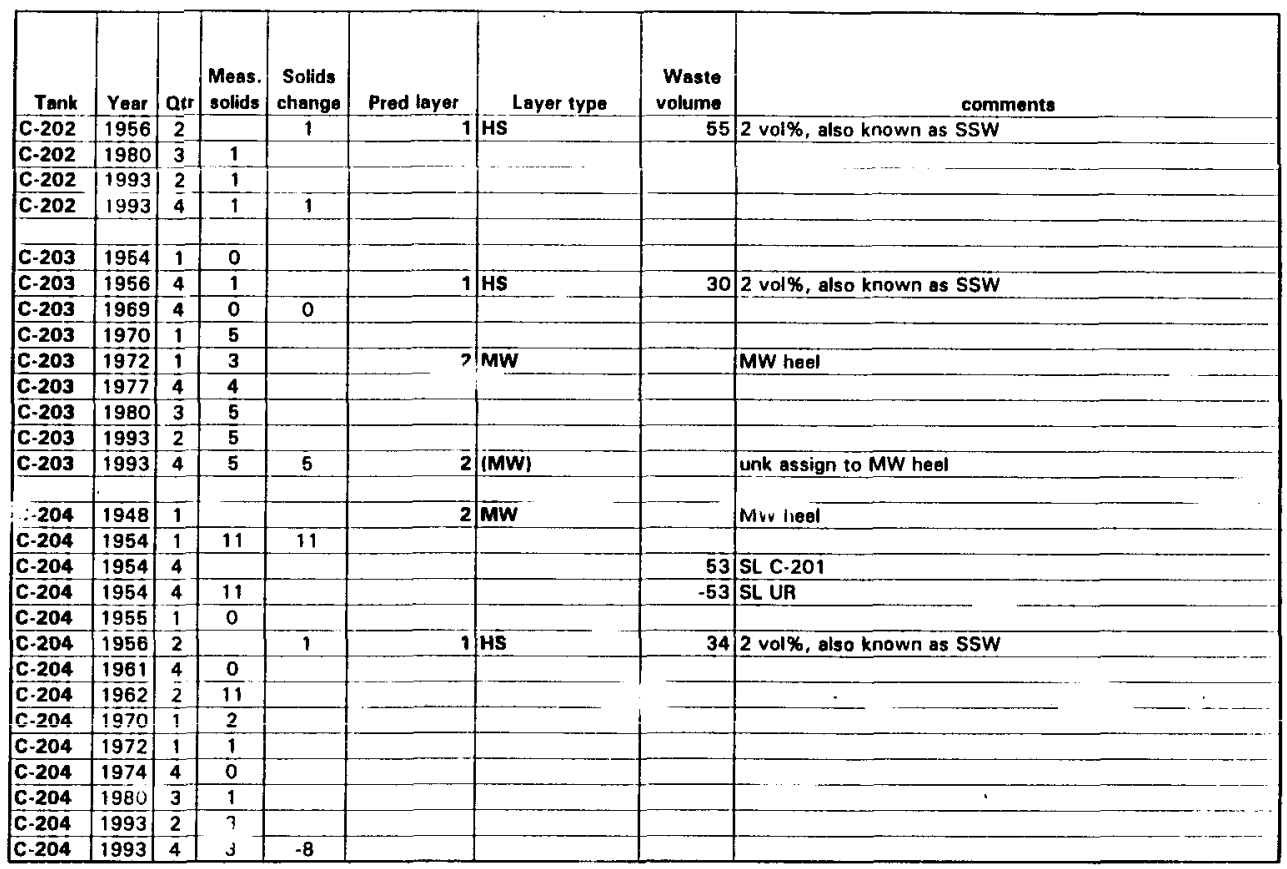




\section{Appendix D.}

\section{SMM / TLM Volumes Tables \\ March 1996}

The SMM (Supematant Mixing Model) provides a description of each tank's free supernatant and supernatant concentrate based on a linear combination of Hanford Defined Waste (HDW) supematants. The output of the SMM is an table whose column are the HDW's and whose rows are the tanks and processes that hold HDW inventory. The fill of the array are composition row vectors for each tank or process and are all given in $\mathrm{kgal}(1 \mathrm{kgal}=1,000 \mathrm{gal})$ of original HDW. The row sum of this table represents a total volume that is usually greater than the actual volume of free supernatant or concentrate within each tank. This difference is because of active evaporation or dilution of waste sometime during its histoly.

The TLM table correspondingly provides composition row vectors for the TLM sludges for each tank. In contrast to the SMM, the row sum of a tank's HDW sludges does equal the total volume of the sludges predicted by the TLM. This value may be still be different from the actual solids level reported for a tank because the salt cakes from later evaporator campaigns are treated as concentrates and therefore predicted by the SMM.

The tank composition table provides a description of each tank's SMM composition in terms of per cent of HDW supernatants in rows that sum to $100 \%$. The HDW distribution table gives per cent distribution of each HDW supernatant in columns summing to $100 \%$.

SMM Rev. 3

TLM Rev. 3

\begin{tabular}{l|l}
\hline \multicolumn{2}{c}{ Table D1. Descriptions of SMM Tables' Columns } \\
\hline Column Headings & Descriptions \\
\hline Columns 2-67 (B-BO) & assigned to Defined Waste Columns \\
\hline Columns 68-71 (BP.BS) & auxiliary waste definitions \\
\hline assume & $\begin{array}{l}\text { original concentration volume of waste from } \\
\text { assumed transactions }\end{array}$ \\
\hline smmvol & $\begin{array}{l}\text { original concentration volume of HDW wastes in the } \\
\text { tank or that went to a secondary process or crib }\end{array}$ \\
\hline supvol & $\begin{array}{l}\text { kgals of supernatant in the tank or that went to } \\
\text { process or crib }\end{array}$ \\
\hline timvol & kgals of TLM residual solids predicted in the tank \\
\hline tankvol & total volume in kgals of waste in the tank \\
\hline traffic & total traffic for a tank or process year to date \\
\hline assume trfc & $\begin{array}{l}\text { total traffic from assumied transactions for a tank or } \\
\text { process year to date }\end{array}$ \\
\hline Max. TOC wt\% & $\begin{array}{l}\text { maximum TOC wt\% experienced by the tank for all } \\
\text { of its history }\end{array}$ \\
\hline date of Max. TOC & date when maximum TOC. wt\% occurred \\
\hline TOC wt\% now & present TOC wt\% in the tank \\
\hline Max. Haz. Index & $\begin{array}{l}\text { maximum Hazard Index experienced by the tank for } \\
\text { all of its history }\end{array}$ \\
\hline Haz. Ind. now & present Hazard Index inow
\end{tabular}




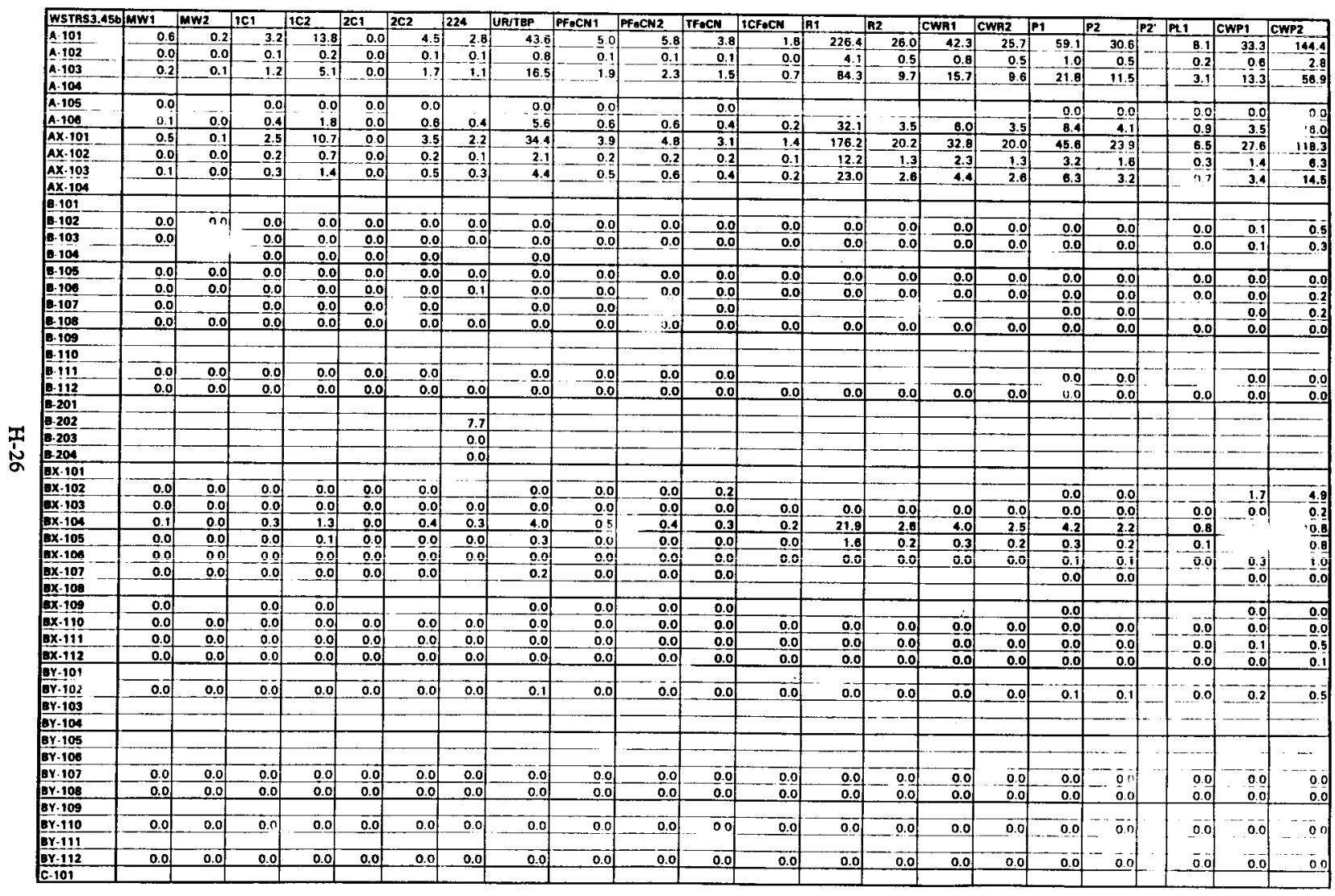




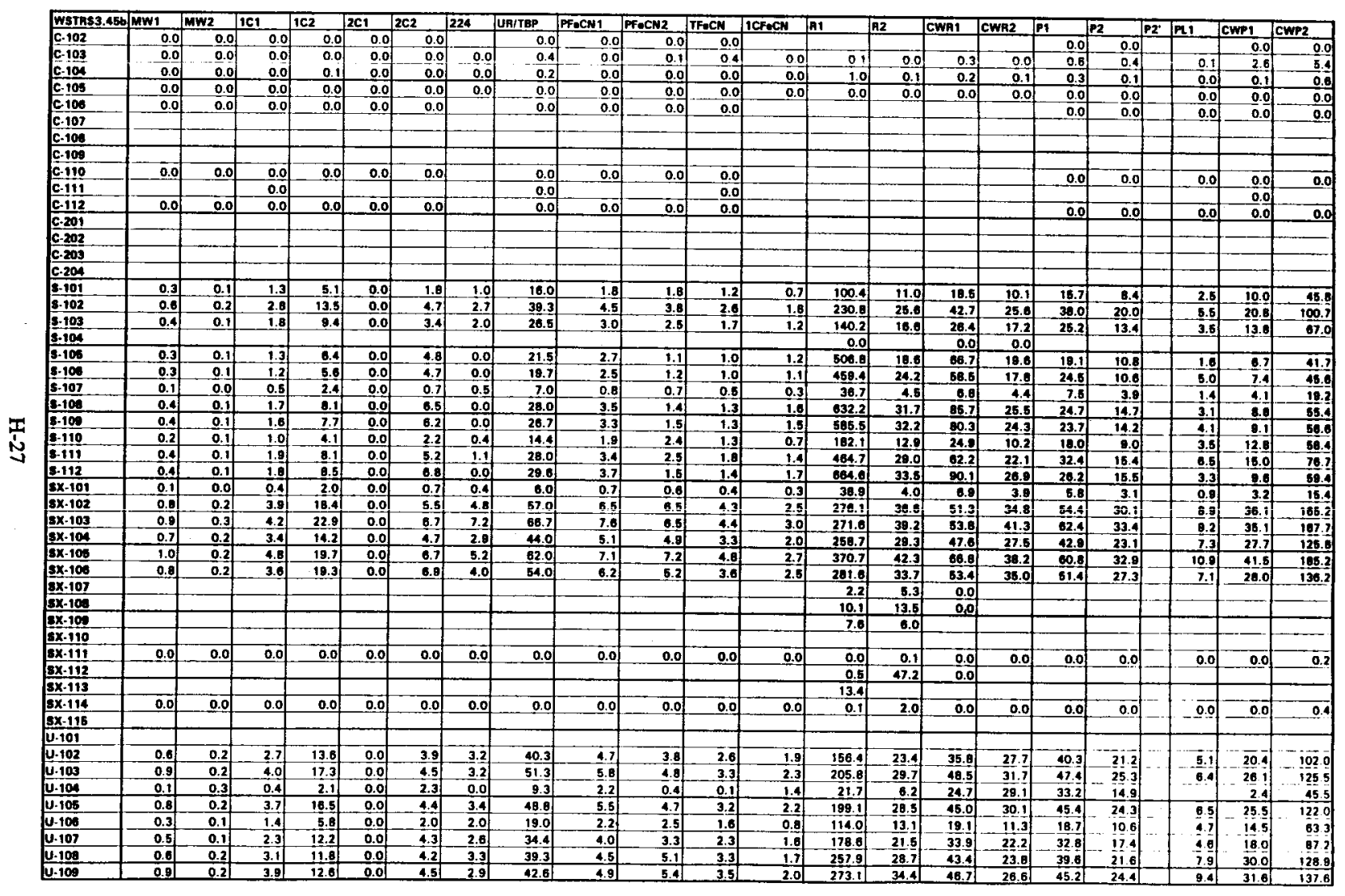




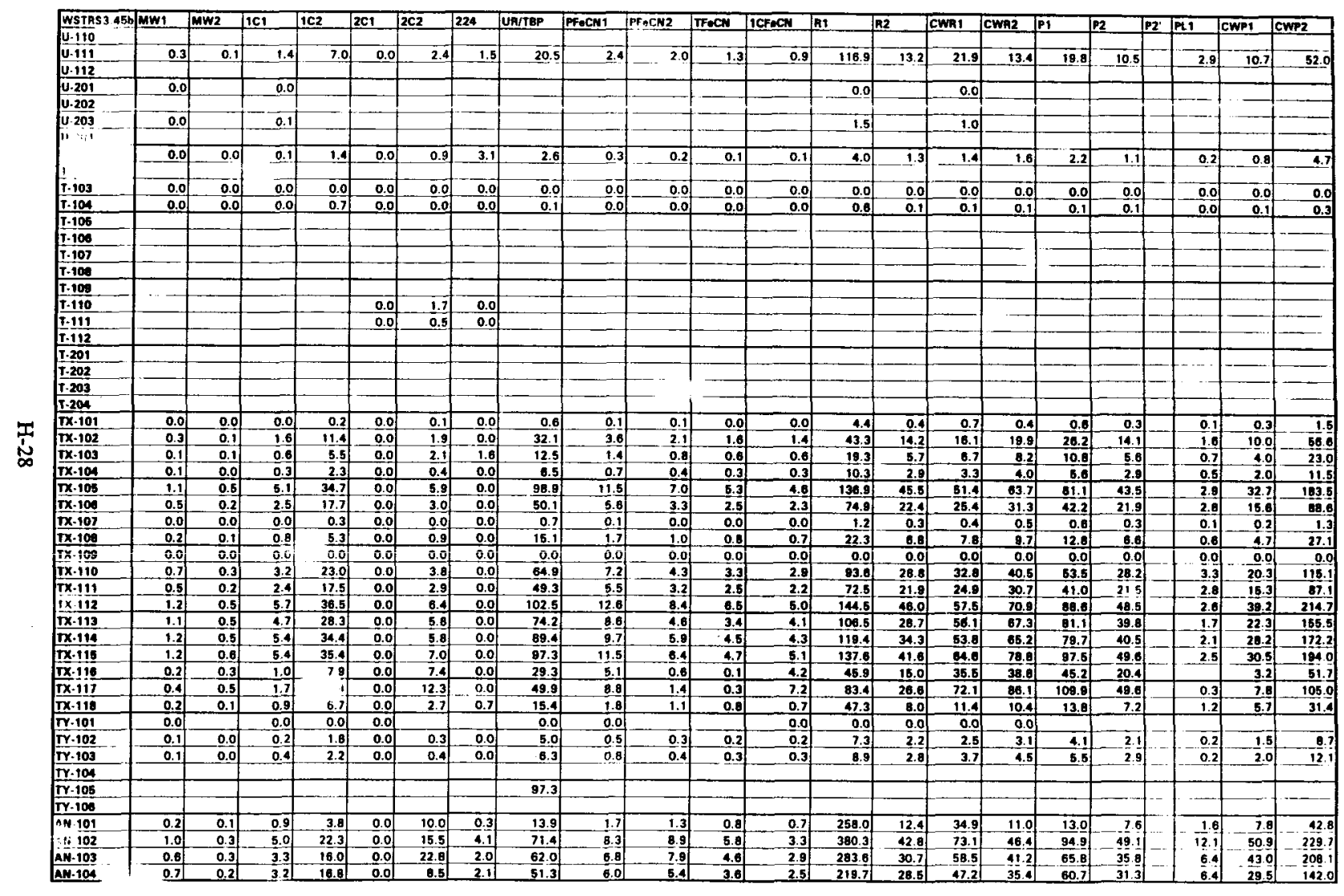




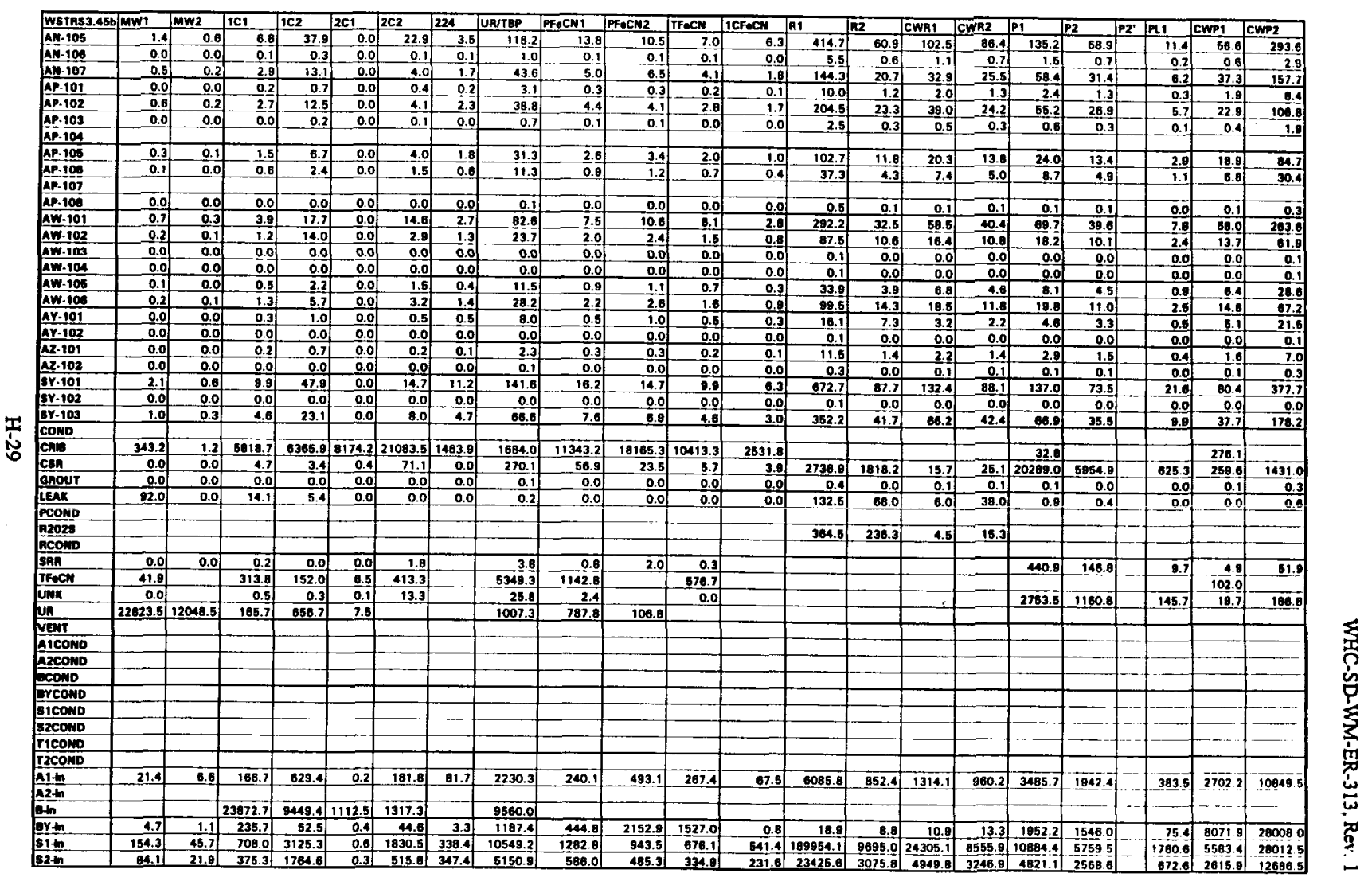




\begin{tabular}{|c|c|c|c|c|c|c|c|c|c|c|c|c|c|c|c|c|c|c|c|c|c|c|}
\hline WSTRS3.456 & mw1 & MW2 & 1C1 & $1 \mathrm{C2}$ & $2 \mathrm{C1}$ & $2 \mathrm{C2}$ & 224 & UA/TBP & PFoCNI & PFoCN2 & TFoCM & TCFoCN & A1 & A2 & cWa1 & CWA2 & P1 & p2 & $\mathbf{P 2}$ & PA1 & cwip1 & CWF 2 \\
\hline$\pi 1+n$ & 1434.8 & & 20847.2 & 10846.9 & 962.5 & & & 9005.8 & & & & 160.5 & & & & & & & & & & \\
\hline $12+n$ & 613.1 & 294.7 & 2813.3 & 19136.2 & 2.2 & 5259.5 & 2.2 & 57788.1 & 8049.4 & 3451.0 & 2500.0 & 3600.1 & 86582.8 & 27489.5 & 39863.7 & 49900.5 & $66 \mathrm{a16.5}$ & 33258.9 & & 1249.0 & 16559.5 & 104431.8 \\
\hline \multicolumn{23}{|l|}{ STATLOSS } \\
\hline B-bot & 0.7 & & 1848.1 & 1143.9 & 76.5 & 384.3 & & 4481.8 & 172.2 & & & & & & & & & & & & & \\
\hline EY.bat & 1.8 & 0.5 & 73.9 & 38.0 & 0.2 & 19.8 & 5.5 & 513.2 & 145.4 & 771.0 & 417.5 & 2.4 & 123.9 & 28.7 & 38.5 & 37.1 & 679.8 & 712.4 & & 159.8 & 3714.8 & 13313.3 \\
\hline \multicolumn{23}{|l|}{ s1-bot } \\
\hline 52.bat & & & & & & & & & & & & & & & & & & & & & & \\
\hline T1-bot & 319.3 & & 1846.8 & 2246.0 & 78.7 & & & 6473.1 & & & & 1033.4 & & & & & & & 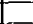 & & & \\
\hline \multicolumn{23}{|l|}{ T2-6ot } \\
\hline \multicolumn{23}{|l|}{ A1-bot } \\
\hline$R-b x$ & 0.0 & 0.0 & 0.7 & 0.6 & 0.0 & 0.1 & & 5.7 & 1.8 & 8.2. & 6.2 & 0.1 & $8534 . \bar{\theta}$ & 6712.3 & 460.1 & 435.3 & 7.6 & 3.7 & & 1.8 & 30.4 & 243.6 \\
\hline expmp & 0.0 & 0.0 & 0.0 & 0.0 & 0.0 & 0.0 & 0.0 & 0.0 & 0.0 & 0.0 & 0.0 & 0.0 & 0.0 & 0.0 & 0.0 & 0.0 & 0.0 & 0.0 & & 0.0 & 0.0 & 0.0 \\
\hline
\end{tabular}




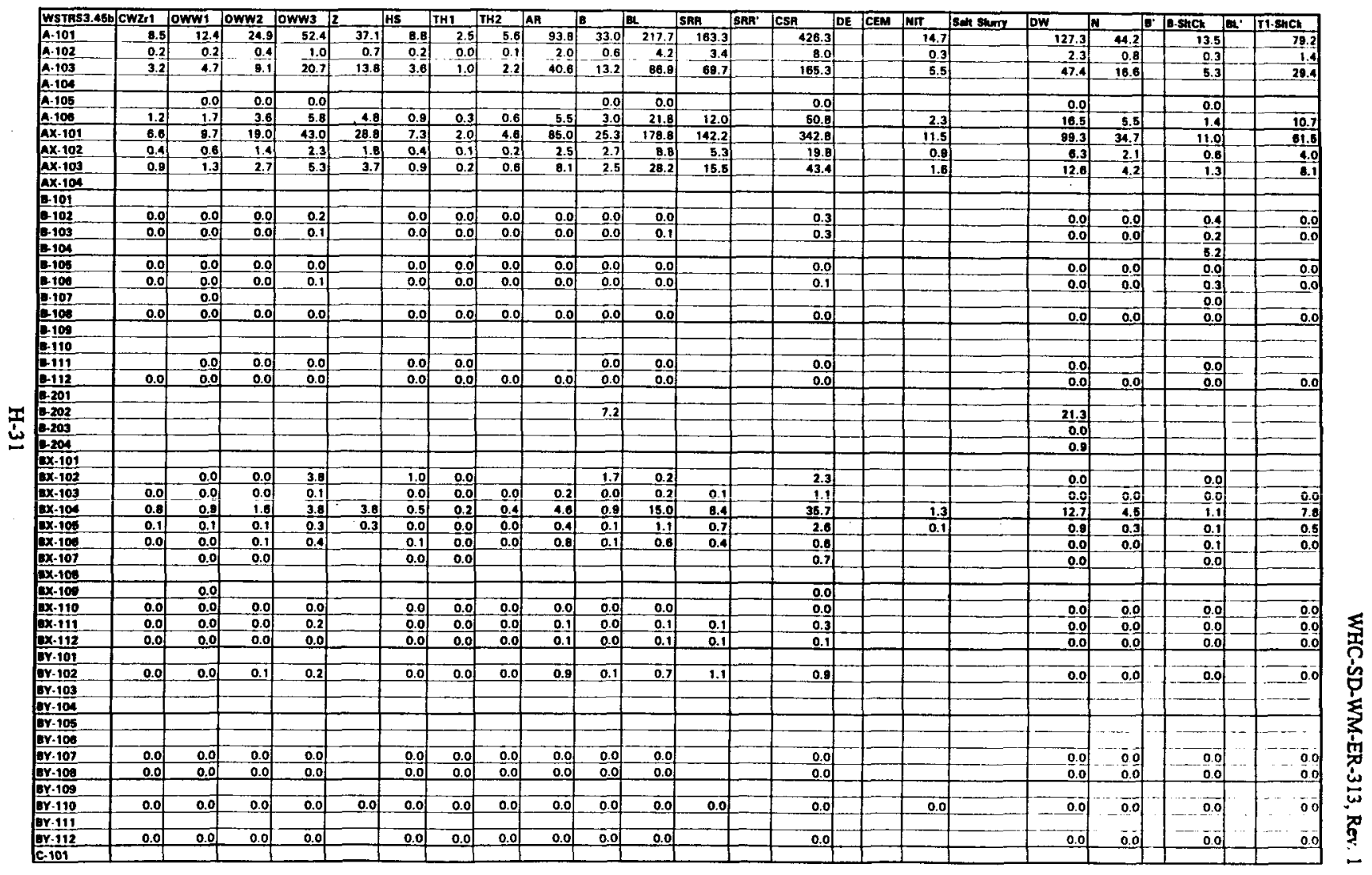




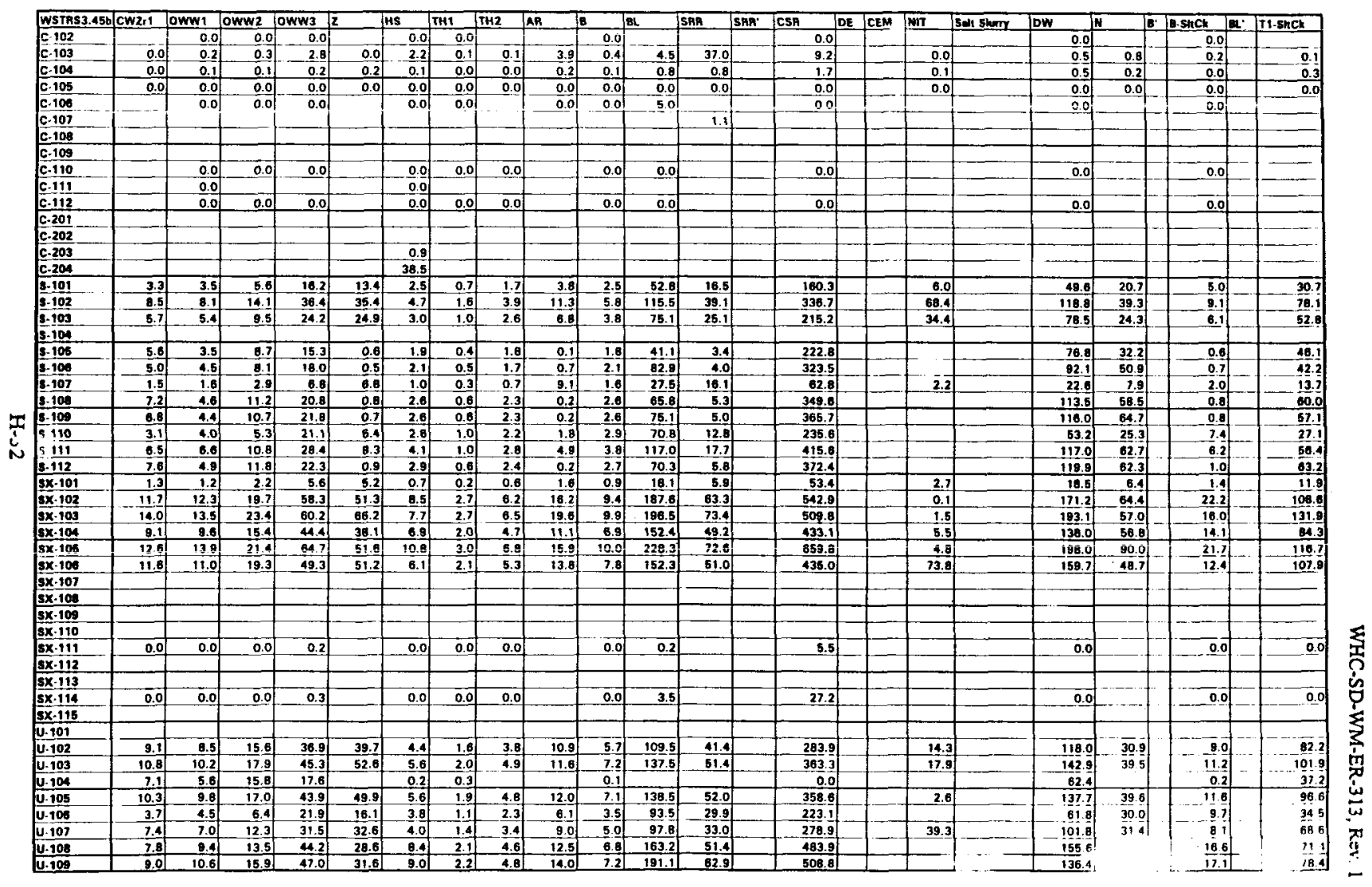




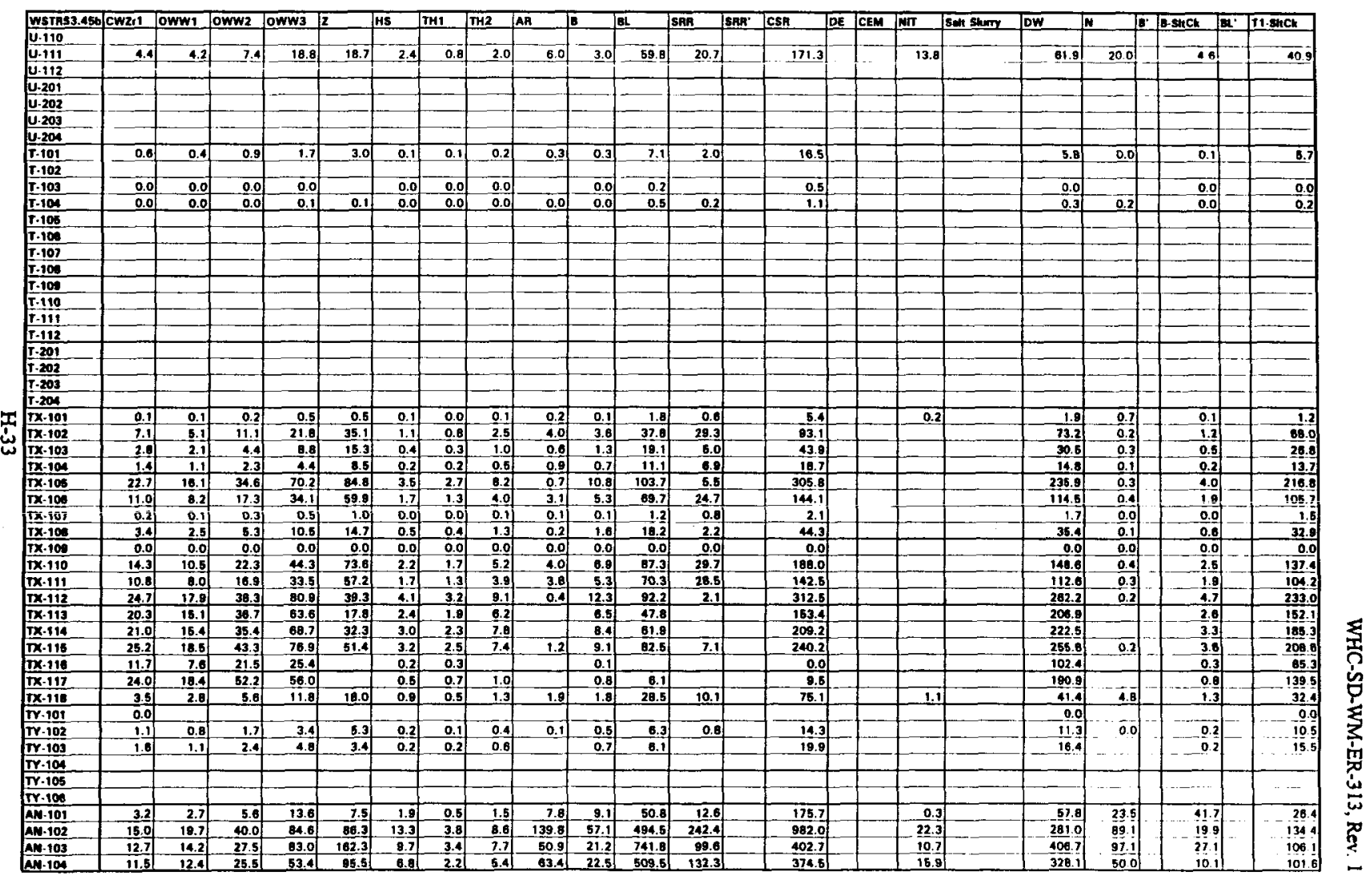




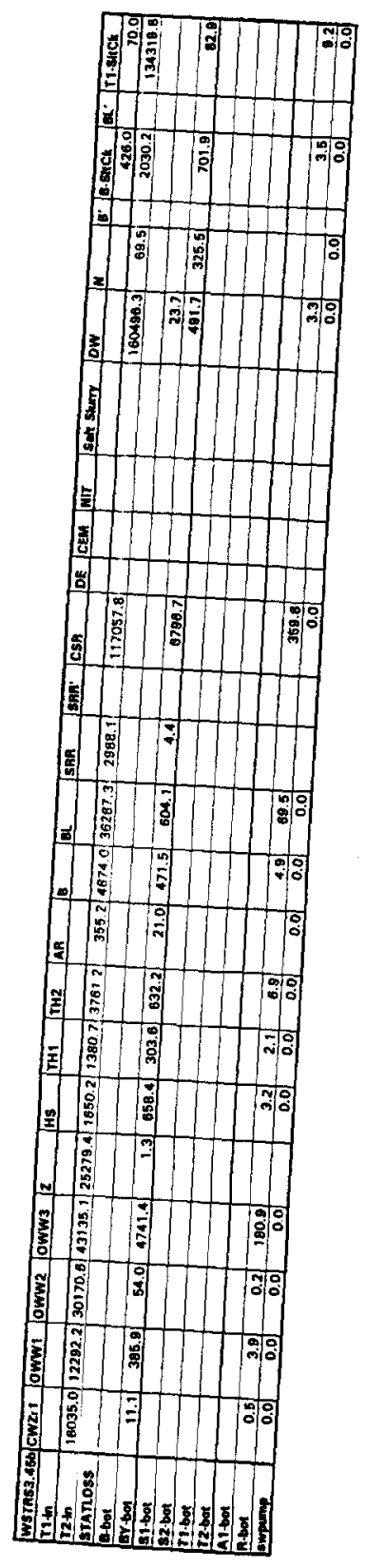

WHC-SD-WM-ER-313, Rev. 1 


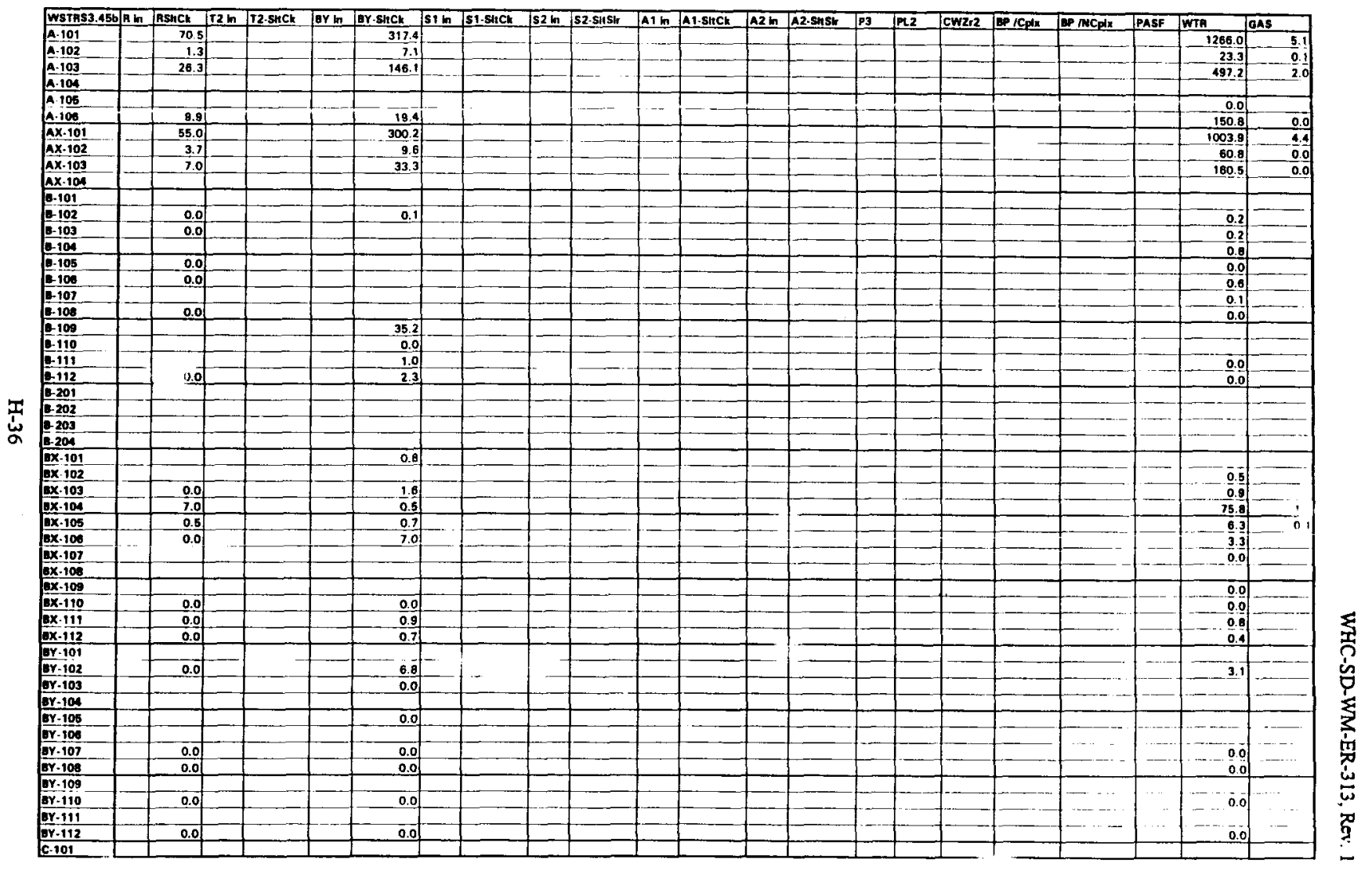




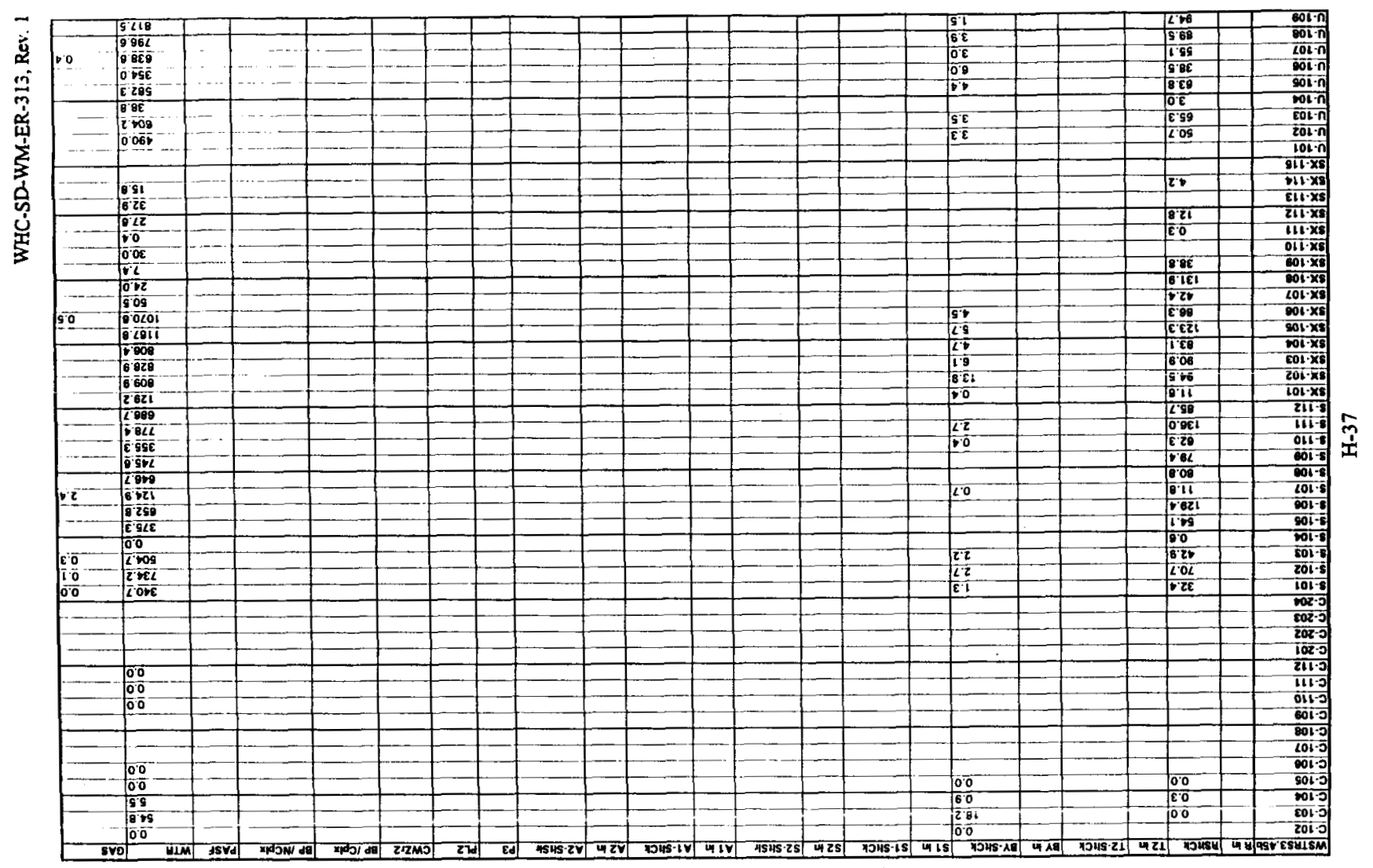




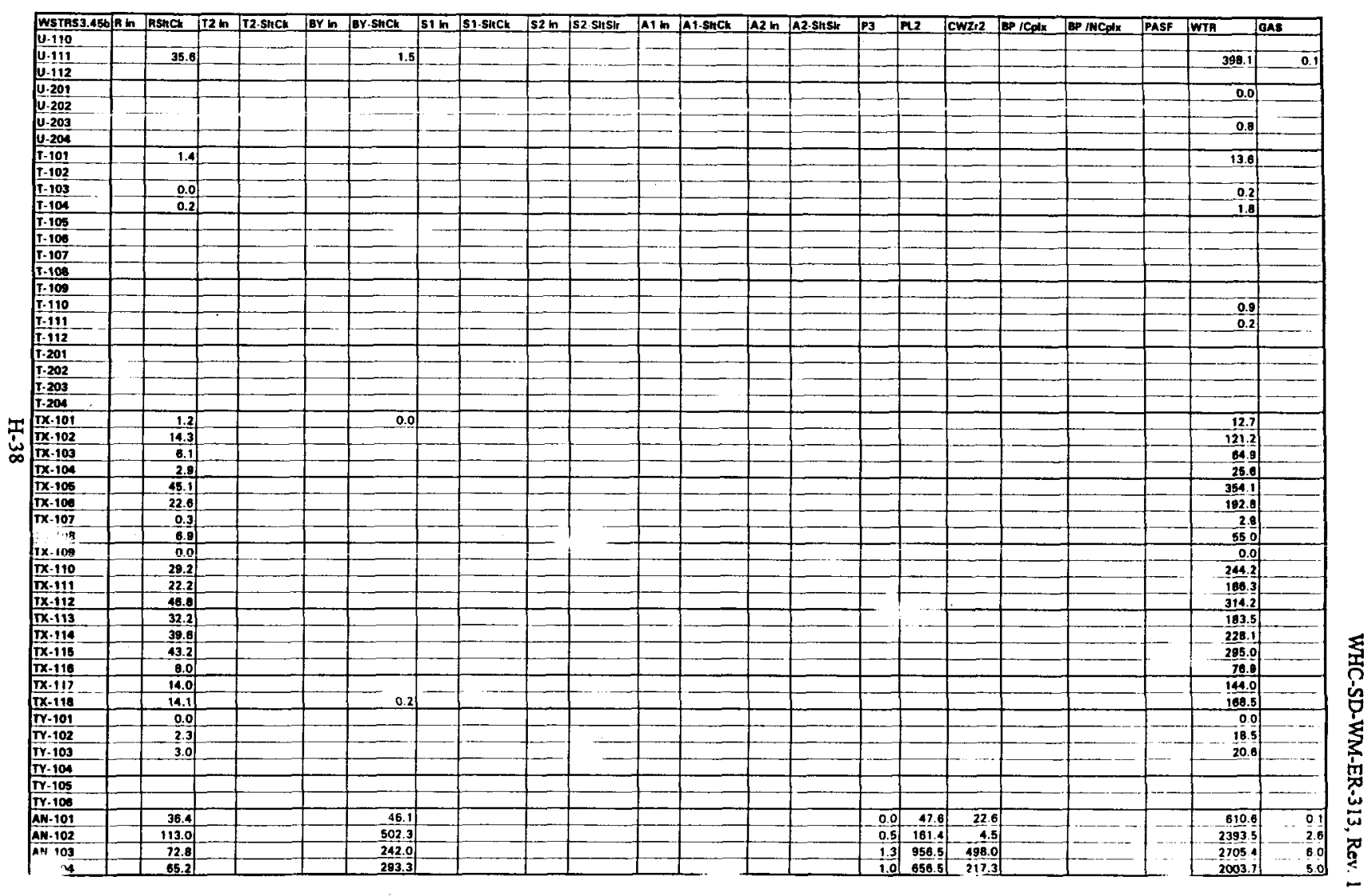




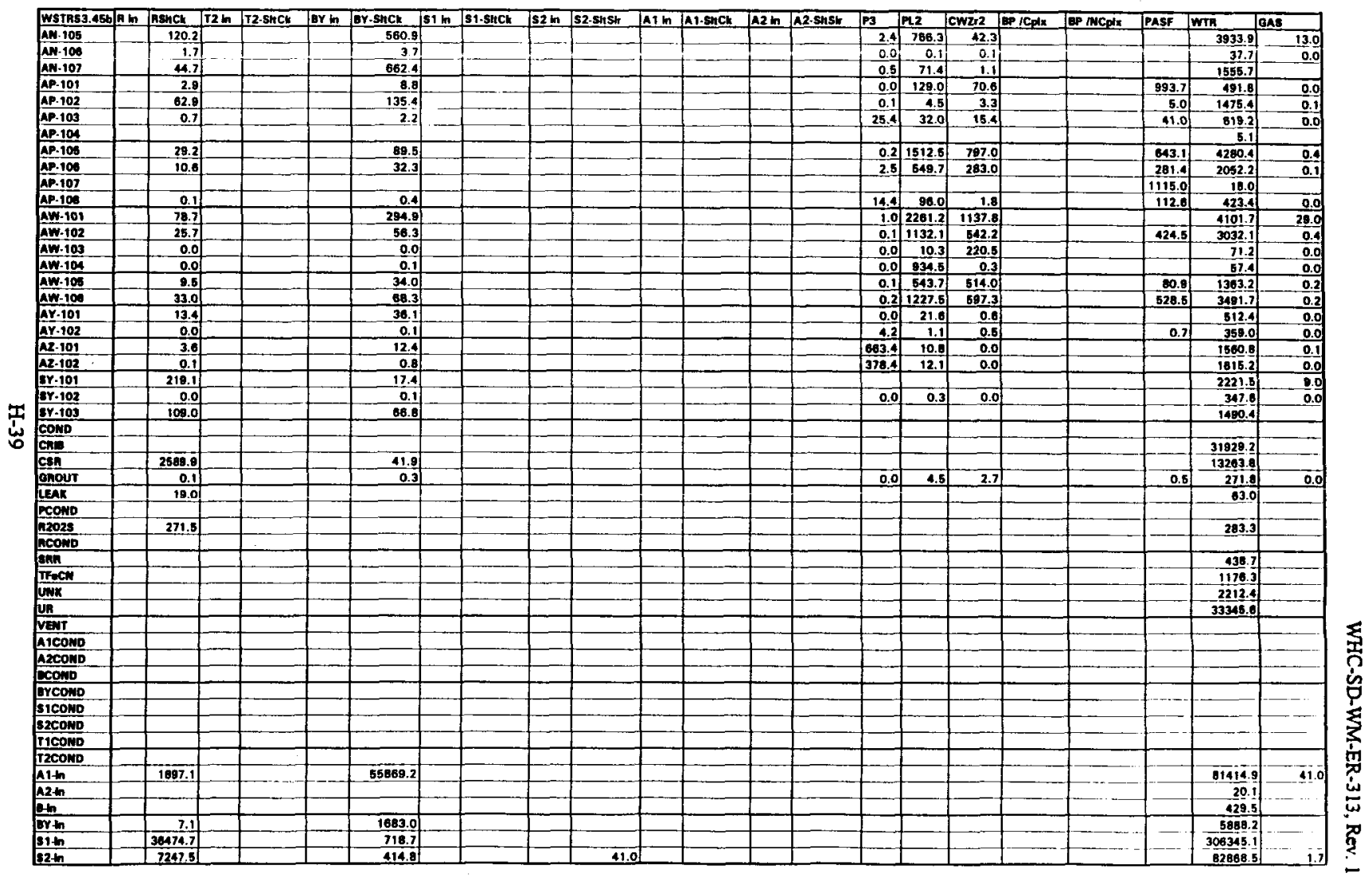




\begin{tabular}{|c|c|c|c|c|c|c|c|c|c|c|c|c|c|c|c|c|c|c|c|c|c|c|}
\hline Wosins3.45b & An: & Asuck & $\sqrt{2} \mathrm{~h}$ & T2-Stck & TEYm & EY.Stch & si in & s1-stck & $52 \mathrm{n}$ & 52-ShtSit & A1 $\mathrm{h}$ & A1.Sthch & A2 $\mathrm{m}$ & A2-Sitsis & P3 & pl2 & CWZ12 & GP/Codx & tep fNCpdx & PASF & WWTR & GAS \\
\hline I1th & & & & & & & & & & & & & & & & & & & & & 3245.5 & \\
\hline$T 2+m$ & & 23672.0 & & & & & & & & & & & & & & & & & & & 174025.2 & \\
\hline StatLoss & 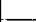 & & & & & & & & & & & & & & & & & & & & 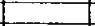 & \\
\hline e-bor & 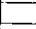 & & & & & & & & & & & & & & & & & & & & 198.8 & \\
\hline SY-bot & & 45.8 & & & & & & & & & & & & & & & & & & + & 3402.8 & \\
\hline 81-bot & & & & & & & & & & & & & & & & & & & & & & \\
\hline $82-b o t$ & - & & & & & L. & & & & & & 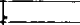 & & & & & & & & 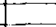 & & \\
\hline T1-bot & 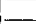 & & & & & 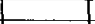 & 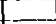 & & - & & & & & 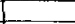 & & & & & & - & 1017.7 & \\
\hline 12 - & & & & & & & & & & & & & & & & & & & & & & \\
\hline A1-609 & 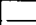 & & & & & & & & & & & & & & & & & & & & & \\
\hline a-bol & & 88.7 & & & & & & & & & & & & & I- & & & & & & 2981.8 & \\
\hline empump & & 0.0 & & & & 7.6 & & & & & & & & & & & & & & & 0.0 & \\
\hline
\end{tabular}

$\frac{1}{6}$ 


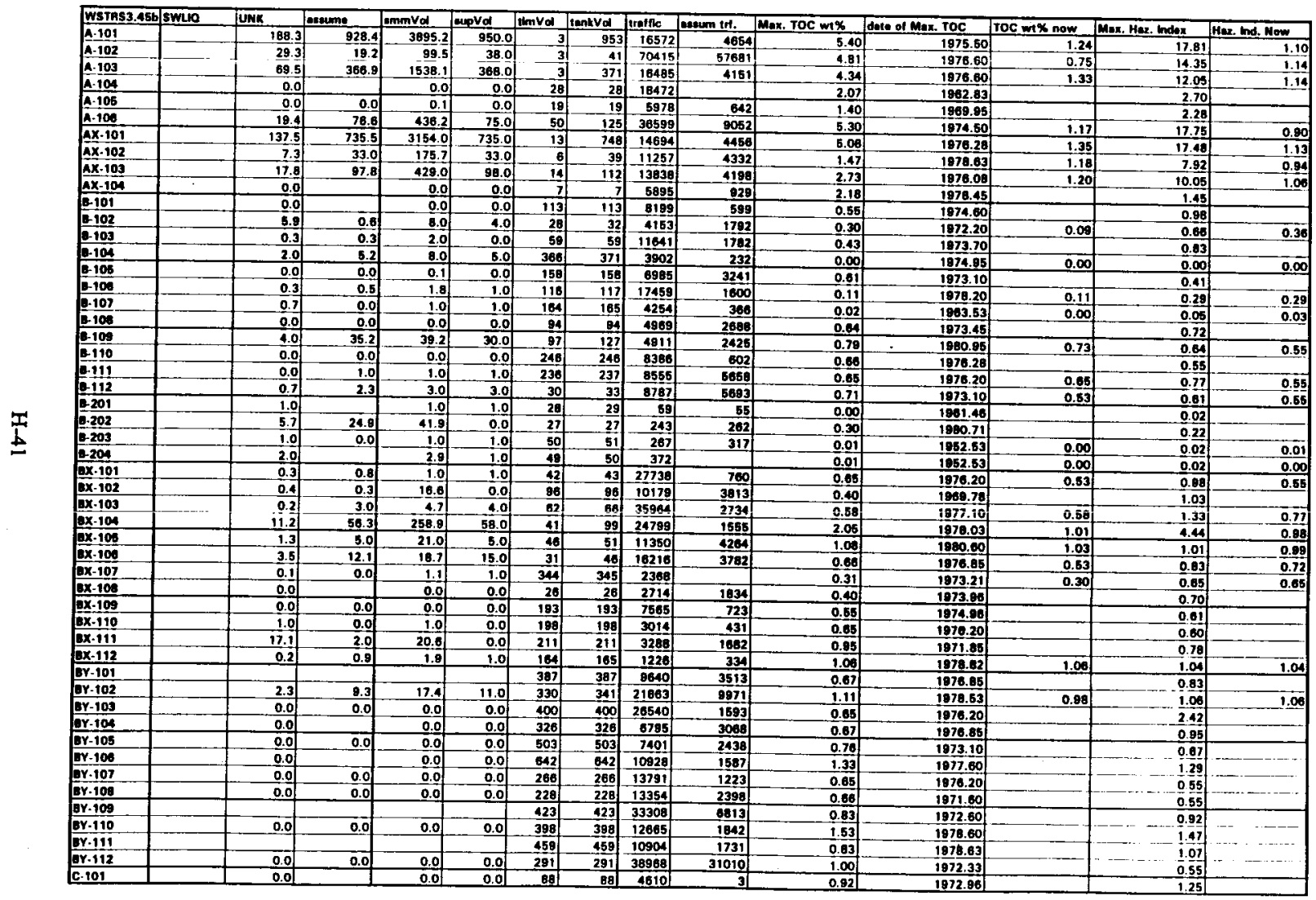




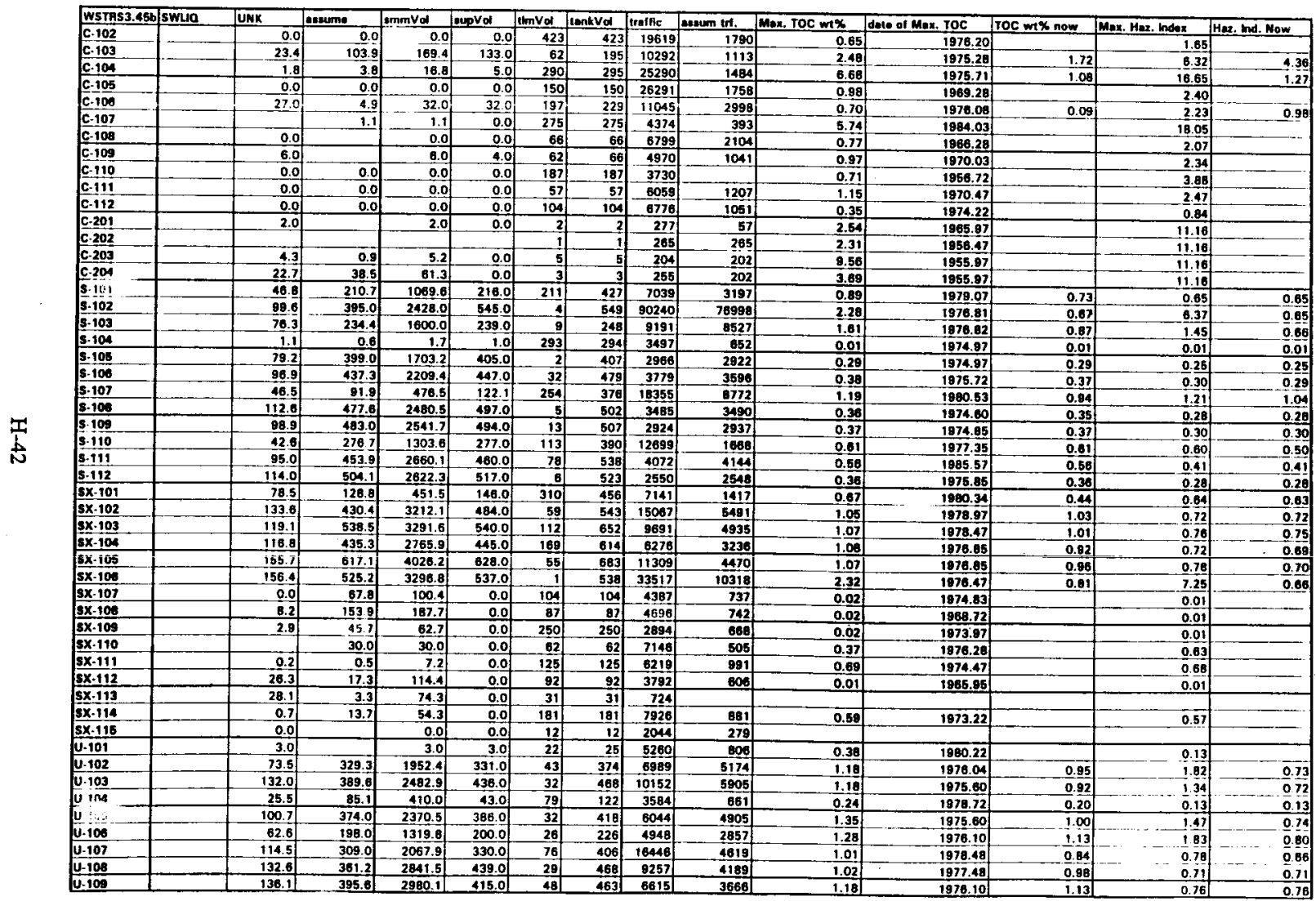




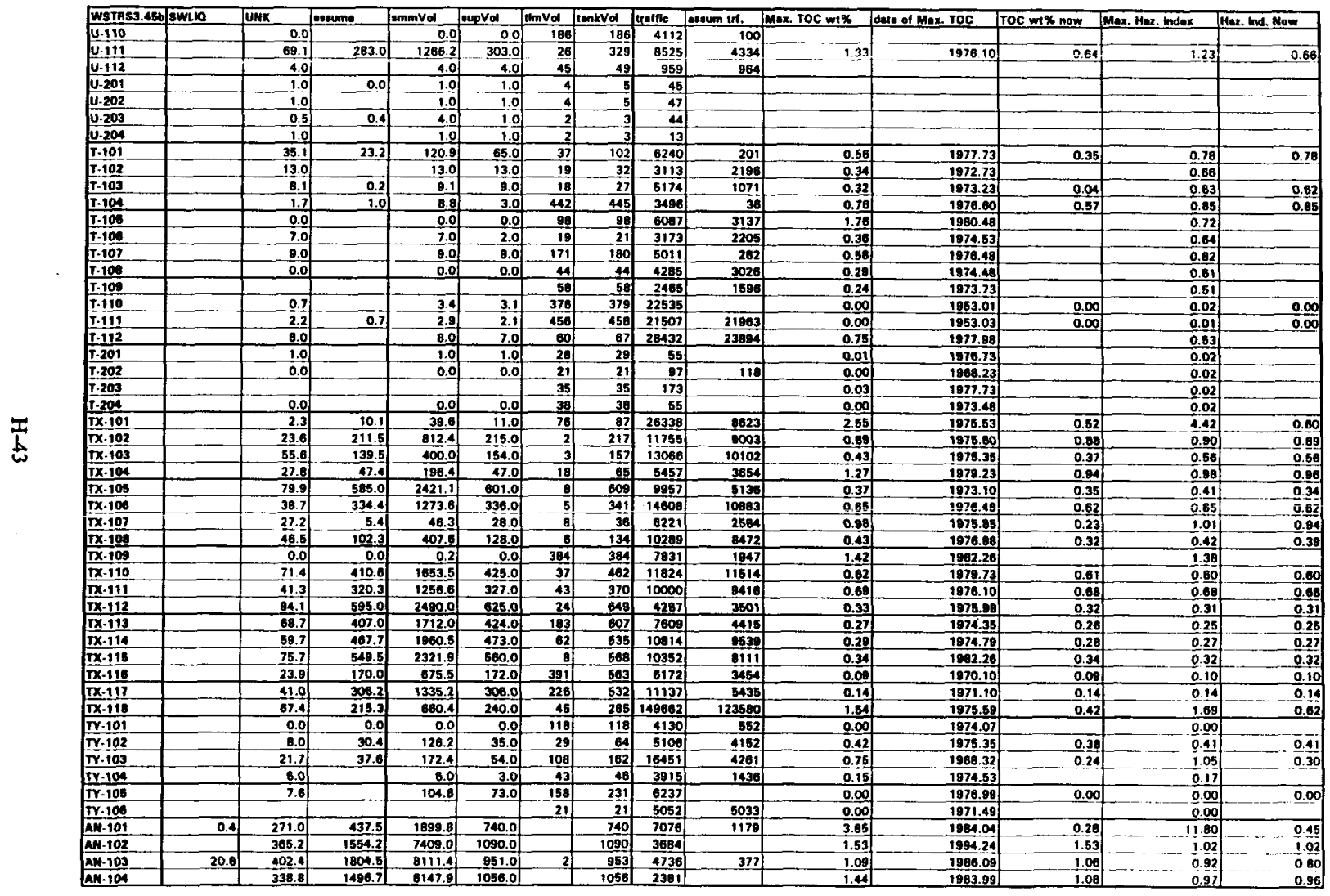




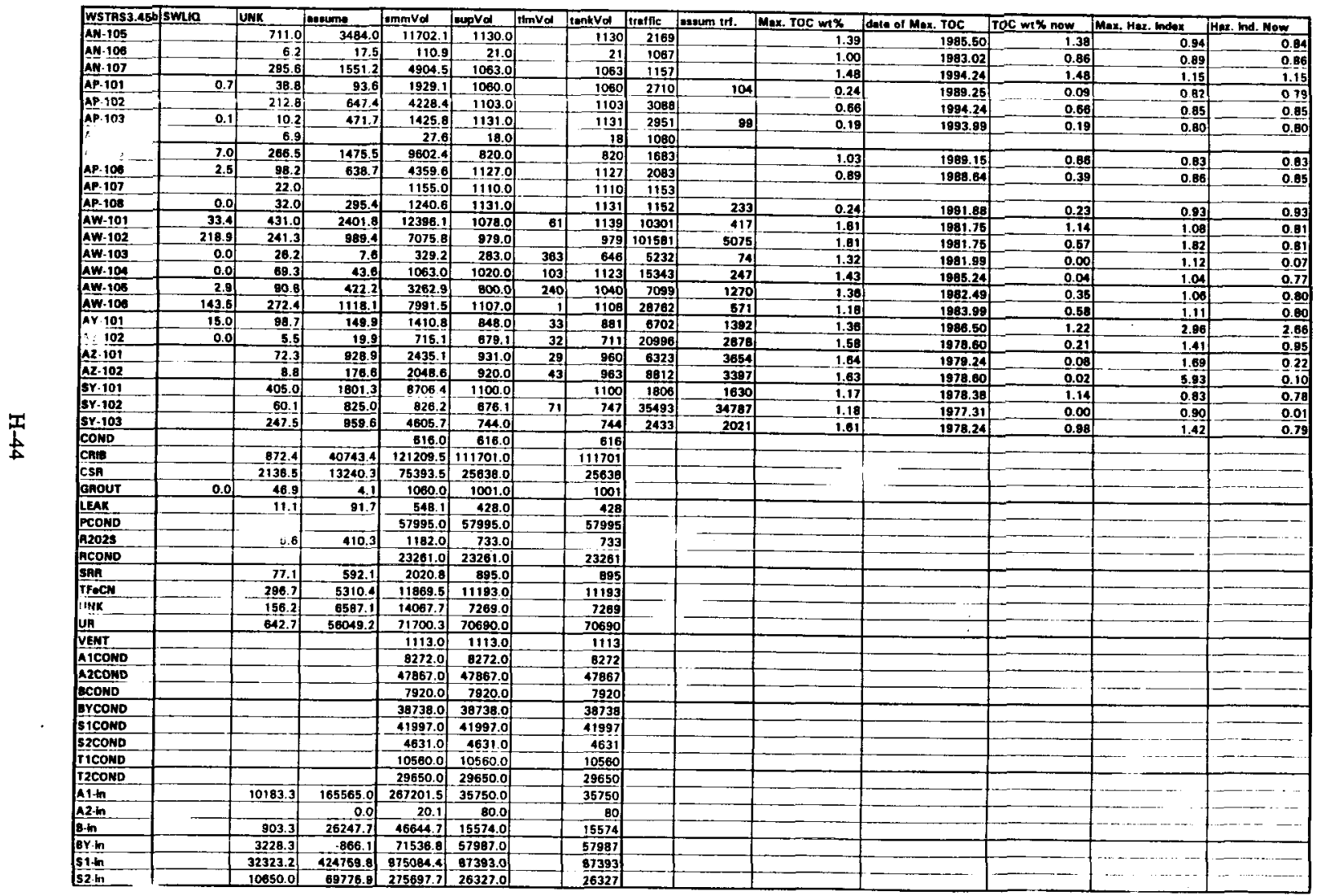




\begin{tabular}{|c|c|c|c|c|c|c|c|c|c|c|c|c|c|c|}
\hline$\ldots$ & & & & & & & ot & & o. & $0 \%$ & $\frac{\sigma^{\prime} c}{0.42}$ & 2 & & Drendm \\
\hline & & & & & & & & & & & & & & log-y \\
\hline & & & & & & & & & & & & & & $209-21$ \\
\hline & & & & & & & $\overline{0109}$ & & O.0109 & ब'00zE! & $2 \cdot 0058$ & 6.991 & & $2009+11$ \\
\hline & & & & & & - & & - & & & & & & $109-28$ \\
\hline & & & & & & & Fi18 & & 0,818 & CgIEZ) & SGEE & 2015 & & $\frac{309-15}{100.09}$ \\
\hline & & & & & & & $\frac{V G E}{69 E T}$ & & O. GSEt & $E \angle Z S B$ & $\frac{10 \% \Omega}{0 . E G E E}$ & 2891 & & $\frac{104 \lambda-10}{100}$ \\
\hline & & & & & & & & & & & & & & ssouvis \\
\hline & & & & & & & $00 i z_{i}$ & & $0010 k 21$ & 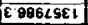 & B. 019699 & g'DCtac & & 4 in \\
\hline mon par ant & 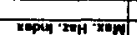 & mote $x \sin 301$ & 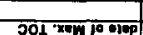 & 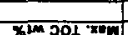 & मु पूरकी & श्यागय & 86802 & 20140 & Oegentz & $\angle 26920$ & G & 9.865 & 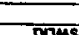 & 451 \\
\hline
\end{tabular}




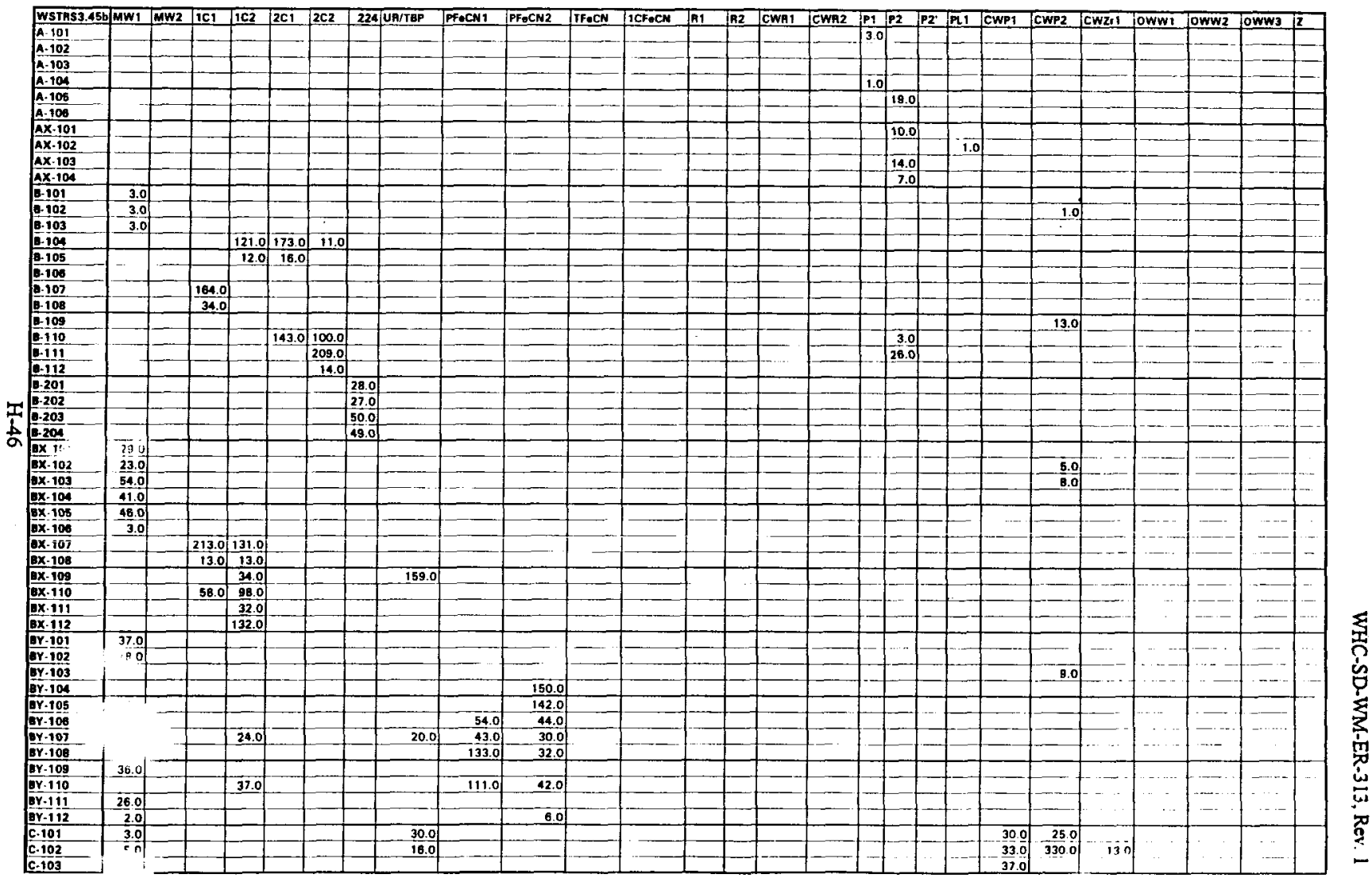




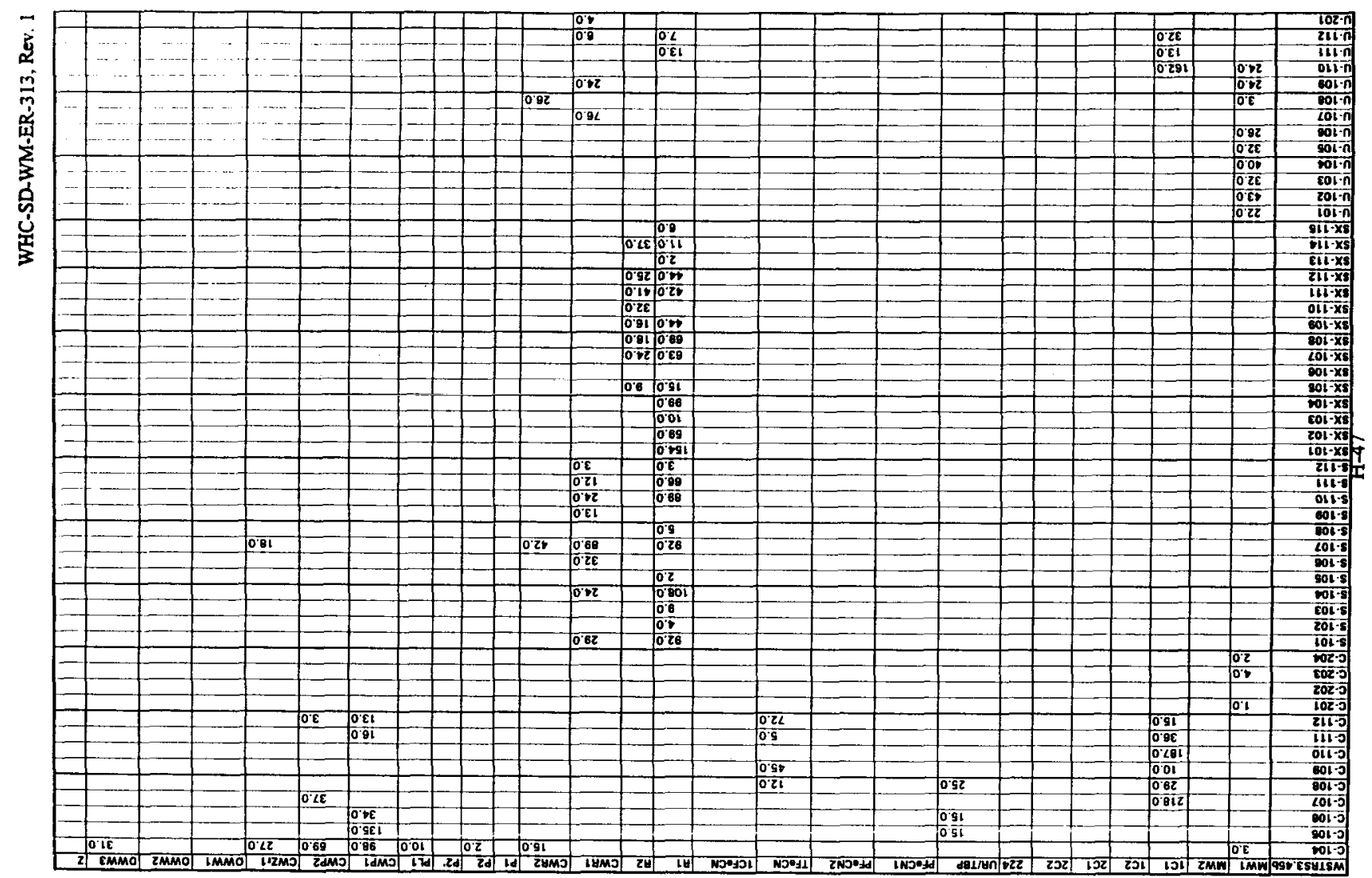




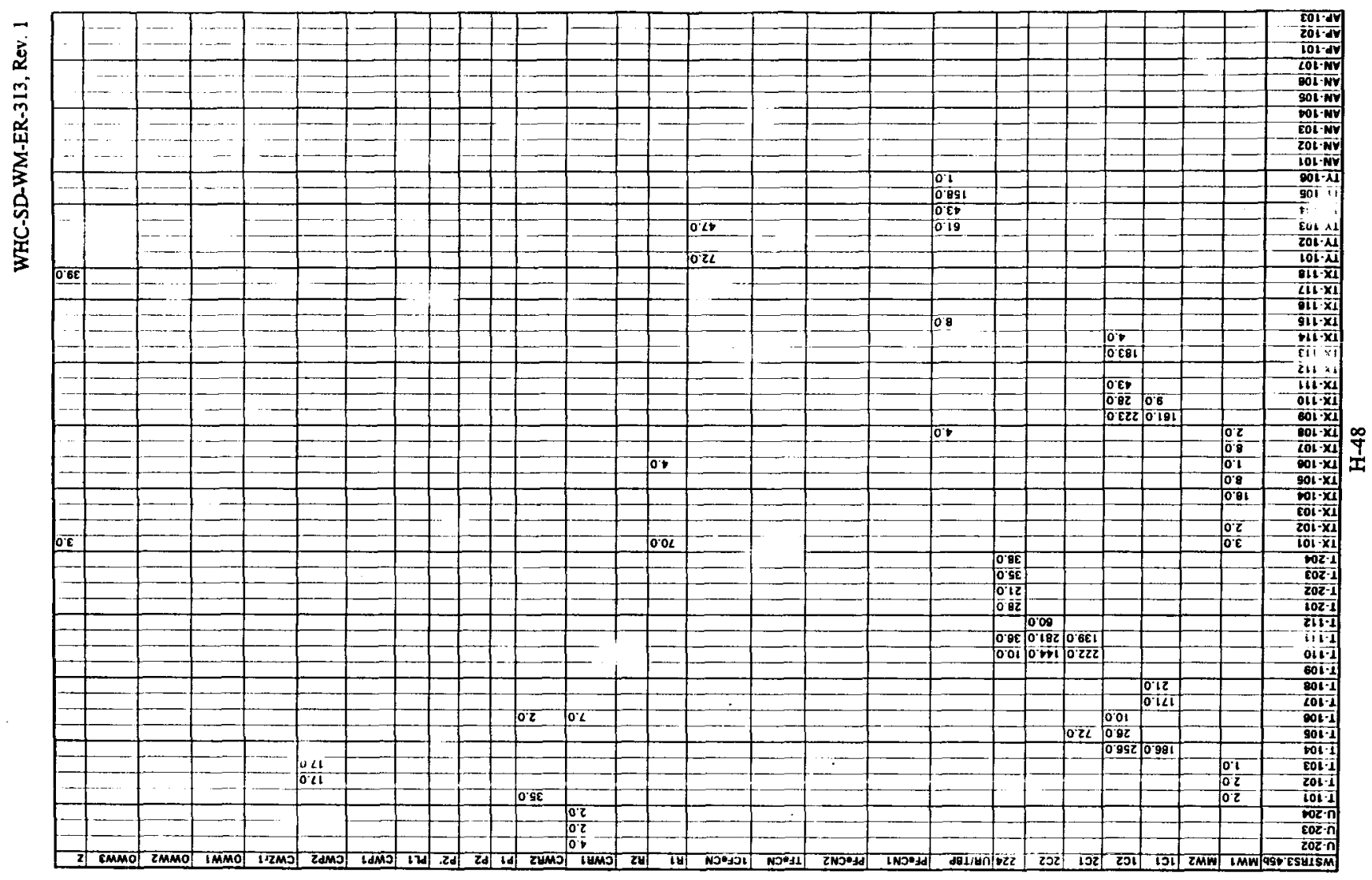




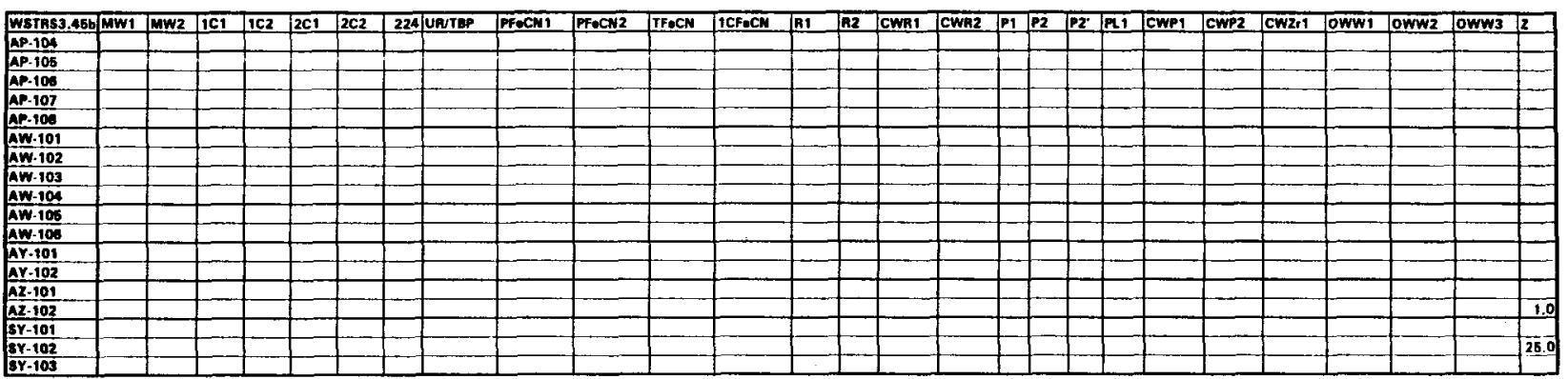

昰 


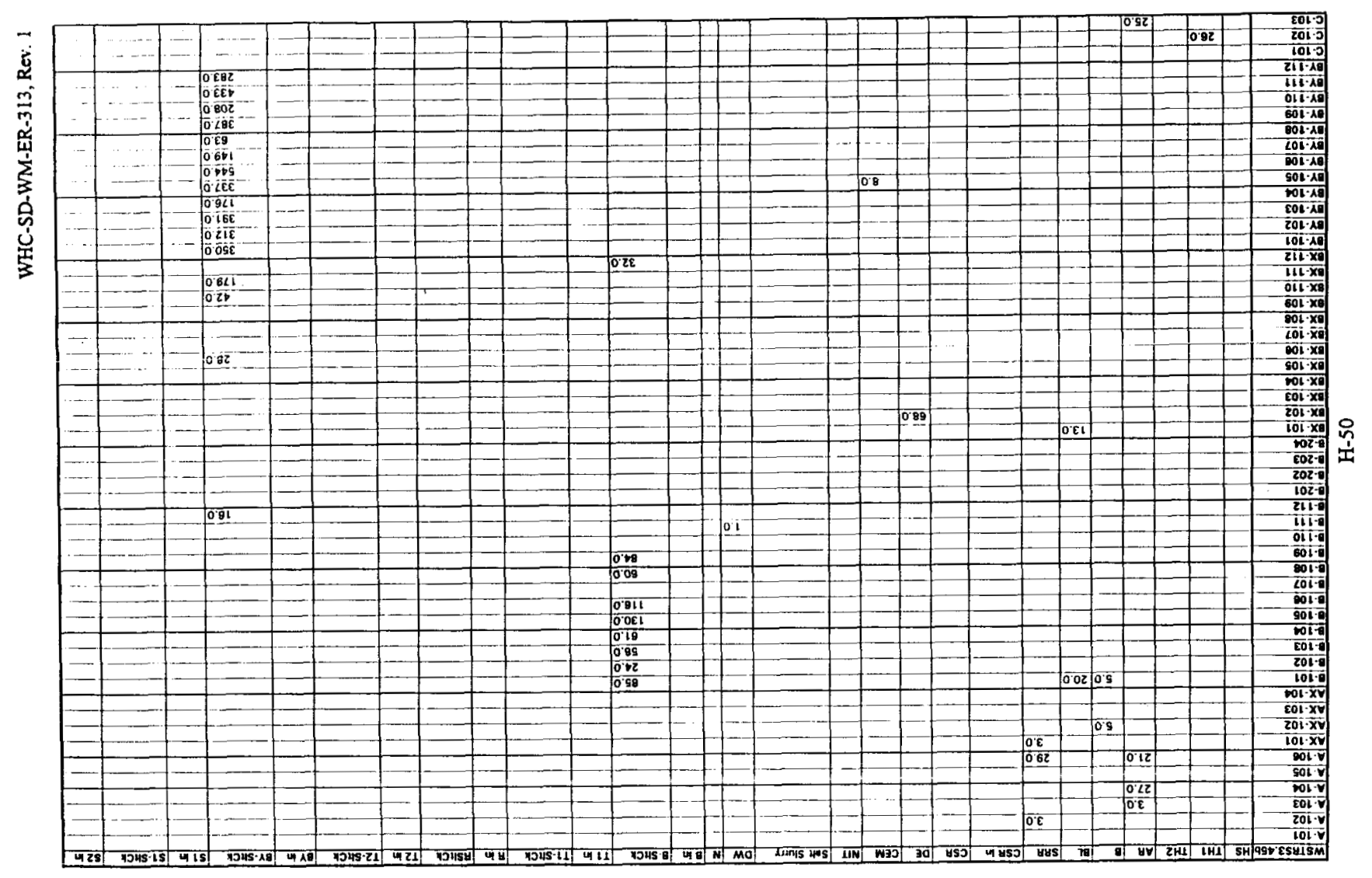


WHC-SD-WM-ER-313, Rev. 1

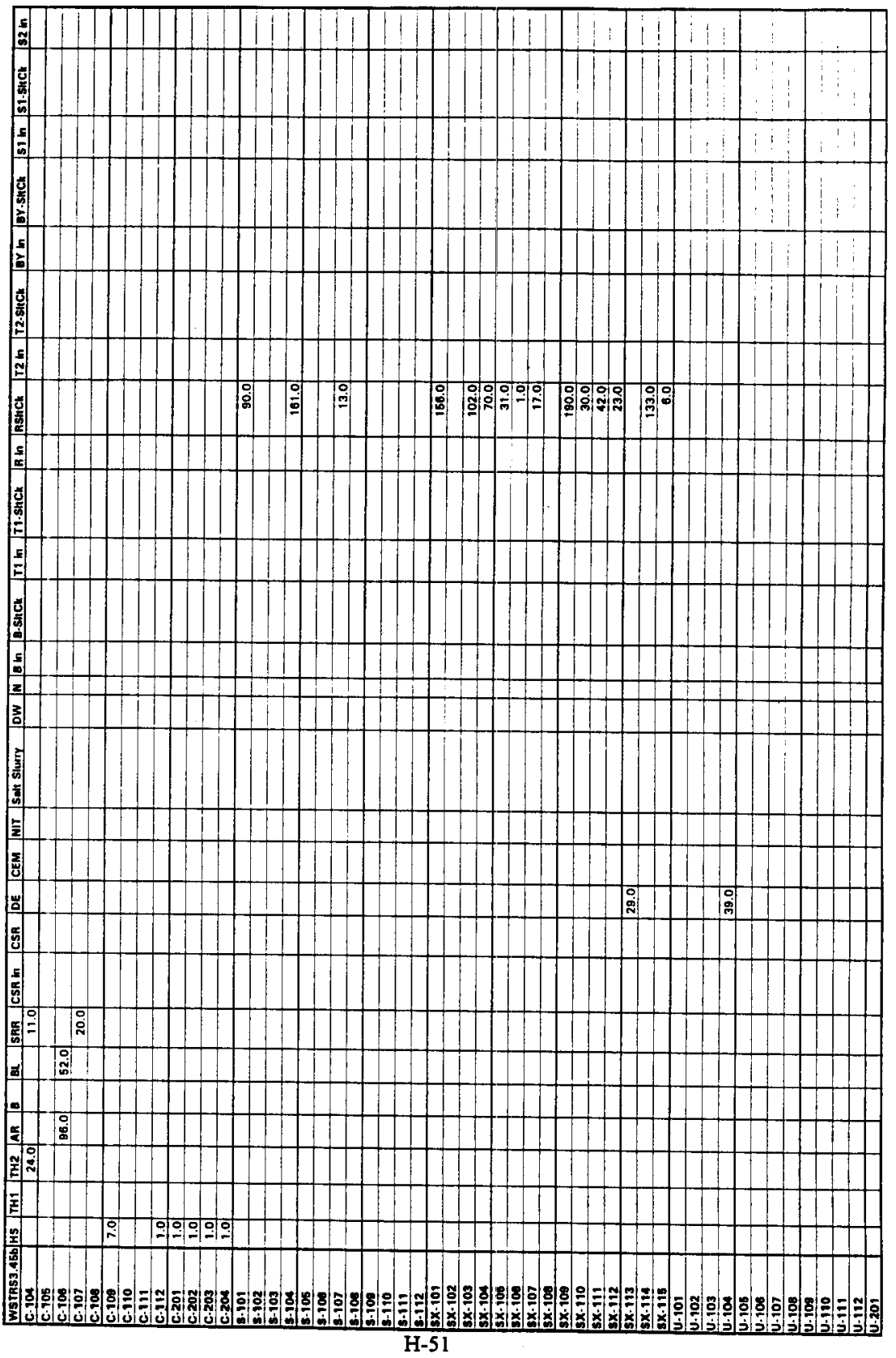




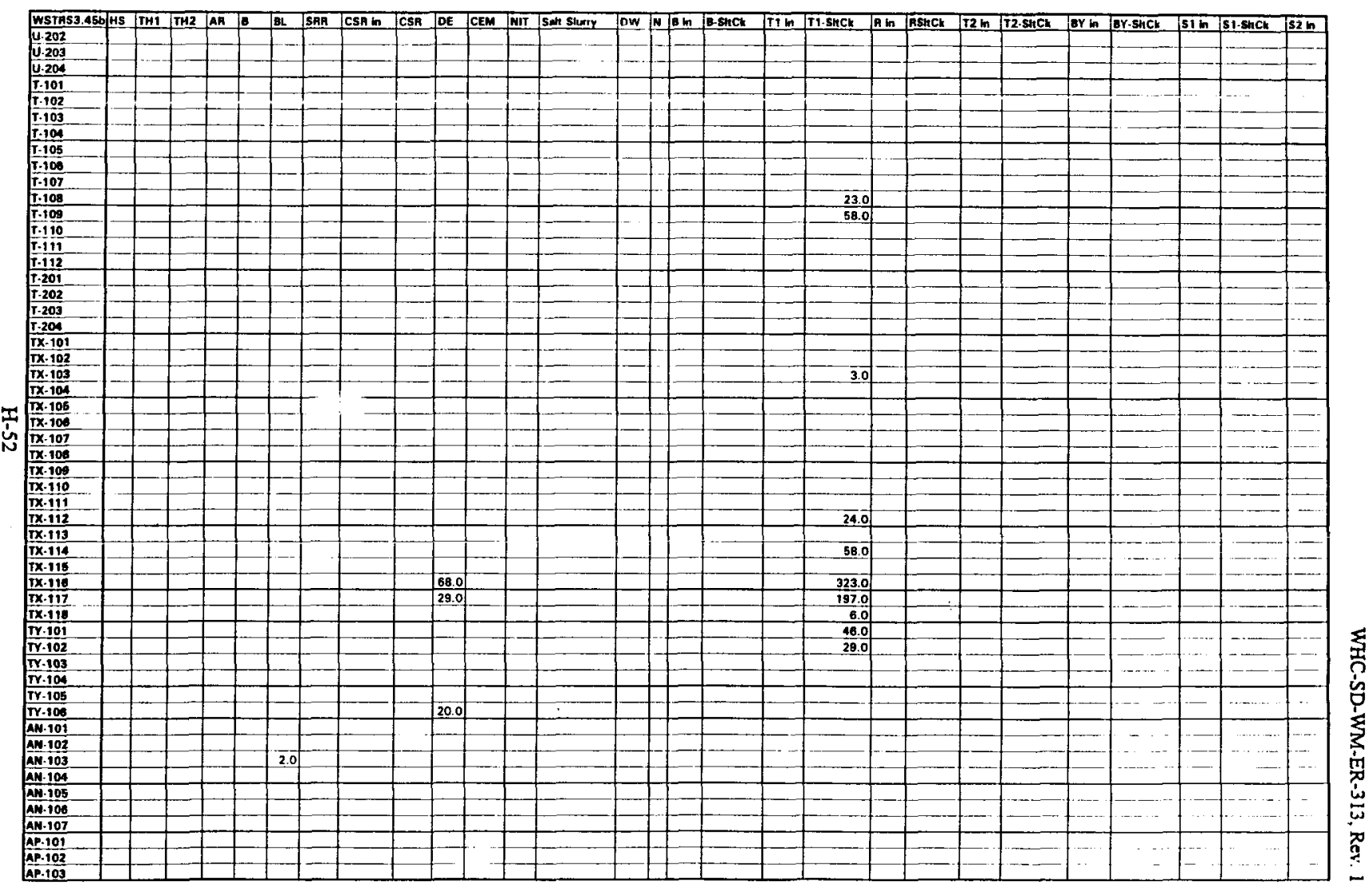




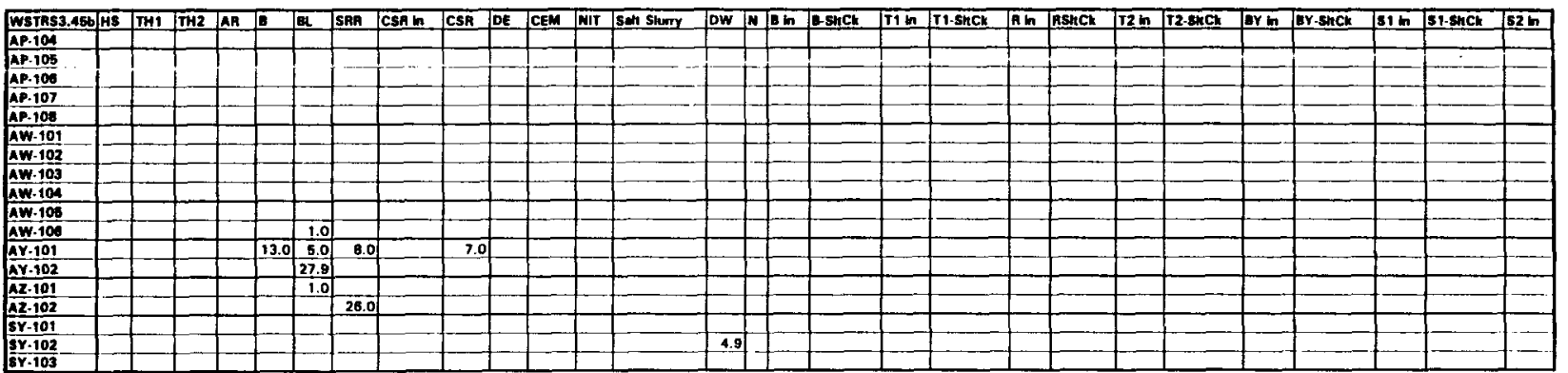

嵒 


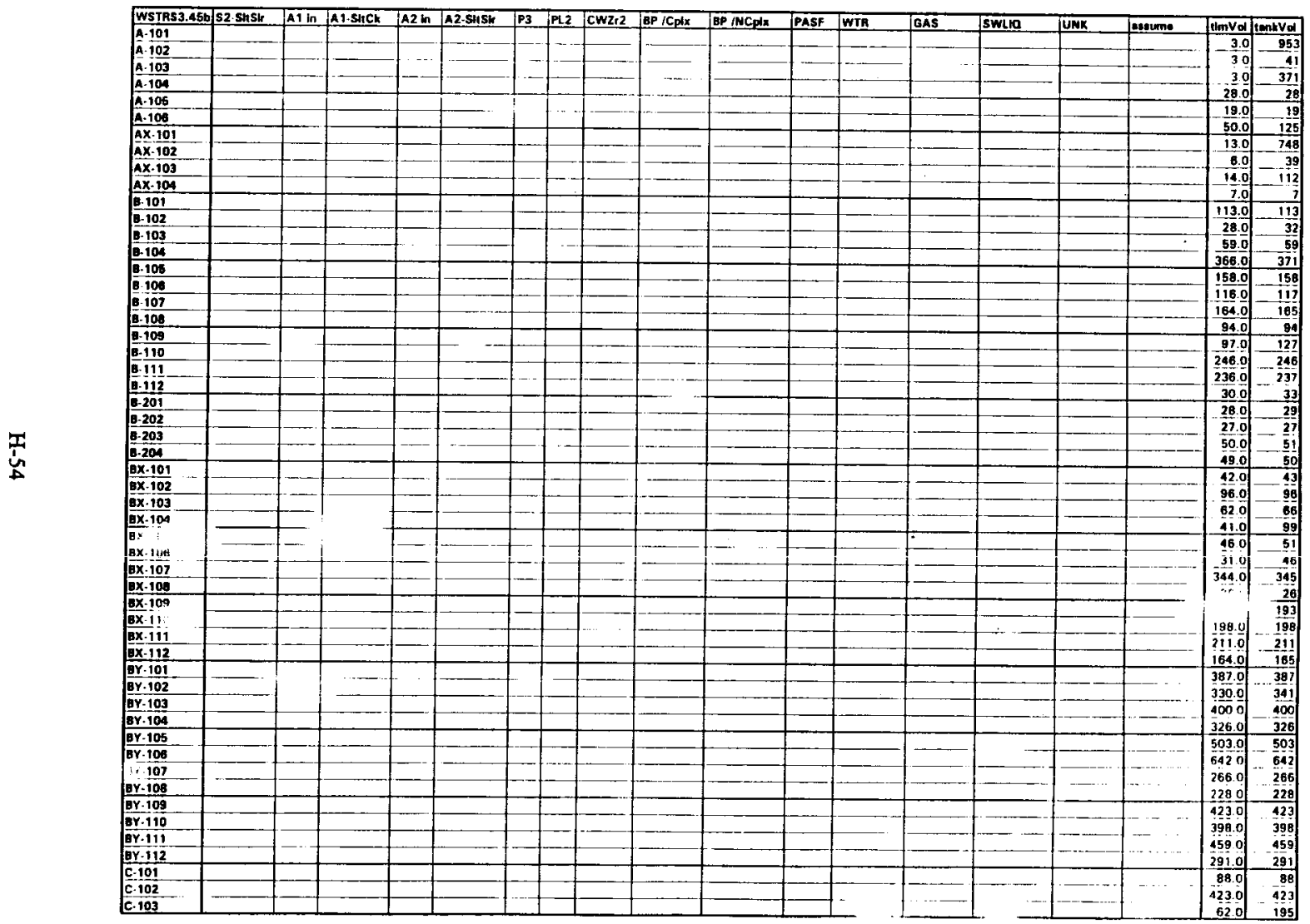




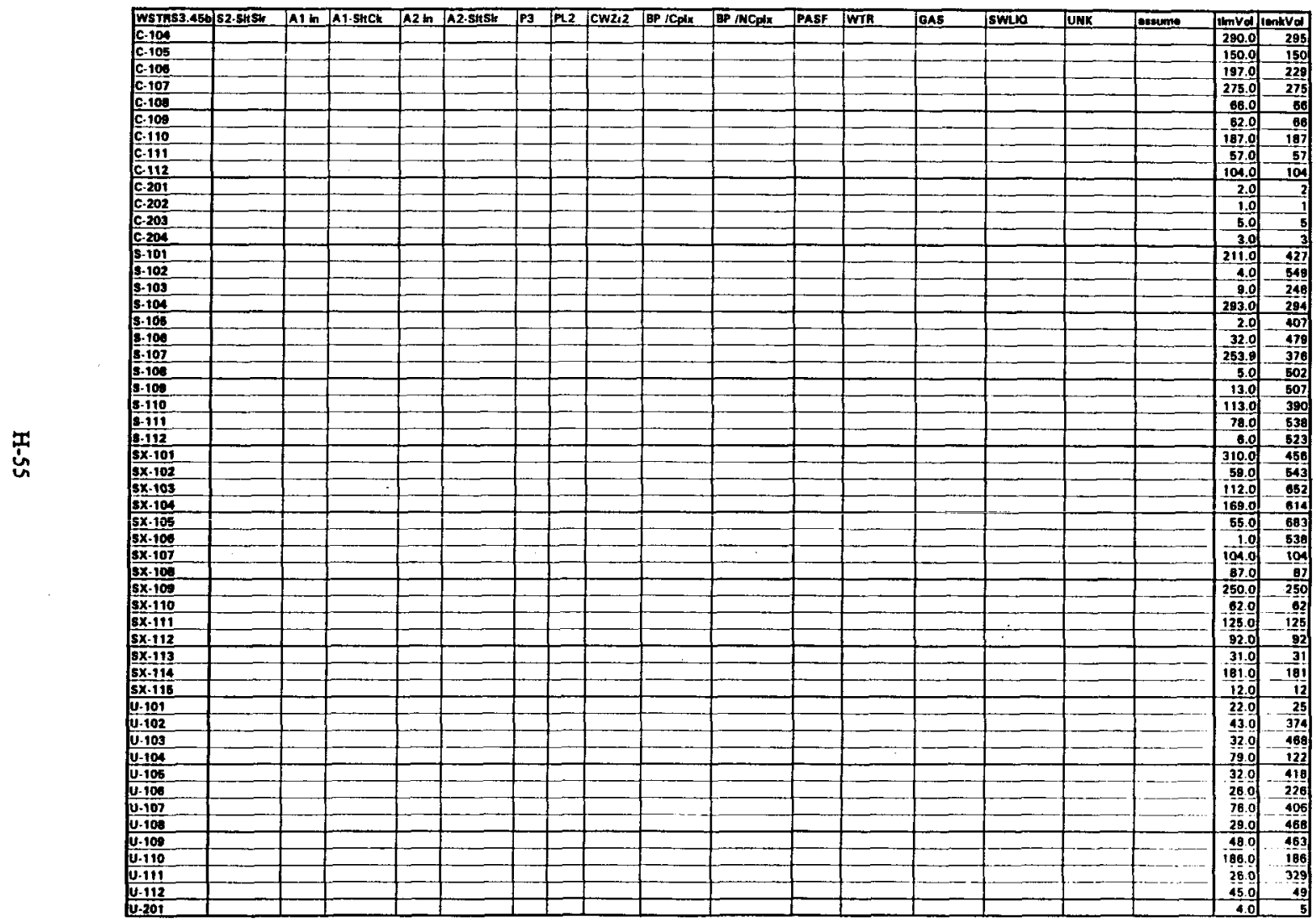




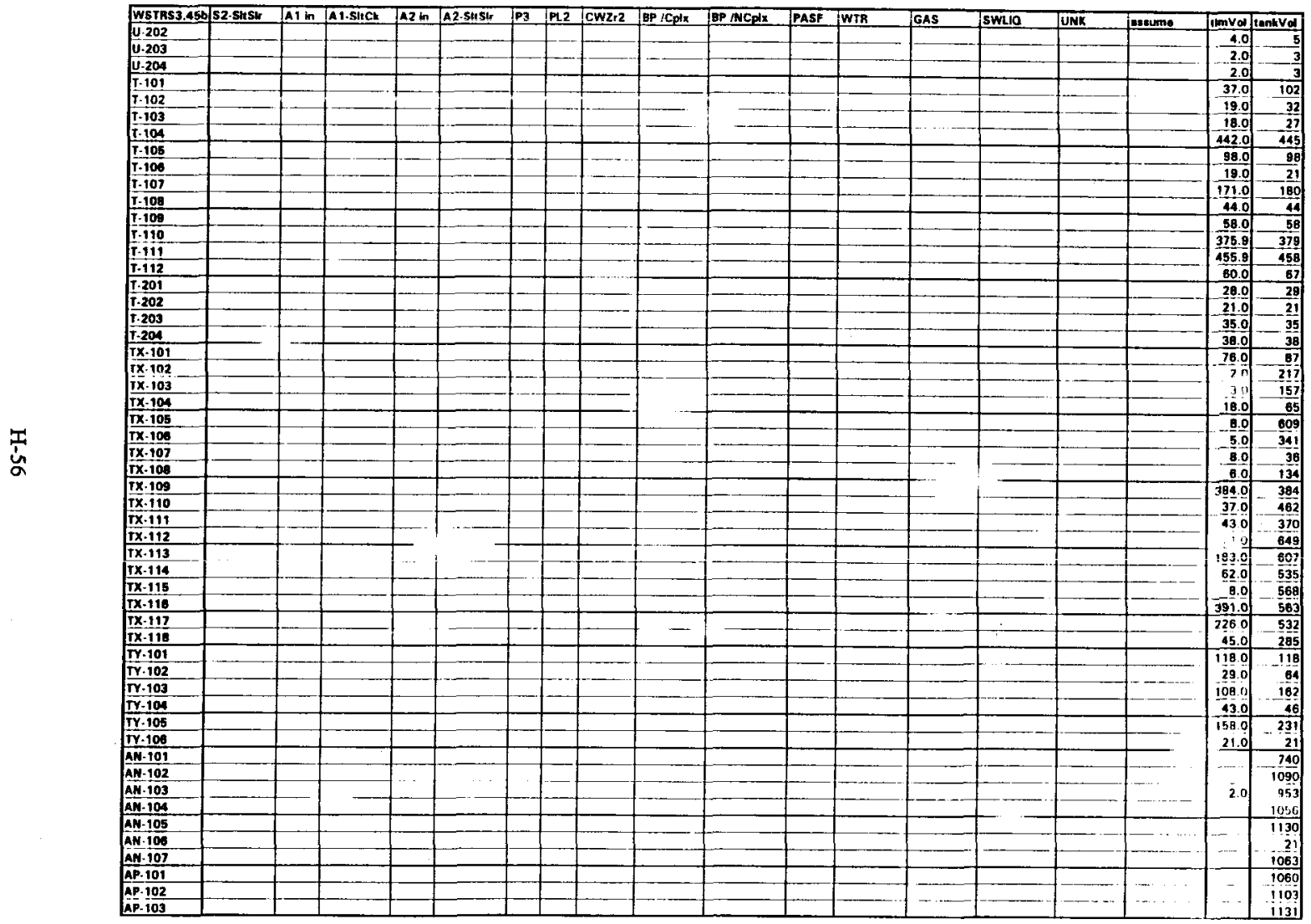




\begin{tabular}{|c|c|c|c|c|c|c|c|c|c|c|c|c|c|c|c|c|c|c|}
\hline WSTAS3.456 & 52-shst & A1m & A1.stch & A2 $n$ & $\sqrt{12-51 t 5 t}$ & $\sqrt{\mathbf{n} 3}$ & PL2 & CWZ;2 & $B P / C p h$ & EP MCplx & PASF & WTA & GAS & swink & UTAK & enverme & thinval & Eontivet \\
\hline AP-104 & & & & & & & & & & & & & & & & & & 18 \\
\hline AP-105 & & & & & & & & & & & & & & & & & & 020 \\
\hline Ap-106 & & & & & & & & & & & $f-$ & - & 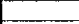 & & 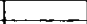 & & & 1127 \\
\hline Ap-107 & & & & & & & & & & & & & & & & & C. & 1110 \\
\hline$A p-100$ & & & & & & & & & & & & & & & & & & 1131 \\
\hline AW-101 & & & & & & & 61.0 & & & & & & & & & & 61.0 & 1139 \\
\hline AW. 102 & & & & & & & & & & & & & & 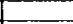 & 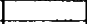 & - & & 979 \\
\hline AW. 103 & & & & & & & & 363.0 & & & & & & & & 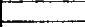 & 363.0 & 646 \\
\hline AT.104 & & & & & & & 98.0 & 5.0 & & & & & & & & & 103.0 & 1123 \\
\hline Aw-105 & & & & & & & 25.0 & 215.0 & & & & & & & & & 240.0 & 1040 \\
\hline Aw. 100 & & & & & & & & & & & & & & & & & 1.0 & 1100 \\
\hline AY.101 & & & & & & & & & & & & & & & & $\ldots$ & 33.0 & 881 \\
\hline AY 102 & & & & & & & 4.0 & & & & & & & & & & 31.9 & 711 \\
\hline$A 2-10$ & & & & & & 27.0 & 1.0 & & & & & & 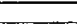 & - & & & 29.0 & 960 \\
\hline$A 2-102$ & & & & & & 13.0 & 3.0 & & & & & & & & & & 43.0 & 963 \\
\hline SY-101 & & & & & & & & & & & & & & & & & & 1100 \\
\hline $3 Y-102$ & 41.0 & & & & & & & & & & - & & $\ldots$ & & & & 70.0 & 74 \\
\hline$\overline{5 Y} \cdot 103$ & & & & & & & & & & & & & & & & & & 740 \\
\hline
\end{tabular}




\section{Appendix $E$.}

\section{Inventory Estimates}

May 1996

Each tank's inventory estimate is given in three tables: TLM Solids Composite. SMM Composite, and Total Inventory Estimates. Furthermore, each table expresses analyte average concentration as mol/h or ppm as well as $\mathrm{kg}$ or MCi inventories. Total s re inventories in Mmols and $\mathrm{kg}$ are also shown for Rev. 3 as well as for previous revisions, Rev. 1 and Rev. 2. These site inventories are further broken down into DST, SST, Crib, and Leak destinations.

\section{NE Quadrant}


WHC-SD-WM-ER-313, Rev 1

\begin{tabular}{|c|c|c|c|}
\hline \multicolumn{4}{|c|}{ Single-Shell Tank 241<-101 } \\
\hline \multicolumn{4}{|c|}{ TLM Solide Composine invertory Escinate" } \\
\hline 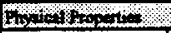 & & $\mathrm{m}_{\mathrm{m}-\mathrm{m}}$ & $\$$ \\
\hline Totsl Solid Warte & $4.74 \mathrm{E}+05 \mathrm{~kg}$ & \multicolumn{2}{|c|}{$(88.0 \mathrm{kgal})$} \\
\hline Heat Load & $2.26 \mathrm{E}-02 \mathrm{~kW}$ & \multicolumn{2}{|c|}{ (77.1 BTU/hr) } \\
\hline Bulk Denaity & \multicolumn{3}{|c|}{$1.42(g / \infty)$} \\
\hline Void Fraction & \multicolumn{3}{|c|}{0.825} \\
\hline Water wi\% & \multicolumn{3}{|c|}{55.9} \\
\hline TOC wt\% C (wet) & \multicolumn{3}{|c|}{$9.59 E-05$} \\
\hline \multicolumn{4}{|l|}{ 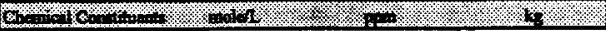 } \\
\hline $\mathrm{Na}^{+}$ & 2.41 & $3.89 \mathrm{E}+04$ & $1.85 \mathrm{E}+04$ \\
\hline $\mathrm{Al}^{3+}$ & 3.42 & $6.48 \mathrm{E}+04$ & $3.07 \mathrm{E}+04$ \\
\hline $\mathrm{Fe}^{3 \tau}$ (totel $\mathrm{Fe}$ ) & 0.727 & $2.85 E+04$ & $1.35 E+04$ \\
\hline$\overline{c r}^{3+}$ & 2.58E-03 & 94.3 & 44.7 \\
\hline $\mathrm{Bi}^{3+}$ & 0 & 0 & 0 \\
\hline $\mathrm{Le}^{5+}$ & 0 & 0 & 0 \\
\hline $\mathrm{Hg}^{2+}$ & 2.54E-03 & 358 & 170 \\
\hline $\mathrm{Zr}\left(\mathrm{as} \mathrm{2NO}(\mathrm{OH})_{2}\right)$ & 0 & 0 & 0 \\
\hline $\mathrm{Pb}^{2+}$ & 0.133 & $1.93 \mathrm{E}+04$ & $9.15 E+03$ \\
\hline $\mathrm{Ni}^{2^{*}}$ & $1.29 \mathrm{E}-03$ & 53.2 & 25.2 \\
\hline $\mathrm{Sr}^{2+}$ & 0 & 0 & 0 \\
\hline $\mathrm{Mn}^{4+}$ & 0 & 0 & 0 \\
\hline $\mathrm{Ca}^{2+}$ & 0.253 & $7.11 \mathrm{E}+03$ & $3.37 \mathrm{E}+03$ \\
\hline $\mathbf{K}$ & $6.32 \mathrm{E}-03$ & 174 & 82.4 \\
\hline $\mathrm{OH}$ & 14.3 & $1.71 \mathrm{E}+0 \mathrm{~S}$ & $8.11 \mathrm{E}+04$ \\
\hline NO3 & 1.09 & $4.73 \mathrm{E}+04$ & $2.23 E+04$ \\
\hline NO2:- & 0.420 & $1.36 \mathrm{E}+04$ & $6.43 \mathrm{E}+03$ \\
\hline $\cos ^{2-}$ & 0.371 & $1.56 \mathrm{E}+04$ & $7.41 \mathrm{E}+03$ \\
\hline $\mathrm{PO}^{3.2}$ & 5.42E-02 & $3.6 .2 \mathrm{E}+03$ & $1.72 \mathrm{E}+03$ \\
\hline $\mathrm{SO}^{2}$ & $5.34 \mathrm{E}-02$ & $3.60 \mathrm{E}+03$ & $1.71 \mathrm{E}+03$ \\
\hline $\mathrm{Si}\left(\right.$ as $\left.\mathrm{SiO}_{3}{ }^{2}\right)$ & $5.82 \mathrm{E}-03$ & 115 & 54.4 \\
\hline$F$ & 0 & 0 & $\mathbf{0}$ \\
\hline CI & $3.63 \mathrm{E}-02$ & 902 & 428 \\
\hline $\mathrm{C}_{6} \mathrm{H}_{3} \mathrm{O}_{7}{ }^{3 .}$ & 0 & 0 & 0 \\
\hline EDTA $^{4}$ & 0 & 0 & 0 \\
\hline HEDTA $^{3 .}$ & 0 & 0 & 0 \\
\hline Bbycolate & 0 & 0 & 0 \\
\hline coctute & 0 & 0 & 0 \\
\hline oxalate ${ }^{2+}$ & 0 & 0 & 0 \\
\hline DEP & 9.48E-06 & 1.77 & 0.840 \\
\hline butunol & $9.48 \mathrm{E}-06$ & 0.494 & 0.234 \\
\hline $\mathrm{NH}_{3}$ & $3.57 \mathrm{E}-04$ & 4.26 & 2.02 \\
\hline $\mathrm{Fe}(\mathrm{CN}){ }^{4}$ & 0 & 0 & 0 \\
\hline \multicolumn{4}{|c|}{ Dolo $=10$} \\
\hline $\mathrm{Pu}$ & & $0.566(\mu \mathrm{Ci} / \mathrm{g})$ & $4.47(\mathrm{~kg})$ \\
\hline $\mathrm{U}$ & $0.208(\mathrm{M})$ & $3.47 \mathrm{E}+04(\mu \mathrm{g} / \mathrm{g})$ & $1.65 \mathrm{E}+04(\mathrm{~kg})$ \\
\hline C & $1.79 \mathrm{E}-03(\mathrm{Ci} / \mathrm{L})$ & $1.26(\mu \mathrm{Ci} / \mathrm{k})$ & $596(\mathrm{Ci})$ \\
\hline Sr & $8.82 \mathrm{E}-03(\mathrm{CH})$ & $6.19(\mu \mathrm{CV} / \mathrm{g})$ & $2.94 \mathrm{E}+03(\mathrm{Ci})$ \\
\hline
\end{tabular}

"Unknowns in tark solids inventory are aswignod by Tank Layering Model (TLM). 


\begin{tabular}{|c|c|c|c|}
\hline \multicolumn{4}{|c|}{ Single-Shell Tank 241-C-101 } \\
\hline \multicolumn{4}{|c|}{ SMM Cormposite inventory Extimnte } \\
\hline 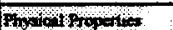 & \% & । & \\
\hline Total Supernatant Wa & $0 \mathbf{k g}$ & \multicolumn{2}{|c|}{ (0 kgal) } \\
\hline Heat Loed & $0 \mathrm{~kW}$ & \multicolumn{2}{|c|}{$(0 \mathrm{BTU} / \mathrm{hr})$} \\
\hline Bulk Density" & \multicolumn{3}{|c|}{$0(g / \propto)$} \\
\hline Water wt\%t & \multicolumn{3}{|c|}{0} \\
\hline TOC wt\% C (wet) & \multicolumn{3}{|c|}{0} \\
\hline \multicolumn{4}{|l|}{ 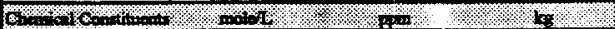 } \\
\hline $\mathrm{Na}^{*}$ & 0 & 0 & 0 \\
\hline $\mathrm{Al}^{\mathrm{3+}}$ & 0 & 0 & 0 \\
\hline $\mathrm{Fe}^{3+}$ (10tal Fe) & 0 & 0 & 0 \\
\hline $\mathrm{Cr}^{3+}$ & 0 & 0 & 0 \\
\hline$B i^{3+}$ & 0 & 0 & 0 \\
\hline $\mathrm{La}^{3+}$ & 0 & 0 & 0 \\
\hline $\mathrm{Hg}^{2+}$ & 0 & 0 & 0 \\
\hline $2 \mathrm{r}\left(\right.$ as $\left.\mathrm{ZrO}(\mathrm{OH})_{h}\right)$ & 0 & 0 & 0 \\
\hline $\mathrm{Pb}^{2+}$ & 0 & 0 & 0 \\
\hline $\mathrm{Ni}^{2+}$ & 0 & 0 & 0 \\
\hline $\mathrm{Sr}^{2+}$ & $\overline{0}$ & 0 & 0 \\
\hline $\mathrm{Mn}^{4+}$ & 0 & 0 & 0 \\
\hline $\mathrm{Ca}^{2+}$ & 0 & 0 & 0 \\
\hline $\mathrm{K}$ & 0 & 0 & 0 \\
\hline $\mathrm{OH}^{-}$ & 0 & 0 & 0 \\
\hline NO3 & 0 & 0 & 0 \\
\hline NO2: & 0 & 0 & 0 \\
\hline $03^{2-}$ & 0 & 0 & 0 \\
\hline $34^{3-2}$ & 0 & 0 & 0 \\
\hline $\mathrm{SO}^{2-}$ & 0) & 0 & 0 \\
\hline $\mathrm{Si}$ (as $\mathrm{SiO}_{3}{ }^{2-1}$ & $\overline{0}$ & 0 & 0 \\
\hline$F$ & 0 & 0 & 0 \\
\hline $\mathrm{Cr}^{-}$ & 0 & 0 & 0 \\
\hline $\mathrm{C}_{n} \mathrm{H}_{3} \mathrm{O}_{7}{ }^{3-2}$ & 0 & 0 & 0 \\
\hline EDTA $^{4+}$ & 0 & 0 & $\mathbf{0}$ \\
\hline HEDTA ${ }^{3 \cdot}$ & 0 & 0 & 0 \\
\hline glycolate & & 0 & 0 \\
\hline acetate & 0 & 0 & $\mathbf{0}$ \\
\hline oxniate:- & 0 & 0 & 0 \\
\hline$\overline{\mathrm{DBP}}$ & 0 & & 0 \\
\hline butanol & 0 & & 0 \\
\hline$\overline{\mathrm{NH}_{\mathbf{3}}}$ & 0 & 0 & 0 \\
\hline $\mathrm{Fe}(\mathrm{CN})_{6}{ }^{4}$ & 0 & 0 & 0 \\
\hline \multicolumn{4}{|c|}{ 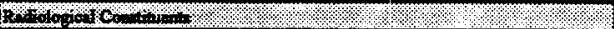 } \\
\hline $\mathrm{Pu}$ & $0(\mu \mathrm{Ci} / \mathrm{L})$ & & 0 (kg) \\
\hline $\mathrm{U}$ & $0(\mathrm{M})$ & $0(\mu g / g)$ & $0(\mathrm{~kg})$ \\
\hline Cs & $O(\mathrm{Ci} / \mathrm{L})$ & $0(\mu \mathrm{Ci} / \mathrm{g})$ & $0(\mathrm{Ci})$ \\
\hline $\mathbf{S r}$ & $0(\mathrm{C} / \mathrm{L})$ & $0(\mu \mathrm{Ci} / \mathrm{g})$ & $0(\mathrm{Ci})$ \\
\hline
\end{tabular}

"Density is caleulated based on $\mathrm{N}_{2} \mathrm{OH}$, and $\mathrm{AlO}_{2}$.

tWater $w \%$ derived from the difference of density and lotal dissolved species. 
WHC-SD-WM-ER-313, Rev. 1

\begin{tabular}{|c|c|c|c|}
\hline \multicolumn{4}{|c|}{ Single-Shell Tank $241+5-101$} \\
\hline \multicolumn{4}{|c|}{ Total lavemory Entimute" } \\
\hline 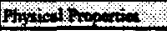 & $\%$ & & \\
\hline Total Wate & $4.74 E+05 \mathrm{~kg}_{8}$ & \multicolumn{2}{|c|}{$(88.0 \mathrm{kgal})$} \\
\hline Heat Laed & $2.26 \mathrm{E}-02 \mathrm{~kW}$ & \multicolumn{2}{|c|}{ (77.1 BTU/hr) } \\
\hline Bulk Denaity" & \multicolumn{3}{|c|}{$1.42(\mathrm{~g} / \mathrm{cc})$} \\
\hline Water wtYot & \multicolumn{3}{|c|}{55.9} \\
\hline TOC w*\% C (wet) $\dagger$ & \multicolumn{3}{|c|}{$9.59 \mathrm{E}-05$} \\
\hline \multicolumn{4}{|l|}{ OAn } \\
\hline $\mathrm{Na}^{+}$ & 2.41 & $3.89 \mathrm{E}+04$ & $1.85 \mathrm{E}+04$ \\
\hline$A 1^{3+}$ & 3.42 & $6.48 \mathrm{E}+04$ & $3.07 \mathrm{E}+04$ \\
\hline $\mathrm{Fe}^{3+}(\operatorname{lot} \mathrm{f} \mathrm{Fe})$ & 0.727 & $2.85 E+04$ & $1.35 \mathrm{E}+04$ \\
\hline $\mathrm{Cr}^{3+}$ & $2.58 \mathrm{E}-03$ & 94.3 & 44.7 \\
\hline $\mathrm{Bi}^{3^{3+}}$ & 0 & 0 & 0 \\
\hline $\mathrm{Le}^{3+4}$ & 0 & 0 & 0 \\
\hline $\mathrm{Hg}^{2+}$ & $2.54 E-03$ & 358 & 170 \\
\hline $\mathrm{Zr}\left(\mathrm{as} \mathrm{ZrO}(\mathrm{OH})_{2}\right)$ & 0 & 0 & 0 \\
\hline $\mathrm{Pb}^{2+}$ & 0.133 & $1.93 \mathrm{E}+04$ & $9.15 E+03$ \\
\hline $\mathrm{Ni}^{2+}$ & $1.29 \mathrm{E}-03$ & 53.2 & 25.2 \\
\hline $\mathrm{sr}^{2+}$ & 0 & 0 & 0 \\
\hline $\mathrm{Mn}^{4+}$ & 0 & 0 & 0 \\
\hline $\mathrm{Ca}^{2+}$ & 0.253 & $7.11 \mathrm{E}+03$ & $3.37 \mathrm{E}+03$ \\
\hline $\mathbf{K}^{+}$ & $6.32 \mathrm{E}-03$ & 174 & 82.4 \\
\hline $\mathrm{OH}$ & 14.3 & $1.71 \mathrm{E}+05$ & $8.11 E+04$ \\
\hline $\mathrm{NO3}^{-}$ & 1.09 & $4.73 \mathrm{E}+04$ & $2.25 \mathrm{E}+04$ \\
\hline NO2: & 0.420 & $1.36 E+04$ & $6.43 \mathrm{E}+03$ \\
\hline $\cos ^{2-}$ & 0.371 & $1.56 \mathrm{E}+04$ & $7.41 E+03$ \\
\hline $\mathrm{PO}_{4}^{3-}$ & $3.42 \mathrm{E}-02$ & $3.62 \mathrm{E}+03$ & $1.72 \mathrm{E}+03$ \\
\hline $\mathrm{SO}^{2-}$ & $5.34 \mathrm{E}-02$ & $3.60 \mathrm{E}+03$ & $1.71 E+03$ \\
\hline $\mathrm{Si}\left(\right.$ as $\mathrm{SiO}_{3}{ }^{2}$ ) & $5.82 \mathrm{E}-03$ & 115 & 54.4 \\
\hline $\mathrm{F}$ & 0 & 0 & 0 \\
\hline $\mathrm{Cr}^{-}$ & $3.63 \mathrm{E}-02$ & 902 & 428 \\
\hline $\mathrm{C}_{6} \mathrm{H}_{3} \mathrm{O}_{7}{ }^{3}$ & 0 & 0 & 0 \\
\hline EDTA $^{4}$ & 0 & 0 & 0 \\
\hline HEDTA $^{3-}$ & 0 & 0 & 0 \\
\hline glycolnte" & 0 & 0 & 0 \\
\hline acelute & 0 & 0 & 0 \\
\hline oxalate ${ }^{2}$ & 0 & 0 & 0 \\
\hline DEP & $9.48 \mathrm{E}-06$ & 1.77 & 0.840 \\
\hline butanol & $9.48 \mathrm{E}-06$ & 0.494 & 0.234 \\
\hline $\mathrm{NH}_{3}$ & $3.57 \mathrm{E}-04$ & 4.26 & 2.02 \\
\hline $\mathrm{Fe}\left(\mathrm{CN}_{6}{ }^{4}\right.$ & 0 & 0 & $\mathbf{0}$ \\
\hline 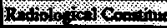 & $\%$ & 6 & \%म \\
\hline Pu & & $0.566(\mu \mathrm{Ci} / g)$ & $4.47(\mathrm{~kg})$ \\
\hline $\bar{U}$ & $0.208(\mathrm{M})$ & $3.47 \mathrm{i}, 04(\mu \mathrm{g} / \mathrm{g})$ & $1.65 \mathrm{E}+04(\mathrm{~kg})$ \\
\hline Cs & $1.79 \mathrm{E}-03$ (CiL) & $1.26(\mu \mathrm{Ci} / \mathrm{g})$ & $596(\mathrm{Ci})$ \\
\hline St & $8.82 \mathrm{E}-03(\mathrm{Ci} / \mathrm{L})$ & $6.19(\mu \mathrm{Cig})$ & $2.94 \mathrm{E}+03(\mathrm{Ci})$ \\
\hline
\end{tabular}

-Unknowns in tank wolids invertory are sarigned by Tank Leyering Model (TLM)

† Volume average for density, mass average Waler wi\% and TOC wh\% C 


\begin{tabular}{|c|c|c|c|}
\hline \multicolumn{4}{|c|}{ Singie-Sheil Tank 241-C-102 } \\
\hline \multicolumn{4}{|c|}{ TLM Solids Compocite Invenuory' Esumate* } \\
\hline 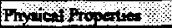 & 8 & 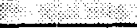 & \\
\hline Total Solid Waste & $2.39 \mathrm{E}+06 \mathrm{~kg}$ & \multicolumn{2}{|c|}{$(423 \mathrm{kgal})$} \\
\hline Heat Loed & $3.93 \mathrm{E}-02 \mathrm{~kW}$ & \multicolumn{2}{|c|}{ (134 BTU/hr) } \\
\hline Bulk Densiry & \multicolumn{3}{|c|}{$1.49(\mathrm{~g} / \mathrm{cc})$} \\
\hline Void Fraction & \multicolumn{3}{|c|}{0.783} \\
\hline Water $1 \%$ & \multicolumn{3}{|c|}{52.8} \\
\hline TOC wt\% C (wet) & \multicolumn{3}{|c|}{$1.06 \mathrm{E}-03$} \\
\hline \multicolumn{2}{|l|}{ 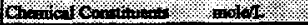 } & $\mathrm{Aewh}$ & \&.: \\
\hline $\mathrm{Na}^{*}$ & 1.68 & $2.59 \mathrm{E}+04$ & $6.18 \mathrm{E}+04$ \\
\hline $\mathrm{A}^{3+2}$ & 5.02 & $9.08 E+04$ & $2.17 \mathrm{E}+05$ \\
\hline $\mathrm{Fe}^{3+}$ (totel Fe) & 0.501 & $1.88 \mathrm{E}+04$ & $4.48 \mathrm{E}+04$ \\
\hline $\mathrm{Cr}^{3+}$ & $2.69 \mathrm{E}-03$ & 93.8 & 224 \\
\hline $\mathrm{Bi}^{3+}$ & 0 & 0 & 0 \\
\hline $\mathrm{Ls}^{3+}$ & \begin{tabular}{l|l}
0 \\
\end{tabular} & 0 & 0 \\
\hline $\mathrm{Hg}^{2+}$ & $4.87 \mathrm{E}-03$ & 655 & $1.56 \mathrm{E}+03$ \\
\hline $\mathrm{Zr}\left( \pm \mathrm{Zr} \mathrm{Z}(\mathrm{OH})_{h}\right)$ & $2.85 \mathrm{E}-02$ & $1.74 \mathrm{E}+03$ & $4.16 \mathrm{E}+03$ \\
\hline $\mathrm{Pb}^{2+}$ & 0.263 & $3.66 \mathrm{E}+04$ & $8.73 E+04$ \\
\hline $\mathrm{Ni}^{2+}$ & $3.56 \mathrm{E}-03$ & 140 & 334 \\
\hline $\mathrm{sr}^{2+}$ & 0 & 0 & o \\
\hline $\mathrm{Mn}^{4+}$ & 0 & 0 & 0 \\
\hline $\mathrm{Ca}^{2+}$ & 0.287 & $7.72 E+03$ & $1.84 \mathrm{E}+04$ \\
\hline$\overline{K^{+}}$ & $9.65 \mathrm{E}-03$ & 253 & 04 \\
\hline $\mathrm{OH}^{-}$ & 18.8 & $2.15 E+05$ & 5.13 \\
\hline NO3: & 0.697 & $290 \mathrm{E}+04$ & 6.92 \\
\hline $\mathrm{NO}_{2}^{-}$ & 0.243 & $7.49 \mathrm{E}+03$ & $\overline{1.79}: \overline{y 4}$ \\
\hline $\cos ^{2-}$ & 0.315 & $1.27 \mathrm{E}+04$ & $3.02 E+04$ \\
\hline $\mathrm{PO}^{3-}$ & $1.44 \mathrm{E}-02$ & 918 & $2.19 \mathrm{E}+03$ \\
\hline $\mathrm{SO}^{2-}$ & $1.74 \mathrm{E}-02$ & $112 \mathrm{E}+03$ & $2.67 \mathrm{E}+03$ \\
\hline Si (as $\mathrm{SiO}_{1}{ }^{2}$ ) & $1.34 \mathrm{E}-03$ & 25.2 & 60.1 \\
\hline$F$ & 0.169 & $2.16 \mathrm{E}+03$ & $5.15 E+03$ \\
\hline $\mathrm{CI}^{-}$ & $1.44 \mathrm{E}-02$ & 342 & 817 \\
\hline $\mathrm{C}_{6} \mathrm{H}_{3} \mathrm{O}_{7}{ }^{3 \cdot}$ & 0 & 0 & 0 \\
\hline EDTA ${ }^{4}$ & n! & 0 & 0 \\
\hline HEDT $^{3}$ & & 0 & 0 \\
\hline glycolste- & & 0 & 0 \\
\hline acetate" & 0 & 0 & 0 \\
\hline oxalate ${ }^{2-}$ & 0 & 0 & $\overline{0}$ \\
\hline DBP & $1.09 \mathrm{E}-04$ & 19.5 & 46.6 \\
\hline butanol & $1.09 \mathrm{E}-04$ & 5.43 & 13.0 \\
\hline $\mathrm{NH}_{3}$ & $2.04 \mathrm{E}-02$ & 232 & 554 \\
\hline $\mathrm{Fe}(\mathrm{CN})_{d}^{4}$ & 0 & 0 & 0 \\
\hline \multicolumn{4}{|l|}{ 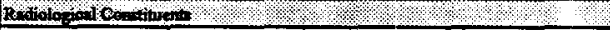 } \\
\hline $\mathrm{Pu}$ & & $1.02(\mu \mathrm{Ci} / \mathrm{g})$ & $40^{-}(\mathrm{kg})$ \\
\hline $\mathrm{U}$ & $0.198(\mathrm{M})$ & $3.16 \mathrm{E}+(04(\mu \mathrm{g} / \mathrm{g})$ & $7.55 \mathrm{E}+04(\mathrm{~kg})$ \\
\hline Cs & $1.83 \mathrm{E}-03(\mathrm{Ci} / \mathrm{L})$ & $1.23(\mu \mathrm{Cig})$ & $2.93 \mathrm{E}+03(\mathrm{Ci})$ \\
\hline Sr & $2.37 E-03(\mathrm{Ci} / \mathrm{L})$ & $1.59(\mu \mathrm{Ci} / \mathrm{g})$ & $3.79 \mathrm{E}+03(\mathrm{Ci})$ \\
\hline
\end{tabular}

*Unknowns in tank wolids invertory are asaigned by Tienk Layering Model (TLM). 


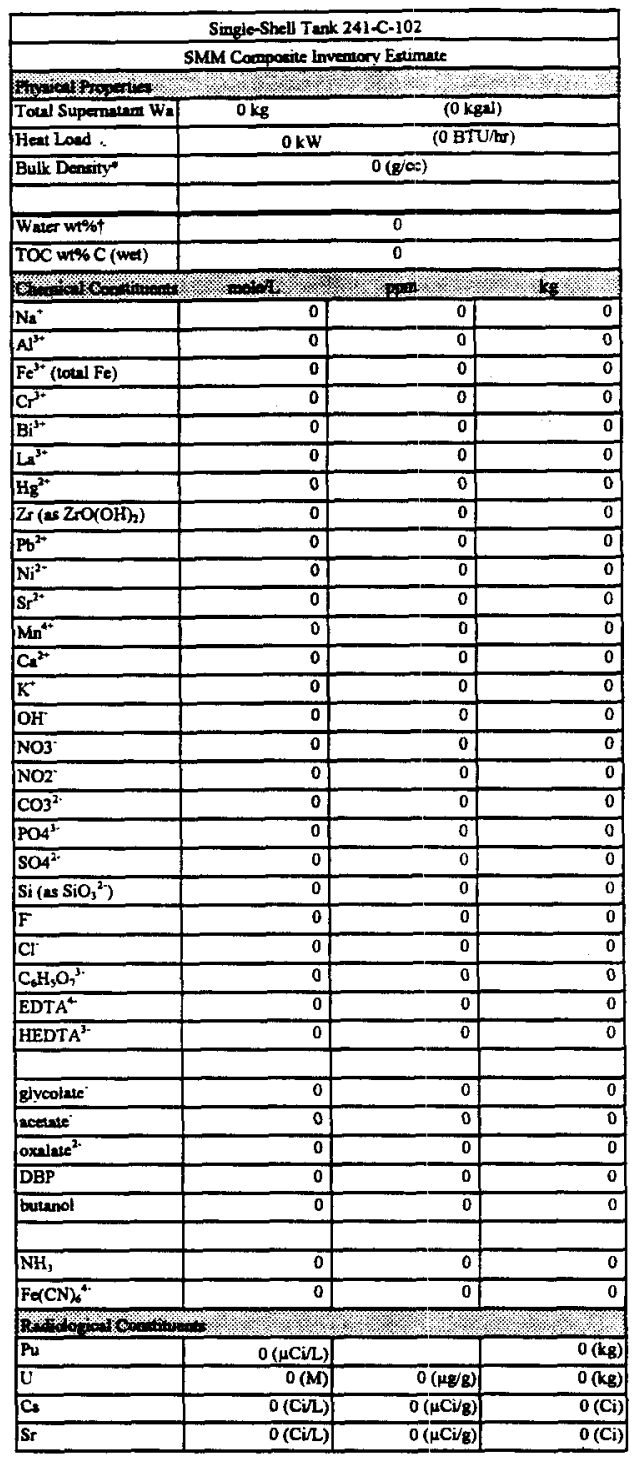

-Derwity is calculated baved on $\mathrm{Na}, \mathrm{OH}$, and $\mathrm{AlO}_{2}$.

$\uparrow$ Water wh\% derived from the difference of density and tetal diseolved species. 
WHC-SD-WM-ER-313, Rev. I

\begin{tabular}{|c|c|c|c|}
\hline \multicolumn{4}{|c|}{ Single-Shell Tank 241-C-102 } \\
\hline \multicolumn{4}{|c|}{ Total Inventory Estimate* } \\
\hline Pho ic I I Fopert & \multirow[b]{2}{*}{$2.39 E+06 \times 8$} & \multicolumn{2}{|c|}{ मिए। } \\
\hline Total Waste & & \multicolumn{2}{|c|}{ (423 kgal) } \\
\hline Heat Lond & $3.93 \mathrm{E}-02 \mathrm{~kW}$ & \multicolumn{2}{|c|}{ (134 BTU/Wr) } \\
\hline Bulk Density ${ }^{+}$ & \multicolumn{3}{|c|}{$1.49(\mathrm{gcc})$} \\
\hline Water w $1 \% \dagger$ & \multicolumn{3}{|c|}{52.8} \\
\hline TOC wt\% C (wet) ${ }^{\prime}$ & \multicolumn{3}{|c|}{$1.06 \mathrm{E}-03$} \\
\hline \multicolumn{2}{|l|}{ 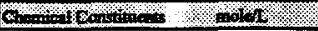 } & $=0$ & $\%$ \\
\hline $\mathrm{Na}^{*}$ & 1.68 & $2.59 \mathrm{E}+04$ & $6.18 \mathrm{E}+04$ \\
\hline$A \mathrm{~A}^{3+}$ & 5.02 & $9.08 \mathrm{E}+04$ & $2.17 E+05$ \\
\hline $\mathrm{Fe}^{37}$ (10tal Fe) & 0.501 & $1.88 E+04$ & $4.48 E+04$ \\
\hline $\mathrm{Cr}^{3+}$ & $2.69 \mathrm{E}-03$ & 93.8 & 224 \\
\hline$B i^{3+}$ & 0 & 0 & 0 \\
\hline $\mathrm{Li}^{3+4}$ & 0 & 0 & 0 \\
\hline $\mathrm{Hg}^{2+}$ & $4.87 \mathrm{E}-03$ & 6.55 & $1.56 \mathrm{E}+03$ \\
\hline $\mathrm{Zr}\left(\right.$ as $\left.\mathrm{ZrO}(\mathrm{OH})_{2}\right)$ & $2.85 \mathrm{E}-02$ & $1.74 \mathrm{E}+03$ & $4.16 \mathrm{E}+03$ \\
\hline $\mathrm{Pb}^{2+}$ & $0 . \overline{263}$ & $3.66 \mathrm{E}+04$ & $8.73 E+04$ \\
\hline $\mathrm{Ni}^{\mathrm{2}}$ & $3.56 \mathrm{E}-03$ & 140 & 334 \\
\hline $5 r^{3+}$ & 0 & 0 & 0 \\
\hline $\mathrm{Mn}^{4+}$ & 0 & 0 & 0 \\
\hline $\mathrm{Ca}^{2+}$ & 0.287 & $7.72 \mathrm{E}$ & $1.84 E+04$ \\
\hline $\mathrm{K}^{+}$ & 9.65E-03 & 253 & 604 \\
\hline $\mathrm{OH}$ & 18.8 & $2.15 \mathrm{E}-0 \mathrm{~S}$ & $5.13 E+05$ \\
\hline NO3* & 0.697 & $2.90 \mathrm{E}+04$ & $6.92 \mathrm{E}+04$ \\
\hline $\mathrm{NO2}$ & 0.243 & $7.49 \mathrm{E}+03$ & $1.79 \mathrm{E}+04$ \\
\hline $\cos ^{2-}$ & 0.315 & $1.27 \mathrm{E}+04$ & $3.02 \mathrm{E}+04$ \\
\hline $\mathrm{PO}^{3-2}$ & $1.44 \mathrm{E}-02$ & 918 & $2.19 \mathrm{E}+03$ \\
\hline $\mathrm{SO}_{4}^{2-}$ & $1.74 \mathrm{E}-02$ & $1.12 \mathrm{E}+03$ & $2.67 \mathrm{E}+03$ \\
\hline Si (as $\mathrm{SiO}_{3}{ }^{2}$ ) & $1.34 \mathrm{E}-03$ & 25.2 & 60.1 \\
\hline$F$ & 0.169 & $2.16 \mathrm{E}+03$ & $5.15 E+03$ \\
\hline $\mathrm{Cl}^{\circ}$ & $1.44 \mathrm{E}-02$ & 342 & 817 \\
\hline $\mathrm{C}_{6} \mathrm{H}_{3} \mathrm{O}_{7}{ }^{3-}$ & 0 & 0 & 0 \\
\hline EDT $4^{*}$ & 0 & 0 & 0 \\
\hline HED IA ${ }^{3-}$ & 0 & 0 & 0 \\
\hline glycolate & 0 & 0 & 0 \\
\hline acetute & 0 & 0 & 0 \\
\hline oxainte ${ }^{2-}$ & 0 & 0 & 0 \\
\hline DBP & $1.09 \mathrm{E}-04$ & 19.5 & 46.6 \\
\hline butanol & $1.09 \mathrm{E}-04$ & 5.43 & 13.0 \\
\hline $\mathrm{NH}_{3}$ & $2.04 \mathrm{E}-02$ & 232 & 554 \\
\hline $\mathrm{Fe}(\mathrm{CN})_{6}^{2}$ & 0 & 0 & 0 \\
\hline 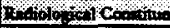 & & 4 & $\%$ \\
\hline Pu & & $1.02(\mu \mathrm{Ci} / \mathrm{g})$ & $40.7(\mathrm{~kg})$ \\
\hline $\mathrm{U}$ & $0.198(\mathrm{M})$ & $3.16 \mathrm{E}+04(\mu \mathrm{g} / \mathrm{g})$ & $7.55 \mathrm{E}+04(\mathrm{~kg})$ \\
\hline Cs & $1.83 \mathrm{E}-03(\mathrm{Ci} / \mathrm{L})$ & $1.23(\mu \mathrm{Ci} / \mathrm{g})$ & $2.93 \mathrm{E}+03(\mathrm{Ci})$ \\
\hline Sr & $2.37 \mathrm{E}-03(\mathrm{Ci} / \mathrm{L})$ & $1.59(\mu \mathrm{Cvg})$ & $3.79 \mathrm{E}+03(\mathrm{Ci})$ \\
\hline
\end{tabular}

Unknowns in tank solids inveruory are assignod by Tank Layering Model (TL.M).

†Volume average for density, mass average Water int\% and TOC wt\% C. 
WHC-SD-WM-ER-313, Rev. 1

\begin{tabular}{|c|c|c|c|}
\hline \multicolumn{4}{|c|}{ Single-Shell Tenk 241-C-103 } \\
\hline \multicolumn{4}{|c|}{ TLM Solids Cormporine Invertory Entimute* } \\
\hline 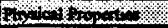 & \multicolumn{3}{|l|}{ 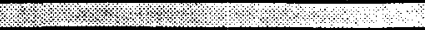 } \\
\hline Toul Solid Ware & $3.21 \mathrm{E}+05 \mathrm{~kg}$ & \multicolumn{2}{|c|}{ (62.0 kgal) } \\
\hline Heat Land & $7.64 \mathrm{~kW}$ & \multicolumn{2}{|c|}{$(2.61 \mathrm{IE}+04 \mathrm{BTU} / \mathrm{hr})$} \\
\hline Bulk Densiny & \multicolumn{3}{|c|}{$1.37(g / x)$} \\
\hline Void Fraction & \multicolumn{3}{|c|}{0.833} \\
\hline Water wh\% & \multicolumn{3}{|c|}{62.2} \\
\hline TOC w\% C (wet) & \multicolumn{3}{|c|}{0} \\
\hline \multicolumn{4}{|l|}{ on } \\
\hline $\mathrm{Na}^{*}$ & 3.44 & $5.79 \mathrm{E}+04$ & $1.86 \mathrm{E}+04$ \\
\hline $\mathrm{Al}^{\mathrm{s}^{+}}$ & 3.10 & $6.13 E+04$ & $1.97 \mathrm{TE}+04$ \\
\hline $\mathrm{Fe}^{3+}($ total Fe) & 0.623 & $2.55 \mathrm{E}+04$ & $8.17 \mathrm{E}+03$ \\
\hline $\mathrm{c}^{3+}$ & $7.26 \mathrm{E}-03$ & 276 & 88.6 \\
\hline $\mathrm{Bi}^{3^{++}}$ & $3.89 \mathrm{E}-06$ & 0.594 & 0.191 \\
\hline La & 0 & 0 & 0 \\
\hline $\mathrm{H}_{8}^{2+}$ & $1.51 E-03$ & 221 & 71.0 \\
\hline $\mathrm{Zr}$ (as $\left.\mathrm{ZrO}(\mathrm{OH})_{2}\right)$ & $1.38 \mathrm{E}-07$ & 9.24E-03 & $2.96 \mathrm{E}-03$ \\
\hline $\mathrm{Pb}^{2+}$ & $7.02 \mathrm{E}-02$ & $1.06 \mathrm{E}+04$ & $3.4 \mathrm{IE}+03$ \\
\hline $\mathrm{Ni}^{2+}$ & $5.68 \mathrm{E}-02$ & $2.44 \mathrm{E}+03$ & 783 \\
\hline $\mathrm{Sr}^{2+}$ & 0 & 0 & $\overline{0}$ \\
\hline $\mathrm{Mn}^{\mathrm{dt}}$ & $8.92 \mathrm{E}-04$ & 35.9 & 11.5 \\
\hline $\mathrm{Cs}^{\mathrm{p}+}$ & 0.116 & $3.40 \mathrm{E}+03$ & $1.09 E+03$ \\
\hline $\bar{K}$ & $3.19 \mathrm{E}-03$ & 91.2 & 29.2 \\
\hline $\mathrm{OH}$ & 12.2 & $1.52 \mathrm{E}+05$ & $4.88 \mathrm{E}+04$ \\
\hline NO3: & 0.336 & $1.53 \mathrm{E}+04$ & $4.89 \mathrm{E}+03$ \\
\hline $\mathrm{NO} 2$ & 0.660 & $2.22 \mathrm{E}+04$ & $7.12 \mathrm{E}+03$ \\
\hline $\cos ^{2}$ & 0.162 & $7.11 \mathrm{E}+03$ & $2.28 \mathrm{E}+03$ \\
\hline $\mathrm{PO}^{3}$ & $7.86 \mathrm{E}-03$ & 546 & 175 \\
\hline $\mathrm{SO}^{22}$ & $3.37 \mathrm{E}-02$ & $2.37 \mathrm{E}+03$ & 760 \\
\hline 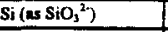 & 0.924 & $1.90 \mathrm{E}+04$ & $6.09 E+03$ \\
\hline$F$ & $1.32 \mathrm{E}-04$ & 1.84 & 0.589 \\
\hline$c t$ & $9.22 \mathrm{E}-03$ & 239 & 76.6 \\
\hline $\mathrm{C}_{4} \mathrm{H}_{3} \mathrm{O}_{7}{ }^{3-}$ & 0 & 0 & 0 \\
\hline EDTA ${ }^{4}$ & 0 & 0 & 0 \\
\hline HEDTA $A^{3-}$ & 0 & 0 & 0 \\
\hline glycolate' & 0 & 0 & 0 \\
\hline ecetinte & 0 & 0 & 0 \\
\hline oxalate & 0 & 0 & 0 \\
\hline DBP & 0 & 0 & 0 \\
\hline burtunol & 0 & 0 & 0 \\
\hline $\mathrm{NH}_{3}$ & $7.79 \mathrm{E}-02$ & 969 & 311 \\
\hline $\mathrm{Fe}(\mathrm{CN})_{0}^{4}$ & 0 & 0 & 0 \\
\hline 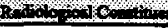 & & $18+\%$ & W \\
\hline Pu & & $3.15(\mu \mathrm{Ci} / \mathrm{g})$ & $16.8(\mathrm{~kg})$ \\
\hline$\overline{\mathrm{U}}$ & $3.98 \mathrm{E}-02(\mathrm{M})$ & $1.04 \mathrm{E}+04(\mu \mathrm{g} / \mathrm{g})$ & $3.34 \mathrm{E}+03(\mathrm{~kg})$ \\
\hline C & $9.38 \mathrm{E}-02(\mathrm{Ci} / \mathrm{L})$ & $68.7(\mu \mathrm{Ci} / \mathrm{g})$ & $2.20 \mathrm{E}+04(\mathrm{Ci})$ \\
\hline Sr & $4.77(\mathrm{Ci} / 2)$ & $3.49 \mathrm{E}+03(\mu \mathrm{Ci} / \mathrm{g})$ & $1.12 \mathrm{E}+06(\mathrm{Ci})$ \\
\hline
\end{tabular}

"Unknowrs in tank solids inventory are anigned by Tank Layering Model (TLM) 
WHC-SD-WM-ER-313, Rev. 1

\begin{tabular}{|c|c|c|c|}
\hline \multicolumn{4}{|c|}{ Single-Shell Tank 241-C-103 } \\
\hline \multicolumn{4}{|c|}{ SMM Cornposite Inventory Estimute } \\
\hline \multicolumn{2}{|l|}{ 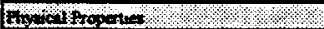 } & \multirow{2}{*}{\multicolumn{2}{|c|}{$(133 \mathrm{kgal})$}} \\
\hline Total Supernitant Wa & $5.68 \mathrm{E}+05 \mathrm{~kg}$ & & \\
\hline Heat Lond & $0.258 \mathrm{~kW}$ & \multicolumn{2}{|c|}{$(880 \mathrm{BTU} / \mathrm{hr})$} \\
\hline Bulk Density* & \multicolumn{3}{|c|}{$1.13\left(g^{\prime} \propto c\right)$} \\
\hline Waler wt $\%$ & \multicolumn{3}{|c|}{78.7} \\
\hline TOC w\% C (wet) & \multicolumn{3}{|c|}{1.72} \\
\hline \multicolumn{2}{|l|}{ Canno } & $4 \mathrm{tin}$ & st \\
\hline $\mathrm{Na}^{+}$ & 2.86 & $5.826+04$ & $3.31 \mathrm{E}+04$ \\
\hline $\mathrm{Al}^{\mathrm{j}+}$ & 0.315 & $7.52 E+03$ & $4.27 \mathrm{E}+03$ \\
\hline $\mathrm{Fe}^{3+}$ (total $\left.\mathrm{Fe}\right)$ & $1.36 \mathrm{E}-03$ & 67.6 & 38.4 \\
\hline $\mathrm{Cr}^{3+}$ & $7.33 \mathrm{E}-03$ & 338 & 192 \\
\hline $\mathrm{Bi}^{3+}$ & $1.83 \mathrm{E}-04$ & 33.8 & 19.2 \\
\hline $\mathrm{La}^{\mathrm{3}}$ & $7.31 \mathrm{E}-07$ & $9.00 \mathrm{E}-02$ & $5.11 \mathrm{E}-02$ \\
\hline $\mathrm{Hg}^{2+}$ & $2.13 \mathrm{E}-06$ & 0.378 & 0.215 \\
\hline $\mathrm{Zr}\left(\mathrm{as} \mathrm{ZrO}\left(\mathrm{OH}_{2}\right)\right.$ & 6.48E-0S & 5.24 & 2.98 \\
\hline $\mathrm{Pb}^{i^{*}}$ & $3.60 \mathrm{E}-04$ & 66.1 & 37.6 \\
\hline $\mathrm{Ni}^{i^{2+}}$ & $7.16 \mathrm{E}-04$ & 37.2 & 21.2 \\
\hline $\mathrm{st}^{2+}$ & $2.44 E-07$ & $1.89 \mathrm{E}-02$ & $1.07 \mathrm{E}-02$ \\
\hline $\mathrm{Mn}^{4+}$ & $9.55 \mathrm{E}-04$ & 46.5 & 26.4 \\
\hline $\mathrm{Ca}^{2+}$ & $6.13 \mathrm{E}-03$ & 218 & 124 \\
\hline$\overline{\mathrm{K}}^{+}$ & $1.46 \mathrm{E}-02$ & 505 & 287 \\
\hline $\mathrm{OH}$ & 1.41 & $2.13 \mathrm{E}+04$ & $1.21 \mathrm{E}+04$ \\
\hline $\mathrm{NO}^{-}$ & 0.811 & $4.45 E+04$ & $2.53 \mathrm{E}+04$ \\
\hline NO2: & 0.470 & $1.92 \mathrm{E}+04$ & $1.09 E+04$ \\
\hline $\cos ^{2 \cdot}$ & 0.158 & $8.40 \mathrm{E}+03$ & $4.77 E+03$ \\
\hline $\mathrm{PO}_{4}^{3-}$ & $1.64 \mathrm{E} \sim 02$ & $1.38 \mathrm{E}+03$ & 785 \\
\hline SO4:- & $7.89 E-02$ & $6.72 \mathrm{E}+03$ & $3.82 E+03$ \\
\hline $\mathrm{Si}\left(\right.$ as $\left.\mathrm{SiO}_{3}{ }^{2+}\right)$ & $1.97 \mathrm{E}-02$ & 490 & 278 \\
\hline$F$ & $1.19 \mathrm{E}-02$ & 201 & 114 \\
\hline $\mathrm{Cr}$ & $5.06 \mathrm{E}-02$ & $1.59 \mathrm{E}+03$ & 902 \\
\hline $\mathrm{C}_{8} \mathrm{H}_{3} \mathrm{O}_{7}{ }^{3-}$ & $7.36 \mathrm{E}-03$ & $1.23 \mathrm{E}+03$ & 701 \\
\hline EDTA ${ }^{*}$ & $4.42 \mathrm{E}-02$ & $1.13 \mathrm{E}+04$ & $6.40 \mathrm{E}+03$ \\
\hline HEDTA ${ }^{3-}$ & $8.39 \mathrm{E}-02$ & $2.04 \mathrm{E}+04$ & $1.16 \mathrm{E}+04$ \\
\hline glycolate & $9.39 \mathrm{E}-02$ & $6.25 E+03$ & $3.55 \mathrm{E}+03$ \\
\hline acetate- & $1.40 \mathrm{E}-02$ & 734 & 417 \\
\hline oxalate ${ }^{2-}$ & $6.25 \mathrm{E}-07$ & $4.88 \mathrm{E}-02$ & $2.77 \mathrm{E}-02$ \\
\hline DB? & $6.28 \mathrm{E}-03$ & $1.48 \mathrm{E}+03$ & 841 \\
\hline butanol & $6.28 \mathrm{E}-03$ & 412 & 234 \\
\hline$\overline{\mathrm{NH}_{3}}$ & $4.57 E-03$ & 68.8 & 39.1 \\
\hline $\mathrm{Fe}(\mathrm{CN})_{6}{ }^{4}$ & 0 & 0 & 0 \\
\hline \multicolumn{4}{|l|}{ 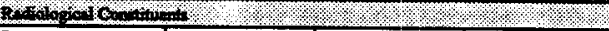 } \\
\hline Pu & $18.8(\mu \mathrm{Ci} / \mathrm{L})$ & & $0.158(\mathrm{~kg})$ \\
\hline U & $2.51 \mathrm{E}-03(\mathrm{M})$ & $530(\mu \mathrm{g} / \mathrm{g})$ & $301(\mathrm{~kg})$ \\
\hline C. & $5.41 \mathrm{E}-02(\mathrm{Ci} / \mathrm{L})$ & $47.9(\mu \mathrm{Ci} / \mathrm{g})$ & $2.72 \mathrm{E}+0.4(\mathrm{Ci})$ \\
\hline Sr & $3.84 \mathrm{E}-02(\mathrm{Ci} / \mathrm{L})$ & $34.0(\mu \mathrm{Ci} / \mathrm{g})$ & $1.93 \mathrm{E}+04(\mathrm{Ci})$ \\
\hline
\end{tabular}

-Density is calculated based on $\mathrm{Na}, \mathrm{OH}$, and $\mathrm{AlO}_{2}$.

†Water wt\% derived from the difference of density and totni dissolved apecies. 


\begin{tabular}{|c|c|c|c|}
\hline \multicolumn{4}{|c|}{ Single-Shell Tank 241-C. 103} \\
\hline \multicolumn{4}{|c|}{ Total lnventorv Estimate* } \\
\hline \multicolumn{4}{|l|}{ 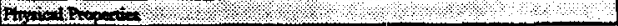 } \\
\hline Total Wane & $8.89 \mathrm{E}+05 \mathrm{~kg}$ & \multicolumn{2}{|c|}{ (193 kgal) } \\
\hline Heat Laed & $7.90 \mathrm{~kW}$ & \multicolumn{2}{|c|}{$(2.70 \mathrm{E}+04 \mathrm{BTU} / \mathrm{hs})$} \\
\hline Bulk Dentity" & \multicolumn{3}{|c|}{$1.20(\mathrm{~g} / \mathrm{ec})$} \\
\hline Water wh\%+ & \multicolumn{3}{|c|}{72.8} \\
\hline TOC w\% C (wet) $\dagger$ & \multicolumn{3}{|c|}{1.10} \\
\hline \multicolumn{2}{|l|}{ 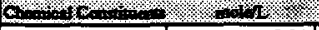 } & \multicolumn{2}{|r|}{3.} \\
\hline $\mathrm{Na}^{+}$ & 3.04 & $5.81 E+04$ & $5.16 \mathrm{E}+04$ \\
\hline $\mathrm{Al}^{2+2}$ & 1.20 & $2.69 E+04$ & $2.39 \mathrm{E}+04$ \\
\hline $\mathrm{Fe}^{\mathrm{j+}}$ (total Fe) & 0.199 & $9.23 \mathrm{E}+03$ & $8.21 E+03$ \\
\hline $\mathrm{Cr}^{\mathrm{3}+}$ & 7.31E-03 & 316 & 281 \\
\hline $\mathrm{Bi}^{3+}$ & $1.26 \mathrm{E}-04$ & 21.8 & 19.4 \\
\hline $\mathrm{La}^{3+}$ & $4.99 \mathrm{E}-07$ & $5.75 \mathrm{E}-02$ & $9.11 \mathrm{E}-02$ \\
\hline $\mathrm{Hg}^{2+}$ & 4.81E-04 & 80.1 & 71.2 \\
\hline $\mathrm{Zr}\left(\mathrm{s} \mathrm{ZrO}(\mathrm{OH})_{h}\right)$ & $4.43 \mathrm{E}-05$ & 3.35 & 2.98 \\
\hline $\mathrm{Fb}^{2+}$ & $2.26 \mathrm{E}-02$ & $3.88 \mathrm{E}+03$ & $3.45 E+03$ \\
\hline $\mathrm{Ni}^{2+}$ & $1.85 \mathrm{E}-02$ & 904 & 804 \\
\hline $\mathrm{Sr}^{2+}$ & $1.66 \mathrm{E}-07$ & $1.21 \mathrm{E}-02$ & $1.07 \mathrm{E}-02$ \\
\hline $\mathrm{Mn}^{4+}$ & 9.35E-04 & 42.7 & 37.9 \\
\hline $\mathrm{Ca}^{2+}$ & 4.11E-02 & $1.37 E+03$ & $1.22 \mathrm{E}+03$ \\
\hline $\mathrm{K}^{*}$ & $1.10 \mathrm{E}-02$ & 356 & 316 \\
\hline OH & 4.85 & $6.85 E+04$ & $6.09 \mathrm{E}+04$ \\
\hline $\mathrm{NO3}^{-}$ & 0.660 & $3.40 \mathrm{E}+04$ & $3.02 \mathrm{E}+04$ \\
\hline NO2 & 0.530 & $2.03 \mathrm{E}+04$ & $1.80 E+04$ \\
\hline $\cos ^{2{ }^{2}}$ & 0.159 & $7.93 \mathrm{E}+03$ & $7.05 E+03$ \\
\hline $\mathrm{PO}^{3 *}$ & 1.37E-02 & $1.08 \mathrm{E}+03$ & 960 \\
\hline $504^{2-}$ & $6.45 \mathrm{E}-02$ & $5.15 \mathrm{E}+03$ & $4.58 \mathrm{E}+03$ \\
\hline $\mathrm{Si}\left(\right.$ as $\left.\mathrm{SiO}_{3}{ }^{2+}\right)$ & 0.307 & $7.17 E+03$ & $6.37 \mathrm{E}+03$ \\
\hline$F$ & $8.17 \mathrm{E}-03$ & 129 & 115 \\
\hline $\mathrm{Cl}$ & $3.74 \mathrm{E}-02$ & $1.10 \mathrm{E}+03$ & 979 \\
\hline $\mathrm{C}_{6} \mathrm{H}_{3} \mathrm{O}_{7}{ }^{3-}$ & $5.02 E-03$ & 789 & 701 \\
\hline EDTA ${ }^{4}$ & $3.01 \mathrm{E}-02$ & $1.21 \mathrm{E}+03$ & $6.40 \mathrm{E}+03$ \\
\hline HEDTA ${ }^{2}$ & $5.72 \mathrm{E}-02$ & $1.30 \mathrm{E}+04$ & $1.16 \mathrm{E}+04$ \\
\hline glycolate & $6.41 \mathrm{E}-02$ & $3.99 \mathrm{E}+03$ & $3.55 \mathrm{E}+03$ \\
\hline ecente: & $9.57 \mathrm{E}-03$ & 469 & 417 \\
\hline oxainue ${ }^{2+}$ & 4.27E-07 & $3.12 \mathrm{E}-02$ & $2.77 \mathrm{E}-02$ \\
\hline DBP & $4.28 \mathrm{E}-03$ & 946 & 841 \\
\hline butanol & $4.28 \mathrm{E}-03$ & 264 & 234 \\
\hline $\mathrm{NH}_{3}$ & $2.79 \mathrm{E}-02$ & 394 & 350 \\
\hline $\mathrm{Fo}(\mathrm{CN}) \mathrm{K}^{-}$ & 0 & 0 & 0 \\
\hline 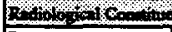 & & & \\
\hline $\mathrm{Pu}$ & & $1.15(\mu \mathrm{Ci} / \mathrm{g})$ & $17.0(\mathrm{~kg})$ \\
\hline $\mathrm{U}$ & $2.07 \mathrm{E}-02(\mathrm{M})$ & $4.10 \mathrm{E}+03(\mu \mathrm{g} / \mathrm{B})$ & $3.64 E+03(\mathrm{~kg})$ \\
\hline Cs & $6.67 \mathrm{E}-02(\mathrm{Ci} / \mathrm{L})$ & $53.4(\mu \mathrm{Ci} / \mathrm{g})$ & $4.93 \mathrm{E}+04(\mathrm{Ci})$ \\
\hline Sr & $1.54(\mathrm{Cin})$ & $1.28 \mathrm{E}+03(\mu \mathrm{Ci} / \mathrm{g})$ & $1.14 \mathrm{E}+06(\mathrm{Ci})$ \\
\hline
\end{tabular}

"Uaknowns in lank solids inverdory are asrigned by Tank Layering Model (TLM).

† Volume average for density, mass average Water we\% and TOC wt\% C. 


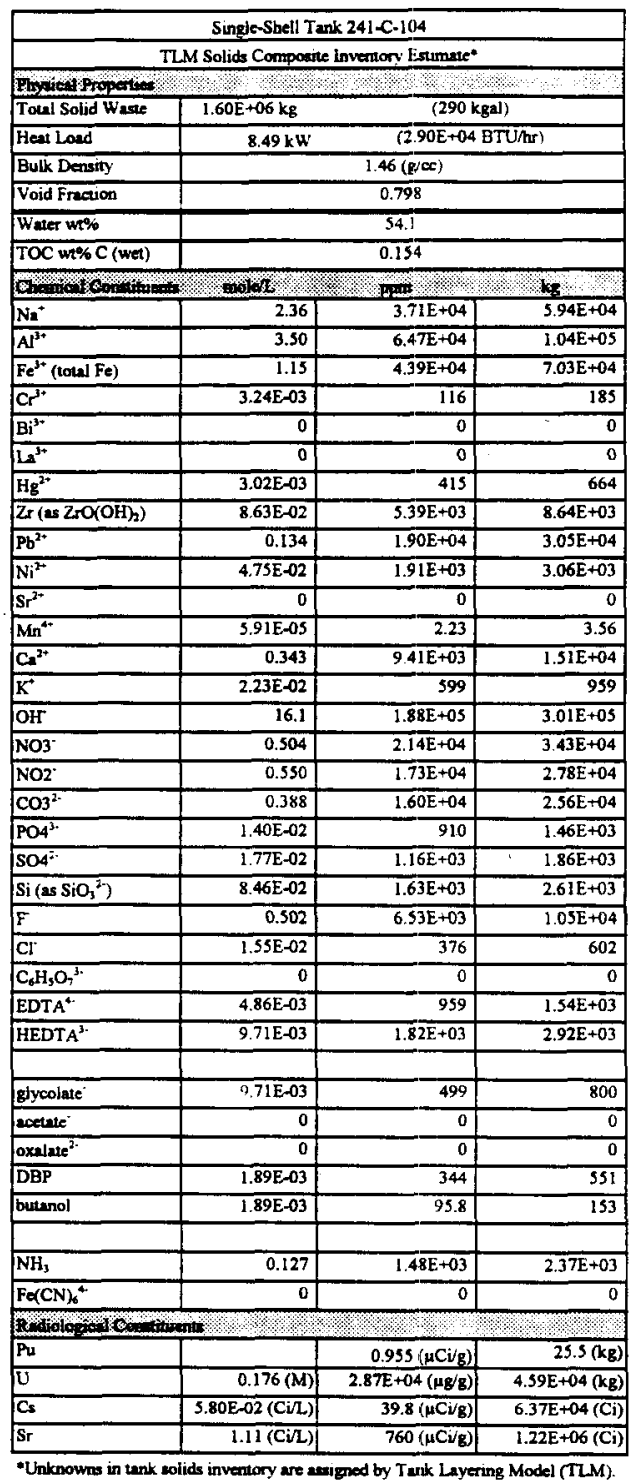


WHC-SD-WM-ER-313, Rev. 1

\begin{tabular}{|c|c|c|c|}
\hline \multicolumn{4}{|c|}{ Single-Shell Tank 241-C-104 } \\
\hline \multicolumn{4}{|c|}{ SMM Composite Inventory Estimnte } \\
\hline 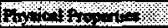 & \multirow[b]{2}{*}{$2.50 \mathrm{E}+04 \mathrm{~kg}$} & \multicolumn{2}{|c|}{ ॥ } \\
\hline Total Supernitant Wa & & \multicolumn{2}{|c|}{ (5.04 kgal) } \\
\hline Heat Load & $2.25 \mathrm{E}-02 \mathrm{~kW}$ & \multicolumn{2}{|c|}{$(76.9 \mathrm{BTU} / \mathrm{hr})$} \\
\hline Bullk Density & \multicolumn{3}{|c|}{$1.31(g / x)$} \\
\hline Water wt\%! & \multicolumn{3}{|c|}{38.1} \\
\hline TOC wt\% C (wet) & \multicolumn{3}{|c|}{1.08} \\
\hline \multicolumn{2}{|l|}{ 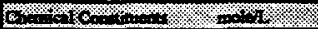 } & 3 & $\mathbf{L}$ \\
\hline $\mathrm{Na}^{+}$ & 6.62 & $1.16 \mathrm{E}+05$ & $2.90 \mathrm{E}+03$ \\
\hline$A \mathrm{~A}^{3+}$ & 0.907 & $1.87 E+04$ & 466 \\
\hline $\mathrm{Fe}^{3+}$ (total $\left.\mathrm{Fe}\right)$ & 3.75E-03 & 160 & 3.99 \\
\hline $\mathrm{Cr}^{3+}$ & $2.87 \mathrm{E}-02$ & $1.14 \bar{E}+03$ & 28.4 \\
\hline $\mathrm{Bi}^{\mathbf{i}^{*}}$ & $6.73 \mathrm{E}-04$ & 107 & 2.68 \\
\hline $\mathrm{Lx}^{3 *}$ & 1.48E-05 & 1.57 & $3.91 \mathrm{E}-02$ \\
\hline $\mathrm{Hg}^{2+}$ & $5.28 E-06$ & 0.809 & $2.02 \mathrm{E}-02$ \\
\hline $\mathrm{Zx}\left(\mathrm{as} \mathrm{ZTO}(\mathrm{OH})_{2}\right)$ & 3.90E-04 & 27.2 & 0.678 \\
\hline $\mathrm{Pb}^{2+}$ & $6.93 \mathrm{E}-04$ & 110 & 2.73 \\
\hline $\mathrm{Ni}^{2^{2+}}$ & 3.04E-03 & 136 & 3.40 \\
\hline $\mathrm{Sr}^{2+}$ & 4.93E-06 & 0.329 & $8.23 \mathrm{E}-03$ \\
\hline $\mathrm{Mn}^{4+}$ & $2.46 \mathrm{E}-03$ & 103 & 2.57 \\
\hline $\mathrm{Ca}^{2+2}$ & $1.70 \mathrm{E}-02$ & 520 & 13.0 \\
\hline $\boldsymbol{K}$ & 3.24E-02 & 968 & 24.2 \\
\hline $\mathrm{OH}$ & 3.96 & $5.14 \mathrm{E}+04$ & $1.28 \mathrm{E}+03$ \\
\hline NO3' & 2.60 & $1.23 \mathrm{E}+05$ & $3.07 \mathrm{E}+03$ \\
\hline $\mathrm{NO2}$ & 1.34 & $4.70 \mathrm{E}+04$ & $1.17 \mathrm{E}+03$ \\
\hline $\cos ^{2}$ & 0.286 & $1.31 \mathrm{E}+04$ & 327 \\
\hline $\mathrm{PO4}^{3-2}$ & 5.00E-02 & $3.63 E+03$ & 90.6 \\
\hline $\mathrm{SO}_{4}^{2-}$ & 0.155 & $1.14 \mathrm{E}+04$ & 284 \\
\hline $\operatorname{Si}\left(\mathrm{As} \mathrm{SiO}_{3}{ }^{2}\right)$ & $4,42 \mathrm{E}-02$ & 949 & 23.7 \\
\hline$F$ & $4.00 \mathrm{E}-02$ & 580 & 14.5 \\
\hline $\mathrm{Cl}$ & 0.118 & $3.18 \mathrm{E}+03$ & 79.3 \\
\hline $\mathrm{C}_{6} \mathrm{H}_{3} \mathrm{O}_{7}^{3-}$ & $1.79 \mathrm{E}-02$ & $2.58 \mathrm{E}+03$ & 64.5 \\
\hline EDTA $^{4}$ & $2.52 \mathrm{E}-02$ & $5.54 \mathrm{E}+03$ & 138 \\
\hline HEDTA ${ }^{3-}$ & $4.66 \mathrm{E}-02$ & $9.74 \mathrm{E}+03$ & 243 \\
\hline giveolate & $8.23 \mathrm{E}-02$ & $4.71 E+03$ & 118 \\
\hline acerate' & $1.23 \mathrm{E}-02$ & 554 & 13.8 \\
\hline oxalate $e^{2-}$ & $1.26 \mathrm{E}-05$ & 0.850 & $2.12 \mathrm{E}-02$ \\
\hline DBP & $1.39 \mathrm{E}-02$ & $2.83 \mathrm{E}+03$ & 70.6 \\
\hline butanol & $1.39 \mathrm{E}-02$ & 788 & 19.7 \\
\hline $\mathrm{NH}_{3}$ & $2.50 \mathrm{E}-02$ & 324 & 8.10 \\
\hline $\mathrm{Fe}(\mathrm{CN})_{6}{ }^{4}$ & 0 & 0 & $\mathbf{0}$ \\
\hline \multicolumn{4}{|l|}{ 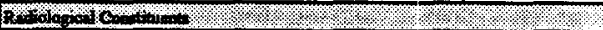 } \\
\hline Pu & $44.1(\mu \mathrm{Ci} / L)$ & & $1.40 \mathrm{E}-02(\mathrm{~kg})$ \\
\hline $\mathrm{U}$ & $6.38 \mathrm{E}-03(\mathrm{M})$ & $1.16 \mathrm{E}+03(\mathrm{\mu g} / \mathrm{g})$ & $28.9(\mathrm{~kg})$ \\
\hline C. & $0.155(\mathrm{Ci} / \mathrm{L})$ & $118(\mu \mathrm{Ci} / \mathrm{g})$ & $2.95 \mathrm{E}+0.3(\mathrm{Ci})$ \\
\hline Sr & $6.76 \mathrm{E}-02(\mathrm{Ci} / \mathrm{L})$ & $51.6(\mu \mathrm{Ci} / \mathrm{g})$ & $1.29 E+03(\mathrm{Ci})$ \\
\hline
\end{tabular}




\begin{tabular}{|c|c|c|c|}
\hline \multicolumn{4}{|c|}{ Single-Shell Tank 24 i-C-104 } \\
\hline \multicolumn{4}{|c|}{ Total Inventory Estrmite" } \\
\hline \multicolumn{2}{|l|}{ Phole Propes } & \multicolumn{2}{|c|}{ में } \\
\hline Total Waste & $1.63 \mathrm{E}+66 \mathrm{~kg}$ & \multicolumn{2}{|c|}{ (295 kgal) } \\
\hline Heat Laed & $52 \mathrm{~kW}$ & \multicolumn{2}{|c|}{$(2.91 \mathrm{E}+04 \mathrm{BTU} / \mathrm{hr})$} \\
\hline Bulk Density ${ }^{+}$ & \multicolumn{3}{|c|}{$1.46(\mathrm{~g} j \mathrm{cc}:$} \\
\hline Water wt $\%^{+}$ & \multicolumn{3}{|c|}{54.2} \\
\hline TOC w1\% C (wet)! & \multicolumn{3}{|c|}{0.169} \\
\hline \multicolumn{2}{|l|}{ 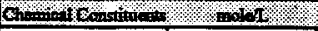 } & fon & 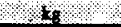 \\
\hline $\mathrm{Na}^{+}$ & 2.43 & $3.83 \mathrm{E}+04$ & $6.23 \mathrm{E}+04$ \\
\hline $\mathrm{Al}^{3+}$ & 3.45 & $6.40 \mathrm{E}+04$ & $1.04 \mathrm{E}+05$ \\
\hline $\mathrm{Fe}^{3+}($ total $\mathrm{Fe})$ & 1.13 & $4.32 \mathrm{E}+04$ & $7.03 \mathrm{E}+04$ \\
\hline $\mathrm{Cr}^{3+}$ & $3: 8 \mathrm{E}-03$ & 131 & 214 \\
\hline $\mathrm{Bi}^{3+}$ & 1. SE-05 & 1.65 & 2.68 \\
\hline $\mathrm{LE}^{3+}$ & $2.52 \mathrm{E}-07$ & $2.41 \mathrm{E}-02$ & $3.91 \mathrm{E}-02$ \\
\hline $\mathrm{Hg}^{2+}$ & 2.97E-03 & 408 & 664 \\
\hline $\mathrm{Zr}$ (as $\left.\mathrm{ZrO}(\mathrm{OH})_{2}\right)$ & $8.48 \mathrm{E}-02$ & $5.31 \mathrm{E}+03$ & $8.64 E+03$ \\
\hline $\mathrm{Pb}^{2+}$ & 0.132 & $1.88 \mathrm{E}+04$ & $3.05 E+04$ \\
\hline $\mathrm{Ni}^{2+}$ & 4.67E-02 & $1.88 \mathrm{E}+03$ & $3.06 \mathrm{E}+03$ \\
\hline $\mathrm{Si}^{2 *}$ & 8.41E-08 & $5.06 \mathrm{E}-03$ & $8.23 E-03$ \\
\hline $\mathrm{Mn}^{4+}$ & $1.00 \mathrm{E}-04$ & 3.77 & 6.14 \\
\hline $\mathrm{Ca}^{2+}$ & 0.337 & $9.27 E+03$ & $1.51 \mathrm{E}+04$ \\
\hline $\mathrm{K}^{+}$ & $2.25 \mathrm{E}-02$ & 604 & 983 \\
\hline $\mathrm{OH}$ & 15.9 & $1.86 \mathrm{E}+05$ & $3.02 \mathrm{E}+05$ \\
\hline $\mathrm{NO3}^{-}$ & 0.540 & $2.30 E+04$ & $3.74 \mathrm{E}+04$ \\
\hline NO2 & 0.564 & $1.78 \mathrm{E}+04$ & $2.89 \mathrm{E}+04$ \\
\hline $\mathrm{CO}^{2}$ & 0.386 & $1.59 E+04$ & $2.59 \mathrm{E}+04$ \\
\hline $\mathrm{PO}^{3-}$ & $1.46 \mathrm{E}-02$ & 952 & $1.55 E+03$ \\
\hline $504^{2-}$ & $2.00 \mathrm{E}-02$ & $1.3 z i+03$ & $2.15 E+03$ \\
\hline $\mathrm{Si}\left(\mathrm{as} \mathrm{SiO}_{3}{ }^{2+}\right)$ & $8.39 E-02$ & $1.62 E+03$ & $2.63 \mathrm{E}+03$ \\
\hline$F$ & 0.494 & $6.44 \mathrm{E}+03$ & $1.05 E+04$ \\
\hline $\mathrm{Cr}$ & $1.72 \mathrm{E}-02$ & 419 & 681 \\
\hline $\mathrm{C}_{6} \mathrm{H}_{9} \mathrm{O}_{7}{ }^{3-}$ & $3.06 \mathrm{E}-04$ & 39.7 & 64.5 \\
\hline EDTA $^{\alpha-}$ & $5.20 \mathrm{E}-03$ & $1.03 \mathrm{E}+03$ & $1.67 \mathrm{E}+03$ \\
\hline HEDTA ${ }^{3 .}$ & $1.03 \mathrm{E}-02$ & $1.95 E+03$ & $3.17 \mathrm{E}+03$ \\
\hline glycolate & $1.10 \mathrm{E}-02$ & 564 & 917 \\
\hline acetate & $2.10 \mathrm{E}-04$ & 8.50 & 13.8 \\
\hline oxalate ${ }^{2}$ & $2.16 \mathrm{E}-07$ & $1.30:-02$ & $2.12 \mathrm{E}-02$ \\
\hline DBP & 2.09E-03 & 52 & 621 \\
\hline butanol & $2.09 \mathrm{E}-03$ & 106 & 173 \\
\hline $\mathrm{NH}_{3}$ & 0.125 & $1.46 \mathrm{E}+03$ & $2.38 \mathrm{E}+03$ \\
\hline $\mathrm{Fe}(\mathrm{CN})_{6}^{4}$ & 0 & 0 & 0 \\
\hline \multicolumn{4}{|c|}{ 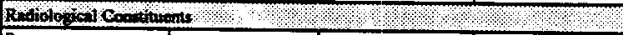 } \\
\hline Pu & & $0.941(\mu \mathrm{Ci} / \mathrm{g})$ & $25.5(\mathrm{~kg})$ \\
\hline $\mathrm{U}$ & $0.173(\mathrm{M})$ & $2.82 \mathrm{E}+04(\mu \mathrm{g} / \mathrm{g})$ & $4.59 \mathrm{E}+04(\mathrm{~kg})$ \\
\hline $\mathrm{Cs}$ & $5.97 \mathrm{E}-02(\mathrm{Ci} / \mathrm{L})$ & $41.0(\mu \mathrm{Ci} / \mathrm{g})$ & $6.67 \mathrm{E}+04(\mathrm{Ci})$ \\
\hline $\mathrm{Sr}$ & $1.09(\mathrm{Ci} / \mathrm{L})$ & $749(\mu \mathrm{Ci} / \mathrm{g})$ & $1.22 \mathrm{E}+06(\mathrm{Ci})$ \\
\hline
\end{tabular}

"Unknowns in lank solids invemtory are astigned by Tank Layering Model (TLM) tVolume average for densiry, mass average Waler wto and TOC wt\% C. 
WHC-SD-WM-ER-313, Rev. 1

\begin{tabular}{|c|c|c|c|}
\hline \multicolumn{4}{|c|}{ Singie-Shell Tenk 241-C-10: } \\
\hline \multicolumn{4}{|c|}{ TLM Solids Composite Inventory Estimate* } \\
\hline 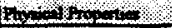 & & -6 & \\
\hline Total Solid Watte & $7.96 \mathrm{E}+05 \mathrm{~kg}$ & \multicolumn{2}{|c|}{ (150 kgal) } \\
\hline Hen Land & $2.00 \mathrm{E}-02 \mathrm{~kW}$ & \multicolumn{2}{|c|}{$(68.4 \mathrm{BTU} / \mathrm{hr})$} \\
\hline Bullk Density & \multicolumn{3}{|c|}{$1.40(g / x)$} \\
\hline Void Fraction & \multicolumn{3}{|c|}{0.842} \\
\hline Water wo & \multicolumn{3}{|c|}{58.1} \\
\hline TOC wt\% C (wet) & \multicolumn{3}{|c|}{$2.86 E-05$} \\
\hline \multicolumn{2}{|l|}{ 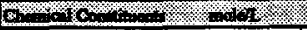 } & 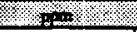 & 12 \\
\hline $\mathrm{Na}^{*}$ & 2.14 & $3.51 E+04$ & $2.79 \mathrm{E}+04$ \\
\hline $\mathrm{Al}^{3+}$ & 4.64 & $8.93 \mathrm{E}+04$ & $7.11 \mathrm{E}+04$ \\
\hline $\mathrm{Fe}^{3+}$ (total Fe) & 0.306 & $1.22 \mathrm{E}+04$ & $9.69 E+03$ \\
\hline $\mathrm{Cr}^{3+}$ & 2.61E-03 & 96.7 & 76.9 \\
\hline$B i^{3+2}$ & 0 & 0 & 0 \\
\hline $\mathrm{Le}^{3+}$ & 0 & 0 & 0 \\
\hline $\mathrm{Hg}^{2+}$ & $2.27 \mathrm{E}-03$ & 325 & 259 \\
\hline $\mathrm{Zr}$ (as ZNOKOH) & 0 & 0 & $\overline{0}$ \\
\hline $\mathrm{Ft}^{2}$ & 0.106 & $1.57 \mathrm{E}+04$ & $1.25 \mathrm{E}+04$ \\
\hline $\mathrm{Ni}^{i^{*}}$ & $1.30 \mathrm{E}-03$ & 54.6 & 43.4 \\
\hline $\mathrm{Sr}^{2+}$ & $\mathbf{0}$ & 0 & 0 \\
\hline $\mathrm{Mn}^{4+4}$ & 0 & 0 & $\overline{0}$ \\
\hline $\mathrm{CA}^{\mathrm{j}^{2}}$ & 0.143 & $4.09 \bar{E}+03$ & $3.25 \mathrm{E}+03$ \\
\hline $\mathrm{K}^{*}$ & $2.64 \mathrm{E}-03$ & 73.7 & 58.6 \\
\hline $\mathrm{OH}$ & 16.3 & $1.98 E+05$ & $1.57 \mathrm{E}+05$ \\
\hline NO3' & 0.726 & $3.21 \mathrm{E}+04$ & $2.56 \mathrm{E}+04$ \\
\hline $\mathrm{NO} 2$ & 0.643 & $2.11 \mathrm{E}+04$ & $1.68 \mathrm{E}+04$ \\
\hline $\cos ^{2-}$ & 0.160 & $6.83 \mathrm{E}+03$ & $5.43 \mathrm{E}+03$ \\
\hline $\mathrm{PO}^{32}$ & $1.19 \mathrm{E}-02$ & 807 & 642 \\
\hline $\mathrm{SO}^{2-2}$ & $2.25 \mathrm{E}-02$ & $1.54 \mathrm{E}+03$ & $1.23 \mathrm{E}+03$ \\
\hline $\mathrm{Si}\left(\mathrm{es} \mathrm{SiO}_{3}{ }^{2}\right)$ & $1.52 \mathrm{E}-02$ & 305 & 243 \\
\hline $\mathbf{F}$ & 0 & 0 & 0 \\
\hline $\mathrm{Cr}$ & $1.43 \mathrm{E}-02$ & 360 & 287 \\
\hline $\mathrm{C}_{6} \mathrm{H}_{9} \mathrm{O}_{7}{ }^{3+}$ & 0 & 0 & 0 \\
\hline EDTA ${ }^{4}$ & 0 & 0 & 0 \\
\hline HEDT $A^{3-}$ & 0 & 0 & 0 \\
\hline glycolnte & 0 & 0 & 0 \\
\hline encetinte & 0 & 0 & 0 \\
\hline oxalate ${ }^{2+}$ & 0 & 0 & 0 \\
\hline DAP & $2.78 \mathrm{E}-06$ & 0.528 & 0.420 \\
\hline burtanol & $2.78 \mathrm{E}-06$ & 0.147 & 0.117 \\
\hline $\mathrm{NH}_{3}$ & $2.24 \mathrm{E}-04$ & 2.71 & 2.16 \\
\hline $\mathrm{Fe}(\mathrm{CN})_{6}^{4}$ & 0 & 0 & 0 \\
\hline 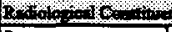 & in & & (5/2) \\
\hline Pu & & $0.527(\mu \mathrm{Ci} / \mathrm{g})$ & $6.99(\mathrm{~kg})$ \\
\hline $\mathrm{U}$ & $0.103(\mathrm{M})$ & $1.74 \mathrm{E}+04(\mu \mathrm{g} / \mathrm{g})$ & $1.39 \mathrm{E}+04(\mathrm{~kg})$ \\
\hline C. & $2.09 \mathrm{E}-03(\mathrm{Ci} / \mathrm{L})$ & $1.49(\mu \mathrm{Ci} / \mathrm{g})$ & $1.18 \mathrm{E}+03(\mathrm{Ci})$ \\
\hline Sr & $3.79 \mathrm{E}-03(\mathrm{Ci} / \mathrm{L})$ & $2.70(\mu \mathrm{Ci} / \mathrm{g})$ & $2.15 \mathrm{E}+03(\mathrm{Ci})$ \\
\hline
\end{tabular}

"Unknowns in tank solids inventory are serigned by Tank. Layering Model (TLM). 


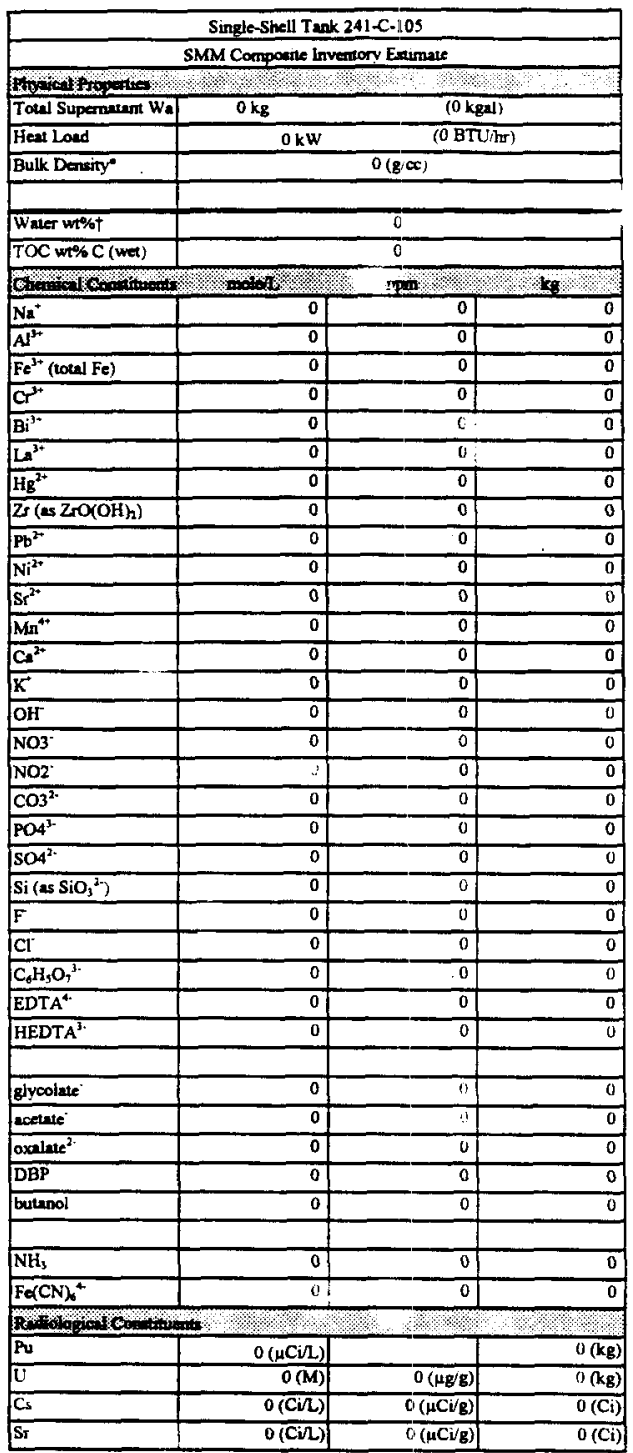

"Density is celeninted baed on $\mathrm{Na}, \mathrm{OH}$. and $\mathrm{AlC}$

†Weter wt\% davived from the difference of densir. and total dissolved species. 


\begin{tabular}{|c|c|c|c|}
\hline \multicolumn{4}{|c|}{ Sinqle-Shell Tunk 241-C-10S } \\
\hline \multicolumn{4}{|c|}{ Toul Inveruory Estimate" } \\
\hline W & \multicolumn{3}{|c|}{ ४ै० } \\
\hline Total Wate & $7.96 \mathrm{E}+05 \mathrm{~kg}$ & \multicolumn{2}{|c|}{$(150 \mathrm{kgal})$} \\
\hline Hent Loed & $2.00 \mathrm{E}-02 \mathrm{~kW}$ & \multicolumn{2}{|c|}{ (68.4 BTU/kr) } \\
\hline Bulk Density' & \multicolumn{3}{|c|}{$1.40(\mathrm{~g} / \propto)$} \\
\hline Wuter wt\%t & \multicolumn{3}{|c|}{58.1} \\
\hline TOC wt\% C (wet)t & \multicolumn{3}{|c|}{$2.86 \mathrm{E}-05$} \\
\hline \multicolumn{4}{|l|}{ 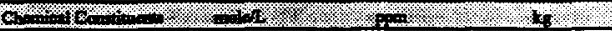 } \\
\hline $\mathrm{Na}^{*}$ & 2.14 & $3.51 \mathrm{E}+04$ & $2.79 E+04$ \\
\hline $\mathrm{Al}^{3+}$ & 4.64 & $8.93 E+04$ & $7.11 E+04$ \\
\hline $\mathrm{Fe}^{3+}($ totul Fe $)$ & 0.306 & $1.22 \mathrm{E}+04$ & $9.69 \mathrm{E}+03$ \\
\hline $\mathrm{cr}^{3+}$ & $2.61 \mathrm{E}-03$ & 96.7 & 76.9 \\
\hline $\mathrm{Bi}^{3+}$ & 0 & 0 & 0 \\
\hline $\mathrm{LA}^{3+}$ & 0 & 0 & 0 \\
\hline $\mathrm{Hg}_{\mathrm{g}}^{2+}$ & $2.27 \mathrm{E}-03$ & 325 & 259 \\
\hline $\mathrm{Zr}(\mathrm{N} \mathrm{ZO}(\mathrm{OH}) \mathrm{h})$ & 0 & 0 & 0 \\
\hline $\mathrm{Pb}^{2+}$ & 0.106 & $1.57 \mathrm{E}+04$ & $1.25 \mathrm{E}+04$ \\
\hline $\mathrm{Ni}^{2+}$ & 1.30E-03 & 54.6 & 43.4 \\
\hline$s r^{2+}$ & 0 & 0 & 0 \\
\hline $\mathrm{Mn}^{4+}$ & 0 & 0 & 0 \\
\hline $\mathrm{Ca}^{2+}$ & 0.143 & $4.09 \mathrm{E}+03$ & $3.25 \mathrm{E}+03$ \\
\hline $\mathbf{K}^{+}$ & $2.64 E-03$ & 73.7 & 58.6 \\
\hline $\mathrm{OH}$ & 16.3 & $1.98 \mathrm{E}+05$ & $1.57 \mathrm{E}+05$ \\
\hline $\mathrm{NO}^{-}$ & 0.726 & $3.21 E+04$ & $2.56 E+04$ \\
\hline NO2: & 0.643 & $2.11 \mathrm{E}+04$ & $1.68 \mathrm{E}+04$ \\
\hline $\cos ^{2+}$ & 0.160 & $6.83 \mathrm{E}+03$ & $5.43 \mathrm{E}+03$ \\
\hline $\mathrm{PO}^{3-}$ & $1.19 \mathrm{E} \sim 02$ & 807 & 642 \\
\hline $504^{2+}$ & $2.25 \mathrm{E}-02$ & $1.54 \mathrm{E}+03$ & $1.23 \mathrm{E}+03$ \\
\hline $\mathrm{Si}\left(\mathrm{as} \mathrm{SiO}_{3}{ }^{2-}\right)$ & $1.52 \mathrm{E}-02$ & 305 & 243 \\
\hline$F$ & 0 & 0 & 0 \\
\hline $\mathrm{CI}$ & $1.43 \mathrm{E}-02$ & 360 & 287 \\
\hline $\mathrm{C}_{6} \mathrm{H}_{9} \mathrm{O}_{7}{ }^{3 .}$ & 0 & 0 & 0 \\
\hline EDTA $^{4-}$ & 0 & 0 & 0 \\
\hline HEDT A ${ }^{3-}$ & 0 & 0 & $\overline{0}$ \\
\hline giycointe' & 0 & 0 & 0 \\
\hline ecertale & 0 & 0 & 0 \\
\hline oxaliate & 0 & 0 & 0 \\
\hline DBP & $2.78 \mathrm{E}-06$ & 0.528 & 0.420 \\
\hline burano! & $2.78 \mathrm{E}-06$ & 0.147 & 0.117 \\
\hline $\mathrm{NH}_{3}$ & $2.24 E-04$ & 2.71 & 2.16 \\
\hline $\mathrm{Fe}(\mathrm{CN})_{6}{ }^{4}$ & 0 & 0 & 0 \\
\hline $\mathrm{R}^{2} \mathrm{H}_{0}, \mathrm{~N}$ & & & \\
\hline Pu & & $0.527(\mu \mathrm{Ci} / \mathrm{g})$ & 6.99 (kg) \\
\hline $\mathrm{U}$ & $0.103(\mathrm{M})$ & $1.74 \mathrm{E}+04(\mu \mathrm{g} / \mathrm{g})$ & $1.39 \mathrm{E}+04(\mathrm{~kg})$ \\
\hline Cs & 2.09E-03 (Ci/L) & $1.49(\mu \mathrm{Cig})$ & $1.18 \mathrm{E}+03(\mathrm{Ci})$ \\
\hline$S r$ & $3.79 \mathrm{E}-03(\mathrm{Ci} / \mathrm{L})$ & $2.70(\mu \mathrm{Ci} / \mathrm{g})$ & $2.1 \mathrm{SE}+03(\mathrm{Ci})$ \\
\hline
\end{tabular}

"Unknowns in tank solids invertory are asaigned by Tank Leyering Model (TLM).

† Volume average for density, mans average Water we:\% and TOC wt\% C. 


\begin{tabular}{|c|c|c|c|}
\hline \multicolumn{4}{|c|}{ Single-Shell Tank $241 C-106$} \\
\hline \multicolumn{4}{|c|}{ TLM Solids Compotire Inventony Esrimnte* } \\
\hline \multicolumn{4}{|l|}{ 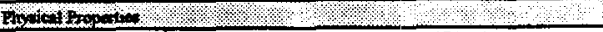 } \\
\hline Total Solid Wante & $1.12 \mathrm{E}+06 \mathrm{~kg}$ & \multicolumn{2}{|c|}{$(197 \mathrm{kgaj})$} \\
\hline Hent Laed & $35.6 \mathrm{~kW}$ & \multicolumn{2}{|c|}{$\left(1.22 \mathrm{E}+05 \mathrm{BT}^{+} \mathrm{hr}\right)$} \\
\hline Bulk Demity & \multicolumn{3}{|c|}{$1.50(\mathrm{~g} / \mathrm{Cc})$} \\
\hline Void Fraction & \multicolumn{3}{|c|}{0.771} \\
\hline Water wt\% & \multicolumn{3}{|c|}{54.4} \\
\hline TOC w\% C (wet) & \multicolumn{3}{|c|}{$5.96 \mathrm{E}-02$} \\
\hline \multicolumn{2}{|l|}{ 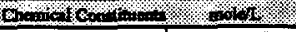 } & Fin & 86 \\
\hline $\mathrm{Na}^{+}$ & 5.11 & $7.82 E+04$ & $8.76 \mathrm{E}+04$ \\
\hline$A \mathrm{I}^{3+}$ & 2.53 & $4.54 \mathrm{E}+04$ & $5.08 \mathrm{E}+04$ \\
\hline $\mathrm{Fe}^{3+}$ (total Fe) & 1.37 & $5.08 \mathrm{E}+04$ & $5.69 \mathrm{E}+04$ \\
\hline $\mathrm{cr}^{*}$ & $7.59 \mathrm{E}-03$ & 263 & 294 \\
\hline$B i^{3+}$ & 4.70E-06 & 0.654 & 0.732 \\
\hline $\mathrm{Ls}^{3 *}$ & 0 & 0 & 0 \\
\hline $\mathrm{Hg}^{2+}$ & $4.36 \mathrm{E}-04$ & 58.3 & 65.2 \\
\hline $\mathrm{Zr}\left(\mathrm{as} \mathrm{ZrO}(\mathrm{OH})_{2}\right)$ & $1.67 \mathrm{E}-07$ & $1.02 \mathrm{E}-02$ & $1.14 \mathrm{E}-02$ \\
\hline $\mathrm{Pb}^{2+}$ & $2.03 \mathrm{E}-02$ & $2.80 \mathrm{E}+03$ & $3.14 E+03$ \\
\hline $\mathrm{Ni}^{2+}$ & 0.387 & $1.51 \mathrm{E}+04$ & $1.69 \mathrm{E}+04$ \\
\hline $\mathrm{Sr}^{\mathrm{r}^{*}}$ & 0 & 0 & 0 \\
\hline $\mathrm{Mn}^{4+4}$ & $1.08 \mathrm{E}-03$ & 39.5 & 44.2 \\
\hline $\mathrm{Cu}^{2+}$ & 0.154 & $4.11 E+03$ & $4.61 E+03$ \\
\hline $\mathbf{K}^{+}$ & $6.46 \mathrm{E}-03$ & 168 & 38 \\
\hline $\mathrm{OH}$ & 13.8 & $1.56 \mathrm{E}+05$ & 1.75 \\
\hline $\mathrm{NO3}^{-}$ & 0.264 & $1.09 \mathrm{E}+04$ & $1.225 \times 44$ \\
\hline $\mathrm{NO}^{-}$ & 0.718 & $2.20 E+04$ & $2.46 \mathrm{E}+04$ \\
\hline $\cos ^{2-}$ & 0.262 & $1.05 \mathrm{E}+04$ & $1.17 \mathrm{E}-04$ \\
\hline $\mathrm{PO}^{3}$ & $2.01 \mathrm{E}-02$ & $1.27 \bar{E}+03$ & $142 \mathrm{E}+03$ \\
\hline $\mathrm{SO}^{2}$ & $5.15 E-02$ & $3.219 \mathrm{E}+03$ & $3.69 \mathrm{E}+03$ \\
\hline $\mathrm{Si}\left(\right.$ as $\left.\mathrm{SiO}_{3}{ }^{2-}\right)$ & 1.74 & $3.25 \mathrm{E}+04$ & $3.64 E+04$ \\
\hline $\mathbf{F}$ & $1.60 \mathrm{E}-04$ & 2.02 & 2.26 \\
\hline $\mathrm{Cl}^{\prime}$ & $2.47 \mathrm{E}-02$ & 584 & 654 \\
\hline $\mathrm{C}_{6} \mathrm{H}_{5} \mathrm{O}_{7}{ }^{3-}$ & $2.28 \mathrm{E}-03$ & 287 & 322 \\
\hline EDTA $^{4}$ & 0 & 0 & 0 \\
\hline HEDTA ${ }^{3}$ & 0 & 0 & 0 \\
\hline giveolate & $3.04 \mathrm{E}-02$ & $1.52 \mathrm{E}+03$ & $1.70 E+03$ \\
\hline acetate & 0 & 0 & 0 \\
\hline exainte & 0 & 0 & 0 \\
\hline DBP & $2.12 \mathrm{E}-06$ & 0.375 & 0420 \\
\hline burtanol & $2.12 E-06$ & 0.105 & 6.117 \\
\hline $\mathrm{NH}_{3}$ & 0.117 & $1.33 \mathrm{E}+03$ & $1.49 \mathrm{E}+03$ \\
\hline $\mathrm{Fe}(\mathrm{CN})^{4-}$ & 0 & 0 & 0 \\
\hline \multicolumn{4}{|l|}{ 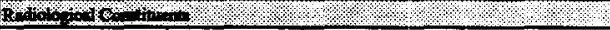 } \\
\hline Pu & & $4.08(\mu \mathrm{Ci} / \mathrm{g})$ & $76.1(\mathrm{~kg})$ \\
\hline $\mathrm{U}$ & $0.177(\mathrm{M})$ & $2.80 \mathrm{E}+04(\mu \mathrm{g} / \mathrm{g})$ & $3.14 \mathrm{E}+04(\mathrm{~kg})$ \\
\hline Cs & $0.112(\mathrm{Ci} / 2)$ & $(\mu \mathrm{Ci} / \mathrm{g})$ & $8.37 \mathrm{E}+04(\mathrm{Ci})$ \\
\hline $\mathbf{S r}$ & $7.01(\mathrm{Ci} / \mathrm{L})$ & $4.67 \mathrm{E}-\mathrm{ij}(\mu \mathrm{KV} \mathrm{g})$ & $5.22 \mathrm{E}+06(\mathrm{Ci})$ \\
\hline
\end{tabular}

"Unknowns in tank solids invertory are assigned by Tank Layering Model (TLM). 
WHC-SD-WM-ER-313, Rev. 1

\begin{tabular}{|c|c|c|c|}
\hline \multicolumn{4}{|c|}{ Single-Shell Tenk 241-C-106 } \\
\hline \multicolumn{4}{|c|}{ SMM Compoaite Inventory Eximule } \\
\hline 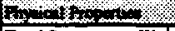 & \multirow{2}{*}{$1.24 \mathrm{E}+05 \mathrm{~kg}$} & \multicolumn{2}{|c|}{18} \\
\hline Total Superninim Wa & & \multicolumn{2}{|c|}{$(32.0 \mathrm{kgal})$} \\
\hline Heat Laed & $4.37 \mathrm{E}-03 \mathrm{~kW}$ & \multicolumn{2}{|c|}{ (14.9 BTU/hr) } \\
\hline Bulk Density* & \multicolumn{3}{|c|}{$1.03(g / \infty)$} \\
\hline Water wi\%t & \multicolumn{3}{|c|}{95.7} \\
\hline TOC wt\% C (wet) & \multicolumn{3}{|c|}{$9.05 \mathrm{E}-1) 2$} \\
\hline \multicolumn{2}{|l|}{ 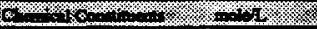 } & 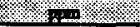 & dxy \\
\hline $\mathrm{Na}^{-}$ & 0.537 & $1.20 \mathrm{E}+04$ & $1.50 E+03$ \\
\hline $\mathrm{Al}^{\mathrm{N}}$ & $8.22 \mathrm{E}-02$ & $2.16 \mathrm{E}+03$ & 269 \\
\hline $\mathrm{Fe}^{3+}$ (tooll $\left.\mathrm{Fe}\right)$ & 3.1SE-04 & 17.1 & 2.13 \\
\hline $\mathrm{Cr}^{3+}$ & 4.66E-08 & 2.36E-03 & $2.94 \mathrm{E}-04$ \\
\hline$B \mathrm{~B}^{\mathrm{N}}$ & $2.40 \mathrm{E}-11$ & $4.88 \mathrm{E}-06$ & 6.07E-07 \\
\hline $\mathrm{LA}^{3+}$ & $6.96 \mathrm{E}-18$ & $9.42 \mathrm{E}-13$ & 1.17E-13 \\
\hline $\mathrm{Hg}^{2+}$ & $4.97 \mathrm{E}-13$ & $9.72 \mathrm{E}-08$ & 1.21E.-08 \\
\hline $\mathrm{Zr}\left(\mathrm{arO}(\mathrm{OH})_{2}\right)$ & $7.3 \mathrm{E}-12$ & 6.55E-07 & 8.15E-08 \\
\hline $\mathrm{Pb}^{2+}$ & $7.70 \mathrm{E}-11$ & $1.56 \mathrm{E}-05$ & $1.93 \mathrm{E}-06$ \\
\hline $\mathrm{Ni}^{2+2}$ & $2.83 \mathrm{E}-04$ & 16.2 & 2.02 \\
\hline $\mathrm{Sr}^{2 *}$ & $2.32 \mathrm{E}-18$ & $1.98 \mathrm{E}-13$ & $2.46 \mathrm{E}-14$ \\
\hline $\mathrm{Mn}^{4+}$ & 2.68E-09 & $1.44 \mathrm{E}-04$ & $1.79 \mathrm{E}-05$ \\
\hline $\mathrm{Ca}^{2+}$ & $1.42 \mathrm{E} .03$ & 55.3 & 6.88 \\
\hline $\mathrm{K}^{+}$ & $2.13 E-03$ & 81.0 & 10.1 \\
\hline $\mathrm{OH}$ & 0.359 & $5.96 \bar{E}+03$ & 740 \\
\hline No3 & 0.257 & $1.55 \mathrm{E}+04$ & $1.93 E+03$ \\
\hline $\mathrm{NO} 2$ & $1.49 \mathrm{E}-02$ & 669 & 83.2 \\
\hline $\cos ^{2-}$ & $4.24 E-02$ & $2.48 \mathrm{E}+03$ & 308 \\
\hline $\mathrm{POA}^{3.5}$ & $1.38 \mathrm{E}-03$ & 146 & 18.2 \\
\hline $\mathrm{SO}^{2-}$ & $6.94 \mathrm{E}-03$ & 650 & 80.8 \\
\hline $\mathrm{Si}\left(a \mathrm{SiO}_{3}{ }^{2}\right)$ & 5.35E-03 & 147 & 18.2 \\
\hline $\mathrm{F}$ & $1.08 \mathrm{E}-09$ & $2.00 \mathrm{E}-0 \mathrm{~S}$ & $2.49 E-06$ \\
\hline $\mathrm{Cl}$ & $9.78 E-03$ & 338 & 42.0 \\
\hline $\mathrm{C}_{6} \mathrm{H}_{3} \mathrm{O}_{7}{ }^{3}$ & $2.37 \mathrm{E}-03$ & 436 & 54.2 \\
\hline EDTA $^{*}$ & $3.66 \mathrm{E}-12$ & $1.03 \mathrm{E}-06$ & $1.28 \mathrm{E}-07$ \\
\hline HEDTA ${ }^{3-}$ & $3.10 \mathrm{E}-12$ & $8.28 \mathrm{E}-07$ & $1.03 E-07$ \\
\hline giycolate: & $3.16 \mathrm{E}-02$ & $2.31 E+03$ & 287 \\
\hline scetnte & $1.36 \mathrm{E}-11$ & $7.81 \mathrm{E}-07$ & $9.71 \mathrm{E}-08$ \\
\hline oxalate- & $5.95 \mathrm{E}-18$ & $5.11 E-13$ & $6.35 E-14$ \\
\hline DBP & 4.03E-09 & $1.05 \mathrm{E}-03$ & $1.30 \mathrm{E}-04$ \\
\hline beranol & $4.03 \mathrm{E}-09$ & $2.91 \mathrm{E}-04$ & $3.62 \mathrm{E}-05$ \\
\hline $\mathrm{NH}_{3}$ & $3.36 \mathrm{E}-05$ & 0.557 & $6.92 \mathrm{E}-02$ \\
\hline $\mathrm{Fe}(\mathrm{CN})_{2}^{4}$ & 0 & 0 & 0 \\
\hline \multicolumn{4}{|l|}{ A } \\
\hline Pu & $4.72(\mu \mathrm{Ci} / \mathrm{L})$ & & $9.54 \mathrm{E}-03(\mathrm{~kg})$ \\
\hline $\mathrm{U}$ & $6.30 \mathrm{E}-04(\mathrm{M})$ & $146(\mu / / B)$ & $18.2(\mathrm{~kg})$ \\
\hline C. & 3.02E-07 (Ci/L) & $2.95 \mathrm{E}-04(\mu \mathrm{Ci} / \mathrm{g})$ & $3.66 \mathrm{E}-02(\mathrm{Ci})$ \\
\hline Sr & 5.35E-03(Ci/L) & $5.22\left(\mu \mathrm{Ci} v_{8}\right)$ & $648(\mathrm{Ci})$ \\
\hline
\end{tabular}

Denarty is calculated besed on $\mathrm{Nn}, \mathrm{OH}$, and $\mathrm{ANO}_{2}$.

+Water wros derived from the differenoce of denaity and total diveolved species. 
WHC-SD-WM-ER-313, Rev. 1

\begin{tabular}{|c|c|c|c|}
\hline \multicolumn{4}{|c|}{ Single-Shell Tank 241-C-106 } \\
\hline \multicolumn{4}{|c|}{ Tocol Inveruory Esimute* } \\
\hline Phorictionopes & & मे & 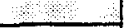 \\
\hline Total Warte & $1.24 \mathrm{E}+06 \mathrm{~kg}$ & \multicolumn{2}{|c|}{$(229 \mathrm{kgal})$} \\
\hline Heat Load & $35.6 \mathrm{~kW}$ & \multicolumn{2}{|c|}{$(1.22 \mathrm{E}+05 \mathrm{BTU} / \mathrm{hr})$} \\
\hline Bulk Density' & \multicolumn{3}{|c|}{$14(g / \infty)$} \\
\hline Water wt\%t & \multicolumn{3}{|c|}{58.5} \\
\hline TOC wt\% C (wet) ${ }^{+}$ & \multicolumn{3}{|c|}{$6.27 \mathrm{E}-02$} \\
\hline $6=1$ & $x+\infty$ & $=$ & 好 \\
\hline $\mathrm{Na}^{+}$ & 4.47 & $7.16 \mathrm{E}+04$ & $8.91 E+04$ \\
\hline $\mathrm{Al}^{3+}$ & 2.18 & $4.10 \mathrm{E}+04$ & $5.11 E+04$ \\
\hline $\mathrm{Fe}^{3+}(\mathrm{total} \mathrm{Fe})$ & 1.17 & $4.57 \mathrm{E}+04$ & $5.69 \mathrm{E}+04$ \\
\hline $\mathrm{Cr}^{3+}$ & $6.52 \mathrm{E}-03$ & 236 & 294 \\
\hline$B i^{3+4}$ & 4.04E-06 & 0.588 & 0.732 \\
\hline $\mathrm{La}^{3+}$ & $9.73 \mathrm{E}-19$ & $9.41 \mathrm{E}-14$ & $1.17 \mathrm{E}-13$ \\
\hline $\mathrm{Hg}^{2+}$ & $3.75 \mathrm{E}-04$ & 52.4 & 65.2 \\
\hline $2 \mathrm{ses} \mathrm{ZrO}(\mathrm{OH}) \mathrm{h})$ & I.44E-07 & $9.15 E-03$ & $1.14 \mathrm{E}-02$ \\
\hline $\mathrm{Pb}^{2+}$ & $1.75 \mathrm{E}-02$ & $2.52 \mathrm{E}+03$ & $3.14 E+03$ \\
\hline $\mathrm{Ni}^{2+}$ & 0.333 & $1.36 \mathrm{E}+04$ & $1.69 \mathrm{E}+04$ \\
\hline $\mathrm{Sr}^{2+}$ & $3.24 \mathrm{E}-19$ & $1.98 \mathrm{E}-14$ & $2.46 \mathrm{E}-14$ \\
\hline $\mathrm{Mo}^{4 *}$ & $9.28 \mathrm{E}-04$ & 35.5 & 44.2 \\
\hline $\mathrm{Ca}^{2+}$ & 0.133 & $3.71 E+03$ & $4.61 \mathrm{E}+03$ \\
\hline $\mathrm{K}^{+}$ & $5.85 \mathrm{E}-03$ & 159 & 198 \\
\hline $\mathrm{OH}$ & 11.9 & $1.41 \mathrm{E}+05$ & $1.76 \mathrm{~F}-05$ \\
\hline No3 & 0.263 & $1.14 \mathrm{E}+04$ & $1.41 \mathrm{E}+04$ \\
\hline NO2: & 0.620 & $1.99 \mathrm{E}+04$ & $2.47 \mathrm{E}+04$ \\
\hline $\mathrm{CO}^{2}$ & 0.231 & $9.66 \mathrm{E}+03$ & $1.20 \mathrm{E}+04$ \\
\hline $\mathrm{PO4}^{3 \cdot-}$ & $1.75 \mathrm{E}-02$ & $1.16 \mathrm{E}+03$ & $1.44 E+03$ \\
\hline $\mathrm{SO4}^{2-}$ & $4.53 \mathrm{E}-02$ & $3.03 \mathrm{E}+03$ & $3.77 \mathrm{E}+03$ \\
\hline 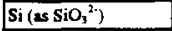 & 1.50 & $293 E+04$ & $3.64 E+04$ \\
\hline$F$ & $1.37 \mathrm{E}-04$ & 1.82 & 2.26 \\
\hline $\mathrm{Cl}^{-}$ & $2.27 \mathrm{E}-02$ & 559 & 696 \\
\hline $\mathrm{C}_{6} \mathrm{H}_{5} \mathrm{O}^{3-5}$ & $2.29 \mathrm{E}-03$ & 302 & 376 \\
\hline EDTA $^{4}$ & $5.12 \mathrm{E}-13$ & $1.03 \mathrm{E}-07$ & $1.28 \mathrm{E}-07$ \\
\hline HEDT ${ }^{3-}$ & $4.33 \mathrm{E}-13$ & $8.27 \mathrm{E}-08$ & $1.03 \mathrm{E}-07$ \\
\hline glycolatc & $3.06 \mathrm{E}-02$ & $1.60 \mathrm{E}+03$ & $1.99 \mathrm{E}+03$ \\
\hline scetnte & $1.90 \mathrm{E}-12$ & $7.81 \mathrm{E}-08$ & $9.71 E-08$ \\
\hline oxalate ${ }^{2-}$ & 8.32E-19 & $5.10 \mathrm{E}-14$ & 6.35E-14 \\
\hline DBP & $1.82 \mathrm{E}-06$ & 0.338 & 0.420 \\
\hline burtunol & $1.82 \mathrm{E}-06$ & $9.41 \mathrm{E}-02$ & 0.117 \\
\hline $\mathrm{NH}_{3}$ & 0.101 & ¿.20E+03 & $1.49 \mathrm{E}+03$ \\
\hline $\mathrm{Fe}(\mathrm{CN})_{6}^{4}$ & 0 & 0 & 0 \\
\hline 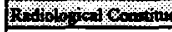 & & & ए \\
\hline $\mathrm{Pu}$ & & $3.67(\mu \mathrm{Ci} / \mathrm{g})$ & 76.1 (kg) \\
\hline $\mathrm{U}$ & $0.152(\mathrm{M})$ & $2.52 \mathrm{E}+04(\mu \mathrm{g} / \mathrm{g})$ & $3.14 \mathrm{E}+04(\mathrm{~kg})$ \\
\hline Cs & $9.66 \mathrm{E}-02(\mathrm{Ci} / \mathrm{L})$ & $67.3(\mu \mathrm{Ci} / \mathrm{g})$ & $8.37 \mathrm{E}+04(\mathrm{Ci})$ \\
\hline Sr & $6.03(\mathrm{Ci} / \mathrm{L})$ & $4.20 \mathrm{E}+03(\mu \mathrm{Ci} / \mathrm{g})$ & $5.23 \mathrm{E}+06(\mathrm{Ci})$ \\
\hline
\end{tabular}

"Unknowns in tank solids invertery are ansigned by Tank Layering Model (TLM).

†Volume average for density, mast average Waler wh\% and TOC w\% C. 
WHC-SD-WM-ER-313, Rev. 1

\begin{tabular}{|c|c|c|c|}
\hline \multicolumn{4}{|c|}{ Single-Shell Tank 241-C-107 } \\
\hline \multicolumn{4}{|c|}{ TLM Solids Conposite Inveruorv Estimate* } \\
\hline \multicolumn{4}{|l|}{ 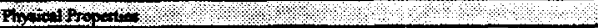 } \\
\hline Total Solid Wate & $1.41 \mathrm{E}+06 \mathrm{~kg}$ & \multicolumn{2}{|c|}{ (275 kgal) } \\
\hline Heat Load & $4.27 \mathrm{kw}$ & \multicolumn{2}{|c|}{$(1.46 \mathrm{E}+04 \mathrm{BTU} / \mathrm{hr})$} \\
\hline Bullk Density & \multicolumn{3}{|c|}{$1.36\left(g^{\prime} / x\right)$} \\
\hline Void Fraction & \multicolumn{3}{|c|}{0.715} \\
\hline Water w\% & \multicolumn{3}{|c|}{65.8} \\
\hline TOC wt\% C (wet) & \multicolumn{3}{|c|}{0.280} \\
\hline \multicolumn{4}{|l|}{ 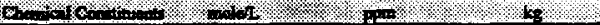 } \\
\hline $\mathrm{Na}$ & 4.50 & $7.62 \mathrm{E}+04$ & $1.08 E+05$ \\
\hline $\mathrm{Al}^{\mathrm{3}^{3+}}$ & 1.17 & $2.32 \mathrm{E}+04$ & $3.27 \mathrm{E}+04$ \\
\hline $\mathrm{Fe}^{3+}$ (totel $\left.\mathrm{Fe}\right)$ & 0.427 & $1.76 \mathrm{E}+04$ & $2.48 \mathrm{E}+04$ \\
\hline $\mathrm{Cr}^{3+}$ & $3.30 \mathrm{E}-03$ & 127 & 179 \\
\hline $\mathrm{Bi}^{3+}$ & $6.10 \mathrm{E}-02$ & $9.40 \mathrm{E}+03$ & $1.33 \mathrm{E}+04$ \\
\hline $\mathrm{La}^{3 *}$ & 0 & 0 & 0 \\
\hline $\mathrm{Hg}^{2+}$ & $8.79 \mathrm{E}-04$ & 130 & 184 \\
\hline $\mathrm{Zs}(\mathrm{as} \mathrm{ZrO}(\mathrm{OK} h)$ & $8.16 \mathrm{E}-03$ & 549 & 775 \\
\hline $\mathrm{Pb}^{3+}$ & $4.38 \mathrm{E}-02$ & $6.69 \mathrm{E}+03$ & $9.45 \mathrm{E}+03$ \\
\hline $\mathrm{Ni}^{2^{2+}}$ & $1.08 \mathrm{E}-03$ & 46.6 & 65.8 \\
\hline $\mathrm{Sr}^{2+}$ & 0 & 0 & 0 \\
\hline $\mathrm{Mn}^{4 *}$ & 0 & 0 & 0 \\
\hline $\mathrm{Ca}^{2+}$ & 0.113 & $3.34 \mathrm{E}+03$ & 4.7IE+03 \\
\hline $\mathrm{K}^{+}$ & $3.65 \mathrm{E}-03$ & 105 & 148 \\
\hline $\mathrm{OH}$ & 5.72 & $7.17 \mathrm{E}+04$ & $1.01 \mathrm{E}+05$ \\
\hline NO3 & 0.366 & $1.67 \mathrm{E}+04$ & $2.36 \mathrm{E}+04$ \\
\hline $\mathrm{NO2}$ & 0.212 & $7.20 \mathrm{E}+03$ & $1.02 \mathrm{E}+04$ \\
\hline $\cos ^{2}$ & 0.128 & $5.65 E+03$ & $7.98 \mathrm{E}+03$ \\
\hline $\mathrm{POA}^{32}$ & 1.06 & $7.39 E+04$ & $1.04 \mathrm{E}+05$ \\
\hline $\mathrm{SO}_{4}^{2+}$ & $4.30 \mathrm{E}-02$ & $3.05 \mathrm{E}+03$ & $4.30 \mathrm{E}+03$ \\
\hline $\mathrm{Si}\left(\mathrm{es} \mathrm{SiO}_{3}{ }^{2}\right)$ & 0.181 & $3.75 E+03$ & $5.30 \mathrm{E}+03$ \\
\hline$F$ & 0.131 & $1.84:+03$ & $2.59 \mathrm{E}+03$ \\
\hline $\mathrm{Cl}^{-}$ & $1.68 \mathrm{E}-02$ & 438 & 619 \\
\hline $\mathrm{C}_{6} \mathrm{H}_{9} \mathrm{O}_{7}{ }^{3-}$ & 0 & 0 & 0 \\
\hline EDTA $^{4-}$ & $9.31 \mathrm{E}-03$ & $1.98 \mathrm{E}+03$ & $2.79 \mathrm{E}+03$ \\
\hline HEDTA $^{3+}$ & $1.86 \mathrm{E}-02$ & $3.76 E+03$ & $5.31 \mathrm{E}+03$ \\
\hline glycoines & $1.86 \mathrm{E}-02$ & $1.03 \bar{E}+03$ & $1.45 \mathrm{E}+03$ \\
\hline acetate & 0 & 0 & 0 \\
\hline oxature ${ }^{2-}$ & 0 & 0 & 0 \\
\hline DBP & $1.89 \mathrm{E}-06$ & 0.370 & 0.522 \\
\hline butanol & $1.89 \mathrm{E}-06$ & 0.103 & 0.145 \\
\hline $\mathrm{NH}_{3}$ & $8.49 \mathrm{E}-03$ & 106 & 150 \\
\hline $\mathrm{Fe}(\mathrm{CN})_{6}^{4}$ & 0 & 0 & $\overline{0}$ \\
\hline 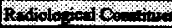 & & & \\
\hline $\mathrm{Pu}$ & & $0.392(\mu \mathrm{CV} / g)$ & $9.22(\mathrm{~kg})$ \\
\hline $\mathrm{U}$ & $0.101(\mathrm{M})$ & $1.78 \mathrm{E}+04(\mu \mathrm{g} / \mathrm{g})$ & $2.51 \mathrm{E}+04(\mathrm{~kg})$ \\
\hline Cs & $1.30 \mathrm{E}-02(\mathrm{Ci} / \mathrm{L})$ & $9.55(\mu \mathrm{CV} / \mathrm{g})$ & $1.35 \mathrm{E}+04(\mathrm{Ci})$ \\
\hline Sr & $0.601(\mathrm{Ci} / 2)$ & $443(\mu \mathrm{Ci} / \mathrm{g})$ & $6.25 E+05(\mathrm{Ci})$ \\
\hline
\end{tabular}


Single-Shell Tank $241-C-107$

SMM Cormposite Inventory Estimate

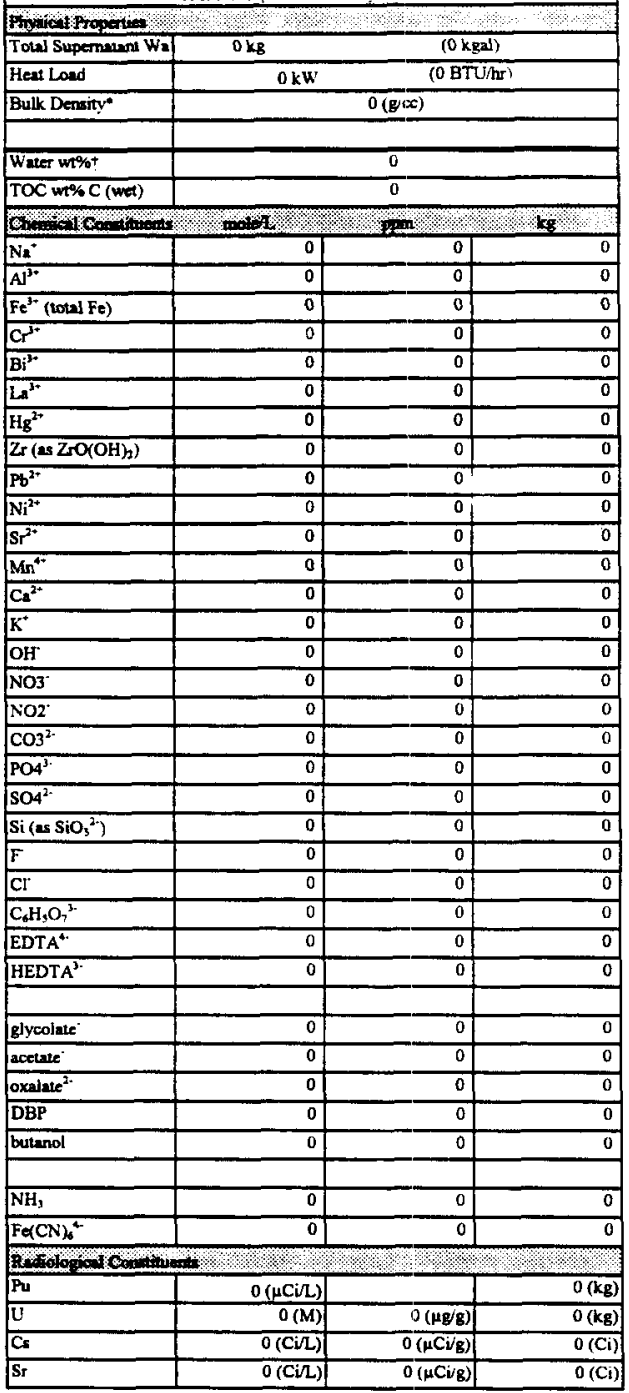

"Density is calculared based on $\mathrm{Na}_{2} \mathrm{OH}$, and $\mathrm{AlO}_{2}$.

$\uparrow$ Water w\% derived from the difference of density and total dissolved apecies. 


\begin{tabular}{|c|c|c|c|}
\hline \multicolumn{4}{|c|}{ Single-Shell Tunk $241-\mathrm{C}-107$} \\
\hline \multicolumn{4}{|c|}{ Total Inventary Esimune" } \\
\hline \multicolumn{4}{|l|}{ 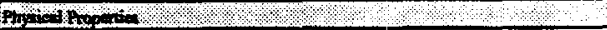 } \\
\hline Total Wate & $1.41 \mathrm{E}+06 \mathrm{~kg}$ & \multicolumn{2}{|c|}{ (275 kgal) } \\
\hline Heat Load & $4.27 \mathrm{~kW}$ & \multicolumn{2}{|c|}{ (1.46E+04 BTUAr) } \\
\hline Bulk Denaityt & \multicolumn{3}{|c|}{$1.36(g / \infty)$} \\
\hline Wale wt\% & \multicolumn{3}{|c|}{65.8} \\
\hline TOC wt\% C (wet) $)^{\dagger}$ & \multicolumn{3}{|c|}{0.280} \\
\hline \multicolumn{2}{|l|}{ 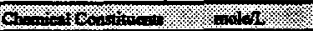 } & Fis & 4. \\
\hline $\mathrm{Na}^{*}$ & 4.50 & $7.62 \mathrm{E}+04$ & $1.08 \mathrm{E}+05$ \\
\hline $\mathrm{Al}^{3+3}$ & 1.17 & $2.32 \mathrm{E}+04$ & $3.27 E+04$ \\
\hline $\mathrm{Fe}^{3 *}$ (total Fe) & 0.427 & $1.76 \mathrm{E}+04$ & $2.48 \mathrm{E}+04$ \\
\hline $\mathrm{cr}^{3+2}$ & $3.30 \mathrm{E}-03$ & 127 & 179 \\
\hline $\mathrm{Bi}^{3+}$ & $6.10 \mathrm{E}-02$ & $9.40 \mathrm{E}+03$ & $1.33 E+04$ \\
\hline $\mathrm{LS}^{3+4}$ & 0 & 0 & 0 \\
\hline $\mathrm{Hg}^{2+}$ & $8.79 \mathrm{E}-04$ & 130 & 184 \\
\hline $\mathrm{Zr}(\mathrm{as} \mathrm{ZrOOH})$ & $8.16 \mathrm{E}-03$ & 549 & 775 \\
\hline $\mathrm{Pb}^{2+}$ & $4.38 \mathrm{E}-02$ & $6.69 \mathrm{E}+03$ & $9.45 \mathrm{E}+03$ \\
\hline $\mathrm{Ni}^{2+}$ & $1.08 \mathrm{E}-03$ & 46.6 & 65.8 \\
\hline$s r^{2+}$ & $\overline{0}$ & 0 & $\overline{0}$ \\
\hline $\mathrm{Mn}^{4+}$ & 0 & 0 & $\overline{0}$ \\
\hline $\mathrm{Ca}^{2}$ & 0.113 & $3.34 \mathrm{E}+03$ & $4.7 \mathrm{LE}+03$ \\
\hline $\mathrm{K}^{+}$ & 3.65E-03 & 105 & 148 \\
\hline $\mathrm{OH}$ & 5.72 & $7.17 \mathrm{E}+04$ & $1.01 E+05$ \\
\hline $\mathrm{NO}^{-}$ & $\overline{0.366}$ & $1.67 \mathrm{E}+04$ & $2.36 \mathrm{E}+04$ \\
\hline $\mathrm{NO} 2$ & 0.212 & $7.20 \mathrm{E}+03$ & $1.02 \mathrm{E}+04$ \\
\hline $\cos ^{2}$ & 0.128 & $5.65 E+03$ & $7.98 \mathrm{E}+03$ \\
\hline $\mathrm{PO}^{3-}$ & 1.06 & $7.39 \mathrm{E}+04$ & $1.04 \mathrm{E}+05$ \\
\hline $\mathrm{SO}^{2-}$ & $4.30 \mathrm{E}-02$ & $3.05 \mathrm{E}+03$ & $4.30 \mathrm{E}+03$ \\
\hline $\mathrm{Si}\left(2 \mathrm{si \textrm {SiO } _ { 3 } { } ^ { 2 } )}\right.$ & 0.181 & $3 . \overline{75 E+03}$ & $5.30 \mathrm{E}+03$ \\
\hline$F$ & 0.131 & $1.84 \mathrm{E}+03$ & $2.59 \mathrm{E}+03$ \\
\hline $\mathrm{Cl}^{\prime}$ & $1.68 \mathrm{E}-02$ & 438 & 619 \\
\hline $\mathrm{C}_{8} \mathrm{H}_{9} \mathrm{O}_{7}{ }^{3-2}$ & 0 & 0 & $\overline{0}$ \\
\hline EDTA ${ }^{4}$ & $9.31 \mathrm{E}-03$ & $1.98 \mathrm{E}+03$ & $2.79 E+03$ \\
\hline HEDTA $^{3 .}$ & $1.86 \mathrm{E}-02$ & $3.76 \mathrm{E}+03$ & $5.31 E+03$ \\
\hline glycolate & $1.86 \mathrm{E}-02$ & $1.03 \mathrm{E}+03$ & $1.45 \mathrm{E}+03$ \\
\hline ecetate & 0 & 0 & 0 \\
\hline oxalate ${ }^{2 *}$ & 0 & 0 & $\overrightarrow{0}$ \\
\hline DBP & 1.89E-06 & 0.370 & 0.522 \\
\hline buranol & $1.89 \mathrm{E}-06$ & 0.103 & 0.145 \\
\hline $\mathrm{NH}_{3}$ & $8.49 \mathrm{E}-03$ & 106 & 150 \\
\hline $\mathrm{Fe}(\mathrm{CN})_{6}^{4}$ & 0 & 0 & 0 \\
\hline \multicolumn{4}{|l|}{ 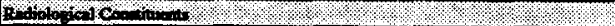 } \\
\hline $\mathrm{Pu}$ & & $0.392(\mu \mathrm{Ci} / g)$ & $9.22(\mathrm{~kg})$ \\
\hline $\bar{U}$ & $0.101(\mathrm{M})$ & $1.78 \mathrm{E}+294(\mu \mathrm{g} / \mathrm{g})$ & $2.51 \mathrm{E}+04(\mathrm{~kg})$ \\
\hline $\mathrm{Cs}$ & $1.30 \mathrm{E}-02(\mathrm{Ci} / \mathrm{L})$ & $9.33(\mu \mathrm{Ci} / \mathrm{g})$ & $1.35 \mathrm{E}+04(\mathrm{Ci})$ \\
\hline St & $0.601(\mathrm{Ci} / \mathrm{L})$ & $443(\mu \mathrm{Ci} / 8)$ & $6.25 \mathrm{E}+05(\mathrm{Ci})$ \\
\hline
\end{tabular}

"Unksowns in lank solids inveruory are auignod by Tank Layering Model (TLM) †Volume average for density, mass svernge Waver wt\% and TOC wr\% C. 


\begin{tabular}{|c|c|c|c|}
\hline \multicolumn{4}{|c|}{ Single-Shell Tank 241-C-108 } \\
\hline \multicolumn{4}{|c|}{ TLM Solids Composite Imverntory Estimate* } \\
\hline \multicolumn{2}{|l|}{ Thysionstropentias } & 1 & \\
\hline Total Solid Waste & $3.33 \mathrm{E}+05 \mathrm{~kg}$ & \multicolumn{2}{|c|}{$(66.0 \mathrm{kgal})$} \\
\hline Heart Load & $0.401 \mathrm{~kW}$ & \multicolumn{2}{|c|}{$(1.37 \mathrm{E}+03 \mathrm{BTU} / \mathrm{hr})$} \\
\hline Bulk Density & \multicolumn{3}{|c|}{$1.33(g / \infty)$} \\
\hline Void Fraction & \multicolumn{3}{|c|}{0.814} \\
\hline Water wr\% & \multicolumn{3}{|c|}{65.3} \\
\hline TOC wt\% C (wet) & \multicolumn{3}{|c|}{0.351} \\
\hline \multicolumn{2}{|l|}{ 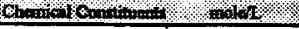 } & Pistre & $k+$ \\
\hline $\mathrm{Na}^{*}$ & 4.12 & $7.11 \mathrm{E}+04$ & $2.37 E+04$ \\
\hline $\mathrm{Al}^{\mathrm{I}^{3+}}$ & 0.239 & $4.84 E+03$ & $1.6 \mathrm{LE}+03$ \\
\hline $\mathrm{Fe}^{3+}$ (total Fe) & 0.803 & $3.37 \mathrm{E}+04$ & \\
\hline $\mathrm{Cr}^{3+}$ & $2.77 \mathrm{E}-03$ & 108 & 36.0 \\
\hline $\mathrm{Bi}^{3+4}$ & $3.38 \mathrm{E}-02$ & $5.31 E+03$ & $1.77 \mathrm{E}+03$ \\
\hline $\mathrm{LA}^{3+}$ & 0 & 0 & 0 \\
\hline $\mathrm{Hg}^{2+}$ & $4.64 \mathrm{E}-05$ & 6.99 & 2.33 \\
\hline $\mathrm{Zr}\left(\mathrm{as} \mathrm{ZrO}(\mathrm{OH})_{h}\right)$ & $4.53 \mathrm{E}-03$ & 310 & 103 \\
\hline $\mathrm{Pb}^{2+}$ & 0 & 0 & 0 \\
\hline $\mathrm{Ni}^{2^{*}}$ & 0.120 & $5.27 \mathrm{E}+03$ & $1.75 \mathrm{E}+03$ \\
\hline $\mathrm{Sr}^{2+}$ & 0 & 0 & 0 \\
\hline $\mathrm{Mn}^{4+}$ & 0 & 0 & 0 \\
\hline $\mathrm{Ca}^{2+}$ & 0.308 & $9.28 \mathrm{E}+03$ & $3.09 \mathrm{E}+03$ \\
\hline $\mathbf{K}^{+}$ & $9.32 \mathrm{E}-03$ & 273 & 91.0 \\
\hline $\mathrm{OH}^{-}$ & 3.76 & $4.80 \mathrm{E}+04$ & $1.60 E+04$ \\
\hline $\mathrm{NO}^{*}$ & 0.996 & $4.64 \mathrm{E}+04$ & $1.54 \mathrm{E}+04$ \\
\hline NO2- & 0.628 & $2.17 E+04$ & $7.22 \mathrm{E}+03$ \\
\hline $\mathrm{CO}^{2-}$ & 0.371 & $1.67 E+04$ & $5.57 E+03$ \\
\hline $\mathrm{PO}^{3 \cdot}$ & 0.652 & $4.65 E+04$ & $1.55 \mathrm{E}+04$ \\
\hline $\mathrm{SO}^{2+}$ & $7.14 \mathrm{E}-02$ & $5.15 E+03$ & $1.71 \mathrm{E}+03$ \\
\hline $\mathrm{Si}\left(\right.$ as $\left.\mathrm{SiO}_{3}{ }^{2}\right)$ & $2.78 \mathrm{E}-02$ & 586 & 195 \\
\hline$F$ & $7.26 \mathrm{E}-02$ & $1.04 E+03$ & 345 \\
\hline $\mathrm{Cl}^{-}$ & $5.08 \mathrm{E}-02$ & $1.35 E+03$ & 450 \\
\hline $\mathrm{C}_{6} \mathrm{H}_{5} \mathrm{O}_{7}{ }^{3-}$ & 0 & 0 & 0 \\
\hline EDTA $^{4}$ & 0 & 0 & 0 \\
\hline HEDTA ${ }^{3-}$ & 0 & 0 & 0 \\
\hline glvcolate & 0 & 0 & 0 \\
\hline acetnte & 0 & 0 & 0 \\
\hline oxalate ${ }^{2}$ & 0 & 0 & 0 \\
\hline DBP & $1.05 \mathrm{E}-05$ & 2.11 & 0.700 \\
\hline butanol & $1.05 \mathrm{E}-05$ & 0.586 & 0.195 \\
\hline $\mathrm{NH}_{3}$ & $4.52 \mathrm{E}-02$ & 577 & 192 \\
\hline $\mathrm{Fe}\left(\mathrm{CN}_{2}{ }^{4}\right.$ & $6.49 E-02$ & $1.32 \mathrm{E}+04$ & $4.39 \mathrm{E}+03$ \\
\hline 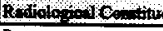 & ants & & 100 \\
\hline Pu & & $-72 \mathrm{E}-03(\mu \mathrm{Ci} / \mathrm{g})$ & $2.06 \mathrm{E}-02(\mathrm{~kg})$ \\
\hline $\mathrm{U}$ & $0.103(\mathrm{M})$ & $184 \mathrm{E}+04(\mu \mathrm{g} / \mathrm{g})$ & $6.14 \mathrm{E}+03(\mathrm{~kg})$ \\
\hline Cs & $0.330(\mathrm{Ci} / \mathrm{L})$ & $248(\mu \mathrm{Ci} / g)$ & $8.26 E+04(\mathrm{Ci})$ \\
\hline $\mathrm{Sr}$ & $8.39 \mathrm{E}-03(\mathrm{Ci} / \mathrm{L})$ & $6.30(\mu \mathrm{C} / \mathrm{g})$ & $2.10 \mathrm{E}+03(\mathrm{Ci})$ \\
\hline
\end{tabular}

"Unknowns in tank solids invenuory are assigned bv Tank Layerang Model (TLM). 


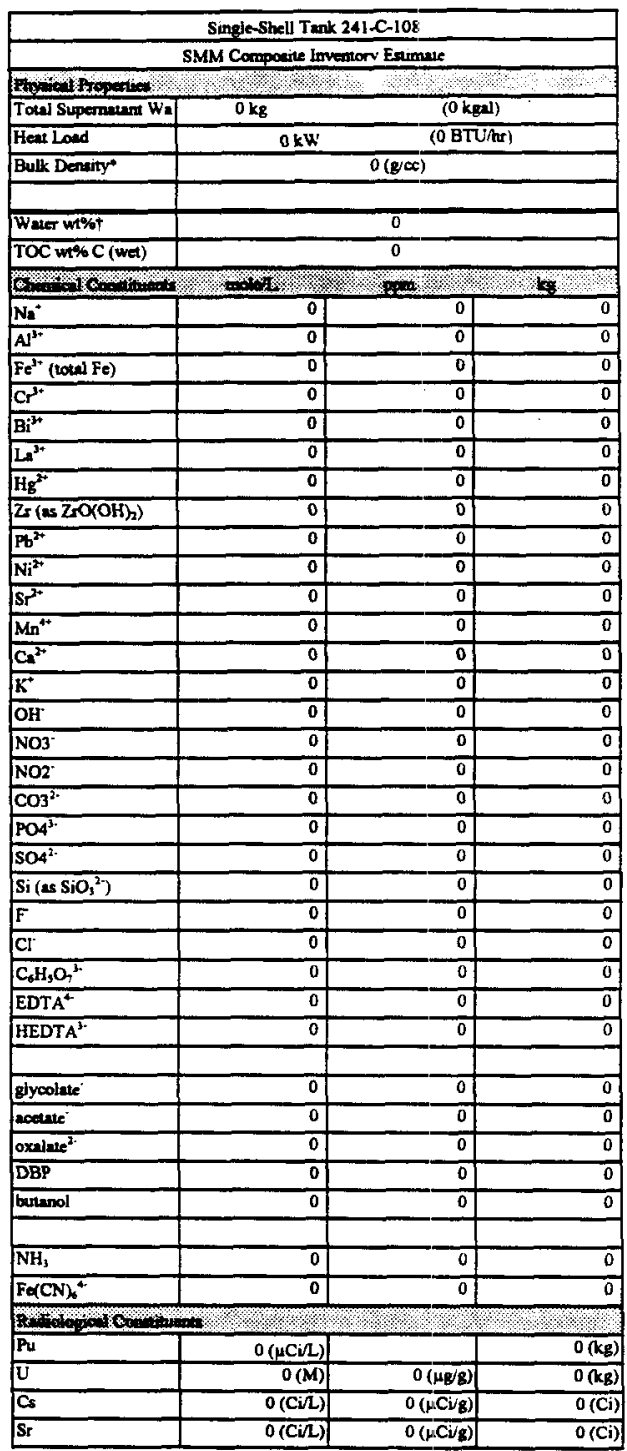

"Denciry is calasined besed on $\mathrm{Na}_{1} \mathrm{OH}$, and $\mathrm{AJO}_{2}$.

tWater wt\% derived from the difference of denaity and total dienolved apocies. 


\begin{tabular}{|c|c|c|c|}
\hline \multicolumn{4}{|c|}{ Single-Shell Tank 241-C.108 } \\
\hline \multicolumn{4}{|c|}{ Toul Inventory Earinate* } \\
\hline Pwotic Properties & \multirow{2}{*}{$3.33 \mathrm{E}+05 \mathrm{~kg}$} & 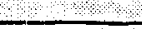 & 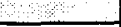 \\
\hline Toul Warte & & \multicolumn{2}{|c|}{$(66.0 \mathrm{kgal})$} \\
\hline Heat Lond & $0.401 \mathrm{~kW}$ & \multicolumn{2}{|c|}{ (1.37E+03 BTU $/ \mathrm{hr})$} \\
\hline Bulk Density't & \multicolumn{3}{|c|}{$1.33(\mathrm{~g} / \mathrm{cc})$} \\
\hline Water wt\%t & \multicolumn{3}{|c|}{65.3} \\
\hline TOC w:\% C (we:) ${ }^{\dagger}$ & \multicolumn{3}{|c|}{0.351} \\
\hline \multicolumn{4}{|l|}{ 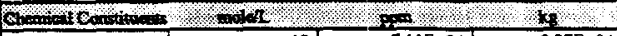 } \\
\hline $\mathrm{Nat}$ & 4.12 & $7.11 \mathrm{E}+04$ & $2.37 \mathrm{E}+04$ \\
\hline $\mathrm{Al}^{3+}$ & 0.239 & $4.84 \mathrm{E}+03$ & $1.61 \mathrm{E}+03$ \\
\hline $\mathrm{Fe}^{3 r}$ (10ted Fe & 0.803 & $3.37 \mathrm{E}+04$ & $1.12 \mathrm{E}+04$ \\
\hline $\mathrm{Cr}^{3+}$ & $2.77 E-03$ & 108 & 36.0 \\
\hline $\mathrm{Bi}^{3+}$ & $3.38 \mathrm{E}-02$ & $5.31 \mathrm{E}+03$ & $1.77 \mathrm{E}+03$ \\
\hline $\mathrm{Les}^{3+}$ & 0 & 0 & 0 \\
\hline $\mathrm{Hg}^{2+}$ & $4.64 \mathrm{E}-05$ & 6.99 & 2.33 \\
\hline $2 \mathrm{r}(\mathrm{as} \mathrm{ZrO}(\mathrm{OH}) h)$ & $4.53 \mathrm{E}-03$ & 310 & 103 \\
\hline $\mathrm{Pb}^{2+}$ & 0 & 0 & 0 \\
\hline $\mathrm{Ni}^{2-}$ & 0.120 & $5.27 \mathrm{E}+03$ & $1.75 E+03$ \\
\hline $\mathrm{Sr}^{\mathrm{r}^{2+}}$ & 0 & 0 & 0 \\
\hline $\mathrm{Mn}^{4+2}$ & 0 & 0 & $\begin{array}{r}0 \\
3.09 \mathrm{E}+03\end{array}$ \\
\hline $\mathrm{Cs}^{2+}$ & 0.308 & $9.28 \mathrm{E}+03$ & \\
\hline $\mathbf{K}^{+}$ & $9.32 \mathrm{E}-03$ & 273 & 91.0 \\
\hline OH & 3.76 & $4.80 \mathrm{E}+04$ & $1.60 \mathrm{E}+04$ \\
\hline $\mathrm{NO3}^{-}$ & 0.996 & $4.64 \mathrm{E}+\sqrt{17}$ & $1.54 \mathrm{E}+04$ \\
\hline NO2 & 0.628 & $2.17 \mathrm{E} *: 1$ & $7.22 \mathrm{E}+03$ \\
\hline $\mathrm{CO}^{2+}$ & 0.371 & $1.67 E+04$ & $5.57 \mathrm{E}+03$ \\
\hline PO- & 0.652 & $4.65 E+04$ & $1.55 \mathrm{E}+04$ \\
\hline $\mathrm{SO}^{\circ}$ & $7.14 \mathrm{E}-02$ & $5.15 E+03$ & $1.71 \mathrm{E}+03$ \\
\hline $\mathrm{Si}\left(\mathrm{as} \mathrm{SiO}_{3}{ }^{2-}\right)$ & $2.78 \mathrm{E}-02$ & 586 & 195 \\
\hline $\mathbf{F}$ & $7.26 \mathrm{E}-02$ & $1.04 \mathrm{E}+03$ & 345 \\
\hline $\mathrm{Cr}$ & $5.08 \mathrm{E}-02$ & $1.35 \mathrm{E}+03$ & 450 \\
\hline $\mathrm{C}_{6} \mathrm{H}_{3} \mathrm{O}_{7}{ }^{3}$ & 0 & 0 & $u$ \\
\hline EDTA ${ }^{*}$ & 0 & 0 & 0 \\
\hline HEDT A $^{3 \cdot}$ & 0 & 0 & 0 \\
\hline Glycoiate & 0 & $i$ & 0 \\
\hline acelate & 0 & $i$ & 0 \\
\hline oxalate ${ }^{2 *}$ & 0 & 0 & 0 \\
\hline DEP & $1.05 \mathrm{E}-05$ & 2.11 & 0.700 \\
\hline burunol & $1.05 \mathrm{E}-05$ & 0.586 & 0.195 \\
\hline $\mathrm{NH}_{3}$ & $4.52 \mathrm{E}-02$ & 577 & 192 \\
\hline $\mathrm{Fe}(\mathrm{CN})_{6}^{4}$ & $6.49 \mathrm{E}-02$ & $1.32 \mathrm{E}+04$ & $4.39 \mathrm{E}+03$ \\
\hline 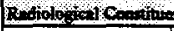 & & & 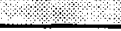 \\
\hline Pu & & $3.72 \mathrm{E}-03(\mu \mathrm{Ci} / \mathrm{g})$ & $2,06 \mathrm{E}-02(\mathrm{~kg})$ \\
\hline $\mathrm{U}$ & $0.103(\mathrm{M})$ & $1.84 \mathrm{E}+04(\mu \mathrm{g} / \mathrm{g})$ & $6.14 \mathrm{E}+03(\mathrm{~kg})$ \\
\hline Cs & $0.330(\mathrm{Ci} / \mathrm{L})$ & $248(\mu \mathrm{Ci} / \mathrm{g})$ & $8.26 \mathrm{E}+04(\mathrm{Ci})$ \\
\hline St & $8.39 \mathrm{E}-03(\mathrm{Ci} / \mathrm{L})$ & $6.30(\mu \mathrm{Ci} / \mathrm{g})$ & $2.10 \mathrm{E}+03\left(\mathrm{C}_{i}\right)$ \\
\hline
\end{tabular}

"Unknowns i. rik solids inveruory are asigned bV Tank Lavering Model (TLM).

†Voiume aver a: '. 'or density, mess avernge Wale' in\% and TOC wt\% C. 


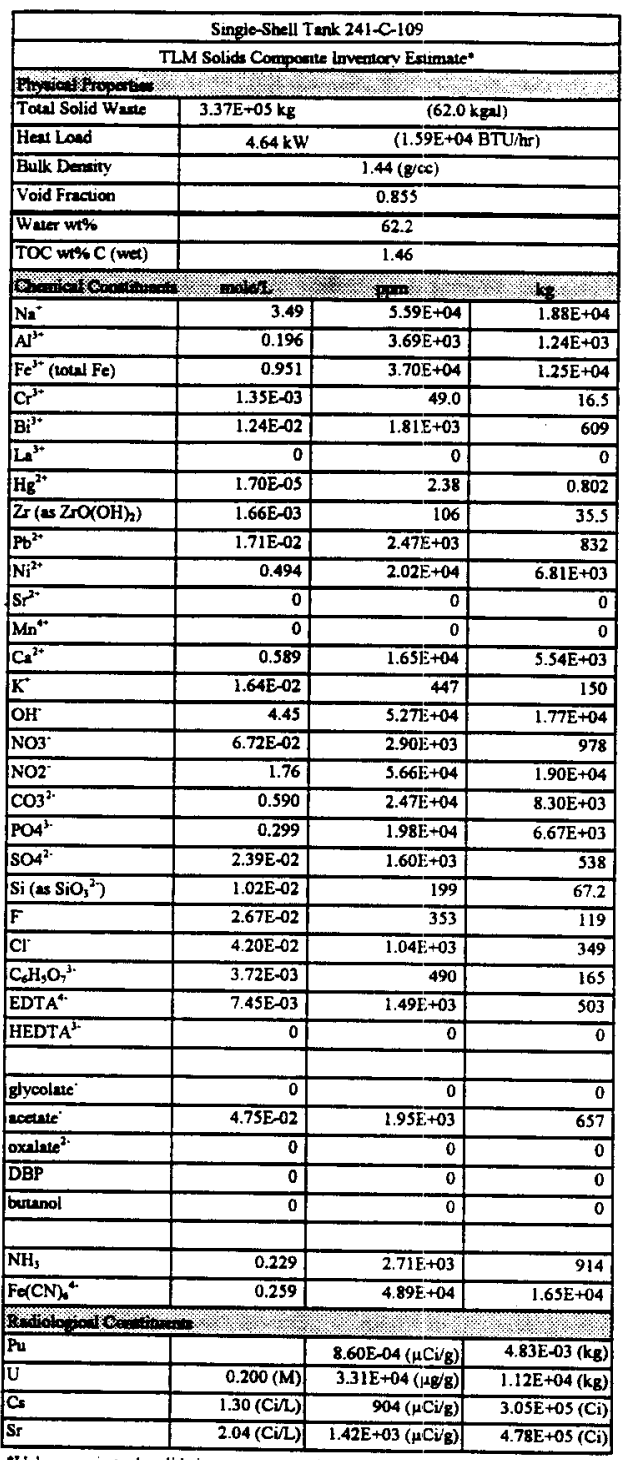

"Uniknowns in tank solids inventory are asigned by Tank Layering Model (TLM) 


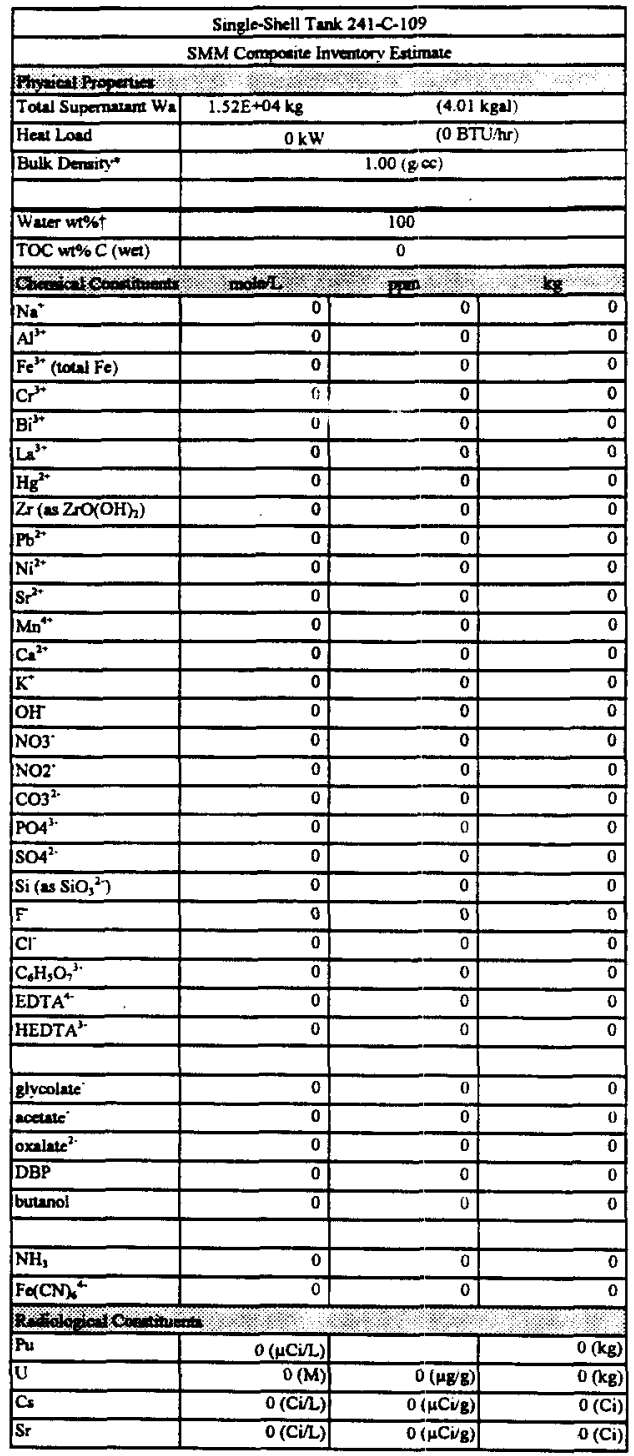

"Dersity is calculated besed on Na, $\mathrm{OH}$, and $\mathrm{AlO}_{2}$

† Water wt\% derived from the difference of density a? I tatal dissolved apecies. 
WHC-SD-WM-ER-313, Rev. 1

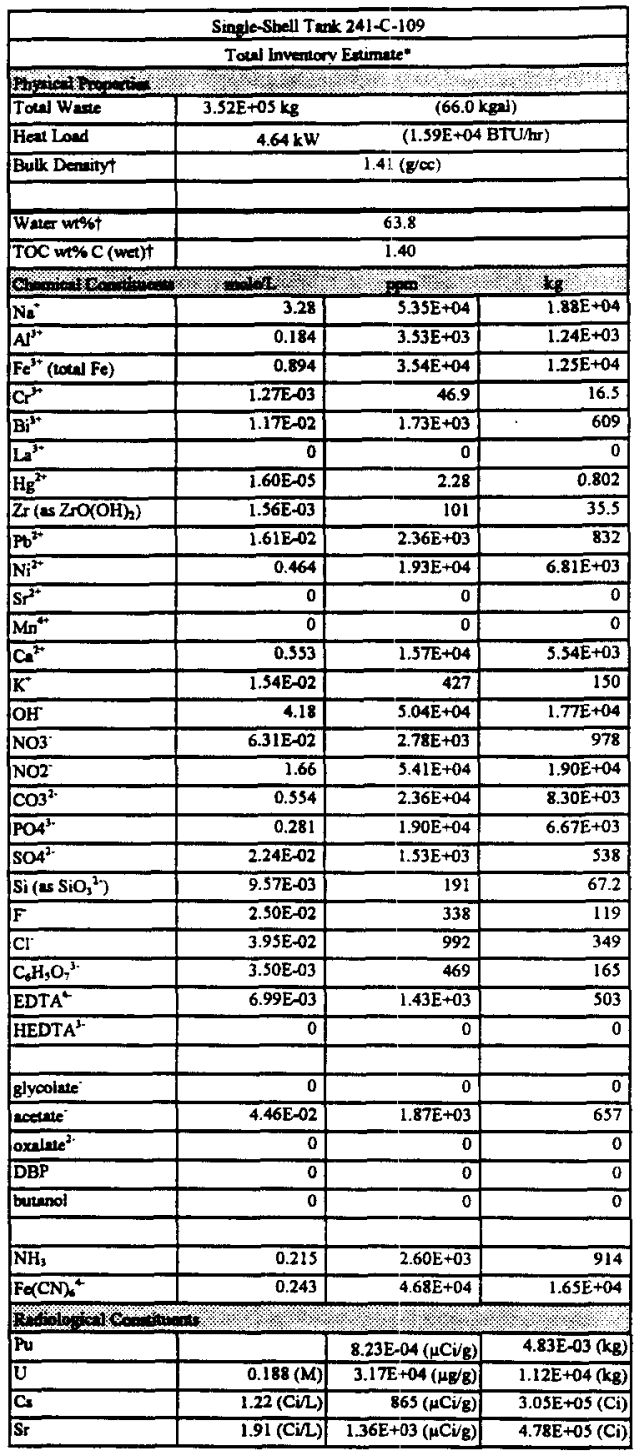

"Unknowm in unk wolids invenrory are asagened by T ank Layering Model (TLM).

†Volupe average for dersity, muss average Waler wt'\% and TOC wt\% C. 
WHC-SD-WM-ER-313, Rev. 1

Single-Shell Tank 241-C-110

TLM Solids Composine Inventory Estimate*

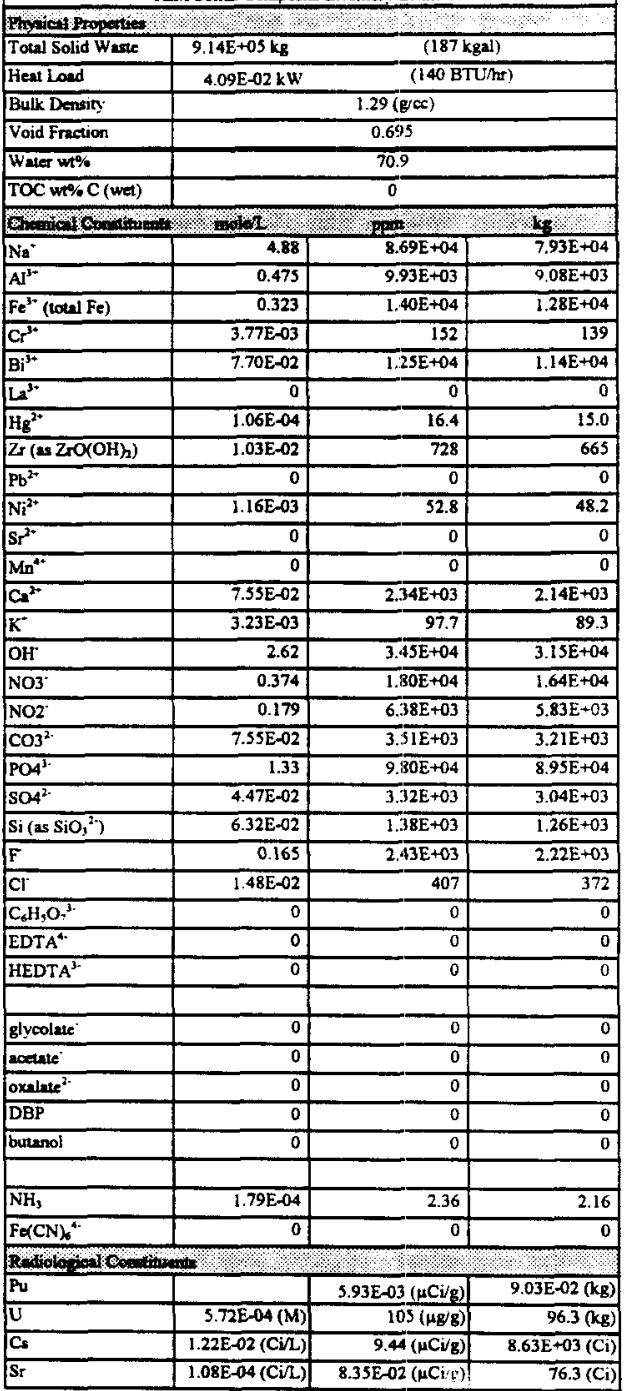

"Unknowns in tank solids inventory are asaigned by Tonk Layenng Model (TLM). 
Single-Shell Tank 241-C- 110

SMM Compoeste Inventory Estinute

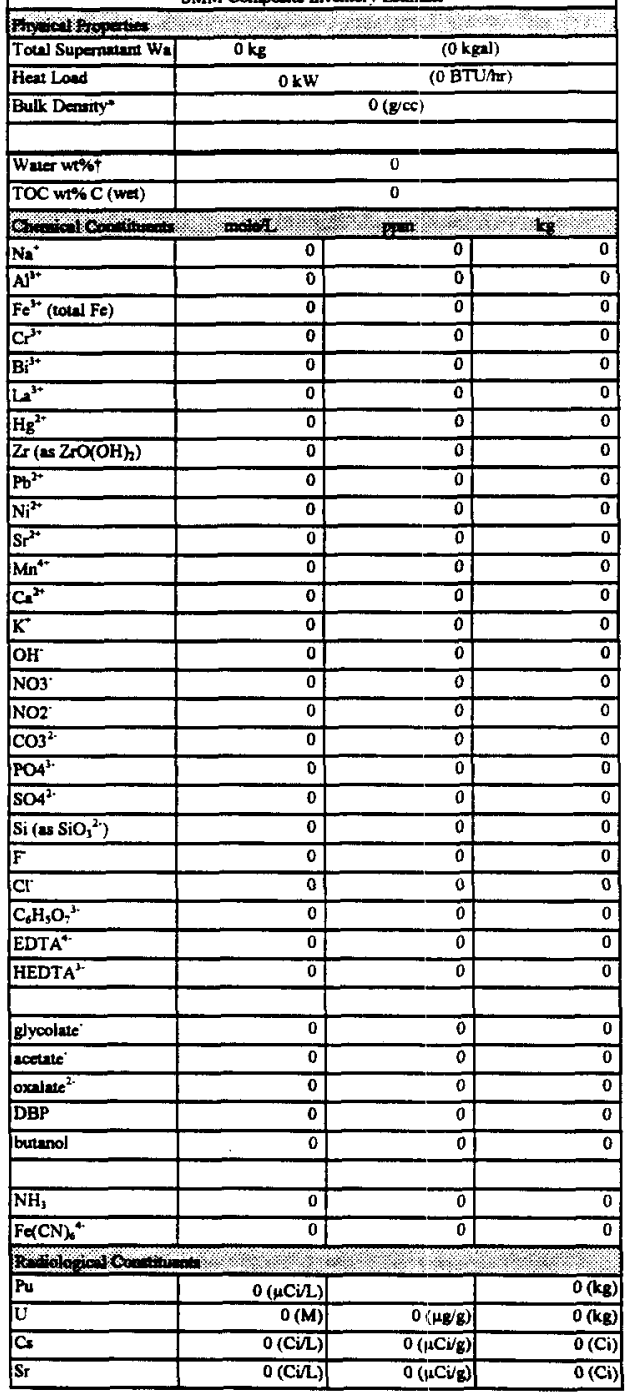

"Deminy is celculared beed on $\mathrm{Na}, \mathrm{OH}$, and $\mathrm{AlO}_{2}$.

tWaer wo\% derived from the tifference of denaity and tolal dienolved apecies. 


\begin{tabular}{|c|c|c|c|}
\hline \multicolumn{4}{|c|}{ Single-Shell Trak 241 C- 110} \\
\hline \multicolumn{4}{|c|}{ Toull biventory Estimante" } \\
\hline Photied thoperito & . & & 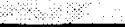 \\
\hline Total Whate & $9.14 \mathrm{E}+0.5 \mathrm{~kg}$ & \multicolumn{2}{|c|}{ (187 kgai) } \\
\hline Heat Land & $4.09 \mathrm{E}-02 \mathrm{~kW}$ & \multicolumn{2}{|c|}{$(140 \mathrm{BT} / \mathrm{hr})$} \\
\hline Bulk Dersxity? & \multicolumn{3}{|c|}{$1.29(\mathrm{~g} / \mathrm{cc})$} \\
\hline Water wit\%! & \multicolumn{3}{|c|}{70.9} \\
\hline TOC wt\% C (wet) $\dagger$ & \multicolumn{3}{|c|}{0} \\
\hline \multicolumn{2}{|l|}{ 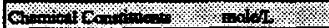 } & 6 & ks \\
\hline $\mathrm{Na}{ }^{*}$ & 4.88 & $8.69 E+04$ & $7.93 E+04$ \\
\hline$\overline{A]^{3+2}}$ & 0.475 & $9.93 \mathrm{E}+03$ & $9.08 \mathrm{E}+03$ \\
\hline $\mathrm{Fe}^{\mathrm{j+}}($ Lotal $\mathrm{Fe})$ & 0.323 & $1.40 \mathrm{E}+04$ & $1.28 \mathrm{E}+04$ \\
\hline $\mathrm{cr}^{3+}$ & $3 . T 7 \mathrm{E}-03$ & 152 & 139 \\
\hline $\mathrm{Bi}^{3+}$ & $7 .=-02$ & $1.25 E+04$ & $1.14 \mathrm{E}+04$ \\
\hline $\mathrm{La}^{3+}$ & 0 & 0 & 0 \\
\hline $\mathrm{Hg}^{2+}$ & $1.06 \mathrm{E}-04$ & 16.4 & 15.0 \\
\hline $\mathrm{Zr}(\mathrm{as \textrm {ZrO } ( \mathrm { OH } )})$ & $1.03 \mathrm{E}-02$ & 728 & 665 \\
\hline $\mathrm{Pb}^{2+}$ & 0 & 0 & 0 \\
\hline $\mathrm{Ni}^{\mathrm{j}^{+}}$ & $1.16 \mathrm{E}-03$ & 52.8 & 48.2 \\
\hline$s r^{2+}$ & 0 & 0 & 0 \\
\hline $\mathrm{Mn}^{4+}$ & 0 & 0 & 0 \\
\hline $\mathrm{CA}^{2+}$ & $7.55 \mathrm{E}-02$ & $2.34 \mathrm{E}+03$ & $2.14 \mathrm{E}+03$ \\
\hline $\mathbf{K}$ & $3.23 \mathrm{E}-03$ & 97.7 & 89.3 \\
\hline OH & 2.62 & $3.45 E+04$ & $3.15 E+04$ \\
\hline NO3: & 0.374 & $1.80 E+04$ & $1.64 \mathrm{E}+04$ \\
\hline NO2 & 0.179 & $6.38 E+03$ & $5.83 \mathrm{E}+03$ \\
\hline $\mathrm{CO}^{3-}$ & $7.55 \mathrm{E}-02$ & $3.51 \mathrm{IE}+03$ & $3.2 \mathrm{IE}+03$ \\
\hline $\mathrm{PO}^{3-}$ & 1.33 & $9.80 \mathrm{E}+04$ & $8.95 E+04$ \\
\hline $\mathrm{SO4}^{2-}$ & $4.47 \mathrm{E}-02$ & $3.32 \mathrm{E}+03$ & $3.04 E+03$ \\
\hline $\mathrm{Si}\left(\mathrm{NS} \mathrm{SiO}_{3}^{2+}\right)$ & $6.32 \mathrm{E}-02$ & $1.38 \mathrm{E}+03$ & $1.26 \mathrm{E}+03$ \\
\hline$F$ & 0.165 & $2.43 E+03$ & $2.22 \mathrm{E}+03$ \\
\hline $\mathrm{Cr}$ & $1.48 \mathrm{E}-02$ & 407 & 372 \\
\hline $\mathrm{C}_{6} \mathrm{H}_{5} \mathrm{O}_{7}{ }^{3-}$ & 0 & 0 & 0 \\
\hline EDTA 4 & 0 & 0 & 0 \\
\hline HEDT ${ }^{3-}$ & 0 & 0 & 0 \\
\hline giveolate & 0 & 0 & 0 \\
\hline acetale & 0 & 0 & $\overline{0}$ \\
\hline oxalate ${ }^{2}$ & 0 & 0 & 0 \\
\hline $\mathrm{DBP}$ & 0 & 0 & 0 \\
\hline butanol & 0 & 0 & 0 \\
\hline $\mathrm{NH}_{3}$ & $1.79 \mathrm{E}-04$ & 2.36 & 2.16 \\
\hline $\mathrm{F} \Leftrightarrow \mathrm{CN})_{6}{ }^{4}$ & 0 & 0 & 0 \\
\hline 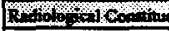 & 5 & 8 & $1 \%$ \\
\hline Pu & & $5.93 \mathrm{E}-03(\mu \mathrm{Ci} / \mathrm{g})$ & $9.03 \mathrm{E}-02(\mathrm{~kg})$ \\
\hline $\mathrm{U}$ & $5.72 \mathrm{E}-04(\mathrm{M})$ & $105(\mu \mathrm{g} / \mathrm{g})$ & $96.3(\mathrm{~kg})$ \\
\hline Cs & $1.22 \mathrm{E}-02(\mathrm{CilL})$ & $5.44(\mu \mathrm{Cig})$ & $8.63 \mathrm{E}+03(\mathrm{Ci})$ \\
\hline $\mathbf{S r}$ & $1.08 \mathrm{E}-04(\mathrm{CV} / \mathrm{L})$ & $8.3 \mathrm{SE}-02(\mu \mathrm{Ci} / \mathrm{g})$ & $76.3(\mathrm{Ci})$ \\
\hline
\end{tabular}

"Unknowns in unk nolids invemtory are assigned by Tank Layering Model (TLM) † Volume average for density, mass average Water wt\% and TOC wt\% C. 


\begin{tabular}{|c|c|c|c|}
\hline \multicolumn{4}{|c|}{ Single-Shell Tenk 241-C-111 } \\
\hline \multicolumn{4}{|c|}{ TLM Solids Comporive Inventory Estimate" } \\
\hline 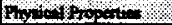 & & 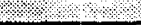 & ॰ \\
\hline Toul Solid Wate & $2.89 \mathrm{E}+05 \mathrm{~kg}$ & \multicolumn{2}{|c|}{$(57.0 \mathrm{kgal})$} \\
\hline Heat Load & $0.167 \mathrm{~kW}$ & \multicolumn{2}{|c|}{ (572 BTUMr) } \\
\hline Bulk Dentify & \multicolumn{3}{|c|}{$1.34(\mathrm{~g} / \infty)$} \\
\hline Void Fraction & \multicolumn{3}{|c|}{$0.75 !$} \\
\hline Water wt\% & \multicolumn{3}{|c|}{66.3} \\
\hline TOC wt\%C (wet) & \multicolumn{3}{|c|}{0.168} \\
\hline \multicolumn{4}{|l|}{ 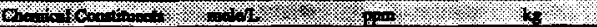 } \\
\hline $\mathrm{Na}^{*}$ & 3.94 & $6.76 E+04$ & $1.95 \mathrm{E}+04$ \\
\hline $\mathrm{A}^{3+}$ & 1.76 & $3.55 \mathrm{E}+04$ & $1.03 E+04$ \\
\hline $\mathrm{Fe}^{3+}$ (total Fe) & 0.282 & $1.17 \mathrm{E}+04$ & $3.39 \mathrm{E}+03$ \\
\hline $\mathrm{Cr}^{3+}$ & $3.10 \mathrm{E}-03$ & 120 & $\overline{34.8}$ \\
\hline$B i^{3+}$ & $4.86 \mathrm{E}-02$ & $7.58 \mathrm{E}+03$ & $2.19 E+03$ \\
\hline $\mathrm{La}^{3+2}$ & 0 & 0 & 0 \\
\hline $\mathrm{Hg}^{2+}$ & $7.76 \mathrm{E}-04$ & 116 & 33.6 \\
\hline $\mathrm{Zx}\left(\mathrm{as} \mathrm{Z} \times \mathrm{O}(\mathrm{OH})_{h}\right)$ & 6.51E-03 & 443 & 128 \\
\hline $\mathrm{Pb}^{2+}$ & $3.30 \mathrm{E}-02$ & $5.11 \mathrm{E}+03$ & $1.48 \mathrm{E}+03$ \\
\hline $\mathrm{Ni}^{2-2}$ & $5.82 \mathrm{E}-02$ & $2.55 E+03$ & 737 \\
\hline $\mathrm{Sr}^{2+}$ & 0 & 0 & 0 \\
\hline $\mathrm{Mn}^{4+1}$ & 0 & 0 & 0 \\
\hline $\mathrm{Ca}^{2+}$ & 0.151 & $4.52 \mathrm{E}+03$ & $1.31 \mathrm{E}+03$ \\
\hline $\mathbf{K}^{+}$ & $3.29 \mathrm{E}-03$ & 96.0 & 27.7 \\
\hline $\mathrm{OH}$ & 6.81 & $8.64 E+04$ & $2.50 \mathrm{E}+04$ \\
\hline NO3 & 0.395 & $1.83 \mathrm{E}+04$ & $5.29 \mathrm{E}+03$ \\
\hline $\mathrm{NO} 2$ & 0.499 & $1.71 \mathrm{E}+04$ & $4.96 \mathrm{E}+03$ \\
\hline $\cos ^{2-}$ & 0.151 & $6.77 \mathrm{E}+03$ & $1.96 E+03$ \\
\hline $\mathrm{PO4}^{3 \cdot}$ & 0.852 & $6.04 E+04$ & $1.74 \mathrm{E}+04$ \\
\hline $\mathrm{SO4}^{2+}$ & $3.24 \mathrm{E}-02$ & $2.33 E+03$ & 672 \\
\hline $\mathrm{Si}\left(\mathrm{ss} \mathrm{SiO}_{3}{ }^{2}\right)$ & $4.47 \mathrm{E}-02$ & 936 & 271 \\
\hline$F$ & 0.104 & $1.48 \mathrm{E}+03$ & 428 \\
\hline $\mathrm{Cl}$ & $1.51 \mathrm{E}-02$ & 400 & 116 \\
\hline $\mathrm{C}_{6} \mathrm{H}_{9} \mathrm{O}_{7}{ }^{3}$ & 0 & 0 & 0 \\
\hline EDTA ${ }^{4}$ & 0 & 0 & 0 \\
\hline HEDTA $^{3-}$ & 0 & 0 & 0 \\
\hline glycolate & 0 & 0 & 0 \\
\hline acethite" & 0 & 0 & 0 \\
\hline oxulate ${ }^{2}$ & 0 & 0 & 0 \\
\hline DBP & 0 & 0 & 0 \\
\hline banunol & 0 & 0 & 0 \\
\hline $\mathrm{NH}_{3}$ & 2.17E-02 & 276 & 79.7 \\
\hline $\mathrm{F} \propto(\mathrm{CN})_{6}{ }^{4}$ & 3.13E-02 & $6.32 \mathrm{E}+03$ & $1.83 \mathrm{E}+03$ \\
\hline \multicolumn{4}{|l|}{ 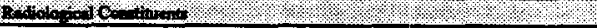 } \\
\hline $\mathbf{P u}$ & & $0.176(\mu \mathrm{Ci} / g)$ & $0.846(\mathrm{~kg})$ \\
\hline $\bar{U}$ & $5.22 \mathrm{E}-02(\mathrm{M})$ & $9.27 \mathrm{E}+03(\mu \mathrm{g} / \mathrm{g})$ & $2.68 \mathrm{E}+03(\mathrm{~kg})$ \\
\hline Cs & $0.163(\mathrm{Ci} / \mathrm{L})$ & $123(\mu \mathrm{Ci} \mathrm{g})$ & $3.55 \mathrm{E}+04(\mathrm{Ci})$ \\
\hline St & $5.62 \mathrm{E}-04(\mathrm{Ci} / \mathrm{L})$ & $0.420(\mu \mathrm{Ci} / \mathrm{g})$ & $121(\mathrm{Ci})$ \\
\hline
\end{tabular}

*Unknowns in lank rolids invenrory are ausigned by Tank Layering Model (TLM). 


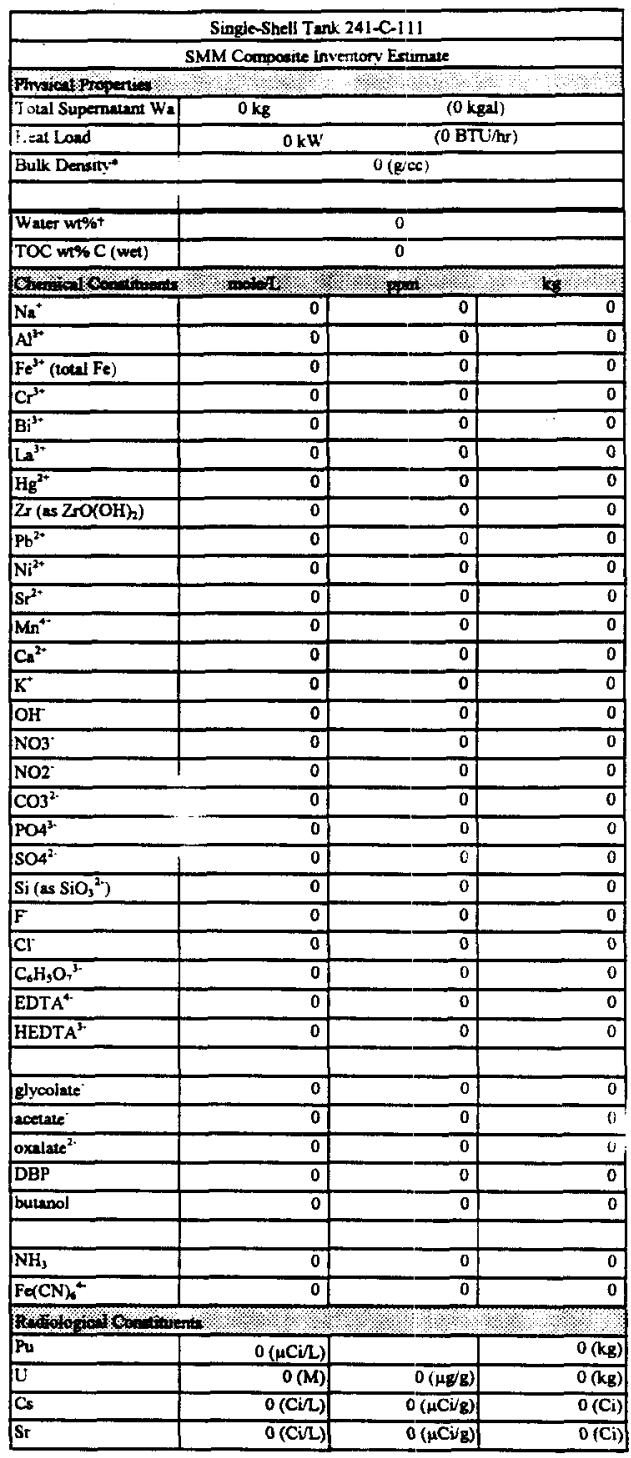

"Density is calculated based on Na, OH, and,$i i i_{2}$.

tWater wt\% derived from the difference of densitv and lotal dissolved species. 
WHC-SD-WM-ER-313, Rev. 1

\begin{tabular}{|c|c|c|c|}
\hline \multicolumn{4}{|c|}{ Single-Shell Tank 241-C-111 } \\
\hline \multicolumn{4}{|c|}{ Total lnventory Entimate" } \\
\hline \multicolumn{4}{|l|}{ 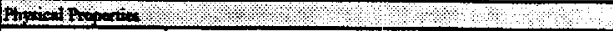 } \\
\hline Total Wane & $2.89 \mathrm{E}+05 \mathrm{~kg}$ & \multicolumn{2}{|c|}{$(57.0 \mathrm{kgal})$} \\
\hline Heat Lond & $0.167 \mathrm{~kW}$ & \multicolumn{2}{|c|}{ (\$72 BTU/Mr) } \\
\hline Bulk Denaity' & \multicolumn{3}{|c|}{$1.34(2 \%)$} \\
\hline Waler wt\%! & \multicolumn{3}{|c|}{66.3} \\
\hline TOC wt\% C (wet) $\dagger$ & \multicolumn{3}{|c|}{0.168} \\
\hline \multicolumn{4}{|l|}{$0, \quad \times 1,1$} \\
\hline $\mathrm{Na}^{*}$ & 3.94 & $6.76 \mathrm{E}+04$ & $1.95 \mathrm{E}+04$ \\
\hline$\overline{\mathrm{Al}^{3+}}$ & 1.76 & $3.95 E+04$ & $1.03 \mathrm{E}+04$ \\
\hline $\mathrm{Fe}^{3+}$ (total Fe) & 0.282 & $1.17 E+04$ & $3.39 \mathrm{E}+03$ \\
\hline $\mathrm{Cr}^{3+}$ & $3.10 \mathrm{E}-03$ & 120 & 34.8 \\
\hline $\mathrm{Bi}^{3+}$ & $4.86 \mathrm{E}-02$ & $7.58 \mathrm{E}+03$ & $2.19 E+03$ \\
\hline $\mathrm{La}^{3+}$ & 0 & 0 & 0 \\
\hline $\mathrm{Hg}^{2+}$ & $7.76 \mathrm{E}-04$ & 116 & 33.6 \\
\hline $\mathrm{Zr}(\mathrm{as} \mathrm{ZTO}(\mathrm{OH})$ & $6.51 \mathrm{E}-03$ & 443 & 128 \\
\hline $\mathrm{Pb}^{2+}$ & $3.30 \mathrm{E}-02$ & $5.11 \mathrm{E}+03$ & $1.48 \mathrm{E}+03$ \\
\hline $\mathrm{Ni}^{i^{2+}}$ & $5.82 \mathrm{E}-02$ & $2.55 \mathrm{E}+03$ & 737 \\
\hline$s^{x^{2}}$ & 0 & 0 & $\overline{0}$ \\
\hline $\mathrm{Mn}^{4+}$ & 0 & 0 & 0 \\
\hline $\mathrm{Ca}^{2+}$ & 0.151 & $4.52 \mathrm{E}+03$ & $1.31 \mathrm{E}+03$ \\
\hline $\mathrm{K}^{*}$ & $3.29 \mathrm{E}-03$ & 96.0 & 27.7 \\
\hline $\mathrm{OH}$ & 6.81 & $8.64 E+04$ & $2.50 E+04$ \\
\hline $\mathrm{NO3}^{-}$ & 0.395 & $1.83 \mathrm{E}+04$ & $5.29 \mathrm{E}+03$ \\
\hline NO2: & 0.499 & $1.71 E+04$ & $4.96 E+03$ \\
\hline $\cos ^{2+}$ & 0.151 & $6.77 \mathrm{E}+03$ & $1.96 \mathrm{E}+03$ \\
\hline $\mathrm{PO}^{3}$ & 0.852 & $6.04 \mathrm{E}+04$ & $1.74 \mathrm{E}+04$ \\
\hline $504^{2-}$ & $3.24 \mathrm{E}-02$ & $2.33 \mathrm{E}+03$ & 672 \\
\hline $\mathrm{Si}\left(25 \mathrm{SiO}_{3}{ }^{27}\right)$ & $4.47 \mathrm{E}-02$ & 936 & 271 \\
\hline $\mathbf{F}$ & 0.104 & $1.48 E+03$ & 428 \\
\hline $\mathrm{Cl}^{-}$ & $1.51 \mathrm{E}-02$ & 400 & 116 \\
\hline $\mathrm{C}_{6} \mathrm{H}_{3} \mathrm{O}_{7}{ }^{2 .}$ & 0 & 0 & 0 \\
\hline EDTA $^{4}$ & 0 & 0 & 0 \\
\hline HEDTA ${ }^{3-}$ & 0 & 0 & 0 \\
\hline glycolate & 0 & 0 & 0 \\
\hline ecentente & 0 & 0 & 0 \\
\hline oxalnte ${ }^{2-}$ & 0 & 0 & 0 \\
\hline DBP & 0 & $\overline{0}$ & 0 \\
\hline butanol & 0 & 0 & 0 \\
\hline $\mathrm{NH}_{3}$ & $2.17 E-02$ & 276 & 79.7 \\
\hline $\mathrm{Fe}(\mathrm{CN})_{6}{ }^{2}$ & $3.13 \mathrm{E}-02$ & $6.32 \mathrm{E}+03$ & $1.83 E+03$ \\
\hline B. & & 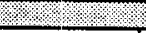 & 10 \\
\hline Pu & & $0.176(\mu \mathrm{Ci} / \mathrm{g})$ & $0.846(\mathrm{~kg})$ \\
\hline $\bar{U}$ & $5.22 \mathrm{E}-02(\mathrm{M})$ & $9.27 \mathrm{E}-03(\mu \mathrm{g} / \mathrm{g})$ & $2.68 \mathrm{E}+03(\mathrm{~kg})$ \\
\hline $\mathrm{Cs}$ & $0.165(\mathrm{Ci} / \mathrm{L})$ & $123(\mu \mathrm{Ci} / g)$ & $3.55 \mathrm{E}+04(\mathrm{Ci})$ \\
\hline$S r$ & 5.62E-04(Ci/L) & $0.420(\mu \mathrm{Ci} / \mathrm{g})$ & $121(\mathrm{Ci})$ \\
\hline
\end{tabular}

*Unknowns in tank solids invertory are anignod by Tank Layering Model (TLM).

+Volume average for density, mass averge Wuer wo and TOC wt\% C. 
Singie-Shell Tark 241-C-112

TLM Solids Composine inventory Estimale*

\begin{tabular}{|c|c|c|c|}
\hline Thyoles of & 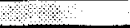 & 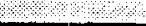 & $\ldots$ \\
\hline Total Solid Weate & $5.65 \mathrm{E}+05 \mathrm{~kg}$ & $(104 \mathrm{~kg}$ & \\
\hline Heat Load & $2.74 \mathrm{~kW}$ & $(9.37 E+031$ & U/mr) \\
\hline Bulk Density & & $1.44(\mathrm{~g} / \mathrm{cc})$ & \\
\hline Void Fraction & & 0.854 & \\
\hline Walet wt\% & & 63.1 & \\
\hline TOC wt\% C (wet) & & 1.25 & \\
\hline 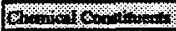 & and & then & na \\
\hline $\mathrm{Na}^{+}$ & 3.38 & $5.42 \mathrm{E}+04$ & $3.06 \mathrm{E}+04$ \\
\hline $\mathrm{Al}^{\mathrm{3*}}$ & 0.996 & $1.87 \mathrm{E}+04$ & $1.06 \mathrm{E}+04$ \\
\hline $\mathrm{Fe}^{3+}($ total $\mathrm{Fe})$ & 0.382 & $1.49 \mathrm{E}+04$ & $8.40 \mathrm{E}+03$ \\
\hline $\mathrm{Cr}^{3+}$ & $9.96 \mathrm{E}-04$ & 36.1 & 20.4 \\
\hline$B i^{3-}$ & $1.11 \mathrm{E}-02$ & $1.62 \mathrm{E}+03$ & 913 \\
\hline $\mathrm{La}^{3+}$ & 0 & 0 & 0 \\
\hline $\mathrm{Hg}^{2+}$ & $5.02 \mathrm{E}-04$ & 70.1 & 39.6 \\
\hline $2 \mathrm{~s}(\mathrm{as} \mathrm{ZrO}(\mathrm{OH}) h)$ & $1.49 \mathrm{E}-03$ & 94.4 & 53.3 \\
\hline $\mathrm{Pt}^{2+}$ & $2.56 \mathrm{E}-02$ & $3.69 \mathrm{E}+03$ & $2.08 \mathrm{E}+03$ \\
\hline $\mathrm{Ni}^{2^{+2}}$ & 0.453 & $1.85 E+04$ & $1.05 \mathrm{E}+04$ \\
\hline $\mathrm{Sr}^{2+}$ & 0 & 0 & 0 \\
\hline $\mathrm{Mn}^{4+}$ & 0 & 0 & 0 \\
\hline $\mathrm{Cs}^{2+}$ & 0.585 & $1.63 \mathrm{E}+04$ & $9.23 \mathrm{E}+03$ \\
\hline $\mathrm{K}^{+}$ & $8.63 \mathrm{E}-03$ & 235 & 133 \\
\hline $\mathrm{OH}^{\circ}$ & 5.27 & $6.2 \leq E+04$ & $3.53 \mathrm{E}+04$ \\
\hline NO3 & 0.146 & $6.10 \mathrm{E}+03$ & $3.56 \mathrm{E}+03$ \\
\hline NO2: & 2.68 & $5.40 \mathrm{E}+04$ & $3.05 \mathrm{E}+04$ \\
\hline $\cos ^{2}$ & 0.586 & $2.45 \mathrm{E}+04$ & $1.38 \mathrm{E}+04$ \\
\hline $\mathrm{PO}^{3-2}$ & 0.273 & $1.81 E+04$ & $1.02 \mathrm{E}+04$ \\
\hline $\mathrm{SO}^{2-2}$ & $1.85 \mathrm{E}-02$ & $1.24 \mathrm{E}+03$ & 700 \\
\hline Si (as $\left.\mathrm{SiO}_{3}{ }^{2}\right)$ & $1.12 \mathrm{E}-02$ & 220 & 124 \\
\hline$F$ & $2.38 \mathrm{E}-02$ & 316 & 178 \\
\hline $\mathrm{Cl}^{+}$ & $3.69 \mathrm{E}-02$ & 910 & 514 \\
\hline $\mathrm{C}_{6} \mathrm{H}_{9} \mathrm{O}_{7}{ }^{3-2}$ & $3.17 \mathrm{E}-04$ & 41.7 & 23.6 \\
\hline EDTA $^{4}$ & $6.34 \mathrm{E}-04$ & 127 & 71.8 \\
\hline HEDTA ${ }^{3-}$ & $\overline{0}$ & 0 & 0 \\
\hline gilycolale & 0 & 0 & 0 \\
\hline acetate & $4.04 \mathrm{E}-03$ & 166 & 93.8 \\
\hline oxalune ${ }^{2-}$ & 0 & 0 & 0 \\
\hline DBP & 0 & 0 & 0 \\
\hline butinol & 0 & 0 & 0 \\
\hline $\mathrm{NH}_{3}$ & 0.175 & $2.07 \mathrm{E}+03$ & $1.17 \mathrm{E}+03$ \\
\hline $\mathrm{F}(\mathrm{CN}){ }^{4-}$ & 0.247 & $4.66 \mathrm{E}+04$ & $2.63 \mathrm{E}+04$ \\
\hline Focilolo $=18 e_{\text {indine }}$ & & \% & \\
\hline $\mathrm{Pu}$ & & $0.109(\mu \mathrm{Cj} / \mathrm{g})$ & $1.03(\mathrm{~kg})$ \\
\hline $\mathrm{U}$ & $0.209(\mathrm{M})$ & $3.47 \mathrm{E}+04(\mu \mathrm{g} / \mathrm{g})$ & $1.96 \mathrm{E}+04(\mathrm{~kg})$ \\
\hline Cs & $1.24(\mathrm{Ci} / \mathrm{L})$ & $863(\mu \mathrm{Ci} / \mathrm{g})$ & $4.87 \mathrm{E}+05(\mathrm{Ci})$ \\
\hline 5 & $0.174(C i / L)$ & $121(\mu \mathrm{Ci} / \mathrm{g})$ & $6.83 \mathrm{E}+04(\mathrm{Ci})$ \\
\hline
\end{tabular}

"Unknowns in tank solids inventory are ansigned by Tank Layering Model (TLM) 


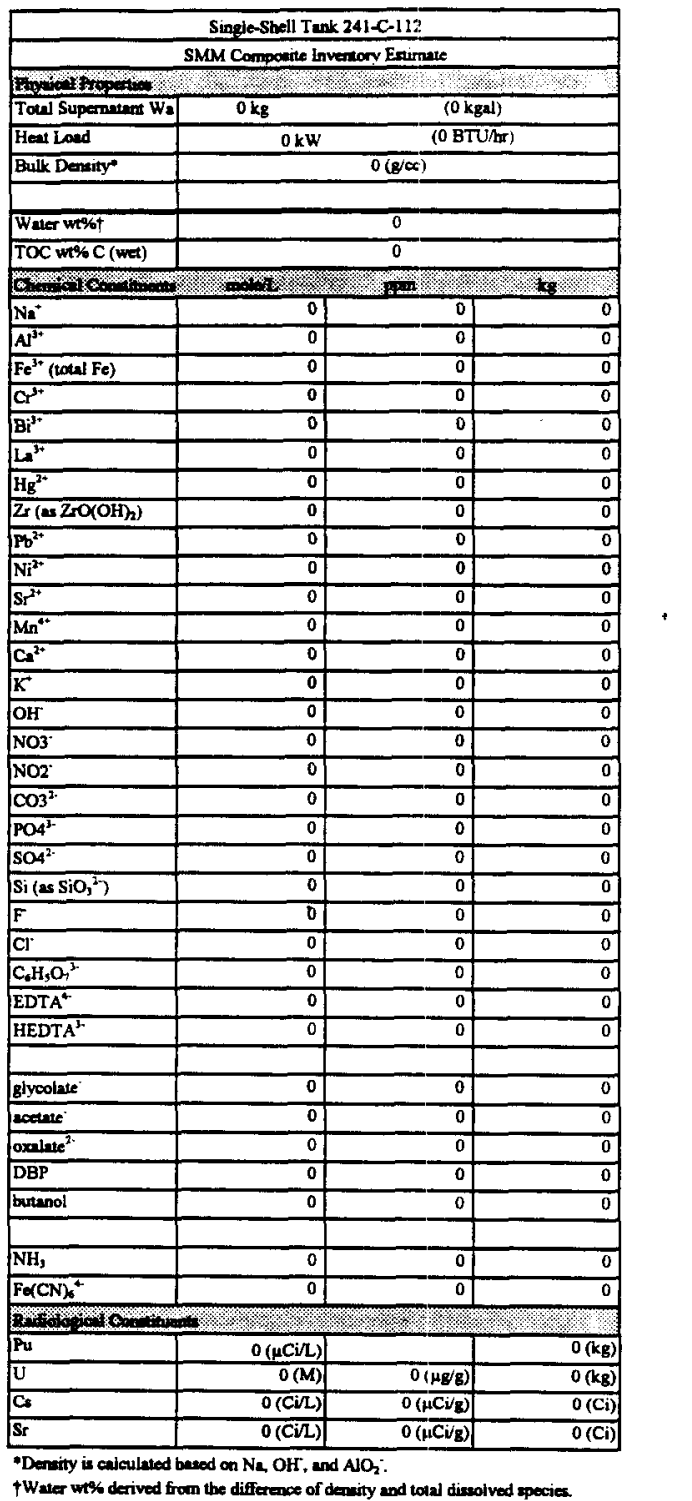




\begin{tabular}{|c|c|c|c|}
\hline \multicolumn{4}{|c|}{ Single-Shell Tank $241 \cdot C-112$} \\
\hline \multicolumn{4}{|c|}{ Total Invertory Estuniate" } \\
\hline 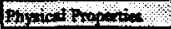 & \multirow{2}{*}{$\frac{1.6}{5.65 \mathrm{E}+05 \mathrm{~kg}}$} & \multicolumn{2}{|c|}{ ४ै। } \\
\hline Total Waste & & \multicolumn{2}{|c|}{ (104 kgal) } \\
\hline Heat Laed & $2.74 \mathrm{~kW}$ & \multicolumn{2}{|c|}{$(9.37 \mathrm{E}+03 \mathrm{BT}(\mathrm{hr})$} \\
\hline Bulk Derssty' & \multicolumn{3}{|c|}{$1.44(g / c c)$} \\
\hline Water wt\%t & \multicolumn{3}{|c|}{63.1} \\
\hline TOC wr\% C (wet) & \multicolumn{3}{|c|}{1.25} \\
\hline \multicolumn{2}{|l|}{ 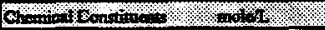 } & \multirow{2}{*}{\multicolumn{2}{|c|}{$\frac{5=0.00}{5.42 E+04}$}} \\
\hline $\mathrm{Na}$ & 3.38 & & \\
\hline $\mathrm{A}^{\mathrm{S}^{3+}}$ & 0.996 & \multicolumn{2}{|r|}{$1.06 \mathrm{E}+04$} \\
\hline $\mathrm{Fe}^{3+}$ (total $\mathrm{Fe}$ ) & 0.382 & $1.49 \mathrm{E}+04$ & $8.40 E+03$ \\
\hline $\mathrm{Cr}^{3+}$ & 9.96E-04 & 36.1 & 20.4 \\
\hline$B i^{3+}$ & $1.11 \mathrm{E}-02$ & $1.62 \mathrm{E}+03$ & 913 \\
\hline $\mathrm{Ls}^{3+}$ & 0 & 0 & 0 \\
\hline $\mathrm{Hg}^{2+}$ & $5.02 \mathrm{E}-04$ & 70.1 & 39.6 \\
\hline $\mathrm{Zr}\left(\right.$ as $\left.\mathrm{ZrO}(\mathrm{OH})_{2}\right)$ & $1.49 \mathrm{E}-03$ & 94.4 & 53.3 \\
\hline $\mathrm{Pb}^{2+}$ & $2.56 \mathrm{E}-02$ & $3.69 \mathrm{E}+03$ & $2.08 \mathrm{E}+03$ \\
\hline $\mathrm{Ni}^{2+}$ & 0.453 & $1.85 \mathrm{E}+04$ & $1.05 \mathrm{E}+04$ \\
\hline $\mathrm{Sr}^{2+}$ & 0 & 0 & 0 \\
\hline $\mathrm{Mn}^{\mathrm{in}}$ & 0 & 0 & 0 \\
\hline $\mathrm{Ca}^{2+}$ & 0.585 & $1.63 \mathrm{E}+04$ & $9.23 \mathrm{E}+03$ \\
\hline$\overline{\mathbf{K}^{+}}$ & $8.63 \mathrm{E}-03$ & 235 & 133 \\
\hline $\mathrm{OH}$ & 5.27 & $6.25 \mathrm{E}+04$ & $3.53 \mathrm{E}+04$ \\
\hline No3 & 0.146 & $6.30 \mathrm{E}+03$ & $3.56 \mathrm{E}+03$ \\
\hline $\mathrm{NO} 2$ & 1.68 & $5.40 \mathrm{E}+04$ & $3.05 \mathrm{E}+04$ \\
\hline $\cos ^{2-}$ & 0.586 & $2.45 E+04$ & $1.38 E+04$ \\
\hline $\mathrm{PO}^{3-}$ & 0.273 & $1.81 \mathrm{E}+04$ & $1.02 E+04$ \\
\hline $\mathrm{SO}^{2-}$ & $1.85 \mathrm{E}-02$ & $1.24 \mathrm{E}+03$ & 700 \\
\hline $\mathrm{Si}\left(\mathbf{a s ~} \mathrm{SiO}_{3}^{2}\right.$ & $1.12 \mathrm{E}-02$ & 220 & 124 \\
\hline$F$ & $2.38 \mathrm{E}-02$ & 316 & 178 \\
\hline $\mathrm{Cl}$ & $3.69 \mathrm{E}-02$ & 910 & 514 \\
\hline $\mathrm{C}_{6} \mathrm{H}_{5} \mathrm{O}_{4}{ }^{3-}$ & $3.17 E-04$ & 41.7 & 23.6 \\
\hline EDTA ${ }^{4-}$ & $6.34 \mathrm{E}-04$ & 127 & 71.8 \\
\hline HEDT ${ }^{3-}$ & 0 & 0 & 0 \\
\hline glyoolate & 0 & 0 & 0 \\
\hline noetute & $4.04 E-03$ & 166 & 93.8 \\
\hline oxalate ${ }^{2}$ & 0 & 0 & 0 \\
\hline DBP & 0 & 0 & 0 \\
\hline burenol & 0 & 3 & 0 \\
\hline $\mathrm{NH}_{3}$ & 0.175 & $2.07 \mathrm{E}+03$ & $1.17 \mathrm{E}+03$ \\
\hline $\mathrm{F}=(\mathrm{CN})_{*}^{4}$ & 0.247 & $4.66 \mathrm{E}+04$ & $2.63 E+04$ \\
\hline 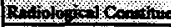 & & ४ & मे \\
\hline Pu & & $0.109(\mu \mathrm{Ci} / \mathrm{g})$ & $1.03(\mathrm{~kg})$ \\
\hline $\mathrm{U}$ & $0.209(\mathrm{M})$ & $3.47 \mathrm{E}+04(\mu \mathrm{g} / \mathrm{g})$ & $1.96 \mathrm{E}+04(\mathrm{~kg})$ \\
\hline$C_{6}$ & $1.24(\mathrm{Ci} / \mathrm{L})$ & $863(\mu \mathrm{Ci} / \mathrm{g})$ & $4.87 \mathrm{E}+05(\mathrm{Ci})$ \\
\hline Sr & $0.174(\mathrm{C} / \mathrm{L})$ & $121(\mu \mathrm{Ci} / \mathrm{B})$ & $6.83 \mathrm{E}+04(\mathrm{Ci})$ \\
\hline
\end{tabular}

-Uniknowns in tank solids inventory are assigned by Tank Lyyering Model (TLM). †Volume average for density, mass average Waler ut\% and TOC wt\% C. 


\begin{tabular}{|c|c|c|c|}
\hline \multicolumn{4}{|c|}{ Single-Shell Tenk 241-C-20! } \\
\hline \multicolumn{4}{|c|}{ TLM Solids Composite invextory Estimate* } \\
\hline 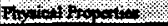 & & & \\
\hline Total Solid Ware & $1.21 \mathrm{E}+04 \mathrm{~kg}$ & \multicolumn{2}{|c|}{$(2.00 \mathrm{kgal})$} \\
\hline Heal Land & $0.459 \mathrm{~kW}$ & \multicolumn{2}{|c|}{$(1.57 \mathrm{E}+03 \mathrm{BTU} / \mathrm{hr})$} \\
\hline Bulk Denaity & \multicolumn{3}{|c|}{$1.60(g / x)$} \\
\hline Void Fraction & \multicolumn{3}{|c|}{0.590} \\
\hline Waser wt\% & \multicolumn{3}{|c|}{44.0} \\
\hline TOC wt\% C (wet) & \multicolumn{3}{|c|}{0.638} \\
\hline \multicolumn{4}{|l|}{, } \\
\hline $\mathrm{Na}^{+}$ & 3.43 & $4.94 E+04$ & 597 \\
\hline $\mathrm{Al}^{3+}$ & 0 & 0 & 0 \\
\hline $\mathrm{Fe}^{3+}(\operatorname{cotal} \mathrm{Fe})$ & 2.89 & $1.01 \mathrm{E}+05$ & $1.22 \mathrm{E}+03$ \\
\hline $\mathrm{Cr}^{\mathrm{s}+}$ & $3.92 \mathrm{E}-03$ & 128 & 1.54 \\
\hline$B i^{3+}$ & 0 & 0 & 0 \\
\hline $\mathrm{LA}^{\mathrm{In}}$ & 0 & 0 & 0 \\
\hline $\mathrm{Hg}^{2+}$ & 0 & 0 & 0 \\
\hline $\mathrm{Zs}\left(\mathrm{as} \mathrm{ZNO}(\mathrm{OH})_{2}\right)$ & 0 & $\overline{0}$ & 0 \\
\hline $\mathrm{Pb}^{24}$ & $7.58 \mathrm{E}-02$ & $9.83 \mathrm{E}+03$ & 119 \\
\hline $\mathrm{Ni}^{\mathrm{i}^{*}}$ & $9.29 \mathrm{E}-02$ & $3.41 \mathrm{E}+03$ & 41.2 \\
\hline $\mathrm{Sr}^{2+}$ & 0 & 0 & 0 \\
\hline $\mathrm{Mn}^{4+}$ & 0 & 0 & 0 \\
\hline $\mathrm{Ca}^{2+}$ & $4.41 \mathrm{E}-02$ & $1.11 \mathrm{E}+03$ & 13.4 \\
\hline $\mathrm{K}^{+}$ & $3.67 \mathrm{E}-02$ & 898 & 10.8 \\
\hline $\mathrm{OH}$ & 15.0 & $1.60 \mathrm{E}+05$ & $1.93 \mathrm{E}+03$ \\
\hline $\mathrm{NO3}^{-}$ & $3.12 \mathrm{E}-02$ & $1.21 \mathrm{E}+03$ & 14.6 \\
\hline $\mathrm{NO}_{2}^{2}$ & 0.453 & $1.31 E+04$ & 158 \\
\hline $\cos ^{2 *}$ & 0.945 & $3.55 \mathrm{E}+04$ & 429 \\
\hline $\mathrm{PO}^{3-2}$ & 0.200 & $1.19 E+04$ & 144 \\
\hline $\operatorname{sos}^{2+}$ & $6.88 \mathrm{E}-02$ & $4.14 \mathrm{E}+03$ & 50.0 \\
\hline $\mathrm{Si}\left(2 \mathrm{siO}{ }_{3}{ }^{2}\right)$ & $7.75 E-04$ & 13.6 & 0.165 \\
\hline$F$ & 0 & 0 & 0 \\
\hline $\mathrm{Cr}$ & $2.09 \mathrm{E}-02$ & 464 & 5.60 \\
\hline $\mathrm{C}_{6} \mathrm{H}_{9} \mathrm{O}_{7}{ }^{3+}$ & $1.65 \mathrm{E}-02$ & $1.95 E+03$ & 23.6 \\
\hline EDTA $^{4}$ & $3.30 \mathrm{E}-02$ & $5.95 E+03$ & 71.8 \\
\hline HEDTA ${ }^{3 .}$ & 0 & $\mathbf{0}$ & 0 \\
\hline glyoolnet & 0 & 0 & 0 \\
\hline ecetinte & 0.210 & $7.77 E+03$ & 93.8 \\
\hline oxalute" & 0 & 0 & 0 \\
\hline$\overline{\mathrm{DBP}}$ & 0 & 0 & 0 \\
\hline butanol & 0 & 0 & 0 \\
\hline $\mathrm{Nh}_{3}$ & 0.223 & $2.37 \mathrm{E}+03$ & 28.6 \\
\hline $\mathrm{F} \propto(\mathrm{CN})_{6}{ }^{4}$ & 0 & 0 & 0 \\
\hline \multicolumn{4}{|c|}{ 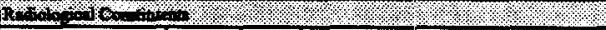 } \\
\hline Pu & & $2.03 \mathrm{E}-03(\mu \mathrm{Ci} / \mathrm{g})$ & $4.09 \mathrm{E}-04(\mathrm{~kg})$ \\
\hline $\mathrm{U}$ & $0.994(\mathrm{M})$ & $1.48 \mathrm{E}+05(\mu \mathrm{g} / \mathrm{g})$ & $1.79 \mathrm{E}+03(\mathrm{~kg})$ \\
\hline $\mathrm{C}$ & $4.20 \mathrm{E}-04(\mathrm{Ci} / \mathrm{L})$ & $0.263(\mu \mathrm{Ci} / \mathrm{g})$ & $3.18(\mathrm{Ci})$ \\
\hline Sr & $9.02(\mathrm{Ci} / \mathrm{L})$ & $5.65 \mathrm{E}+03(\mu \mathrm{Ci} / \mathrm{g})$ & $6.82 \mathrm{E}+04(\mathrm{Ci})$ \\
\hline
\end{tabular}

-Unkenown in tunk solids inveatory are anized by Tank. Leyering Model (TLM). 


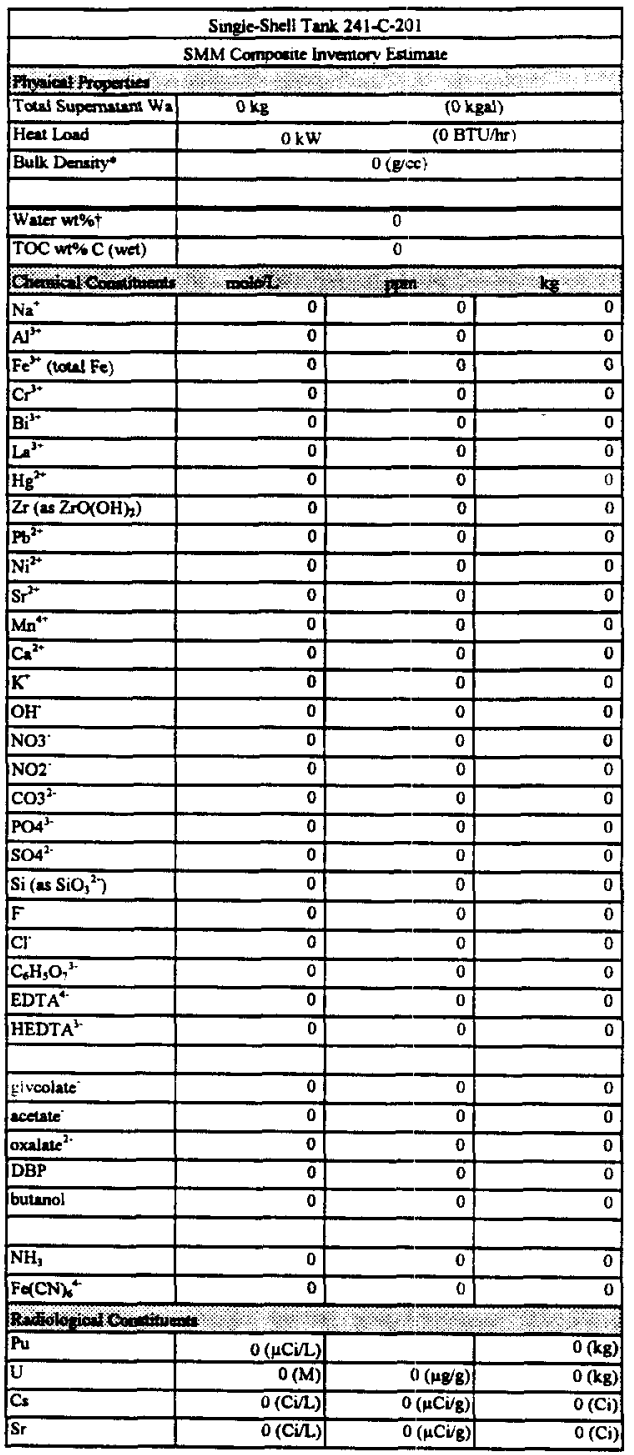

*Density is calculated based on $\mathrm{N}_{2} \mathrm{OH}$, and $\mathrm{AlO}_{2}$.

†Water wt\% derived from the difference of density and toal dissolved species. 


\begin{tabular}{|c|c|c|c|}
\hline \multicolumn{4}{|c|}{ Single-Shell Tunk 241 C. 201} \\
\hline \multicolumn{4}{|c|}{ Tots invertory Erimute* } \\
\hline \multicolumn{4}{|l|}{ 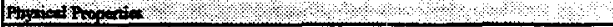 } \\
\hline Total Wate & $1.21 \mathrm{E}+04 \mathrm{~kg}$ & \multicolumn{2}{|c|}{$(2.00 \mathrm{kga})$} \\
\hline Heat Laad & $0.459 \mathrm{~kW}$ & \multicolumn{2}{|c|}{ (1.STE+03 BTU/hr) } \\
\hline Bulk Dersity ${ }^{\dagger}$ & \multicolumn{3}{|c|}{$1.60(\mathrm{~g} / \mathrm{cc})$} \\
\hline Water wt\%! & \multicolumn{3}{|c|}{44.0} \\
\hline TOC w\% C (wet) $\dagger$ & \multicolumn{3}{|c|}{0.638} \\
\hline \multicolumn{4}{|l|}{$0.13 \%$} \\
\hline $\mathrm{Ni}^{*}$ & 3.43 & $4.94 E+04$ & 597 \\
\hline$A S^{3+2}$ & 0 & 0 & 0 \\
\hline $\mathrm{Fe}^{3+}$ (total Fe) & 2.89 & $1.01 \mathrm{E}+05$ & $1.22 \mathrm{E}+03$ \\
\hline $\mathrm{Cr}^{\mathrm{j}+}$ & 3.92E-03 & 128 & 1.54 \\
\hline $\mathrm{Bi}^{\text {"* }}$ & 0 & 0 & 0 \\
\hline $\mathrm{La}^{3+}$ & 0 & 0 & 0 \\
\hline $\mathrm{Hg}^{2+}$ & 0 & 0 & 0 \\
\hline $\mathrm{Zr}\left(\mathrm{as} \mathrm{ZrO}(\mathrm{OH})_{h}\right)$ & 0 & 0 & 0 \\
\hline $\mathrm{Pb}^{2+}$ & $7.58 \mathrm{E}-02$ & $9.83 \mathrm{E}+03$ & 119 \\
\hline $\mathrm{Ni}^{2+}$ & $9.29 \mathrm{E}-02$ & $3.41 E+03$ & 41.2 \\
\hline $\mathrm{sr}^{2+}$ & 0 & 0 & 0 \\
\hline $\mathrm{Mn}^{4+}$ & 0 & 0 & 0 \\
\hline $\mathrm{Cs}^{2+}$ & $4.41 E-02$ & $1.11 \mathrm{E}+03$ & 13.4 \\
\hline$\overline{\mathbf{K}}$ & $3.67 \mathrm{E}-02$ & 898 & 10.8 \\
\hline OH & 15.0 & $1.60 \mathrm{E}+05$ & $1.93 \mathrm{E}+03$ \\
\hline $\mathrm{NO}^{-}$ & $3.12 \mathrm{E}-02$ & $1.21 E+03$ & 14.6 \\
\hline NO2: & 0.453 & $1.31 \mathrm{E}+0.4$ & 158 \\
\hline $\cos ^{2+}$ & 0.945 & $3.55 \mathrm{E}+04$ & 429 \\
\hline $\mathrm{PO}^{\mathrm{3}+}$ & 0.200 & $1.19 E+04$ & 144 \\
\hline $\mathrm{SO}^{22}$ & $6.88 \mathrm{E}-02$ & $4.14 \mathrm{E}+03$ & 50.0 \\
\hline $\mathrm{Si}\left(2 \mathrm{SiO}{ }_{3}{ }^{2+}\right)$ & $7.75 \mathrm{E}-04$ & 13.6 & 0.165 \\
\hline $\mathrm{F}$ & 0 & 0 & 0 \\
\hline $\mathrm{Cl}$ & 2.09E-02 & 464 & 5.60 \\
\hline $\mathrm{C}_{6} \mathrm{H}_{9} \mathrm{O}_{7}{ }^{3 \cdot}$ & $1.65 \mathrm{E}-02$ & $1.95 \mathrm{E}+03$ & 23.6 \\
\hline EDTA & $3.30 \mathrm{E}-02$ & $5.95 \mathrm{E}+03$ & 71.8 \\
\hline HEDTA $^{3 .}$ & 0 & 0 & 0 \\
\hline glycolate & 0 & 0 & 0 \\
\hline acente- & 0.210 & $7.77 \mathrm{E}+03$ & 93.8 \\
\hline oxalate ${ }^{2}$ & 0 & 01 & 0 \\
\hline DBP & 0 & 0 & 0 \\
\hline butenol & 0 & 0 & $\overline{0}$ \\
\hline $\mathrm{NH}_{3}$ & 0.223 & $2.37 \mathrm{E}+03$ & 28.6 \\
\hline $\mathrm{F} \alpha\left(\mathrm{CN}_{2}{ }^{4}\right.$ & 0 & 0 & 0 \\
\hline 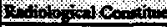 & & \% & m \\
\hline Pu & & $2.03 \mathrm{E}-03(\mu \mathrm{Ci} / \mathrm{g})$ & $4.09 \overline{\mathrm{E}}-0.04(\mathrm{~kg})$ \\
\hline $\mathrm{U}$ & $0.994(\mathrm{M})$ & $1.48 E+05(\mu g / g)$ & $1.79 \mathrm{E}+03(\mathrm{~kg})$ \\
\hline Cs & 4.20E-04(Ci/L) & $0.263(\mu \mathrm{Ci} / \mathrm{g})$ & $3.18(\mathrm{Ci})$ \\
\hline Sr & $9.02(\mathrm{Ci} / \mathrm{L})$ & $5.65 \mathrm{E}+1) 3(\mu \mathrm{Ci} / \mathrm{g})$ & $6.82 \mathrm{E}+04(\mathrm{Ci})$ \\
\hline
\end{tabular}

*Unkenows in tunk wolids invertory are axaigned by Tenk Leyering Model (TLM).

+Volume average for dentity, mass average Water wt\% and TOC wt\% C. 
Singie-Shell Tank 241-C-202

TLM Solids Composine Inveriory Erumate*

\begin{tabular}{|c|c|c|c|}
\hline 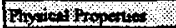 & & \&: & \\
\hline Total Solid Warte & $5.48 \mathrm{E}+03 \mathrm{~kg}$ & $(1.00 \mathrm{~b}$ & \\
\hline Heat Load & $0.460 \mathrm{~kW}$ & $(1.57 E+03$ & $(\mathrm{U} / \mathrm{hr})$ \\
\hline Bulk Density & & $1.45(\mathrm{~B} / \mathrm{cc})$ & \\
\hline Void fraction & & 0.823 & \\
\hline Water wt\% & & 43.6 & \\
\hline TOC wt\% C (wet) & & 1.41 & \\
\hline O & $=1 \%$ & $8 \mathrm{pan}$ & Ka? \\
\hline $\mathrm{Na}$ & 1.83 & $2.90 \mathrm{E}+04$ & 159 \\
\hline $\mathrm{Al}^{3+}$ & 0 & 0 & 0 \\
\hline $\mathrm{Fe}^{3+}$ (totel $\mathrm{Fe}$ ) & 5.67 & $2.19 E+05$ & $1.20 E+03$ \\
\hline $\mathrm{Cr}^{3+}$ & $6.59 \mathrm{E}-03$ & 237 & 1.30 \\
\hline $\mathrm{Bi}^{\mathrm{i+}}$ & 0 & 0 & 0 \\
\hline $\mathrm{La}^{3+}$ & 0 & 0 & 0 \\
\hline $\mathrm{Hg}^{2+2}$ & 0 & 0 & 0 \\
\hline $\mathrm{Zr}\left(\mathrm{as} \mathrm{ZNO}(\mathrm{OH}){ }_{h}\right)$ & 0 & $0 !$ & 0 \\
\hline $\mathrm{Pb}^{2+}$ & 0.152 & $2.17 \mathrm{E}+0$ & 119 \\
\hline $\mathrm{Ni}^{2+}$ & 0.185 & $7.91 E+03$ & 41.1 \\
\hline $\mathrm{Sr}^{2+}$ & 0 & 0 & 0 \\
\hline $\mathrm{Mn}^{3+}$ & 0 & 0 & 0 \\
\hline $\mathrm{Ca}^{x}$ & $4.04 E-03$ & 112 & 0.613 \\
\hline $\mathrm{K}^{*}$ & $7.31 \mathrm{E}-02$ & $1.98 \mathrm{E}+03$ & 10.8 \\
\hline $\mathrm{OH}$ & 17.8 & $2.09 \mathrm{E}+05$ & $1.14 E+03$ \\
\hline $\mathrm{NO3}^{-}$ & $1.49 \mathrm{E}-17$ & $6.38 \mathrm{E}-13$ & $3.49 \mathrm{E}-15$ \\
\hline NO2 & 0.897 & $2.85 \mathrm{E}+04$ & 156 \\
\hline $\cos ^{2}$ & $4.04 \mathrm{E}-03$ & 167 & 0.917 \\
\hline $\mathrm{PO4}^{3 \cdot}$ & 0 & 0 & 0 \\
\hline $\mathrm{SO}^{2-}$ & $5.56 \mathrm{E}-02$ & $3.69 E+03$ & 20.2 \\
\hline $\mathrm{Si}\left(\mathrm{uS} \mathrm{SiO}_{3}{ }^{2-}\right)$ & 0 & 0 & 0 \\
\hline$F$ & 0 & 0 & 0 \\
\hline $\mathrm{Cl}^{-}$ & 4.05E 02 & 992 & 5.44 \\
\hline $\mathrm{C}_{6} \mathrm{H}_{9} \mathrm{O}_{7}{ }^{3}$ & $3.30 \mathrm{E}-02$ & $4.31 E+03$ & 23.6 \\
\hline EDTA $^{4}$ & $6.59 E-02$ & $1.31 \overline{E+04}$ & 71.9 \\
\hline HEDTA ${ }^{3-}$ & 0 & 0 & 0 \\
\hline glycolate & 0 & 0 & 0 \\
\hline Icetale & 0.420 & $1.71 \mathrm{E}+04$ & 93.9 \\
\hline oxalate ${ }^{2}$ & 0 & 0 & 0 \\
\hline DBP & 0 & 0 & 0 \\
\hline butano: & 0 & 0 & 0 \\
\hline $\mathrm{NH}_{3}$ & 0.445 & $5.23 \mathrm{E}+03$ & 28.7 \\
\hline $\mathrm{F}=\left(\mathrm{CN}_{6}{ }^{4}\right.$ & 0 & 0 & 0 \\
\hline Rofrola, 100 & & $\infty$ & 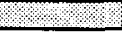 \\
\hline Pu & & $0(\mu \mathrm{Ci} / \mathrm{g})$ & $0(\mathrm{~kg})$ \\
\hline $\mathrm{U}$ & $0(\mathrm{M})$ & $0(\mu \mathrm{g} / \mathrm{g})$ & $0(\mathrm{~kg})$ \\
\hline C. & $0(\mathrm{Ci} / \mathrm{L})$ & $0(\mu \mathrm{Ci} / \mathrm{g})$ & $0(\mathrm{Ci})$ \\
\hline $\mathrm{Sr}$ & $18.0(\mathrm{Ci} / \mathrm{L})$ & $1.25 \mathrm{E}+04(\mu \mathrm{Ci} / \mathrm{g})$ & $6.83 \mathrm{E}+04(\mathrm{Ci})$ \\
\hline
\end{tabular}

-Unknowns in tank rolids inventory are aseigned by Teuk Layering Model (TLM) 


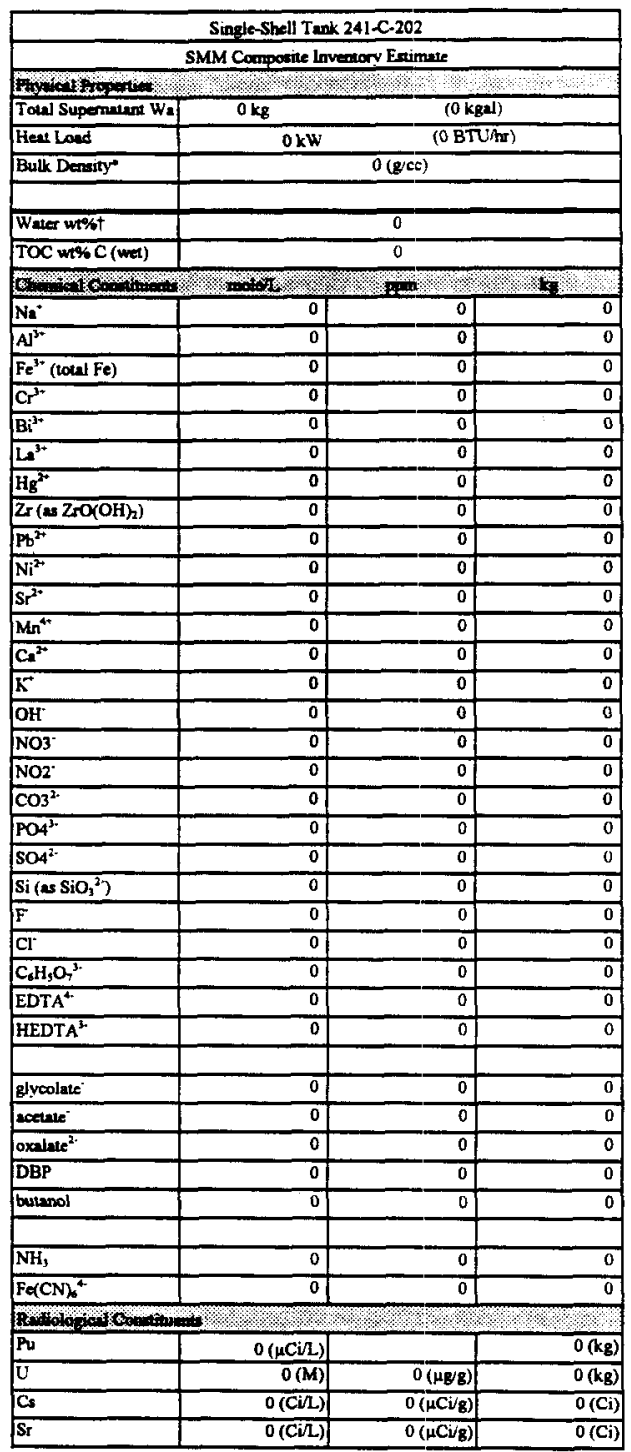

"Density is calcuisted based on $\mathrm{N}_{2}, \mathrm{OH}$, and $\mathrm{AlO}_{2}$ :

+Water we\% derived from the differeace of dentity and total diwolved species 
WHC-SD-WM-ER-313, Rev. 1

\begin{tabular}{|c|c|c|c|}
\hline \multicolumn{4}{|c|}{ Sugle-Shell Tunk 241-C-202 } \\
\hline \multicolumn{4}{|c|}{ Total tnventory Esturinte" } \\
\hline 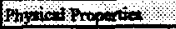 & 8 & 3 & \\
\hline Total Waste & $5.48 \mathrm{E}+0.3 \mathrm{~kg}$ & \multicolumn{2}{|c|}{$(1.00 \mathrm{kgal})$} \\
\hline Hen: Land & $0.460 \mathrm{~kW}$ & \multicolumn{2}{|c|}{$(1.57 \mathrm{E}+03 \mathrm{BTT} / \mathrm{hr})$} \\
\hline Buin Densityt & \multicolumn{3}{|c|}{$1.45(\mathrm{gec})$} \\
\hline Walter wt\% & \multicolumn{3}{|c|}{43.6} \\
\hline TOC wt\% C (wet) ${ }^{t}$ & \multicolumn{3}{|c|}{1.41} \\
\hline \multicolumn{4}{|l|}{ 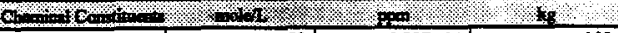 } \\
\hline $\mathrm{Ns}^{*}$ & 1.83 & $2.90 \mathrm{E}+04$ & 139 \\
\hline $\mathbf{A l}^{3+}$ & 0 & 0 & 0 \\
\hline $\mathrm{Fe}^{3+}(\mathrm{toth} \mathrm{Fe})$ & 5.67 & $2.19 \mathrm{E}+05$ & $1.20 \mathrm{E}+03$ \\
\hline $\mathrm{cr}^{3+}$ & $6.59 \mathrm{E}-03$ & 237 & 1.30 \\
\hline$B i^{j+2}$ & 0 & 0 & 0 \\
\hline $\mathrm{La}^{3 *}$ & 0 & 0 & 0 \\
\hline $\mathrm{Hg}^{2+}$ & 0 & 0 & 0 \\
\hline $\mathrm{Zr}\left(\omega \mathrm{ZrO}(\mathrm{OH})_{3}\right.$ & 0 & 0 & 0 \\
\hline $\mathrm{Pb}^{2+}$ & 0.152 & $2.17 E+04$ & 119 \\
\hline $\mathrm{Ni}^{2+}$ & 0.185 & $7.51 E+03$ & 41.1 \\
\hline $\mathrm{Sr}^{2+}$ & 0 & 0 & 0 \\
\hline $\mathrm{Mn}^{4+2}$ & 0 & $\overline{0}$ & 0 \\
\hline $\mathrm{Ca}^{2+}$ & $4.04 \mathrm{E}-03$ & 112 & 0.613 \\
\hline $\mathbf{K}^{+}$ & $7.31 \mathrm{E}-02$ & $1.98 \mathrm{E}+03$ & 10.8 \\
\hline $\mathrm{OH}^{-}$ & 17.8 & $2.09 \mathrm{E}+05$ & $1.14 \mathrm{E}+03$ \\
\hline $\mathrm{NOS}^{-}$ & $1.49 \mathrm{E}-17$ & $6.38 \mathrm{E}-13$ & $3.49 \mathrm{E}-15$ \\
\hline NO2 & 0.897 & $2.85 \mathrm{E}+04$ & 156 \\
\hline $\cos ^{2-}$ & $4.04 \mathrm{E}-03$ & 167 & 0.917 \\
\hline PO4 & 0 & 0 & 0 \\
\hline $504^{2-}$ & $5.56 \mathrm{E}-02$ & $3.69 \mathrm{E}+03$ & 20.2 \\
\hline $\mathrm{Si}\left(\mathrm{as} \mathrm{SiO}_{3}{ }^{2}\right.$ ) & 0 & 0 & 0 \\
\hline $\mathrm{F}$ & $\mathbf{0}$ & 0 & 0 \\
\hline $\mathrm{Cl}^{-}$ & $4.05 \mathrm{E}-02$ & 992 & 5.44 \\
\hline $\mathrm{C}_{6} \mathrm{H}_{5} \mathrm{O}_{7}{ }^{3-}$ & $3.30 \mathrm{E}-02$ & $4.31 \mathrm{E}+03$ & 23.6 \\
\hline EDTA $^{4}$ & $6.59 \mathrm{E}-02$ & $1.31 \mathrm{E}+04$ & 71.9 \\
\hline HEDTA ${ }^{3}$ & 0 & 0 & 0 \\
\hline glycolate & 0 & 0 & 0 \\
\hline acelnte- & 0.420 & $1.71 E+04$ & 93.9 \\
\hline oxalate ${ }^{2+}$ & 0 & 0 & 0 \\
\hline DBP & 0 & 0 & 0 \\
\hline butanol & 0 & 0 & 0 \\
\hline $\mathrm{NH}_{3}$ & 0.445 & $5.23 \mathrm{E}+03$ & 28.7 \\
\hline $\mathrm{F}(\mathrm{CN})_{b}{ }^{4}$ & 0 & 0 & 0 \\
\hline \multicolumn{4}{|c|}{ Wow 10,160 thols } \\
\hline $\mathrm{Pu}$ & & $0(\mu \mathrm{Ci} / \mathrm{g})$ & $0(\mathrm{~kg})$ \\
\hline $\mathrm{U}$ & $0(M)$ & $0(\mu \mathrm{g} / \mathrm{g})$ & 0 (kg) \\
\hline $\mathrm{Cs}$ & $0(\mathrm{CIN})$ & $0(\mu \mathrm{Ci} / \mathrm{g})$ & $\mathbf{D}(\mathrm{Ci})$ \\
\hline S: & $18.0(\mathrm{Ci} / \mathrm{L})$ & $1.25 \mathrm{E}+04(\mu \mathrm{CV} / \mathrm{g})$ & $6.83 \mathrm{E}+04(\mathrm{Ci})$ \\
\hline
\end{tabular}

-Unk nowns in tank solids inventory are ssaigned by Tank Layering Model (TLM)

†Volume average for density, mavs average Wate wt\% and TOC wt\% C. 


\begin{tabular}{|c|c|c|c|}
\hline \multicolumn{4}{|c|}{ Single-Shell Tank $241-C_{-} 203$} \\
\hline \multicolumn{4}{|c|}{ TLM Solids Composire Inventory Esumate* } \\
\hline \multicolumn{4}{|l|}{ 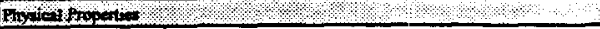 } \\
\hline Toten Solid Wante & $3.19 \mathrm{E}+04 \mathrm{~kg}$ & \multicolumn{2}{|c|}{$(5.00 \mathrm{kgal})$} \\
\hline Hen Land & $0.460 \mathrm{~kW}$ & \multicolumn{2}{|c|}{ (1.57E+03 BTU/rs) } \\
\hline Bulk Density & \multicolumn{3}{|c|}{$1.69(g / 6 x)$} \\
\hline Void Fraction & \multicolumn{3}{|c|}{0.451} \\
\hline Water wt\% & \multicolumn{3}{|c|}{44.2} \\
\hline TOC wt\% C (wet) & \multicolumn{3}{|c|}{0.241} \\
\hline \multicolumn{4}{|l|}{ 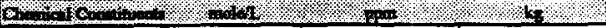 } \\
\hline $\mathrm{Na}^{*}$ & 4.40 & $5.99 \mathrm{E}+04$ & $1.91 \mathrm{E}+03$ \\
\hline $\mathrm{Al}^{3+2}$ & 0 & 0 & 0 \\
\hline $\mathrm{Fe}^{3+}$ (total Fe) & 1.23 & $4.06 \mathrm{E}+04$ & $1.30 \mathrm{E}+03$ \\
\hline $\mathrm{Cr}^{3 *}$ & $2.31 \mathrm{E} 003$ & 71.2 & 2.27 \\
\hline $\mathrm{Bi}^{3+}$ & 0 & 0 & 0 \\
\hline $\mathrm{La}^{\mathrm{jt}}$ & 0 & 0 & 0 \\
\hline $\mathrm{H}_{8} \mathrm{~g}^{2+}$ & 0 & 0 & 0 \\
\hline $\mathrm{Zr}(\mathrm{as} \mathrm{ZOCOOH})$ & 0 & 0 & 0 \\
\hline $\mathrm{Pb}^{2+}$ & $3.03 E-02$ & $3.72 E+03$ & 119 \\
\hline $\mathrm{Ni}^{2+}$ & $3.75 \mathrm{E}-02$ & $1.30 \mathrm{E}+03$ & 41.6 \\
\hline $\mathrm{Sr}^{2+}$ & 0 & 0 & 0 \\
\hline $\mathrm{Mn}^{\circ+}$ & 0 & 0 & 0 \\
\hline $\mathrm{Cu}^{2+}$ & $6.81 E-02$ & $1.62 \mathrm{E}+03$ & 51.7 \\
\hline $\mathbf{K}^{+}$ & $1.48 \mathrm{E}-02$ & 343 & 11.0 \\
\hline $\mathrm{OH}$ & 13.4 & $1.35 \mathrm{E}+05$ & $4.30 \mathrm{E}+03$ \\
\hline $\mathrm{NO3}^{-}$ & $5.00 \mathrm{E}-02$ & $1.84 \mathrm{E}+03$ & 58.6 \\
\hline NO2 & 0.186 & $5.09 \mathrm{E}+03$ & 162 \\
\hline $\mathrm{CO}^{2-}$ & 1.51 & $3.37 \mathrm{E}+04$ & $1.71 \mathrm{E}+03$ \\
\hline $\mathrm{PO}^{3 .}$ & 0.320 & $1.80 \mathrm{E}+04$ & 575 \\
\hline $\mathrm{SO}^{2-}$ & $7.67 \mathrm{E}-02$ & $4.375+03$ & 139 \\
\hline $\mathrm{Si}\left(\operatorname{as~} \mathrm{SiO}_{1}{ }^{2}\right)$ & $1.24 \mathrm{E}-03$ & 20.7 & 0.659 \\
\hline$F$ & 0 & 0 & 0 \\
\hline $\mathrm{Cl}^{-}$ & $9.10 \mathrm{E}-03$ & 191 & 6.10 \\
\hline $\mathrm{C}_{6} \mathrm{H}_{5} \mathrm{O}_{-}^{3-}$ & $6.58 \mathrm{E}-03$ & 738 & 23.5 \\
\hline EDTA $^{4}$ & $1.32 \mathrm{E}-02$ & $2.25 \mathrm{E}+03$ & 71.8 \\
\hline HEDTA ${ }^{3-}$ & 0 & 0 & 0 \\
\hline giycolate- & 0 & 0 & 0 \\
\hline mectate & $8.39 \mathrm{E}-02$ & $2.94 \mathrm{E}+03$ & 93.7 \\
\hline oxalate ${ }^{2}$ & 0 & 0 & 0 \\
\hline DBP & 0 & 0 & D \\
\hline butenol & 0 & 0 & 0 \\
\hline $\mathrm{NH}_{3}$ & $8.90 \mathrm{E}-02$ & 897 & 28.6 \\
\hline $\mathrm{F} \alpha \mathrm{CN} \lambda^{+}$ & 0. & 0 & D \\
\hline \multicolumn{4}{|l|}{ 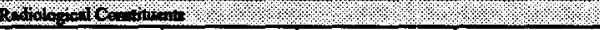 } \\
\hline$\overline{P u}$ & & $3.08 \mathrm{E}-03(\mu \mathrm{Ci} / \mathrm{g})$ & $1.64 \mathrm{E}-03(\mathrm{~kg})$ \\
\hline $\mathrm{U}$ & $1.59(\mathrm{M})$ & $2.24 \mathrm{E}+05(\mu \mathrm{g} / \mathrm{g})$ & $7.16 \mathrm{E}+03(\mathrm{~kg})$ \\
\hline Cs & $6.72 \mathrm{E}-04(\mathrm{Ci} / \mathrm{L})$ & $0.399(\mu \mathrm{Ci} / \mathrm{g})$ & $12.7(\mathrm{Ci})$ \\
\hline $\mathrm{sr}$ & $3.61(\mathrm{C} \Omega)$ & $2.14 \mathrm{E}+03(\mu \mathrm{Ci} / \mathrm{g})$ & $6.82 \mathrm{E}+04(\mathrm{Ci})$ \\
\hline
\end{tabular}

"Unknowns in tank solide invemory are asaigned by Tank Layering Model (TLM) 


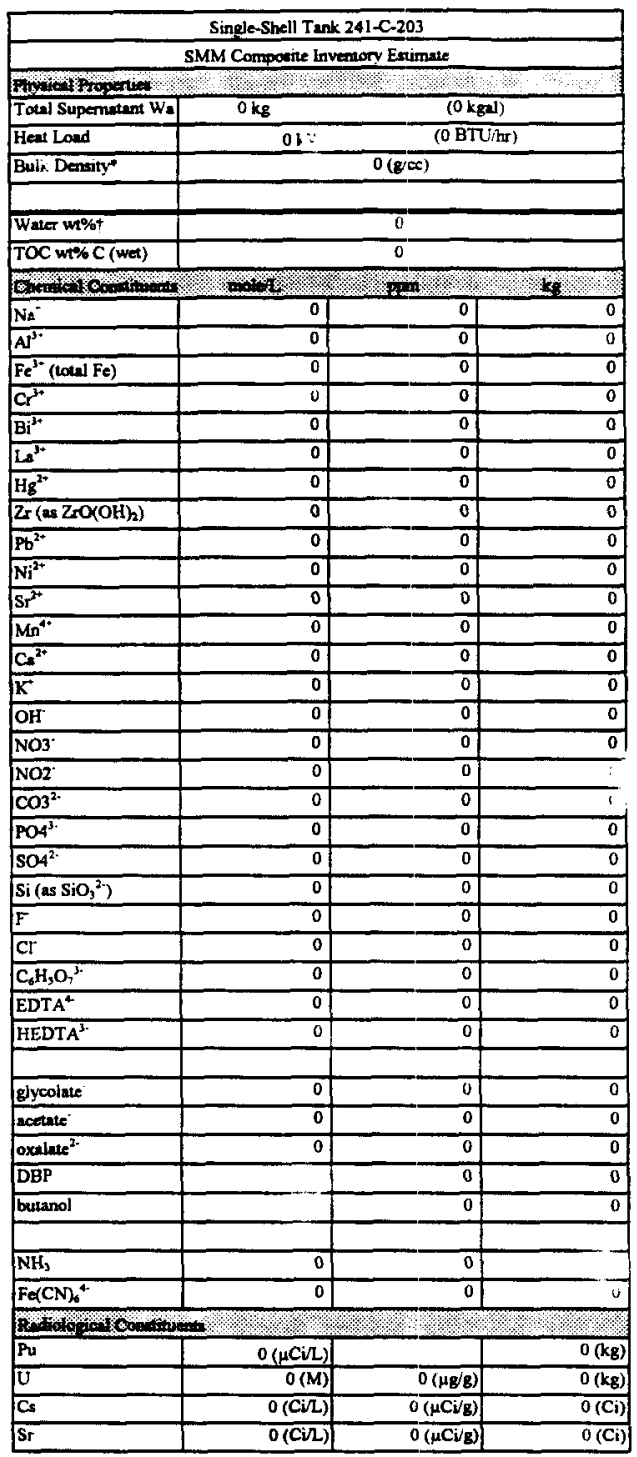

-Density is calculated besed on $\mathrm{N}_{2}, \mathrm{OH}$, and $\mathrm{AlO}_{2}$.

$\uparrow$ Water wt\% derived from the difference of density and total dissoived species. 


\begin{tabular}{|c|c|c|c|}
\hline \multicolumn{4}{|c|}{ Singie-Sbell Tank 241-C-203 } \\
\hline \multicolumn{4}{|c|}{ Total Inventory Eximare" } \\
\hline \multicolumn{4}{|l|}{ 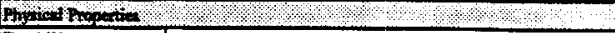 } \\
\hline Toul Ware & $3.19 \mathrm{E}+04 \mathrm{~kg}$ & \multicolumn{2}{|c|}{ (5.00 kgal) } \\
\hline Heal Lond & $0.460 \mathrm{~kW}$ & \multicolumn{2}{|c|}{$(1.57 \mathrm{E}+03 \mathrm{BTU} / \mathrm{h})$} \\
\hline Bulk Density $†$ & \multicolumn{3}{|c|}{$1.69(\mathrm{~g} / \mathrm{cc})$} \\
\hline Water wet ${ }^{\dagger}$ & \multicolumn{3}{|c|}{44.2} \\
\hline TOC w\% C (wet) & \multicolumn{3}{|c|}{0.241} \\
\hline \multicolumn{2}{|l|}{ 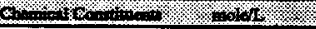 } & $8 x=10$ & 8 \\
\hline $\mathrm{Na}^{+}$ & 4.40 & $5.99 E+04$ & $1.91 \mathrm{E}+03$ \\
\hline$A]^{3+}$ & 0 & 0 & 0 \\
\hline $\mathrm{Fe}^{\mathrm{jir}}$ (toted Fe) & 1.23 & $4.06 \bar{E}+04$ & $1.30 \mathrm{E}+03$ \\
\hline $\mathrm{Cr}^{3+}$ & $2.31 E-03$ & 71.2 & 2.27 \\
\hline $\mathrm{Bi}^{3+}$ & 0 & 0 & 0 \\
\hline $\mathrm{Le}^{34}$ & 0 & 0 & 0 \\
\hline $\mathrm{Hg}^{2+}$ & 0 & 0 & $\overline{0}$ \\
\hline $\mathrm{Zx}\left(\mathrm{as} \mathrm{ZTO}(\mathrm{OH})_{2}\right)$ & 0 & 0 & 0 \\
\hline $\mathrm{Pb}^{2+}$ & $3.03 \mathrm{E}-02$ & $3.72 E+03$ & 119 \\
\hline $\mathrm{Ni}^{2+}$ & $3.75 \mathrm{E}-02$ & $1.30 \mathrm{E}+03$ & 41.6 \\
\hline $\mathrm{Sr}^{2+}$ & 0 & 0 & 0 \\
\hline $\mathrm{Mn}^{4+}$ & 0 & 0 & 0 \\
\hline $\mathrm{Ca}^{2+}$ & $6.81 \mathrm{E}-02$ & $1.62 \mathrm{E}+03$ & 51.7 \\
\hline $\bar{K}$ & $1.48 \mathrm{E}-02$ & 343 & 11.0 \\
\hline $\mathrm{OH}$ & 13.4 & $1.35 \mathrm{E}+05$ & $4.30 \mathrm{E}+03$ \\
\hline $\mathrm{NO}$ & $5.00 \mathrm{E}-02$ & $1.84 \mathrm{E}+03$ & 58.6 \\
\hline $\mathrm{NO} 2$ & 0.186 & $5.09 \mathrm{E}+03$ & 162 \\
\hline $\cos ^{2 \cdot}$ & 1.51 & $5.37 \mathrm{E}+04$ & $1.71 \mathrm{E}+03$ \\
\hline $\mathrm{PO}^{3-5}$ & 0.320 & $1.80 \mathrm{E}+04$ & 575 \\
\hline $\mathrm{SO}^{2}$ & $7.67 \mathrm{E}-02$ & $4.37 \mathrm{E}+03$ & 139 \\
\hline $\mathrm{Si}\left(\mathrm{as} \mathrm{\textrm {SiO } _ { 3 } { } ^ { 2 } )}\right.$ & $1.24 \mathrm{E}-03$ & 20.7 & 0.659 \\
\hline $\mathbf{F}$ & 0 & 0 & 0 \\
\hline $\mathrm{Cl}^{-}$ & $9.10 \mathrm{E}-03$ & 191 & 6.10 \\
\hline $\mathrm{C}_{6} \mathrm{H}_{5} \mathrm{O}_{7}{ }^{3}$ & $6.58 \mathrm{E}-03$ & 738 & 23.5 \\
\hline EDTA ${ }^{4}$ & $1.32 \mathrm{E}-02$ & $2.25 E+03$ & 71.8 \\
\hline HEDTA ${ }^{3 .}$ & \begin{tabular}{l|l}
0 \\
\end{tabular} & 0 & 0 \\
\hline glycolate & 0 & 0 & 0 \\
\hline Icersté & 8.39E-02 & $2.94 \mathrm{E}+03$ & 93.7 \\
\hline oxalute:- & 0 & 0. & 0 \\
\hline DBP & 0 & 0 & 0 \\
\hline butanoi & 0 & 0 & 0 \\
\hline $\mathrm{NH}_{3}$ & $8.90 E-02$ & 897 & 28.6 \\
\hline $\mathrm{Fe}(\mathrm{CN})_{6}^{6-}$ & \begin{tabular}{l|l}
0 \\
\end{tabular} & 0. & 0 \\
\hline \multicolumn{4}{|c|}{ S- } \\
\hline Pu & & $3.08 \mathrm{E}-03(\mu \mathrm{Ci} / \mathrm{g})$ & $1.64 \mathrm{E}-03(\mathrm{~kg})$ \\
\hline $\mathrm{U}$ & $1.59(\mathrm{M})$ & $2.24 \mathrm{E}+05(\mu \mathrm{g} / \mathrm{g})$ & $7.16 \mathrm{E}+03(\mathrm{~kg})$ \\
\hline Cs & $6.72 \mathrm{E}-04(\mathrm{Ci} / \mathrm{L})$ & $0.399(\mu \mathrm{C} / \mathrm{g})$ & $12.7(\mathrm{Ci})$ \\
\hline $\mathbf{S r}$ & $3.61(\mathrm{Ci} / \mathrm{L})$ & $2.14 \mathrm{E}+03(\mu \mathrm{Ci} / \mathrm{g})$ & $6.82 \mathrm{E}+04(\mathrm{Ci})$ \\
\hline
\end{tabular}

"Unknowns in unk wolida inventory are ausigned by Tank Layering Model (TLM).

†Volume average for density, mats average Water wt\% and TOC wt\% C. 
Single-Shell Tanik 241-C-204

TLM Solids Composite Inveruory Estimate*

\begin{tabular}{|c|c|c|c|}
\hline \multirow{2}{*}{ 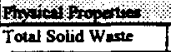 } & 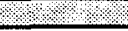 & \multicolumn{2}{|c|}{$\$}$, \\
\hline & $1.87 \mathrm{E}+04 \mathrm{~kg}$ & \multicolumn{2}{|c|}{$(3.00 \mathrm{kgal})$} \\
\hline Heat Lond & $0.460 \mathrm{~kW}$ & \multicolumn{2}{|c|}{ (1.57E+03 BTUihr) } \\
\hline Bulk Density & \multicolumn{3}{|c|}{$1.65(g / c)$} \\
\hline Void Fraction & \multicolumn{3}{|c|}{0.513} \\
\hline Water wt\% & \multicolumn{3}{|c|}{4.1} \\
\hline TOC wt\% C (wet) & \multicolumn{3}{|c|}{$6 \cdot 2$} \\
\hline \multicolumn{2}{|l|}{ Ohat 6} & \multirow{2}{*}{$\frac{6 \mathrm{drax}}{3.54 \mathrm{E}+04}$} & kt \\
\hline $\mathrm{Na}^{+}$ & 3.97 & & $1.04 E+03$ \\
\hline $\mathrm{Al}^{3+}$ & 0 & 0 & 0 \\
\hline $\mathrm{Fe}^{3+}(\mathrm{total} \mathrm{Fe})$ & 1.97 & $6.67 \mathrm{E}+04$ & $1.25 \mathrm{E}+03$ \\
\hline $\mathrm{Cr}^{\mathrm{r}^{*}}$ & $3.02 \mathrm{E}-03$ & 95.5 & 1.78 \\
\hline$B i^{3+2}$ & 0 & 0 & 0 \\
\hline $\mathrm{L}^{3+}$ & 0 & 0 & 0 \\
\hline $\mathrm{Hg}^{2+}$ & 0 & 0 & 0 \\
\hline $\mathrm{Zr}\left(\mathrm{ar} \mathrm{ZrO}(\mathrm{OH})_{h}\right)$ & 0 & 0 & 0 \\
\hline $\mathrm{pb}^{2+}$ & $3.05 \mathrm{E}-02$ & $6.35 \mathrm{E}+03$ & 119 \\
\hline $\mathrm{Ni}^{2+}$ & $6.21 E-02$ & $2.21 \mathrm{E}+03$ & 41.4 \\
\hline $\mathrm{Sr}^{2+}$ & 0 & 0 & 0 \\
\hline $\mathbf{M n}^{4+}$ & 0 & 0 & 0 \\
\hline $\mathrm{Ca}^{2+}$ & $5.74 \mathrm{E}-02$ & $1.40 \mathrm{E}+03$ & 26.1 \\
\hline $\mathbf{K}^{*}$ & 2.45E $\sim 02$ & 583 & 10.9 \\
\hline $\mathrm{OH}^{-}$ & 14.1 & $1.46 \mathrm{E}+05$ & $2.72 \mathrm{E}+03$ \\
\hline No3- & $4.16 \mathrm{E}-02$ & $1.57 \mathrm{E}+03$ & 29.3 \\
\hline $\mathrm{NO} 2$ & 0.305 & $8.52 \mathrm{E}+03$ & 159 \\
\hline $\cos ^{2-}$ & 1.26 & $4.59 \mathrm{E}+04$ & 858 \\
\hline $\mathrm{PO}^{32}$ & 0.267 & $1.5 \mathrm{AE}+04$ & 287 \\
\hline $\mathrm{SO}_{4}^{2-}$ & $7.32 E-02$ & $4.27 E+03$ & 79.8 \\
\hline $\mathrm{Si}\left(\right.$ as $\left.\mathrm{SiO}_{3}{ }^{2}\right)$ & $1.03 E-03$ & 17.6 & 0.330 \\
\hline$F$ & 0 & 0 & 0 \\
\hline$\overline{C r}$ & $1.43 \mathrm{E}-02$ & 309 & 5.77 \\
\hline $\mathrm{C}_{8} \mathrm{H}_{9} \mathrm{O}_{7}^{3+}$ & $1.10 \mathrm{E}-02$ & $1.26 \pm+03$ & 23.6 \\
\hline EDTA $^{4-}$ & $2.20 \mathrm{E}-02$ & $3.84 \mathrm{E}+03$ & 71.8 \\
\hline HEDTA ${ }^{3}$ & 0 & 0 & 0 \\
\hline givcolate & 0 & 0 & 0 \\
\hline acetate" & 0.140 & $\therefore 02 \mathrm{E}+03$ & 93.8 \\
\hline oxalare ${ }^{2}$ & 0 & 0 & 0 \\
\hline $\mathrm{DBP}$ & 0 & 0 & 0 \\
\hline butanol & 0 & 0 & 0 \\
\hline $\mathrm{NH}_{3}$ & 0.148 & $1.53 \mathrm{E}+03$ & 28.6 \\
\hline $\mathrm{F}:(\mathrm{CN})^{4}$ & 0 & 0 & 0 \\
\hline 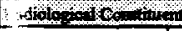 & & & \\
\hline$?$ & & $2.63 \mathrm{E}-03(\mu \mathrm{CV} / \mathrm{g})$ & $8.18 \mathrm{E}-04(\mathrm{~kg})$ \\
\hline $\mathrm{L}$ & $1.33(\mathrm{M})$ & $1.92 \mathrm{E}+0.5(\mu \mathrm{g} / \mathrm{g})$ & $3.58 \mathrm{E}+03(\mathrm{~kg})$ \\
\hline Cs & $5.60 \mathrm{E}-04(\mathrm{Ci} / \mathrm{L})$ & $0.340(\mu \mathrm{Ci} / \mathrm{B})$ & $6.36(\mathrm{Ci})$ \\
\hline 5 & $6.01(\mathrm{Ci} / \mathrm{L})$ & $3.65 \mathrm{E}+6.5(\mu \mathrm{Ci} / \mathrm{g}$ & $6.82 \mathrm{E}+04(\mathrm{Ci})$ \\
\hline
\end{tabular}

-Unknowns in tank wolids inventory are ascigned by Tank Lay. g Model (TLM). 


\begin{tabular}{|c|c|c|c|}
\hline \multicolumn{4}{|c|}{ Single-Shell Tank 241-C-204 } \\
\hline \multicolumn{4}{|c|}{ SMM Componite Invertory Ertinute } \\
\hline 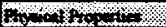 & & & 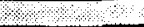 \\
\hline Total Supermetint W/a & $0 \mathbf{k g}$ & \multicolumn{2}{|c|}{$(0 \mathrm{kgal})$} \\
\hline Heat Land & $0 \mathrm{~kW}$ & \multicolumn{2}{|c|}{ (0 BTU/hr) } \\
\hline Bulk Demity" & \multicolumn{3}{|c|}{$0(g / \infty)$} \\
\hline Water wi\% & \multicolumn{3}{|c|}{0} \\
\hline TOC wt\% C (wet) & \multicolumn{3}{|c|}{0} \\
\hline \multicolumn{4}{|l|}{ 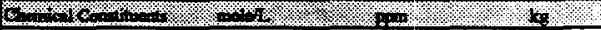 } \\
\hline $\mathrm{Na}^{+}$ & 0 & 0 & 0 \\
\hline $\mathrm{A}^{3+}$ & 0 & 0 & 0 \\
\hline $\mathrm{Fe}^{3+}$ (totnl Fe) & 0 & 0 & 0 \\
\hline$c^{3+}$ & 0 & 0 & $\overline{0}$ \\
\hline $\mathrm{Bi}^{\mathrm{i}^{++}}$ & 0 & 0 & $\overline{0}$ \\
\hline $\mathrm{Le}^{3+2}$ & 0 & 0 & $\overline{0}$ \\
\hline $\mathrm{Hg}^{2+}$ & 0 & 0 & $\overline{0}$ \\
\hline $\mathrm{Zr}\left(\mathrm{ar} \mathrm{Z \textrm {OO }}(\mathrm{OH})_{2}\right)$ & 0 & 0 & 0 \\
\hline $\mathrm{Pb}^{3+}$ & 0 & 0 & 0 \\
\hline $\mathrm{Ni}^{2^{2}}$ & 0 & 0 & 0 \\
\hline $\mathrm{sr}^{2+}$ & 0 & 0 & 0 \\
\hline $\mathrm{Mn}^{4+}$ & 0 & 0 & 0 \\
\hline $\mathrm{Ca}^{2-2}$ & 0 & 0 & 0 \\
\hline $\mathbf{K}^{+}$ & 0 & 0 & $\mathbf{0}$ \\
\hline OH & 0 & 0 & 0 \\
\hline $\mathrm{NO}^{-}$ & 0 & 0 & 0 \\
\hline NO2:- & 0 & 0 & 0 \\
\hline $\cos ^{2}$ & 0 & 0 & 0 \\
\hline $\mathrm{POA}^{3-}$ & 0 & 0 & $\overline{0}$ \\
\hline $\mathrm{SO}^{2-}$ & 0 & 0 & 0 \\
\hline $\mathrm{Si}\left(\mathrm{as} \mathrm{SiO}_{3}{ }^{2}\right)$ & 0 & 0 & 0 \\
\hline$\vec{F}$ & 0 & 0 & 0 \\
\hline $\mathrm{Cl}^{+}$ & 0 & 0 & 0 \\
\hline $\mathrm{C}_{6} \mathrm{H}_{9} \mathrm{O}_{7}{ }^{32}$ & 0 & 0 & $\overline{0}$ \\
\hline EDTA $^{4}$ & 0 & 0 & 0 \\
\hline HEDTA $^{3-}$ & 0 & 0 & $\overline{0}$ \\
\hline glycolate & 0 & 0 & $\overline{0}$ \\
\hline acetalte & 0 & 0 & 0 \\
\hline oxalute & 0 & 0 & $\overline{0}$ \\
\hline DEP & 0 & 0 & $\mathbf{0}$ \\
\hline butanol & 0 & 0 & 0 \\
\hline $\mathrm{NH}_{3}$ & 0 & 0 & 0 \\
\hline $\mathrm{F} \in(\mathrm{CN})_{6}^{4}$ & 0 & 0 & $\overline{0}$ \\
\hline \multicolumn{4}{|c|}{ 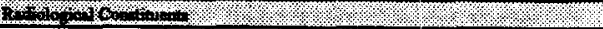 } \\
\hline Pu & $0(\mu \mathrm{C} / \mathrm{L})$ & & $0(\mathrm{~kg})$ \\
\hline$\overline{\mathrm{U}}$ & $0(\mathrm{M})$ & $0(\mu \mathrm{g} / \mathrm{g})$ & $0(\mathrm{~kg})$ \\
\hline C. & $0(\mathrm{Ci} / \mathrm{L})$ & $0(\mu \mathrm{Ci} / \mathrm{g})$ & $0(\mathrm{Ci})$ \\
\hline Sr & $O(\mathrm{Ci} L)$ & $\mathrm{O}(\mu \mathrm{Ci} / \mathrm{g})$ & $0(\mathrm{Ci})$ \\
\hline
\end{tabular}

-Density is calculated based on $\mathrm{Na}, \mathrm{OH}$, and $\mathrm{AlO}_{2}$.

†Water who derived from the differenoe of dersity and lotil diseoived spocies. 


\begin{tabular}{|c|c|c|c|}
\hline \multicolumn{4}{|c|}{ Single-Shell Tank $241-C-204$} \\
\hline \multicolumn{4}{|c|}{ Total invertorv Extimate" } \\
\hline Whylo of troperes & 3 & & \\
\hline Toun Wane & $1.87 \mathrm{E}+04 \mathrm{~kg}$ & \multicolumn{2}{|c|}{$(3.00 \mathrm{kga})$} \\
\hline Heat Loed & $0.460 \mathrm{~kW}$ & \multicolumn{2}{|c|}{$(1.57 \mathrm{E}+03 \mathrm{BT} \cup \mathrm{bs})$} \\
\hline Bulk Density & \multicolumn{3}{|c|}{$1.65(\mathrm{~g} / \mathrm{cc})$} \\
\hline Waver wt\%" & \multicolumn{3}{|c|}{44.1} \\
\hline TOC wt\% C (wet) $)^{+}$ & \multicolumn{3}{|c|}{0.412} \\
\hline \multicolumn{4}{|l|}{ H. } \\
\hline $\mathrm{Na}=$ & 3.97 & \multirow{2}{*}{\multicolumn{2}{|c|}{$\frac{1.04 \mathrm{E}+03}{0}$}} \\
\hline$\overline{\mathrm{A}^{3+2}}$ & 0 & & \\
\hline $\mathrm{Fe}^{3+}$ (toul Fe) & 1.97 & \multicolumn{2}{|r|}{$1.25 \mathrm{E}+03$} \\
\hline $\mathrm{Cr}^{3+}$ & $3.02 E-03$ & \multicolumn{2}{|r|}{1.78} \\
\hline $\mathrm{Bi}^{\mathbf{3}^{3+}}$ & 0 & \multicolumn{2}{|r|}{0} \\
\hline $\mathrm{La}^{3+}$ & 0 & \multicolumn{2}{|r|}{0} \\
\hline $\mathrm{Hg}^{2+}$ & 0 & \multicolumn{2}{|r|}{0} \\
\hline $\left.\mathrm{Zr}(\mathrm{as} \mathrm{Z} \mathrm{Z} \mathrm{O}(\mathrm{OH}))_{2}\right)$ & 0 & \multicolumn{2}{|r|}{0} \\
\hline $\mathrm{Pb}^{2+}$ & 5.0SE-02 & \multicolumn{2}{|l|}{$6.35 \bar{E}+03$} \\
\hline $\mathrm{Ni}^{2+}$ & $6.21 \mathrm{E}-02$ & \multicolumn{2}{|l|}{$2.21 E+03$} \\
\hline $55^{2+}$ & 0 & \multicolumn{2}{|r|}{0} \\
\hline $\mathrm{Mn}^{4+}$ & 0 & \multicolumn{2}{|r|}{0} \\
\hline $\mathrm{Ca}^{2+}$ & $5.74 \mathrm{E}-02$ & \multicolumn{2}{|l|}{$1.40 E+03$} \\
\hline $\mathbf{K}^{*}$ & $2.45 \mathrm{E}-02$ & \multicolumn{2}{|r|}{10.9} \\
\hline $\mathrm{OH}$ & 14.1 & $1.46 E+05$ & $2.72 \mathrm{E}+03$ \\
\hline $\mathrm{NO3}^{-}$ & $4.16 \mathrm{E}-02$ & $1.57 \mathrm{E}+03$ & 29.3 \\
\hline $\mathrm{NO2}$ & 0.305 & $8.52 E+03$ & 159 \\
\hline $\cos ^{2+}$ & 1.26 & $4.59 \mathrm{E}+04$ & 858 \\
\hline $\mathrm{PO}^{3+}$ & 0.267 & $1.54 \mathrm{E}+04$ & 287 \\
\hline $\mathrm{sO}^{2}$ & $7.32 \mathrm{E}-02$ & $4.27 E+03$ & 79.8 \\
\hline $\mathrm{Si}\left(\mathbf{u s} \mathrm{SiO}_{3}{ }^{2}\right)$ & $1.03 \mathrm{E}-03$ & 17.6 & 0.330 \\
\hline$F$ & 0 & 0 & 0 \\
\hline $\mathrm{Cl}^{-}$ & $1.43 \mathrm{E}-02$ & 309 & 5.77 \\
\hline $\mathrm{C}_{6} \mathrm{H}_{5} \mathrm{O}_{7}{ }^{3}$ & $1.10 \mathrm{E}-02$ & $1.26 \mathrm{E}+03$ & 23.6 \\
\hline EDTA $^{4}$ & $2.20 \mathrm{E}-02$ & $3.84 E+03$ & 71.8 \\
\hline HEDTA ${ }^{3-}$ & 0 & 0 & 0 \\
\hline glyoolate & 0 & & 0 \\
\hline mectinte & 0.140 & $5.02 \mathrm{E}+03$ & 93.8 \\
\hline oxalate ${ }^{1-}$ & 0 & 0 & 0 \\
\hline DBP & 0 & 0 & 0 \\
\hline butanol & 0 & 0 & 0 \\
\hline $\mathrm{NH}_{3}$ & 0.148 & $1.53 \mathrm{E}+03$ & 28.6 \\
\hline $\mathrm{Fo}(\mathrm{CN})_{6}{ }^{4}$ & 0 & 0 & 0 \\
\hline 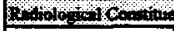 & & 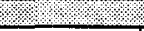 & $\longrightarrow$ \\
\hline Pu & & $2.63 \mathrm{E}-03(\mu \mathrm{Ci} / \mathrm{g})$ & $8.18 \mathrm{E}-04(\mathrm{~kg})$ \\
\hline $\mathrm{U}$ & $1.33(\mathrm{M})$ & $1.92 \mathrm{E}+05(\mu \mathrm{g} / \mathrm{g})$ & $3.58 \mathrm{E}+03(\mathrm{~kg})$ \\
\hline Cs & $5.60 \mathrm{E}-04(\mathrm{Ci} / \mathrm{L})$ & $0.340(\mu \mathrm{Ci} / \mathrm{g})$ & $6.36(\mathrm{Ci})$ \\
\hline $\mathbf{S r}$ & $6.01(\mathrm{Ci} / \mathrm{h})$ & $3.65 \mathrm{E}+03(\mu \mathrm{Cig})$ & $6.82 \mathrm{E}+0.4(\mathrm{Ci})$ \\
\hline
\end{tabular}

*Uniknowns in tank solids inventory are aseigned by Tank Lavering Model (TLM).

+Volume average for density, mass average Water wh\% and TOC wh\% C. 
WHC-SD-WM-ER-313, Rev, 1

\section{DISTRIBUTION SHEET}

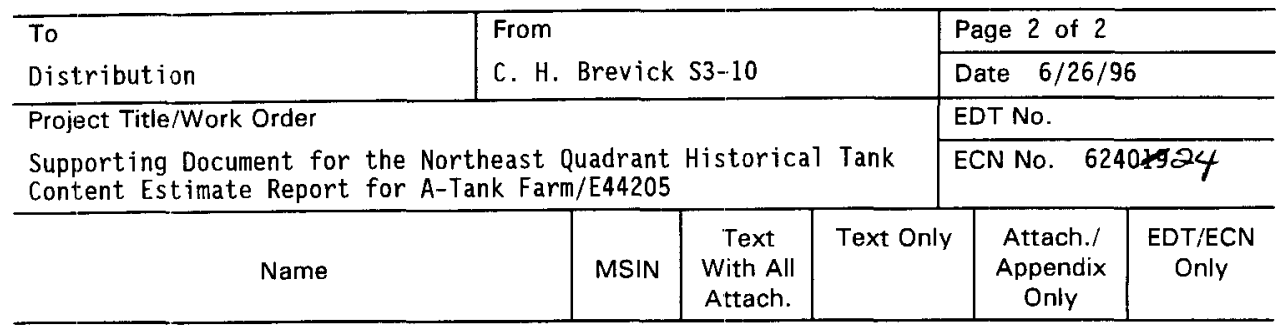

\section{OFFSITE}

Los Alamos National Laboratory

S. F. Agnew

$X$

CST-14, MS-J586

P.0. Box 1663

Los ATamos, New Mexico 87545

Los Alamos Technical Associates

T. T. Tran

$x$

903 Bradley

Richl and, Washington 99352 
WHC-SD-WM-ER-313, Rev. 1

\begin{tabular}{|c|c|c|c|c|c|}
\hline \multicolumn{6}{|c|}{ DISTRIBUTION SHEET } \\
\hline To & \multirow{2}{*}{\multicolumn{3}{|c|}{$\begin{array}{l}\text { From } \\
\text { C. H. Brevick S3-10 }\end{array}$}} & \multicolumn{2}{|l|}{ Page 1 of 2} \\
\hline Distribution & & & & \multicolumn{2}{|c|}{ Date $6 / 26 / 96$} \\
\hline \multicolumn{4}{|l|}{ Project Title/Work Order } & \multicolumn{2}{|l|}{ EDT No. } \\
\hline \multicolumn{4}{|c|}{$\begin{array}{l}\text { Supporting Document for the Northeast Quadrant Historical Tank } \\
\text { Content Estimate Report for A-Tank Farm/E44205 }\end{array}$} & \multicolumn{2}{|c|}{ ECN No. 62401924} \\
\hline Name & MSIN & $\begin{array}{c}\text { Text } \\
\text { With All } \\
\text { Attach. }\end{array}$ & Text Only & $\begin{array}{l}\text { Attach./ } \\
\text { Appendix } \\
\text { Only }\end{array}$ & $\begin{array}{l}\text { EDT/ECN } \\
\text { Only }\end{array}$ \\
\hline
\end{tabular}

\section{West inghouse Hanford Company}

T. M. Brown

$\mathrm{R} 2-12 \quad \mathrm{X}$

J. W. Cammann

R2-12

R2-12

S. J. Eber]ein

R2-12

J. W. Hunt

H6-35

G. Jansen

R2-12

B. C. Simpson

Central Files

L8-04

Environmental Resource Center

$\mathrm{R} 1-51$

Tank Characterization Resource Center R2-12

$x$
$x$
$x$
$x$
$x$
$x$

Pacific Northwest National Laboratory

T. L. Traub (WSU Reading Room)

$\mathrm{H} 2-53$

K5-12

P. D. Whitney

K. D. Wiemer's

K6-51

$X$
$X$
$X$

ICF Kaiser Hanford Company

C. H. Brevick

S3-10

J. W. Funk

E. D. Johnson

$53-09$

S3-09

R. L. Newe 11

S3-10

Document Control

R1-29

Publications

E6-63

Department of Energy - Richland Operations
J. F. Thompson
S7-54
$X$ 